
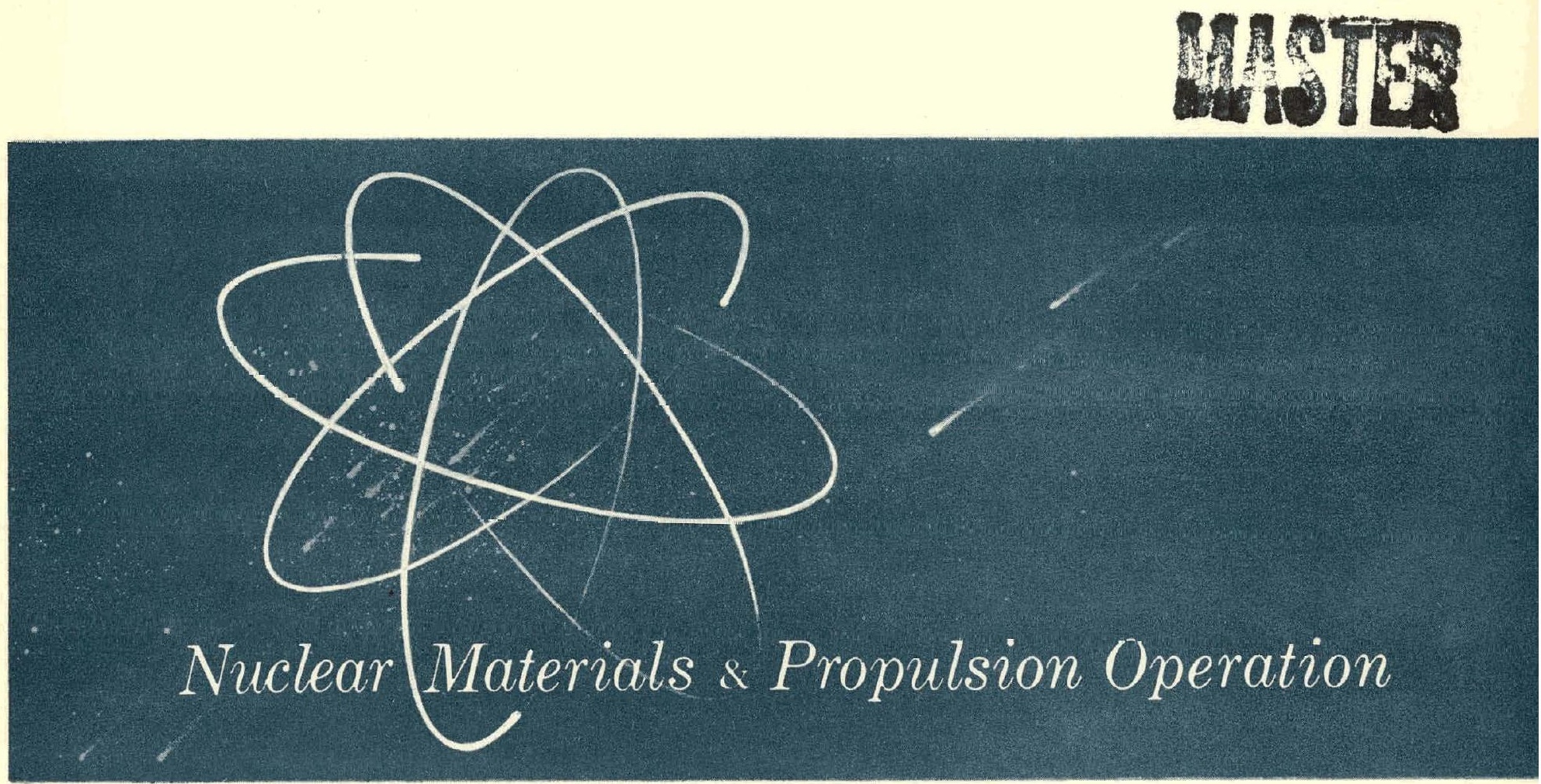

\title{
SIXTH ANNUAL REPORT -
}

HIGH - TEMPERATURE MATERIALS PROGRAM

Part A

March 31, 1967

NUCLEAR TECHNOLOGY DEPARTMENT NUCLEAR ENERGY DIVISION 


\section{DISCLAIMER}

This report was prepared as an account of work sponsored by an agency of the United States Government. Neither the United States Government nor any agency Thereof, nor any of their employees, makes any warranty, express or implied, or assumes any legal liability or responsibility for the accuracy, completeness, or usefulness of any information, apparatus, product, or process disclosed, or represents that its use would not infringe privately owned rights. Reference herein to any specific commercial product, process, or service by trade name, trademark, manufacturer, or otherwise does not necessarily constitute or imply its endorsement, recommendation, or favoring by the United States Government or any agency thereof. The views and opinions of authors expressed herein do not necessarily state or reflect those of the United States Government or any agency thereof. 


\section{DISCLAIMER}

Portions of this document may be illegible in electronic image products. Images are produced from the best available original document. 


\section{LEGAL NOTICE}

This report was prepared as an account of Government sponsored work. Neither the United States, nor the Commission, nor any person acting on behalf of the Commission:

A. Makes any warranty or representation, expressed or implied, with respect to the accuracy, completeness, or usefulness of the information contained in this report, or that the use of any information, apparatus, material, method, or process disclosed in this report may not in fringe privately ownod rights; or

B. Assumes any liabilities with respect to the use of, or for darnages resulting from the use of any information, apparatus, material, method, or process disclosed in this report.

As used in the above, "person acting on behalf of the Commission" includes any employee or contractor of the Commission, or employee of such contractor, to the extent that such employee or contractor of the Commission, or employee of such contractor prepares, disseminates, or provides access to, any information pursuant to his employment or contract with the Commission or his employment with such contractor.

Printed in the United States of America

Available from

Clearinghouse for Federal Scientific and Technical Information

National Bureau of Standards, U.S. Department of Commerce

Springfield, Virginia 22151

Price: Printed Copy $\$ 3.00$; Microfiche $\$ 0.65$ 
7.0. $3.00: .65$

\section{SIXTH ANNUAL REPORT -}

\section{HIGH - TEMPERATURE MATERIALS PROGRAMS}

\section{Part A}

March 31, 1967

\section{NUCLEAR MATERIALS and PROPULSION OPERATION \\ NUCLEAR TECHNOLOGY DEPARTMENT \\ NUCLEAR ENERGY DIVISION \\ GENERAL ELETRIC}

Cincinnati, Ohio 45215

\section{1} LEGAL NOTICE

This report was prepared as an account of Government sponsored work. Nelther the United States, nor the Commission, nor any person acting on behalf of the Commlssion:

A. Makes any warranty or representation, expressed or implied, with respect to the accuracy. completeness, or usefuiness of the information contained in this report, or that the use of any information, apparatus, method, or process disclosed In this report may not infringe privately owned rights; or

B. Assumes any liabilitles with respect to the use of; or for damages resulting from the use of any information, apparatus, method, or process disclosed in this report.

As used in the above, "person acting on behalf of the Commlssion" includes any employee or contractor of the commlssion, or employee of such contractor, includes any emsuch employee or contractor of the Commission, or employee of such contractor prepares disseminates, or provides access to, any information pursuant to hls employment or contract 
EXTERNAL

AEC Headquarters

G. K. Dicker F. C. Schwenk

D. E. Erb J. M. Simmons (3)

H. G. Hembree M. J. Whitman

AEC, CAO

C. L. Karl

AEC, OROO

W. J. Larkin . D. S. Zachry, Jr.

AEC, Division of Naval Reactors

R. H. Steele

AEC, Division of Space Nuclear Systems

B. W. Colston

AEC, REG

J. DiNunno

AEC, RDT-OSR (GE-NMPO)

$\because$ J. F. Weissenberg

AEC, RDT-OSR (ORNL)

D. F. Cope

AF Weapons Laboratory

Lt. D. Brooks

Argonne National Laboratory

L. Baker R. Mayfield

H. Kittel R. Noland

Atomics International

S. C. Carniglia C. E. Weber

Battelle-Northwest

F. W. Albaugh J. J. Cadweil BMI

S. Paprocki

\section{INTERNAL}

J. Barnard, NTD

W. G. Baxter

J. C. Blake

B. Bonini

H. C. Brassfield

R. W. Brisken

L. P. Bupp, NL

V. P. Calkins

B. A. Chandler

K. P. Cohen, APO

C. G. Collins (2)

E. S. Collins

J. F. Collins

P. K. Conn

J. B. Conway (2)
D. H. Culver (3)

H. S. Edwards

E. W. Filer

P. N. Flagella

R. E. Fryxell

E. S. Funstón

A. B. Greninger, NTD

J. O. Hibbits

A. N. Holden, APED (2)

L. D. Jordan

E. F. Juenke

F. Kingsbury

G. Korton

W. C. Kuhlman

J: E. McConnelee
General Atomic

D. Ragone

Institute for Defense Analyses

R. C. Hamilton

Jet Propulsion Laboratory

J. Davis

LASL

R. D. Baker.

Lawrence Radiation Laboratory
C. Cline
A. J. Rothman

L. W. Roberts

B. Rubin

NASA Headquarters

J. J. Lynch

NASA, Lewis Research Center

J. W. Creagh F. E. Rom N. Saunders

T. P. Moffitt L. Rosenblum H. Schwartz

T. A. Moss N. D. Sanders

ORNL

R. E. Blanco W. O. Harmes P. Patriarca (2)

W. R. Grimes G. Parker

Sandia Corporation (Albuquerque)

R. P. Stromberg J. Jacobs

Westinghouse Astronuclear Lab.

D. C. Goldberg

TRW Space Technology Lab.

H. Lurie
L. R. McCreight, MSD

W. I... Mc Cullough

L. McEwen; IPO

J. A. McGurty

J. W. "Morfitt

J. Moteff

R. E. Motsinger

G. T. Muehlenkamp

S. Nay mark

C. E. Niemeyer

W. E. Niemuth

G. W. Pomeroy

R. Reid

R. B. Richards, APED

F. C. Robertshaw
E. J. Schmidt, ATS

L. H. Sjodahl

T. Slot

J. P. Smith

H. R. Stephan

R. E. Tallman

C. O. Tare

P. P. Turner

F. O. Urban

J. E. Van Hoomissen, NT PO

G. R. Van Houten

H. E. Wagner

J. F. White

V. C. Wilson, R\&DC

R. E. Wood

Library (25) 


\section{PREFACE}

This report, GEMP-475A, is one of two volumes comprising the sixth annual report on the High-Temperature Materials Program being conducted by the General Electric Company's Nuclear Materials and Propulsion Operation under contract AT(40-1)-2847, issued by the Fuels and Materials Branch, Division of Reactor Development and Technology, of ${ }^{\circ}$ the Atomic Energy Commission.

The unclassified portions of the program are reported in this volume which covers the period from January 31, 1966, to January 31 , 1967. Volume B (GEMP-475B) related the progress made on the classified tasks from January 31 to December 31,1966 . Some programs were terminated at the close of Fiscal Year 1966, other are continuations or revisions of Fiscal Year 1966 programs, and still others were initiated in Fiscal Year 1967. The status of each program is indicated in the more detailed breakdown of each volume presented below.

This unclassified volume also includes work conducted from October 31, 1966, to January 31,1967 , and thus replaces quarterly progress report, GEMP-65. The next unclassified quarterly report will be GEMP-67.

Volume A (GEMP-475A), Unclassified

1. High-Temperature Reactor Materials Research (57003; continuation)

2. Radiation Effects on Fast Reactor Cladding and Structural Materials (57004; continuation)

3. Refractory-Metal Alloy Research and Development (57015; continuation)

4. Physical Metallurgy of Refractory-Metal Alloys (57077; initiated FY-67)

5. Advanced Long-Life Reactor Fuel Cladding and Structural Materials Development (57019; revised: formerly, "Oxidation Fuel Element Materials Research," 57001)

6. Physico-Chemical Studies of Fe-Cr-Al-Clad Fuel Elements (57076; continuation)

7. Effects of Radiation on Heat-Resistant Metals and Alloys (57018; continuation)

8. Evaluations of the Plastic Fatigue Properties of Heat-Resistant Alloys (57016; continuation)

9. Advanced Pressure Vessel Materials (57021; initiated FY-67)

10. Physico-Chemical Studies of $\mathrm{Clad}^{\mathrm{UO}_{2}}$ in Potential Meltdown Environments (57075; continuation)

11. High-Temperature Thermocouple and Electrical Materials Research (57014; continuation) 
12. High-Temperature Research on Carbides for Fuel and Structural Applications (57073; continuation)

13. Radiation Effects in BeO (57063; terminated FY-66)

Volume B (GEMP-475B), Confidential

1. Studies of Substoichiometric Urania and Urania Solid Solutions (57071; continuation).

2. Refractory-Metal Fuel Element Materials Research (57005; continuation)

3. High-Temperature Materials Engineering Properties Evaluation (57017; continuation)

4. Advanced Long-Life Reactor Fuel Element Moderator, Control, and Shield Materials Development [57020; revised: formerly, "Moderator (Fueled and Unfueled), Controls, and Shield Materials Research," 57.002]

5. Fission Product Transport Processes in Refractory-Metal Fuel Systems (57070; continuation)

6. Burnup Capabilities of $\mathrm{Y}_{2} \mathrm{O}_{3}$-Stabilized $\mathrm{UO}_{2}$ and BeO-Stabilized Fuel Materials (57068; terminated FY-66) 
INTRODUCTION AND SUMMARY $\ldots \ldots \ldots \ldots \ldots \ldots \ldots \ldots \ldots \ldots \ldots \ldots \ldots \ldots \ldots \ldots \ldots$

1. HIGH-TEMPERATURE REACTOR MATERIALS RESEARCH $(57003) \ldots \ldots$

1.1 Mechanical Property Evaluations .......................... 13

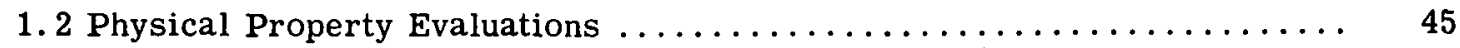

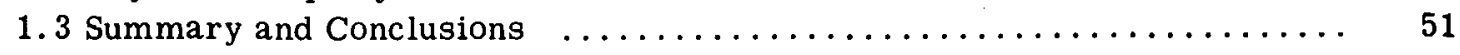

1.4 Plans and Recommendations .......................... 52

2. RADIATION EFFECTS ON FAST REACTOR CLADDING AND STRUCT URA L MATERIALS (57004) $\ldots \ldots \ldots \ldots \ldots \ldots \ldots \ldots \ldots \ldots \ldots \ldots \ldots \ldots \ldots \ldots \ldots$

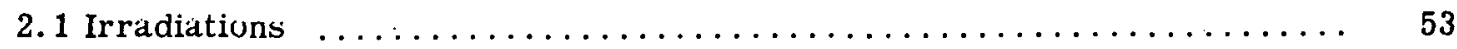

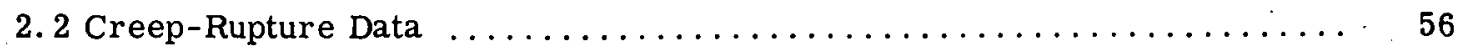

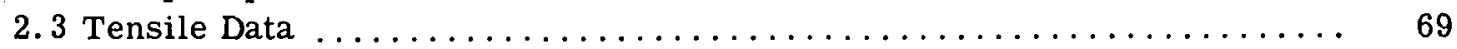

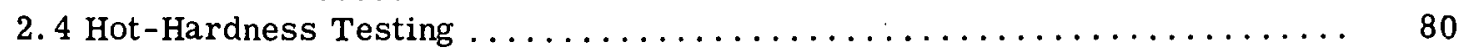

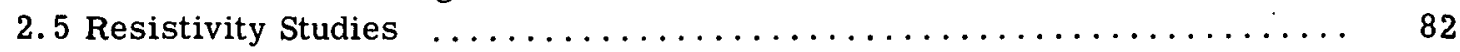

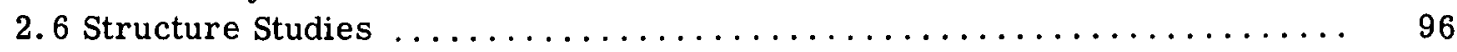

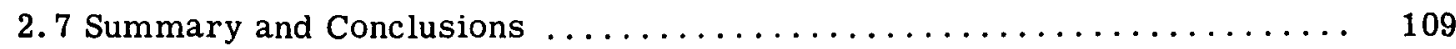

2.8 Plans and Recommendations $\ldots \ldots \ldots \ldots \ldots \ldots \ldots \ldots \ldots \ldots \ldots \ldots \ldots \ldots \ldots \ldots \ldots \ldots \ldots$

3. REFRACTORY-METAL ALLOY RESEARCH AND

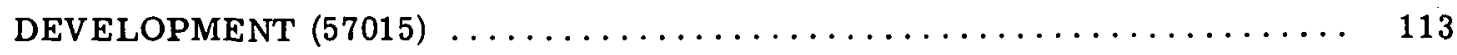

3.1 Development of Refractory-Metal Processing Procedures .......... 113

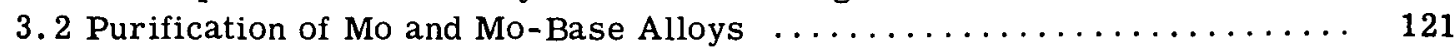

3.3 Aging and Stress-Relief Studies of W-Re-Mo Alloys $\ldots \ldots \ldots \ldots \ldots \ldots \ldots 127$

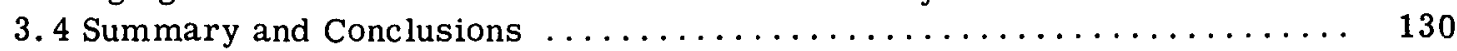

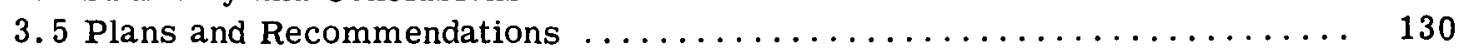

4. PHYSICAL METALLURGY OF REFRACTORY-METAL

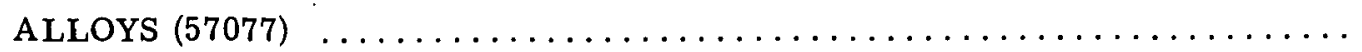

4.1 Morphology of Aging of W - 25Re - 30Mo and W - 30Re - 30Mo

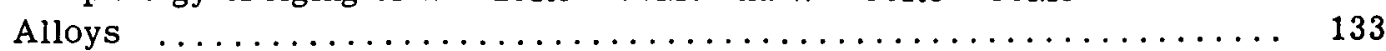

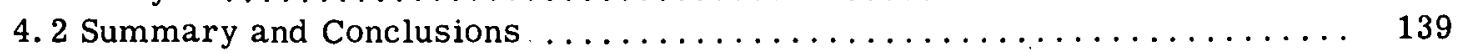

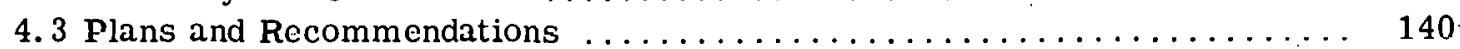

5. ADVANCED LONG-LIFE REACTOR FUEL CLADDING AND STRUCTURAL MATERIALS DEVELOPMENT (57019) ............. 143

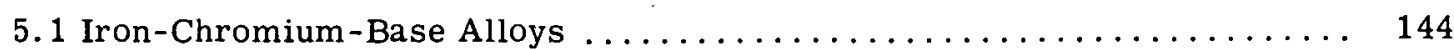

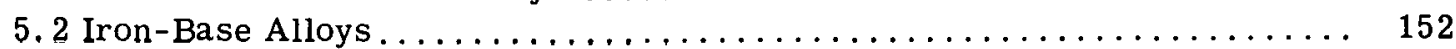

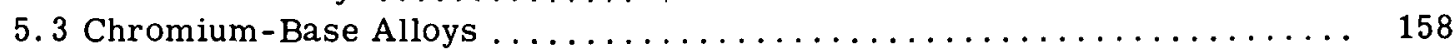

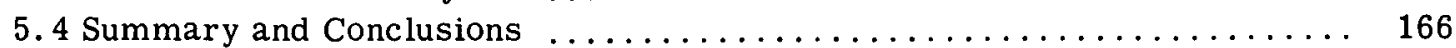

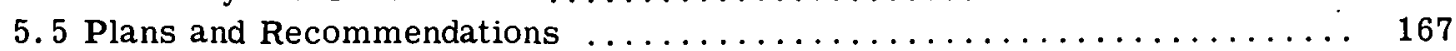

5. 6 Summary of Task 57001, "Oxidation-Resistant Fuel Element

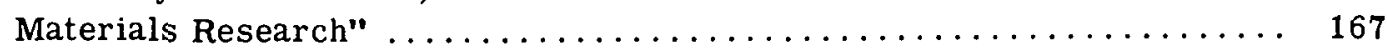


6. PHYSICO-CHEMICAL STUDIES OF Fe-Cr-Al-CLAD FUEL

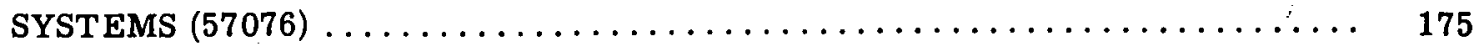

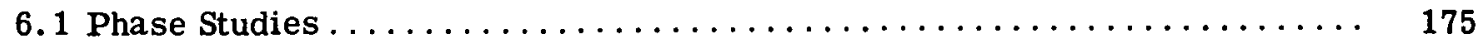

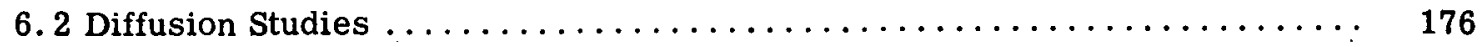

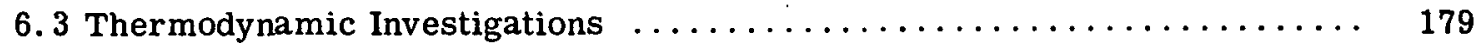

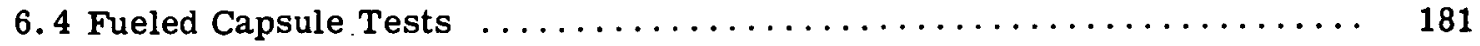

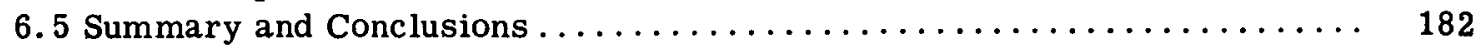

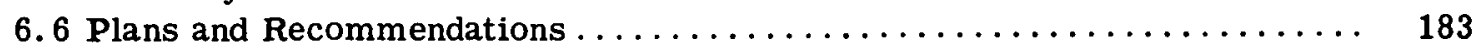

7. EFFECT OF RADIATION ON HEAT-RESISTANT METALS AND

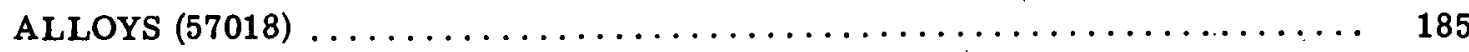

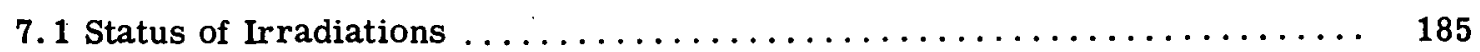

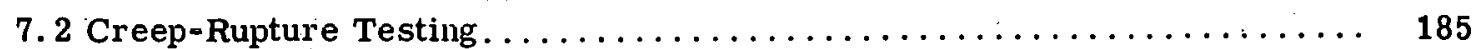

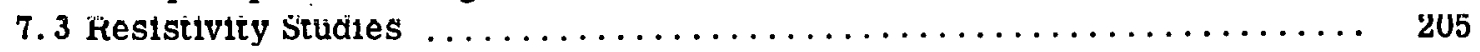

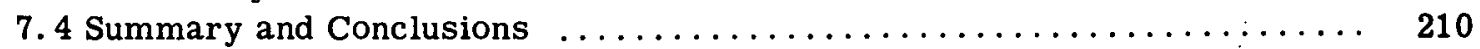

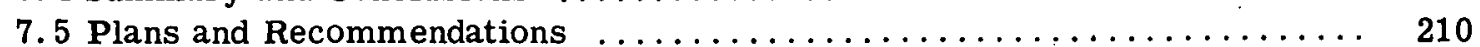

8. EVAluations OF THE Plastic FAtigue PROPERTIES OF HEAT-

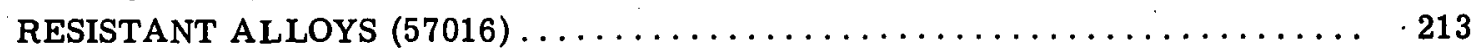

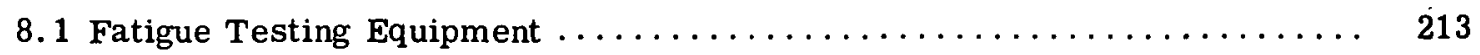

8. 2 Low-Cycle Fatigue Test Results for Type 348 Stainless Steel ......... 216

8. 3 Analytical Determination of Stress Distribution in Notched Sheet

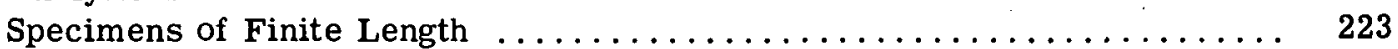

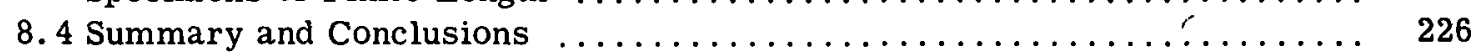

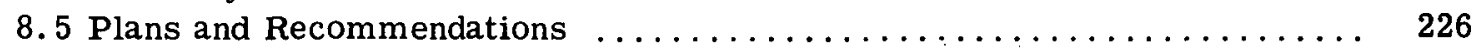

9. ADVANCED PRESSURE VESSEL MATERIALS $(57021) \ldots \ldots \ldots \ldots \ldots \ldots \ldots . \ldots 29$

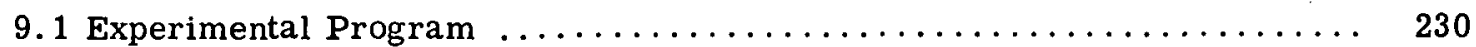

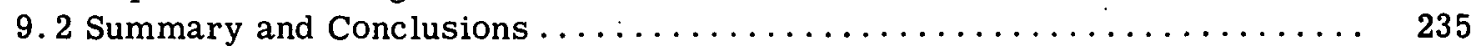

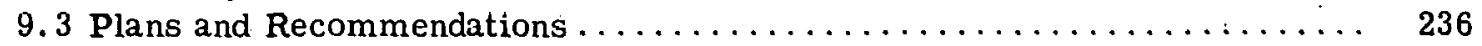

10. PHYSICO-CHEMICAL STUDIES OF CLAD UO 2 IN POTENTIAL

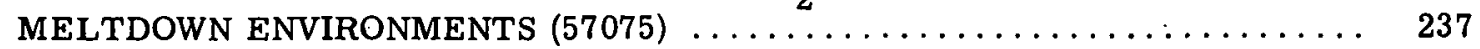

10.1 Reaction Mechanisms and Kinetics ..................... 237

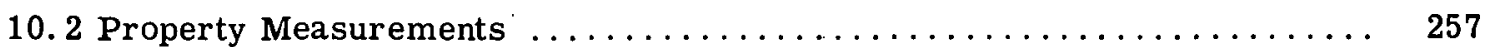

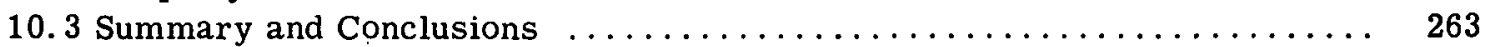

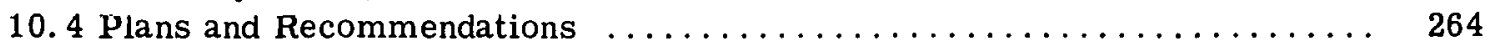

11. HIGH-TEMPERATURE THERMOCOUPLE AND ELECTRICAL

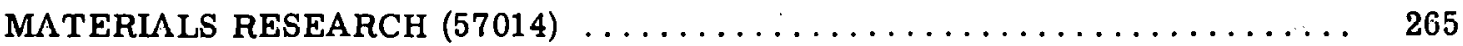

11.1 Thermocouple Systems for Hydrogen - Graphite Environment . . . . . . 265

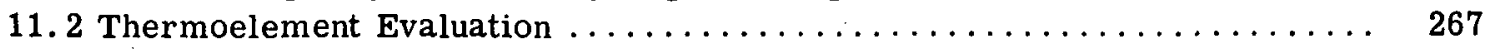

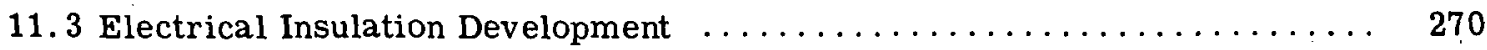

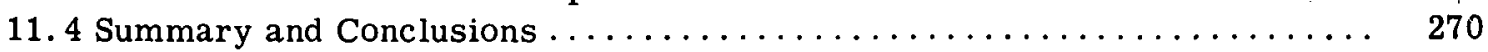

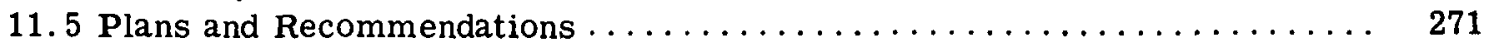

12. HIGH-TEMPERATURE RESEARCH ON CARBIDES FOR FUEL AND STRUCTURAL APPLICATIONS $(57073) \ldots \ldots \ldots \ldots \ldots \ldots \ldots \ldots \ldots \ldots \ldots \ldots \ldots \ldots$

12.1 Equilibrium Studies on Tantalum Carbide $\ldots \ldots \ldots \ldots \ldots \ldots \ldots \ldots \ldots \ldots . \ldots \ldots$

12. 2 Equilibrium Studies on Uranium Carbide $\ldots \ldots \ldots \ldots \ldots \ldots \ldots \ldots \ldots \ldots .276$ 


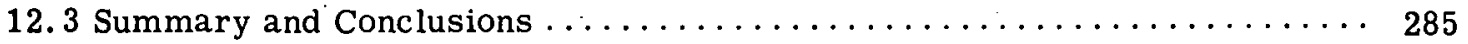

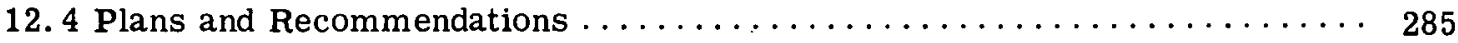

13. RADIATION EFFECTS IN BeO (57063) $\ldots \ldots \ldots \ldots \ldots \ldots \ldots \ldots \ldots \ldots \ldots \ldots \ldots \ldots \ldots \ldots$

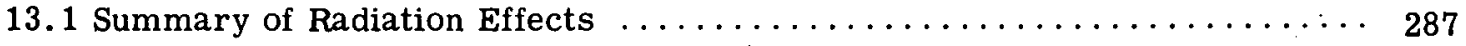

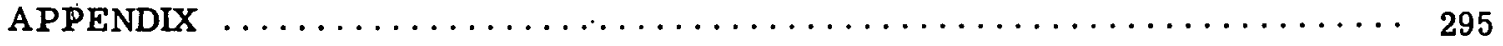




\section{CONVERSION TABLE}

Atmospheres $\ldots \ldots \ldots \ldots \ldots \ldots \ldots \ldots$ Pounds $/$ inch $^{2} \ldots \ldots \ldots \ldots \ldots \ldots 14.7$

Calories (mean) ................. Btu (mean) ............... 0.00397

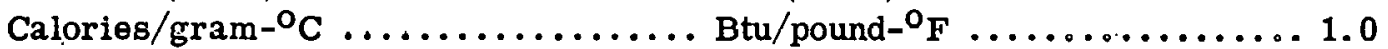

Calories $/ \mathrm{sec}-\mathrm{cm}-{ }^{\circ} \mathrm{C} \ldots \ldots \ldots \ldots \ldots \ldots$ Btu $/ \mathrm{hr}-\mathrm{ft}-{ }^{\circ} \mathrm{F} \ldots \ldots \ldots \ldots \ldots \ldots .241 .8$

Calories $/ \mathrm{sec}-\mathrm{cm}^{2} \ldots \ldots \ldots \ldots \ldots \ldots \ldots \ldots$ Btu $/ \mathrm{hr}-\mathrm{ft}^{2} \ldots \ldots \ldots \ldots \ldots \ldots \ldots 1.32 \times 10^{4}$

Calories $/ \mathrm{sec}-\mathrm{cm}^{2}{ }^{\circ} \mathrm{C} \ldots \ldots \ldots \ldots \ldots \ldots$ Btu $/ \mathrm{hr}-\mathrm{ft}^{2}{ }^{\circ} \mathrm{F} \ldots \ldots \ldots \ldots \ldots \ldots . \ldots 7370$

Centimeters ................. Feet.................. 0.03281

Inches .................... 0.3937

Cubic centimeters

Cubic feet $\ldots \ldots \ldots \ldots \ldots \ldots \ldots . . . . . .331 \times 10^{-5}$

Cubic inches ............... 0.06103

Grams

Pounds .................. 0.002205

Grams $/ \mathrm{cm}^{3}$

Pounds $/ \mathrm{ft}^{3} \ldots \ldots \ldots \ldots \ldots \ldots . \ldots 62.43$

Grams $/ \mathrm{cm}^{2}$

psi ...................... 0.01422

Kilograms

Pounds ...................2.205

Kilograms $/ \mathrm{cm}^{2}$

Atmospheres ............... 0.9678

Pounds $/ \mathrm{ft}^{2}$................. 2048:

Pounds/inch ${ }^{2} \ldots \ldots \ldots \ldots \ldots \ldots \ldots 14.22$

Kilograms $/ \mathrm{mm}^{2} \ldots \ldots \ldots \ldots \ldots \ldots \ldots \ldots$ Pounds $/$ inch $^{2} \ldots \ldots \ldots \ldots \ldots \ldots \ldots 1422.32$

Kilowatts $\ldots \ldots \ldots \ldots \ldots \ldots \ldots \ldots \ldots$ Btu/sec ............... 0.948

Liters ..................... Cubic feet $\ldots \ldots \ldots \ldots \ldots \ldots \ldots . . \ldots 0353$

Meters ..................... Inches ................. 39.37

Millimeters of mercury ............ Atmospheres ............... 0.001316

Square centimeters ............... Square feet................ 0.001076

Square inches .............. 0.155

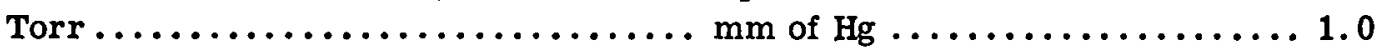

Atmuspheres ................. 0.001316

Watts $/ \mathrm{cm}^{\circ}{ }^{\circ} \mathrm{C} \ldots \ldots \ldots \ldots \ldots \ldots \ldots \ldots$ Btu $/ \mathrm{hr}-\mathrm{ft}-{ }^{\circ} \mathrm{F} \ldots \ldots \ldots \ldots \ldots .67 .8$

Watt-seconds ................... Btu ................... 0.000948

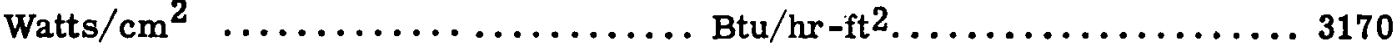

Watts $/ \mathrm{cm}^{2}{ }^{0}{ }^{0} \mathrm{C} \ldots \ldots \ldots \ldots \ldots \ldots \ldots . . \ldots$ Btu $/ \mathrm{hr}-\mathrm{ft}^{2}{ }^{2}{ }^{0} \mathrm{~F} \ldots \ldots \ldots \ldots \ldots . \ldots 1760$

Centimeters $/$ sec $\ldots \ldots \ldots \ldots \ldots \ldots \ldots$. Feet $/$ sec .................. 0.03281

Meters $/$ sec $\ldots \ldots \ldots \ldots \ldots \ldots \ldots \ldots \ldots$ Feet $/$ sec $\ldots \ldots \ldots \ldots \ldots \ldots \ldots \ldots . . \ldots . \ldots \ldots 1$ 


\section{INTRODUCTION AND SUMMARY}

This report, GEMP-475A, is one of two volumes of the sixth annual report on GE-NMPO high-temperature materials programs conducted during calendar year 1966 under Contract No. AT(40-1)-2847. This volume covers 13 unclassified materials development programs: (1) properties of refractory materials in the $1000^{\circ}$ to $3000^{\circ} \mathrm{C}$ temperature range; (2) radiation effects on the time-, temperature-, and stress-dependent properties of refractory metals; (3) development of refractory metals; (4) physical metallurgy of refractory metals; (5) long-life reactor fuel cladding and structural materials; (6) physico-chemical studies of stability and reactions between $\mathrm{Fe}-\mathrm{Cr}-\mathrm{Al}$ alloys and $\mathrm{UO}_{2}$; (7) radiation effects on the time--, temperature-, and stress-dependent properties of heat-resistant alloys; (8) low-cycle, plastic fatigue properties of heat-resistant alloys; (9) advanced pressure vessel materials; (10) the behavior of Zircaloy-4-clad and Type 304 stainless steel-clad $\mathrm{UO}_{2}$ in meltdown environments; (11) high-temperature thermocouple and electrical materials; (12) refractory carbides for fuel and structural applications; and (13) radiation effects in $\mathrm{BeO}$ interms of composition and microstructure.

Significant results achieved in these programs were as follows:

The creep resistance and rupture life of wrought, arc-cast $\mathrm{W}-25 \mathrm{Re}$ sheet exceeded that of arc-cast tungsten at $1600^{\circ} \mathrm{C}$ and stresses of $4.2 \mathrm{~kg} / \mathrm{mm}^{2}$ or lower; at $2200^{\circ} \mathrm{C}$ and a stress of $0.56 \mathrm{~kg} / \mathrm{mm}^{2}$, the rupture life of tungsten was greater. In the W-Re-Mo system, alloys containing 20 and 30 atomic percent molybdenum with 17 to 18 atomic percent rhenium appeared to have the greater creep resistance and ductility at $1600^{\circ} \mathrm{C}$; at $2200^{\circ} \mathrm{C}$, the alloys with 20 and 30 atomic percent molybdenum with 20 to 23 atomic percent rhenium appeared to be better. A modified de Lacombe equation was found to give the best results of several equations evaluated in describing the entire creep curve for tungsten at $2400^{\circ} \mathrm{C}$. Different mechanisms for creep in arc-cast tungsten were operational at $1800^{\circ} \mathrm{C}$ and $2400^{\circ} \mathrm{C}$. At $1800^{\circ} \mathrm{C}$, coarse and fine slip bands were present with some grains showing a network of cross-slip lines; at $2400^{\circ} \mathrm{C}$, cell formation was well developed and outlined by rows of dislocation etch pits. The thermal conductivity from $400^{\circ}$ to $2300^{\circ} \mathrm{C}$ of $\mathrm{W}-\mathrm{UO}_{2}$ composites in the range of 20 to 60 volume percent $\mathrm{UO}_{2}$ decreased fairly linearly with increasing $\mathrm{UO}_{2}$ content; at $2000^{\circ} \mathrm{C}$, the thermal conductivity of $\mathrm{W}-60 \mathrm{UO}_{2}$ is about one-third that of $\mathrm{W}-20 \mathrm{UO}_{2}$.

Irradiating tungsten to $1.4 \times 10^{20} \mathrm{n} / \mathrm{cm}^{2}\left(E_{\mathrm{n}} \geq 1 \mathrm{Mev}\right.$ ) at $1100^{\circ}$ to $1350^{\circ} \mathrm{C}$ indicated creeprupture ductility was a function of irradiation and test temperatures. Specimens irradiated at reactor ambient temperature and tested at $1100^{\circ} \mathrm{C}$ showed the effect of different reactor spectra was mainly due to the production of rhenium by the $(n, \gamma)$ reaction. Tensile tests of irradiated tungsten at $400^{\circ} \mathrm{C}$ showed the yield-strength increase was proportional to the square root of fast neutron fluence. Annealing an irradiated $\left(1.4 \times 10^{20} \mathrm{n} / \mathrm{cm}^{2}\right)$ specimen at $1200^{\circ} \mathrm{C}$ for 1 hour resulted in about 80 -percent recovery of yield and ultimate strengths but very little recovery of ductility; annealing specimens irradiated to $8 \times 10^{19} \mathrm{n} / \mathrm{cm}^{2}$ at $1300^{\circ} \mathrm{C}$ produced complete recovery of both strength and ductility. Radiation effects on tungsten resistivity appeared to reach saturation at a fast neutron fluence of about $1.5 \times 10^{21} \mathrm{n} / \mathrm{cm}^{2}$. A fluence threshold region existed in tungsten between $5.9 \times 10^{18}$ and 
$3.8 \times 10^{19} \mathrm{n} / \mathrm{cm}^{2}\left(E_{n} \geq 1 \mathrm{Mev}\right)$ over which an abrupt increase in size and concentration of clusters occurred, leading to a drastic loss in tensile ductility. Irradiated molybdenum tested at $580^{\circ} \mathrm{C}$ evidenced accelerated creep at a fluence level of $5 \times 10^{18} \mathrm{n} / \mathrm{cm}^{2}\left(E_{n} \geq 1 \mathrm{Mev}\right.$ ) but not at a higher fluence level of $3 \times 10^{19} \mathrm{n} / \mathrm{cm}^{2}$. Delayed creep was observed at $600^{\circ} \mathrm{C}$ and $700^{\circ} \mathrm{C}$ for irradiated molybdenum but not at $580^{\circ}, 850^{\circ}$, or $900^{\circ} \mathrm{C}$. In resistivity studies of irradiated molybdenum, the radiation-induced resistivity showed a maximum at $10^{20}$ $\mathrm{n} / \mathrm{cm}^{2}$, the first evidence of saturation of neutron irradiation damage. Recovery studies of the hot-hardness and tensile properties of Mo, Mo-TZM, Mo-50Re, W, W - 25Re, and $\mathrm{W}-25 \mathrm{Re}-30 \mathrm{Mo}$, irradiated at reactor ambient temperature, showed that these properties are generally recovered at temperatures greater than $0.22 \mathrm{~T}_{\mathrm{m}}$ for the alloys and above $0.35 \mathrm{~T}_{\mathrm{m}}$ for the unalloyed metals.

A complete fabrication procedure for the production of quality seamless tubing of W-Re-Mo alloys was developed. In this system, those alloys with 30 atomic percent rhenium showed significant age-hardening at $1800^{\circ} \mathrm{C}$. Purification procedures in the fabrication of powder-metallurgy molybdenum resulted in sheet having the desired ductility after welding and after heating to $2400^{\circ} \mathrm{C}$.

The as-processed structure (elongated grains after $4.75 \%$ cold reduction and stress relieved at $1400^{\circ} \mathrm{C}$ ) of $\mathrm{W}-25 \mathrm{Re}-30 \mathrm{Mo}$ and $\mathrm{W}-30 \mathrm{Re}-30 \mathrm{Mo}$ (both at. \%) was relatively stable; grain growth of only about 20 percent to equiaxed grains occurred in 1000 hours at $2600^{\circ} \mathrm{C}$ and the hardness decreased from 450 to $350 \mathrm{DPH}$. Bend ductility was about 90 degrees after all thermal treatments above $1600^{\circ} \mathrm{C}$, but after several hundred hours at $1200^{\circ}$ to $1400^{\circ} \mathrm{C}$, the bend ductility dropped to 20 to 30 degrees. Cold reductions up to 19 percent did not promote extensive recrystallization. Molybdenum loss from the surface of $\mathrm{W}-30 \mathrm{Re}-30 \mathrm{Mo}$ was appreciable at elevated temperatures; surface molybdenum concentration decreased from 30 to 17 percent in 100 hours at $2600^{\circ} \mathrm{C}$ or in 4500 hours at $2200^{\circ} \mathrm{C}$.

Compositions were identified in the $\mathrm{Fe}-\mathrm{Cr}$-base, $\mathrm{Fe}$-base, and $\mathrm{Cr}$-base alloy systems which were processable and appeared compatible with static sodium at $750^{\circ} \mathrm{C}$. In the $\mathrm{Fe}-$ base and $\mathrm{Cr}$-base compositions, short-time strengths were comparable to those for austenitic stainless steels at $750^{\circ} \mathrm{C}$ and, for the Fe-base, far exceeded them at lower temperatures.

The solubility of uranium in $\mathrm{Fe}-\mathrm{Cr}-\mathrm{Al}$ alloys was about 0.1 weight percent at $600^{\circ}$ to $1200^{\circ} \mathrm{C}$; however, there was extensive solubility of the $\mathrm{Fe}, \mathrm{Cr}$, and $\mathrm{Al}$ in the U. Free uranium from substoichiometric urania diffused readily (6 hours) through $0.076-\mathrm{cm}$-thick $\mathrm{Fe}-\mathrm{Cr}-\mathrm{Al}$ cladding at $1200^{\circ} \mathrm{C}$ but not at $800^{\circ} \mathrm{C}$ in 400 hours. Cladding composition affected the rate of accumulation of surface uranium; in aluminum-free compositions, the rate was about one-half at $1200^{\circ} \mathrm{C}$.

The creep-rupture life of Hastelloy $\mathrm{N}$ was reduced by irradiation by a factor of 20 to 30 at $650^{\circ} \mathrm{C}$ and 2 to 3 at $815^{\circ} \mathrm{C}$; the loss in rupture life was apparently affected by the maximum temperature regardless of irradiation or subsequent testing. Pre- and post-irradiation annealing indicated rupture life may be recoverable; however, techniques that improved rupture life did not improve post-irradiation ductility. The fracture of unirradiated Hastelloy $\mathrm{N}$ was transgranular at $650^{\circ} \mathrm{C}$ but intergranular at $815^{\circ} \mathrm{C}$. The radiation-induced embrittlement of A-286 was not caused by coalescence of helium bubbles on grain boundaries; rather, it appeared that the helium bubbles were pinning dislocations. Irradiated Hastelloy R-235 containing a fixed boron content but varying amounts of $\mathrm{B}^{\mathbf{1 0}}$ showed a loss in rupture life at $870^{\circ} \mathrm{C}$, with the loss increasing with increasing $\mathrm{B}^{10}$ content. Tensile tests at temperatures to $1000^{\circ} \mathrm{C}$ of $\mathrm{Fe}-15 \mathrm{Cr}-4 \mathrm{Al}-1 \mathrm{Y}$ alloy, irradiated at reactor ambient temperature or $700^{\circ} \mathrm{C}$ to a fluence of 6 to $8 \times 10^{19} \mathrm{n} / \mathrm{cm}^{2}$, showed no radiation-induced embrittlement. 
Low-cycle fatigue data generated for Type 348 stainless steel permit prediction of the fatigue life in the range from 100 to 100,000 loading cycles for temperatures of $430^{\circ}$, $650^{\circ}$, and $816^{\circ} \mathrm{C}$. The results pertain to uniaxial loading at a rate of 0.4 percent strain per second. Testing at strain rates smaller by factors of 10 and 100 are in progress. The results for $430^{\circ} \mathrm{C}$ are in agreement with the Coffin-Manson relation that predicts low-cycle fatigue life at temperatures below the creep range. Such agreement was not found for $650^{\circ} \mathrm{C}$ and $816^{\circ} \mathrm{C}$.

The presence of an oxide film on the Zircaloy-4 cladding of $\mathrm{UO}_{2}$ affected its flow behavior above the melting point of Zircaloy-4; an oxide film of 200 microns or greater prevented cladding flow at $1900^{\circ} \mathrm{C}$. The isothermal corrosion by steam of Zircaloy-4, Type 304 stainless steel, and $\mathrm{UO}_{2}$ followed a parabolic law. For Zircaloy 4 corrosion, the activation energy was $-40,000 \mathrm{kcal} / \mathrm{mole}$ between $1200^{\circ}$ and $1800^{\circ} \mathrm{C}$ : for Type 304 stainless steel, it was $-84,000 \mathrm{kcal} / \mathrm{mole}$ between $1000^{\circ}$ and $1350^{\circ} \mathrm{C}$; and for $\mathrm{UO}_{2}$, it was $-50,800$ $\mathrm{kcal} / \mathrm{mole}$ between $1100^{\circ}$ and $1500^{\circ} \mathrm{C}$. The thermal conductivity of Zircaloy -4 showed a linear increase from $0.1 \mathrm{watt} / \mathrm{cm}-{ }^{\circ} \mathrm{C}$ at $300^{\circ} \mathrm{C}$ to 2.6 at $1000^{\circ} \mathrm{C}$; above $1000^{\circ} \mathrm{C}$, it increased more rapidly to 4.2 at $1500^{\circ} \mathrm{C}$. The ultimate tensile strength of Zircaloy -4 was only 0.4 $\mathrm{kg} / \mathrm{mm}^{2}$ at $1200^{\circ} \mathrm{C}$ and about $0.03 \mathrm{~kg} / \mathrm{mm}^{2}$ at $1800^{\circ} \mathrm{C}$.

A thermocouple system was constructed which gave a relatively stable thermoelectric output for 1 hour at $2500^{\circ} \mathrm{C}$ in a graphite.- hydrogen environment. A reactor test of W versus $W-25 R e$ thermoelements to a total dusage of $6.0 \times 10^{20}$ nvt thermal and $1.0 \times 10^{20}$ nvt fast indicated a maximum error of $15^{\circ} \mathrm{C}$, considerably different from that predicted from synthesized compositions compounded on the basis of transmutation calculations.

Carbon activity of tantalum and uranium monocarbides increased as the carbon-to-metal ratio increased and as the temperature increased; for tantalum monocarbide, the activity increased from 0.0014 at $1800^{\circ} \mathrm{C}$ for $\mathrm{C} / \mathrm{Ta}=0.805$ to 1.000 at $2300^{\circ} \mathrm{C}$ for $\mathrm{C} / \mathrm{Ta}=0.994$; for uranium monocarbide, the activity increased from 0.010 at $1500^{\circ} \mathrm{C}$ for $\mathrm{C} / \mathrm{U}=0.993$ to 0.0728 at $1700^{\circ} \mathrm{C}$ for $\mathrm{C} / \mathrm{U}=0.990$. The carbon activity coefficient for singly occupied carbon sites was essentially the same for TaC and UC and was equal to about $27 \mathrm{kcal} / \mathrm{mole}$. Compatibility studies between $\mathrm{UC}_{\mathrm{X}}$ and rhenium showed that $\mathrm{URe}_{2}$ was formed at $2000^{\circ} \mathrm{C}$. in hydrogen; however, in the presence of excess carbon, $\mathrm{URe}_{2}$ was not formed and all reaction products contained carbon. Diffusion coefficients for carbon diffusion in rhenium were $1.1 \times 10^{-8} \mathrm{~cm}^{2} / \mathrm{sec}$ at $1500^{\circ} \mathrm{C}$ and $1.9 \times 10^{-6} \mathrm{~cm}^{2} / \mathrm{sec}$ at $2300^{\circ} \mathrm{C}$ and the activation energy was $58.2 \mathrm{kcal} / \mathrm{mole}$.

A brief, overall summary of the results of the radiation effects in $\mathrm{BeO}$ is presented. The optimum material for irradiation resistance should have fine grain size ( $\leq 5$ microns); high density $\left(2.9 \mathrm{~g} / \mathrm{cm}^{3}\right)$ material has somewhat better irradiated strength whereas low density $\left(\sim 2.6 \mathrm{~g} / \mathrm{cm}^{3}\right)$ material exhibited less swelling. The optimum irradiation temperature is above $600^{\circ} \mathrm{C}$, higher temperatures being required the higher the neutron flux. 
THIS PAGE

\section{WAS INTENTIONALLY \\ LEFT BLANK}




\title{
1. HIGH-TEMPERATURE REACTOR MATERIALS RESEARCH
}

\section{(57003)}

\author{
J. B. Conway,* P. N. Flagella ${ }^{\dagger}$
}

The purpose of this program is to measure and evaluate high-temperature physical and mechanical properties of commercially available and newly developed refractory materials being considered for use in fueled and nonfueled high-temperature $\left(1000^{\circ}\right.$ to $\left.3000^{\circ} \mathrm{C}\right) \mathrm{reac}-$ tor applications.

\subsection{MECHANICAL PROPERTY EVALUATIONS}

\section{CREEP-RUPTURE STUDIES}

\section{$\mathrm{W}-25 \mathrm{Re}$}

As reported previously, ${ }^{1}$ evaluation of the creep-rupture characteristic, of wrought arccast and powder-metallurgy $0.05-\mathrm{cm}$-thick $\mathrm{W}-25 \mathrm{Re}$ (wt \% $)^{\dagger}$ sheet obtained from seven different commercial vendors led to results which varied considerably from one sheet to another. These measurements consisted of creep resistance, rupture life, and ductility at rupture at $1600^{\circ} \mathrm{C}$ and $4.22 \mathrm{~kg} / \mathrm{mm}^{2}$ and at $2000^{\circ} \mathrm{C}$ and $2.11 \mathrm{~kg} / \mathrm{mm}^{2}$ in hydrogen. Wrought arccast material was procured from two vendors and wrought powder-metallurgy material from the other five. The results obtained for arc-cast material were considered to be representative and reproducible properties for $\mathrm{W}-25 \mathrm{Re}$ since it was previously demonstrated ${ }^{2}$ that wrought arc-cast unalloyed molybdenum sheet had uniform creep-rupture properties independent of the source, whereas the wrought powder-metallurgy material did not.

Additional creep-rupture tests of wrought arc-cast W-25Re sheet (material source EV-1 $)^{1}$ were performed at temperatures from $1600^{\circ}$ to $2600^{\circ} \mathrm{C}$ in a hydrogen atmosphere to obtain representative data on the creep resistance, rupture life, and ductility. The time to various strain values and rupture and the total strain at rupture for test times ranging from 2.4 to 2685 hours are presented in Table 1.1. The data presented in terms of the Larson-Miller parameter are shown in Figure 1.1. A computer program was used to give the line of best fit and the optimum $C$ value for each percent strain and rupture time.

At $1600^{\circ} \mathrm{C}$, the creep curves for the wrought arc-cast $\mathrm{W}-25 \mathrm{Re}$ sheet exhibited a sig। ficant amount of primary creep as well as a detectable amount of secondary creer, but the major portion of the deformation process was found to be confined to third-stage creep.

\footnotetext{
*Project leader.

†Principal investigator.

‡Unless otherwise noted, all compositions in this section are in atomic percent.

1"'Fifth Annual Report-High-Temperature Materials Programs, Part A," GE-NMPO, GEMP-400A, February 28, 1966, p. 33.

2F. N. Flagella, "High-Temperature Stress-Rupture Characteristics of Mo and Some Mo Alloys," GE-NMPO, GE-TM 65-4-39, June 1965.
} 
TABLE 1.1

CREEP-RUPTURE RESULTS FOR ARC-CAST W - 25Re SHEET ${ }^{\mathrm{a}}$ IN HYDROGEN ${ }^{\mathrm{b}}$

\begin{tabular}{|c|c|c|c|c|c|c|c|c|c|c|}
\hline \multirow{3}{*}{$\begin{array}{c}\text { Temperature, } \\
{ }^{\circ} \mathrm{C}\end{array}$} & \multirow{3}{*}{$\begin{array}{r}\text { Stress, } \\
\mathrm{kg} / \mathrm{mm}^{2}\end{array}$} & \multirow{2}{*}{\multicolumn{7}{|c|}{ Time to Indicated Strain, hr }} & \multicolumn{2}{|c|}{ Rupture } \\
\hline & & & & & & & & & \multirow{2}{*}{$\begin{array}{c}\text { Time, } \\
\text { hr }\end{array}$} & \multirow{2}{*}{$\begin{array}{c}\text { Strain } \\
\%\end{array}$} \\
\hline & & $\overline{0.2 \%}$ & $0.5 \%$ & $1 \%$ & $2 \%$ & $3 \%$ & $5 \%$ & $10 \%$ & & \\
\hline 1600 & 7.03 & 0.20 & 0.64 & 1.36 & 2.60 & 3. 75 & 5.73 & 9.55 & 24.0 & 86 \\
\hline 1600 & 5.62 & 0.29 & 1.13 & 2.60 & 5.70 & 8.70 & 14.0 & 24.6 & 62.1 & 84 \\
\hline 1600 & 4.92 & 0.72 & 2.08 & 5.05 & 11.5 & 17.9 & 29.0 & 50.7 & 119 & 73 \\
\hline 1600 & 4.22 & 1.00 & 2.95 & 7.10 & 16.2 & 25.5 & 42.0 & 75.9 & 195 & 87 \\
\hline 1600 & 3. 37 & 0.94 & 4.40 & 15.3 . & 42.7 & 70.0 & 117. & 213 & 513 & 71 \\
\hline 1600 & 2.11 & 3.70 & 20.1 & 96.2 & 375 & 513 & 894 & 1445 & c & c \\
\hline 2000 & 3. 52 & 0.06 & 0.12 & 0.20 & 0.35 & 0.47 & 0.68 & 1.06 & 2. 40 & 81 \\
\hline 2000 & 2.11 & 0.50 & 1.10 & 1. 88 & 3.23 & 4.43 & 6.30 & 9.85 & 21.9 & 86 \\
\hline 2000 & 1.41 & 2.00 & 5.00 & 8.50 & 15.1 & 20.1 & 28.6 & 46.9 & 107 & 103 \\
\hline 2000 & 1. 05 & 3.60 & 10.8 & 22.0 & 39.5 & 53.8 & 77.2 & 121 & 266 & 96 \\
\hline 2200 & 0.56 & 3.96 & 11.6 & 21.3 & 38.1 & 53.0 & 80.1 & 129 & 252 & 64 \\
\hline 2400 & 0.70 & 0,12 & 0.33 & 0.62 & 1.10 & 1.48 & 2.15 & 3.54 & 7.30 & .44 \\
\hline 2400 & 0.56 & 0.49 & 1.16 & 2.15 & 3.95 & 5.60 & 8.25 & 12.7 & 27.7 & 40 \\
\hline 2400 & 0.46 & 1.00 & 2.45 & 4.55 & 8.40 & 11.8 & 17.3 & 25.4 & .33 .1 & 28 \\
\hline 2400 & 0.35 & 2.64 & 6.47 & 12.6 & 24.2 & 33.7 & 48.8 & 65.6 & 82.0 & 26 \\
\hline 2600 & 0.35 & 0.32 & 0.85 & 1.68 & 3.01 & 3.91 & 4.91 & 6.38 & . 7.04 & 20 \\
\hline
\end{tabular}

a 0.05 -cm-thick sheet specimen with $0.64-\mathrm{cm}$ by $2.54-\mathrm{cm}$ gage section.

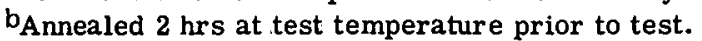

${ }^{c}$ Terminated at $2,685.5$ hours with $34.2 \%$ strain.

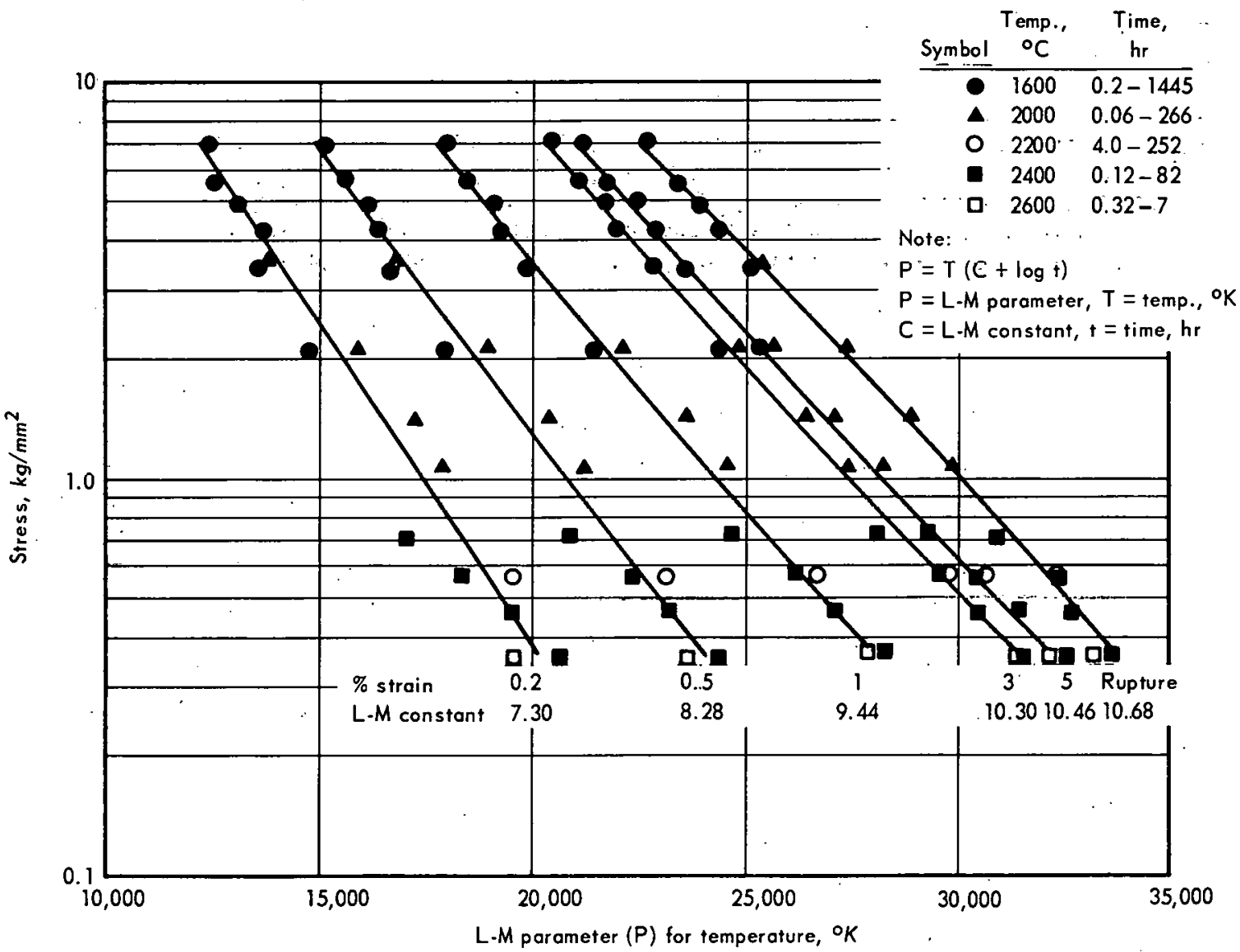

Fig. 1.1 - Larson-Miller parameter for arc-cast W-25Re sheet 
At $2400^{\circ} \mathrm{C}$, there was no detectable amount of primary or secondary creep and third-stage creep occurred from time zero. The indication is that strain hardening is non-existent or is not sufficient to overcome the effect of annealing during the initial portion of the creep process at $2400^{\circ} \mathrm{C}$. This was not the case for wrought arc-cast unalloyed tungsten, because, when tested from $1600^{\circ}$ to $3000^{\circ} \mathrm{C}$, primary and secondary stages of creep $u$ əre observed at all temperatures. ${ }^{3}$

Although the primary reason for the rhenium addition to tungsten is to obtain increased ductility Juring fabrication, the creep resistance and rupture life of arc-cast $W-25 \mathrm{Re}$ exceeds that of arc-cast unalloyed tungsten at $1600^{\circ} \mathrm{C}$ and $2000^{\circ} \mathrm{C}$. As shown in Figure 1.2, the difference appears to decrease as the temperature is increased. Above $2000{ }^{\circ} \mathrm{C}$, the rupture life for tungsten exceeds that of $\mathrm{W}-25 \mathrm{Re}$ for the same test conditions. This same relationship between the two materials was also observed when comparing the time required to give 10-percent strain. The decrease in the creep resistance and rupture life above $2000^{\circ} \mathrm{C}$ for $\mathrm{W}-25 \mathrm{Re}$ when compared to tungsten is apparently related to the differences in melting temperatures $\left(3410^{\circ} \mathrm{C}\right.$ for tungsten and $3130^{\circ} \mathrm{C}$ for $\left.\mathrm{W}-25 \mathrm{Re}\right)$. This is shown in Fig . re 1.3 where the stress required to cause rupture in 100 hours for each material is related to the percent of he absolute melting temperature (homologous temperature). On this basis, the rupture stress of the $\mathrm{W}-25 \mathrm{Re}$ alloy exceeds that of the unalloyed tungsten over the entire temperature range investigated. Also shown in Figure 1.3 are data for arccast unalloyed molybdenum. The data are coincident with those of tungsten. The same relationship also exists between tungsten and molybdenum for 1 and 10 hours to rupture. ${ }^{4}$

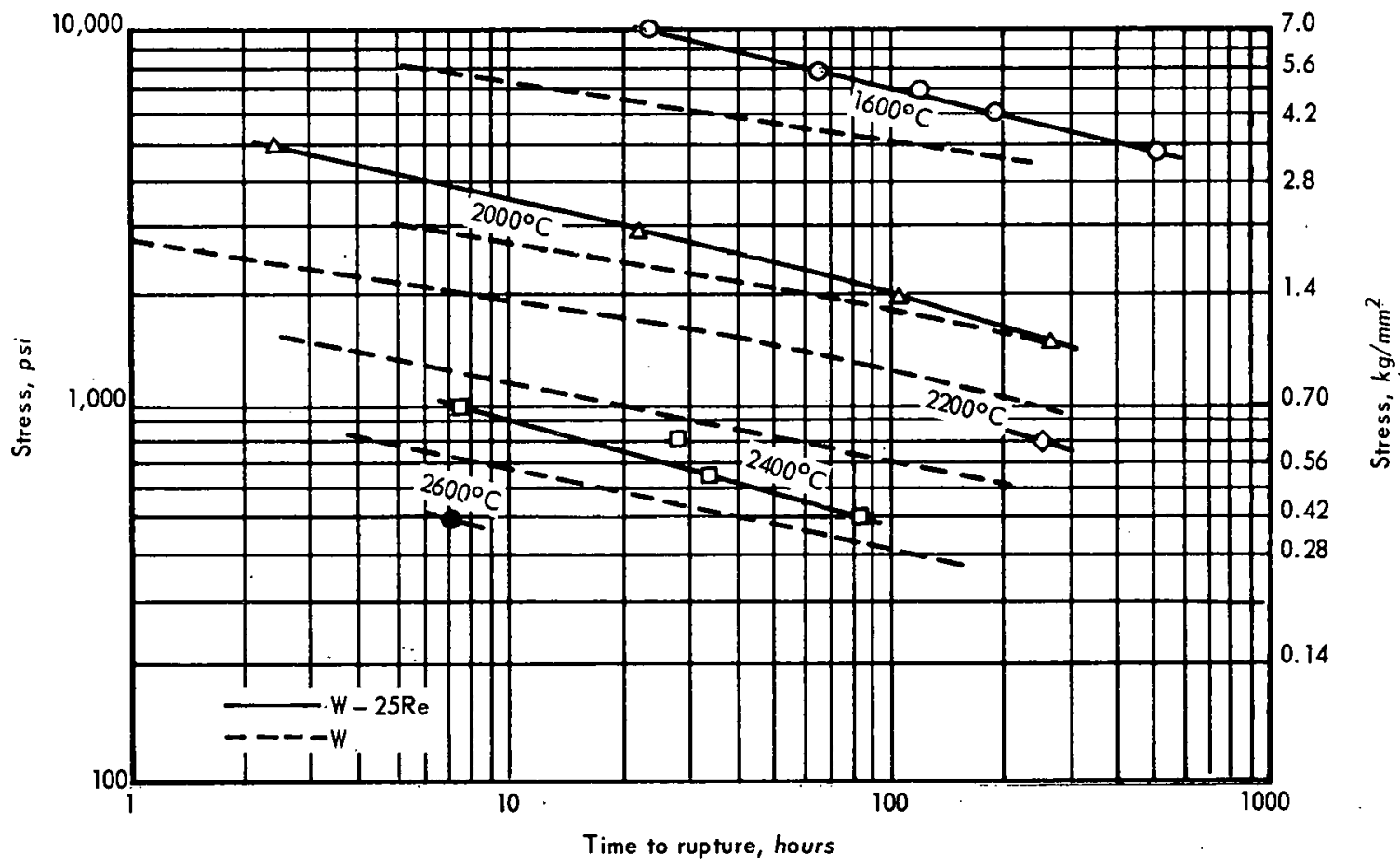

Fig. 1.2 - Stress-rupture curves for arc-cost W-25Re compared to arc-cast W, both tested in hydrogen

3،'High-Temperature Materials Program Progress Report No. 47, Yart A,' GE-NMPO, GEMP-47A, Mày 28, 1965, p. 30.

${ }^{4}$ GEMP-400A, p. 34. 


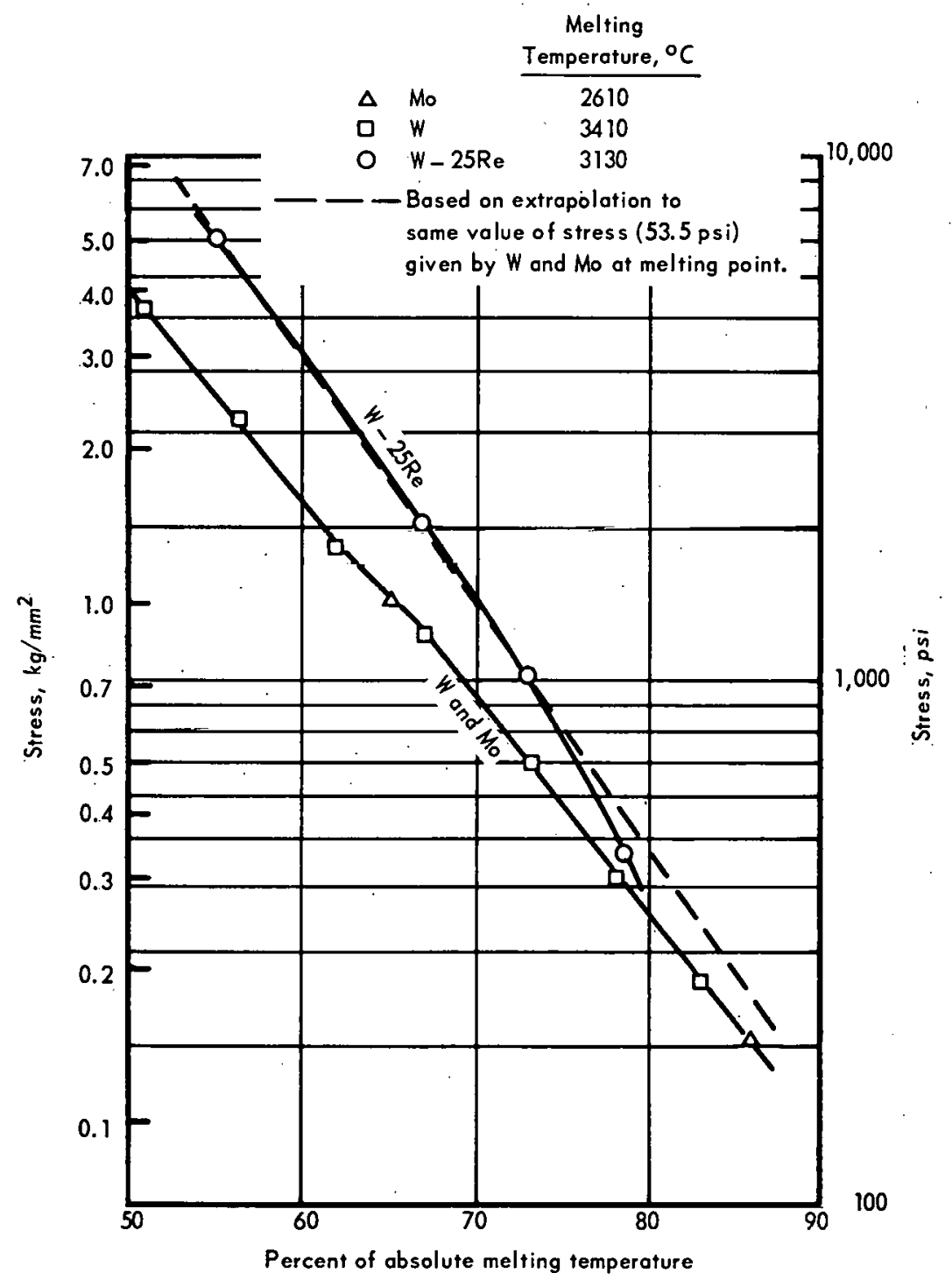

Fig. 1.3 - Stress required to cause rupture in 100 hours for arc-cost W, Mo, and $W-25 R e$

\section{W-Re-Mo}

The fabricability and stability of W-Re-Mo alloys are being investigated under Task 57015 , "Refractory-Metal Alloy Development" (section 3) as components for high-temperature reactor systems. In support of this effort, creep-rupture tests for 34 different alloy compositions were performed to determine the comparative creep resistance, rupture life, ductility, and metallographic structures. The material was fabricated by a power-metallurgy technique which involved sintering at $2600^{\circ} \mathrm{C}$ in hydrogen, rolling into $0.05-\mathrm{cm}$-thick sheet, and annealing at $1400^{\circ} \mathrm{C}$. in hydrogen. Creep-rupture specimens with a gage section $0.63 \mathrm{~cm}$ wide and $2.54 \mathrm{~cm}$ long were used to obtain creep measurements using an optical extensometer sighting on fiducial marks at each end of the gage section. A portion of the W-Re-Mo phase diagram indicating the compositions (by code number) which were creep-rupture tested is shown in Figure 1.4. 


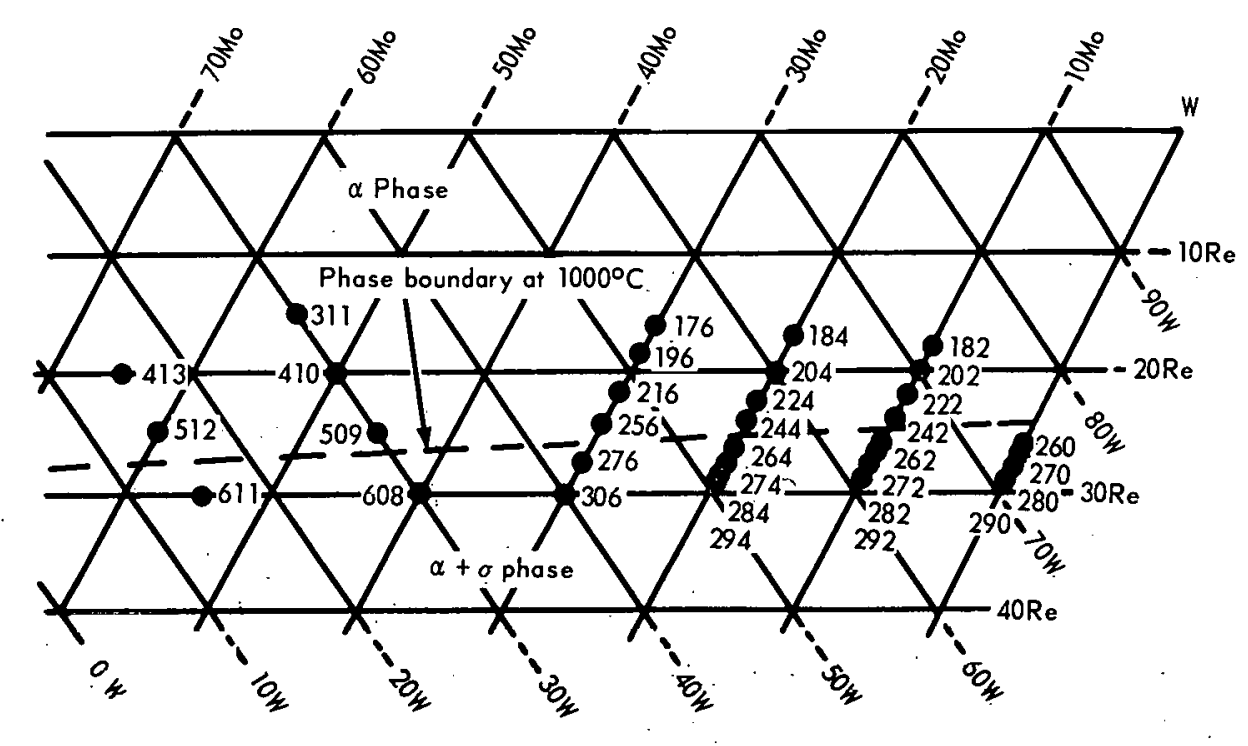

Fig. 1.4-Portion of W-Re-Mo phase diagram (at. \%) showing location of alloys evaluated and the ir code numbers

A summary of the results for the alloys containing $0,10,20$, and 30 atomic percent molybdenum is presented in Tables 1.2 and 1.3 for tests at $1600^{\circ} \mathrm{C}$ and $2200^{\circ} \mathrm{C}$, respectively. Figure 1.5 presents a summary of the results at $1600^{\circ} \mathrm{C}$ indicating the effect of composition on rupture strain and the time required to give 5-percent strain. In general, there is a transition in the ductility (based on strain at rupture) and the creep resistance in the region of 23- to 25-percent rhenium. This is apparently the effect of the phase boundary existing in this region at $1600^{\circ} \mathrm{C}$. Also, the ductility and creep resistance are decreased in the two-phase region by the addition of molybdenum for the same rhenium content (decreasing tungsten content): In the single-phase region, for alloys with 20- and 30-percent molybdenum, both ductility (at temperature) and creep resistance are increased with decreasing rhenium content (increasing tungsten content) below about 20 percent rhenium. Assuming that the material is reasonably fabricable, alloys containing $20-$ and 30-percent molybdenum with 18 - and 17-percent rhenium, respectively, are promising alloys for performance at $1600^{\circ} \mathrm{C}$ since both the creep resistance and ductility are favorable and these alloys are single phase (solid-solution alloys).

A similar summary of results for the same alloys at $2200^{\circ} \mathrm{C}$ is given in Figure 1.6. These data show a more pronounced effect due to the phase boundary. In this region the ductility is at a minimum with a significant rise on either side of the boundary. A transition in the creep resistance also occurs at the phase boundary with the solid-solution alloys being significantly stronger. It, therefore, appears that the alloys having moderate creep resistance and ductility at $2200^{\circ} \mathrm{C}$ are those containing 20 - and 30 -percent molybdenum and rhenium contents from 20 to 23 percent. Since these are solid-solution alloys, no precipitation at temperature will occur to influence the properties.

It was also noted, with one exception, that when these W-Re-Mo alloys were tested at lower stresses, at both $1600^{\circ} \mathrm{C}$ and $2200^{\circ} \mathrm{C}$, not only did the creep resistance increase (as expected) but the ductility also increased. The exception was for the $\mathrm{W}-25 \mathrm{Re}-30 \mathrm{Mo}$ alloy, both at $1600^{\circ} \mathrm{C}$ and $2200^{\circ} \mathrm{C}$. This apparently is related to the proximity of the phase boundary for this alloy. 
TABLE 1.2

CREEP-RUPTURE RESULTS ${ }^{a}$ FOR W-Re-Mo ALLOYS ${ }^{b}$ AT $1600^{\circ} \mathrm{C}$ IN HYDROGEN

\begin{tabular}{|c|c|c|c|c|c|c|c|c|c|c|c|c|c|c|}
\hline \multirow{2}{*}{$\begin{array}{l}\text { Specimen } \\
\text { No. } \\
\end{array}$} & \multirow[b]{2}{*}{ Composition, at. \% } & \multicolumn{4}{|c|}{ Stress, $\mathrm{kg} / \mathrm{mm}^{2}$} & \multicolumn{6}{|c|}{ Time to Indicated Strain, $\mathrm{hr}$} & \multicolumn{2}{|c|}{ Rupture } & \multirow{2}{*}{$\begin{array}{l}\text { Linear Creep } \\
\text { Rate, min. }-1\end{array}$} \\
\hline & & 4.22 & 3.37 & 2.11 & $0.2 \%$ & $0.5 \%$ & $1 \%$ & $2 \%$ & $3 \%$ & $5 \%$ & $10 \%$ & $\begin{array}{c}\text { Time, } \\
\text { hr }\end{array}$ & $\begin{array}{c}\text { Strain, } \\
\%\end{array}$ & \\
\hline $260-1$ & $\mathrm{~W}-26 \mathrm{Re}$ & $\mathbf{x}$ & & & 0.64 & 2.0 & 4.3 & 9.0 & 13.5 & 21.5 & 35.8 & 45.4 . & 15 & $3.9 \times 10^{-5}$ \\
\hline $270-2$ & W $-27 R e$ & $\mathbf{x}$ & & & 0.15 & 0.78 & 2.0 & 4.9 & 7.7 & 13.3 & 24.5 & 39.6 & 21 & $5.9 \times 10^{-5}$ \\
\hline $280-2$ & W-28Re & $\mathbf{x}$ & - & & 0.04 & 0.17 & 0.52 & 1.6 & 2.7 & 5.5 & 13.3 & 36.8 & 40 & $1.0 \times 10^{-4}$ \\
\hline $290-2$ & $W-29 R e$ & $\mathbf{x}$ & & & 0.02 & 0.08 & 0.23 & 0.64 & 1.2 & 2.5 & 6.4 & 26.3 & 54 & $2.1 \times 10^{-4}$ \\
\hline $182-1$ & $\mathrm{~W}-18 \mathrm{Re}-10 \mathrm{Mo}$ & $\mathbf{x}$ & & & 0.64 & 2.6 & 6.9 & 16.9 & 26.1 & 39.3 & - & 48.5 & 8. 5 & $1.7 \times 10^{-5}$ \\
\hline $202-1$ & $\mathrm{~W}-20 \mathrm{Re}-10 \mathrm{Mo}$ & $\mathbf{x}$ & & & 1.2 & 3.5 & 7.9 & 17.2 & 25.8 & 38.4 & - & 50.3 & 9.0 & $1.8 \times 10^{-5}$ \\
\hline $222-2$ & W-22Re - 10Mo & $\mathbf{x}$ & & & 1.2 & 3.2 & 6.5 & 13.1 & 19.3 & 28.4 & - & 36.6 & 7.9 & $2.5 \times 10^{-5}$ \\
\hline $242-2$ & W - 24Re - 10Mo & $\mathbf{x}$ & & & 0.39 & 1.9 & 4.3 & 9.0 & 13.8 & 20.7 & $\dot{-}$ & 25.8 & 7.7 & $3.5 \times 10^{-5}$ \\
\hline $262-2$ & $\mathrm{~W}-26 \mathrm{Re}-10 \mathrm{Mo}$ & $\mathbf{x}$ & & & 0.65 & 1.9 & 4.0 & 7.7 & 10.6 & - & - & 16.4 & 6.0 & $4.0 \times 10^{-5}$ \\
\hline $262-4$ & $\mathrm{~W}-26 \mathrm{Re}-10 \mathrm{Mo}$ & $\mathbf{x}$ & & & 0.46 & 1.6 & 3.3 & 6.5 & 9.3 & 13.3 & _ & 17.2 & 9.0 & $4.7 \times 10^{-5}$ \\
\hline $272-2$ & $\mathrm{~W}-27 \mathrm{Re}-10 \mathrm{Mo}$ & $\mathbf{x}$ & & & 0.55 & 1.7 & 3.2 & 6.4 & 9.6 & 15.2 & .24 .7 & 28.7 & 14 & $5.2 \times 10^{-5}$ \\
\hline $272-4$ & W-27Re - 10Mo & $\mathbf{x}$. & & & 0.42 & 1.2 & 2.4 & 4.5 & 6.4 & 9.5 & 13.6 & 13.6 & 10 & - \\
\hline $282-2$ & $\mathrm{~W}-28 \mathrm{Re}-10 \mathrm{Mo}$ & $\mathrm{x}$ & & $\cdot \cdot$ & 0.07 & 0.40 & 1.0 & 2.5 & 4. 1 : & 7.5 & 14.8 & 25.1 & 28 & $1.0 \times 10^{-4}$ \\
\hline $292-2$ & $\mathrm{~W}-29 \mathrm{Re}-10 \mathrm{Mo}$ & $\mathbf{x}$ & & & - & 0.05 & 0.20 & 0.56 & 1.0 & 2.2 & 5. 8 & 16.4 & 29 & $2.3 \times 10^{-4}$ \\
\hline $184-1$ & $\mathrm{~W}-18 \mathrm{Re}-20 \mathrm{Mo}$ & $\dot{x}$ & & & 0.50 & 2.0 & 5: 2 & 11.6 & 18.1 & 30.2 & 55.7 & 95.7 & 23 & $2.6 \times 10^{-5}$ \\
\hline 204-1 & $\mathrm{W}-20 \mathrm{Re}-20 \mathrm{Mo}$ & $\mathrm{x}$ & & & 0.43 & 1.5 & 3.7 & 8.7 & 13.0 & 19.8 & - & 25.5 & 9.0 & $3.3 \times 10^{-5}$ \\
\hline $224-3$ & $\mathrm{~W}-22 \mathrm{Re}-20 \mathrm{Mo}$ & $\mathbf{x}$ & & & 1.0 & 2.6 & 5.2 & 10.2 & 14.1 & 19.2 & _ & 23.1 & 9.0 & $3.0 \times 10^{-5}$ \\
\hline $224-4$ & $\mathrm{~W}-22 \mathrm{Re}-20 \mathrm{Mo}$ & & $\dot{x}$ & & $2.2^{\circ}$ & 5.8 & 12.1 & 25.0 & 35.3 & 52.0 & 70.0 & 71.6 & 11.0 & $1.3 \times 10^{-5}$ \\
\hline 244-1 & $\mathrm{W}-24 \mathrm{Re}-20 \mathrm{Mo}$ & $\mathbf{x}$ & & & 0.35 & 1.4 & 3.0 & 5.6 & 7.3 & - & - & 9.2 & 4.4 & $4.7 \times 10^{-5}$ \\
\hline 264-1 & $\mathrm{W}-26 \mathrm{Re}-20 \mathrm{Mo}$ & $\mathbf{x}$ & & & 0.81 & 1.9 & .3 .5 & 6.1 & 7.8 & 10.1 & - & 12.2 & 9.0 & $4.7 \times 10^{-5}$ \\
\hline $264-4$ & $\mathrm{~W}-26 \mathrm{Re}-20 \mathrm{Mo}$ & $\mathbf{x}$ & & & 0.24 & 0.88 & 1.9 & 3.8 & 5.2 & 7.2 & 9.2 & 9.2 & 12 & - \\
\hline 274-2 & $\mathrm{W}-27 \mathrm{Re}-20 \mathrm{Mo}$ & $\mathrm{x}$ & & & 0.58 & 1.4 & .2 .7 & 5.0 & 7.1 & 10.0 & 13.5 & 14.5 & 16 & $5.8 \times 10^{-5}$ \\
\hline $274-4$ & W $-27 \mathrm{Re}-20 \mathrm{Mo}$ & $\mathbf{x}$ & & & 0.59 & 1.2 & 2.1 & 3.8 & 5.0 & 6.7 & 8.4 & 8.4 & 10 & - \\
\hline $284-4$ & $\mathrm{~W}-28 \mathrm{Re}-20 \mathrm{Mo}$ & $\mathbf{x}$ & & & 0.46 & 1.1 & 2.2 & 4.3 & 6.4 & 9.7 & 14.7 & 17. 0 & 13 & $7.4 \times 10^{-5}$ \\
\hline $294-2$ & $\mathrm{~W}-29 \mathrm{Re}-20 \mathrm{Mo}$ & $\mathbf{x}$ & . & & 0.10 & 0.53 & 1.3 & 2.8 & 4.3 & 7,0 & $11: 9$ & 17.2 & 21 & $1.1 \times 10^{-4}$ \\
\hline $176-1$ & $\mathrm{~W}-17 \mathrm{Re}-30 \mathrm{Mo}$ & $\mathbf{x}$ & & & 0.34 & 1.1 & 2.8 & 8.2 & 15.4 & 33.0 & 72.3 & 99.4 & 16 & $1.9 \times 10^{-5}$ \\
\hline $196-2$ & $\mathrm{~W}-19 \mathrm{Re}-30 \mathrm{Mo}$ & $\mathbf{x}$ & & & 0.55 & 1.4 & 3.2 & 6.6 & 9.6 & 13.8 & - & 15.3 & 6.0 & $4.8 \times 10^{-5}$ \\
\hline $216-1$ & W-21Re - 30Mo & $\mathbf{x}$ & & & 0.26 & 1.1 & 2.5 & 5.1 & .7 .2 & 10.1 & - & 11.4 & 7.0 & $5.9 \times 10^{-5}$ \\
\hline $256-1$ & $\mathrm{~W}-25 \mathrm{Re}-30 \mathrm{Mo}$ & $\mathbf{x}$ & & & 0.70 & 1.5 & 2.8 & 5.3 & 7.6 & 10.6 & 13.9 & 14.8 & 14 & $6.1 \times 10^{-5}$ \\
\hline $256-2$ & $\mathrm{~W} .-25 \mathrm{Re}-30 \mathrm{Mo}$ & & $\mathbf{x}$ & & 1.2 & 2.7 & 5.1 & 9.7 & 13.4 & 18.9 & 24.9 & 25.9 & 12 & $1.7 \times 10^{-5}$ \\
\hline $276-2$ & $\mathrm{~W}-27 \mathrm{Re}-30 \mathrm{Mo}$ & $\mathbf{x}$ & & & 0.32 & 0.90 & 1.6 & 2.7 & 3.7 & 5.1 & - & 6.6 & 9.5 & $9.0 \times 10^{-5}$ \\
\hline $276-3$ & $\mathrm{~W}-27 \mathrm{Re}-30 \mathrm{Mo}$ & & & $\mathbf{x}$ & 5.9 & 12.4 & 25.6 & 51.6 & 76.5 & 119 & 194 & 241.0 & 17 & $6.3 \times 10^{-6}$ \\
\hline $306-8$ & $\mathrm{~W}-30 \mathrm{Re}-30 \mathrm{Mo}$ & $\mathbf{x}$ & & & 0.03 & 0.08 & 0.22 & 0.54 & 0.93 & 1.9 & 4.7 & 10.0 & 25 & $3.0 \times 10^{-4}$ \\
\hline $306-7$ & $\mathrm{~W}-30 \mathrm{Re}-30 \mathrm{Mo}$ & & $\mathbf{x}$ & & 0.06 & 0.19 & 0.40 & 0.94 & 1.6 & 3.3 & 8.6 & 21.6 & 28 & $1.6 \times 10^{-4}$ \\
\hline $306-6$ & $\mathrm{~W}-30 \mathrm{Re}-30 \mathrm{Mo}$ & & & $\mathbf{x}$ & 0.19 & 0.51 & 1.2 & 3.2 & 6.1 & 14.1 & 39.2 & 133.7 & 42 & $3.1 \times 10^{-5}$ \\
\hline
\end{tabular}

${ }^{2}$ After annealing at $1600^{\circ} \mathrm{C}$ for 2 hours in $\mathrm{H}_{2}$.

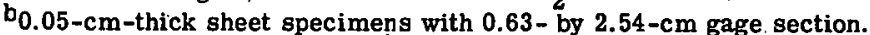


TABLE 1.3

CREEP-RUPTURE RESULTS ${ }^{2}$ FOR W-Re-Mo ALLOYS ${ }^{b}$ AT $2200^{\circ} \mathrm{C}$ IN HYDROGEN

\begin{tabular}{|c|c|c|c|c|c|c|c|c|c|c|c|c|c|}
\hline \multirow[b]{2}{*}{$\begin{array}{l}\text { Specimen } \\
\text { No. } \\
\end{array}$} & \multirow[b]{2}{*}{ Composition, at. $\%$} & \multirow{2}{*}{\multicolumn{2}{|c|}{ Stress, $\mathrm{kg} / \mathrm{mm}^{2}$}} & \multirow{2}{*}{\multicolumn{7}{|c|}{ Time to Indlcated Straln, $\mathrm{hr}$}} & \multicolumn{2}{|c|}{ Rupture } & \multirow[b]{2}{*}{$\begin{array}{l}\text { Linear Creop } \\
\text { Rate, min.-1 }\end{array}$} \\
\hline & & & & & & & & & & & Time, & strain, & \\
\hline $260-2$ & $\mathbf{W}-26 \operatorname{Re}$ & $\mathbf{x}$ & & 0.18 & 0.61 & 1.3 & 2.8 & 4. 3 & 7.0 & 13.8 & 30.6 & 45 & $1.1 \times 10^{-4}$ \\
\hline $270-3$ & W - 27Re & $\mathbf{x}$ & & 0.06 & 0.38 & 1.0 & 2.1 & 3. 3 & 5.0 & 10.9 & 24.5 & .42 & $1.4 \times 10^{-4}$ \\
\hline $270-1$ & $\mathbf{W}-27 \mathrm{Re}$ & & $\mathrm{x}$ & 0.34 & 0.80 & 1.9 & 3.9 & 6.0 & 10.2 & .20 .9 & 68.6 & 58 & $7.9 \times 10^{-5}$ \\
\hline $280-3$ & W - 28Re & $\mathbf{x}$ & & 0.14 & 0.48 & 1.1 & 2.3 & 3. 5 & 6.0 & 11.2 & 23.9 & 42 & $1.4 \times 10^{-4}$ \\
\hline $280-1$ & W - 28Re & & $\mathbf{x}$ & 0.38 & 0.94 & 2.0 & 4.0 & 6. 3 & 10.8 & 21.5 & 62.2 & 56 & $7.2 \times 10^{-5}$ \\
\hline $290-3$ & W - 29Re & $\mathbf{x}$ & & 0.21 & 0.63 & 1.4 & 2.8 & 4.3 & 7.0 & 12.7 & 21.8 & 32 & $1.1 \times 10^{-4}$ \\
\hline $290-1$ & W-29Re & & $\mathbf{x}$ & 0.46 & 1.2 & 2.5 & 5.3 & 8. 4 & 14.6 & 27.8 & 59.8 & 41 & $5.4 \times 10^{-5}$ \\
\hline $182-2$ & $W-18 \mathrm{Re}-10 \mathrm{Mo}$ & $\mathbf{x}$ & & 0.62 & 1.7 & 3.6 & 7.8 & 11.8 & 20.6 & 42.2 & 128.2 & 46 & $3.8 \times 10^{-5}$ \\
\hline 202-2 & $\mathrm{W}-20 \mathrm{Re}-10 \mathrm{Mo}$ & $\mathbf{x}$. & & 0.40 & 1.1 & 2.4 & 5.3 & 8. 5 & 15.0 & 31.5 & 96.1 & 42 & $5.1 \times 10^{-5}$ \\
\hline $222-1$ & W - 22Re - $10 \mathrm{MO}$ & $\mathrm{x}$ & & 0.23 & 0.98 & 2.3 & 4.8 & 7.6 & 13.1 & 26.6 & 73.0 & 40 & $6.1 \times 10^{-5}$ \\
\hline $242-1$ & $\mathrm{~W}-24 \mathrm{Re}-10 \mathrm{Mo}$ & $\mathbf{x}$ & & 0.37 & 0.96 & 2.0 & 4.0 & 6. 3 & 10.7 & 21.6 & 55.4 & 36 & $7.6 \times 10^{-5}$ \\
\hline $262-3$ & $\mathrm{~W}-26 \mathrm{Re}-10 \mathrm{Mo}$ & $\mathbf{x}$ & & 0.36 & 1.0 & 2.0 & 4.0 & 6.1 & 10.0 & 18.0 & 32.0 & 32 & $8.1 \times 10^{-5}$ \\
\hline $262-5$ & $W-26 R e-10 M O$ & $\mathbf{x}$ & & 0.25 & 0.51 & 0.98 & 2.0 & 3. 0 & 4.8 & 9.2 & 15.6 & 25 & $1.7 \times 10^{-4}$ \\
\hline $262-1$ & $\mathrm{~W}-26 \mathrm{Re}-10 \mathrm{Mo}$ & & $\mathbf{x}$ & 0.66 & 1.6 & 3.2 & 6.5 & 9. 7 & 16.1 & 30,6 & 77.3 & 52 & $5.2 \times 10^{-5}$ \\
\hline $272-3$ & $w-27 R e-10 M o$ & $\mathbf{x}$ & & 0.24 & 0.72 & 1.3 & 2.6 & 3. 8 & 6.2 & 11,0 & 20.5 & 38 & $1.3 \times 10^{-4}$ \\
\hline $272-5$ & W-27Re - 10Mo & $\mathrm{x}$ & & 0.17 & 0.41 & 0.80 & 1.6 & 2.5 & 4.2 & 8.5 & 23.8 & 38 & $1.9 \times 10^{-4}$ \\
\hline $282-3$ & $\mathrm{~W}-28 \mathrm{Re}-10 \mathrm{Mo}$ & $\ddot{x}$ & & 0.24 & 0.57 & 1.1 & 2.2 & 3. 4 & 5.4 & 9.5 & 16.6 & 40 & $1.5 \times 10^{-4}$ \\
\hline $282-1$ & W - 28Re - 10Mo & & $\mathbf{x}$ & 0.30 & 0.78 & 1.6 & 3. 2 & 4.9 & 8.4 & 17.0 & 45.4 & 58 & $9.7 \times 10^{-5}$ \\
\hline $292-3$ & $\mathrm{~W}-29 \mathrm{Re}-10 \mathrm{Mo}$ & $\mathbf{x}$ & & 0.18 & 0.52 & 1.2 & 2.4 & 3.6 & 5.8 & 10.1 & $\begin{array}{l}16.6 \\
16.6\end{array}$ & 32 & $1.3 \times 10^{-4}$ \\
\hline $184-2$ & $\mathrm{~W}-18 \mathrm{Re}-20 \mathrm{Mo}$ & $\mathbf{x}$ & & 0.33 & 0.83 & 1.7 & 3.5 & 5.5 & 9.7 & 20.2 & 54.7 & 43 & $7.9 \times 10^{-5}$ \\
\hline 204-2 & $\mathrm{W}-20 \mathrm{Re}-20 \mathrm{Mo}$ & $\mathrm{x}$ & & 0.41 & 1.2 & 2.7 & 5.8 & 8. 8 & 15.0 & 28.1 & 56.7 & 31 & $5.4 \times 10^{-5}$ \\
\hline $224-1$ & $\mathrm{~W}-22 \mathrm{Re}-20 \mathrm{MO}$ & $\mathbf{x}$ & & 0.50 & 1.5 & 3.0 & 6.3 & 9.6 & 16.2 & 30.0 & 58.5 & 31 & $5.0 \times 10^{-5}$ \\
\hline $224-2$ & $\mathrm{~W}-22 \operatorname{Re}-20 \mathrm{Mo}$ & & $\mathbf{x}$ & 0.75 & 2.0 & 4.3 & 9.4 & 14.8 & 25.9 & 54.5 & 183.1 & 45 & $2.9 \times 10^{-5}$ \\
\hline 244-2 & $\mathrm{W}-24 \mathrm{Re}-20 \mathrm{Mo}$ & $\mathbf{x}$ & & 0.48 & 1.3 & $2: 8$ & 5.9 & 9.3 & 16.2 & 33.4 & 73.6 & 30 & $4.8 \times 10^{-5}$ \\
\hline $264-2$ & $\mathrm{~W}-26 \mathrm{Re}-20 \mathrm{Mo}$ & $\mathrm{x}$ & & 0.37 & 0.94 & 1.9 & 3. 8 & 5.6 & 9.0 & 15.4 & 23.0 & 23 & $8.8 \times 10^{-5}$ \\
\hline $264-3$ & $\mathrm{~W}-26 \mathrm{Re}-20 \mathrm{Mo}$ & $\mathbf{x}$ & & 0.35 & 1.1 & 2.2 & 4.6 & 7.2 & 12.4 & 25.4 & $\mathbf{5 1 . 5}$ & 28 & $6.4 \times 10^{-5}$ \\
\hline $274-3$ & $\mathrm{~W}-27 \mathrm{Re}-20 \mathrm{Mo}$ & $\mathrm{x}$ & & 0.62 & 1.6 & 3.3 & 6.6 & 10.0 & 15.8 & 24.8 & 29.0 & 15 & $5.0 \times 10^{-5}$ \\
\hline $274-1$ & $\mathrm{~W}-2 \mathrm{~T}_{\mathrm{Re}}-20 \mathrm{Mo}$ & $\mathbf{x}$ & & 0.40 & 1.1 & 2.5 & 5.6 & 8.2 & 13.2 & 21.9 & 27.9 & 16 & $5.4 \times 10^{-5}$ \\
\hline $274-5$ & $\mathrm{~W}-27 \mathrm{Re}-20 \mathrm{Mo}$ & $\mathrm{x}$ & & 0.35 & 0.74 & 1.4 & 3.0 & 4.5 & 7.4 & 14.0 & 24.2 & 26 & $1.1 \times 10^{-4}$ \\
\hline $284-3$ & $\mathrm{~W}-28 \mathrm{Re}-20 \mathrm{Mo}$ & $\mathbf{x}$ & & 0.14 & 0.42 & $0: 90$ & 1.8 & 2.7 & 4.2 & 7.4 & 14.5 & 33 & $1.8 \times 10^{-4}$ \\
\hline $284-1$ & $\mathrm{~W}-28 \mathrm{Re}-20 \mathrm{Mo}$ & & $\mathrm{x}$ & 0.40 & 1: 1 & 2.3 & 4.7 & 7.0 & 11.3 & 20.5 & 42.0 & 40 & $7.0 \times 10^{-5}$ \\
\hline $294-3$ & $\mathrm{~W}-29 \mathrm{Re}-20 \mathrm{Mo}$ & $\mathrm{x}$ & & 0.10 & 0.32 & 0.72 & 1.5 & 2.3 & 3.8 & 6.8 & 12.6 & 35 & $2.1 \times 10^{-4}$ \\
\hline & $\mathrm{W}-17 \mathrm{Re}-30 \mathrm{Mo}$ & $\mathrm{x}$ & & 8.2 & & & 86.5 & & & - & 173.7 & 6 & $3.8 \times 10^{-6}$ \\
\hline $196-1$ & $\mathrm{w}-19 \mathrm{Re}-30 \mathrm{Mo}$ & $\hat{x}$ & & 0.69 & 1.8 & 3.8 & $\begin{array}{r}7.9 \\
7.9\end{array}$ & 12.1 & 20.4 & 38.1 & 70.4 & 31 & $3.9 \times 10^{-5}$ \\
\hline $196-3$ & $\mathrm{~W}-19 \mathrm{Re}-30 \mathrm{Mo}$ & & $\mathrm{x}$ & 1.2 & 3.2 & 6.7 & 14.3 & 22.4 & 39.4 & 81.5 & 240.4 & 42 & $1.9 \times 10^{-5}$ \\
\hline $216-2$ & $\mathrm{~W}-21 \operatorname{Re}-30 \mathrm{Mo}$ & $\mathbf{x}$ & & 0.40 & 1.5 & 3.1 & 6.8 & 10.6 & 18.2 & 35.7 & 70.5 & 30 & $4.4 \times 10^{-5}$ \\
\hline $236-1$ & $\mathrm{~W}-23 \mathrm{Re}-30 \mathrm{Mo}$ & $\mathrm{x}$ & & 0.69 & 1.7 & 3.4 & 6.8 & 10.3 & 17.1 & 33.1 & 68.6 & 31 & $4.9 \times 10^{-5}$ \\
\hline $256-3$ & $\mathrm{~W}-25 \mathrm{Re}-30 \mathrm{Mo}$ & $\mathbf{x}$ & & 0.20 & 0.90 & 1.9 & 3. 9 & 6.0 & 10.1 & 19.2 & 28.8 & 18 & $8.1 \times 10^{-5}$ \\
\hline $256-4$ & $\mathrm{~W}-25 R e-30 \mathrm{Mo}$ & & $\mathrm{x}$ & 0.40 & 1.3 & 3.0 & 6.8 & 11.6 & 22.7 & 59.4 & 102.0 & 18 & $2.2 \times 10^{-5}$ \\
\hline $276-1$ & $\mathrm{~W}-27 \mathrm{Re}-30 \mathrm{Mo}$ & $\mathbf{x}$ & & 0.25 & 0.84 & $1: 8$ & 3. 9 & .6 .0 & 10.1 & 20.5 & 43.2 & 31 & $7.8 \times 10^{-5}$ \\
\hline $306-11$ & $\mathrm{~W}-30 \mathrm{Re}-30 \mathrm{Mo}$ & $\mathbf{x}$ & & 0.17 & 0.43 & 0.80 & 1.9 & 2.8 & 4.9 & 9.7 & 22.0 & 32 & $1.6 \times 10^{-4}$ \\
\hline $306-10$ & $\mathrm{~W}-30 \mathrm{Re}-30 \mathrm{Mo}$ & & $\mathrm{x}$ & 0.32 & 0.76 & $\begin{array}{l}1.6 \\
1.6\end{array}$ & 3. 3 & 5.2 & 8.9 & 18.9 & 70.0 & 54 & $8.4 \times 10^{-5}$ \\
\hline
\end{tabular}

$0.05-\mathrm{cm}$-thick sheet specimens with $0.63-$ by $2.54-\mathrm{cm}$ gage section 

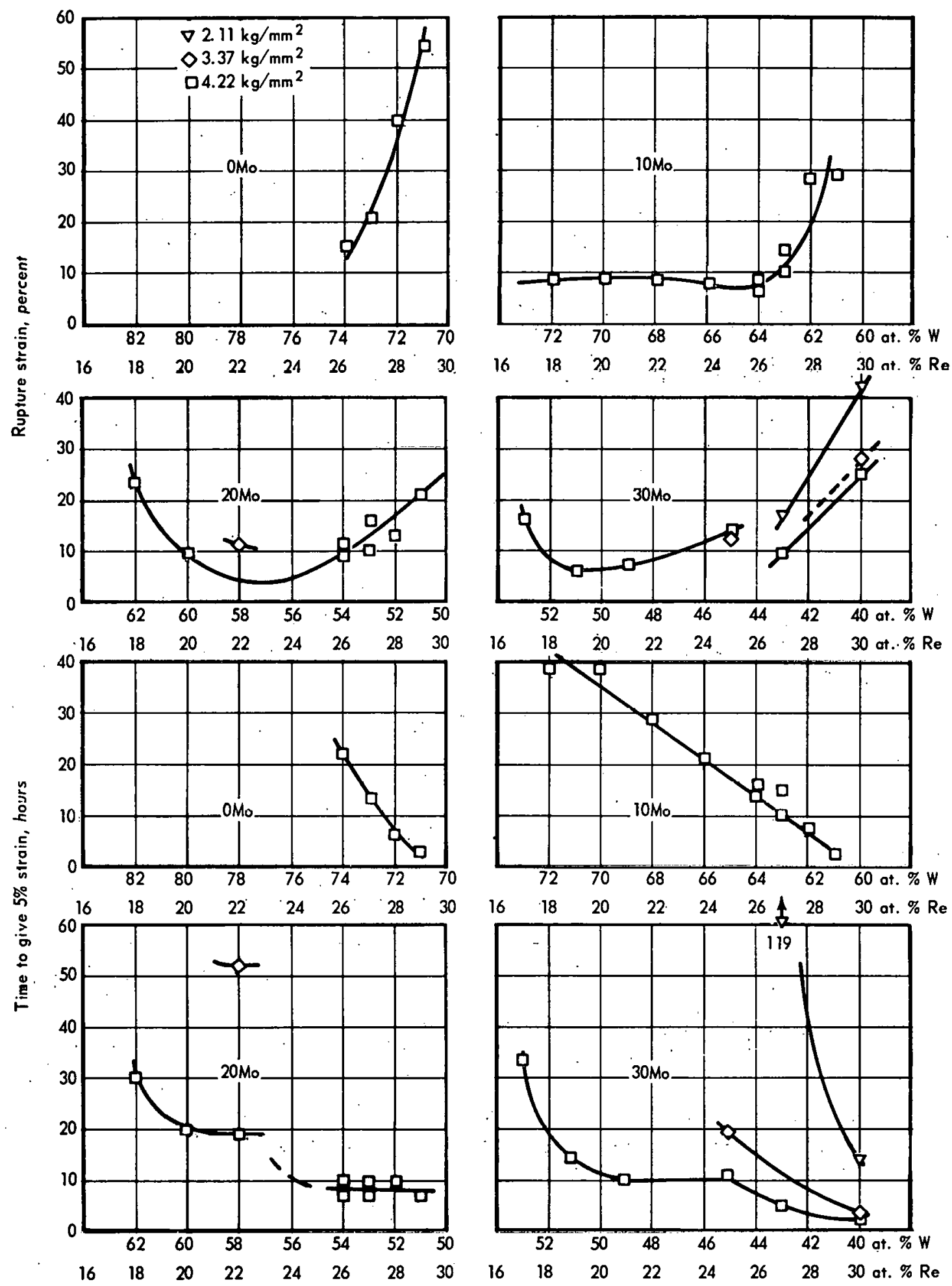

Fig. 1.5 - Creep-rupture results for W-Re-Mo alloys at $1600^{\circ} \mathrm{C}$ in hydrogen 

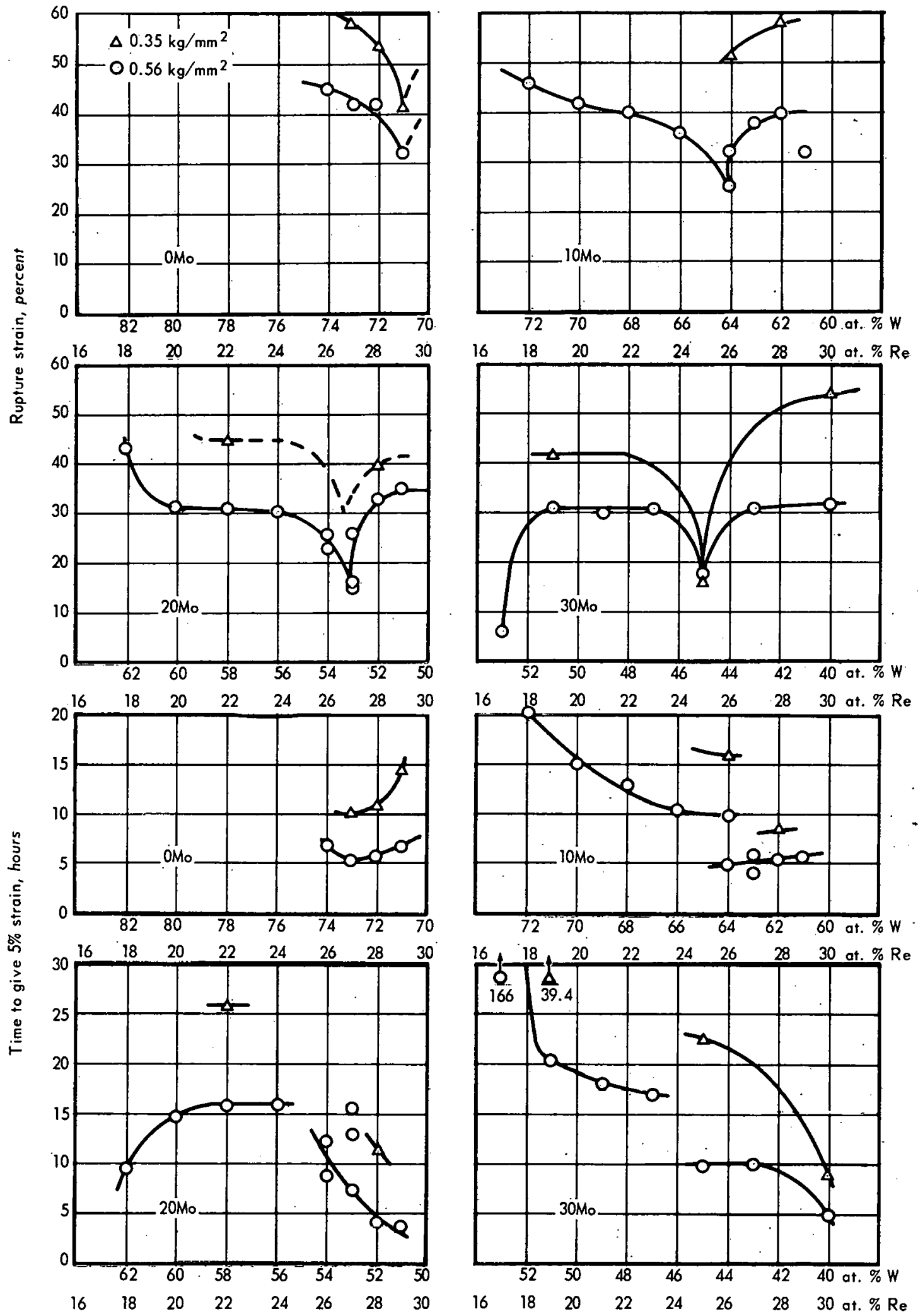

Fig. 1.6 - Creep-rupture results for W-Re-Mo alloys af $2200^{\circ} \mathrm{C}$ in hydrogen 
Typical microstructures of the various W-Re-Mo test specimens both before and after testing are shown in Figure 1.7; microstructures of additional compositions were shown previously..$^{5}$ No significant differences in the corresponding structures were observed except for some of the material with the higher amounts of rhenium which exhibited pronounced sigma phase; but the amount of sigma phase decreased as the amount of molybdenum was increased. The grain boundary separation due to the strain was also similar for each alloy at both $1600^{\circ} \mathrm{C}$ and $2200^{\circ} \mathrm{C}$.

A similar summary of the creep-rupture results for the W-Re-Mo alloys along the 15 and 30 atomic percent tungsten lines of the phase diagram (Figure 1.4) is given in Tables 1.4 and 1.5 for tests at $1600^{\circ} \mathrm{C}$ and $2200^{\circ} \mathrm{C}$, respectively. Figure 1.8 shows the effect of alloy composition on both the ductility and creep resistance at $1600^{\circ} \mathrm{C}$ and $2200^{\circ} \mathrm{C}$ for various stress levels. At $1600^{\circ} \mathrm{C}$, the ductility, based on the strain at rupture, is relatively insensitive to both stress and composition. Creep resistance of the two alloys with 15-per cent tungsten is also relatively insensitive to composition. Creep resistance of the alloys with 30-percent tungsten decreases with increasing rhenium and decreasing molybdenum content. The behavior is about the same at both stress levels evaluated. At $2200^{\circ} \mathrm{C}$ (see Figure 1.8), ductility is noticeably sensitive to composition for both the 15- and 30-percent tungsten alloys; ductility increases with increasing rhenium and decreasing molybdenum content. In addition, ductility increases as the stress is decreased. Creep resistance, based on the time to give 5-percent strain, decreases as the ductility increases. This characteristic is about the same at the different stress levels investigated. At $2200^{\circ} \mathrm{C}$, the alloys containing 25-: and 30-percent rhenium with either 15- or 30 -percent tungsten have approximately the same creep resistance. The trade-off of molybdenum for tungsten apparently has no effect on the creep resistance. The significant change is in the ductility of the 25 - and 30-percent rhenium alloys. Those containing 30 -percent tungsten are at least twice as ductile as 15-percent tungsten alloys. This difference is about the same at the three different stress levels studied.

Microstructures of these tungsten alloys were shown previously. ${ }^{6}$ No significant differences were observed due to variations in the rhenium and molybdenum contents. The grain size at $1600^{\circ} \mathrm{C}$ was about the same as that observed at $2200^{\circ} \mathrm{C}$. The $\mathrm{W}-30 \mathrm{Re}-40 \mathrm{Mo}$ alloy dis- . played a significant amount of sigma phase in both the as-fabricated material and in the specimen tested at $1600^{\circ} \mathrm{C}$; at $2200^{\circ} \mathrm{C}$, the sigma phase was apparently in solution. The other alloys displayed no unusual characteristics.

\section{Comparison of Test Data}

Figures 1.9 and 1.10 present the creep curves for a number of refractory metals and alloys at $1600^{\circ} \mathrm{C}$ for stresses of 3.37 and $4.22 \mathrm{~kg} / \mathrm{mm}^{2}$ and at $2200^{\circ} \mathrm{C}$ for stresses of 0.35 and $0.56 \mathrm{~kg} / \mathrm{mm}^{2}$, respectively. At $1600^{\circ} \mathrm{C}$, the unalloyed rhenium is the most creep resistant at both stress levels for the total range of strain although the time to rupture (at

$4.22 \mathrm{~kg} / \mathrm{mm}^{2}$ ) is not significantly different from that of $\mathrm{W}-25 \operatorname{Re}$ or $\mathrm{W}-30 \mathrm{Re}$. At $2200^{\circ} \mathrm{C}$, unalloyed molybdenum is obviously the least creep resistant (Figure 1.10) of the materials evaluated. Since the slopes of the creep curves in Figures 1.9 and 1.10 vary with strain from one material to another, a material which is more creep resistant than another at 1 hour, is not necessarily more creep resistant than the other at 100 hours. The reasons for this are not completely understood but are probably related to a number of variables such as the material processing history, grain size at test temperature, the mechanism for creep, and melting temperature.

\footnotetext{
S، 'High-Temperature Materials Program Progress Report No. 59, Part A, " GE-NMPO, GEMP-59A, May 31, 1966, Figure 3.13, pp. 35-37.

6،'High-Temperature Materials Program Progress Report No. 61, "GE-NMPO, GEMP-61, September 30, 1966, Figures 2.6 and 2.7 , pp. 22-23.
} 


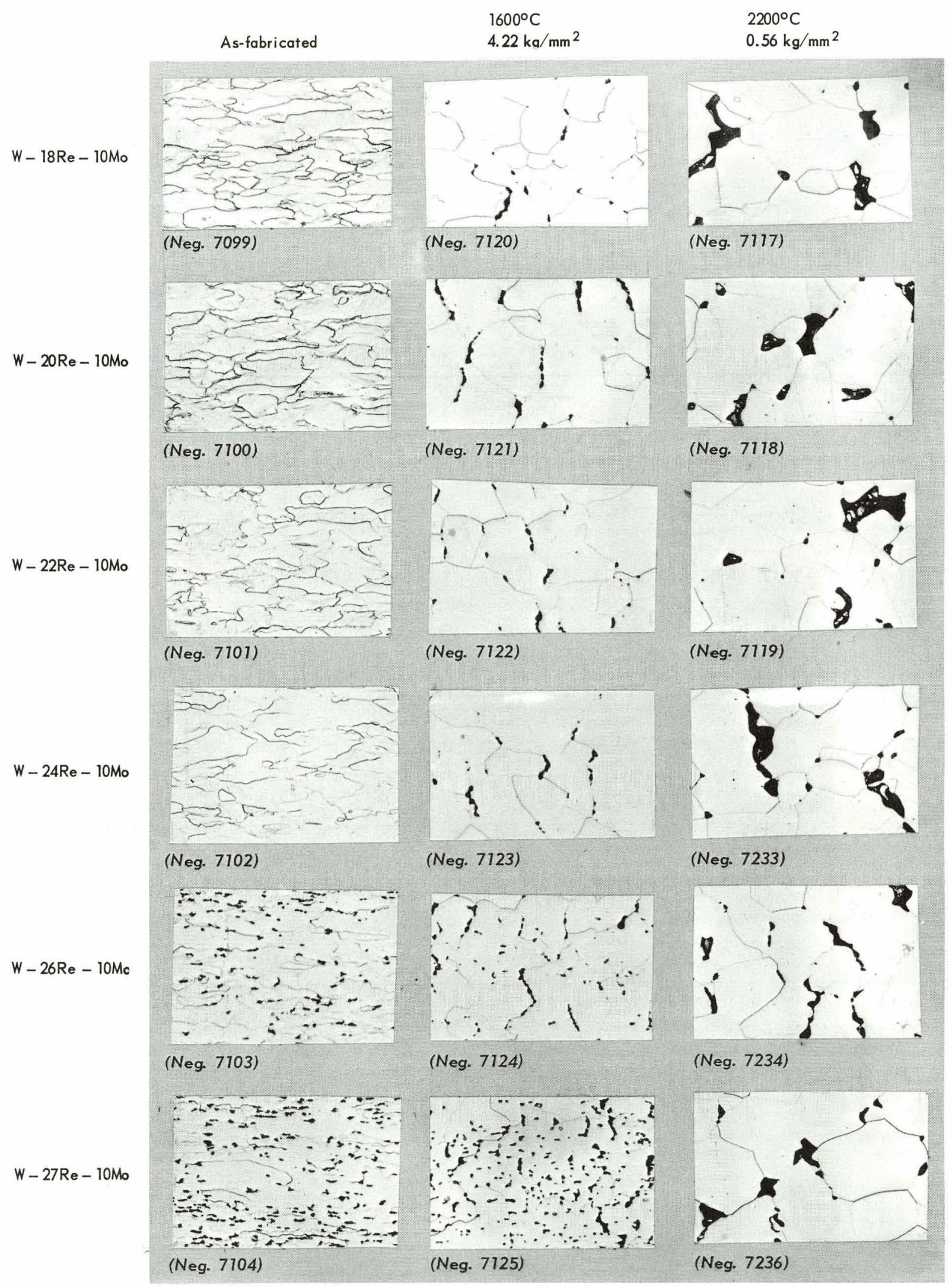

Fig. 1.7-Photomicrographs of W-Re-Mo (at. \%) sheet before and after creep-rupture testing (250X) 
TABLE 1.4

CREEP-RUPTURE RESULTS OF W-RE-MO ALLOYS TESTED AT $1600^{\circ} \mathrm{C}$ IN HYDROGEN ${ }^{\mathrm{a}}$

\begin{tabular}{|c|c|c|c|c|c|c|c|c|c|c|c|c|c|}
\hline \multirow{3}{*}{$\begin{array}{l}\text { Specimen } \\
\text { No. }\end{array}$} & \multirow{2}{*}{\multicolumn{3}{|c|}{$\begin{array}{l}\text { Composition, } \\
\text { at. \% }\end{array}$}} & \multirow{3}{*}{$\begin{array}{l}\text { Stress, } \\
\mathrm{kg} / \mathrm{mm}^{2}\end{array}$} & \multirow{2}{*}{\multicolumn{6}{|c|}{ Time to Indicated Strain, $\mathrm{hr}$}} & \multicolumn{2}{|c|}{ Rupture } & \multirow{3}{*}{$\begin{array}{c}\text { Linear } \\
\text { Creep Rate, } \\
\text { min-1 }^{-1}\end{array}$} \\
\hline & & & & & & & & & & & \multirow{2}{*}{$\frac{\text { Time, }}{\mathrm{hr}}$} & \multirow{2}{*}{$\frac{\text { Strain, }}{\%}$} & \\
\hline & $\overline{\mathrm{W}}$ & $\mathrm{Re}$ & Mo & & $0.5 \%$ & $1 \%$ & $2 \%$ & $3 \%$ & $5 \%$ & $10 \%$ & & & \\
\hline $311-1$ & 30 & 15 & 55 & 4.22 & 0.65 & 1.55 & 4.00 & 6.80 & 12.0 & 18.0 & 18.0 & 10 & $6.0 \times 10^{-5}$ \\
\hline $410-1$ & & 20 & 50 & 4.22 & 0.40 & 1.00 & 2. 64 & 4.69 & 8.95 & 17. 3 & 20.2 & 13 & $7.7 \times 10^{-5}$ \\
\hline $509-1$ & & 25 & 45 & 4.22 & 0.37 & 0.66 & 1.18 & 1.61 & 2.30 & 3. 24 & 3.31 & 10 & - \\
\hline $608-1$ & & 30 & 40 & 4.22 & 0.20 & 0.46 & 0.96 & 1.44 & 2. 32 & 3. 84 & 4.53 & 15 & - \\
\hline 413 & 15 & 20 & 65 & 4.22 & - & - & - & - & - & - & - & - & - \\
\hline $512-1$ & & 25 & 60 & 4.22 & 0.07 & 0.20 & 0.43 & 0.62 & 0.94 & - & 1.34 & 9.5 & - \\
\hline $611-1$ & & 30 & 55 & 4.22 & 0.26 & 0.41 & 0.66 & 0.88 & 1.22 & 1.67 & 1. 73 & 11 & - \\
\hline 311 & 30 & 15 & 55 & 3. 37 & - & - & - & - & - & - & - & - & - \\
\hline 410 & & 20 & 50 & 3.37 & - & - & - & - & - & - & - & - & - \\
\hline $509-3$ & & 25 & 45 & 3,37 & 1. 29 & 2.47 & 4.38 & 6.10 & 8.95 & - & 12.8 & 9.2 & $6.8 \times 10^{-5}$ \\
\hline $608-3$ & & 30 & 40 & 3.37 & 0.63 & 1.28 & 2. 59 & 3.89 & 6.20 & 10.4 & 12.8 & 16 & 1. $3 \times 10^{-4}$ \\
\hline 413 & 15 & 20 & 65 & 3.37 & - & - & - & - & - & - & - & - & - \\
\hline $512-3$ & & 25 & 60 & 3.37 & 0.38 & 0.78 & 1.60 & 2.35 & 3. 53 & - & 4.63 & 9.0 & $2.1 \times 10^{-4}$ \\
\hline $611-3$ & & 30 & 55 & 3.37 & 0.34 & 0.74 & 1.43 & 2.00 & 2.91 & 4.11 & 4.23 & 11 & $2.2 \times 10^{-4}$ \\
\hline
\end{tabular}

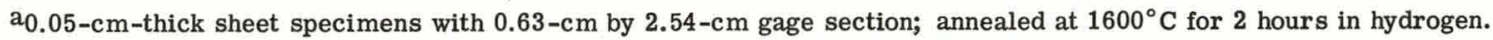

TABLE 1.5

CREEP-RUPTURE RESULTS OF W-Re-MO ALLOYS TESTED AT $2200^{\circ} \mathrm{C}$ IN HYDROGENa

\begin{tabular}{|c|c|c|c|c|c|c|c|c|c|c|c|c|c|}
\hline \multirow[b]{2}{*}{$\begin{array}{l}\text { Specimen } \\
\text { No. }\end{array}$} & \multirow{2}{*}{\multicolumn{3}{|c|}{$\begin{array}{l}\text { Composition, } \\
\text { at. \% }\end{array}$}} & \multirow[b]{2}{*}{$\begin{array}{l}\text { Stress, } \\
\mathrm{kg} / \mathrm{mm}^{2}\end{array}$} & \multirow{2}{*}{\multicolumn{6}{|c|}{ Time to Indicated Strain, $\mathrm{hr}$}} & \multicolumn{2}{|c|}{ Rupture } & \multirow{2}{*}{$\begin{array}{c}\text { Linear } \\
\text { Creep Rate, } \\
\text { min-1 }\end{array}$} \\
\hline & & & & & & & & & & & $\begin{array}{l}\text { Time, } \\
\mathrm{hr}\end{array}$ & $\begin{array}{c}\text { Strain, } \\
\%\end{array}$ & \\
\hline $311-2$ & 30 & 15 & 55 & 0.56 & 3.25 & 7. 75 & 17.8 & 27.0 & 42.4 & - & 48.1 & 7.5 & $1.6 \times 10^{-5}$ \\
\hline $410-2$ & & 20 & 50 & 0.56 & 1.08 & 2.48 & 5.07 & 7.83 & 12.5 & - & 13.4 & 6.0 & $6.0 \times 10^{-5}$ \\
\hline $509-2$ & & 25 & 45 & 0.56 & 0.46 & 0.95 & 1.99 & 3.05 & 5.13 & 10.1 & 21.9 & 30 & $1.6 \times 10^{-4}$ \\
\hline $608-2$ & & 30 & 40 & 0.56 & 0.25 & 0.52 & 1.07 & 1.64 & 2. 78 & 5.62 & 18. 8 & 46 & $2.9 \times 10^{-4}$ \\
\hline $413-1$ & 15 & 20 & 65 & 0.56 & 0.69 & 1.34 & 2.19 & 2. 55 & - & - & 2. 58 & 3.3 & $1.1 \times 10^{-4}$ \\
\hline $512-2$ & & 25 & 60 & 0.56 & 0.33 & 0.73 & 1. 50 & 2.12 & 3.03 & 4.18 & 4.34 & 12 & $2.1 \times 10^{-4}$ \\
\hline $611-2$ & & 30 & 55 & 0.56 & 0.32 & 0.64 & 1. 22 & 1.68 & 2.44 & 3.46 & 3.94 & 17 & $2.6 \times 10^{-4}$ \\
\hline 311 & 30 & 15 & 55 & 0.35 & - & - & - & - & - & - & - & - & - \\
\hline $410-3$ & & 20 & 50 & 0.35 & 9.90 & 22.0 & 46.5 & 69.0 & 109 & 164 & 166 & 11 & $6.8 \times 10^{-6}$ \\
\hline $509-4$ & & 25 & 45 & 0.35 & 0.81 & 1.66 & 3.39 & 5.11 & 9.00 & 18.4 & 58.1 & 50 & $9.7 \times 10^{-5}$ \\
\hline $608-4$ & & 30 & 40 & 0.35 & 0.40 & 0.86 & 1.80 & 2.75 & 4.80 & c & c & $8.6^{\mathrm{b}}$ & - \\
\hline 413 & 15 & 20 & 65 & 0.35 & - & - & - & - & - & - & - & - & - \\
\hline $512-4$ & & 25 & 60 & 0.35 & 0.74 & 1. 52 & 3.20 & 4.90 & 7.85 & 13.3 & 18.5 & 16 & $1.0 \times 10^{-4}$ \\
\hline $611-4$ & & 30 & 55 & 0.35 & 0.54 & 1.07 & 2. 04 & 2. 86 & 4.24 & 6.47 & 8.60 & 21 & $1.6 \times 10^{-4}$ \\
\hline 311 & 30 & 15 & 55 & 0.21 & - & - & - & - & - & - & - & - & - \\
\hline 410 & & 20 & 50 & 0.21 & - & - & - & - & - & - & - & - & - \\
\hline $509-5$ & & 25 & 45 & 0.21 & 1.28 & 2.67 & 5.65 & 8.85 & 15.4 & 32.7 & 166 & 70 & $4.7 \times 10^{-5}$ \\
\hline 608 & & 30 & 40 & 0.21 & - & - & - & - & - & - & - & - & - \\
\hline 413 & 15 & 20 & 65 & 0.21 & - & - & - & - & - & & - & - & - \\
\hline $512-5$ & & 25 & 60 & 0.21 & 1.58 & 3.10 & 6.30 & 9.60 & 16.1 & 30.0 & 49.9 & 26 & $5.0 \times 10^{-5}$ \\
\hline $611-6$ & & 30 & 55 & 0.21 & 1.03 & 2.07 & 4.04 & 6.00 & 9.80 & 17.9 & 36.5 & 38 & $8.3 \times 10^{-5}$ \\
\hline
\end{tabular}

a $0.05-\mathrm{cm}$-thick sheet specimens with $0.63-\mathrm{cm}$ by $2.54-\mathrm{cm}$ gage section; annealed at $2200^{\circ} \mathrm{C}$ for 2 hours in hydrogen. $\mathrm{b}_{\mathrm{Cr}}$ eep was zero after $8.6 \%$ strain from 10 to 93 hours. 

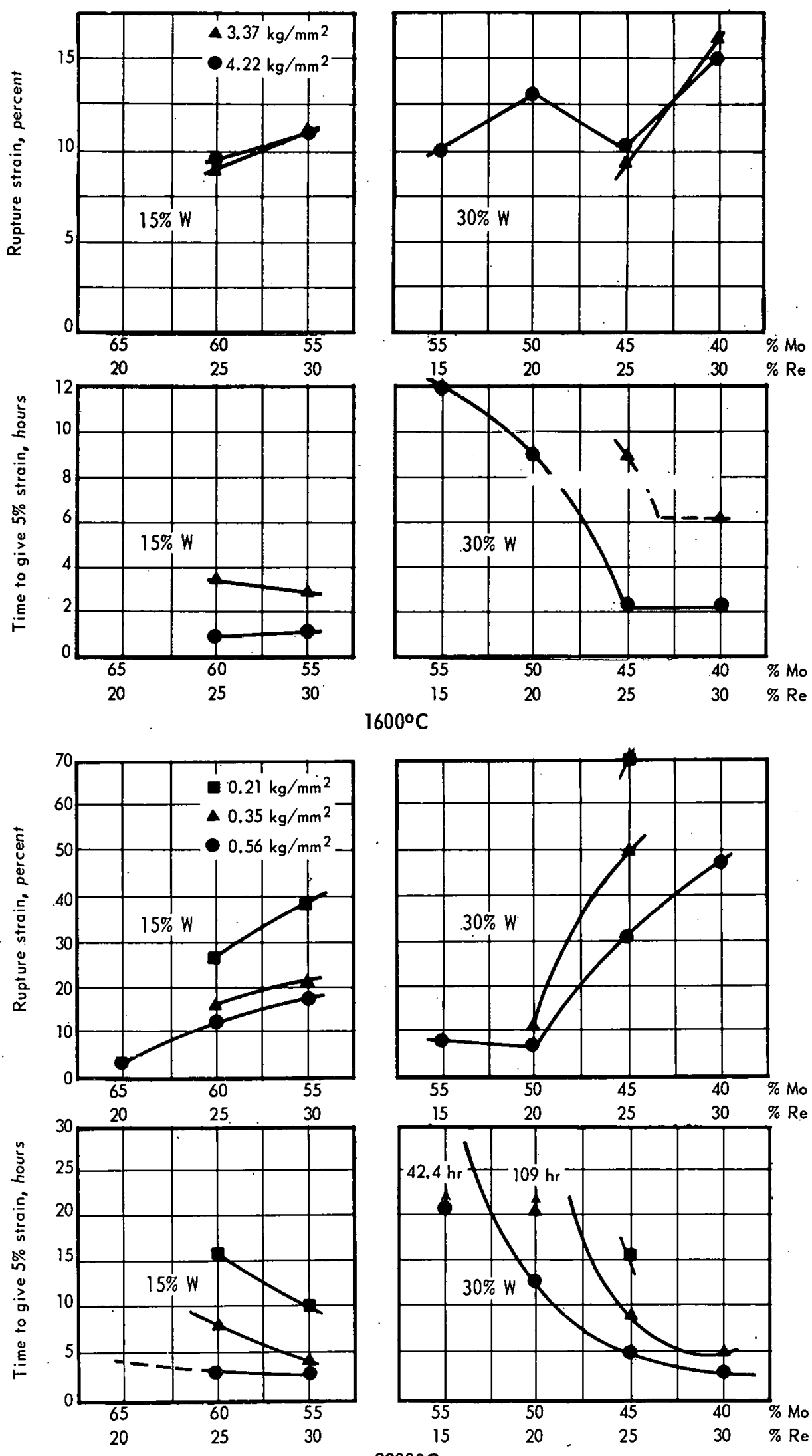

Fig. 1.8-Composition effect on ductility and creep resistance for W-Re-Mo alloys of $1600^{\circ} \mathrm{C}$ and $2200^{\circ} \mathrm{C}$ in hydrogen 

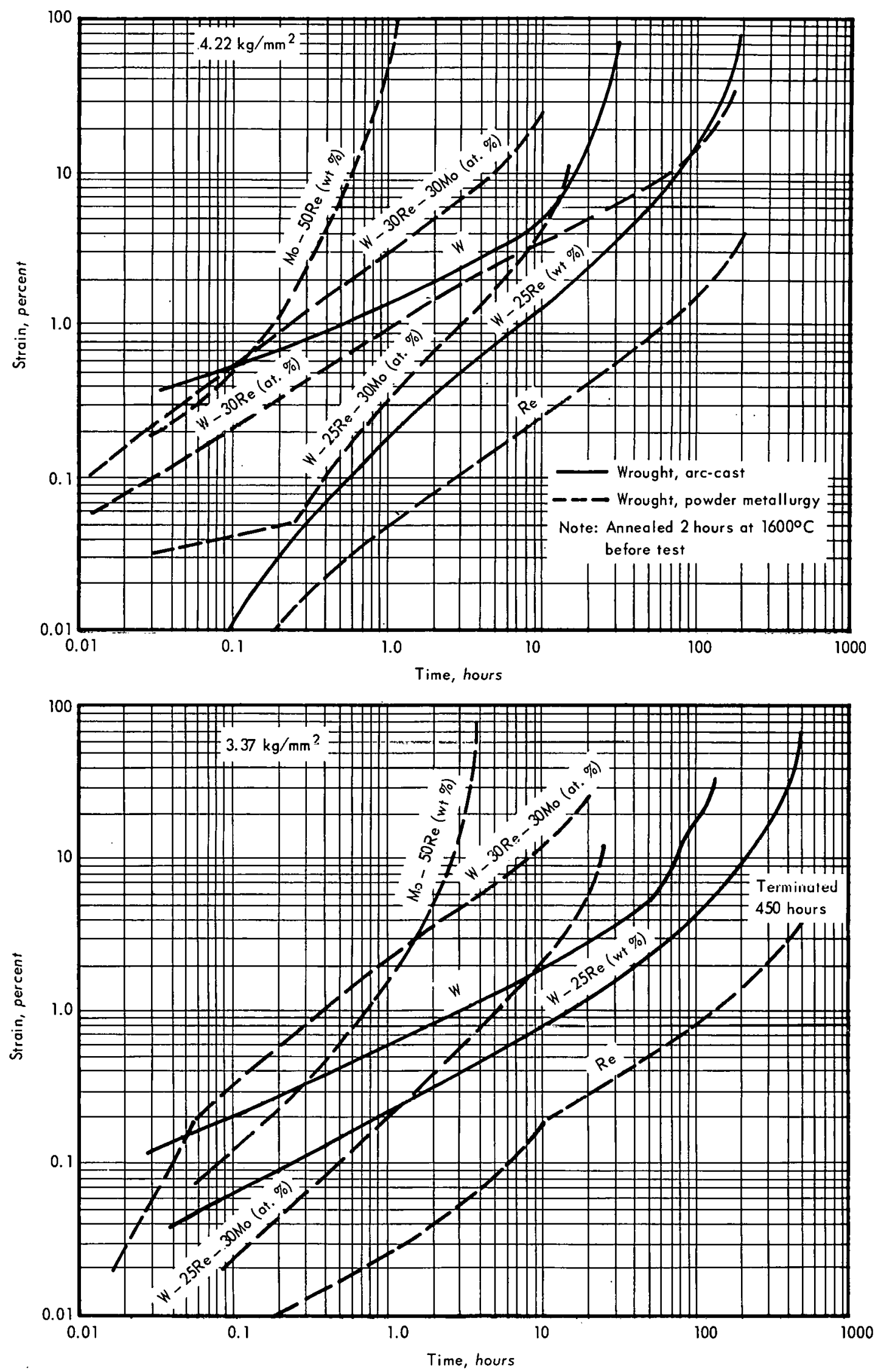

Fig. 1.9 - Creep-rupture curkes for various refractory metols at $1600^{\circ} \mathrm{C}$ in hydrogen 

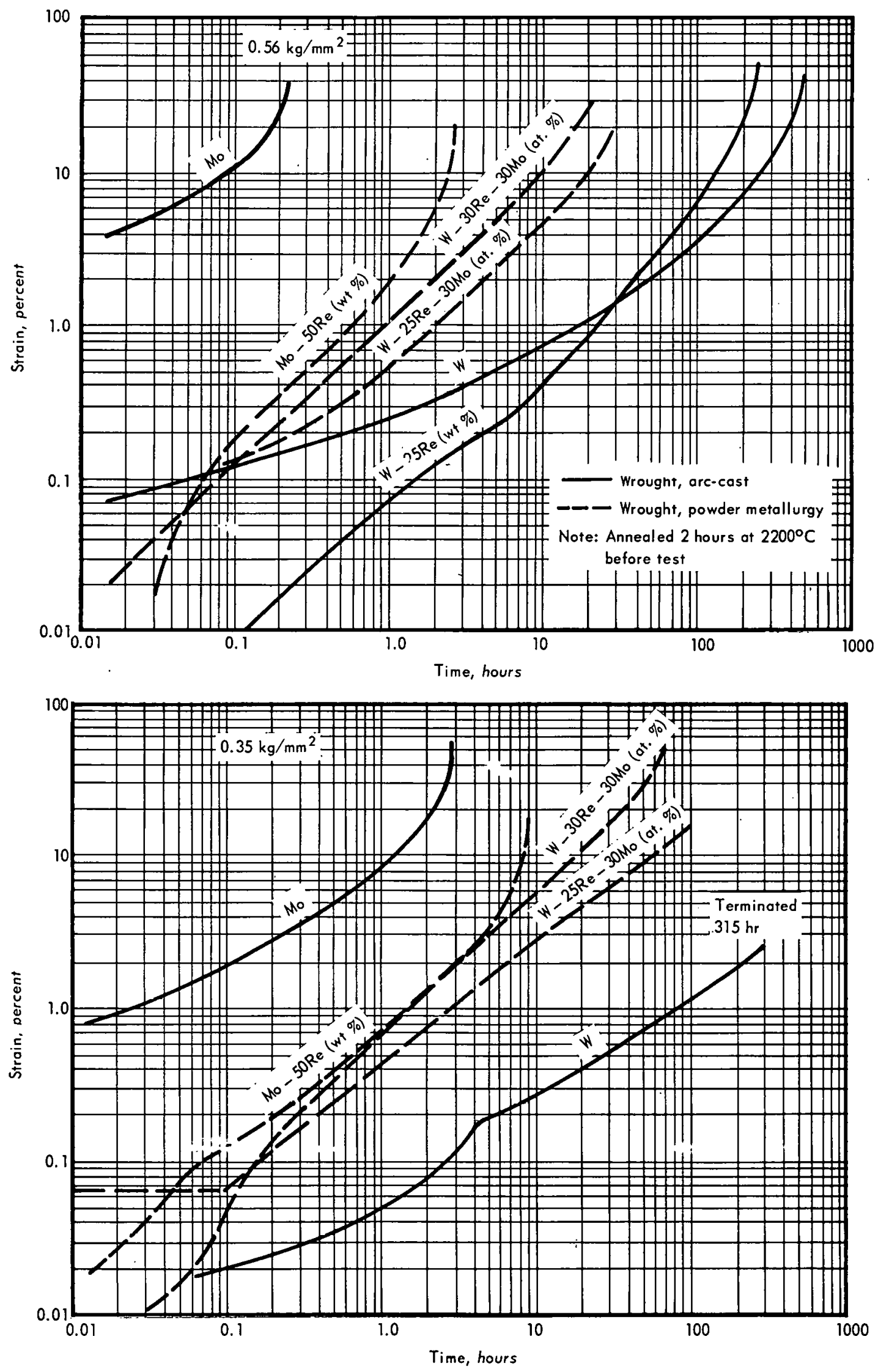

Fig. 1.10 - Creep-rupture curves for various refractory metals at $2200^{\circ} \mathrm{C}$ in hydrogen 


\section{CORRELATION AND ANALYSIS OF CREEP-RUPTURE DATA}

Creep Equations

A fairly comprehensive evaluation of the effectiveness of various types of first-stage creep equations was previously reported, ${ }^{7,8}$ based on an analysis of constant-load creep data. Also reported recently ${ }^{7,9}$ was a study of various equation forms for use in expressing combined first- and second-stage creep behavior. Subsequent studies were initiated to investigate the ability of a single creep equation to describe the strain - time behavior for the entire curve. Obviously, those equations which approach a linear strain - time relation as the time values increase would be of no value since the accelerating creep behavior characteristic of third-stage creep could not be represented. Hence, for this evaluation the Garofalo, Cottrell-Aytekin, and third-degree polynomial in $\mathrm{t}^{1 / 3}$ equations, which yielded excellent results in the analysis of combined first- and second-stage data, were eliminated. Of the various equation types capable of describing the entire creep curve, those chosen for study were:

$$
\begin{aligned}
& \epsilon=a+b t^{1 / 3}+c t+d t^{3 / 2} \\
& \epsilon=a+b t^{1 / 3}+c t+d t^{4 / 3} \\
& \epsilon=a+b t^{1 / 3}+c t+d t^{3} \\
& \epsilon=a+b t^{m}+c t^{n} \\
& \epsilon=a+b t^{m}+c t^{n}+d t^{p}
\end{aligned}
$$

The Andrade equation was also studied since it has a shape which is similar to the complete creep curve. However, it was found that this expression was not as effective as the other equation types chosen for this study.

The equations selected for evaluation include a simple polynomial in $\mathrm{t}^{1 / 2}$, a modified Cottrell-Aytekin ${ }^{10}$ equation with a $t^{4 / 3}$ term added; a Graham-Walles ${ }^{11}$ equation containing a $\mathrm{t}^{3}$ term, a delacombe ${ }^{12}$ equation (two variable exponents), and a modified delacombe equation which originated in the current study. Least squares procedures were employed in each case to yield values for the equation constants. While this calculation approach is fairly straightforward in the case of the first three equation types, a special nonlinear regression analysis was necessary in the solution of the expression involving variable exponents.

In evaluating the effectiveness of the above equation forms, the creep data for arc-cast tungsten at $2400^{\circ} \mathrm{C}$ were employed. A summary of the results obtained is presented in Table 1.6 where the creep equation constants are listed along with the value for the standard deviation, $\mu$ (corrected for the number of equation constants); the smaller the value for $\mu$, the more effective the representation.

In general, it was found that for the data employed in this analysis, the least effective equation form was that involving the $t^{4 / 3}$ term followed by the third-degree polynomial in $t^{1 / 2}$. The expression involving $t^{3}$ was definitely superior to both the equation involving $t^{4 / 3}$ and the third-degree polynomial in $\mathrm{t}^{1 / 2}$ and it was found to be just about as effective as

${ }^{7}$ GEMP-400A, p. 37.

${ }^{8}$ J. B. Conway and M. J. Mullikin, "An Evaluation of Various Equations for Expressing First-Stage Creep Behavior,"

Transactions of Metallurgical Society, AIME, Vol. 236, 1966, p. 1496.

${ }^{9}$ J. B. Conway and M. J. Mullikin, "Techniques for Analyzing Combined First- and Second-Stage Creep Data," Transactions of Metallurgical Society, AlME, Vol. 236, 1966, p. 1629.

${ }^{10}$ A. H. Cottrell and V. Aytekin, "Andrade's Creep Law and the Flow of Zinc Crystals," Nature, Vol. 160, 1947, p. 328.

${ }^{11}$ A. Graham and K. F. A. Walles, "Relationships Between Long and Short Time Creep and Tensile Properties of a Commercial Alloy," Journal of lron and Steel Institute, Vol. 179, 1955, p. 105.

${ }^{12} \mathrm{~J}$. deLacombe, "A Method of Representing Creep Curves," Rev. Metal., Vol. 36, 1939, p. 178. 
TABLE 1. 6

COMBINED FIRST-, SECOND-, AND THIRD-STAGE CREEP DATA FOR ARC-CAST TUNGSTEN AT $2400^{\circ} \mathrm{C}$ ANALYZED IN TERMS OF VARIOUS EQUATIONS

\begin{tabular}{|c|c|c|c|c|c|}
\hline \multicolumn{6}{|c|}{$\epsilon=a+b t^{1 / 2}+c t+d t^{3 / 2}$} \\
\hline $\begin{array}{l}\text { Stress, } \\
\mathrm{kg} / \mathrm{mm}^{2}\end{array}$ & $\mathrm{a} \times 10^{3}$ & $b \times 10^{3}$ & c & $\mathrm{d}$ & $\mu \times 10^{4}$ \\
\hline 0.46 & 0.253 & 0.851 & $2.94 \times 10^{-7}$ & $3.61 \times 10^{-7}$ & 9.2 \\
\hline 0.56 & 0.099 & 1. 67 & $-2.89 \times 10^{-5}$ & $1.68 \times 10^{-6}$ & 7.5 \\
\hline 0.70 & 1.18 & 3.05 & $-8.47 \times 10^{-5}$ & 8. $15 \times 10^{-6}$ & 9.8 \\
\hline 0.84 & -1.84 & 7. 25 & $-5.13 \times 10^{-4}$ & 3. $47 \times 10^{-5}$ & 22.0 \\
\hline 1.05 & -1.32 & 13. 5 & $-1.81 \times 10^{-3}$ & $1.83 \times 10^{-4}$ & 31.0 \\
\hline \multicolumn{6}{|c|}{$\epsilon=a+b t^{1 / 3}+c t+d t^{4 / 3}$} \\
\hline $\begin{array}{l}\text { Stress, } \\
\mathrm{kg} / \mathrm{mm}^{2}\end{array}$ & $\mathrm{a} \times 10^{3}$ & $b \times 10^{3}$ & c & $d$ & $\mu \times 10^{4}$ \\
\hline 0.46 & -1.70 & 2. 21 & $8.99 \times 10^{-7}$ & 1. $72 \times 10^{-6}$ & 10.9 \\
\hline 0.56 & -2.49 & 3.83 & $-3.09 \times 10^{-5}$ & $7.26 \times 10^{-6}$ & 11.5 \\
\hline 0.70 & -2.01 & 5. 92 & $-7.77 \times 10^{-5}$ & 2. $84 \times 10^{-5}$ & 12.6 \\
\hline 0.84 & -9.25 & 14.10 & $-5.96 \times 10^{-4}$ & $1.22 \times 10^{-4}$ & 28.3 \\
\hline 1.05 & -10.05 & 21: 90 & $-1.90 \times 10^{-3}$ & $5.04 \times 10^{-4}$ & 33.2 \\
\hline
\end{tabular}

$\epsilon=a+b t^{1 / 3}+c t+d t^{3}$

\begin{tabular}{cccccr}
$\begin{array}{c}\text { Stress, } \\
\mathrm{kg} / \mathrm{mm}^{2}\end{array}$ & $\mathrm{a} \times 10^{3}$ & $\mathrm{~b} \mathrm{x} 10^{3}$ & $\mathrm{c}$ & $\mathrm{d}$ & $\mu \times 10^{4}$ \\
\hline 0.46 & 0.45 & 1.195 & $2.67 \times 10^{-5}$ & $3.17 \times 10^{-13}$ & 7.08 \\
0.56 & 0.48 & 1.928 & $5.36 \times 10^{-5}$ & $4.58 \times 10^{-12}$ & 3.31 \\
0.70 & 1.081 & 3.427 & $1.46 \times 10^{-4}$ & $1.26 \times 10^{-10}$ & 3.45 \\
0.84 & 0.313 & 6.022 & $2.69 \times 10^{-4}$ & $9.66 \times 10^{-10}$ & 8.34 \\
1.05 & -1.24 & 11.91 & $4.14 \times 10^{-4}$ & $3.82 \times 10^{-8}$ & 24.0 \\
\hline
\end{tabular}

$\epsilon=a+b t^{m}+c t^{n}$

\begin{tabular}{ccccccc}
$\begin{array}{c}\text { Stress, } \\
\mathrm{kg} / \mathrm{mm}^{2}\end{array}$ & $\mathrm{a} \times 10^{3}$ & \multicolumn{1}{c}{$\mathrm{b}$} & $\mathrm{m}$ & $\mathrm{c}$ & $\mathrm{n}$ & $\mu \times 10^{4}$ \\
\hline 0.46 & 2.01 & $2.20 \times 10^{-4}$ & 0.734 & $1.13 \times 10^{-9}$ & 2.12 & 7.42 \\
0.56 & 1.96 & $6.56 \times 10^{-4}$ & 0.65 & $9.19 \times 10^{-9}$ & 2.10 & 2.98 \\
0.70 & 4.15 & $1.06 \times 10^{-3}$ & 0.708 & $2.81 \times 10^{-9}$ & 2.58 & 3.83 \\
0.84 & 5.71 & $1.86 \times 10^{-3}$ & 0.713 & $2.06 \times 10^{-9}$ & 2.90 & 8.09 \\
1.05 & 10.60 & $2.58 \times 10^{-3}$ & 0.808 & $9.87 \times 10^{-21}$ & 8.98 & 8.70 \\
\hline \multicolumn{7}{c}{$\epsilon=\mathrm{a}+\mathrm{bt}^{\mathrm{m}}+\mathrm{ct}^{\mathrm{n}}+\mathrm{dt}^{\mathrm{p}}$}
\end{tabular}

\begin{tabular}{ccccccccc}
$\begin{array}{c}\text { Stress, } \\
\mathrm{kg} / \mathrm{mm}^{2}\end{array}$ & $\mathrm{a} \times 10^{3}$ & $\mathrm{~b}$ & $\mathrm{~m}$ & $\mathrm{c}$ & $\mathrm{n}$ & $\mathrm{d}$ & $\mathrm{p}$ & $\mu \times 10^{4}$ \\
\hline 0.46 & 1.20 & $4.92 \times 10^{-17}$ & 3.88 & $1.87 \times 10^{-6}$ & 1.29 & $5.54 \times 10^{-4}$ & 0.545 & 7.21 \\
0.56 & 1.27 & $3.43 \times 10^{-11}$ & 2.74 & $9.74 \times 10^{-6}$ & 1.18 & $1.15 \times 10^{-3}$ & 0.499 & 2.80 \\
0.70 & 3.54 & $8.79 \times 10^{-34}$ & 10.84 & $7.51 \times 10^{-8}$ & 2.10 & $1.38 \times 10^{-3}$ & 0.647 & 3.59 \\
0.84 & 2.87 & $6.24 \times 10^{-11}$ & 3.43 & $1.93 \times 10^{-4}$ & 1.06 & $4.02 \times 10^{-3}$ & 0.423 & 7.45 \\
1.05 & $(-32.59)$ & $2.74 \times 10^{-25}$ & 11.1 & $8.21 \times 10^{-4}$ & 1.03 & 32.60 & $1.048 \times 10^{-4}$ & 2.87 \\
\hline
\end{tabular}

the delacombe equation. While the effectiveness of the modified delacombe equation (involving three variable exponents) does not appear to be much better than the $\mathrm{t}^{3}$ or delacombe equations at stresses below $1.05 \mathrm{~kg} / \mathrm{mm}^{2}$, the better results obtained at $1.05 \mathrm{~kg} / \mathrm{mm}^{2}$ are particularly striking. None of the other equations studied was capable of providing as low a value of $\mu$ as that obtained with this more c omplex expression. Some disadvantage might be assigned to the large negative value of $\epsilon_{\mathrm{o}}$ ("a" in this" case) but positive strain values are obtained with this expression for time values beyond 1 minute.

Several examples of the effective representations afforded by the various equation types studied are presented in Figure 1.11: It is clear that the $\mathrm{t}^{3}$ equation type is definitely su- 

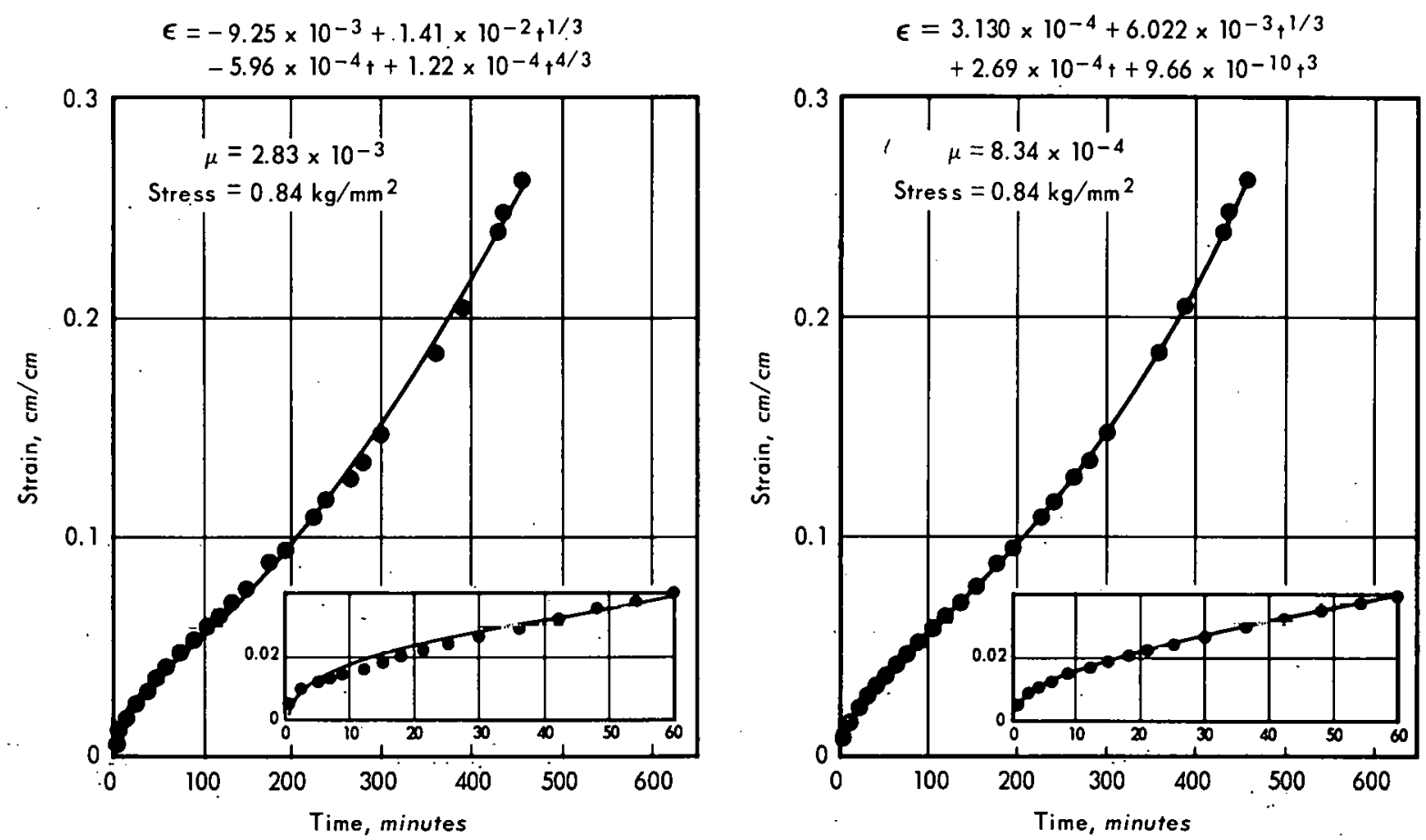

- Experimental points

- Calculated from creep equation
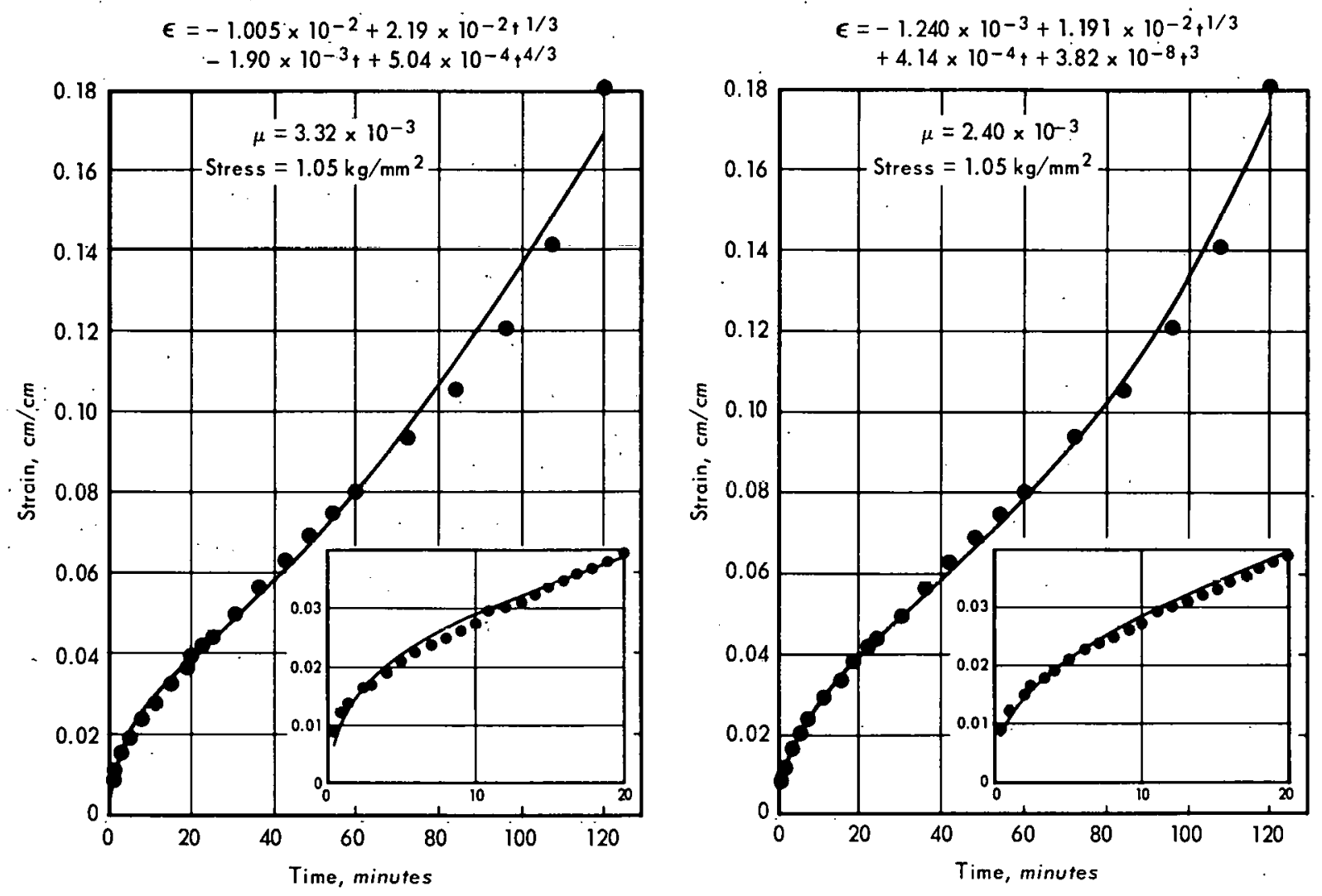

Fig. 1.11-Combined first-, second-, and third-stage creep dato for arc-cost tungsten at $: 2400^{\circ} \mathrm{C}$ represented by various equation forms 

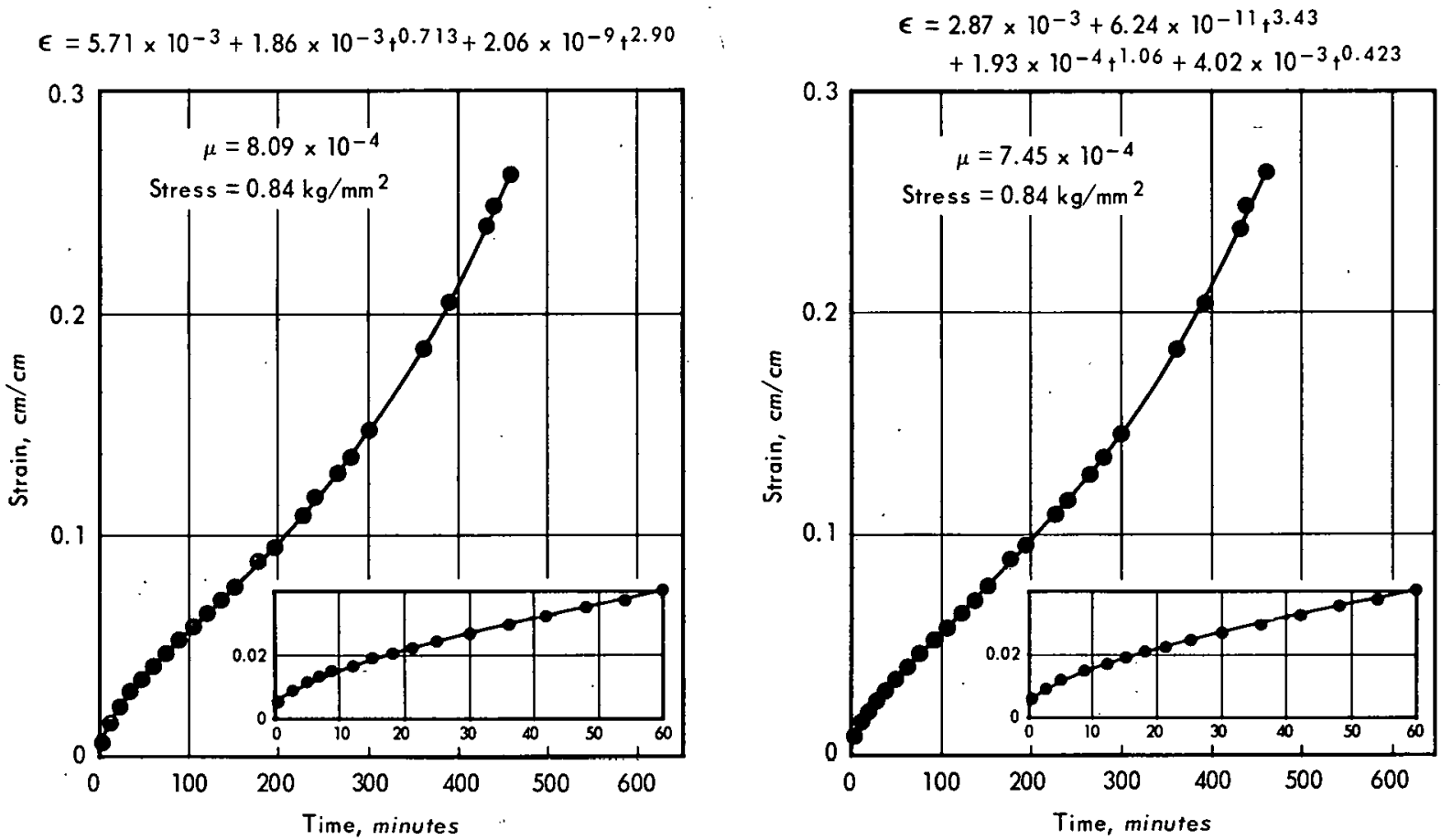

- Experimental poinls

- Calculated from creep equation
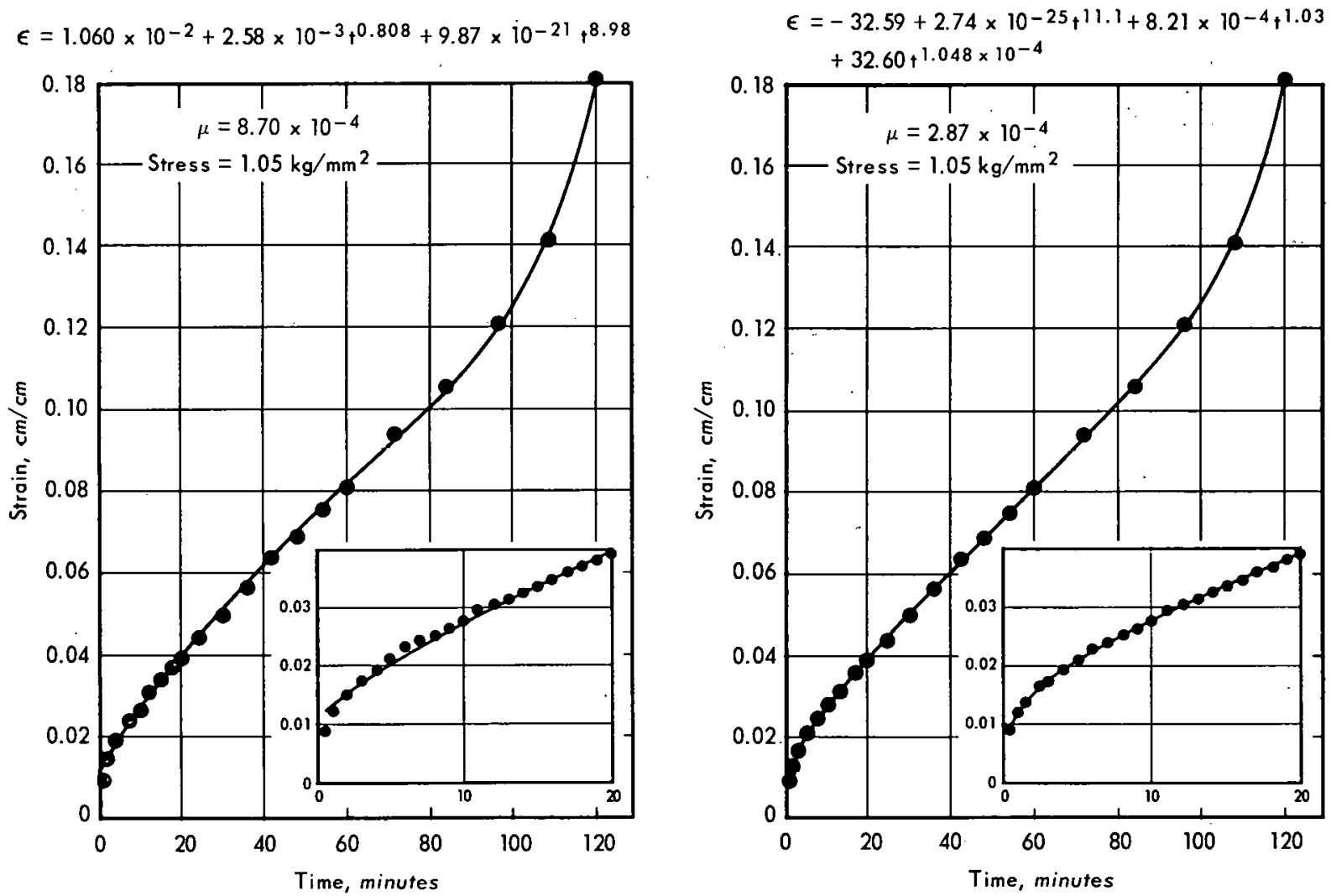

Fig. 1.11 (Cont.) - Combined first-, second-, and third-stage creep data for arc-cast tungsten at $2400^{\circ} \mathrm{C}$ represented by various equation forms 
perior to the $t^{4 / 3}$ expression. Also the delacombe equation is seen to provide excellent representations particularly at $1.05 \mathrm{~kg} / \mathrm{mm}^{2}$. Finally, the effectiveness of the modified delacombe equation is demonstrated by the excellent representation of the data at 1.05 $\mathrm{kg} / \mathrm{mm}^{2}$.

Combined first- and second-stage creep data for arc-cast tungsten in the range from $2200^{\circ}$ to $2600^{\circ} \mathrm{C}$ were also analyzed in terms of the temperature-compensated time parameter. ${ }^{13}$ Results of this correlation are presented in Figure 1.12 for two different stress levels. Similar agreement was also obtained at $0.84 \mathrm{~kg} / \mathrm{mm}^{2}$. Because of the similarity in the slope of the curves in Figure 1.12, a further modification of the temperature-compensated time parameter was suggested. A term involving $\sigma^{\mathbf{n}}$ was added to yield the general correlation shown in Figure 1.13 for temperatures of $2200^{\circ}, 2400^{\circ}$, and $2600^{\circ} \mathrm{C}$.

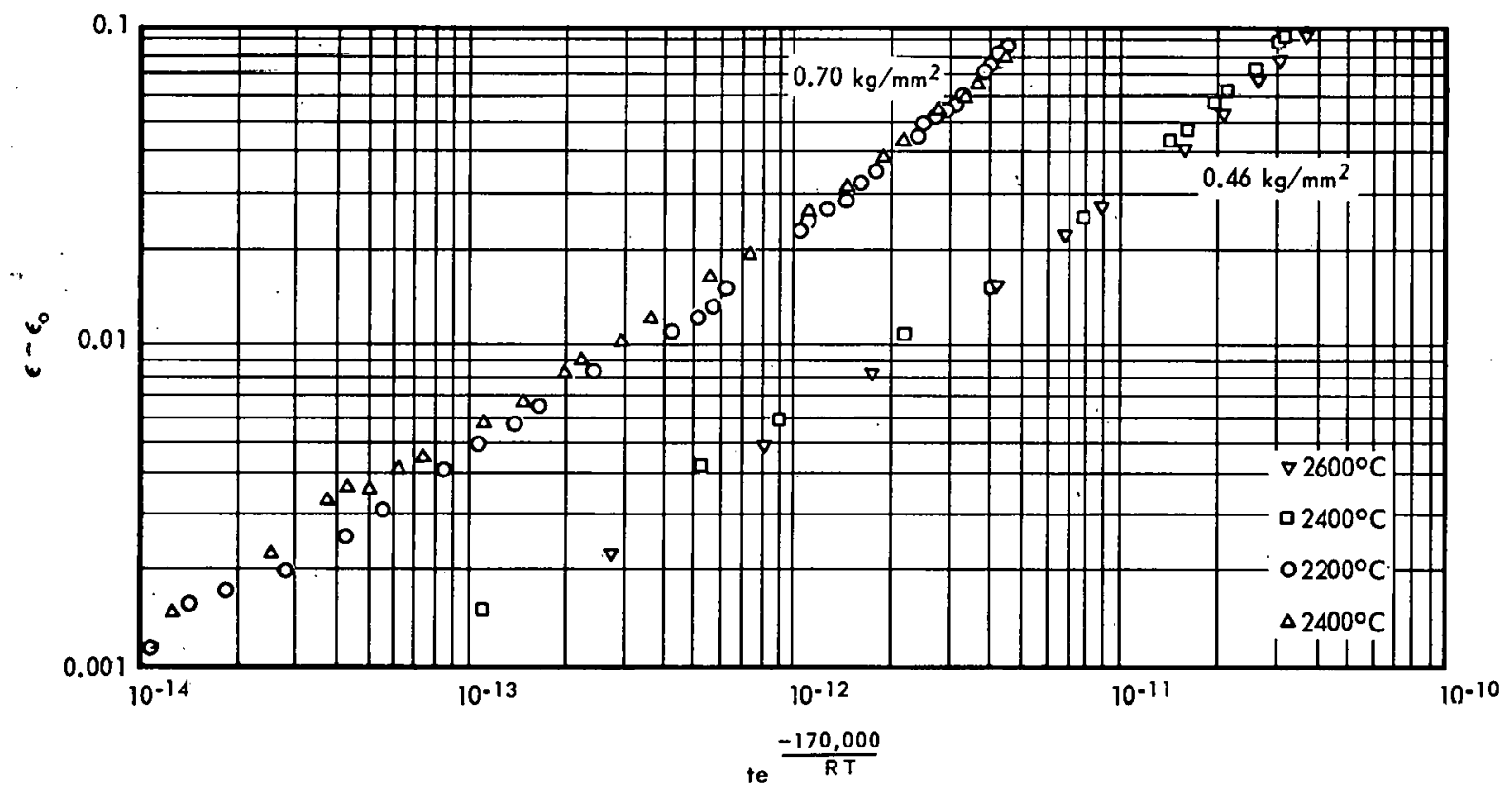

Fig. 1.12-Combined first-and second-stage creep data for arc-cast tungsten correlated in terms of the temperature-compensated time parameter

Recently reported ${ }^{14}$ creep data for arc-cast molybdenum at $1600^{\circ} \mathrm{C}$ showed two distinctly different types of transient creep curves. At higher stresses (above $1.75 \mathrm{~kg} / \mathrm{mm}^{2}$ ), the strain - time data plotted on logarithmic coordinates yielded the usual concave upward relationship suggestive of a parabolic creep form with a positive $\epsilon_{\mathrm{O}}$. value. At lower stresses, the curves become concave downward at the lower strain values, Such behavior is somewhat unusual and cannot be expressed by the usual parabolic form. Other examples of this type of strain - time behavior are given by the data for copper, ${ }^{15}$ a $97 \mathrm{Cu}-3 \mathrm{Ni}$ alloy, ${ }^{16}$ and an austenitic stainless steel. ${ }^{17}$ In view of these distinctly different strain - time plots on

\footnotetext{
${ }^{13}$ GEMP-61, p. 28.

${ }^{14}$ GEMP-61, p. 25.

15O. H. Wyatt, "Transient Creep in Pure Metals," Proceedings of Physical Society, Vol. 66B, 1953, p. 459.

${ }^{16}$ G. C. E. Olds, "Mechanisms of Creep in a Precipitation Hardened Alloy," Proceedings of Physical Society, Vol. 67B, 1954, p. 832.

${ }^{17}$ F. Garofalo, Fundamentals of Creep and Creep-Rupture in Metals, Macmillan Co., New York, 1965.
} 


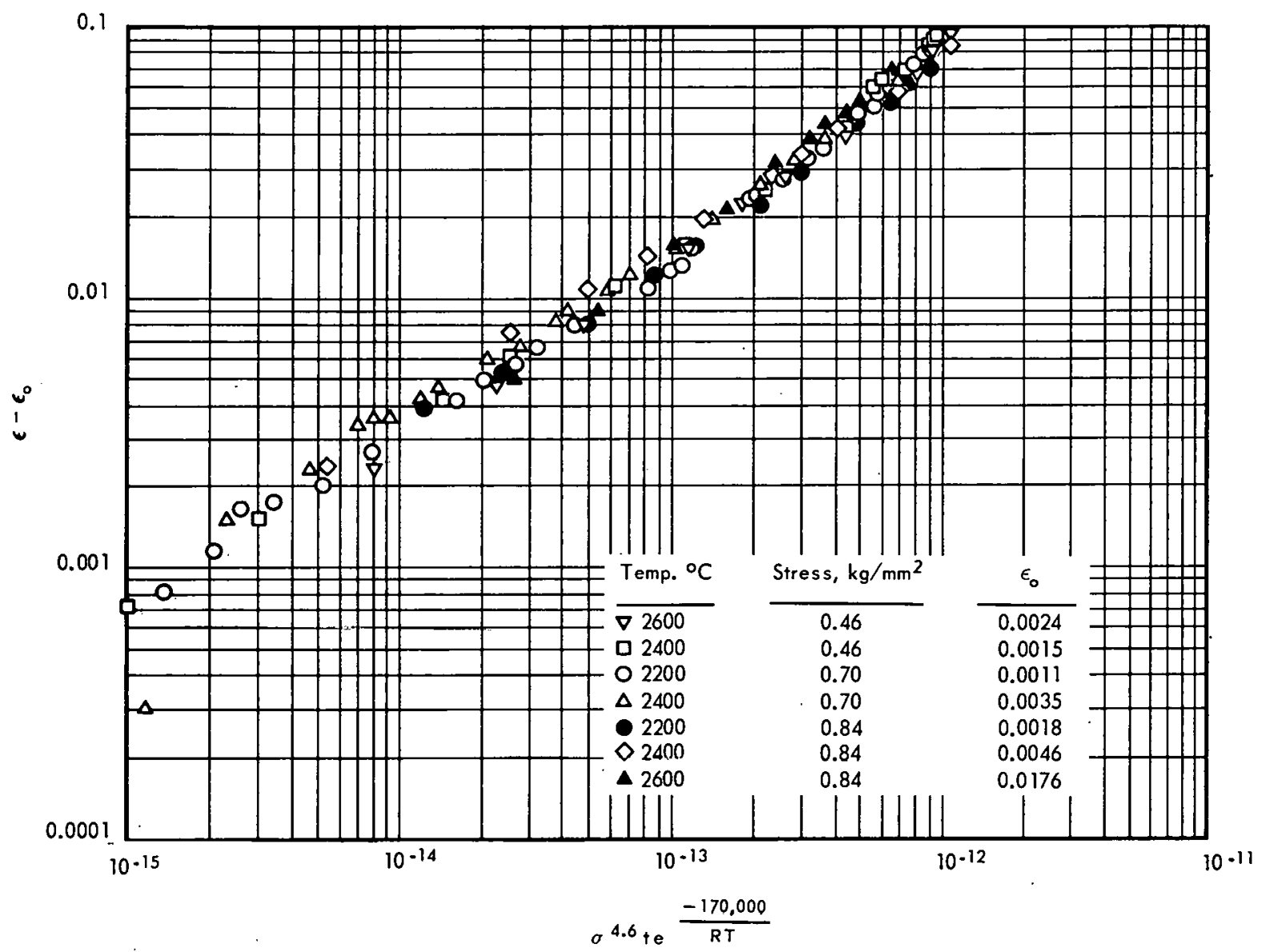

Fig. 1.13- Combined first- and second-stage creep data for arc-cast tungsten correlated in terms of stress and temperature-compensated time parameter

logarithmic coordinates, it would seem that two different types of creep curves should be recognized: one type characterized by a linear or concave upward log strain versus $\log$ time plot and a second type which yields a concave downward relation when this method of plotting is employed. Both types have the same general shape on rectangular strain - time plots; hence, only the logarithmic method of plotting can distinguish between the two types of creep curves.

Not all creep equation forms can describe strain - time behavior which is concave downward on logarithmic coordinates. Therefore, some distinction must be made in this regard to recognize that certain creep equation forms are only applicable to the type-1 (concave upward) creep curve. An analysis of some of the more frequently employed creep equations has led to the summary shown in Table 1.7. If a type-2 equation is indicated by a concave downward log strain versus log time plot, then a type-1 equation should not be employed in an attempt to represent these creep data. Also within the type-2 equations, a further distinction is made depending upon whether a strain - time plot on semilogarithmic coordinates leads to a concave upward or concave downward relationship. Examples of both types are available in published data. 
TABLE 1.7

SUMMARY OF THE CHARACTERISTICS OF VARIOUS EQUAATIONS FOR USE IN EXPRESSING TRANSIENT CREEP DATA

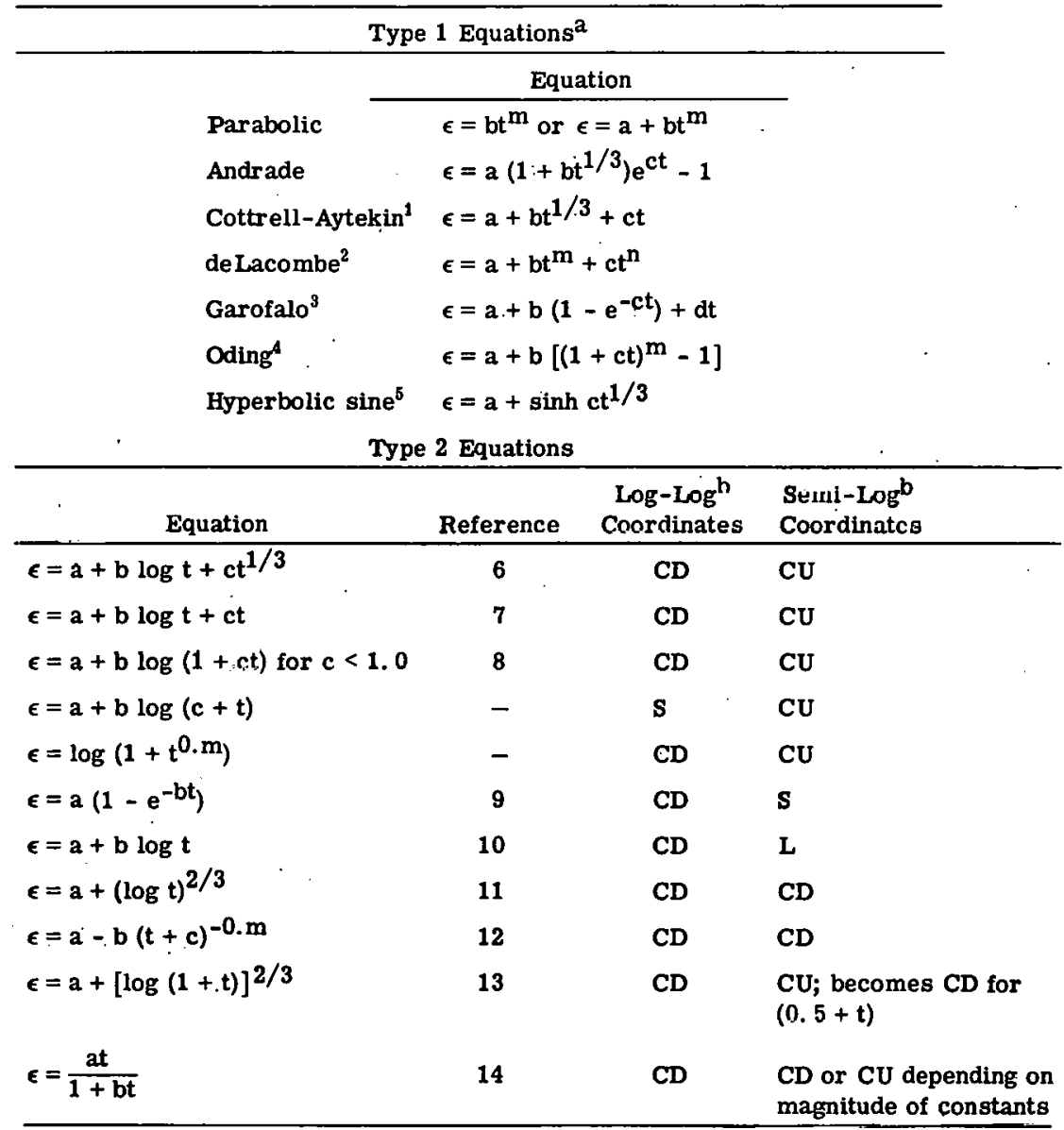

${ }^{a}$ All linear or concave upward on both logarithmic and semi-logarithmic coordinates.

${ }^{b} \mathrm{CD}$ : concave downward; CU: concave upward; s: S-shaped (approaches $\mathrm{CD}$ at high $\mathrm{t}$ values); L: linear.

'A. H. Cottrcll and V. Aytekin, "Andrade's Creep Law and the Flow of Zinc Crystals," Nature, Vol. 160, 1947, p. 328.

2 J. deLacombe, "A Method of Representing Creep Curves," Rev. Metal., Vol. 36, 1939, p. 178.

${ }^{3}$ F. Garofalo, "An Empirical Relation Defining the Stress Dependence of Minimum Creep Rate in Metals," Trans. Met. Soc. AIME, Vol. 227, 1963, p. 351.

${ }^{4}$ I. A. Oding, Creep and Stress Relaxation in Metals, Oliver and Boyd, London, 1965.

5J. B. Conway and M. J. Mullikin, "An Evaluation of Various Equations for Expressing First Stage Creep Behavior," Trans. Met. Soc. AIME, Vol. 230, 1966, p. 1496.

${ }^{6}$ O. H. Wyatt, "Transient Creep in Pure Metals," Proc. Phys. Suc., Vol. 66B, 1953, p. 459

'S. H. Weaver, "The Creep Curves and Stability of Steels at Constant Stress and Temperature," Trans. ASME, Vol. 58, 1936, p. 745.

${ }^{8} \mathrm{H}$. Conrad, "An Investigation of the Rate Contrnlling Mechanisms for Plactio Flow of Copper Crystals at $90^{\circ}$ and $170^{\circ} \mathrm{K}, "$ Acta Met., Vol. 6, 1958, p. 339.

${ }^{\circ}$ I. H. Swift and E. P. T. Tyndall, "Elasticity in Creep of Lead Single Crystals," Phys. Rev., Vol. 61,1942 , p. 359 .

${ }^{10} \mathrm{~F}$. Phillips, "The Slow Stretch in India Rubber, Glass and Metal Wires when Subjected to Constant Pull," Phil. Mag., Vol. 9, 1905, p. 513.

${ }^{11}$ M. Davis and N. Thompson, "Creep in a Precipitation Hardened Alloy," Proc. Phys. Soc., Vol. 63B, 1950 , p. 847.

${ }^{12}$ C. Crussard, "Thirty Years of Dislocation Theory and Rheology - A Study of Transient Creep," ASM Trans. Quarterly, Vol. 57, 1964, p. 779.

${ }^{13}$ N. F. Mott and F. R. N. Nabarro, 'Report of a Conference on the Strength of Solids," The Physical Society of London, 1948.

${ }^{14}$ A. M. Freudenthal, "Theory of Wide Span Arches in Concrete and Reinforced Concrete," Bridge and Structural Engineers, Vol. 4, 1936, p. 249. 


\section{Parameter Correlations}

Computer programs, based on a least squares analysis, were written to permit rupture data to be analyzed in terms of either the Larson-Miller, Dorn, or Manson-Haferd parameters. Recent analyse ${ }^{18}$ of the data for arc-cast Mo, W, and W-25Re from $1200^{\circ}$ to $3000^{\circ} \mathrm{C}$ were described in which rupture times ranged from 0.06 to 584 hours. A typical result of this analysis approach is shown in Figure 1.14 for the arc-cast molybdenum dala. In addition to the standard plot of the Larson-Miller parameter versus stress, a plot of the isotherms reconstructed from this plot is shown to indicate the excellence of this analysis.
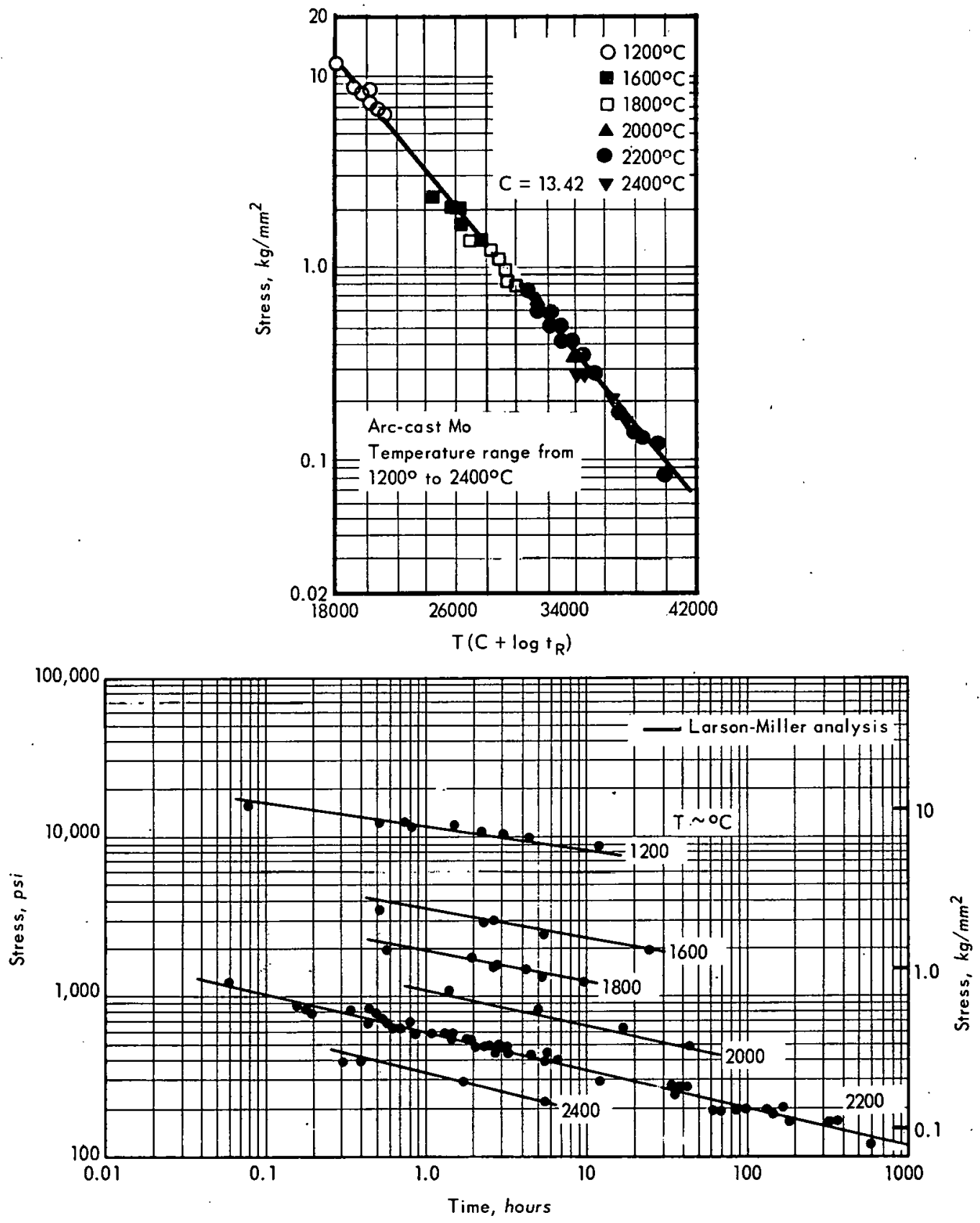

Fig. 1.14-Rupture data for arc-cast molybdenum analyzed in terms of the Larson-Miller Parameter

.18“'High-Temperature Materials Program Progress Report No. 63," GE-NMPO, GEMP-63, December 30, 1966; p. 13. 


\section{STUDIES OF CREEP MECHANISMS}

The creep behavior of arc-cast tungsten was observed to undergo a definite change between $1800^{\circ}$ and $2400^{\circ} \mathrm{C}$. For example, plots of stress-rupture and linear creep rate results obtained at $2000^{\circ} \mathrm{C}$ and $2200^{\circ} \mathrm{C}$ show a marked change in slope..$^{19}$ To explain this be havior, more thorough studies were made on two creep test specimens annealed in hydrogen at $2800^{\circ} \mathrm{C}$ for 2 hours. This was done so that the grain structure of both specimens would be identical before initiation of the test. One specimen was tested in hydrogen at $1800^{\circ} \mathrm{C}$ at $2.46 \mathrm{~kg} / \mathrm{mm}^{2}$ for 8 hours and the other was tested in hydrogen at $2400^{\circ} \mathrm{C}$ at 0.56 $\mathrm{kg} / \mathrm{mm}^{2}$ for 8 hours. Although the former underwent an elongation of 13.6 percent and the latter only 7.8 percent, both tests were stopped approximately halfway through the linear creep stage and rapidly cooled in hydrogen to room temperature to prevent any major changes in the structure. Test specimens were then examined by metallography and X-ray diffraction to characterize differences which might explain their phenomenological behavior. Another sample of the same arc-cast tungsten sheet which had received only the pre-annealing treatment was used as a standard reference material in this study.

The grain size after annealing ranged from 2 to $10 \mathrm{~mm}$ in diameter and remained constant during the tests; hence, individual grains were large enough to be examined by the Laue back-reflection technique. With the standard photographic method, exposures of 1 hour using unfiltered $\mathrm{Cu}$ radiation at $40 \mathrm{kv}$ and $20 \mathrm{ma}$ gave good results for a specimen-to-film distanre. of $3 \mathrm{~cm}$. When the Polaroid attachment was used under the same conditions, exposures of 1.5 minutes were found to be satisfactory.

The metallographic analysis was made on sections cut from the tungsten sheet. These sections were: longitudinal - looking at the sheet surface perpendicular to the stress axis; transverse - looking at the cross section of the sheet down the stress axis; and edge - looking along the edge of the sheet perpendicular to the stress axis. Specimens were mounted, polished, and etched electrolytically in a 2-percent $\mathrm{NaOH}$ solution to develop dislocation etch pits.

Surfaces of the tested specimens are shown in Figure 1.15. Both samples are highly distorted with a wrinkled surface appearance. There are no major external differences, although the specimen tested at $1800^{\circ} \mathrm{C}$ to 13.7 -percent strain contains many more fine crystallographic slip bands than the one tested at $2400^{\circ} \mathrm{C}$ (to 7.8 -percent strain) which has some grains containing practically no slip lines.

Photomicrographs of the specimen tested at $1800^{\circ} \mathrm{C}\left(0.56 \mathrm{~T}_{\mathrm{m}}\right.$; where $\mathrm{T}_{\mathrm{m}}$ is the absolute melting temperature) are presented in Figure 1.16 as longitudinal (a), transverse (b), and edge (c). All three views. show the formation of numerous small subgrains between rows of slip lines. In Figure 1.16a and c, the parallel slip traces make an angle of about 45 degrees to the stress direction. Slip lines in the grains of Figure 1.16a, having different orientations, meet at about 90 degrees along the grain boundary. It is of interest that the long axis of the dislocation etch pits is roughly parallel to the polygonization walls which outline the slip bands.

The presence of severe strain in this material is also revealed in the Laue back-reflection photographs shown in Figure 1.17. These were taken of the grain shown in Figure 1.15a and of the right-hand grain in Figure 1.15b. Note; in particular, the extreme elongation in the stress-axis direction. The multiplicity of small spots for each Laue reflection is characteristic of a structure containing many subgrains misoriented by tilt boundaries containing many piled-ưp dislocations.

\footnotetext{
19 ''High-Temperature.Materials Program Progress Report No. 49, Part A," GE-NMPO, GEMP-49A, July 28, 1965, p. 31.
} 


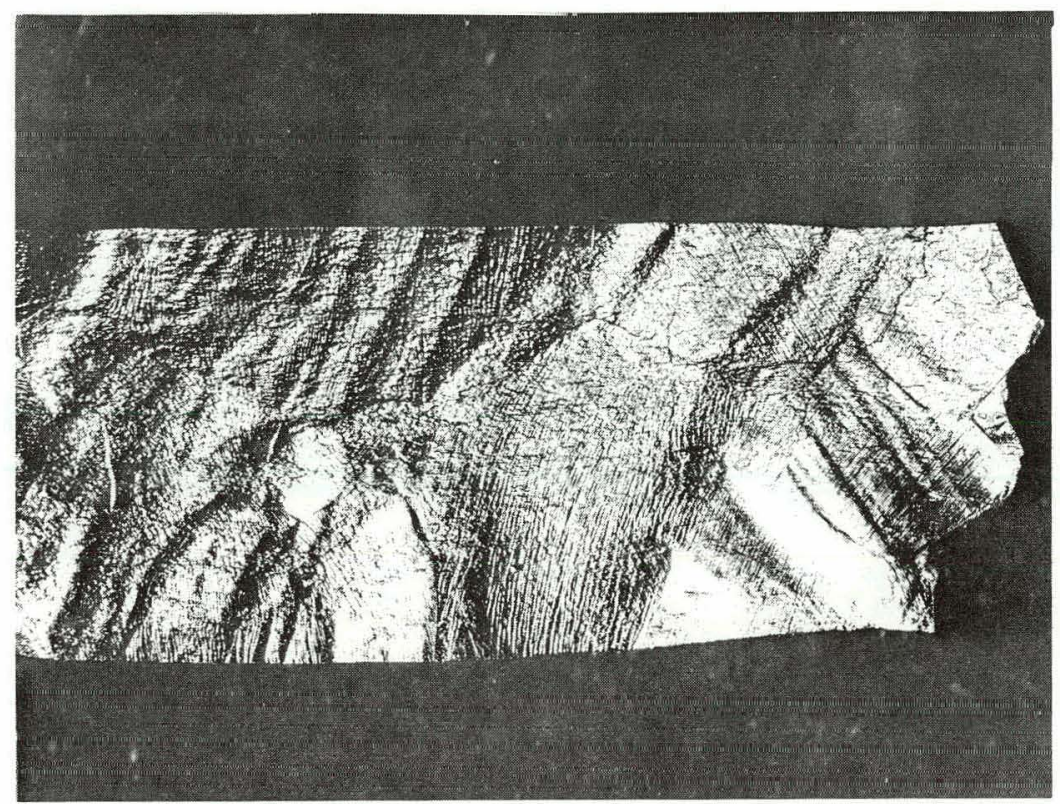

a. Tested for 8 hours in hydrogen at $1800^{\circ} \mathrm{C}$ and $2.46 \mathrm{~kg} / \mathrm{mm}^{2}$; $13.6 \%$ strain (Neg. 6667)

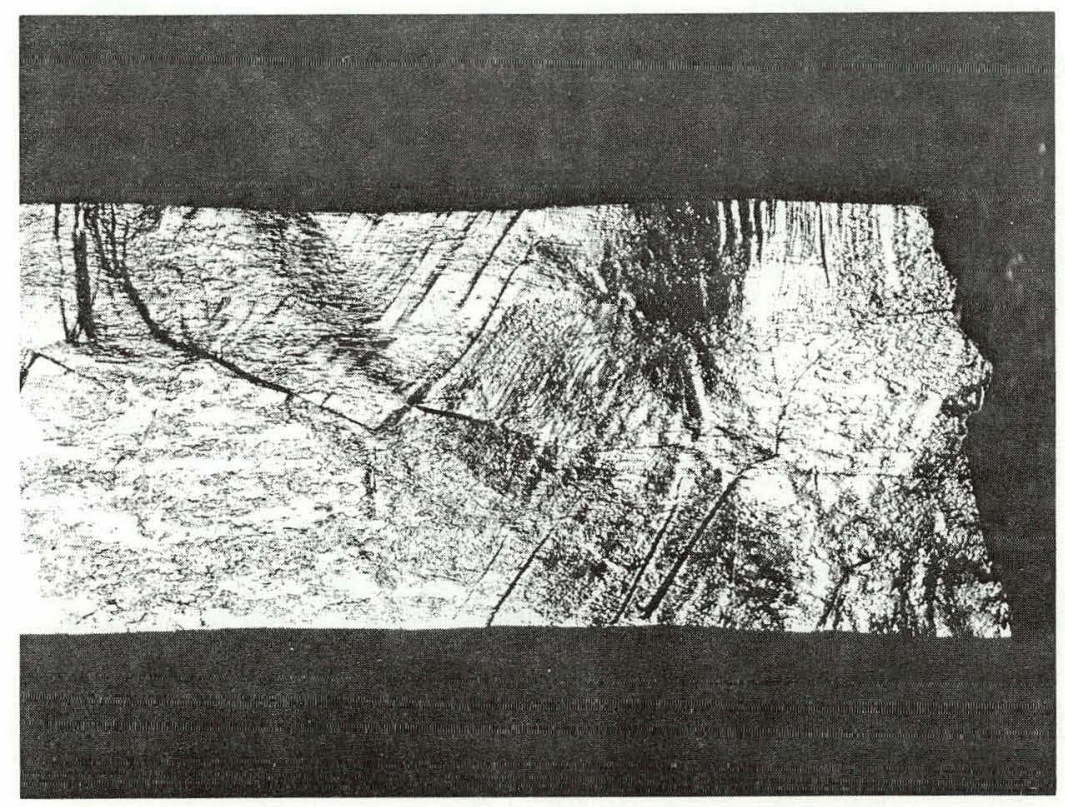

b. Tested for 8 hours in hydrogen at $2400^{\circ} \mathrm{C}$ and $0.56 \mathrm{~kg} / \mathrm{mm}^{2}$; $7.8 \%$ strain (Neg. 6659)

Fig. 1.15 - Photomacrographs of arc-cast tungsten after creep testing $(7 X)$ 


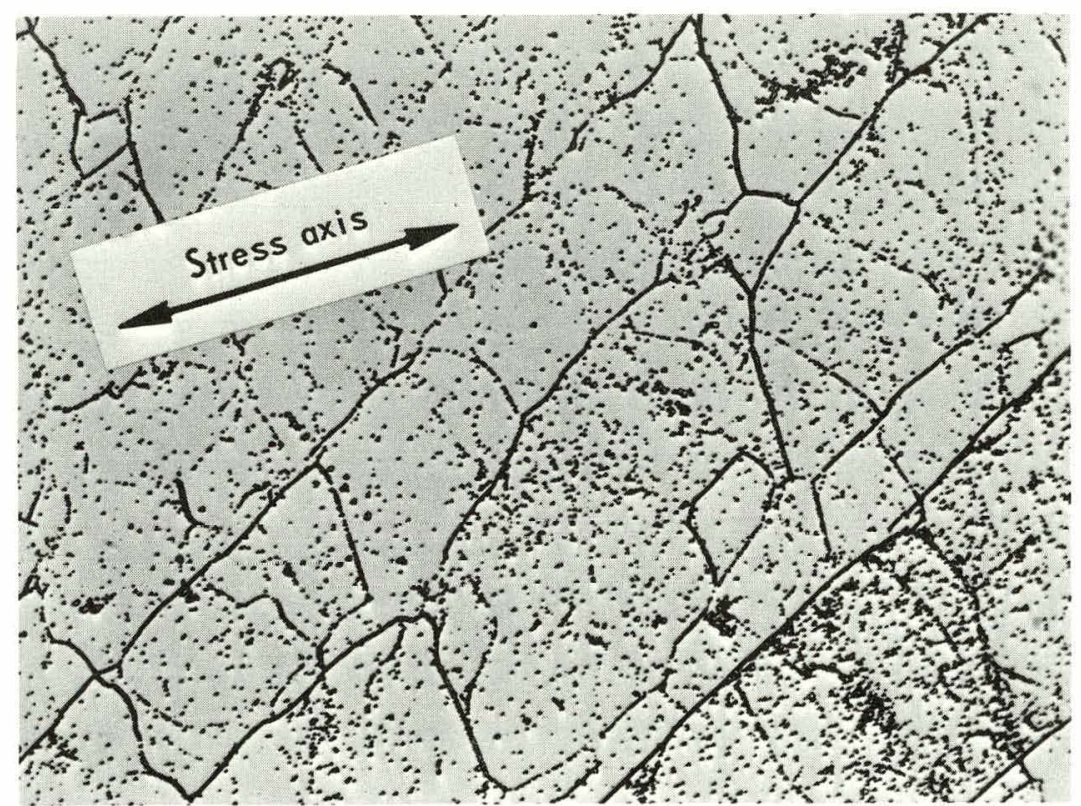

a. Longitudinal section (Neg. 6672)

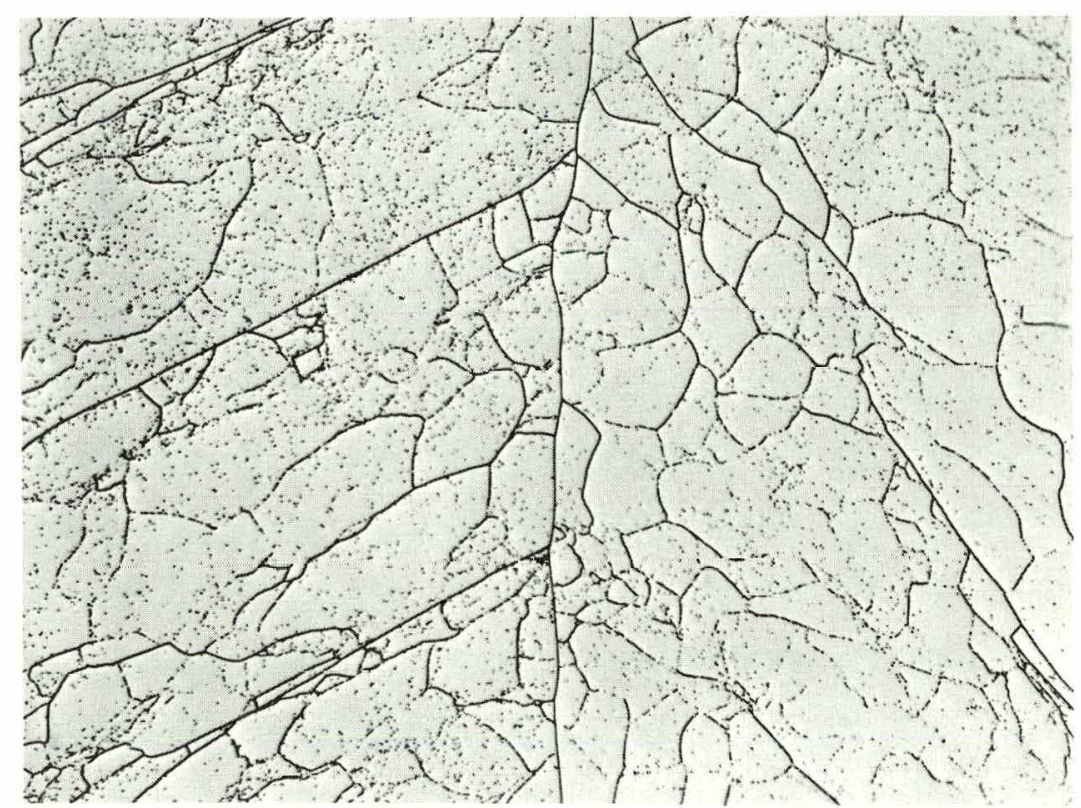

b. Transverse section (Neg. 6669)

Fig. 1.16-Photomicrographs of arc-cast tungsten after creep testing for 8 hours in hydrogen at $1800^{\circ} \mathrm{C}$ and $2.46 \mathrm{~kg} / \mathrm{mm}^{2}(250 X)$ 


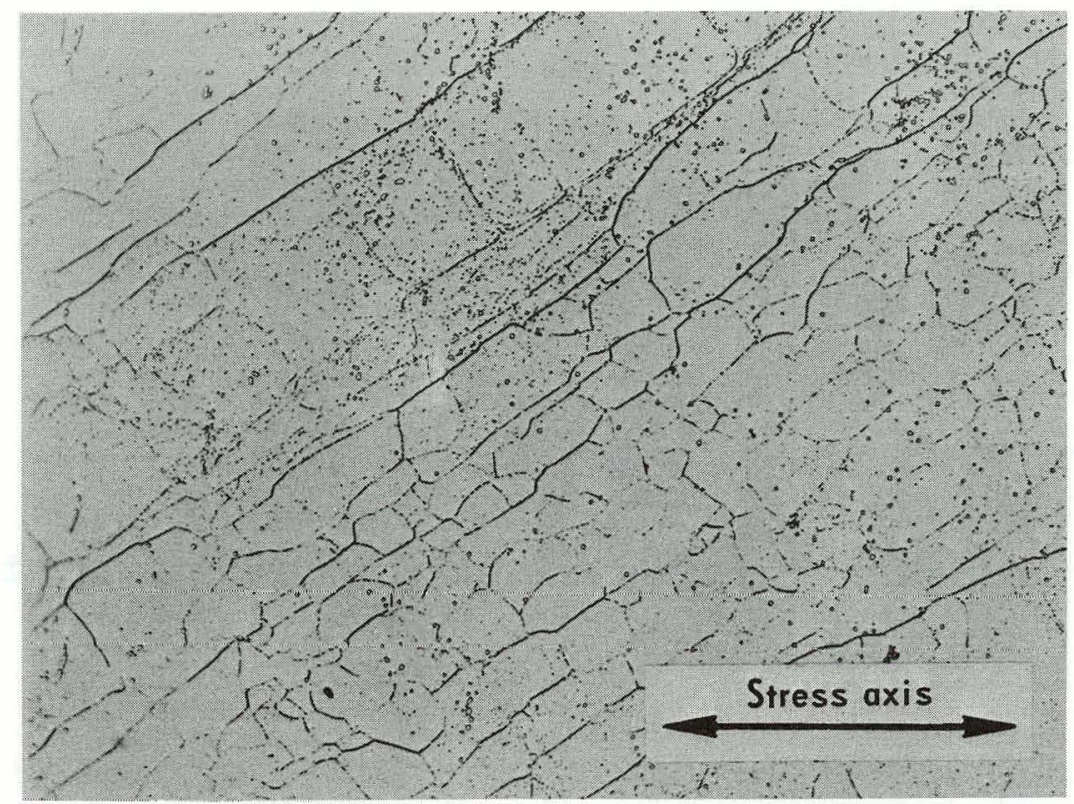

c. Edge section (Neg. 6671)

Fig. 1.16 (Cont.) - Photomicrographs of arc-cast tungsten after creep testing for 8 hours in hydrogen at $1800^{\circ} \mathrm{C}$ and $2.46 \mathrm{~kg} / \mathrm{mm}^{2}(250 X)$

The appearance of various grains after test at $2400^{\circ} \mathrm{C}\left(0.73 \mathrm{~T}_{\mathrm{m}}\right)$ is illustrated in Figure 1.18, longitudinal (a), transverse (b), and edge (c). These photomicrographs show a rather random distribution of dislocation etch pits throughout the grains, with well-identified "cells" (major subgrains) which contain smaller subgrain boundaries in the process of formation. In the views perpendicular to the stress direction, there is a tendency for alignment of dislocations into boundaries at 45 degrees to this direction. However, these boundaries are much less pronounced than in the specimen tested at $1800^{\circ} \mathrm{C}$. Grains having an orientation near [011] or [113] have been chosen to illustrate the substructure because it has previously been found ${ }^{20}$ that electrolytic etching more readily develops dislocation etch pits on these surfaces than on [001] or [112].

Laue back-reflection photographs of the grains shown in Figure 1.18a and b are shown in Figure 1.19a and $b$, respectively. Note that the individual Laue reflections are fairly coherent because the angular spread of a given spot is relatively.small. This is a further indication that the substructure is composed of rather large perfect cells separated from each other by rows of dislocations producing a small angular tilt boundary. The new (smaller) subgrains have not as yet become sufficiently pronounced to produce additional Laue splitting.

The test temperature of $1800^{\circ} \mathrm{C}$ and $2400^{\circ} \mathrm{C}$ are homologous temperatures of $0.56 \mathrm{~T}$ m and $0.73 \mathrm{~T}_{\mathrm{m}}$, respectively. At temperatures above about $0.5 \mathrm{~T}_{\mathrm{m}}$, the creep rate of metals is diffusion controlled, as Dorn ${ }^{21}$ has conclusively demonstrated. Below one-half the absolute melting temperature, creep occurs by the movement of dislocations along slip planes in the metal. The specimens studied were tested in a temperature region where both of these processes are competing; the predominant mechanism undoubtedly depends not only upon the temperature but also upon the creep rate itself.

20 “'High-Temperature Materials Program Progress Report No. 55, Part A," GE-NMPO, GEMP-55A, January 21, 1966, p. 45.

${ }^{21}$ J. E. Dorn, Creep and Recovery, ASTM, Cleveland, 1956, p. 225. 


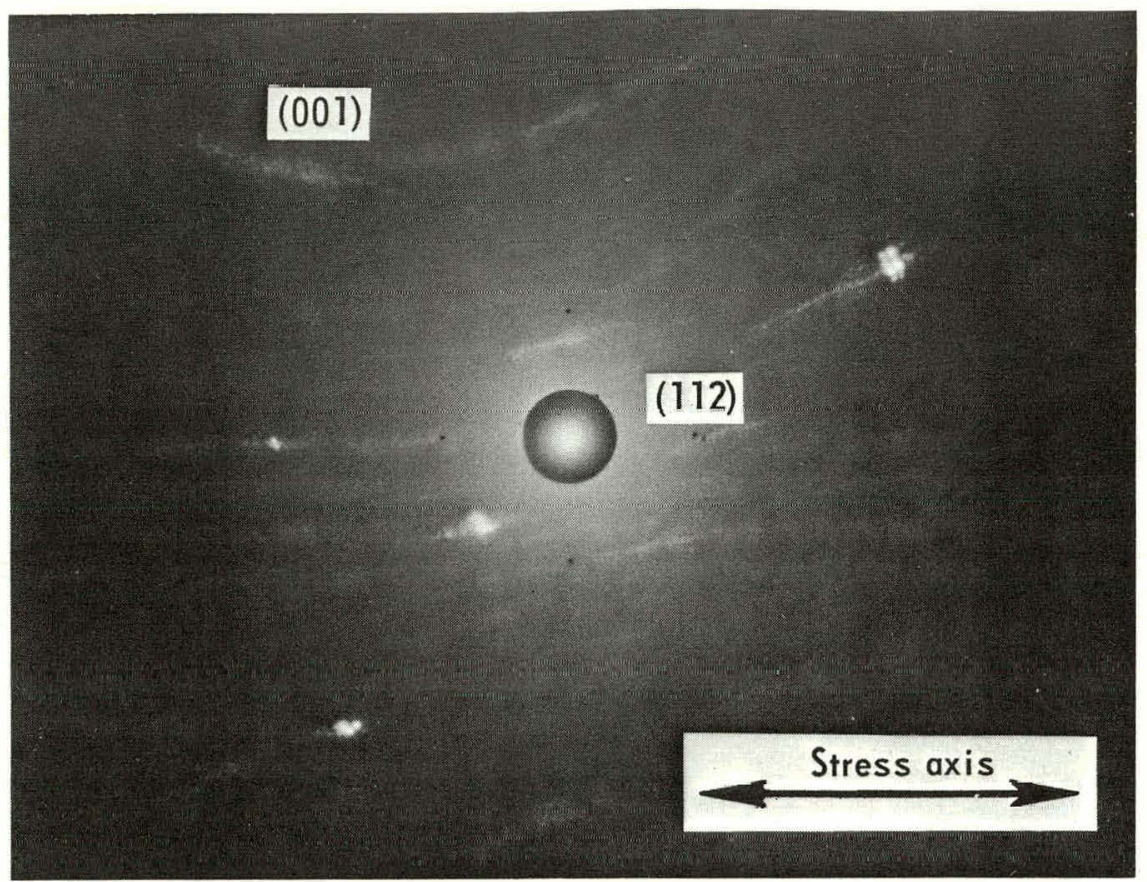

a. Longitudinal section (Neg. M-9160A)

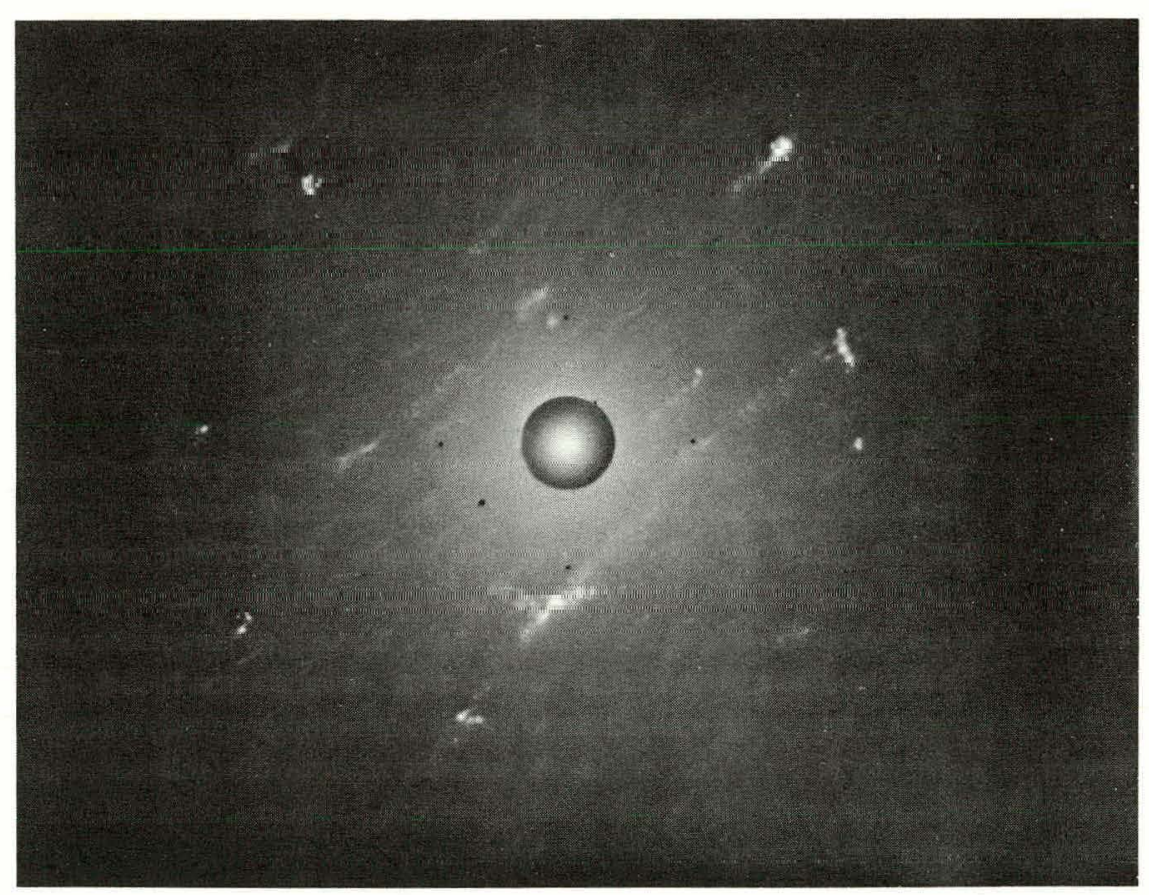

b. Transverse section (stress axis perpendicular to page) (Neg. M-9159(6))

Fig. 1.17 - Laue back-reflection photographs of arc-cast tungsten after creep testing for 8 hours in hydrogen at $1800^{\circ} \mathrm{C}$ and $2.46 \mathrm{~kg} / \mathrm{mm}^{2}$ 


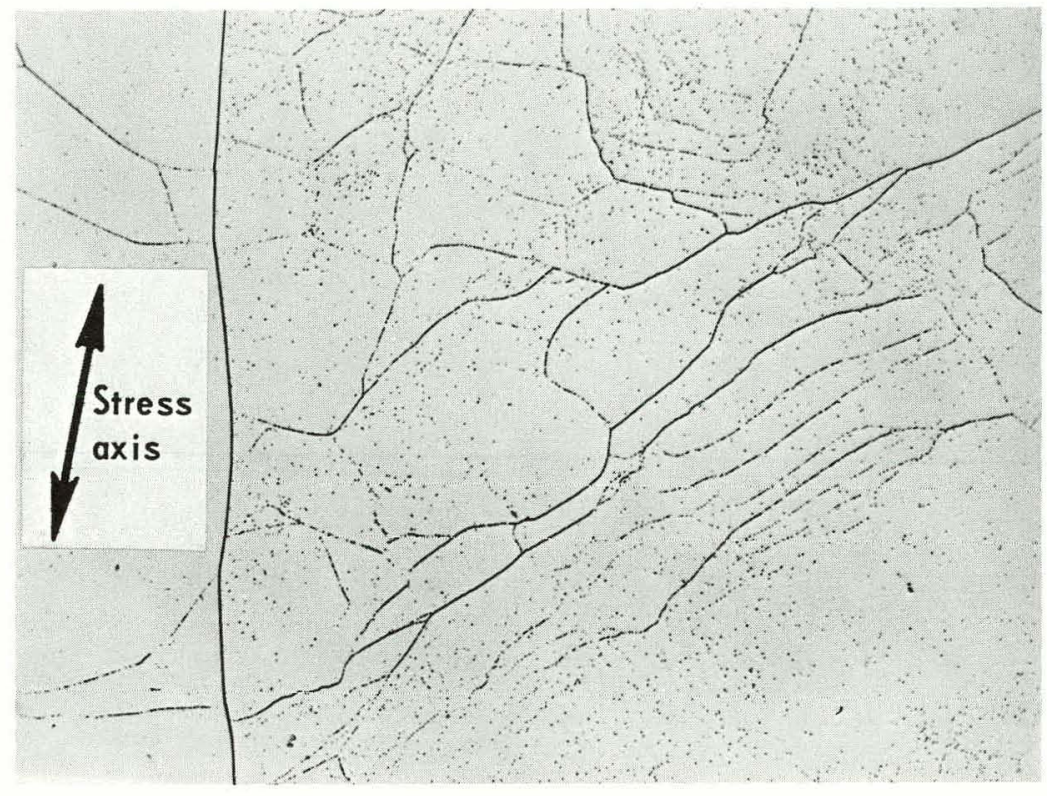

a. Longitudinal section (Neg. 6667)

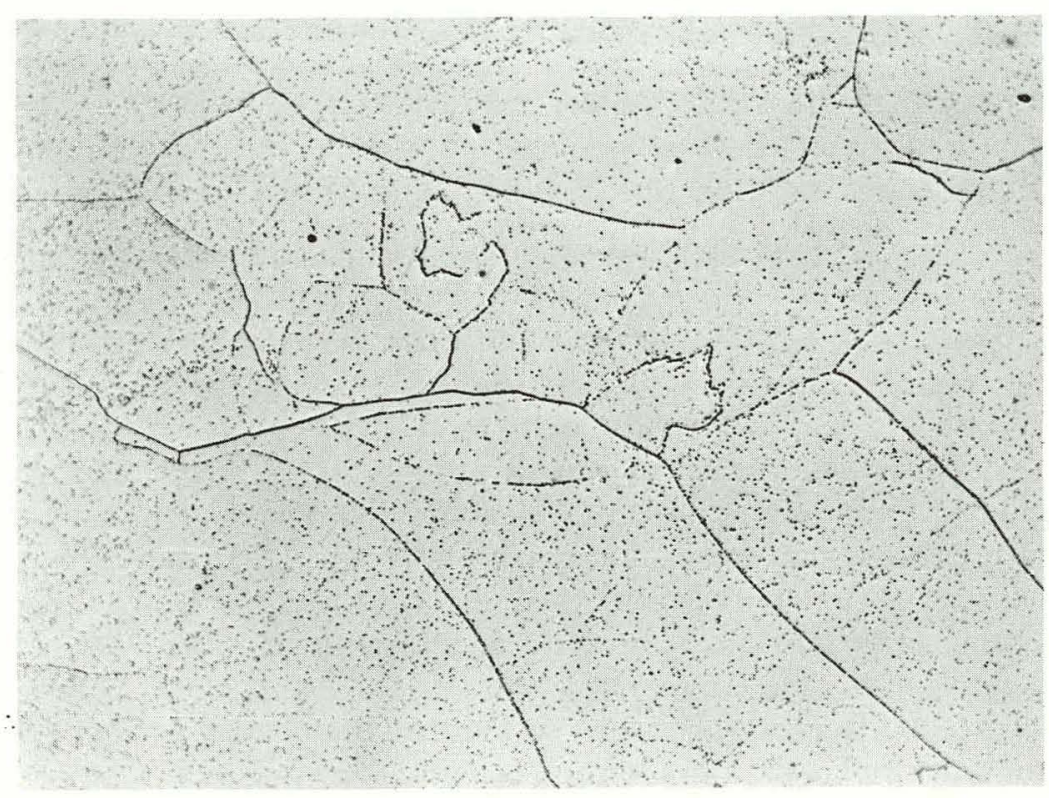

b. Transverse section (Neg. 6665)

Fig. 1.18-Photomicrographs of arc-cast fungsten after creep testing for 8 hours in hydrogen at $2400^{\circ} \mathrm{C}$ and $0.56 \mathrm{~kg} / \mathrm{mm}^{2}(250 X)$ 


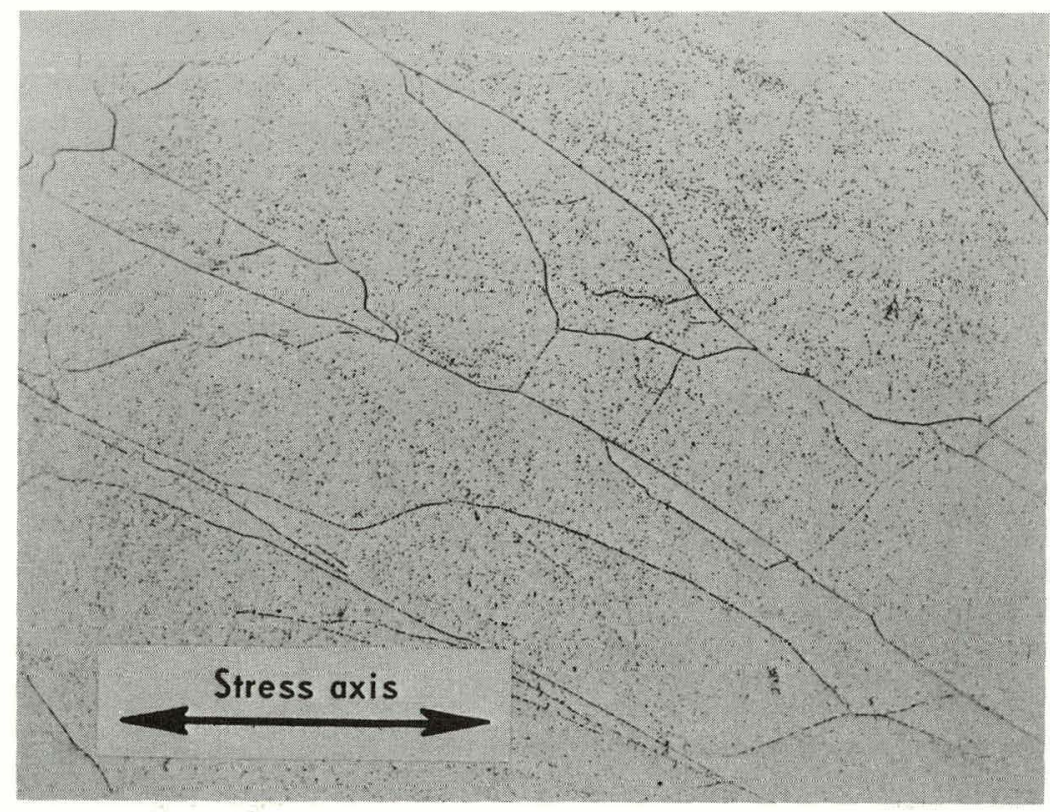

c. Edge section (Neg. 6668)

Fig. 1.18 (Cont.) - Photomicrographs of arc-cast tungsten after creep testing for 8 hours in hydrogen at $2400^{\circ} \mathrm{C}$ and $0.56 \mathrm{~kg} / \mathrm{mm}^{2}(250 X)$

The most dramatic demonstration that different mechanisms of creep are operating in these two samples is seen in Figure 1.20 . At $1800^{\circ} \mathrm{C}$, coarse and fine slip bands are very evident, with some grains showing a network of cross-slip lines. The specimen tested at $2400^{\circ} \mathrm{C}$ shows that cell formation has become well developed. The large subgrains or cells, as outlined by rows of dislocation etch pits, are generally equiaxed in appearance.

Differences between creep behavior at these two temperatures can also be seen by more detailed examination of previous high-magnification (250X) photomicrographs. Figure $1.16\left(1800^{\circ} \mathrm{C}\right.$ test specimen) reveals bands of the major slip system running at $45 \mathrm{de}-$ grees to the stress axis, intersected by wavy lines of a secondary slip system. The presence of easy cross-slip in bcc metals is believed to be due to their high stacking-fault energy. From Figure 1.17, the crystallographic slip direction is [111], and the Laue reflections are roughly six times as long in this direction as they are wide. Hence, the primary mode of deformation under these conditions of intermediate temperature and higher strain rate is a general disordering of the structure by grain boundary migration and intragranular slip. Glide of dislocations in the [111] direction along planes favorably oriented to the stress direction would produce the slip lines and bands which have been observed. At this temperature, self-diffusion is relatively slow so that the dislocations progress through the metal by glide only on close-packed atomic planes.

For the $2400^{\circ} \mathrm{C}$ test specimen, the degree and mechanism of deformation is markedly different. At the higher temperature and lower strain rate, the creep process appears to be mainly governed by self-diffusion. Dislocations now move not only by glide but by climb and therefore can bypass obstacles to reach the surface. This leads to the formation of structurally perfect subgrains separated from each other by small tilt boundaries containing entrapped dislocations. This polygonization is shown quite well in Figures $1.20 \mathrm{~b}$ and 1. 18. The random distribution of dislocation etch pits in Figure 1.18 implies a greater freedom of movement through the metal. The substructure is less strained as the backreflection photograph in Figure 1.19 illustrates. The reflections are composed of large 


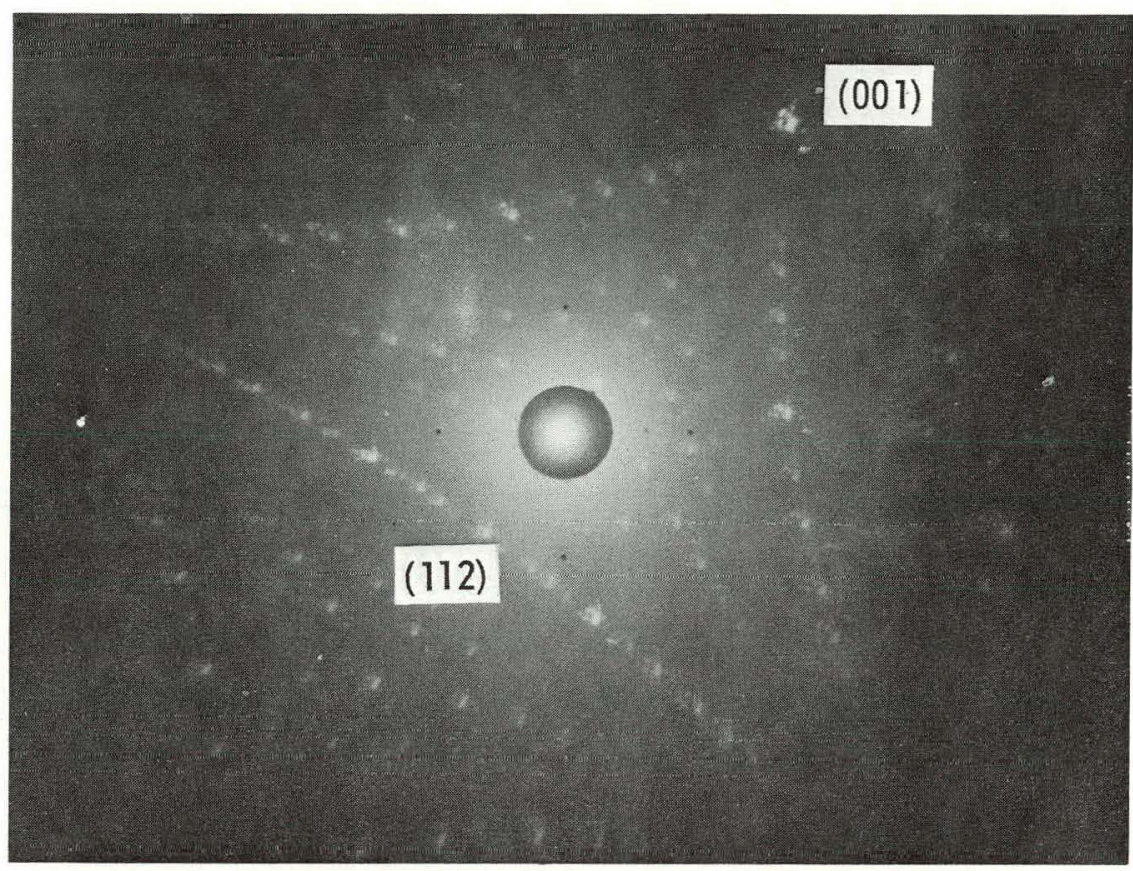

a. Longitudinal section (Neg. M-9158A)

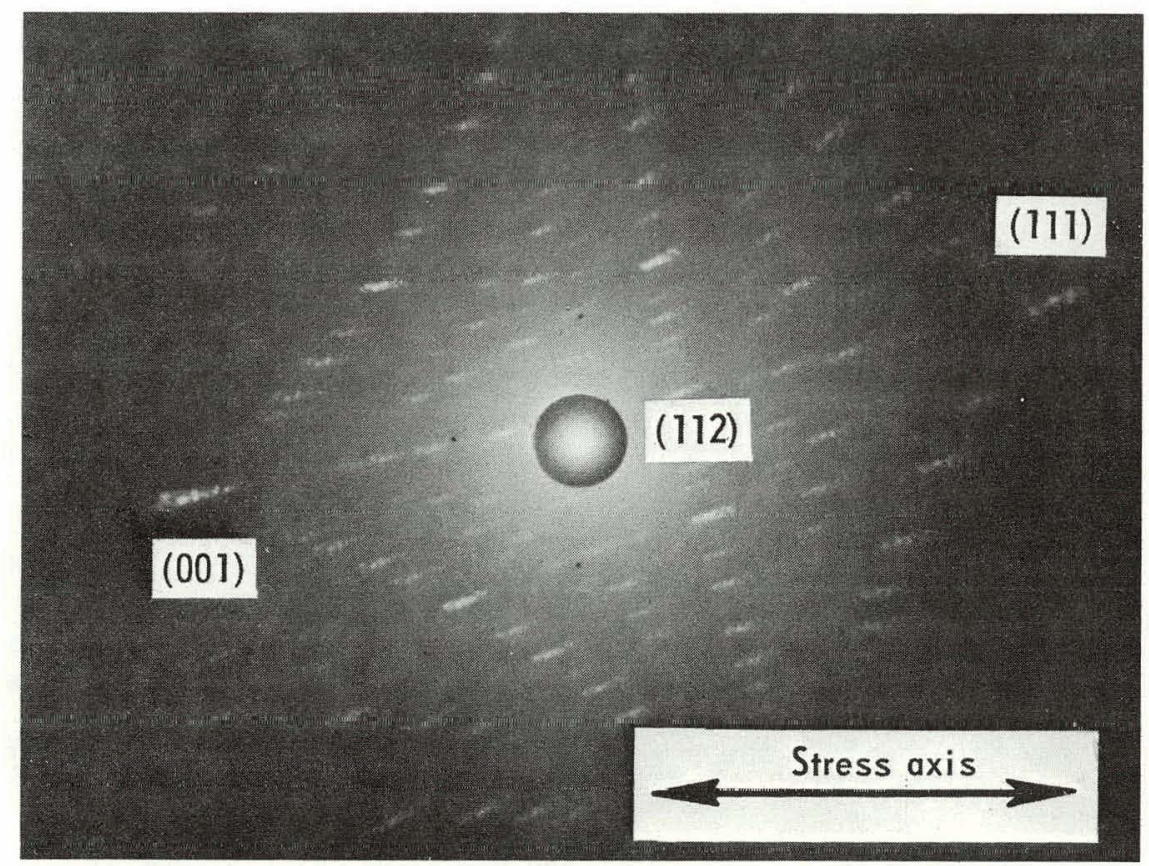

b. Transverse section (stress axis perpendicular to page) (Neg. M-9157)

Fig. 1.19-Laue back-reflection photographs of arc-cast tungsten after creep testing for 8 hours in hydrogen at $2400^{\circ} \mathrm{C}$ and $0.56 \mathrm{~kg} / \mathrm{mm}^{2}$ 


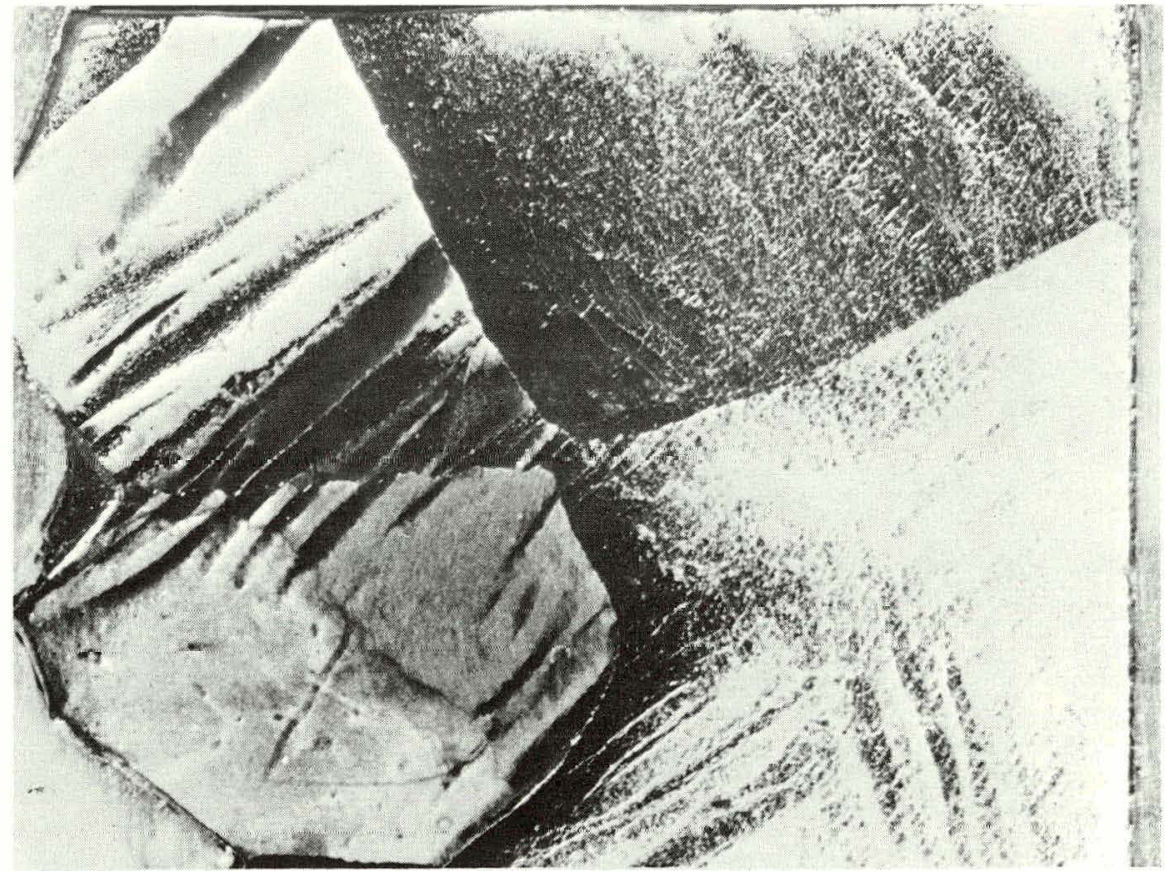

a. Tested for 8 hours at $1800^{\circ} \mathrm{C}$ and $2.46 \mathrm{~kg} / \mathrm{mm}^{2}$; $13.7 \%$ strain (Neg. 6664)

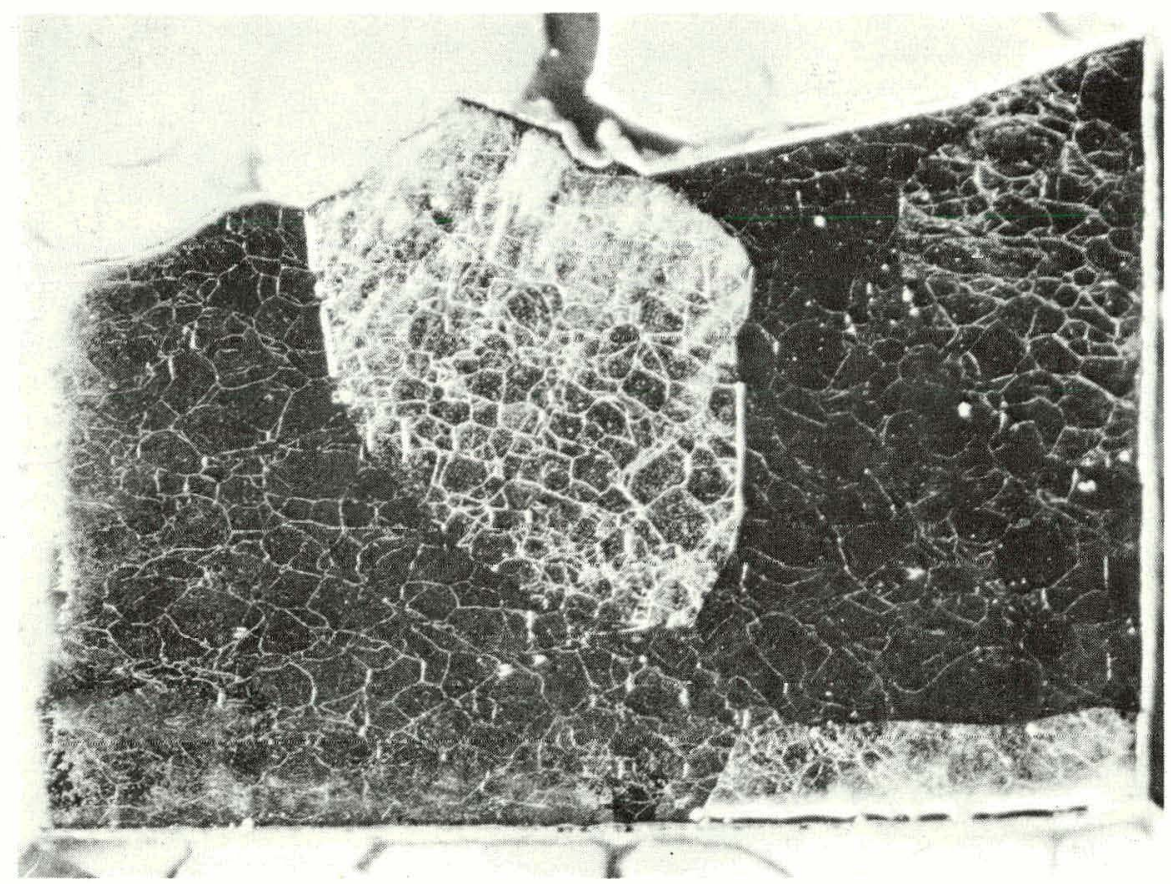

b. Tested for 8 hours in hydrogen at $2400^{\circ} \mathrm{C}$ and $0.56 \mathrm{~kg} / \mathrm{mm}^{2}$; $7.8 \%$ strain (Neg. 6663)

Fig. 1.20 - Photomacrographs of arc-cast tungsten after creep testing (18X) 
individual spots very near each other which indicates much less distortion of the grain structure. These observations are in accord with the cell formation described by Wood and his collaborator . $^{22}$

A change in the mechanism of deformation during creep has also been observed in tantalum between $0.6 \mathrm{~T}_{\mathrm{m}}$ and $0.9 \mathrm{~T}_{\mathrm{m}}$ by Green. ${ }^{23}$ He found that the coarse slip-band defor mation was very important at high stresses, while the subgrain size increased with temperature at lower stresses. It is of interest that such a change occurs at about $0.6 \mathrm{~T}_{\mathrm{m}}$ for tungsten, also.

One other bcc metal recently studied was a niobium alloy by Harris. ${ }^{24}$ It was concluded that crystallographic slip was predominant at $980^{\circ} \mathrm{C}\left(0.55 \mathrm{~T}_{\mathrm{m}}\right)$ but becomes less important as the temperature is increased. Cell-formation begins to occur at $1205^{\circ} \mathrm{C}(0.65 \mathrm{~T} \mathrm{~m})$ and becomes the controlling mechanism at $1315^{\circ} \mathrm{C}\left(0.70 \mathrm{~T}_{\mathrm{m}}\right)$. These results are noteworthy because they agree remarkably well with those for tantalum and tungsten. At a homologous temperature of $0.6 \mathrm{~T}_{\mathrm{m}}$ for these three bcc metals, a transition in the deformation mechanism has been observed. Below this temperature, creep is not diffusion-controlled but dislocation glide produces crystallographic slip and cross-slip. Above $0.6 \mathrm{~T}_{\mathrm{m}}$, however, selfdiffusion begins to predominate by the mechanism of dislocation climb.

\subsection{PHYSICAL PROPERTY EVALUATIONS}

\section{THERMAL EXPANSION}

Some attention has been given to establishing certain materials as high-temperature thermal expansion standards. At the present time, no such standards exist for use above $1000^{\circ} \mathrm{C}$ despite the fact that many thermal expansion measurements have recently been reported for temperatures approaching $3000^{\circ} \mathrm{C}$. It seems, therefore, that such a hightemperature standard is needed for assessing the effectiveness of various expansion measurement techniques as well as for evaluating the validity of published data.

A review of the available data ${ }^{25-29}$ dealing with the thermal expansion characteristics of tungsten led to the comparison shown in Figure 1.21. The agreement of the data of Conway and Losekamp ${ }^{25}$ and that of Amonenko, et al.,$^{26}$ is outstanding considering that an optical technique was employed by the former, whereas a vacuum dilatometer was employed by the latter. As a matter of fact, the good agreement by all the data presented in the figure would seem to provide evidence enough to permit these data to be accepted as characteristic of the expansion behavior of tungsten. A least squares fit of the data in Figure 1.21 yields:

$$
\frac{\mathrm{L}-\mathrm{L}_{25^{\circ} \mathrm{C}}}{\mathrm{L}_{25^{\circ} \mathrm{C}}} \times 100=1.14 \times 10^{-3}+3.68 \times 10^{-4} \mathrm{t}+8.24 \times 10^{-8_{\mathrm{t}}}
$$

which is shown as the solid curve in Figure 1.21 ( $t$ in ${ }^{\circ} \mathrm{C}$ ).

22W. A. Wood, et al., Journal of lnstitute of Metals, Vol. 75, 1948-1949, p. 693; ;bid., Vol. 76, 1949-1950; ibid., Vol. 77, 1950, p. 423; ibid., Vol. 79, 1951, p. 1959.

${ }^{23}$ W. V. Green, Transactions of the AIME, Vol. 233, 1965, p. 1818.

${ }^{24}$ B. Harris, Journal of Less Common Metals, Vol. 9, 1965, p. 244.

${ }^{25} \mathrm{~J}$. B. Conway and A. C. Losekamp, "Thermal Expansion Characteristics of Several Refractory Metals to $2500^{\circ} \mathrm{C}$," Transactions of Metallurgical Society, AIME, Vol. 236, 1966, p. 702.

${ }^{26}$ V. M. Amonenko, P. N. V'yugov, and V. S. Gumenyuk, "Thermal Expansion of Tungsten, Molybdenum, Tantalum, Niobium and Zirconium at High Temperatures," High Temperature, Vol. 2, 1964, p. 22.

${ }^{27}$ A. Goldsmith, T. E. Waterman, and H. J. Hirschhorn, "Thermophysical Properties of Solid Materials, Vol. I," WADC TR-58-476, August 1960.

${ }^{28}$ A. G. Worthing, "The Thermal Expansion of Tungsten at Incandescent Temperatures," Physical Review, Vol. 10, 1917 , p. 638 .

${ }^{29} \mathrm{~J}$. Demarquay, "New Method for the Study of Expansion of Solids at High Temperatures. The Expansion of Tungsten and Molybdenum," Compt. Rend., Vol. 220, 1945, p. 81. 


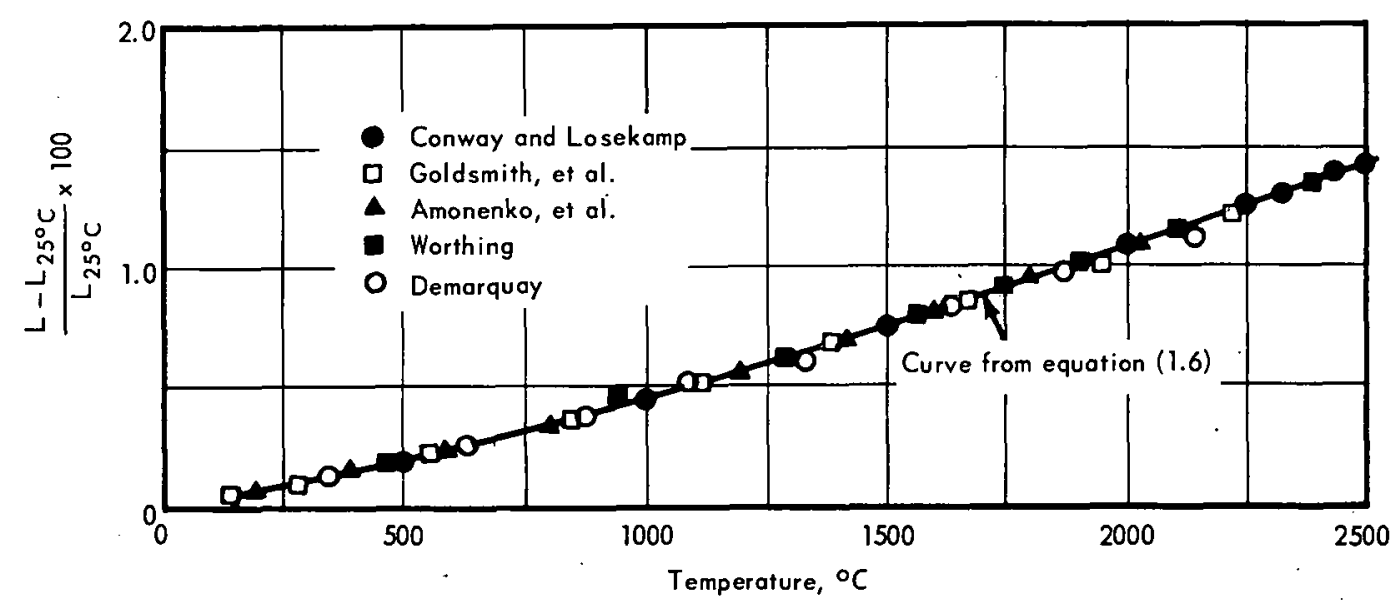

Fig. 1.21 - A comparison of linear thermal expansion data for tungsten

An equation similar to equation (1.6) was developed by imposing the restraint that the ordinate be zero at $25^{\circ} \mathrm{C}$. The result is:

$$
\frac{\mathrm{L}-\mathrm{L}_{25^{\circ} \mathrm{C}}}{\mathrm{L}_{25^{\circ} \mathrm{C}}} \times 100=3.88 \times 10^{-4}(\mathrm{t}-25)+7.7 \times 10^{-8}(\mathrm{t}-25)^{2}
$$

This expression provides an excellent fit for the data in Figure 1.21 and has a standard deviation which is just slightly larger than that of equation (1.6).

An analysis technique was identified which appears to have some merit in assessing the internal consistency of thermal expansion data. It was noted that fairly distinct linearity is obtained when thermal expansion data (as $\Delta \mathrm{L} / \mathrm{L}$ ) are plotted against temperature in ${ }^{\circ} \mathrm{C}$ on logarithmic coordinates. Several examples of this type of plot are presented in Figure 1.22. In addition to the linearity, a striking parallelism can be seen. This behavior suggests the relationship:

$$
100 \frac{\Delta \mathrm{L}}{\mathrm{L}}=\frac{\mathrm{L}-\mathrm{L}_{25^{\circ} \mathrm{C}}}{\mathrm{L}_{25^{\circ} \mathrm{C}}} \times 100=a t^{\mathrm{b}}
$$

where $t$ is temperature in ${ }^{\circ} \mathrm{C}$ and $a$ and $b$ are constants with $b$ (slope of lines in Figure 1. 22) having a value between 1.15 and 1.20 .

It is felt that deviations from linearity in Figure 1.22 are probably errors in the experimental data. For example, the high-temperature data for nickel and chromium exhibit such deviations and hence should be viewed with some suspicion.

Similar plots for several of the refractory metals are shown in Figure 1.23. As before, a linear relationship is obtained and also the lines are parallel. Slope measurements yield a value close to 1.20 which is in good agreement with the slope measurements in Figure 1.22.

Also shown in Figure 1.23 are the expansion data ${ }^{30}$ for single-crystal $\mathrm{Al}_{2} \mathrm{O}_{3}$ (57.6-degree orientation). These too are linear in Figure 1.23 and interestingly enough the slope of this line is very close to that of the $\mathrm{W}$, Mo, and $\mathrm{Nb}$ lines.

${ }^{30} \mathrm{~J}$. B. Wachtman, T. G. Scuderi, and G. W. Cleek, "Linear Thermal Expansion of Aluminum Oxide and Thorium Oxide from $100^{\circ}$ to $1100 \mathrm{~N}_{\mathrm{K}}, "$ Journal of Americun Chemical Society, Vol. 45, 1962, p. 319. 


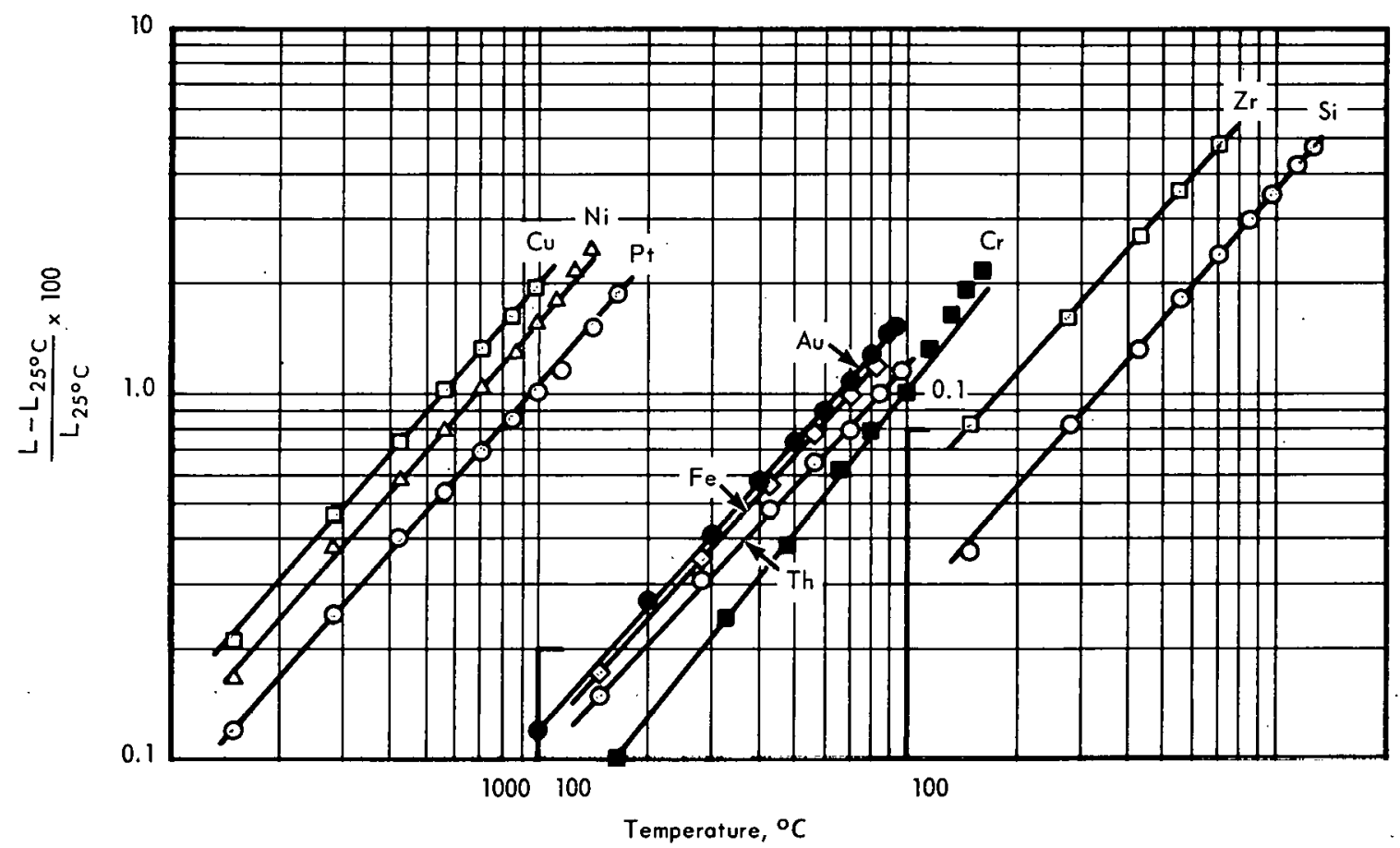

Fig. 1.22 - Thermal expansion data of several metals plotted to yield a linear relationship

Some attempts have been made to correlate the thermal expansion data for several of the refractory metals in terms of homologous temperatures (ratio of absolute test temperature to absolute melting temperature). It was found that this approach led to completely unsatisfactory results. Even when the data were limited to the Group VI-A metals no consistent behavior was observed. However, very excellent results were obtained for the data of the Group VI-A metals when the "relative temperature ratio" (test temperature divided by the melting temperature, both in ${ }^{\circ} \mathrm{C}$ ) was employed. While no precedent or justification can be cited for the use of this parameter, it does appear to provide for an excellent correlation. For example, the data for W, Mo, and $\mathrm{Cr}$, as shown in Figure 1.24, are found to be in very good agreement. While this seems to be the first use of the relative temperature ratio in any type of data correlation, the results in Figure 1.24 suggest that this approach may have some value not only in assessing the consistency of some data but also in predicting expansion data for a metal in a given group once data for other metals in this same group are known. Predicting data for vanadium, for example, might follow from this type of analysis using the known data for tantalum and niobium (all Group V-A metals).

\section{THERMAL CONDUCTIVITY}

$\underline{\mathrm{W}-\mathrm{UO}} 2$

Thermal conductivity measurements were made on $\mathrm{W}-\mathrm{UO}_{2}$ compacts containing a uniform dispersion of 20,40 , and 60 volume percent $\mathrm{UO}_{2}$. The specimens tested were fabricated by a Dynapak process to densities from 95 to 97.4 percent of theoretical. Since the densities were high, no correction was made to the data. 


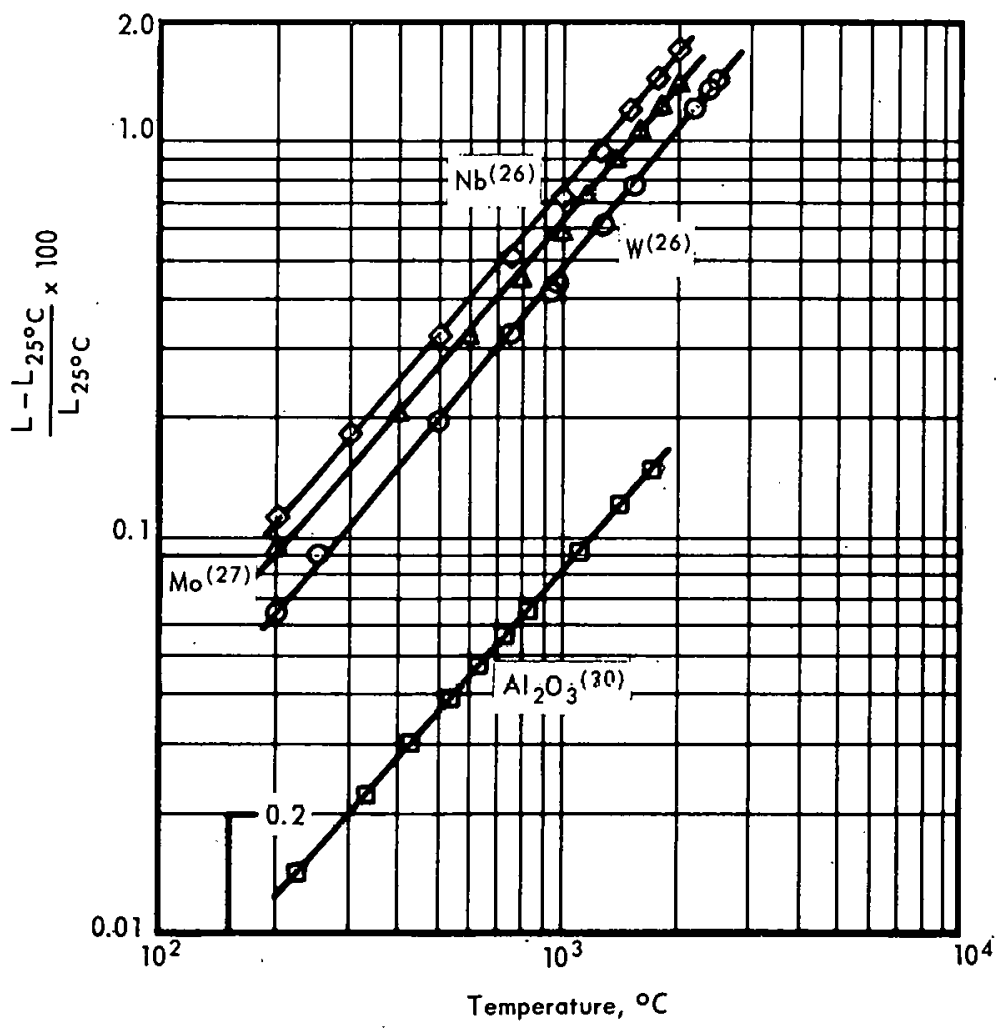

Fig. 1.23-Plots of $\frac{\Delta L}{L}$ versus $T^{\circ} \mathrm{C}$ for $\mathrm{W}_{1}, \mathrm{Mo}, \mathrm{Nb}$, and $\mathrm{Al}_{2} \mathrm{O}_{3}$

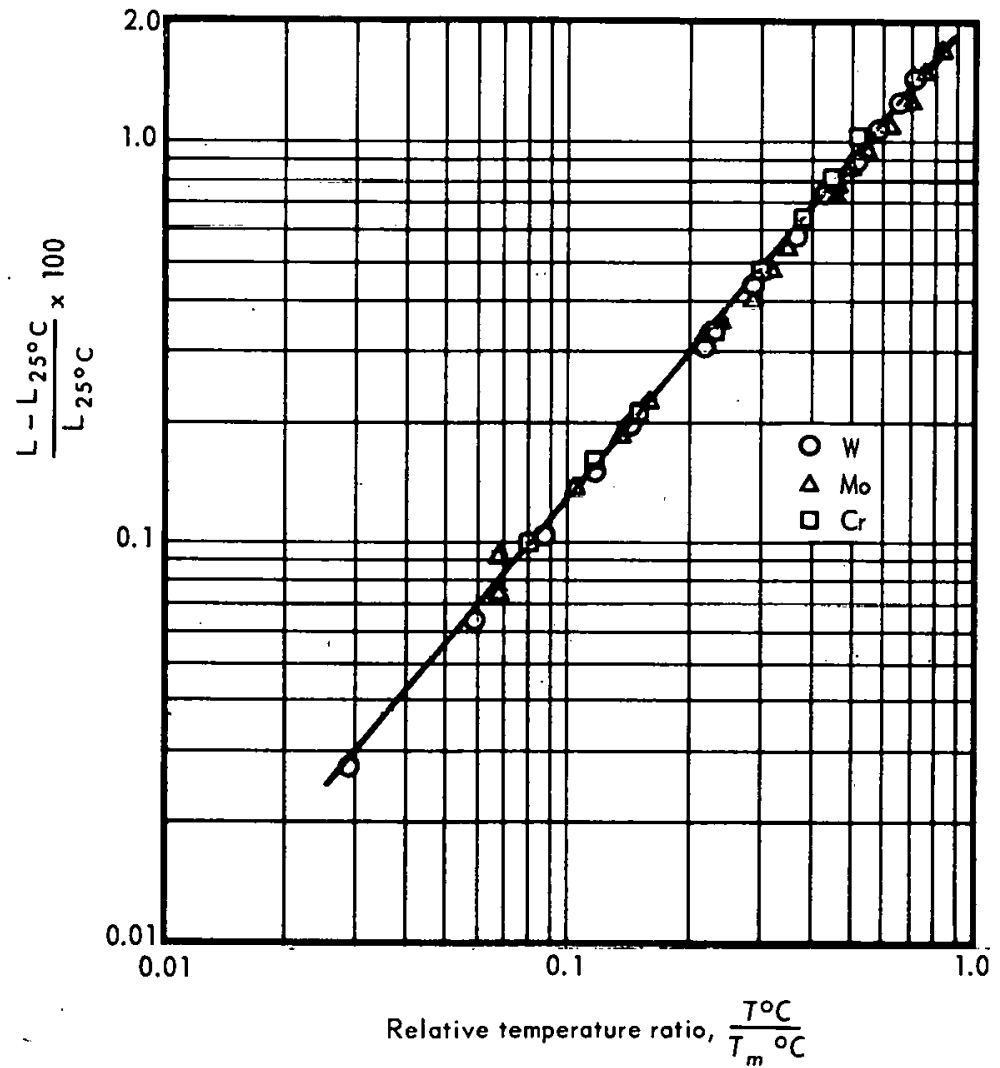

Fig. 1.24 - Linear thermal expansion data for the group VI-A metals plotted as a function of the relative temperafure ratio 
The work was performed in the radial heat flow apparatus which has been previously described. ${ }^{31}$ Figure 1.25 shows the data for these compositions compared to curves for tungsten $^{32}$ and $\mathrm{UO}_{2}{ }^{33}$. The influence of composition on the thermal conductivity of $\mathrm{W}-\mathrm{UO}_{2} \mathrm{Com}^{-}$ pacts can be readily seen from this comparison. To date, there have been insufficient studies to determine the mechanisms of heat transport in this material or the effect of shape and orientation of the oxide particles on the thermal conductivity.

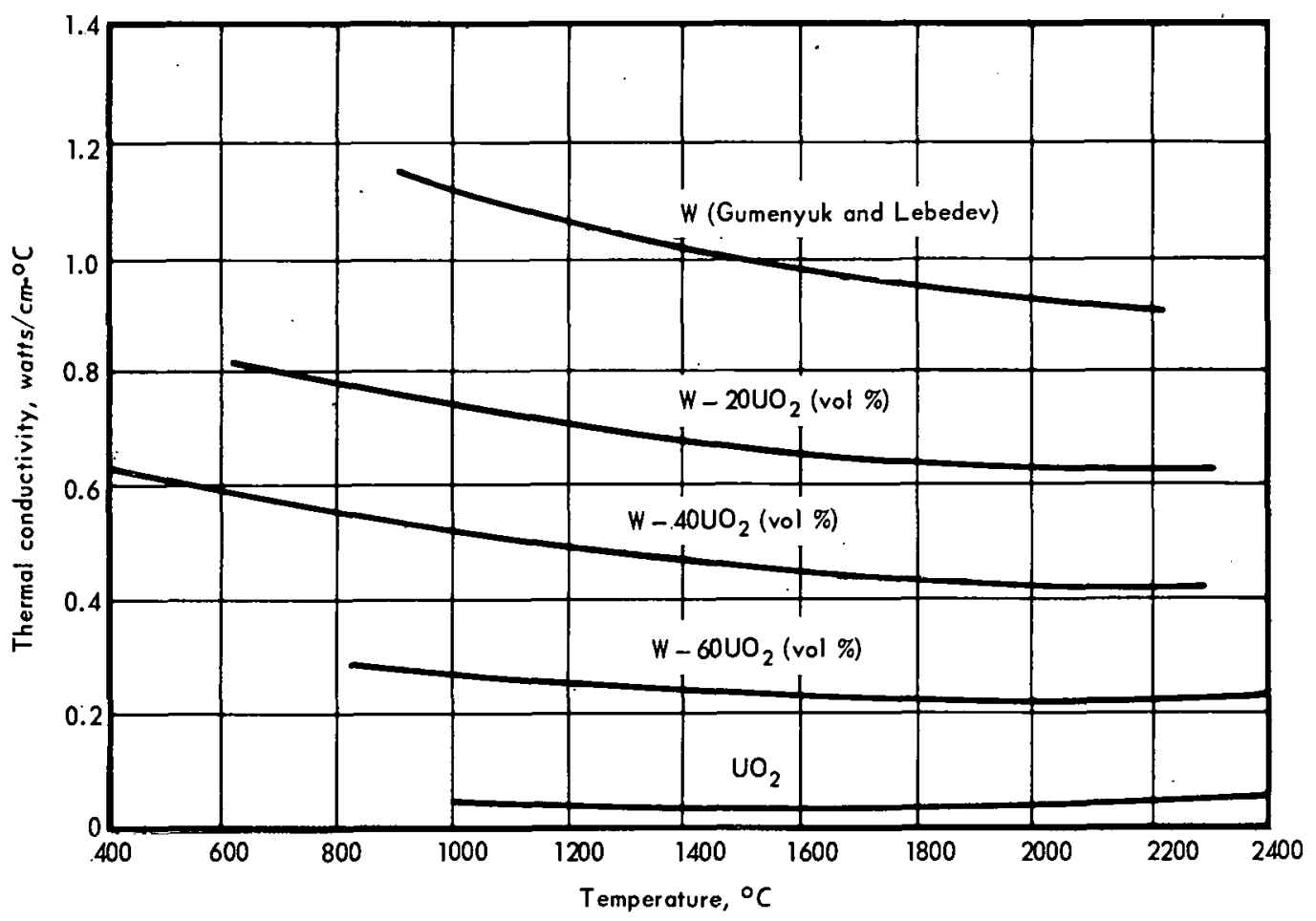

Fig. 1.25 - Thermal conductivity versus temperature for $\mathrm{W}^{-\mathrm{UO}_{2}}$ and composites

\section{ENTHALPY}

Ta and Ta-Base Alloys

The drop technique used in conjunction with an adiabatic calorimeter was employed to measure the enthalpy of unalloyed $\mathrm{Ta}, \mathrm{Ta}-10 \mathrm{~W}$ (wt \%), T-111 ( Ta $-8 \mathrm{~W}-2 \mathrm{Hf}$, wt $\%$ ), and $\mathrm{T}-222\left(\mathrm{Ta}-9.5 \mathrm{~W}-2.5 \mathrm{Hf}-0.01 \mathrm{C}\right.$, wt \%) in the temperature range of $1000^{\circ}$ to $2300^{\circ} \mathrm{C}$. The results of these measurements are given in Figure 1.26 and indicate that the enthalpy values for the alloys are about the same as those for the pure tantalum metal. This good agreement was expected since the heat contents for tantalum and tungsten are about the same. A comparison of the present enthalpy data for tantalum and some available literature values is

${ }^{31}$ A. D. Feith, "A Radial Heat Flow Apparatus for High Temperature Thermal Conductivity Measurements," GE-NMPO, GEMP-296, August 31, 1964.

32 V. S. Gumenyuk and V. V. Lebedev, "Investigating the Heat and Electrical Conductivities of Tungsten and Graphite at High Temperatures," Fizika Metallov and Metallovedeniye, Vol. 2, January 1961, NR/pp. 29-31, Translation USAEC-NP-TR-733.

${ }^{33}$ A. D. Feith, "Thermal Conductivity of Several Ceramic Materials to $2500^{\circ} \mathrm{C}$," Advances in Thermophysical Properties at Extreme Temperatures and Pressures, ASME, 1965, p. 328. 

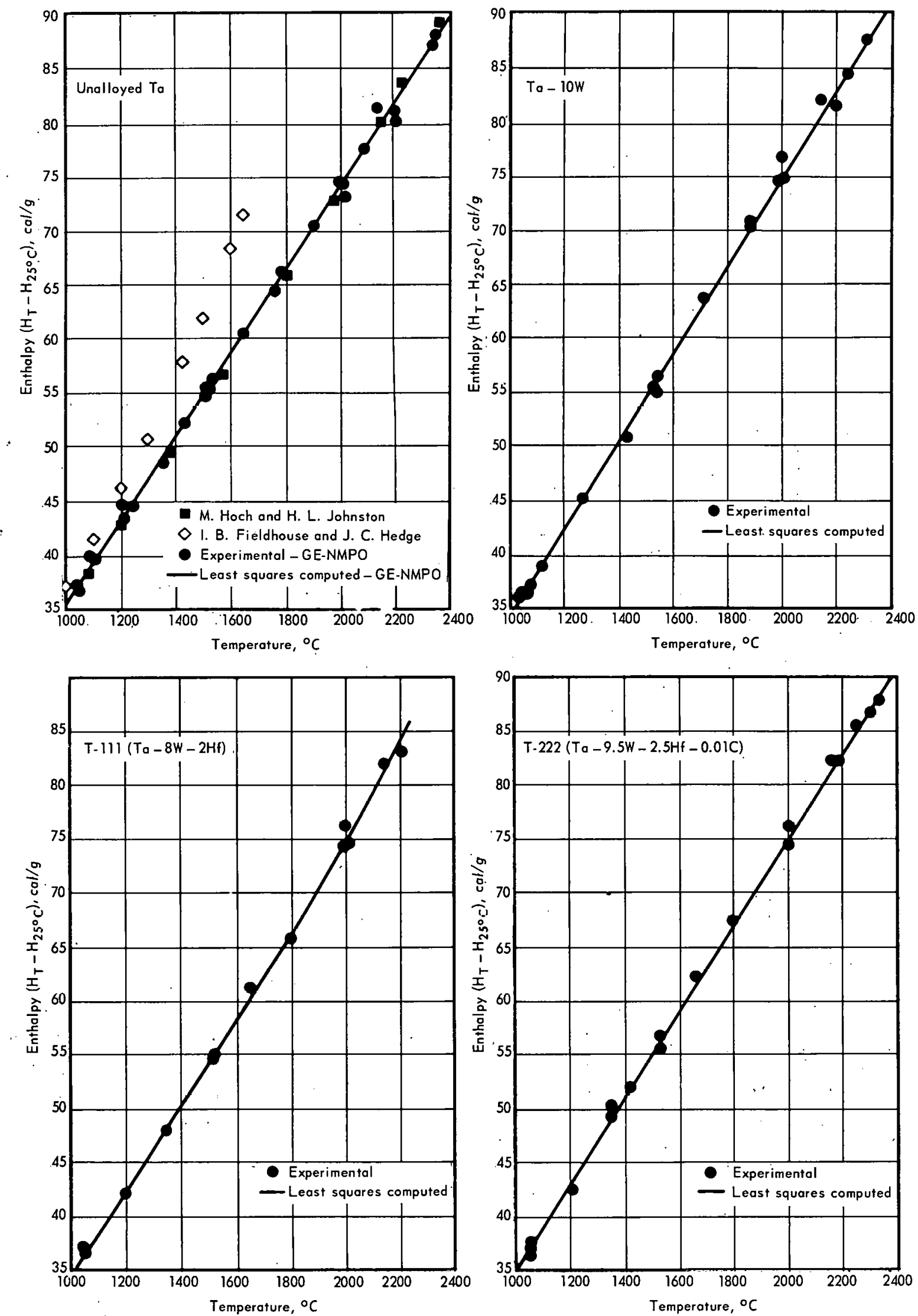

Fig. 1.26 - Enthalpy - temperature data for unalloyed tantalum and some alloys of tantalum 
also shown in Figure 1.26. The Hoch and Johnston ${ }^{34}$ data are in excellent agreement with GE-NMPO data while the Fieldhouse and Hedge ${ }^{35}$ data show only fair agreement at low temperatures and appear to be about 15 percent higher at the elevated temperatures.

\subsection{SUMMARY AND CONCLUSIONS}

The stress-rupture and creep characteristics for wrought, arc-cast $\mathrm{W}-25 \mathrm{Re}$ sheet were determined at $1600^{\circ}, 2000^{\circ}$, and $2400^{\circ} \mathrm{C}$ in hydrogen with rupture times from 2.4 to 513 hours. The creep resistance and rupture life exceeds that of arc-cast unalloyed tungsten at $1600^{\circ} \mathrm{C}$. Above $2000^{\circ} \mathrm{C}$, the rupture life for tungsten exceeds that of $\mathrm{W}-25 \mathrm{Re}$ for the same conditions.

Creep-rupture tests of 34 different W-Re-Mo alloy compositions in sheet form were performed at $1600^{\circ} \mathrm{C}$ and $2200^{\circ} \mathrm{C}$ in hydrogen to evaluate the comparative creep resistance, rupture life, ductility, and structure. At $1600^{\circ} \mathrm{C}$, alloys containing 20 - and 30percent molybdenum with 18- and 17-percent rhenium, respectively, appear to be the more favorable on the basis of creep resistance and ductility. At $2200^{\circ} \mathrm{C}$, the alloys containing 20- and 30-percent molybdenum with 20- to 23-percent rhenium, respectively, appear to be the more favorable. These alloys, identified at each temperature, are solid-solution alloys and hence no precipitation will occur to influence the properties.

A comparison of the creep-rupture characteristics at $1600^{\circ} \mathrm{C}$ and $2200^{\circ} \mathrm{C}$ for various refractory metals and alloys are presented. At $1600^{\circ} \mathrm{C}$, unalloyed rhenium is the most creep resistant, followed by $\mathrm{W}-25 \mathrm{Re}$. At $2200^{\circ} \mathrm{C}$, unalloyed molybdenum is the least creep resistant and is followed by Mo - 50Re.

A study investigating the ability of a single creep equation to describe the strain - time behavior for the entire creep curve (at constant load) was made. A modified delacombe equation was found to give the best results in describing the creep data for arc-cast tungsten at $2400^{\circ} \mathrm{C}$ followed by the Graham-Walles equation containing a $\mathrm{t}^{3}$ term.

Combined first- and second-stage creep data for arc-cast tungsten at $2200^{\circ}$ to $2600^{\circ} \mathrm{C}$ have been analyzed in terms of the compensated-time parameter. A modification to the parameter involving $\sigma^{n}$ provided a good correlation of the data.

Computer programs were written to analyze stress-rupture data in terms of either the Larson-Miller, Dorn, or Manson-Haferd parameters. Analysis of the data for Mo, W, and $\mathrm{W}-25 \mathrm{Re}$ from $1200^{\circ}$ to $3000^{\circ} \mathrm{C}$ were described for rupture times ranging from 0.06 to 584 hours.

Creep mechanism studies for arc-cast tungsten tested at $1800^{\circ} \mathrm{C}$ and $2400^{\circ} \mathrm{C}$ were performed using metallographic and Laue back-reflection techniques. Different mechanisms of creep were observed for the two temperatures. At $1800^{\circ} \mathrm{C}$, coarse and fine slip bands were very evident with some grains showing a network of cross-slip lines. At $2400^{\circ} \mathrm{C}$, the cell formation was well developed, outlined by rows of dislocation etch pits, and generally equiaxed.

The thermal expansion characteristics of tungsten to $2000^{\circ} \mathrm{C}$ are presented. In addition, an analysis technique was identified to aid in assessing the internal consistency of thermal expansion data. A fairly distinct linearity is obtained when thermal expansion data as $\Delta \mathrm{L} / \mathrm{L}$ are plotted against temperature in ${ }^{\circ} \mathrm{C}$ on logarithmic coordinates. No precedent or justlf1cation can be cited for this technique, but it does appear to provide excellent correlation.

\footnotetext{
${ }^{34} \mathrm{M}$. Hoch and H. L. Johnston, "A High Temperature Drop Calorimeter. The Heat Capacities of Tantalum and Tungsten Between $1000^{\circ}$ and $3000^{\circ} \mathrm{K}$," Journal of Physical Chemistry, Vol. 65, 1961, pp. 855-860.

${ }^{35}$ I. B. Fieldhouse and J. C. Hedge, "Measurements of Thermal Properties," WADC TR-55-495, Part 1, 1956, p. 64.
} 
Thermal conductivity data for $\mathrm{W}-\mathrm{UO}_{2}$ material containing 20,40 , and 60 volume percent $\mathrm{UO}_{2}$ from $400^{\circ}$ to $2300^{\circ} \mathrm{C}$ are presented. The conductivity of the composites is related to the amount of $\mathrm{UO}_{2}$ contained in the tungsten.

Enthalpy data are presented for unalloyed tantalum and some alloys of tantalum from $100^{\circ}$ to $2300^{\circ} \mathrm{C}$. The results indicate that the enthalpy values for $\mathrm{T}-10 \mathrm{~W}, \mathrm{~T}-111$, and T-222 are essentially the same as those of unalloyed tantalum.

\subsection{PLANS AND RECOMMENDATIONS}

Stress-rupture and creep studies of refractory metals and alloys will be continued at temperatures from $1600^{\circ}$ to $3000^{\circ} \mathrm{C}$. Materials to be evaluated in this temperature range will include both commercially available and developmental alloys. Evaluations will be performed to determine the more creep-resistant materials for certain design applications. Also attempts will be made to develop àn understanding of the crystallographic and mechanistic phenomena associated with creep at elevated temperatures.

Additional creep analysis techniques will be investigated to determine if equation forms are capable of describing experimental creep curves which do not follow the conventional primary-secondary-tertiary form.

Some physical propertiès will be determined for various refractory metals to assist in the design of proposed high-temperature reactors. Properties such as thermal conductivity, thermal expansion, and enthalpy will be determined to $2500^{\circ} \mathrm{C}$ as well as thermal diffusivity to $1000^{\circ} \mathrm{C}$. 


\section{RADIATION EFFECTS \\ ON FAST REACTOR CLADDING AND STRUCTURAL MATERIALS}

(57004)

J. Moteff, F. Kingsbury ${ }^{\dagger}$

The objective of this program is to determine the effects of radiation on the time-, temperature-, and stress-dependent properties of selected refractory metals and alloys, to identify the causes of any observed changes in these properties, and to develop remedial measures.

The experimental program to study the effect of neutron irradiation on the creep-rupture, tensile, hardness, and resistivity properties of refractory metals and alloys is continuing. In addition to these studies, both theoretical calculations on the nature of neutroninduced defects and direct observations of defects by the use of the transmission electron. microscope are being performed.

A summary of the mechanical properties under various irradiation and test conditions is presented in Table 2.1.

2.1 IRRADIATIONS (F. D. Kingsbury, W. S. Chenault, J.' L. Kamphause, J. Moteff) STATUS OF IRRADIATIONS

All irradiations in CY-66 were performed in the Oak Ridge Research Reactor (ORR) or in the Engineering Test Reactor (ETR) at the National Reactor Test Station in Idaho. Irradiations were performed both at reactor ambient and elevated temperatures $\left(700^{\circ}\right.$ to $\left.1300^{\circ} \mathrm{C}\right)$.

It was planned to conduct a series of fast spectrum irradiations in the Fermi reactor. These plans were cancelled due to a reactor malfunction. This fast reactor irradiation program has been re-oriented to the use of the EBR- $\Pi$ reactor, and capsule designs are in progress. Specimens of a new configuration have been fabricated.

The irradiation conditions and capsule specimen loadings for CY -66 irradiations are summarized in Table 2.2. As may be noted, molybdenum and tungsten were irradiated at elevated temperatures.

\section{DOSIMETRY}

Dosimetry data from ORR and ETR capsules were recently reviewed. An up-dated summary of the data is presented in Tables 2.3 and 2.4; in cases where dosimetry data are not available, an estimate of the fluence levels are given. The activation reactions, cross sections, and half-lives used in the calculations romain the same as previously reported. ${ }^{1}$

\footnotetext{
*Project leader.

$\dagger_{\text {Principal investigator. }}$

1"'Fifth Annual Report - High-Temperature. Materials Programs, Part A," GE-NMPO, GEMP-400A, February 28, 1966, Table 2.6, p. 69 .
} 
TABLE 2.1

SUMMARY OF MECHANICAL PROPERTIES IN REFRACTORY -METALS RADLATION EFFECTS ?ROGRAM

\begin{tabular}{|c|c|c|c|c|c|c|c|c|c|c|c|c|c|c|}
\hline \multirow[b]{2}{*}{ Property } & \multirow{2}{*}{\multicolumn{3}{|c|}{ Tes: Specimen }} & \multicolumn{4}{|c|}{ Irradiation Conditions $\mathbf{c}$} & \multicolumn{2}{|c|}{$\begin{array}{l}\text { Post-Irradiation } \\
\text { Heat Treatment }\end{array}$} & & \multicolumn{3}{|c|}{ Percent Change in Property } \\
\hline & & & & $\begin{array}{l}\text { Capsule } \\
\text { Number }\end{array}$ & $\begin{array}{c}\text { Temp., } \\
{ }^{\circ} \mathrm{C}\end{array}$ & Neutrons $/ \mathrm{cm}^{2}$ & $\frac{n \mathrm{~ns} / \mathrm{cm}^{2}}{\mathrm{E}_{\mathrm{n}} \geq 1 \mathrm{Mev}}$ & $\begin{array}{l}\text { Temp., } \\
\text { 'C }\end{array}$ & $\begin{array}{c}\text { Time, } \\
h r\end{array}$ & \multicolumn{2}{|c|}{$\frac{\text { Test Conditions }}{\mathrm{T}^{\circ} \mathrm{J} \mathrm{J}, \mathrm{kg} / \mathrm{mm}^{2}}$} & $\begin{array}{l}\text { Creep } \\
\text { Rate }\end{array}$ & $\begin{array}{c}\text { Rupture } \\
\text { Life }\end{array}$ & Elongation \\
\hline \multirow[t]{7}{*}{ Creep-rupture } & $\mathbf{w}$ & Rod & $\begin{array}{l}\text { MK } 137 \text { (PM)-J } \\
\text { MK } 137 \text { (PM)-M } \\
\text { MK } 137 \text { (PM)-M } \\
\text { MK } 137 \text { (PM)-M } \\
\text { MK } 137 \text { (PM)-E }\end{array}$ & $\begin{array}{l}33 \mathrm{MT}-137 \\
33 \mathrm{MT}-137 \\
33 \mathrm{MT}-137 \\
33 \mathrm{MT}-137 \\
33 \mathrm{MT}-137\end{array}$ & $\begin{array}{l}1350 \\
1120 \\
1190 \\
1330 \\
1200\end{array}$ & $\begin{array}{l}2.4 \times 10^{20} \\
2.4 \times 10^{20} \\
2.4 \times 10^{20} \\
2.4 \times 10^{20} \\
2.4 \times 10^{20}\end{array}$ & $\begin{array}{l}1.4 \times 10^{20} \\
1.4 \times 10^{20} \\
1.4 \times 10^{20} \\
1.4 \times 10^{20} \\
1.4 \times 10^{20}\end{array}$ & 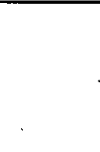 & 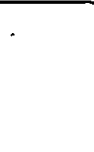 & $\begin{array}{r}900 \\
1100 \\
1400 \\
1700 \\
1600\end{array}$ & $\begin{array}{r}22.64 \\
18.28 \\
10.55 \\
4.59 \\
1.90\end{array}$ & $\begin{array}{l}-98 \\
-70 \\
+77 \\
-17\end{array}$ & $\begin{array}{r}+1084 \\
+728 \\
+28 \\
-61 \\
-15\end{array}$ & $\begin{array}{l}-40 \\
-69 \\
-61 \\
-42 \\
-11\end{array}$ \\
\hline & $\theta$ & Rod & $\begin{array}{l}\text { NKK } 152(P M)-Q \\
\text { NK } 152(P M)-Q \\
\text { NK } 152(P M)-Q \\
\text { MK } 152(P M)-Q \\
\text { MK } 152(P M)-Q \\
\text { MK } 152(P M)-Q\end{array}$ & $\begin{array}{l}\text { ORM-32 } \\
\text { ORM-31 } \\
\text { ORM-33 } \\
\text { ORM-34 } \\
\text { ORM-37 } \\
\text { ORM }-35\end{array}$ & $\begin{array}{l}70 \\
70 \\
70 \\
70 \\
70 \\
70\end{array}$ & $\begin{array}{l}6.8 \times 10^{18} \\
3.9 \times 10^{19} \\
4.1 \times 10^{19} \\
2.3 \times 10^{20} \\
2.5 \times 10^{19} \\
7.7 \times 10^{20}\end{array}$ & $\begin{array}{l}8.5 \times 10^{17} \\
4.0 \times 10^{18} \\
5.9 \times 10^{18} \\
3.8 \times 10^{19} \\
3.9 \times 10^{19} \\
1.4 \times 10^{20}\end{array}$ & . & & $\begin{array}{l}1100 \\
1100 \\
1100 \\
1100 \\
1100 \\
1100\end{array}$ & $\begin{array}{l}18.28 \\
18.28 \\
18.28 \\
18.28 \\
18.28 \\
18.28\end{array}$ & $\begin{array}{l}+9 \\
-38 \\
-41 \\
-64 \\
-48 \\
-95\end{array}$ & $\begin{array}{r}-2 \\
+79 \\
+126 \\
+496 \\
+108 \\
+2673\end{array}$ & $\begin{array}{r}+12 \\
-8 \\
+6 \\
-12 \\
-8 \\
+11\end{array}$ \\
\hline & $\mathbf{w}$ & Rod & $\begin{array}{l}\text { MK } 152(P M)-Q \\
\text { MK } 152(P M)-Q \\
\text { MK } 152(P M)-Q\end{array}$ & $\begin{array}{l}\text { GEFP2-233 } \\
\text { GEFP2-232 } \\
\text { GEFP2-234 }\end{array}$ & $\begin{array}{l}70 \\
70 \\
70\end{array}$ & $\begin{array}{l}3.0 \times 10^{20} \\
5.6 \times 10^{20} \\
2.7 \times 10^{21}\end{array}$ & $\begin{array}{l}1.4 \times 10^{20} \\
2.3 \times 10^{20} \\
1.5 \times 10^{21}\end{array}$ & & & $\begin{array}{l}1100 \\
1100 \\
1100\end{array}$ & $\begin{array}{l}18.28 \\
18.28 \\
18.28\end{array}$ & $\begin{array}{l}-77 \\
-93 \\
-99+\end{array}$ & $\begin{array}{r}+813 \\
+822 \\
+4920\end{array}$ & $\begin{array}{l}+7 \\
-58 \\
-88\end{array}$ \\
\hline & $\mathbf{w}$ & Rod & $\begin{array}{l}\text { MK } 137(P M)-J \\
\text { MK } 137(P M)-E \\
\text { MK } 137(P M)-E \\
\text { MK } 137(P M)-J \\
\text { MK } 137(P M)-J \\
\text { MK } 137(P M)-J\end{array}$ & $\begin{array}{l}\text { ORM }-17 \\
\text { ORM-17 } \\
\text { ORM-19 } \\
\text { ORM-17 } \\
\text { ORM-17 } \\
\text { ORM-17 }\end{array}$ & $\begin{array}{l}70 \\
70 \\
70 \\
70 \\
70 \\
70\end{array}$ & $\begin{array}{l}4.7 \times 10^{19} \\
4.7 \times 10^{19} \\
3.2 \times 10^{20} \\
3.2 \times 10^{20} \\
3.2 \times 10^{20} \\
3.2 \times 10^{20}\end{array}$ & $\begin{array}{l}1.0 \times 10^{19} \\
1.0 \times 10^{19} \\
7.3 \times 10^{19} \\
7.3 \times 10^{19} \\
7.3 \times 10^{19} \\
7.3 \times 10^{19}\end{array}$ & & & $\begin{array}{r}900 \\
1100 \\
1100 \\
1400 \\
1500 \\
1700\end{array}$ & $\begin{array}{r}.22 .64 \\
18.28 \\
18.28 \\
10.55 \\
8.44 \\
5.62\end{array}$ & $\begin{array}{r}-76 \\
-16 \\
-76 \\
-6 \\
-8 \\
-13\end{array}$ & $\begin{array}{r}+280 \\
+28 \\
+490 \\
+38 \\
+10 \\
+9\end{array}$ & $\begin{array}{r}-26 \\
-10 \\
-6 \\
19 \\
-29 \\
-28\end{array}$ \\
\hline & Mo & Sheet & $\begin{array}{l}\mathrm{C}-6605(\mathrm{AC}) \\
\mathrm{C}-6605(\mathrm{AC})\end{array}$ & $\begin{array}{l}\text { ORM }-3.3 \\
\text { ORM-3.3 }\end{array}$ & $\begin{array}{l}70 \\
70\end{array}$ & $\begin{array}{l}5.2 \times 10^{20} \\
5.2 \times 10^{20}\end{array}$ & $\begin{array}{l}1.1 \times 10^{20} \\
1.1 \times 10^{20} .\end{array}$ & & & $\begin{array}{l}980 \\
700\end{array}$ & $\begin{array}{l}10.55 \\
20.00\end{array}$ & $\begin{array}{l}+3.5 \\
-33\end{array}$ & $\begin{array}{l}+23 \\
+52\end{array}$ & $\begin{array}{l}- \\
-5\end{array}$ \\
\hline & & & $\begin{array}{l}C-7720(\mathrm{AC}) \\
C-7720(\mathrm{AC}) \\
C-7720(\mathrm{AC})\end{array}$ & $\begin{array}{l}\text { ORM }-43 \\
\text { ORM }-44 \\
\text { ORM }-44\end{array}$ & $\begin{array}{l}70 \\
70 \\
70\end{array}$ & $\begin{array}{l}2.0 \times 10^{19} \\
3.7 \times 10^{19} \\
3.7 \times 10^{19}\end{array}$ & $\begin{array}{l}3.0 \times 10^{19} \\
4.8 \times 10^{18} \\
4.8 \times 10^{18}\end{array}$ & & & $\begin{array}{l}600 \\
580 \\
580\end{array}$ & $\begin{array}{l}19.40 \\
19.40 \\
20.00\end{array}$ & $\begin{array}{l}-99 \\
190 \\
100\end{array}$ & $\begin{array}{c}249 \\
-56 \\
-\end{array}$ & $\begin{array}{l}-26 \\
+11 \\
-\end{array}$ \\
\hline & & & & & & & & & & & & $\begin{array}{c}\begin{array}{c}\text { Yield } \\
\text { Strength }\end{array} \\
\end{array}$ & $\begin{array}{l}\text { Tensile } \\
\text { Strength }\end{array}$ & Elongation \\
\hline \multirow[t]{4}{*}{ Tensile } & $50 \mathrm{Mo}-50 \mathrm{Re}$ & $\begin{array}{l}\text { Sheet } \\
\text { Sheet }\end{array}$ & $\operatorname{MR}(2)(P M)$ & $\begin{array}{l}\text { ORM-21 } \\
\text { ORM-20 }\end{array}$ & $\begin{array}{l}70 \\
70\end{array}$ & $\begin{array}{l}7.6 \times 10^{19} \\
1.6 \times 10^{20}\end{array}$ & $\begin{array}{l}2.7 \times 10^{19} \\
4.2 \times 10^{19}\end{array}$ & & & $\begin{array}{l}25 \\
25\end{array}$ & & $\begin{array}{l}+59 \\
+89\end{array}$ & $\begin{array}{l}+26 \\
+52\end{array}$ & $\begin{array}{l}-57 \\
-72\end{array}$ \\
\hline & $W-25 R e-30 \mathrm{MO}$ & Sheet & COT 10 (PM) & ORM-43 & 70 & $2.0 \times 10^{20}$ & $3.0 \times 10^{19}$ & & & 25 & & - & -4 & -70 \\
\hline & Mo & Sheet & C-6605 (AC) & ORM-38 & 70 & $5.2 \times 10^{20}$ & $1.1 \times 10^{20}$ & & & 25 & & - & +18 & -99.5 \\
\hline & $w$ & Rod & $\begin{array}{l}\text { MK } 142 \text { (PM)-G } \\
\text { MK } 142 \text { (PM)-G } \\
\text { MK } 142 \text { (PM)-G } \\
\text { MK } 142 \text { (PM)-G } \\
\text { MK } 142 \text { (PM)-G } \\
\text { MK } 142 \text { (PM)-G }\end{array}$ & $\begin{array}{l}\text { ORM-31 } \\
\text { ORM-33 } \\
\text { ORM-34 } \\
\text { ORM-37e } \\
\text { ORM-36 } \\
\text { ORM-35 }\end{array}$ & $\begin{array}{l}70 \\
70 \\
70 \\
70 \\
70 \\
70\end{array}$ & $\begin{array}{l}3.9 \times 10^{19} \\
4.1 \times 10^{19} \\
2.3 \times 10^{20} \\
2.5 \times 10^{19} \\
4.9 \times 10^{20} \\
7.7 \times 10^{20}\end{array}$ & $\begin{array}{l}4.0 \times 10^{18} \\
5.9 \times 10^{18} \\
3.8 \times 10^{19} \\
3.9 \times 10^{19} \\
7.9 \times 10^{19} \\
1.4 \times 10^{20}\end{array}$ & & & $\begin{array}{l}400 \\
400 \\
400 \\
400 \\
400 \\
400\end{array}$ & & $\begin{array}{r}+57 \\
+74 \\
+184 \\
+166 \\
+250 \\
+302\end{array}$ & $\begin{array}{r}+6 \\
+0 \\
+47 \\
+37 \\
+81 \\
+107\end{array}$ & $\begin{array}{l}-8 \\
-13 \\
-90 \\
-99+ \\
-99+ \\
-99+\end{array}$ \\
\hline
\end{tabular}


TABLE 2.1 (Cont.)

SUMMARY OF MECHNICAL PROPERTIES IN REFRACTORY -METALS RADIATION EFFECTS PROGRAM

\begin{tabular}{|c|c|c|c|c|c|c|c|c|c|c|c|c|c|c|}
\hline \multirow[b]{2}{*}{ Property } & \multirow{2}{*}{\multicolumn{3}{|c|}{ Test Specimen }} & \multicolumn{4}{|c|}{ Irradiation Conditions $\mathrm{c}^{\mathrm{c}}$} & \multicolumn{2}{|c|}{$\begin{array}{l}\text { Post-Irradiat ion } \\
\text { Heat Treatment }\end{array}$} & \multirow{2}{*}{\multicolumn{2}{|c|}{ Test Conditions }} & \multicolumn{3}{|c|}{ Percent Change in Property ${ }^{d}$} \\
\hline & & & & $\begin{array}{l}\text { Capsule } \\
\text { Number }\end{array}$ & $\begin{array}{l}\text { Temp., } \\
{ }^{\circ} \mathrm{C}\end{array}$ & Neutrons $/ \mathrm{cm}^{2}$ & $\frac{\mathrm{ns} / \mathrm{cm}^{2}}{\mathrm{E}_{\mathrm{n}} \geq 1 \mathrm{Mev}}$ & $\begin{array}{l}\text { Temp., } \\
{ }^{\circ} \mathrm{C}\end{array}$ & $\begin{array}{c}\text { Time, } \\
\text { hr }\end{array}$ & & & $\begin{array}{c}\text { Creep } \\
\text { Rate }\end{array}$ & $\begin{array}{c}\text { Rupture } \\
\text { Life }\end{array}$ & Elongation \\
\hline \multirow[t]{7}{*}{ Creep-rupture } & $\mathbf{w}$ & Rod & $\begin{array}{l}\text { MK } 137 \text { (PM)-M } \\
\text { MK } 137 \text { (PM)-M }\end{array}$ & $\begin{array}{l}\text { 33MT-137 } \\
\text { 33MT-137 }\end{array}$ & $\begin{array}{l}1270 \\
1310\end{array}$ & $\begin{array}{l}2.4 \times 10^{20} \\
2.4 \times 10^{20}\end{array}$ & $\begin{array}{l}1.4 \times 10^{20} \\
1.4 \times 10^{20}\end{array}$ & $\begin{array}{l}1700 \\
1700\end{array}$ & $\begin{array}{l}30 \\
29\end{array}$ & $\begin{array}{r}900 \\
1100\end{array}$ & $\begin{array}{l}22: 64 \\
18.28\end{array}$ & $\begin{array}{r}-58 \\
+4\end{array}$ & $\begin{array}{r}+114 \\
+6\end{array}$ & $\begin{array}{r}+1 \\
-16\end{array}$ \\
\hline & & & $\begin{array}{l}\text { MK } 137 \text { (PM)-M } \\
\text { MK } 137(P M)-M\end{array}$ & $\begin{array}{l}\text { ORM-19 } \\
\text { ORM-19 }\end{array}$ & $\begin{array}{l}70 \\
70\end{array}$ & $\begin{array}{l}3.2 \times 10^{20} \\
3.2 \times 10^{20}\end{array}$ & $\begin{array}{l}7.3 \times 10^{19} \\
7.3 \times 10^{19}\end{array}$ & $\begin{array}{l}17.00 \\
1700\end{array}$ & $\begin{array}{r}43 \\
1\end{array}$ & $\begin{array}{l}900 \\
900\end{array}$ & $\begin{array}{l}22.64 \\
22.64\end{array}$ & $\begin{array}{l}-80 \\
-98\end{array}$ & +710 & 4 \\
\hline & & & MK $137(P M M)-E$ & ORM-19 & 70 & $3.2 \times 10^{20}$ & $7.3 \times 10^{19}$ & 1400 & 1 & 1100 & 18. 28 & -64 & 210 & -6 \\
\hline & & & MK $137(P M)-Q$ & GEFP2-234 & 70 & $2.7 \times 10^{21}$ & $1.5 \times 10^{20}$ & 1700 & 30 & 1100 & 18.28 & -98 & 9064 & -66 \\
\hline & $\begin{array}{l}\text { w } \\
\text { Mo }\end{array}$ & $\begin{array}{l}\text { Sheet }{ }^{f} \\
\text { Sheet }\end{array}$ & $\begin{array}{l}\text { PF (PM) } \\
\text { KIM-515(AC) }\end{array}$ & $\begin{array}{l}\text { ORM-12 } \\
\text { ORM-23 }\end{array}$ & $\begin{array}{l}70 \\
70\end{array}$ & $\begin{array}{l}1.4 \times 10^{20} \\
7.0 \times 10^{19}\end{array}$ & $\begin{array}{l}4.2 \times 10^{19} \\
2.1 \times 10^{19}\end{array}$ & $\begin{array}{r}1100 \\
757\end{array}$ & $\begin{array}{l}3 \\
8\end{array}$ & $\begin{array}{r}1100 \\
580\end{array}$ & $\begin{array}{l}37.26 \\
21.09\end{array}$ & $\begin{array}{l}-39 \\
-27\end{array}$ & $\begin{array}{l}+52 \\
+62\end{array}$ & $\begin{array}{r}-4 \\
-21\end{array}$ \\
\hline & $W-25 R e$ & Sheet & RWS (PM) -3 & $\begin{array}{l}\text { ORM-21 } \\
\text { ORM }-21\end{array}$ & $\begin{array}{l}70 \\
70\end{array}$ & $\begin{array}{l}7.6 \times 10^{19} \\
7.6 \times 10^{19}\end{array}$ & $\begin{array}{l}2.7 \times 10^{19} \\
2.7 \times 10^{19}\end{array}$ & $\begin{array}{l}1494 \\
1700\end{array}$ & $\begin{array}{r}30 \\
4\end{array}$ & $\begin{array}{l}800 \\
850\end{array}$ & $\begin{array}{l}77.34 \\
65.39\end{array}$ & $\begin{array}{l}-89 \\
-80\end{array}$ & $\begin{array}{l}+475 \\
+286\end{array}$ & $\overline{-99+}$ \\
\hline & & & & & & & & & & & & $\begin{array}{c}\text { Yield } \\
\text { Strength }\end{array}$ & $\begin{array}{c}\text { Tensile } \\
\text { Strength }\end{array}$ & Elongation \\
\hline \multirow[t]{6}{*}{ Tensille } & 50Mo-50Re & 8heet & MR (2) (PM) & $\begin{array}{l}\text { ORM-21 } \\
\text { ORM-20 }\end{array}$ & $\begin{array}{l}70 \\
70\end{array}$ & $\begin{array}{l}7.6 \times 10^{19} \\
1.6 \times 10^{20}\end{array}$ & $\begin{array}{l}2.7 \times 10^{19} \\
4.2 \times 10^{19}\end{array}$ & $\begin{array}{l}250 \\
250\end{array}$ & $\begin{array}{l}1 \\
1\end{array}$ & $\begin{array}{l}25 \\
25\end{array}$ & & $\begin{array}{l}+54 \\
+75\end{array}$ & $\begin{array}{l}+23 \\
+45\end{array}$ & $\begin{array}{l}-43 \\
-70\end{array}$ \\
\hline & & & & $\begin{array}{l}\text { ORM-21 } \\
\text { ORM-20 }\end{array}$ & $\begin{array}{l}70 \\
70\end{array}$ & $\begin{array}{l}7.6 \times 10^{19} \\
1.6 \times 10^{20}\end{array}$ & $\begin{array}{l}2.7 \times 10^{19} \\
4.2 \times 10^{19}\end{array}$ & $\begin{array}{l}400 \\
400\end{array}$ & $\begin{array}{l}1 \\
1\end{array}$ & $\begin{array}{l}25 \\
25\end{array}$ & & $\begin{array}{r}+5 \\
+19\end{array}$ & $\begin{array}{r}+4 \\
+10\end{array}$ & $\begin{array}{r}-6 \\
-21\end{array}$ \\
\hline & & & & $\begin{array}{l}\text { ORM-21 } \\
\text { ORM-20 }\end{array}$ & $\begin{array}{l}70 \\
70\end{array}$ & $\begin{array}{l}7.6 \times 10^{19} \\
1.6 \times 10^{20}\end{array}$ & $\begin{array}{l}2.7 \times 10^{19} \\
4.2 \times 10^{19}\end{array}$ & $\begin{array}{l}700 \\
700\end{array}$ & $\begin{array}{l}1 \\
1\end{array}$ & $\begin{array}{l}25 \\
25\end{array}$ & & $\begin{array}{l}+2 \\
+4\end{array}$ & $\begin{array}{l}+3 \\
+4\end{array}$ & $\begin{array}{l}-7 \\
-7\end{array}$ \\
\hline & $W-25 R_{e}-30 M o$ & Sheet & $\cot 10$ (PM) & $\begin{array}{l}\text { ORM-43 } \\
\text { ORM-43 } \\
\text { ORM-43 }\end{array}$ & $\begin{array}{l}70 \\
70 \\
70\end{array}$ & $\begin{array}{l}2.0 \times 10^{20} \\
2.0 \times 10^{20} \\
2.0 \times 10^{20}\end{array}$ & $\begin{array}{l}3.0 \times 10^{19} \\
3.0 \times 10^{19} \\
3.0 \times 10^{19}\end{array}$ & $\begin{array}{l}175 \\
451 \\
690\end{array}$ & $\begin{array}{l}1 \\
1 \\
1\end{array}$ & $\begin{array}{l}25 \\
25 \\
25\end{array}$ & & $\overline{-}$ & $\begin{array}{r}0 \\
+2 \\
+1\end{array}$ & $\begin{array}{l}-50 \\
-73 \\
-13\end{array}$ \\
\hline & Mo & Sheet & $C-6805(A C)$ & $\begin{array}{l}\text { ORM }-38 \\
\text { ORM-38 } \\
\text { ORM-38 } \\
\text { ORM-38 } \\
\text { ORM-38 } \\
\text { ORM } 38\end{array}$ & $\begin{array}{l}70 \\
70 \\
70 \\
70 \\
70 \\
70\end{array}$ & $\begin{array}{l}5.2 \times 10^{20} \\
5.2 \times 10^{20} \\
5.2 \times 10^{20} \\
5.2 \times 10^{20} \\
5.2 \times 10^{20} \\
5.2 \times 10^{20}\end{array}$ & $\begin{array}{l}1.1 \times 10^{20} \\
1.1 \times 10^{20} \\
1.1 \times 10^{20} \\
1.1 \times 10^{20} \\
1.1 \times 10^{20} \\
1.1 \times 10^{20}\end{array}$ & $\begin{array}{r}550 \\
700 \\
830 \\
1025 \\
1100 \\
1200\end{array}$ & $\begin{array}{l}1 \\
1 \\
1 \\
1 \\
1 \\
1\end{array}$ & $\begin{array}{l}25 \\
25 \\
25 \\
25 \\
25 \\
25\end{array}$ & & $\begin{array}{r}- \\
- \\
+71 \\
+36 \\
0 \\
-14\end{array}$ & $\begin{array}{r}-1 \\
+14 \\
+49 \\
+16 \\
+8 \\
+1\end{array}$ & $\begin{array}{l}-99+ \\
-99+ \\
-98 \\
-37 \\
-7.2 \\
-13.9\end{array}$ \\
\hline & $\mathbf{w}$ & Rod & MK $142(P M)-G$ & $\begin{array}{l}\text { ORM-35 } \\
\text { ORM-33 } \\
\text { ORM-34 } \\
\text { ORM-37e } \\
\text { ORM-36 }\end{array}$ & $\begin{array}{l}70 \\
70 \\
70 \\
70 \\
70\end{array}$ & $\begin{array}{r}7.7 \times 10^{20} \\
.4 .1 \times 10^{19} \\
2.3 \times 10^{20} \\
.2 .5 \times 10^{19} \\
4.9 \times 10^{20}\end{array}$ & $\begin{array}{l}1.4 \times 10^{20} \\
5.9 \times 10^{18} \\
3.8 \times 10^{19} \\
3.9 \times 10^{19} \\
7.9 \times 10^{19}\end{array}$ & $\begin{array}{l}1200 \\
1300 \\
1300 \\
1300 \\
1300\end{array}$ & $\begin{array}{l}1 \\
1 \\
1 \\
1 \\
1\end{array}$ & $\begin{array}{l}400 \\
400 \\
400 \\
400 \\
400\end{array}$ & & $\begin{array}{r}+58 \\
-18 \\
-3 \\
-7 \\
-2\end{array}$ & $\begin{array}{r}-9 \\
-8 \\
- \\
+2 \\
0\end{array}$ & $\begin{array}{r}-97 \\
+14 \\
-- \\
+4 \\
-7\end{array}$ \\
\hline
\end{tabular}

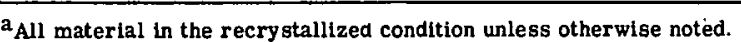

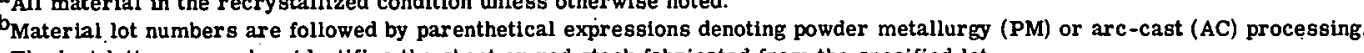

The last letter or number identifles the sheet or rod stock fabricated from the specified lot.
cThe listed irradiation conditions represent values based on dosimetry results given in Tables 2.4 and 2.5. For those capsules not listed in Tables 2.4 ana 2.5 ,

the fluence levels given represent estimated values.

${ }^{d}$ property changes represent increases due to the indicated trradiations and test conditions when compared to a corresponding unirradiated test specimen.

Negative values represent a decrease in the specified property.

Shielded with $0.5-\mathrm{mm}$ cadmium. 
TABLE 2.2

CAPSULES IRRADIATED IN CÁLENDAR YEAR 1966

\begin{tabular}{|c|c|c|c|c|c|c|c|}
\hline \multirow[b]{2}{*}{ Capsule } & \multirow[b]{2}{*}{ Reactor } & \multirow{2}{*}{$\begin{array}{c}\text { Irradiation } \\
\text { Temperature, }{ }^{\circ} \mathrm{C}\end{array}$} & \multicolumn{2}{|r|}{ Specimens } & \multicolumn{3}{|c|}{ Specimen Loading } \\
\hline & & & Shape & . Material & Creep-Rupture & Tensile & Resistivity \\
\hline \multirow[t]{2}{*}{ ORM-43 } & ORR & Ambient & Flat & $\mathbf{M o}^{\mathbf{a}}$ & 8 & $\dot{-}$ & - \\
\hline & & & & NMPO-256 alloyb & 8 & - & - \\
\hline-44 & ORR & Ambient & Flat & $\mathrm{Mo}^{\mathrm{a}}$ & 8 & - & - \\
\hline-46 & ORR & Ambient & Flat & $\mathrm{Mo}^{\mathrm{a}}$ & 8 & - & - \\
\hline \multirow[t]{3}{*}{-48} & ORR & Ambient & Flat & $W-25 R e$ & 12 & - & - \\
\hline & & 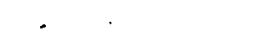 & & Mo & 4 & - & - \\
\hline & & & & Mo $-0.5 \mathrm{Ti}$ & 8 & - & - \\
\hline \multirow[t]{2}{*}{ GEFP2-234 } & ETR & Ambient & Round & $\mathrm{w}$ & 3 & 9 & 3 \\
\hline & & & & Mo & 3 & - & 3 \\
\hline \multirow[t]{2}{*}{-235} & ETR & Ambient & Flat & $\mathrm{Mo}^{\mathrm{a}}$ & 8 & - & - \\
\hline & & & & Mo $-0.5 \mathrm{Ti}$ & 8 & - & - \\
\hline \multirow[t]{2}{*}{-240} & ETR & Ambient & Flat & $\mathbf{T a}$ & 8 & - & - \\
\hline & & & & $\mathrm{Ta}-10 \mathrm{~W}$ & 8 & - & - \\
\hline \multirow[t]{2}{*}{-241} & ETR & Ambient & Flat & $W-25 R e^{c}$ & 8 & - & - \\
\hline & & . & & w & 8 & - & - \\
\hline \multirow[t]{4}{*}{-242} & ETR & Ambient & Flat & $w-73 \% c w^{d}$ & 6 & - & - \\
\hline & & & & $w-98 \% c w^{d}$ & 6 & - & - \\
\hline & & & & W $-73 \%+$ Ann. & 2 & - & - \\
\hline & & & & $\mathrm{W}-98 \%+$ Ann. & 2 & - & - \\
\hline-133 & ETR & 1300 & Round & w & 9 & - & - \\
\hline-153 & ETR & 1000 & Round & w & 9 & - & - \\
\hline-136 & ETR & 1000 & Round & Mo ${ }^{d}$ & $9 \mathrm{e}$ & - & - \\
\hline-154 & ETR & 700 & Round & Mod & $9^{\mathrm{e}}$ & - & - \\
\hline
\end{tabular}

$\mathrm{a}_{\text {Low-carbon vacuum arc-cast molybdenum. }}$

${ }^{b}$ Specimens from a $0.25-\mathrm{mm}$ strip of $. \mathrm{W}-25 \mathrm{Re}-30 \mathrm{Mo}$ (at. \%).

cArc-cast $W-25 R e(w t \%)$.

$\mathrm{d}_{73 \%}$ and $98 \%$ cold-worked.

Eix each regular Mo, three each low-carbon Mo.

\section{2 CREEP-RUPTURE DATA (F. D. Kingsbury, J. Moteff)}

Creep-rupture testing of $\mathrm{W}, \mathrm{W}-25 \mathrm{Re}$, and Mo specimens was performed in the temperature range from $580^{\circ}$ to $1900^{\circ} \mathrm{C}$. In several cases, specimens were post-irradiation annealed at various temperatures and times prior to testing to determine the effect of annealing on the neutron-induced changes in the creep-rupture properties: Tests included specimens from ambient- and elevated-temperature irradiations.

\section{TUNGSTEN}

\section{High-Temperature Irradiations}

An investigation was conducted to study the effect of test temperatures from $900^{\circ}$ to $1900^{\circ} \mathrm{C}$ on the ductility at fracture of recrystallized tungsten (powder-metallurgy) specimens, irradiated at temperatures from $1100^{\circ}$ to $1350^{\circ} \mathrm{C}$ to a fast neutron fluence of approximately $1.4 \times 10^{20}$ neutrons $/ \mathrm{cm}^{2}\left(E_{\mathrm{n}} \geq 1 \mathrm{Mev}\right)$. The test results on control and irradiated specimens are presented in Table 2.5.

Elongation-versus-time plots for control and as-irradiated specimens at each test temperature are shown in Figure 2.1. At $900^{\circ}, 1100^{\circ}$, and $1400^{\circ} \mathrm{C}$, the irradiated specimens exhibited creep rates which were significantly less than those of the control specimens; consequently, the rupture times were greater. Tests at $1700^{\circ} \mathrm{C}$ and $1900^{\circ} \mathrm{C}$ showed that the irradiated specimens had shorter rupture lives than the control specimens. 
TABLE 2.3

DOSIMETRY DATA FROM ORR CAPSULES

\begin{tabular}{|c|c|c|c|c|c|}
\hline \multirow[b]{2}{*}{ Capsule } & \multirow[b]{2}{*}{ Dosimeter } & \multirow[b]{2}{*}{ Facility } & \multicolumn{2}{|c|}{ Fluence, nvt } & \multirow{2}{*}{$\begin{array}{l}\text { Irradiation } \\
\text { Time, }{ }^{\mathbf{a}} \mathbf{h r}\end{array}$} \\
\hline & & & Thermal & Fast $\left(E_{n} \geq 1 \mathrm{Mev}\right)$ & \\
\hline ORM $-4^{\mathrm{b}}$ & & F-9 & $4.6 \times 10^{18}$ & $5.9 \times 10^{17}$ & 12.0 \\
\hline ORM- $6^{\mathrm{b}}$ & & $\mathbf{F - 2}$ & $2.8 \times 10^{19}$ & $8.3 \times 10^{18}$ & 47. 5 \\
\hline ORM-7 & 156 & F-2 & $2.6 \times 10^{19}$ & $5.1 \times 10^{18}$ & 47.5 \\
\hline ORM $-8^{b}$ & 157 & F-2 & $1.4 \times 10^{20}$ & $4.2 \times 10^{19}$ & 240.0 \\
\hline ORM-9b & 158 & F-2 & $2.8 \times 10^{19}$ & $8.3 \times 10^{18}$ & 47.5 \\
\hline ORM-10 $\mathrm{b}$ & 159 & $\mathbf{F}-2$ & $1.4 \times 10^{20}$ & $4.2 \times 10^{19}$ & 240.0 \\
\hline ORM-11 & 160 & F-2 & $1.2 \times 10^{20}$ & $3.1 \times 10^{19}$ & 240.0 \\
\hline ORM-12b & 161 & $\mathbf{F - 2}$ & $1.4 \times 10^{20}$ & $4.2 \times 10^{19}$ & 240.0 \\
\hline ORM-13 ${ }^{b}$ & & F-9 & $4.9 \times 10^{19}$ & $5.8 \times 10^{18}$ & 130.1 \\
\hline ORM-14b & & $\mathbf{F}-9$ & $9.3 \times 10^{19}$ & $1.1 \times 10^{19}$ & 249.1 \\
\hline ORM-15b & & RAB-14 & $1.3 \times 10^{20}$ & $2.7 \times 10^{19}$ & 213.0 \\
\hline ORM-16 ${ }^{b}$ & & F-9 & $1.0 \times 10^{20}$ & $1.2 \times 10^{19}$ & 264.0 \\
\hline ORM-17 & B117 & F-2 & $4.7 \times 10^{19}$ & $1.0 \times 10^{19}$ & 120.2 \\
\hline ORM-18 & B112 & F-2 & $1.1 \times 10^{20}$ & $2.3 \times 10^{19}$ & 221.0 \\
\hline ORM-19 & B113 & $\mathbf{F}-2$ & $3.2 \times 10^{20}$ & $7.3 \times 10^{19}$ & 617.9 \\
\hline ORM-20 & B121 & F-2 & $1.9 \times 10^{20}$ & $4.8 \times 10^{15}$ & 559.2 \\
\hline ORM-20 & B122 & F-2 & $1.6 \times 10^{20}$ & $3.5 \times 10^{19}$ & 559.2 \\
\hline ORM-21 & B123 & F-2 & $7.6 \times 10^{19}$ & $2.7 \times 10^{19}$ & 130.0 \\
\hline ORM-21 & B124 & F-2 & & & \\
\hline ORM -22 & B125 & F-2 & $1.8 \times 10^{20}$ & $6.2 \times 10^{19}$ & 246.7 \\
\hline ORM-23b & - & F-2 & $7.0 \times 10^{19}$ & $2.1 \times 10^{19}$ & 120.0 \\
\hline ORM-24 & B127 & $\mathbf{F - 2}$ & $2.4 \times 10^{19}$ & $7.9 \times 10^{18}$ & 60.0 \\
\hline ORM-26 & B129 & RAB-14 & $7.4 \times 10^{19}$ & $1.7 \times 10^{19}$ & 119.6 \\
\hline ORM-27 & B130 & RAB-14 & $1.4 \times 10^{19}$ & $3.1 \times 10^{18}$ & 24.0 \\
\hline ORM-28 & B131 & RAB-14 & $2.2 \times 10^{20}$ & $5.1 \times 10^{19}$ & 433.9 \\
\hline ORM-29 & B132 & RAB-14 & $1.9 \times 10^{20}$ & $4.1 \times 10^{19}$ & 215.7 \\
\hline ORM-30 & B133 & RAB-14 & $9.6 \times 10^{19}$ & $1.9 \times 10^{19}$ & 210.6 \\
\hline ORM-31 & B138 & A-2 & 3. $9 \times 10^{19}$ & $4.0 \times 10^{18}$ & 400.0 \\
\hline ORM-32 & B139 & $A-2$ & $6.8 \times 10^{18}$ & $8.5 \times 10^{17}$ & 20.0 \\
\hline ORM-33 & B140 & A-2 & $4.1 \times 10^{19}$ & 5. $9 \times 10^{18}$ & 80.0 \\
\hline ORM-34 & B141 & A-2 & $2.3 \times 10^{20}$ & $3.8 \times 10^{19}$ & 480.0 \\
\hline ORM-35 & 143-35 & $A-2$ & $7.0 \times 10^{20}$ & $1.4 \times 10^{20}$ & 1600.0 \\
\hline ORM-36 & B143 & $A-2$ & $4.9 \times 10^{20}$ & $7.9 \times 10^{19}$ & 814.0 \\
\hline ORM-37d & B144 & $A-2$ & $2.5 \times 10^{19}$ & $3.9 \times 10^{19}$ & 480.0 \\
\hline ORM-37 & B145 & $A-2$ & $1.2 \times 10^{20}$ & $4.0 \times 10^{19}$ & 480.0 \\
\hline ORM-38 & B147 M38 & $A-2$ & $5.2 \times 10^{20}$ & $1.1 \times 10^{20}$ & 1593.6 \\
\hline ORM-39 & M-39-1 & RAB-13 & 3. $3 \times 10^{18}$ & $4.1 \times 10^{17}$ & 5.5 \\
\hline ORM-40 & M40 & RAB-14 & $5.7 \times 10^{19}$ & $1.0 \times 10^{19}$ & 100.0 \\
\hline ORM -43 & M43-1 & A-2 & $1.7 \times 10^{20}$ & $3.1 \times 10^{19}$ & 703.3 \\
\hline ORM -43 & M43-1 & & $2.2 \times 10^{20}$ & $2.9 \times 10^{19}$ & 703.3 \\
\hline ORM-44. & M44-1 & A-2 & $3.8 \times 10^{19}$ & $5.2 \times 10^{18}$ & 150.1 \\
\hline ORM-44 & M44-2 & & 3. $5 \times 10^{19}$ & $4.3 \times 10^{18}$ & 150.1 \\
\hline ORM-45 & M45-1 & A-2 & $1.8 \times 10^{20}$ & $3.0 \times 10^{19}$ & 415.0 \\
\hline & M45-2 & & $1.6 \times 10^{20}$ & $2.7 \times 10^{19}$ & 415.0 \\
\hline ORM-49 & $49-1$ & $A-2$ & $9.0 \times 10^{18}$ & $9.0 \times 10^{17}$ & 8.0 \\
\hline & 49-3 & & $3.9 \times 10^{19}$ & $6.0 \times 10^{18}$ & 54.8 \\
\hline & $49-4$ & & $7.8 \times 10^{19}$ & $1.1 \times 10^{19}$ & 132.0 \\
\hline & $49-5$ & & $3.8 \times 10^{20}$ & $4.5 \times 10^{19}$ & 859.0 \\
\hline & $49-6$ & & $3.0 \times 10^{20}$ & $4.2 \times 10^{19}$ & 529.1 \\
\hline
\end{tabular}

${ }^{\mathrm{a}}$ In-pile irradiation time at $30 \mathrm{Mw}$.

${ }^{b}$ Fluence values based on average thermal and fast fluxes estimated from previous dosimetry data obtained in the given facility.

c positioned off-peak flux; located on top of core.

$\mathrm{d}$ Dosimeter and specimens were surrounded by a cadmium jacket. 
TABLE 2.4

DOSIMETRY DATA FROM ETR CAPSULES

\begin{tabular}{|c|c|c|c|c|c|}
\hline \multirow[b]{2}{*}{ Capsule } & \multirow[b]{2}{*}{ Dosimeter. } & \multirow[b]{2}{*}{ Facility } & \multicolumn{2}{|r|}{ Fluence, nvt } & \multirow[b]{2}{*}{$\begin{array}{l}\text { Irradiation } \\
\text { Time },^{a} \mathrm{hr}\end{array}$} \\
\hline & & & Thermal & $\begin{array}{c}\text { Fast } \\
\left\langle E_{n} \geq 1 \text { Mev }\right)\end{array}$ & \\
\hline $33 \mathrm{MT}-138$ & $\begin{array}{l}\text { B114-138 } \\
\text { B115-138 } \\
\text { B116-138 }\end{array}$ & E5 & $\begin{array}{l}3.7 \times 10^{20} \\
3.6 \times 10^{20} \\
3.7 \times 10^{20}\end{array}$ & $\begin{array}{l}9.7 \times 10^{19} \\
9.8 \times 10^{19} \\
9.8 \times 10^{19}\end{array}$ & . \\
\hline $\begin{array}{c}33 \mathrm{Mt}-137 \\
\text { (GEFP2-125) }\end{array}$ & $\begin{array}{l}\text { B118 } \\
\text { B120. }\end{array}$ & E5 NE & $\begin{array}{l}2.4 \times 10^{20} \\
2.4 \times 10^{20}\end{array}$ & $\begin{array}{l}1.2 \times 10^{20} \\
1.5 \times 10^{20}\end{array}$ & 751 \\
\hline GEFP2-232 & $\begin{array}{l}232-1 \\
232-2 \\
232-3 \\
232-4\end{array}$ & F-13 sw. & $\begin{array}{l}5.1 \times 10^{20} \\
5.7 \times 10^{20} \\
5.6 \times 10^{20} \\
6.0 \times 10^{20}\end{array}$ & $\begin{array}{l}2.1 \times 10^{20} \\
2.4 \times 10^{20} \\
2.3 \times 10^{20} \\
2.2 \times 10^{20}\end{array}$ & 538 \\
\hline GEFP2-233 & $\begin{array}{l}233-1 \\
233-2 \\
233-3 \\
233-4\end{array}$ & $J-14 N W$ & $\begin{array}{r}3.0 \times 10^{20} \\
-2.9 \times 10^{20} \\
3.0 \times 10^{20} \\
3.1 \times 10^{20}\end{array}$ & $\begin{array}{l}1.4 \times 10^{20} \\
1.4 \times 10^{20} \\
1.4 \times 10^{20} \\
1.3 \times 10^{20}\end{array}$ & 325 \\
\hline GEFP2-234 & $\begin{array}{l}234-1 \\
234-2 \\
234-3 \\
234-4\end{array}$ & $\mathrm{~J}-14 \mathrm{NW}$ & $\begin{array}{l}2.7 \times 10^{21} \\
2.6 \times 10^{21} \\
2.8 \times 10^{21} \\
2.6 \times 10^{21} .\end{array}$ & $\begin{array}{l}1.5 \times 10^{21} \\
1.6 \times 10^{21} \\
1.4 \times 10^{21} \\
1.4 \times 10^{21}\end{array}$ & $.1,889$ \\
\hline GEFP2-236 & $\begin{array}{l}236-1 \\
236-2 \\
236-3 \\
236-4\end{array}$ & E5 NE & $\begin{array}{l}4.8 \times 10^{20} \\
4.3 \times 10^{20} \\
4.3 \times 10^{20} \\
4.5 \times 10^{20}\end{array}$ & $\begin{array}{l}1.6 \times 10^{20} \\
1.2 \times 10^{20} \\
1.1 \times 10^{20} \\
1.5 \times 10^{20}\end{array}$ & 489 \\
\hline GEFP2-237 & $\begin{array}{l}237-1 \\
237-2 \\
237--3 \\
237-4\end{array}$ & E5:SW. & $\begin{array}{l}2.7 \times 10^{20} \\
3.6 \times 10^{20} \\
3.8 \times 10^{20} \\
4.2 \times 10^{20}\end{array}$ & $\begin{array}{l}6.4 \times 10^{19} \\
8.5 \times 10^{19} \\
7.6 \times 10^{19} \\
1.4 \times 10^{20}\end{array}$ & 489 \\
\hline $\begin{array}{c}\text { GEFP2-238 } \\
\ldots\end{array}$ & $\begin{array}{l}238-1 \\
238-2 \\
238-3 \\
238-4\end{array}$ & E5 NE & $\begin{array}{l}5.1 \times 10^{20} \\
3.5 \times 10^{20} \\
5.3 \times 10^{20} \\
4.7 \times 10^{20}\end{array}$ & $\begin{array}{l}1.3 \times 10^{19} \\
8.8 \times 10^{19} \\
1.2 \times 10^{20} \\
1.4 \times 10^{20}\end{array}$ & 766 \\
\hline
\end{tabular}

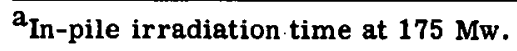


TABLE 2.5

CREEP-RUPTURE RESULTS FOR TUNGSTEN TESTED AT $900^{\circ} \mathrm{TO} 1900^{\circ} \mathrm{C}$ FOLLOWING ELEVATED TEMPERATURE IRRADIATIONS ${ }^{\mathrm{a}}$

\begin{tabular}{|c|c|c|c|c|c|c|c|c|c|c|}
\hline $\begin{array}{l}\text { Specimen } \\
\text { No. }\end{array}$ & Rod & Condition & $\begin{array}{c}\text { Irradiation } \\
\text { Temperature, }{ }^{\circ} \mathrm{C}\end{array}$ & $\begin{array}{l}\text { Post-Irradiation } \\
\text { Annealing, }{ }^{\circ} \mathrm{C} \\
\end{array}$ & $\begin{array}{c}\text { Test } \\
\text { Temperature, }{ }^{\circ} \mathrm{C}\end{array}$ & $\begin{array}{l}\text { Stress, } \\
\mathrm{kg} / \mathrm{mm}^{2}\end{array}$ & $\begin{array}{l}\text { Rupture } \\
\text { Life, hr }\end{array}$ & $\begin{array}{l}\text { Linear Creep } \\
\text { Rate, } \text { sec }^{-1}\end{array}$ & $\begin{array}{l}\text { Elongation } \\
\text { in } 4.45 \mathrm{~cm}, \%\end{array}$ & $\begin{array}{c}\text { Reduction in } \\
\text { Area, } \%\end{array}$ \\
\hline 1265 & $\mathbf{J}$ & Control & - & None & 900 & 22.64 & 12.5 & $2.32 \times 10^{-6}$ & 36.2 & 96.6 \\
\hline 1256 & J & Irradiated & 1350 & None & 900 & 22.64 & 148.0 & $1.72 \times 10^{-7}$ & 21.7 & 68.1 \\
\hline 1255 & $\mathbf{J}$ & Irradiated & 1340 & None & 900 & 22.64 & 77.3 & $2.80 \times 10^{-7}$ & 19.5 & 62.1 \\
\hline 1257 & $\mathbf{J}$ & Irradiated & 1230 & None & 900 & 22.64 & 140.0 & $3.07 \times 10^{-8}$ & 4. 5 & 23.3 \\
\hline 1203 & $\mathbf{E}$ & Irradiated & 1240 & None & 900 & 22.64 & 462.0 & $4.47 \times 10^{-8}$ & 7.9 & 25.5 \\
\hline 1247 & $\mathbf{M}$ & Control & - & None & 900 & 22.64 & 30.3 & $1.02 \times 10^{-6}$ & 31. 9 & 96.1 \\
\hline 1228 & $\mathbf{M}$ & Irrad iated & 1270 & $1700-30 \mathrm{hr}-\mathrm{Ar}$ & 900 & 22.64 & 64.7 & $4.30 \times 10^{-7}$ & 32. 2 & 92.6 \\
\hline 1246 & $\mathbf{M}$ & Control & - & None & 1100 & 18.28 & 18.1 & $1.94 \times 10^{-6}$ & 30. 7 & 96.5 \\
\hline 1235 & $\mathbf{M}$ & Irradiated & 1120 & None & 1100 & 18.28 & 149.9 & $3.57 \times 10^{-8}$ & 9.6 & 45.5 \\
\hline 1230 & $\mathrm{M}$ & Irradiated & 1310 & $1700-29 h r-A r$ & 1100 & 18.28 & 19.1 & $2.02 \times 10^{-6}$ & 26.4 & 80.1 \\
\hline 1229 & $\mathbf{M}$ & Irradiated & 1290 & $1700-30 \mathrm{hr}-\mathrm{H}_{2}$ & 1100 & 18. 28 & 15.7 & 2. $22 \times 10^{-6}$ & 32. 2 . & 82.5 \\
\hline 1249 & $\mathbf{M}$ & Control & - & None & 1400 & 10.55 & 22.0 & $3.02 \times 10^{-7}$ & 17.0 & 30.1 \\
\hline 1237 & $\mathbf{M}$ & Irradiated & 1190 & None & 1400 & $10.55^{\prime}$ & 28.1 & $9.13 \times 10^{-8}$ & 6.7 & 13.7 \\
\hline 1250 & $\mathrm{M}$ & Control & - & None & 1400 & 10.55 & 20.6 & $2.54 \times 10^{-7}$ & 13. 7 & 38.5 \\
\hline 1236 & $\mathbf{M}$ & Irradiated & 1150 & None & 1400 & 10.55 & 26.3 & $8.2 \times 10^{-8}$ & 7.5 & 21.3 \\
\hline 1233 & $\mathbf{M}$ & Irradiated & 1270 & None. & 1400 & 10.55 & 13.9 & $3.6 \times 10^{-7}$ & 4.1 & 8.2 \\
\hline 1231 & $\mathbf{M}$ & Irradiated & 1330 & None & 1700 & 4. 50 & 13.7 & $2.32 \times 10^{-7}$ & 3.3 & 6.1 \\
\hline 1248 & M & Control & - & None & 1700 & 4. 59 & 35.0 & $1.31 \times 10^{-7}$ & 5.7 & 9.4 \\
\hline 1331 & $\mathbf{M}$ & Irradiated & 1300 & None & 1700 & 4.00 & 14.0 & $1.87 \times 10^{-7}$ & 1.0 & 8.0 \\
\hline 1232 & $\mathbf{M}$ & Irradiated & 1230 & None & 1700 & 4.00 & 14.8 & $1.47 \times 10^{-7}$ & 2.5 & 8.8 \\
\hline 1251 & $\mathbf{M}$ & Control & - & None & 1700 & 4.00 & 47.6 & $8.62 \times 10^{-8}$ & 4.8 & 12.4 \\
\hline 1253 & M & Control & - & None & 1900 & 2.00 & 22.6 & $5.51 \times 10^{-7}$ & 7.9 & 14.2 \\
\hline 1224 & $\mathbf{E}$ & Control & - & None & 1900 & 1.90 & 46.0 & $2.02 \times 10^{-7}$ & 8.2 & 16.0 \\
\hline 1202 & $\mathbf{E}$ & Irradiated & 1200 & None & 1900 & 1.90 & 39.0 & $1.67 \times 10^{-7}$ & 7.3 & 6.9 \\
\hline 1225 & $\mathbf{E}$ & Control & - & None & 1900 & 1.80 & 83.7 & 1. $25 \times 10^{-7}$ & 7.6 & 9.7 \\
\hline 1201 & $E$ & Irradiated & 1160 & None & 1900 & 1.80 & 50.3 & $1.30 \times 10^{-7}$ & 5. 6 & 5.1 \\
\hline
\end{tabular}

a $33 \mathrm{MT}-137$ cartridge irradiated in ETR-E5 NE to $1.4 \times 10^{20} \mathrm{nvt}\left(E_{\mathrm{n}} \geq 1 \mathrm{Mev}\right)$ at the approximate elevated temperatures indicated. All tests conducted in hydrogen atmosphere.

b Specimens from $0.508-\mathrm{cm}$-diameter tungsten rod annealed at $1750^{\circ} \mathrm{C}$ in hydrogen for 1 hour prior to fabrication; stress-relieved at $1600^{\circ} \mathrm{C}$ for 1 hour in hydrogen following grinding.

The influence of test temperature on the fracture ductility of tungsten is shown in Figure 2. 2. The ductility of control and irradiated specimens decreased with increasing test temperature from $900^{\circ}$ to $1700^{\circ} \mathrm{C}$ and then increased at $1900^{\circ} \mathrm{C}$. All as-irradiated specimens exhibited less ductility than control specimens at each temperature. The greatest differences occurred at the lower temperatures. Three specimens that were post-irradiation annealed for 30 hours at $1700^{\circ} \mathrm{C}$ showed complete recovery of ductility in $900^{\circ} \mathrm{C}$ and $1100^{\circ} \mathrm{C}$ tests.

The different ductility bands (Figure 2.2) for the specimens irradiated above and below $1250^{\circ} \mathrm{C}$ indicate that the temperature of irradiation has an effect on the fracture ductility at temperatures below $1250^{\circ} \mathrm{C}$; specimens irradiated at temperatures above $1250^{\circ} \mathrm{C}$ and tested at $900^{\circ} \mathrm{C}$ were about 3 times more ductile than specimens irradiated below $1250^{\circ} \mathrm{C}$. Apparently, different radiation-induced defect states exist when specimens are either irradiated or post-irradiation annealed above and below a temperature of about $1250^{\circ} \mathrm{C}$ (approximately $0.41 \mathrm{~T}_{\mathrm{m}}{ }^{*}$ ). This change was noted previously ${ }^{2}$ in annealing studies on reactor ambient-irradiated specimens that were creep-rupture tested at $900^{\circ} \mathrm{C}$. Thermal hardening ${ }^{\dagger}$ observed in the $900^{\circ} \mathrm{C}$ creep tests was similar to that found in tensile tests on tungsten (discussed in Section 2.3) where the maximum hardening occurred at $1200^{\circ} \mathrm{C}$. Annealing at $1300^{\circ} \mathrm{C}$ substantially reduced the hardening. The change in creep rate which occurs between $1200^{\circ} \mathrm{C}$ and $1300^{\circ} \mathrm{C}$ suggests that the radiation-induced defects which cause hardening are altered in some manner, although transmission electron microscopy showed no changes in the substructure (see Section 2.6).

${ }^{*} \mathrm{~T}_{\mathrm{m}}$ is the absolute melting temperature of the metal.

2"“Fourth Annual Report - High-Temperature Materials and Reactor Components Development Programs, Volume IMaterials," GE-NMPO, GEMP-334A, February 26, 1965, Figures 2.10 and 2.11, p. 65.

$\dagger_{A}$ term used to indicate that some further hardening in addition to that observed in the as-irradiated condition occurs in irradiated material following annealing heat treatments. 

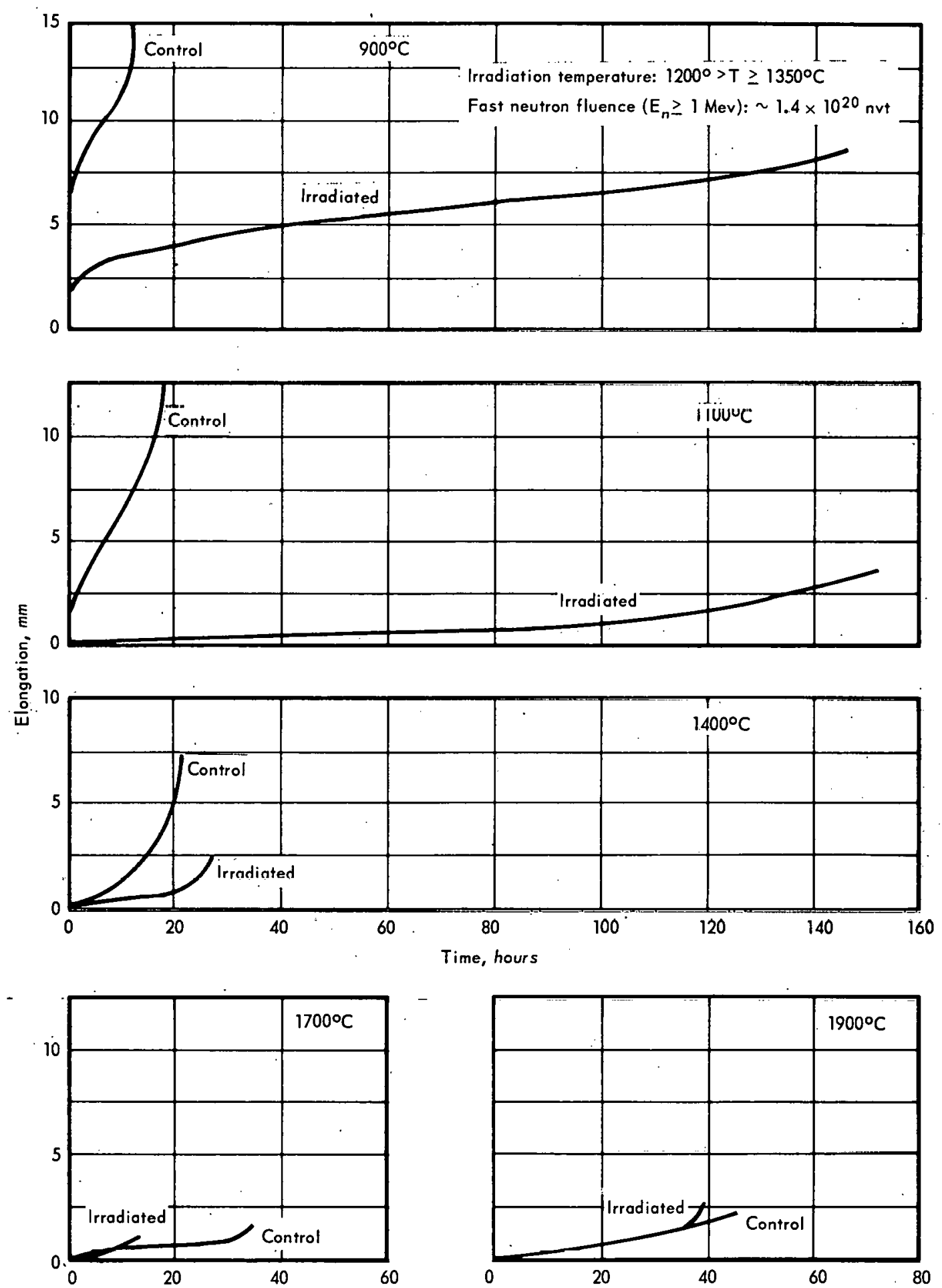

Time, hours

Fig. 2.1 - Creep curves for control and irradiated polycrystalline tungsten specimens tested at various temperature and stress levels 


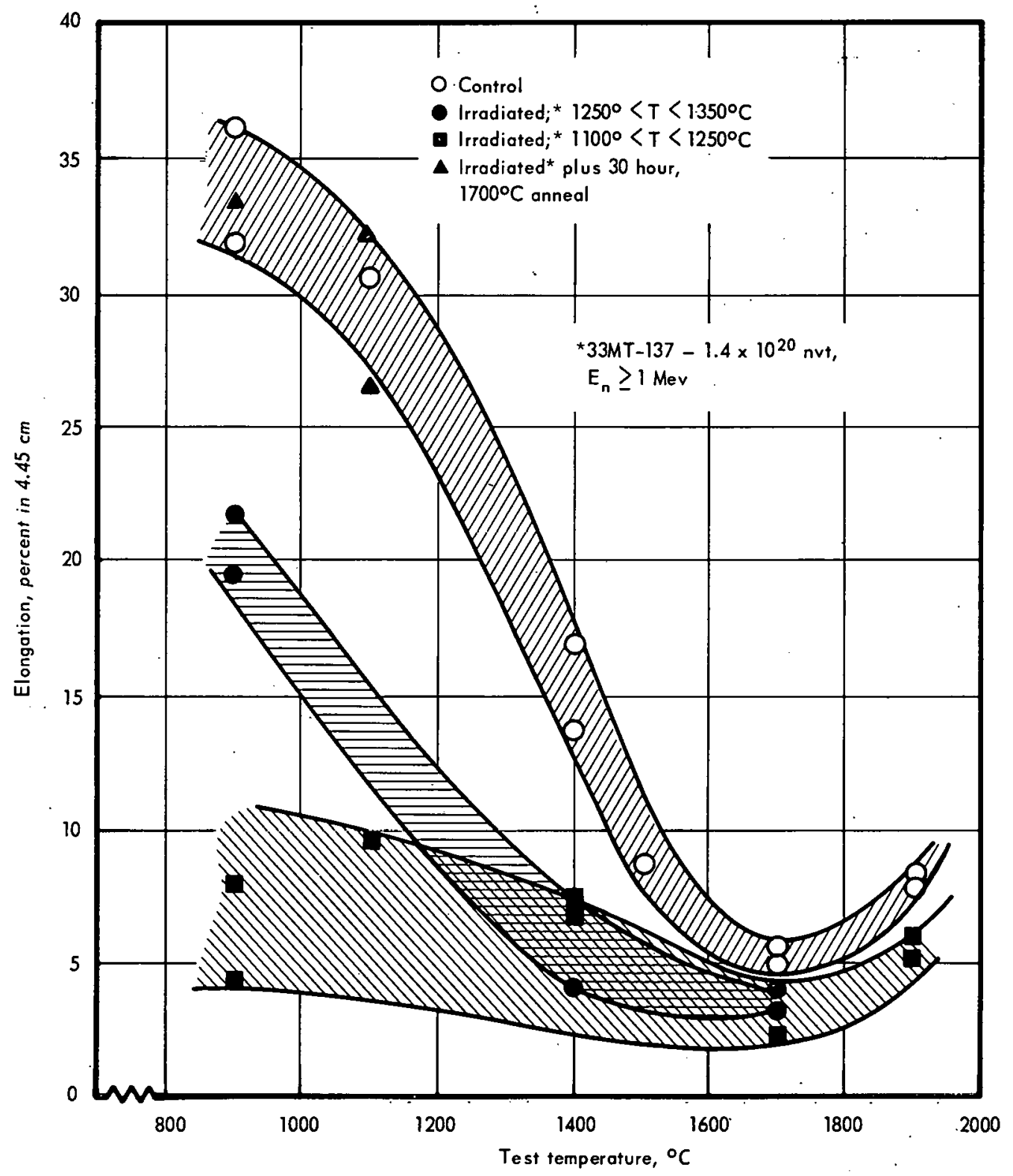

Fig. 2.2 - Creep-rupture ductility of tungsten as a function of test temperature for specimens irradiated at elevated temperature and control specimens 
The fractured portions of the control and irradiated specimens tested at the various temperatures $\left(900^{\circ}\right.$ to $\left.1900^{\circ} \mathrm{C}\right)$ were examined metallographically. These studies reveal that both the control and irradiated specimens tested at $900^{\circ} \mathrm{C}$ and $1100^{\circ} \mathrm{C}$ failed by transgranular fracture, Figure 2.3. The irradiated specimens which were annealed at $1750^{\circ} \mathrm{C}$ for 1 hour and then tested at $900^{\circ} \mathrm{C}$ or $1100^{\circ} \mathrm{C}$ also exhibited transgranular fracture. Control and irradiated specimens tested at $1400^{\circ}, 1700^{\circ}$, and $1900^{\circ} \mathrm{C}$ exhibited predominantly intergranular fractures. The control specimen tested at $1900^{\circ} \mathrm{C}$ (Figure 2.3c) showed extensive grain growth while the irradiated specimen (Figure 2.3d) exhibited no grain growth. This phenomena is being checked on the other specimens tested at the higher temperatures. It appears from these preliminary examinations that the mode of fracture is a function of the test temperature and not the condition of the material; i. e., control, irradiated, or irradiated plus annealed condition. Additional fractographic studies are planned on this series of test specimens.

Neutron Fluence Dependency

An investigation to determine the influence of thermal and fast neutron fluence on the creep-rupture properties of tungsten at $1100^{\circ} \mathrm{C}$ was conducted. The specimens were ir radiated in either the ORR or ETR at reactor ambient temperature to fast fluence levels of $8.5 \times 10^{17}$ to $1.5 \times 10^{21}$ neutrons $/ \mathrm{cm}^{2}\left(E_{n} \geq 1 \mathrm{Mev}\right)$. The data from these tests, all conducted at a stress level of $18.28 \mathrm{~kg} / \mathrm{mm}^{2}$, are presented in Table 2.6 and Figures 2. 4 and 2. 5 .

Creep rate or rupture life versus fast $(E \geq 1 \mathrm{Mev}$ ) neutron fluence plots (Figure 2.4a and b) show that increasing the fluence results in a significant decrease in creep rate and an increase in the rupture life. The creep rate, for instance, was reduced by a factor of 500; the rupture life was increased by a factor of about 40 and the elongation at fracture was reduced from an average value of 30 percent down to about 3.8 percent.

The effect of the different reactor neutron spectra may be noted in these plots. The distinct discontinuities in the curves for the ORR or ETR irradiations are principally due to the differences in the ratio of the respective thermal to fast neutron flux densities. This effect can be especially seen in the ORR-irradiated specimen where the ratio of thermal to fast neutron flux was deliberately altered by shielding the specimen with $0.5-\mathrm{mm}$-thick cadmium cover. ${ }^{*}$ Here, the specimen with its lower ratio of thermal to fast neutron fluence exhibited a higher creep rate and shorter rupture life than would be predicted on the basis of fast neutron fluence level. Since the fast neutron fluence of the corresponding unshielded specimen was essentially the same as that of the shielded specimen, the main difference between the two is the rhenium content caused by transmutation due to the $(n, \gamma)$ reaction with tungsten.

As shown in Figure 2.5a and b, a much better ordering of experimental data is obtained in these thermal neutron fluence plots; i.e., they do not show discontinuities in the curves due to the different reactor spectra. The cadmium-shielded, ORR-irradiated specimen also shows a reasonable fit to both the creep-rate and rupture-life curves. At this test temperature $\left(1100^{\circ} \mathrm{C}\right)$, where most of the neutron-induced displacement defects are believed to be completely annealed out, the remaining radiation-induced defects would be the transmutation products rhenium and osmium; e.g., it was calculated ${ }^{3}$ that 2.5 -percent rhenium atoms are produced from tungsten at a thermal neutron fluence of $2.7 \times 10^{21}$ neutrons $/ \mathrm{cm}^{2}$. The decrease in the effective flow stress for a fixed applied stress due to the added strengthening of the tungsten by rhenium atoms would account for the observed decrease in creep rate. Preliminary calculations, assuming that solution hardening is proportional to the square root of the rhenium atom concentration, shows good agreement with the experimental data.

*This resulted in a factor of $\mathbf{1 0}$ fewer thermal neutrons for the same fast neutron fluence.

${ }^{3}$ GEMP-400A, Figure 2.29, p. 94. 


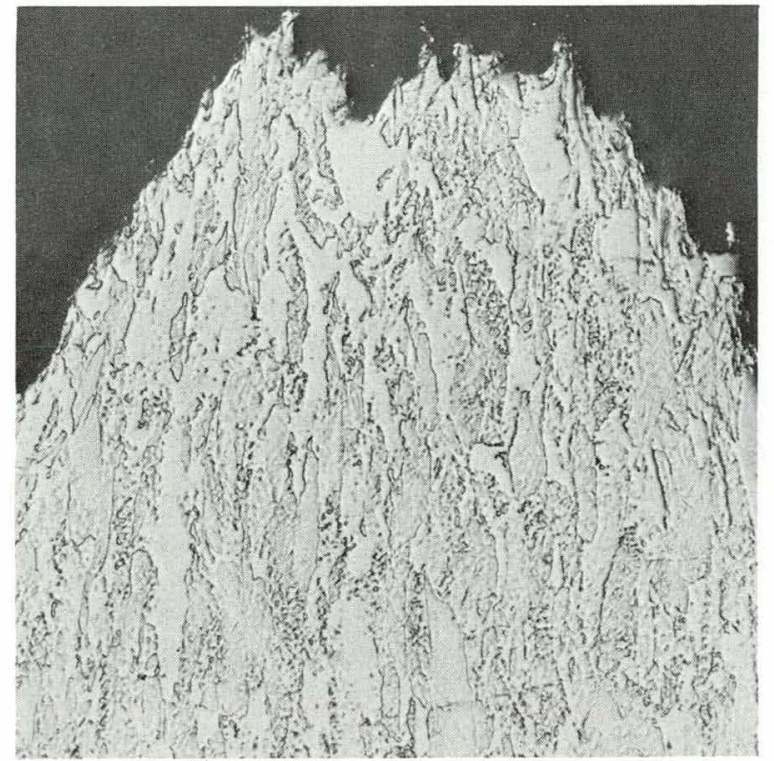

a. Control (Neg. R-1781)

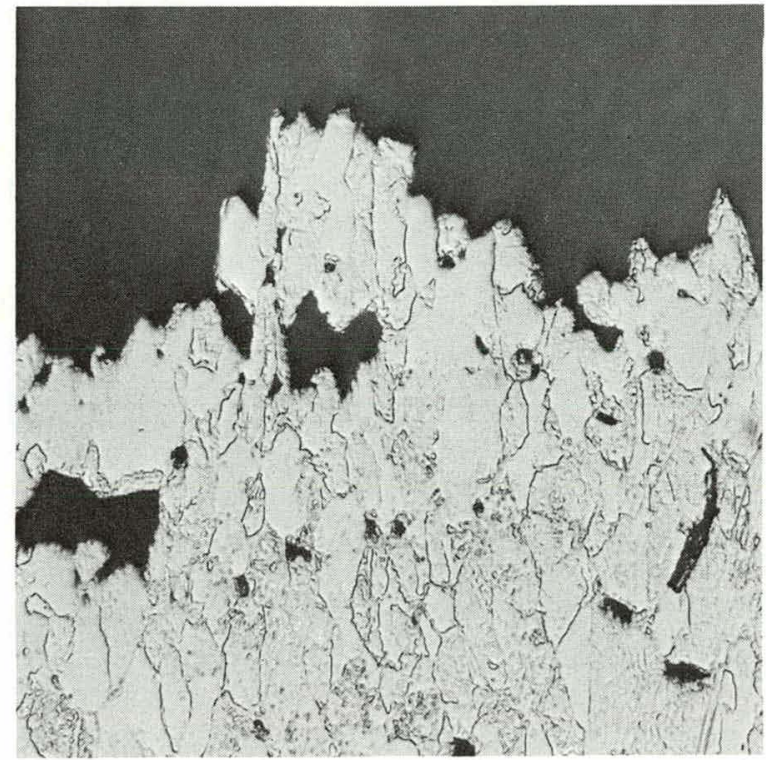

b. Irradiated (Neg. R-1782)

$1100^{\circ} \mathrm{C}$

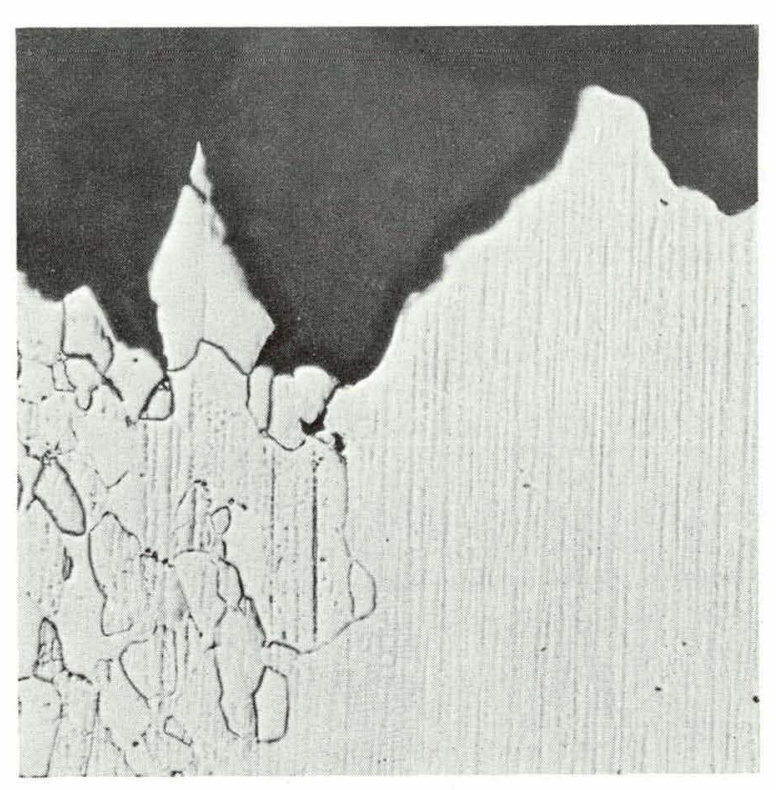

c. Control (Neg. R-1783)

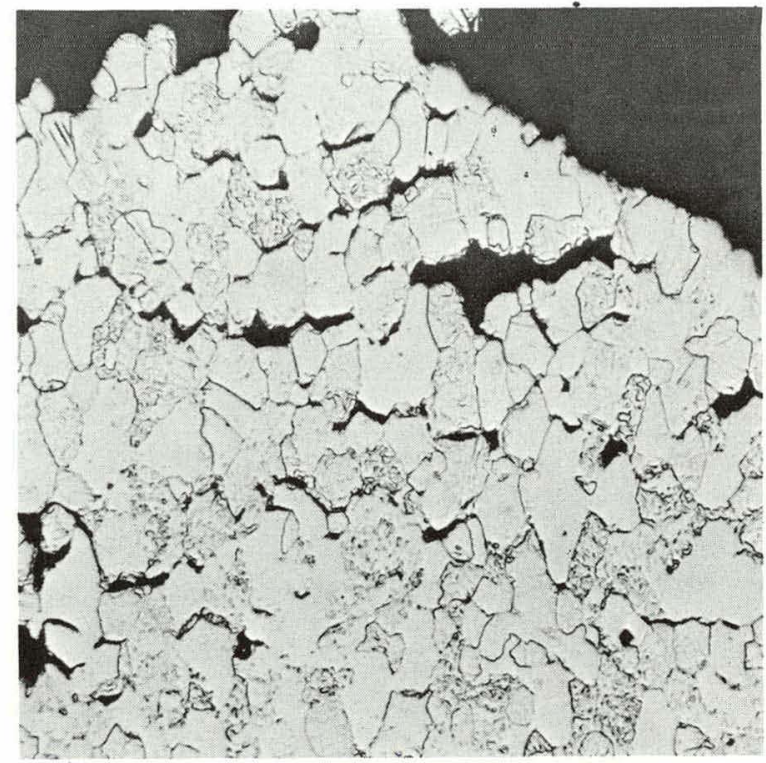

d. Irradiated (Neg. R-1788)

$1900^{\circ} \mathrm{C}$

Fig. 2.3-Photomicrographs of fracture areas of confrol and irradiated tungsten specimens creep-rupture tested at $1100^{\circ} \mathrm{C}$ and $1900^{\circ} \mathrm{C}(100 \mathrm{X})$ 


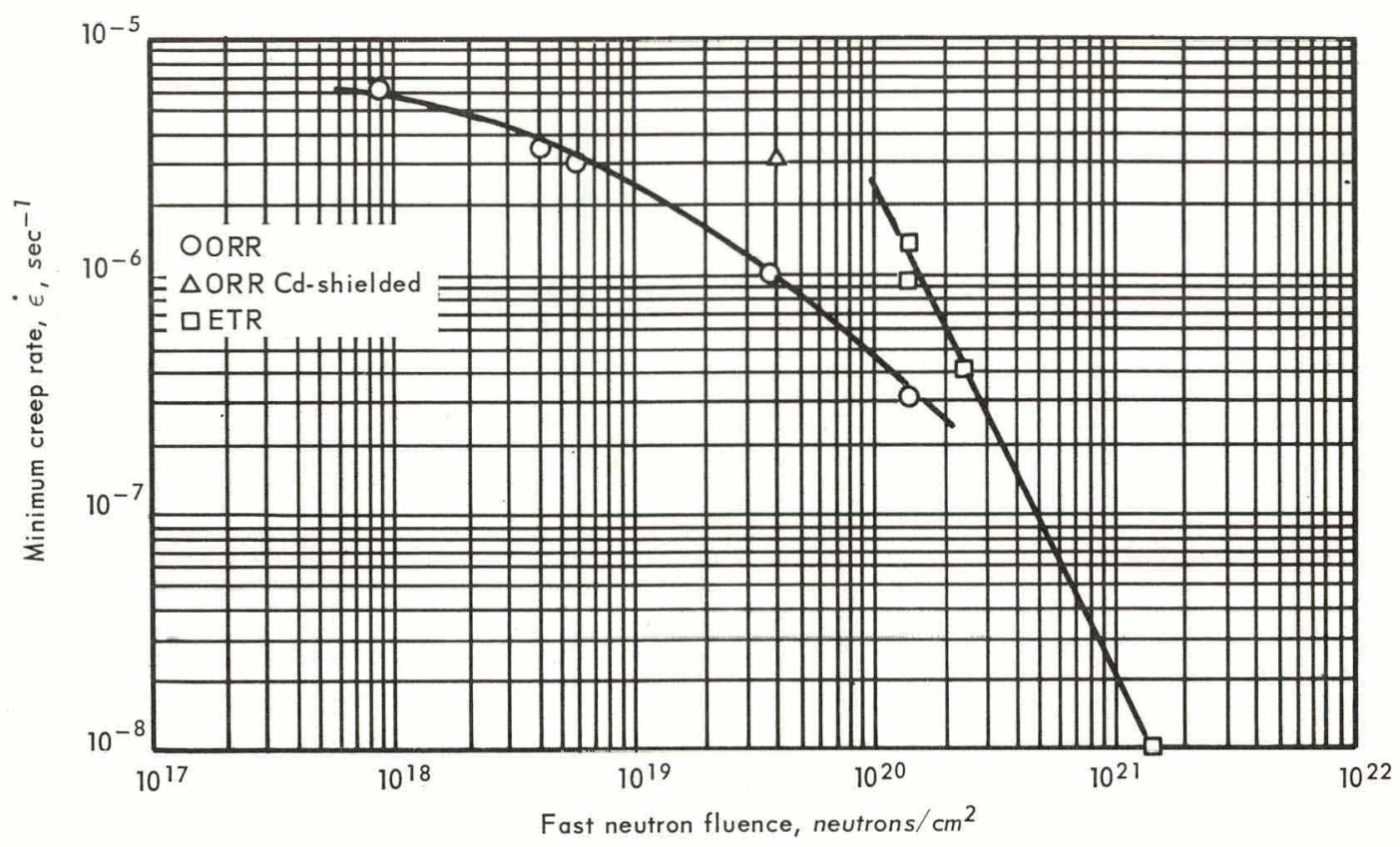

a. Minimum creep rate

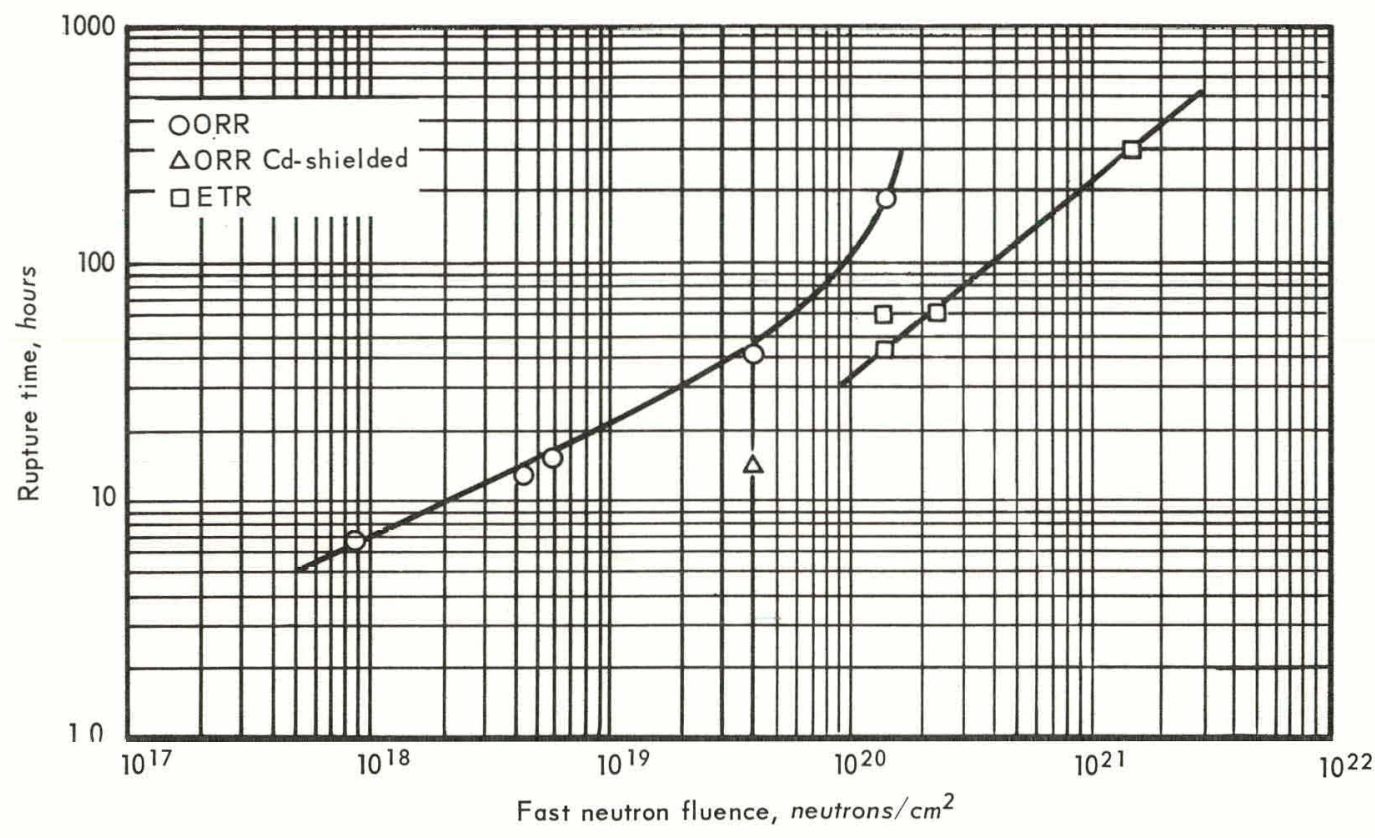

b. Rupture life

Fig. 2.4-Minimum creep rate and rupture life of irradiated polycrystalline tungsten, Rod Q, at $1100^{\circ} \mathrm{C}$ and an applied stress of 18.28 $\mathrm{kg} / \mathrm{mm}^{2}$ as a function of fast neutron fluence ( $E \geq 1 \mathrm{Mev}$ ) 


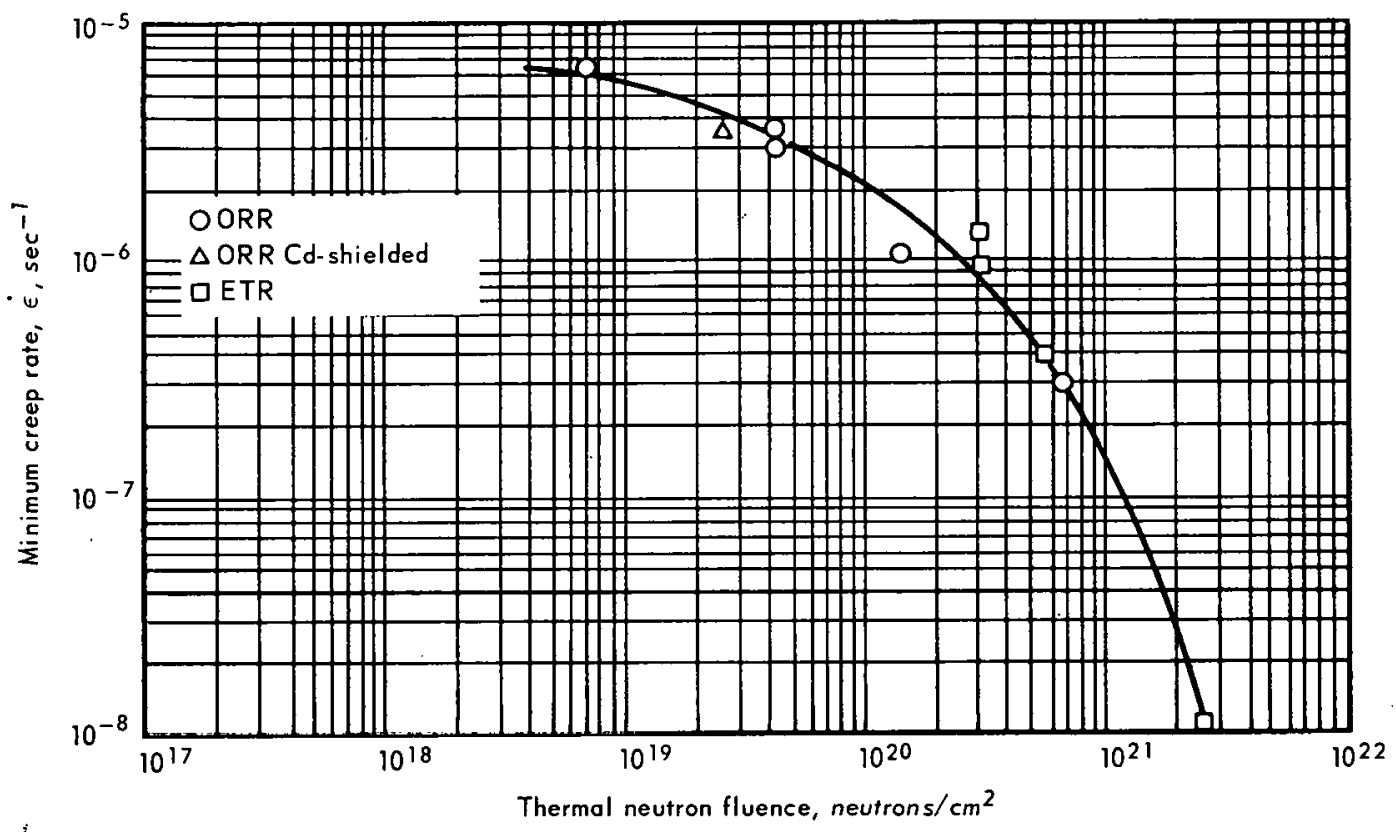

a. Minimum creep rate

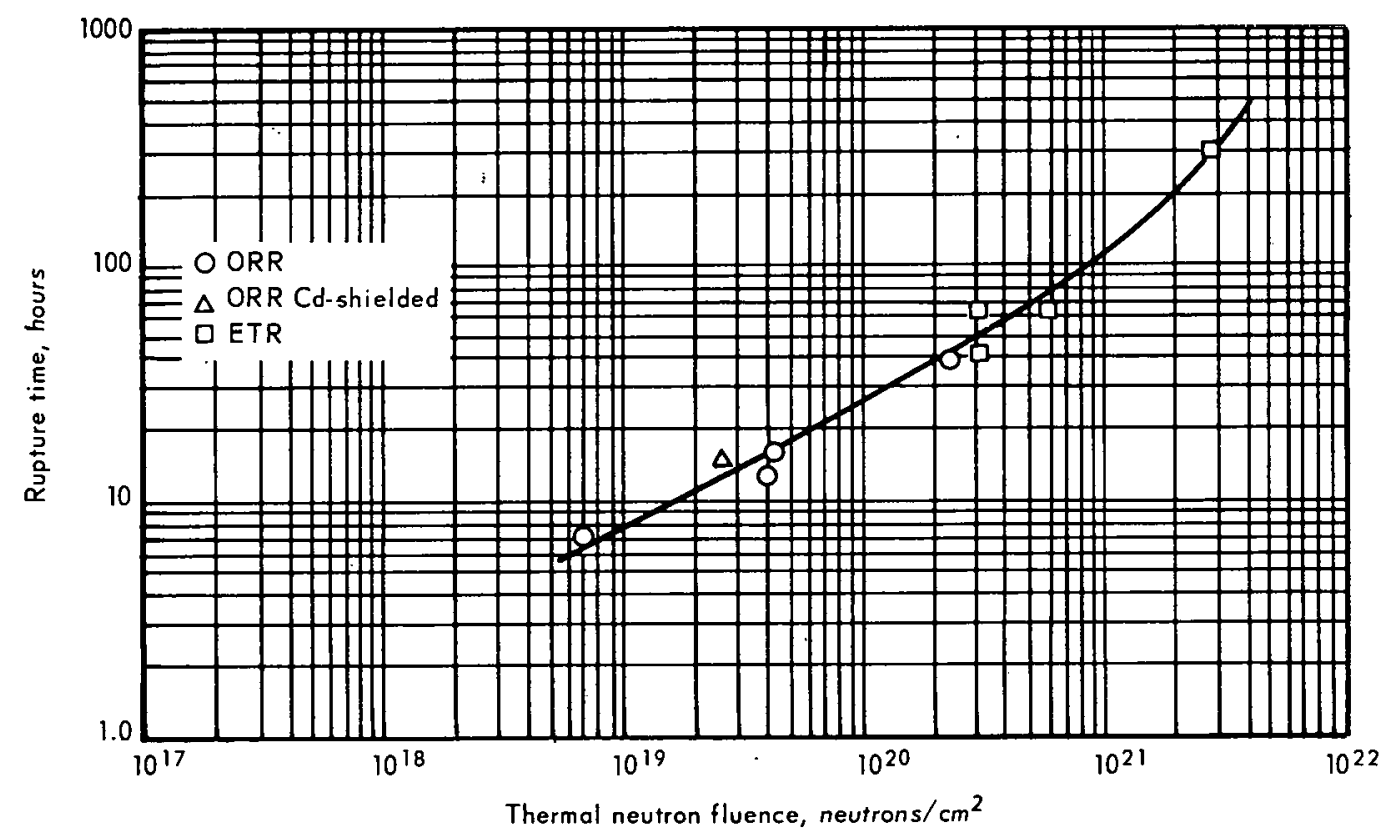

b. Rupture life

Fig. 2.5 - Minumum creep rate and rupture life of irradiated polycrystalline fungsten at $1100^{\circ} \mathrm{C}$ and an applied stress of $18.28 \mathrm{~kg} / \mathrm{mm}^{2}$ os a function of thermal neutron fluence 
TABLE 2.6

SUMMARY OF CREEP-RUPTURE TESTS ON TUNGSTEN SPECIMENS AT $1100^{\circ} \mathrm{C}$ AND $18.28 \mathrm{~kg} / \mathrm{mm}^{2}$

\begin{tabular}{|c|c|c|c|c|c|c|c|}
\hline \multirow{2}{*}{$\begin{array}{c}\text { Specimen } \\
\text { No. }{ }^{2}\end{array}$} & \multirow[b]{2}{*}{ Capsule } & \multicolumn{2}{|c|}{ Fluence, nvt } & \multirow{2}{*}{$\begin{array}{c}\text { Linear Ċreep Rate, } \\
\dot{\epsilon} ;\left(\sec ^{-1}\right)\end{array}$} & \multirow{2}{*}{$\begin{array}{c}\text { Rupture Life, } \\
\mathbf{t}_{\mathbf{r}},(\mathrm{hr})\end{array}$} & \multirow{2}{*}{$\begin{array}{c}\text { Elongation, } \\
\%\end{array}$} & \multirow{2}{*}{$\begin{array}{c}\text { Reduction in Area, } \\
\%\end{array}$} \\
\hline & & Thermal & Fast $\left(E_{n} \geq 1 \mathrm{Mev}\right)$ & & & & \\
\hline \multicolumn{7}{|c|}{ Rod P Specimens } & \\
\hline 1336 & Control & & & $4.46 \times 10^{-6}$ & 7.99 & - & - \\
\hline 1351 & ORM-31C & $3.9 \times 10^{19}$ & $4.0 \times 10^{18}$ & $3.87 \times 10^{-6}$ & 12.65 & 35.7 & 90.0 \\
\hline 1359 & ORM -33 & $4.1 \times 10^{19}$ & $5.9 \times 10^{18}$ & 2. $86 \times 10^{-6}$ & 15. 22 & 29.8 & 94.9 \\
\hline 1362 & ORM -34 & $2.3 \times 10^{20}$ & 3. $8 \times 10^{19}$ & $1.20 \times 10^{-6}$ & 43.98 & 24.4 & 92.9 \\
\hline 1377 & ORM $-37^{\mathrm{d}}$ & $2.5 \times 10^{19}$ & $3.9 \times 10^{19}$ & $5.0 \times 10^{-7}$ & 21. 04 & 14.0 & 93.5 \\
\hline 1373 & ORM-36 & $4.9 \times 10^{20}$ & $7.9 \times 10^{19}$ & $1.23 \times 10^{-7}$ & 58. 38 & 12.2 & 89.0 \\
\hline 1369 & ORM-35e & $7.7 \times 10^{20}$ & $1.2 \times 10^{20}$ & $2.66 \times 10^{-8}$ & 352.1 & 28.9 & 87.4 \\
\hline \multicolumn{8}{|c|}{ Rod Q Specimens } \\
\hline 1390 & Control & & & $5.13 \times 10^{-6}$ & 7. 82 & 31.0 & 98.3 \\
\hline 1391 & Control & & & $6.39 \times 10^{-6}$ & 6.23 & 30.3 & 98.7 \\
\hline 1393 & Control & & & 4. $52 \times 10^{-6}$ & 9.10 & 32.4 & 70.2 \\
\hline 1384 & ORM-32 & $6.8 \times 10^{18}$ & $8.5 \times 10^{17}$ & $6.26 \times 10^{-6}$ & 6.87 & 33.9 & 95.9 \\
\hline 1383 & ORM - 31 & $3.9 \times 10^{19}$ & $4.0 \times 10^{18}$ & 3. $60 \times 10^{-6}$ & 12.61 & 28.0 & 90.0 \\
\hline 1385 & ORM-33 & $4.1 \times 10^{19}$ & $5.9 \times 10^{18}$ & $3.4 \times 10^{-6}$ & 15. 92 & 32.2 & 95.1 \\
\hline 1395 & ORM-34 & $2.3 \times 10^{20}$ & $3.8 \times 10^{10}$ & $1.08 \times 10^{-6}$ & 41.92 & 20.3 & 92.3 \\
\hline 1394 & ORM -37 $a$ & 2. $5 \times 10^{19}$ & $3.9 \times 10^{19}$ & $3.0 \times 10^{-0}$ & 14.64 & 28.0 & 90.0 \\
\hline 1388 & ORM-35 & $7.7 \times 10^{20}$ & $1.4 \times 10^{20}$ & $2.98 \times 10^{-7}$ & 194.9 & 33.5 & 92.4 \\
\hline 1397 & $2-233^{e}$ & $3.0 \times 10^{20}$ & $1.4 \times 10^{20}$ & 1. $30 \times 10^{-6}$ & 64.16 & 32.3 & 92.9 \\
\hline 1400 & $2-233$ & $3.0 \times 10^{20}$ & $1.4 \times 10^{20}$ & $9.6 \times 10^{-7}$ & 42.47 & 22.9 & 54.6 \\
\hline 1386 & $2-232$ & $5.6 \times 10^{20}$ & $2.3 \times 10^{20}$ & $4.1 \times 10^{-7}$ & 64.86 & 12.7 & 57.3 \\
\hline 1403 & $2-234$ & $2.7 \times 10^{21}$ & $1.5 \times 10^{21}$ & $1.08 \times 10^{-8}$ & 315.41 & 3. 79 & 32.5 \\
\hline 1405 & $2-234^{f}$ & 2. $7 \times 10^{21}$ & $1.6 \times 10^{21}$ & $2.87 \times 10^{-8}$ & 644.33 & 10.2 & 43.9 \\
\hline
\end{tabular}

aspecimens from $0.508-\mathrm{cm}$-diameter tungsten rod (powder metallurgy) post-grind annealed at $1750^{\circ} \mathrm{C}$ for 1 hour in hydrogen.

$\mathrm{b}$ percent in $4.54-\mathrm{cm}$ gage length.

CORM-31 through -37 represent numbers of capsules irradiated at reactor ambient temperatures in ORR-A2 facility.

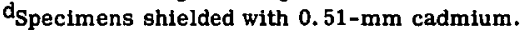

e 2-232 through 2-234 represent identifications of capsules irradiated in the ETR F-13 and J-14 facilities at reactor

ambient temperature.

$f_{\text {Annealed at }} 1700^{\circ} \mathrm{C}$ for 30 hours in hydrogen prior to creep-rupture testing.

W - 25Re

Creep tests of recrystallized, vacuum arc-melted sheet were performed in hydrogen to determine the apparent activation energy for creep in the $775^{\circ}$ to $930^{\circ} \mathrm{C}\left(0.32\right.$ to $\left.0.37 \mathrm{~T}_{\mathrm{m}}\right)$ temperature range. The specimens were annealed at $1700^{\circ} \mathrm{C}$ for 1 hour in vacuum prior to testing. The incremental temperature change was approximately $25^{\circ} \mathrm{C}$ and most temper atures were repeated on a given specimen to check the reproductibility of creep rates. A summary of results is presented in Figure 2. 6 based on the expression:

$$
\dot{\epsilon}=\mathrm{Cf}(\sigma) \exp \left(-\Delta \mathrm{H}_{\mathrm{c}} / \mathrm{RT}\right)
$$

where: $\mathbf{C}, \mathbf{R}=$ constants

$$
\dot{\epsilon}=\text { linear creep rate, } \mathrm{sec}^{-1}
$$

$f(\sigma)=$ some function of applied stress (assumed to be the same for each stress level considered)

$\mathrm{T}=$ temperature, ${ }^{\circ} \mathrm{K}$

$\Delta \mathrm{H}_{\mathrm{c}}=$ apparent activation energy for creep

The slope of the lines for the three stress levels indicate an apparent activation energy for creep of $112 \mathrm{kcal} / \mathrm{mole}$. This is a slightly higher value than the activation energy of $103 \mathrm{kcal} / \mathrm{mole}$ from the data of $\mathrm{Pugh}^{4}$ for recrystallized polycrystalline tungsten in tests conducted at $871^{\circ} \mathrm{C}$ and $982{ }^{\circ} \mathrm{C}$.

\footnotetext{
${ }^{4}$ J. W. Pugh, Proceedingss of ASTII, Vol. 57, 1957, pp. 906-915.
} 


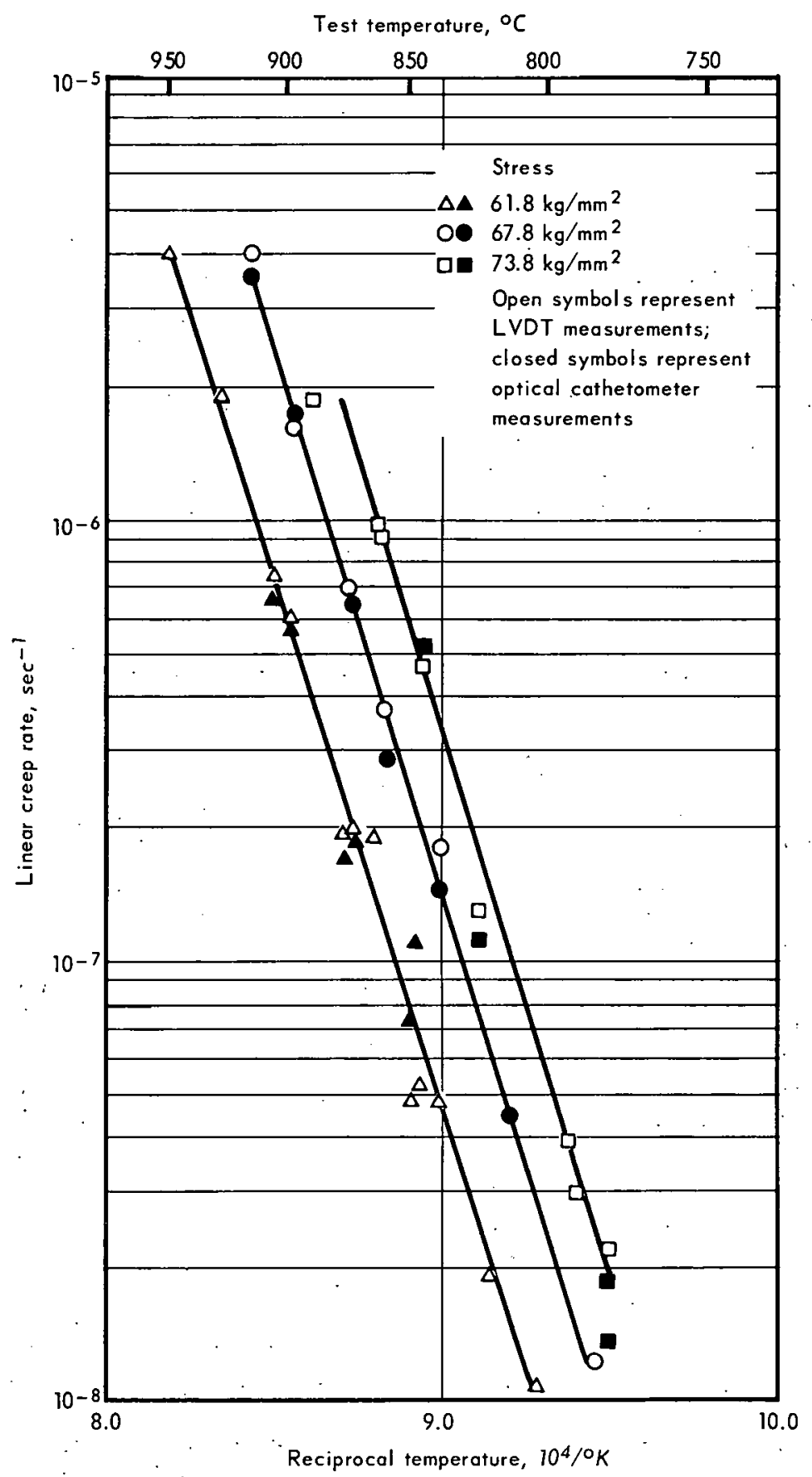

.

Fig. 2.6-Summary of creep rate versus reciprocal temperature for unirradiated W- $25 R e$ sheet (multitemperature creep tests at constant load) 


\section{MOLYBDENUM}

Tests were conducted on arc-cast molybdenum to investigate the effect of test temperature on the creep-rupture properties and on the ductility at fracture and also to further investigate any accelerated creep rates or reductions in the time to rupture in the material irradiated at the lower neutron fluences. Accelerated creep rates had been exhibited previously ${ }^{5}$ in the 0.29 to $0.32 \mathrm{~T}_{\mathrm{m}}$ range $\left(560^{\circ}\right.$ to $\left.650^{\circ} \mathrm{C}\right)$ in specimens irradiated 2 to $5 \times 10^{19}$ neutrons $/ \mathrm{cm}^{2}\left(E_{n} \geq 1 \mathrm{Mev}\right)$.

Specimens fabricated from two heats of material were tested. One heat was a commercial heat containing 290-ppm carbon and 10-ppm oxygen. The other. heat contained 30-ppm carbon and approximately 26 -ppm oxygen and was vacuum stress-relieved by the vendor. The higher carbon content material possessed greater strength and hence, was not directly comparable to the other heat.

The test results in the temperature range from $580^{\circ}$ to $980^{\circ} \mathrm{C}$ are presented in Table 2.7. It can be seen that specimens irradiated to a fast neutron fluence of $1.1 \times 10^{20}$ neutrons $/ \mathrm{cm}^{2}$ had longer rupture lives and lower creep rates than that of the corresponding control specimens whereas the specimens.irradiated at the lower fast neutron fluences of $3.0 \times 10^{19}$ and $4.8 \times 1018$ neutrons $/ \mathrm{cm}^{2}$ possessed shorter rupture lives and higher creep rates.

TABLE 2.7

SUMMARY OF MOLYBDENUM CREEP-RUPTURE DATA

\begin{tabular}{|c|c|c|c|c|c|c|c|}
\hline $\begin{array}{l}\text { Specimen } \\
\text { No. }{ }^{2}\end{array}$ & $\begin{array}{l}\text { Heat } \\
\text { No. b }\end{array}$ & Condition ${ }^{c}$ & $\begin{array}{c}\text { Test } \\
\text { Temperature, } \\
{ }^{\circ} \mathrm{C}\end{array}$ & $\begin{array}{l}\text { Stress, } \\
\mathrm{kg} / \mathrm{mm}^{2}\end{array}$ & $\begin{array}{l}\text { Rupture } \\
\text { Life, hr }\end{array}$ & $\begin{array}{l}\text { Linear Creep } \\
\text { Rate, } \mathrm{sec}^{-1}\end{array}$ & $\underset{\%}{\text { Elongation, }}$ \\
\hline 2115 & C- 6605 & ORM-38 & 980 & 10.55 & 13.54 & $7.44 \times 10^{-6}$ & 77.0 \\
\hline 2120 & $C-6605$ & Control & 980 & 10.55 & $>10.6$ & $7.19 \times 10^{-6}$ & $(>56.8)^{e}$ \\
\hline 2123 & $C-6605$ & Control & 850 & 14.00 & 57.52 & $1.56 \times 10^{-6}$ & 73.0 \\
\hline 2116 & $C-6605$ & ORM-38 & 850 & 13.82 & 80.12 & $1.17 \times 10^{-6}$ & 68.8 \\
\hline 2118 & $C-6605$ & ORM-38 & 850 & 13.30 & 107.44 & $9.94 \times 10^{-7}$ & 63.5 \\
\hline 2124 & $C-6605$ & Control & 700 & 19.00 & 288.01 & $-3 \times 10^{-7}$ & 00.2 \\
\hline 2103 & C -6605 & Control & 700 & 20.00 & 118.91 & $6.09 \times 10^{-7}$ & 49.2 \\
\hline 2122 & $C-6605$ & ORM-38 & 700 & 20.00 & 180.48 & $4.11 \times 10^{-7}$ & 46.8 \\
\hline 2664 & $c-7720$ & Control & 600 & 19.40 & 59.1 & $6.22 \times 10^{-7}$ & 44.3 \\
\hline 2685 & C- -7720 & ORM-43 & 600 & 19.40 & 206.98 & $7.15 \times 10^{-9}$ & 32.7 \\
\hline 2656 & C-7720 & Control & 580 & 19.40 & 221.15 & $1.87 \times 10^{-7}$ & 45.2 \\
\hline 2684 & $C-7720$ & ORM-43 & 580 & 19.40 & $(259)^{f}$ & $\left(<1 \times 10^{-9}\right)$ & - \\
\hline 2679 & $C-7720$ & ORM-44 & 580 & 19.40 & 98.45 & $5.43 \times 10^{-7}$ & 50.1 \\
\hline 2670 & $C-7720$ & Control & 580 & 20.00 & 81.4 & $3.75 \times 10^{-7}$ & 40.1 \\
\hline 2696 & C-7720 & ORM-44 & 580 & 20.00 & 132.35 & $4.04 \times 10^{-7}$ & 51.4 \\
\hline 2711 & C-7720 & Control & 580 & 20.00 & $(246)^{f}$ & $2.02 \times 10^{-7}$ & - \\
\hline
\end{tabular}

${ }^{\text {a }}$ Specimens from $0.5-\mathrm{mm}$-thick arc-cast molybdenum sheet post-grind annealed at $1200^{\circ} \mathrm{C}$ in vacuum for 1 hour.

$\mathrm{b}_{\text {Heat }} \mathrm{C}-6605$ is commercial molybdenum with $290-\mathrm{ppm}$ carbon content and $10-\mathrm{ppm} \mathrm{O}_{2}$ content.

Heat C-7720 is low-carbon molybdenum with $30-\mathrm{ppm}$ carbon content and $26-\mathrm{ppm} \mathrm{O}_{2}$ content.

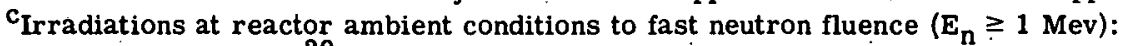
ORM-38, $1.1 \times 10^{20}$

ORM-43, $3.0 \times 10^{19}$

ORM-44, $4.8 \times 10^{18}$

dpercent in $2.54-\mathrm{cm}$ gage length

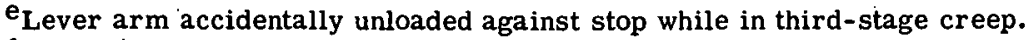

f Test discontinued at time indicated.

5،'High-Temperature Materials Program Progress Report No. 43, Part A,' GE-NMPO, GEMP-43A, January 29, 1965, pp. $47-52$. 
The irradiated $\left(1.2 \times 10^{20}\right.$ neutrons $\left./ \mathrm{cm}^{2}\right)$ specimen tested at $700^{\circ} \mathrm{C}$ exhibited about a 30 -hour incubation period in which the creep was abnormally low (Figure 2.7). Although this phenomenon had been noted previously ${ }^{6}$ in irradiated (ambient temperature) tungsten specimens; it had not been observed in molybdenum specimens. Specimens irradiated to the same fast neutron fluence and tested at higher temperatures $\left(850^{\circ} \mathrm{C}\right.$ and $\left.980^{\circ} \mathrm{C}\right)$ did not show any pronounced incubation period. ${ }^{?}$

The $580^{\circ} \mathrm{C}$ and $600^{\circ} \mathrm{C}$ tests involved specimens from the low carbon heat of molybdenum. The preliminary results (Figure 2.7) from this series of tests show accelerated creep at $580^{\circ} \mathrm{C}$ for the lower neutron fluence $\left(4.8 \times 10^{18}\right.$ neutrons $\left./ \mathrm{cm}^{2}\right)$ irradiated specimens. This accelerated creep was exhibited at two stress levels (Table 2.7). One specimen irradiated to $3 \times 10^{19}$ neutrons $/ \mathrm{cm}^{2}$ showed negligible creep for 259 hours at $580^{\circ} \mathrm{C}$ and the test was terminated.

The irradiated specimen $\left(3 \times 10^{19}\right.$ neutrons $\left./ \mathrm{cm}^{2}\right)$ tested at $600^{\circ} \mathrm{C}$ exhibited (Figure 2.7) a relatively long incubation period of approximately 165 hours in which the creep rate was extremely low. This stage was followed by an abrupt accelerated flow rate terminating in fracture. It appears that some defect which caused the hardening required a long period of time at the relatively low temperature to be removed sufficiently to permit dislocation mobility.

\subsection{TENSILE DATA (F. D. Kingsbury, A. R. Begany, A. J. Lovell, J. Moteff)}

\section{TUNGSTEN}

A series of tensile tests were performed to determine the effect of fast neutron fluence on the properties of irradiated recrystallized tungsten rod. The specimens were irradiated in the ORR to fast neutron fluence values ranging from $4 \times 10^{18}$ to about $1.4 \times 10^{20}$ neutrons $/ \mathrm{cm}^{2}\left(E_{\mathrm{n}} \geq 1 \mathrm{Mev}\right)$. The tests were conducted at $400^{\circ} \mathrm{C}$ in gettered argon and are tabulated in Table 2.8. Several irradiated specimens were annealed at $1200^{\circ} \mathrm{C}$ or $1300^{\circ} \mathrm{C}$ and subsequently tested at $400^{\circ} \mathrm{C}$.

The initial portions of the stress-versus-strain curves for the control and irradiated specimens are shown in Figure 2.8. The irradiated specimens exhibited increased yield . strengths with increasing fluence values. Specimens irradiated at $7.0 \times 10^{19}$ neutrons $/ \mathrm{cm}^{2}$ $\left(E_{n} \geq 1 \mathrm{Mev}\right)$ and above fractured before the 0.2 -percent offset yield strength point was reached.

The tendency toward embrittlement with increased neutron exposure is demonstrated by the complete stress-versus-strain curves (Figure 2.9). A marked loss in ductility is shown in specimens irradiated above $5.9 \times 1018$ neutrons/ $\mathrm{cm}^{2}$. Specimen 1329 (Figure 2.9, curve 3) exhibited a period of plastic flow at eonstant stress after the initial yield hardening.

Thermal neutrons (sub-cadmium) have a measurable influence on the tensile properties of tungsten, presumably because of the rhenium atoms formed during irradiation. This effect is shown by curve 4, Figure 2.9 for the cadmium-shielded specimen which exhibited a brittle fracture having a 0.3 -percent elongation value compared to the 4.4 -percent elongation measured for an unshielded specimen (curve 5, Figure 2.9) irradiated to about the same fast neutron fluence.

A $\log -\log$ plot of the increase in yield strength $\left(0.05 \%\right.$ offset) at $400^{\circ} \mathrm{C}$ versus fast neutron fluence is shown in Figure 2.10. The data fit a straight line with a slope of about 0.5 indicating that the yield strength increases in proportion to the square root of the fast neutron fluence.

\footnotetext{
${ }^{6}$ GEMP-334A, p. 60.

7 ' 'High-Temperature Materials Program Progress Report No. 63," GE-NMPO, GEMP-63, December 30, 1966, Figures 3.9 and 3.10, p. 45.
} 

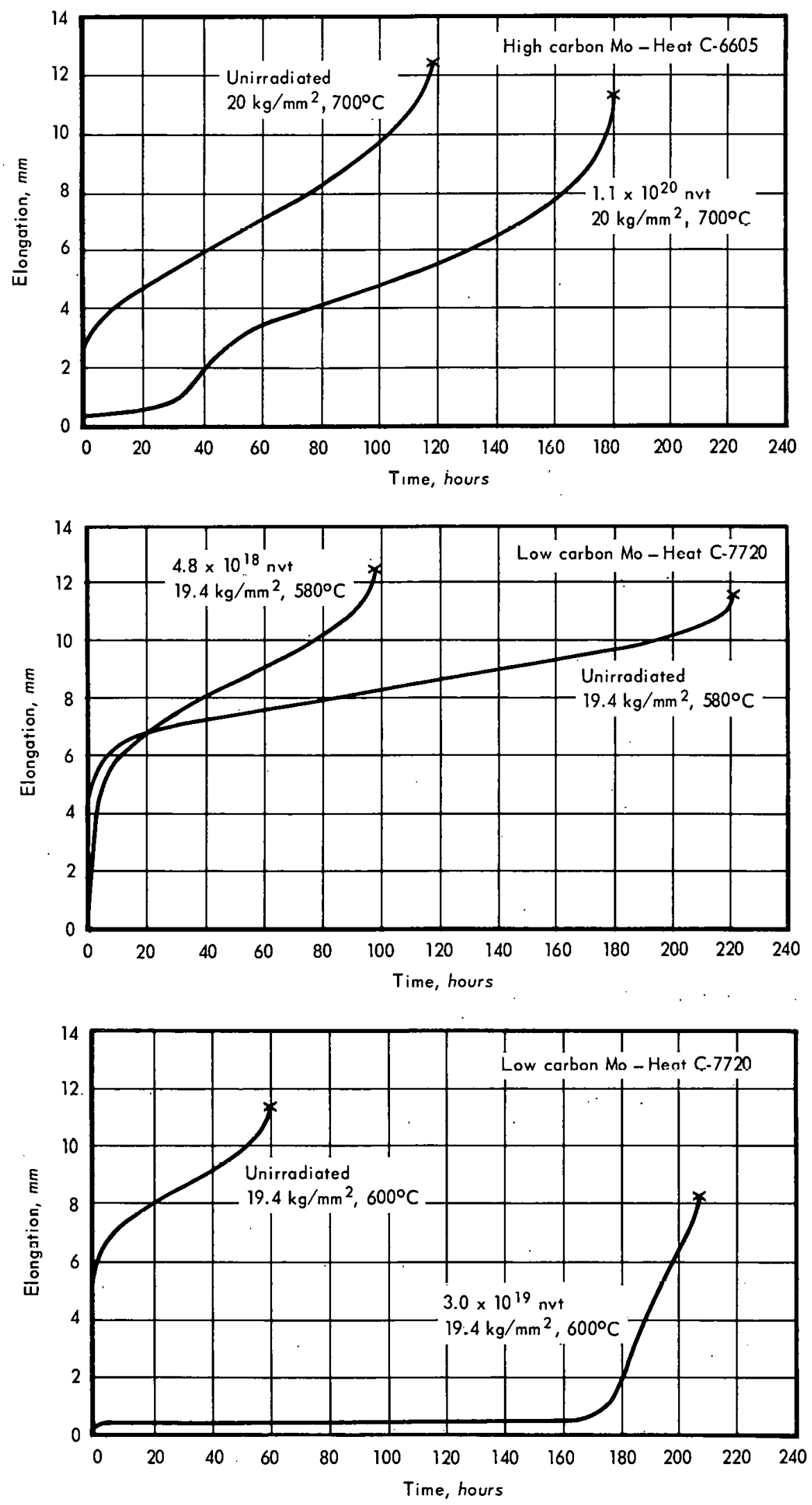

Fig. 2.7-Elongation versus time curves for unirradiated and irradiated molybdenum specimens tested at various temperatures and stresses 


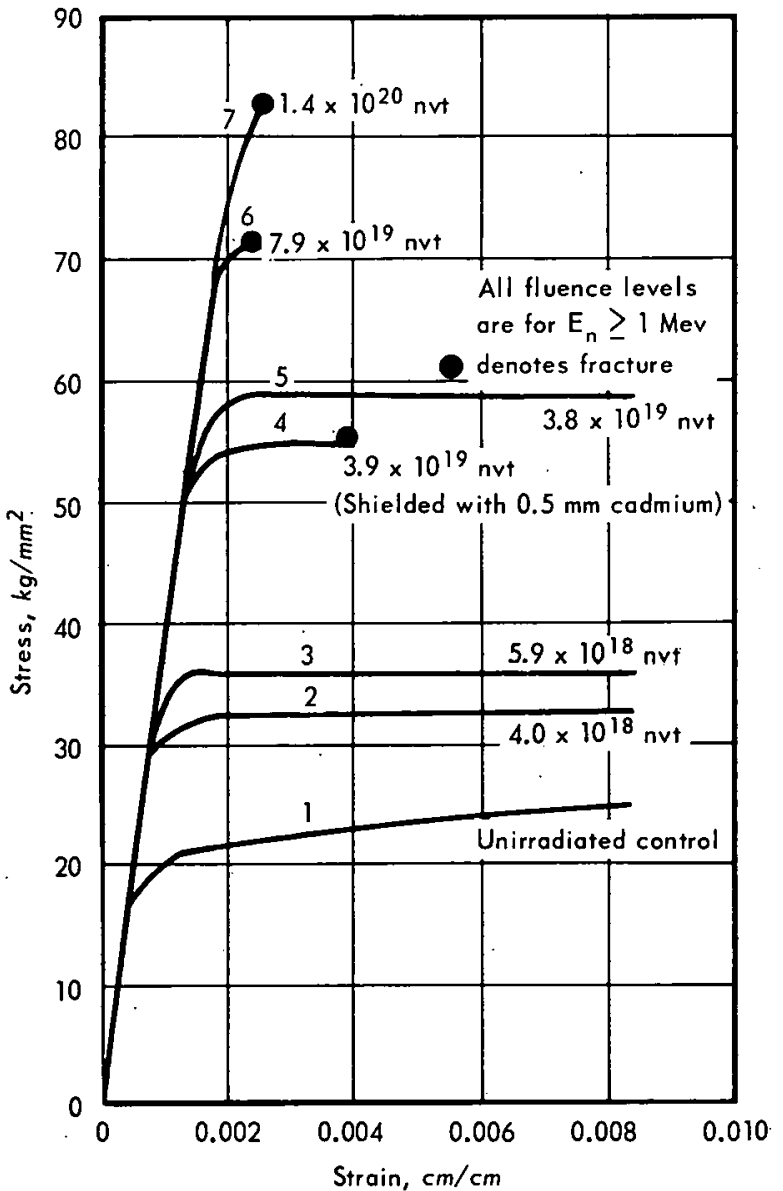

Fig. 2.9-Stress versus strain curves for control and irradiated tungsten specimens tested at $400^{\circ} \mathrm{C}$
Fig. 2.8 - Stress versus strain curves for control and irradiated tungsten specimens tested of $400^{\circ} \mathrm{C}$

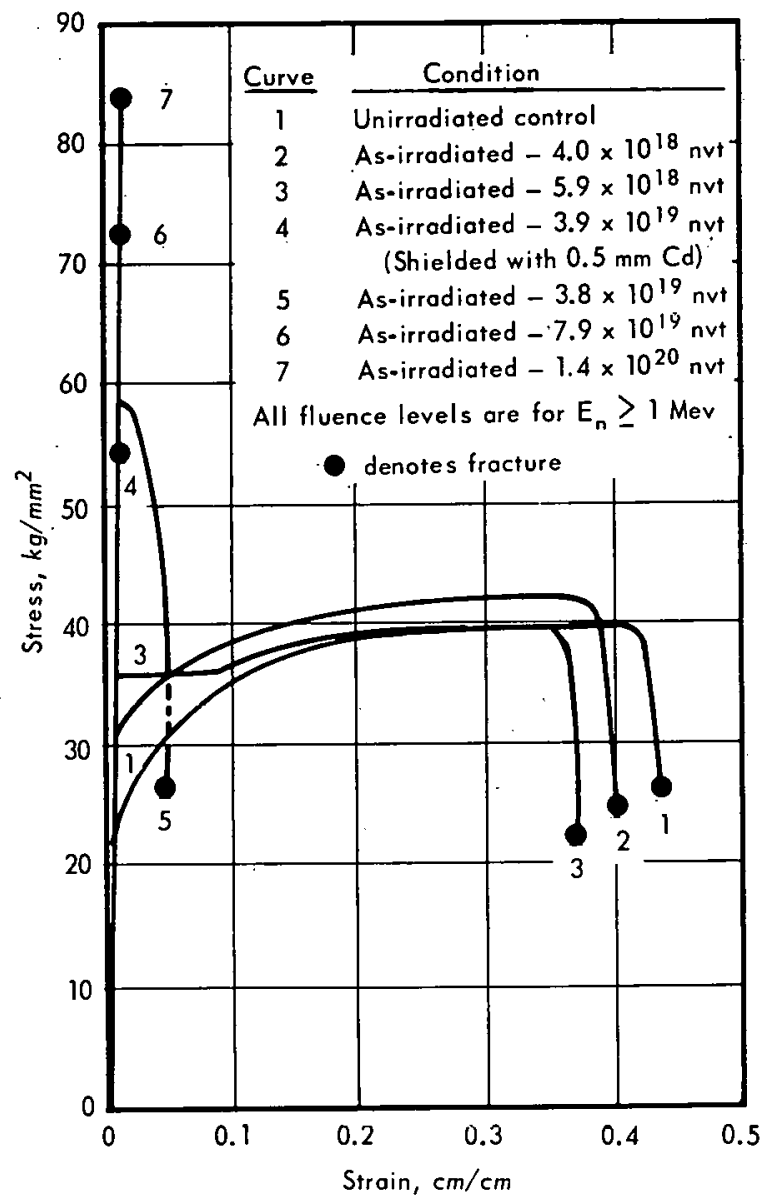


TABLE 2.8

TUNGSTEN TENSILE TEST DATA ${ }^{a}$

\begin{tabular}{|c|c|c|c|c|c|c|c|c|}
\hline \multirow{3}{*}{$\begin{array}{c}\text { Specimen } \\
\text { No. }\end{array}$} & \multicolumn{3}{|c|}{ Irradiation Conditions $\mathbf{b}^{\mathbf{b}}$} & \multirow{3}{*}{$\begin{array}{l}\text { Post-Irradiation } \\
\text { Annealing } \\
\text { Temperature, }{ }^{\circ} \mathrm{C}\end{array}$} & \multirow{3}{*}{$\begin{array}{c}\text { Test } \\
\text { Temperature, } \\
{ }^{\circ} \mathrm{C}\end{array}$} & \multirow{3}{*}{$\begin{array}{c}\text { Yield Strength } \\
\text { (0. } 2 \% \text { Offset), } \\
\mathrm{kg} / \mathrm{mm}^{2}\end{array}$} & \multirow{3}{*}{$\begin{array}{l}\text { Ultimate } \\
\text { Strength, } \\
\mathrm{kg} / \mathrm{mm}^{2}\end{array}$} & \multirow{3}{*}{$\begin{array}{c}\text { Elongation } \\
\text { in } 3.18 \mathrm{~cm} \text {, } \\
\%\end{array}$} \\
\hline & \multirow{2}{*}{$\begin{array}{c}\text { Capsule } \\
\text { No. }\end{array}$} & \multicolumn{2}{|c|}{ Neutron Fluence } & & & & & \\
\hline & & Thermal & Fast $\left(E_{n} \geq 1\right.$ Mev $)$ & & & & & \\
\hline 1316 & - & None & None & - & 121 & $49.6^{c}$ & 49.6 & 0.32 \\
\hline 1317 & - & None & None & - & 163 & 44.2 & 58.0 & 3.20 \\
\hline 1313 & - & None & None & - & 204 & 40.9 & 57.4 & 24.8 \\
\hline 1337 & - & None & None & - & 400 & 20.6 & 39.9 & 43.0 \\
\hline 1332 & - & None & None & - & 400 & 21.9 & 39.8 & 45.6 \\
\hline 1325 & ORM $=31$ & $3.9 \times 10^{19}$ & $4.0 \times 10^{18}$ & - & 400 & 32.4 & 42.4 & $39.6 \mathrm{~d}$ \\
\hline 1329 & ORM-33 & $4.1 \times 10^{19}$ & $5.9 \times 10^{18}$ & - & 400 & 35.9 & 39.8 & $37.2^{\mathrm{d}}$ \\
\hline 1330 & ORM-33 & $4.1 \times 10^{19}$ & $5.9 \times 10^{18}$ & 1300 & 400 & 17.6 & 36.6 & $48.8^{\mathrm{d}}$ \\
\hline 1343 & ORM-37e & $2.5 \times 10^{19}$ & $3.9 \times 10^{19}$ & 1. & 400 & $54.8^{\mathrm{c}}$ & 54.8 & $0.25^{d}$ \\
\hline 1344 & ORM-37 ${ }^{\mathrm{e}}$ & $2.5 \times 10^{19}$ & $3.9 \times 10^{19}$ & 1300 . & 400 & 19.1 & 40.8 & $44.8^{d}$ \\
\hline 1331 & ORM-34 & $2.3 \times 10^{20}$ & $3.8 \times 10^{19}$ & - & 400 & $58.5^{\mathrm{c}}$ & 58.5 & 4.4 \\
\hline 1333 & ORM-34 & $2.3 \times 10^{20}$ & $3.8 \times 10^{19}$ & 1300 & 400 & 19.9 & $(24.2)^{f}$ & - \\
\hline 1340 & ORM-36 & $4.9 \times 10^{20}$ & $7.9 \times 10^{19}$ & - & 400 & $72.0^{\mathrm{c}}$ & 72.0 & Nil \\
\hline 1341 & ORM-36 & $4.9 \times 10^{20}$ & $7.9 \times 10^{19}$ & 1300 & 400 & 30.1 & 39.8 & $40.0^{d}$ \\
\hline 1334 & ORM-36 & $7.0 \times 10^{20}$ & $1.4 \times 10^{20}$ & - & 400 & $82.7^{\mathrm{c}}$ & 82.7 & Nil \\
\hline 1335 & UKM-J5 & $7.0 \times 10^{20}$ & $1.4 \times 10^{20}$ & 1200. & 400 & 32.5 & 36.5 & $1.3^{\mathrm{d}}$ \\
\hline 1309 & $33 \mathrm{MT}-118$ & $3.7 \times 10^{20}$ & $9.8 \times 10^{19}$ & - & 371 & c & $71.3 \mathrm{~g}$ & Nil \\
\hline 1311 & $33 \mathrm{MT}-118$ & $3.7 \times 10^{20}$ & $9.8 \times 10^{19}$ & - & 427 & c & $65.5^{f}$ & Nil \\
\hline 1315 & $33 \mathrm{MT}-118$ & $3.7 \times 10^{20}$ & $9.8 \times 10^{19}$ & - & 482 & c & $29.3^{f}$ & NII \\
\hline 1314 & $33 \mathrm{MT}-118$ & $3.7 \times 10^{20}$ & $0.8 \times 10^{19}$ & - & 510 & - & 54.3 & 5.3 \\
\hline 1312 & $33 \mathrm{MT}-118$ & $3.7 \times 10^{20}$ & $\because 9.8 \times 10^{19}$ & - & 538 & - & 63.3 & 5.0 \\
\hline
\end{tabular}

${ }^{\text {a }}$ Specimens from $0.343-\mathrm{cm}$-diameter powder-metallurgy tungsten rod (Rod G) annealed at $1900^{\circ} \mathrm{C}$ for 1 hour prior to fabrication; stress relieved at $1600^{\circ} \mathrm{C}$ for 1 hour in hydrogen following grinding.

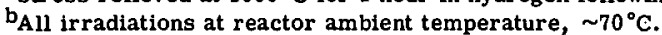

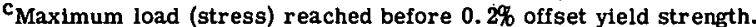

dEstimated from load-elongation charts.

Specimens shielded with $0.51-\mathrm{mm}$-thick cadmium.

f Defect in specimen observable in fracture.

Fracture strength.

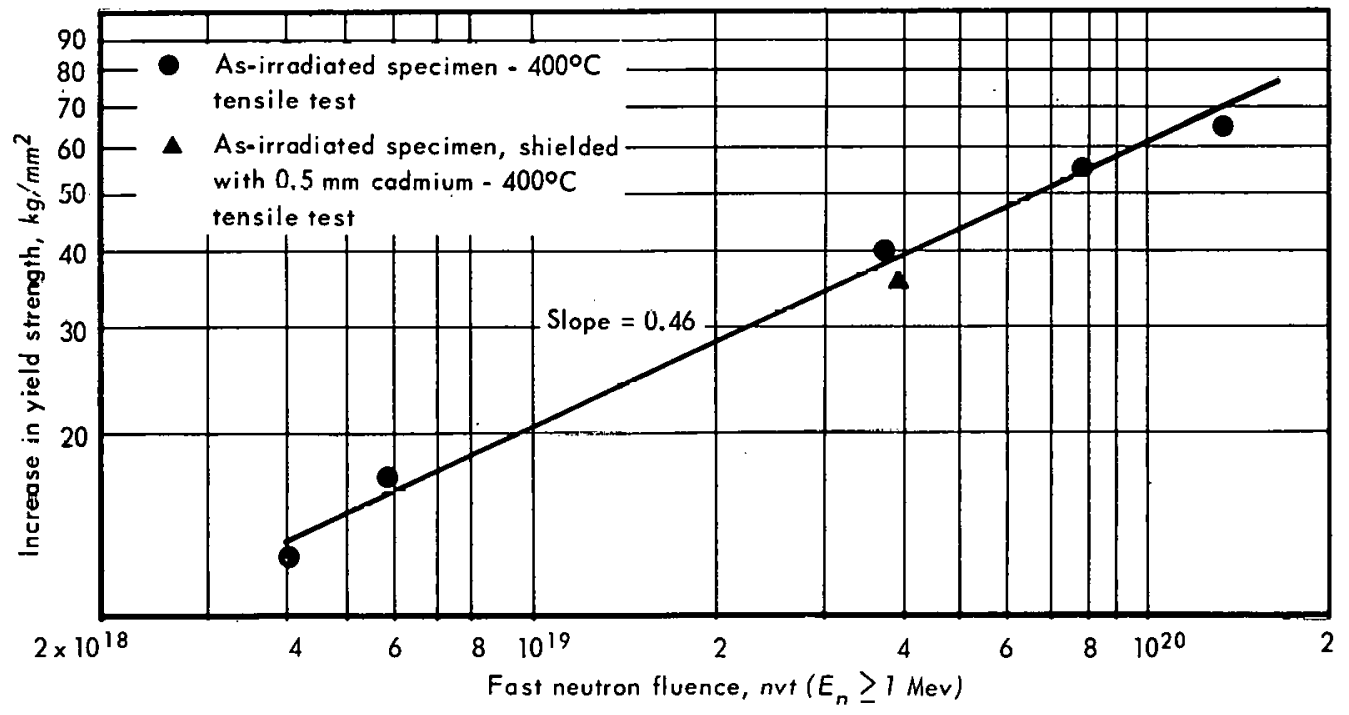

Fig. 2.10 - Increase in 0.05 percent yield strength versus fast neutron fluence for tungsten tensile specimens tested at $400^{\circ} \mathrm{C}$ 
A limited study was performed to determine the effect of annealing on the tensile properties of specimens irradiated to several fast neutron fluence levels. The $1200^{\circ} \mathrm{C}$ anneal for 1 hour in hydrogen resulted (Figure 2.11) in partial recovery of the neutron-induced changes; however, it still exhibited a brittle type of fracture. Ir radiated specimens of four different fluence levels annealed at $1300^{\circ} \mathrm{C}$ for 1 hour in hydrogen exhibited complete recovery of the tensile properties as shown in Figure 2.12 and Table 2.8. All showed a return of ductility equal to the control specimen.

It should be noted that the changes observed in the $1200^{\circ} \mathrm{C}$ and $1300^{\circ} \mathrm{C}$ anneals are not directly comparable since the lowest temperature anneal was given to the specimen with the highest fluence level $\left(1.4 \times 10^{20}\right.$ neutrons $\left./ \mathrm{cm}^{2}, \mathrm{E}_{\mathrm{n}} \geq 1 \mathrm{Mev}\right)$.

W-25Re - 30Mo

A study of the effect of annealing on the room-temperature tensile properties of irradiated, recrystallized $\mathrm{W}-25 \mathrm{Re}-30 \mathrm{Mo}$ (at. \%) alloy was conducted. The specimens were irradiated in the ORR to a fast neutron fluence of $3.0 \times 1019$ neutrons $/ \mathrm{cm}^{2}\left(E_{n} \geq 1 \mathrm{Mev}\right)$. The test results for the control and irradiated specimens which were post-irradiation annealed in gettered argon at $175^{\circ}, 450^{\circ}$, and $690^{\circ} \mathrm{C}$ are tabulated in Table 2.9.

Stress - strain curves plotted in Figure 2.13 show the general behavior of a control and two post-irradiation-annealed specimens. The curves indicate that an annealing temperature between $450^{\circ} \mathrm{C}$ and $690^{\circ} \mathrm{C}$ is sufficient to remove most radiation-induced defects in contrast to temperatures of $1100^{\circ}$ to $1200^{\circ} \mathrm{C}$ required for unalloyed tungsten ${ }^{8}$ irradiated to approximately the same fast fluence level as discussed in the previous section.

\section{MOLYBDENUM}

A study was conducted on the effect of annealing treatments on the room-temperature tensile properties of irradiated, recrystallized arc-cast molybdenum. A companion hardness study ${ }^{y}$ was also performed on identical material from the same ORR irradiation $\left(1.1 \times 10^{20}\right.$ neutrons $\left./ \mathrm{cm}^{2}, \mathrm{E}_{\mathrm{n}} \geq 1 \mathrm{Mev}\right)$.

Irradiated and control specimens were post-irradiation annealed at a series of temperatures in the temperature range from $550^{\circ}$ to $1200^{\circ} \mathrm{C}$ and tested. The results are shown in Figures 2.14 and 2.15 and tabulated in Table 2.10.

The changes in room-temperature tensile properties with increasing annealing temperatures may be noted in Figure 2.14. The as-irradiated specimens exhibited an increase in ultimate strength and had nil ductility. The as-irradiated specimen and those irradiated specimens annealed at $550^{\circ} \mathrm{C}$ and $700^{\circ} \mathrm{C}$ failed in the elastic portion of the stress - strain curve with a brittle fracture. Annealing above $830^{\circ} \mathrm{C}$ initiated the recovery of the neutroninduced defects as evidenced by the recovery of ductility. Full recovery to values exhibited by control specimens were observed following a $1200^{\circ} \mathrm{C}$ anneal.

Stress - strain curves shown in Figure 2.15 demonstrate the behavior of specimens given post-irradiation anneals above $800^{\circ} \mathrm{C}$ compared to that of a control specimen. The absence of a lower yield point in the $830^{\circ} \mathrm{C}$ and $950^{\circ} \mathrm{C}$ annealed specimens suggests a change in the flow mechanism. Pronounced yield point recovery was exhibited in specimens annealed at $1025^{\circ} \mathrm{C}$ and $1200^{\circ} \mathrm{C}$.

Mo-50Re

A study of the effect of annealing on the room-temperature tensile properties of irradiated, recrystallized Mo - 50Re (wt \%) sheet was conducted on specimens irradiated to two fast

${ }^{8}$ GEMP-400A, Tables 2.9 and 2.10, p. 78 .

${ }^{9}$ GEMP-63, Figure 3.5, p. 41. 


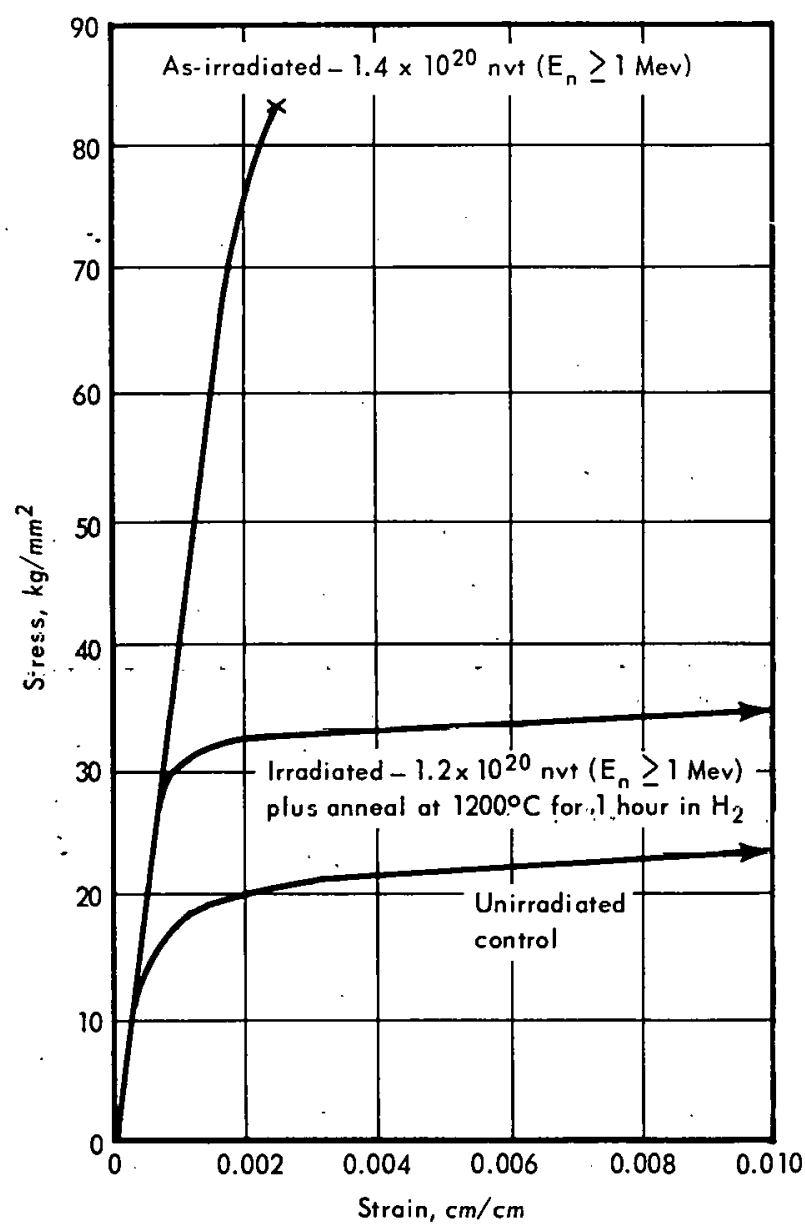

Fig. 2.12-Stress versus strain curves for control, irradiated, and irradiated plus annealed tungsten specimens tested of $400^{\circ} \mathrm{C}$
Fig. 2.11-. Stress versus strain curves for control, irradiated, and irradiated plus annealed tungsten specimens tested at $400^{\circ} \mathrm{C}$

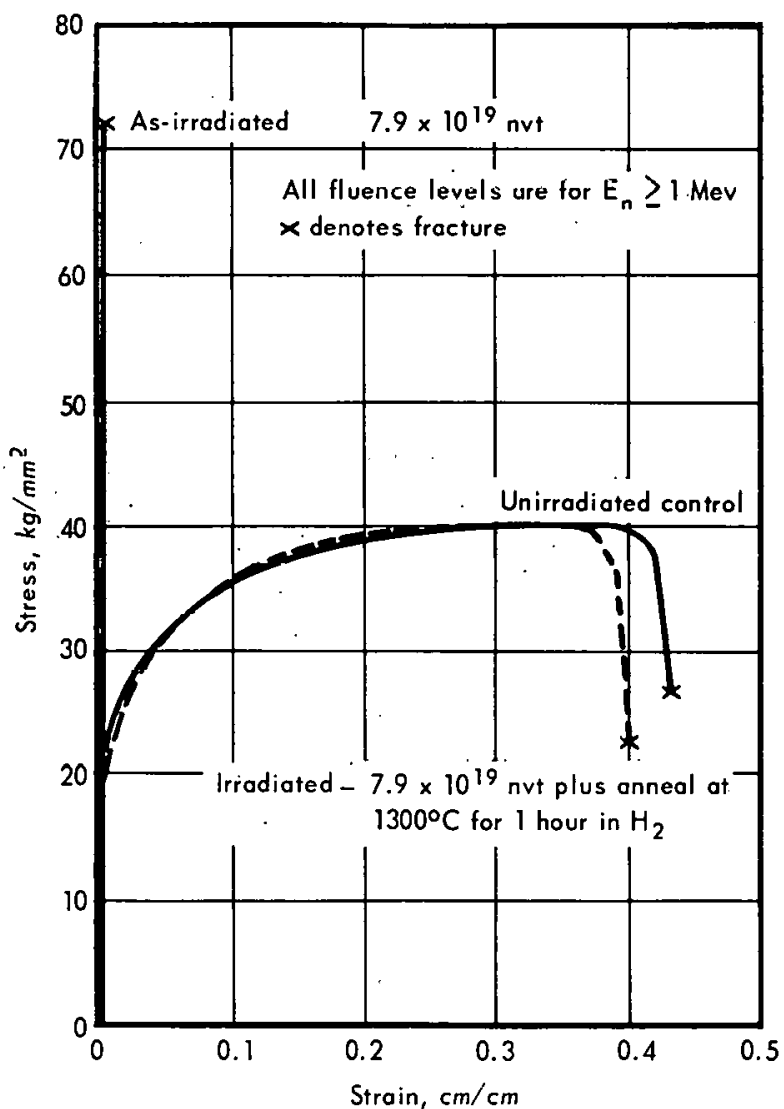


TABLE 2.9

ROOM-TEMPERATURE TENSILE DATA FOR W - 25Re - 30MO SHEET

\begin{tabular}{|c|c|c|c|c|c|c|}
\hline $\begin{array}{l}\text { Specimen } \\
\text { Number }\end{array}$ & $\begin{array}{c}\text { Post Irradiation } \\
\text { Annealing Temperature, a } \\
{ }^{\circ} \mathrm{C}\end{array}$ & Condition & $\begin{array}{l}\text { Yield Str ength- } \\
0.2 \% \text { Offset, } \\
\mathrm{kg} / \mathrm{mm}^{2}\end{array}$ & $\begin{array}{l}\text { Ultimate } \\
\text { Strength, } \\
\mathrm{kg} / \mathrm{mm}^{2}\end{array}$ & $\begin{array}{c}\text { Elongation } \\
\text { in } 2.54 \mathrm{~cm}, \%\end{array}$ & $\begin{array}{c}\text { Elastic Modulus, } \\
\mathrm{kg} / \mathrm{mm}^{2}\end{array}$ \\
\hline 2646 & None & Control $^{b}$ & 106.7 & 127.3 & 11.1 & 46,600 \\
\hline 2648 & None & Control & 107.3 & 132.4 & 13.1 & 45,800 \\
\hline 2737 & None & Control $^{c}$ & 101.0 & 117.7 & 8.7 & - \\
\hline 2734 & 175 & Control & 99.7 & 117.2 & 11.1 & 46,200 \\
\hline 2735 & 450 & Control & 99.7 & 117.7 & 10.8 & 47,000 \\
\hline 2736 & 690 & Control & 99.7 & 117.9 & 11.0 & 44,600 \\
\hline 2740 & None & Irradiated $c, d$ & - & 112.7 & 2.6 & 38,600 \\
\hline 2744 & 175 & Irradiated & - & 117.5 & 5.6 & - \\
\hline 2745 & 450 & Irradiated & - & 120.2 & 2.9 & 40,100 \\
\hline 2748 & 690 & Irradiated & 106.0 & 118.1 & 9.6 & 37,600 \\
\hline
\end{tabular}

${ }^{a}$ One-hour anneals in gettered argon at temperatures indicated.

${ }^{b}$ Specimens from $0.508-\mathrm{mm}$-thick sheet in as-received condition.

Specimens from $0.254-\mathrm{mm}$-thick sheet, vacuum-annealed at $1750^{\circ} \mathrm{C}$ for 1 hour.

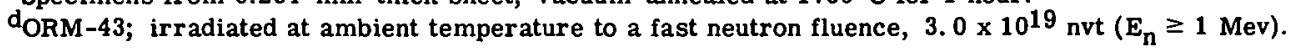

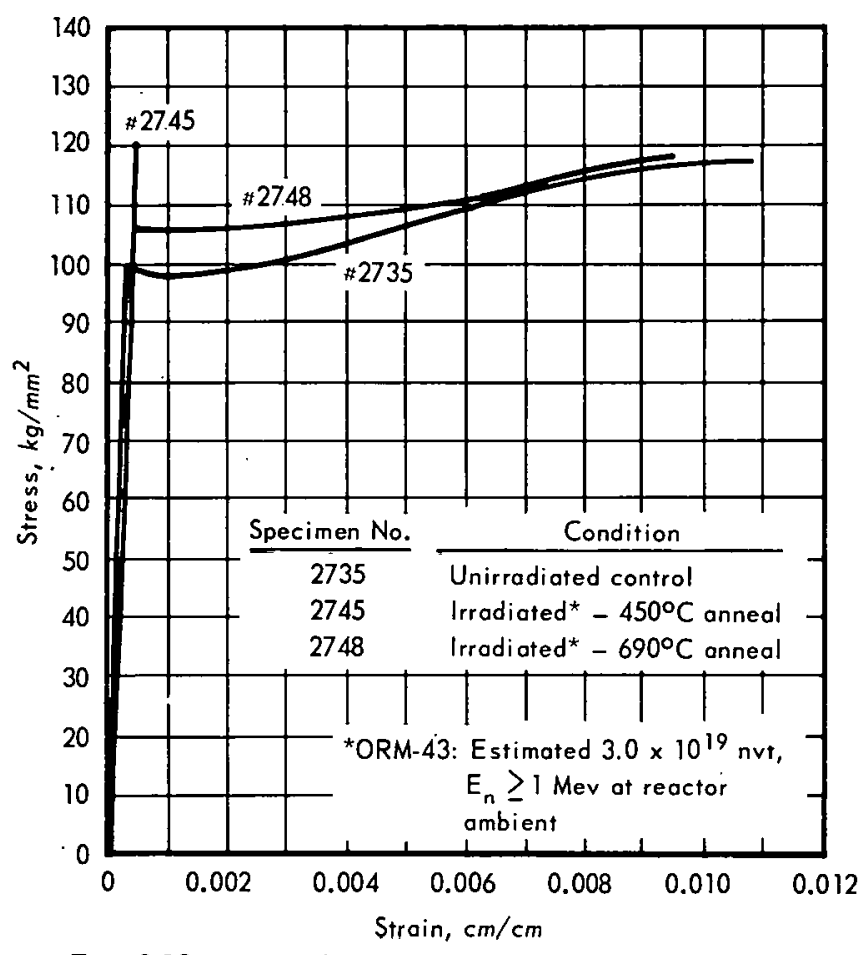

Fig. 2.13-Nominal stress - strain curves of control and irradiated plus annealed $W-25 R e-30 M_{0}$ specimens tested at room temperature 

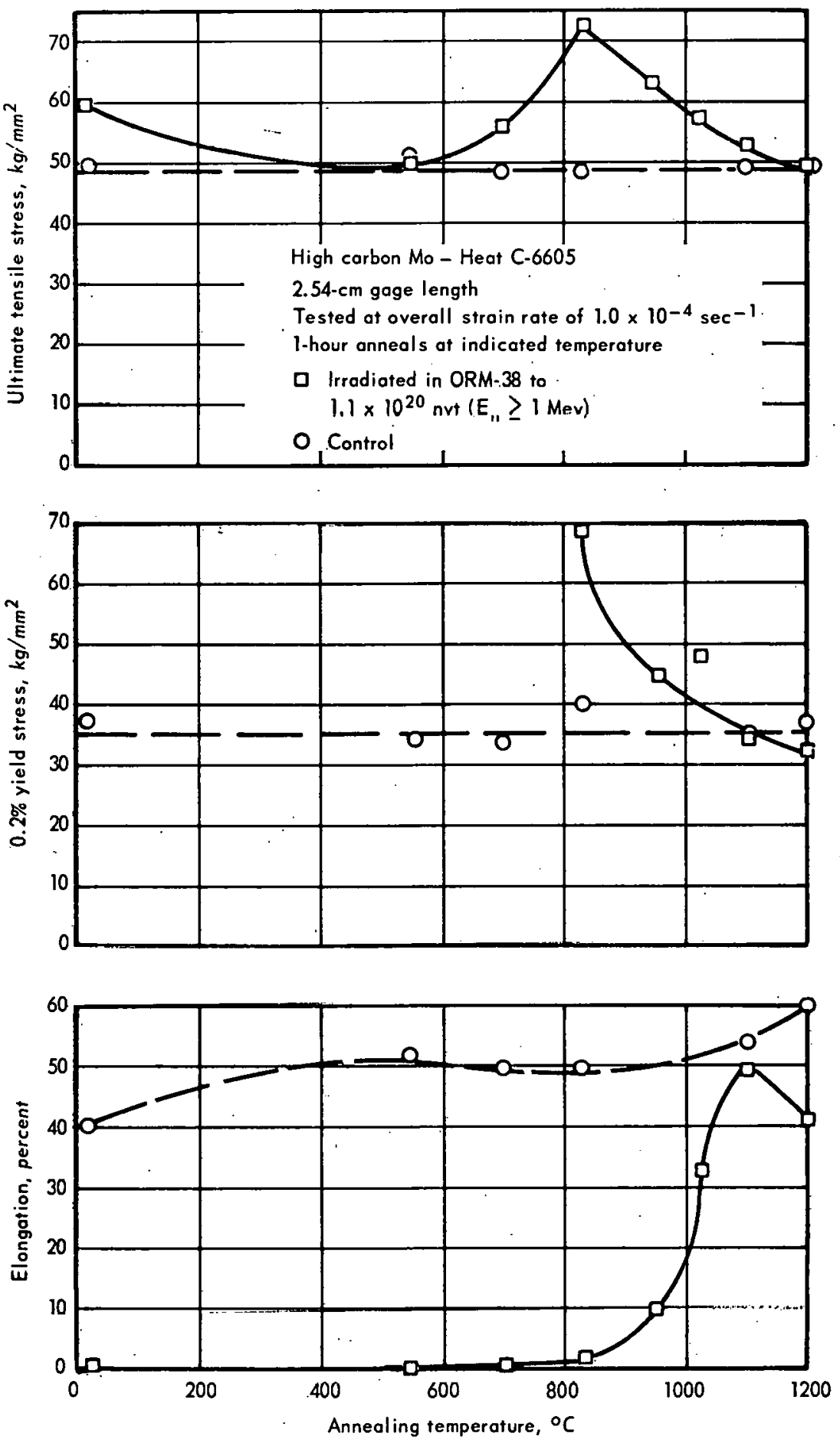

Fig. 2.14-Room-temperoture tensile properties of molybdenum sheet specimens versus post-irradiation annealing temperature 

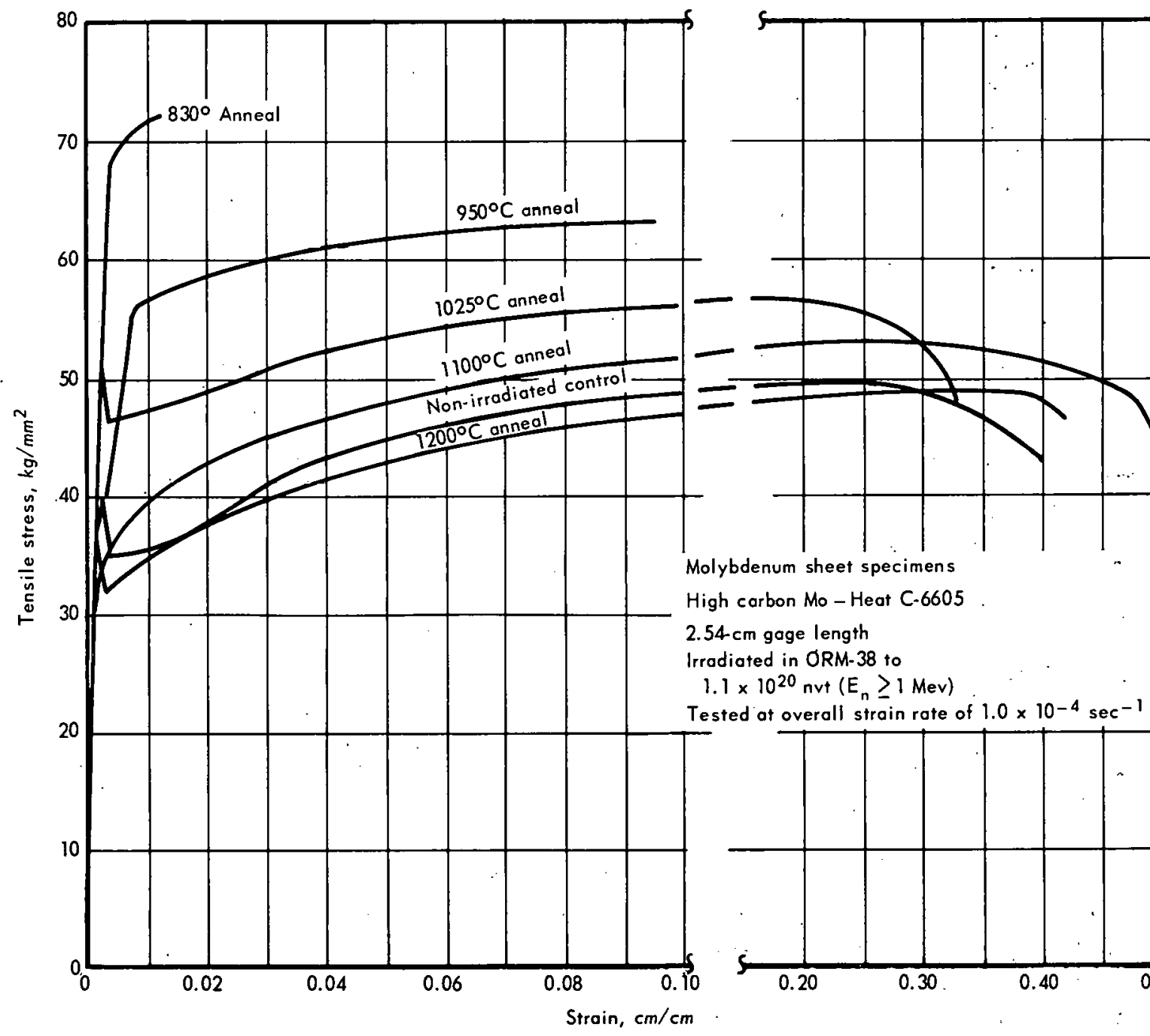

High carbon Mo - Heat C.6605

$2.54 \mathrm{~cm}$ gage length

Irradiated in ORM-38 to

$1.1 \times 10^{20}$ nvt $\left(E_{n} \geq 1 \mathrm{Mev}\right)$

Tested at overall strain rate of $1.0 \times 10^{-4} \mathrm{sec}^{-1}$

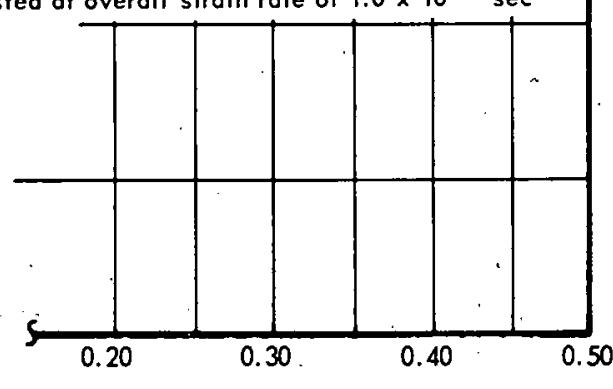

Fig. 2.15-Room-temperature stress versus strain curves for irradiated (ORM-38) molybdenum post-irradiation annealed at indicated temperatures 
TABLE 2.10

ROOM-TEMPERATURE TENSILE DATA FOR MOLYBDENUM SHEET

\begin{tabular}{|c|c|c|c|c|c|}
\hline Specimen $^{\mathrm{a}}$ & $\begin{array}{c}\text { Post } \\
\text { Irradiation } \\
\text { Annealing Temperature, }{ }^{\mathrm{b}} \\
{ }^{\circ} \mathrm{C}\end{array}$ & $\begin{array}{c}\text { Yield } \\
\text { Strength } \\
(0.05 \% \text { Offset }) \\
\mathrm{kg} / \mathrm{mm}^{2} \\
\end{array}$ & $\begin{array}{c}\text { Yield } \\
\text { Strength } \\
(0.2 \% \text { Off set }) \\
\mathrm{kg} / \mathrm{mm}^{2}\end{array}$ & $\begin{array}{l}\text { Ultimate } \\
\text { Strength, } \\
\mathrm{kg} / \mathrm{mm}^{2}\end{array}$ & $\begin{array}{l}\text { Elongation } \\
\text { in } 2.54 \mathrm{~cm} \\
\text { Gage Length, } \\
\%\end{array}$ \\
\hline \multicolumn{6}{|l|}{ Cuntrol } \\
\hline 2100 & None. & 37.7 & 37.6 & 50.0 & 40.0 \\
\hline 2107 & 550 & 40.8 & 34.4 & 50.0 & 51.5 \\
\hline 2117 & 700 & 31.3 & $33: 5$ & 49.0 & 49.6 \\
\hline 2111 & 830 & 43.1 & 40.2 & 48. 2 & 50.3 \\
\hline 2102 & 1100 & 38.0 & 34.3 & 48. 8 & 53.8 \\
\hline 2119 & 1200 & 39.7 & 36.8 & 48.3 & 60.5 \\
\hline \multicolumn{6}{|l|}{ Irradiated $^{c}$} \\
\hline 2104 & None & - & - & 59.0 & 0.30 \\
\hline 2113 & $55 \underline{0} 0$ & - & $=$ & 49.5 & 0.16 \\
\hline 2114 & 700 & - & - & 55.9 & 0.25 \\
\hline 2110 & 830 & 64.9 & 68.6 & 71.7 & 1. 23 \\
\hline 2112 & 950 & 31.5 & 44.4 & 63.1 & 9,56 \\
\hline $2108^{\circ}$ & 1025 & 50.8 & 47.6 & 56.6 & 32.7 \\
\hline 2106 & 1100 & 31.7 & 34.4 & 52.8 & 49.9 \\
\hline 2121 & 1200 & 36.9 & 31.7 & 48. 8 & 41: 8 \\
\hline
\end{tabular}

Specimens from 0.5-mm-thick arc-cast molybdenum sheet (heat C-6605), post-grind annealed at $1200^{\circ} \mathrm{C}$ in vacuum for 1 hour. $2.54-\mathrm{cm}$ gage length, tested at overall strain rate of $0.1 \times 10^{-4} \mathrm{sec}^{-1}$.

${ }^{\mathrm{b}}$ One-hour anneals in gettered argon up to $950^{\circ} \mathrm{C}, 1$-hour anneals in purified hydrogen above $950^{\circ} \mathrm{C}$ at temperature indicated.

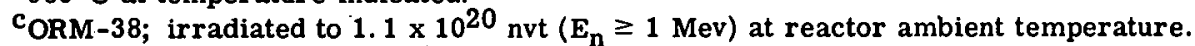

$\left(E_{n} \geq 1 \mathrm{Mev}\right)$ neutron fluence levels, $4.2 \times 10^{19}$ and $2.7 \times 10^{19}$ neutrons $/ \mathrm{cm}^{2}$. Control and irradiated specimens from each irradiation were post-irradiation annealed at $250^{\circ}, 400^{\circ}$, and $700^{\circ} \mathrm{C}$. The temperatures were selected on the basis of previous hot-hardness studies ${ }^{9}$ on the same material. The results of the present tests are given in Table 2.11 and shown in Figures 2.16 and 2.17.

Annealing at temperatures greater than $200^{\circ} \mathrm{C}$ initiated very significant recovery of the neutron-induced strengthening. Following the $250^{\circ} \mathrm{C}$ anneal, the yield strength and ultimate strength of specimens irradiated to $4.2 \times 10^{19}$ neutrons $/ \mathrm{cm}^{2}$ ( $E_{\mathrm{n}} \geq 1 \mathrm{Mev}$ ) still exhibited increases of 75 percent and 45 percent, respectively, compared to control specimens. The increases were reduced to 21 percent and 9 percent following the $400^{\circ} \mathrm{C}$ anneal. Higher temperature annealing $\left(700^{\circ} \mathrm{C}\right)$ reduced the strength to levels only slightly above those of the control specimens.

This behavior is quite unlike the effect of annealing noted in the room-temperature tensile tests on molybdenum ${ }^{10}$ (discussed above), niobium, ${ }^{11}$ and the $240^{\circ} \mathrm{C}$ tests on tungsten. ${ }^{12}$ Unalloyed metals show a thermal strengthening component with an increase in annealing temperature, whereas the alloys do not exhibit this component. In addition, the alloys show recovery of strength and ductility at much lower temperatures than do the base metals.

${ }^{10}$ A. S. Wronski and A. A. Johnson, "A Hardening Effect Associated Stage III Recovery in Neutron Irradiated Molybdenum," Philosophical Magazine, Vol. 8, No. 90, June 1963, pp. 1067-1070.

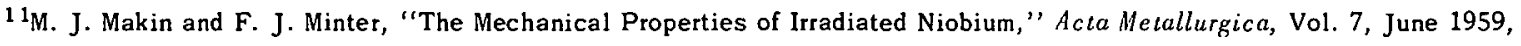
pp. 361-366.

${ }^{12}$ GEMP-400A, pp. $76-77$. 
TABLE 2.11

ROOM-TEMPERATURE TENSILE DATA FOR Mo - 50Re

\begin{tabular}{|c|c|c|c|c|c|}
\hline $\begin{array}{l}\text { Specimen }^{2} \\
\text { No. }\end{array}$ & Condition & $\begin{array}{c}\text { Post- } \\
\text { Irradiation } \\
\begin{array}{c}\text { Anneal Temperature }{ }^{b}, \\
{ }^{\circ} \mathrm{C}\end{array}\end{array}$ & $\begin{array}{l}\text { Yield } \\
\text { Strength, } \\
0.2 \% \text { Offset, } \\
\mathrm{kg} / \mathrm{mm}^{2}\end{array}$ & $\begin{array}{l}\text { Ultimate } \\
\text { Strength, } \\
\mathrm{kg} / \mathrm{mm}^{2}\end{array}$ & $\begin{array}{c}\text { Elongation } \\
\text { in } 2.54 \mathrm{~cm} \text {. gage length, } \\
\%\end{array}$ \\
\hline 36 & Control & None & 80.9 & 100.5 & 31.0 \\
\hline 25 & Control & None & 80.9 & 102.7 & 26.1 \\
\hline 37 & Control & 250 & 81.6 & 99.2 & 31.0 \\
\hline 39 & Control & 400 & 78.1 & 100.6 & 31.0 \\
\hline 38 & Control & 700 & 76.7 & 99.2 & 30.3 \\
\hline 32 & Irradiated ${ }^{c}$ & None & 125.9 & 126.3 & 13.1 \\
\hline 33 & Irradiated $\mathrm{C}$ & 250 & 121.7 & 123.2 & 17.3 \\
\hline 35 & Irradiated $^{c}$ & 400 & 83.7 & 103.8 & 28.3 \\
\hline 34 & Irradiated $\mathrm{C}$ & 700 & 80.9 & 103.4 & 28.0 . \\
\hline 26 & Irradiated $^{d}$ & None & 149.8 & 151.5 & 8.6 \\
\hline 27 & Irradiated ${ }^{d}$ & 250 & 139.2 & 145.4 & 9.2 \\
\hline 30 & Irradiated ${ }^{d}$ & 400 & 94.2 & 110.0 & 24.0 \\
\hline 28 & Irradiated ${ }^{d}$ & 700 & 82.3 & 103.7 & 28.0 \\
\hline
\end{tabular}

aspecimens from $0.5-\mathrm{mm}$ sheet (Lot.RMS-5) post-grind annealed at $1500^{\circ} \mathrm{C}$ in hydrogen for 1 hour. bone-hour anneals in gettered argon at temperature indicated.

cORM-21; irradiated $\left(2.7 \times 10^{19} \mathrm{nvt}, \mathrm{E}_{\mathrm{n}} \geq 1 \mathrm{Mev}\right)$ at reactor ambient temperature in ORR-F2 facility.

dORM-20; irradiated ( $4.2 \times 10^{19} \mathrm{nvt}, \mathrm{E}_{\mathrm{n}} \geq 1 \mathrm{Mev}$ ) at reactor ambient temperature in ORR-F2 facility.

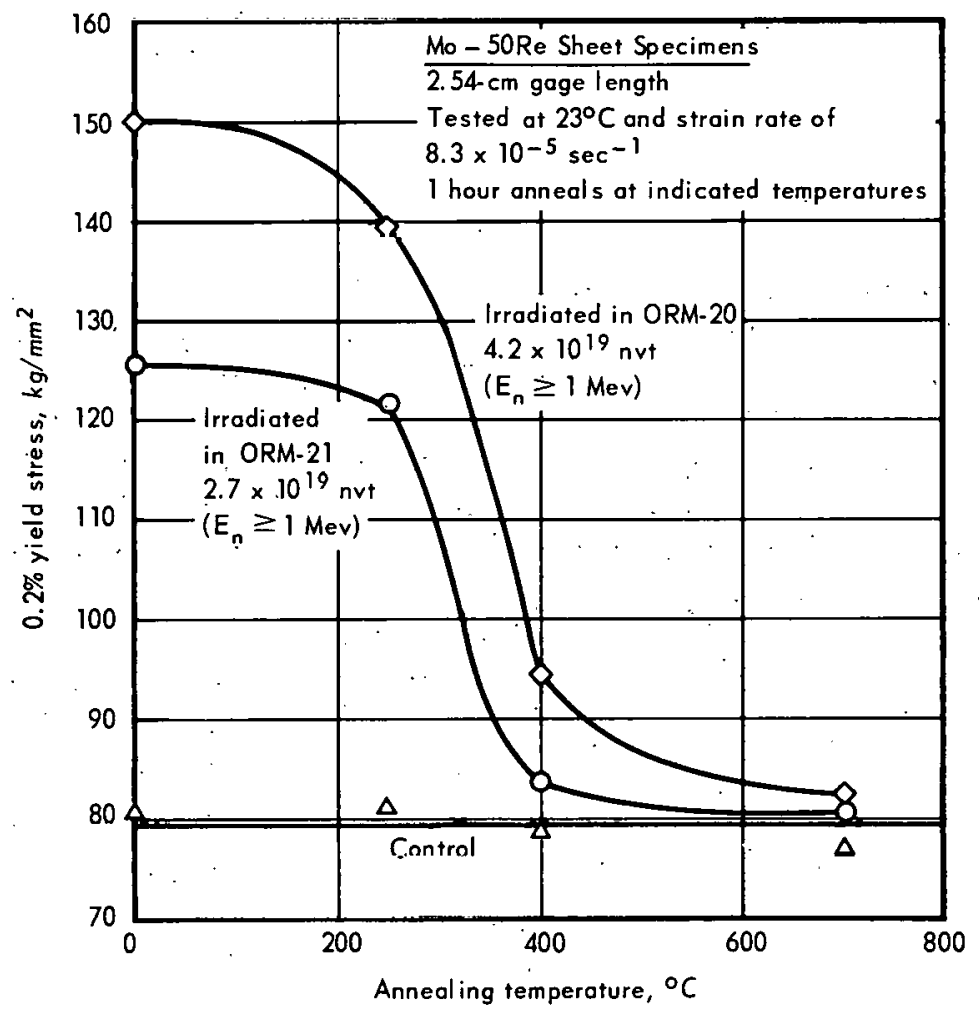

Fig. 2.16-Room-temperature 0.2 percent yield strength of irradiated Mo-50Re sheet as a function of post-irradiation annealing temperature 


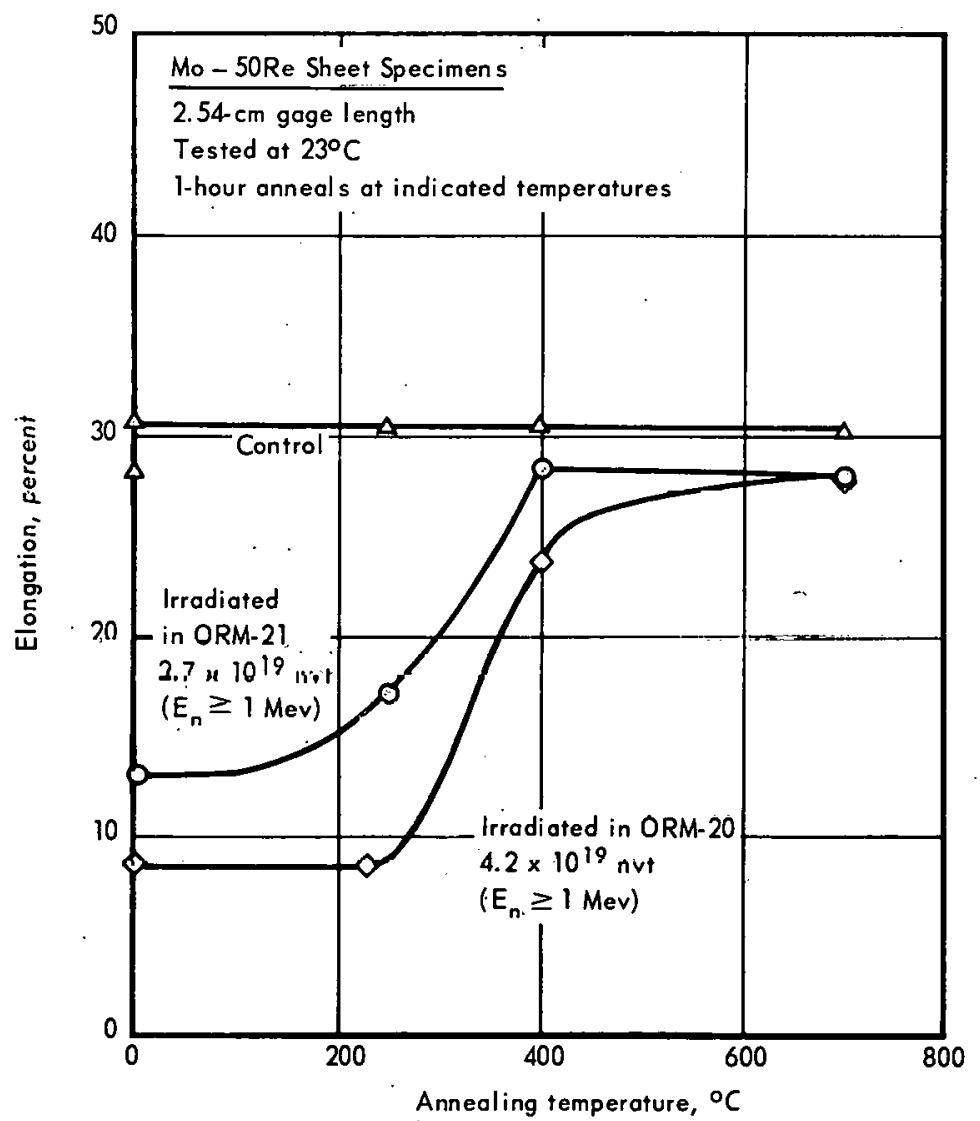

Fig. 2:17 - Room-temperature ductility of irrodiated Mo - 50Re sheet as a function of post-irradiation annealing. temperature

The recovery of ductility was also pronounced in the $200^{\circ}$ to $400^{\circ} \mathrm{C}$ temperature range (Figure 2.17). Approximately 60 percent of the loss in ductility of the higher fluence level irradiated specimens was recovered in the $400^{\circ} \mathrm{C}$ anneal. Annealing at $700^{\circ} \mathrm{C}$ did not fully return the ductility to the control value as a 7 -percent loss was still observed. A residual 5 -percent radiation-induced change was also noted at annealing temperatures to $1100^{\circ} \mathrm{C}$ in earlier hot-microhardness studies. ${ }^{13}$ This effect is believed to be due to the transmutations of rhenium atoms to osmium atoms through the thermal neutron $(n, \gamma)$ reaction.

\subsection{HOT-HARDNESS TESTING (J. L. Kamphouse, J. Moteff)}

Hot-hardness measurement $\mathrm{s}^{14}$ were made on neutron-irradiated tungsten single crystals and on polycrystalline specimens of $\mathrm{W}-25 \mathrm{Re}, \mathrm{W}-25 \mathrm{Re}-30 \mathrm{Mo}$ (at. \%), Mo, Mo-TZM, and Mo-50Re. Similar measurements are now being performed on control and irradiated tungsten specimens containing 73-percent and 98-percent cold-work.

Critical temperatures at which the radiation-induced defects are removed are clearly shown in Figure 2.18 for molybdenum and its alloys and in Figure 2.19 for tungsten and its alloys.

\footnotetext{
${ }^{13} \mathrm{GEMP}-400 \mathrm{~A}$, Figure 2.15 , p. 84 , and Figure 2.21, p. 87.
}

${ }^{14}$ GEMP-400A, pp. 80-92. 

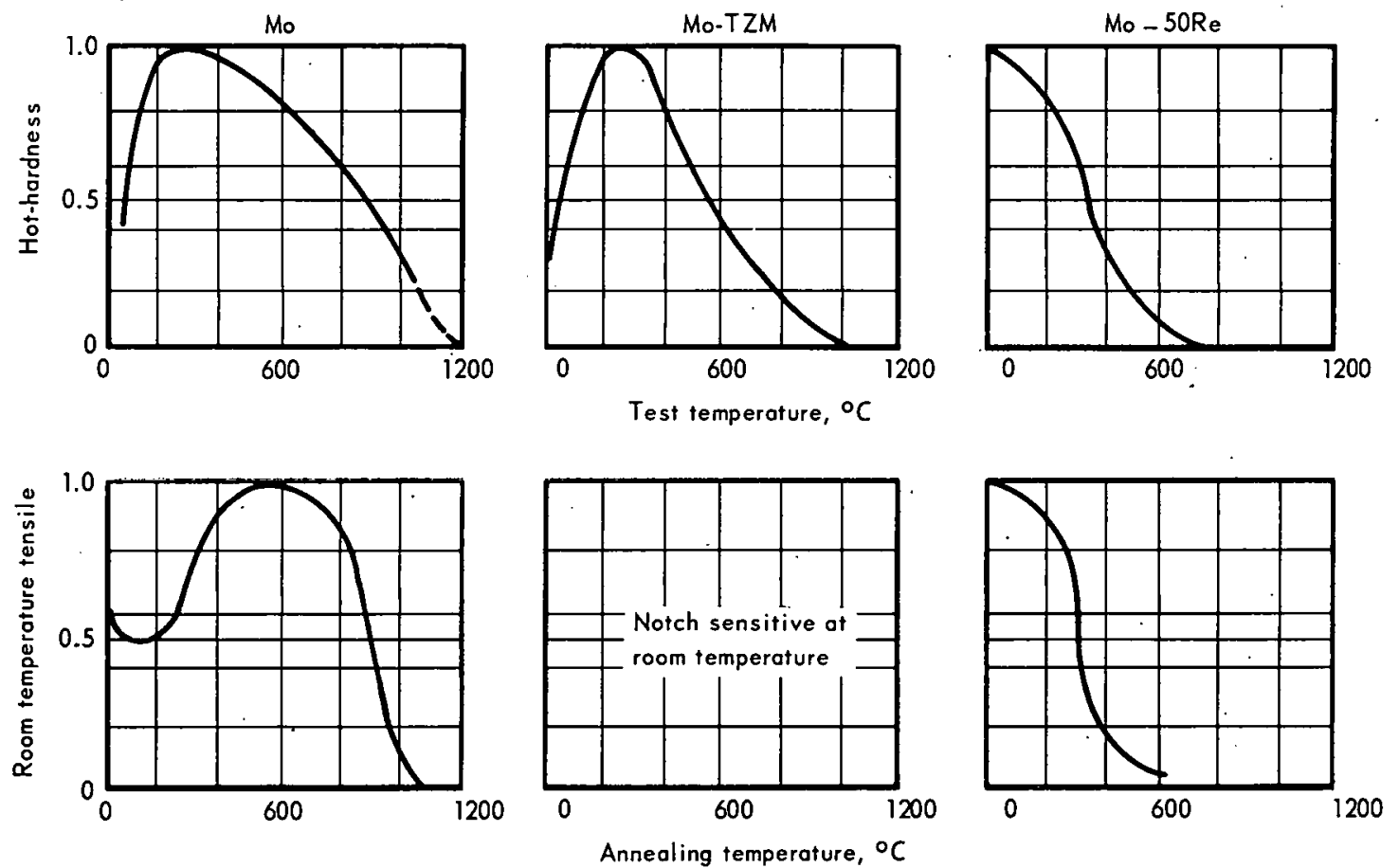

Fig. 2.18- Normalized irradiation induced defect recovery parameter $\Delta P=\frac{P_{I}-P_{C}}{P_{C}}$; where $P_{I}=$ value of property in irradiated condition, and $P_{C}=$ value of property in unirradiated condition versus temperature for Mo and Mo-base alloys
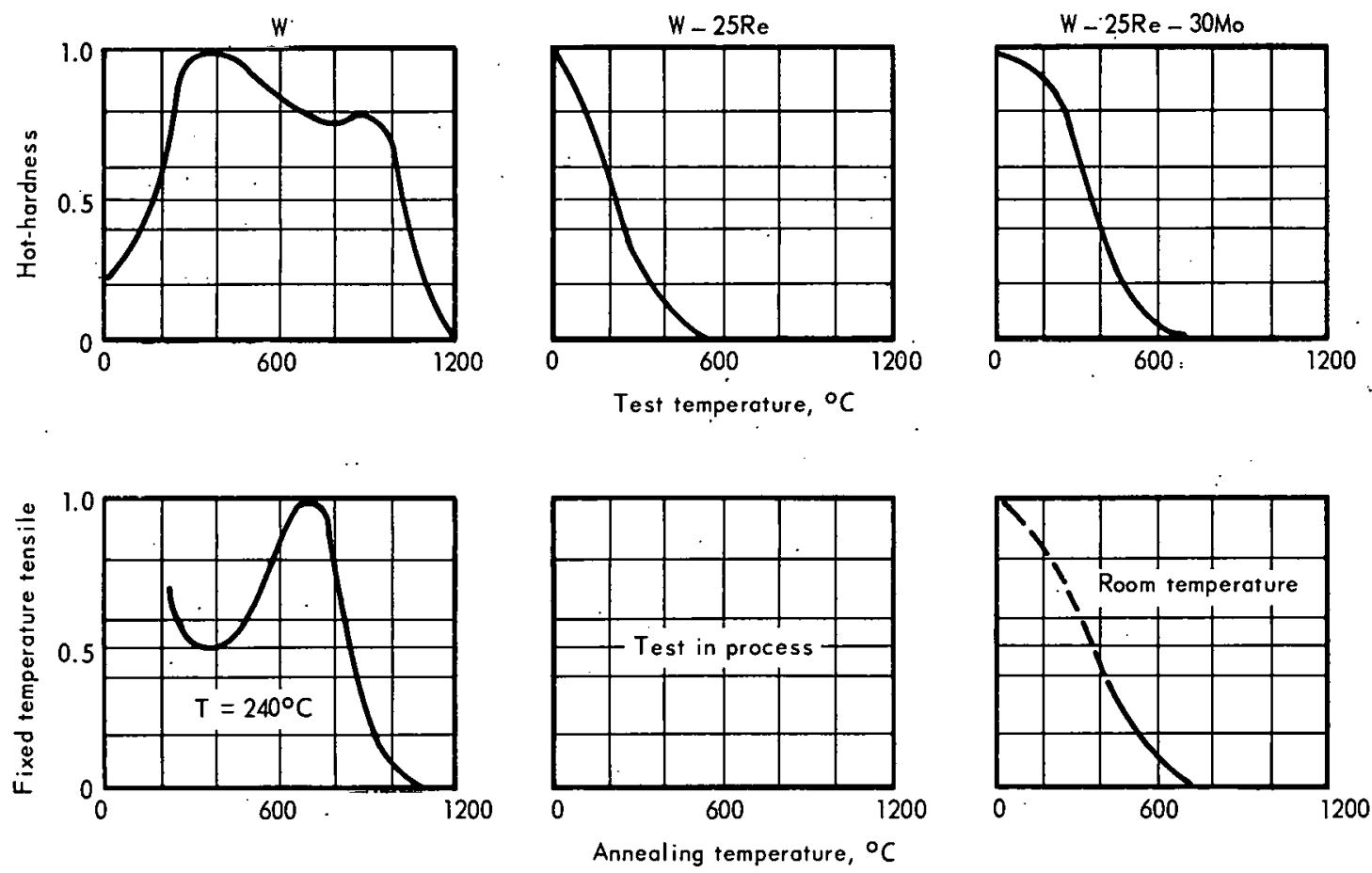

Fig. 2.19-Normalized irradiation induced defect recovery parameter $\Delta P=\frac{P_{I}-P_{C}}{P_{C}}$; where $P_{I}=$ value of property in irradiated condition, and $P_{C}=$ value of property in unirradiated condition versus temperature for $W$ and $W$-base alloys 
Recovery behavior shown by the family of curves in Figure 2.18 suggests that molybdenum and a dilute alloy (Mo-TZM) recover at a temperature below $1100^{\circ} \mathrm{C}$. On the other hand, the binary alloy, Mo $-50 \mathrm{Re}$, shows almost complete recovery at temperatures slightly above $600^{\circ} \mathrm{C}$. Similar behavior is also noted in Figure 2.19 for the tungsten-base material in that the unalloyed metal recovers at much higher temperatures than the binary (W-25Re) or the ternary (W $-25 \mathrm{Re}-30 \mathrm{Mo})$ alloys.

Thermal hardening is very prominent in the pure metals and the dilute alloys but not in higher alloys. This type of behavior indicates that there are several mechanisms for migration of radiation-induced defects and for dislocation-defect interactions. in the unalloyed material and that these mechanisms are different from those occurring in the alloyed materials.

The important conclusion derived from all the results to date is that the radiation-induced hardening, which often is accompanied by radiation-induced embrittlement, will not be as serious for alloys as for unalloyed metals at relatively low operating temperatures. Based on the present experimental data for low and intermediate fluence values, i. e., less than $5 \times 1019$ neutrons $/ \mathrm{cm}^{2}$, it appears that, as a general rule, the alloys show recovery at temperatures above $0.22 \mathrm{~T}_{\mathrm{m}}$ and that the unalloyed metals show recovery above $0.35 \mathrm{~T}_{\mathrm{m}}$.

\subsection{RESISTIVITY STUdIES (L. K. Keys, J. P. Smith, J. Moteff)}

The previously reported studies ${ }^{15}$ of the isochronal resistivity recovery of defects, introduced into several pre-annealed W, Mo, Mo-TZM (Mo $-0.5 \mathrm{Ti}-0.08 \mathrm{Zr}$ ), and W-25Re specimens by irradiation with fast $\left(E_{n} \geq 1 \mathrm{Mev}\right)$ neutrons at ambient $\left(70^{\circ}\right.$ to $\left.80^{\circ} \mathrm{C}\right)$ reactor temperatures, were completed. The results of these studies indicate that the high-temperature recovery mechanisms are very complex, and are greatly modified by the presence of impurities and because of the production of impurity elements by neutron-activated transmutations. Studies of these effects are needed to gain better knowledge of the influence which point defects and cluster defects as well as impurities may have on the mechanical properties of these alloys. The specimens were polycrystalline and were annealed in a flowing argon atmosphere for 1 hour; the tungsten and $\mathrm{W}-25 \mathrm{Re}$ specimens were given a $1900^{\circ} \mathrm{C}$ anneal while molybdenum and Mo-T'ZM specimens were annealed at about $1250^{\circ} \mathrm{C}$. All recovery studies were carried out under the same experimental conditions. The resistivity measurements were made at $-196^{\circ} \mathrm{C}$ using a previously described resistivity bridge..$^{15}$

\section{TUNGSTEN}

A number of recrystallized, polycrystalline tungsten specimens were irradiated in various reactor facilities to fast $\left(E_{n} \geq 1 \mathrm{Mev}\right)$ neutron fluences ranging from $8.5 \times 10^{17}$ to $1.5 \times 10^{21}$ neutrons $/ \mathrm{cm}^{2}$. The isochronal resistivity recovery increment $(\Delta \rho)$, from $0^{\circ}$ to $1500^{\circ} \mathrm{C}$, was used as a measure of the radiation-induced damage in these specimens; this resistivity increment is plotted in Figure 2.20 versus the annealing temperature for several specimens. The derivative $\left[\frac{\mathrm{d}}{\mathrm{dT}}\left(\frac{\Delta \rho}{\Delta \rho_{\mathrm{o}}}\right)\right]$ of the normalized resistivity recovery increment
$\Delta \rho$ $\frac{\Delta \rho}{\Delta \rho_{0}}$ with respect to temperature is presented in Figure 2.21. It is evident that there are several recovery regions or peaks present as indicated by the numerous maxima observed in this plot. Particular significance is attached to recovery regions as they relate to the melting temperature, $\mathrm{T}_{\mathrm{m}}\left(3410^{\circ} \mathrm{C}\right)$. These important regions are: $0.15 \mathrm{~T}_{\mathrm{m}}, 0.22 \mathrm{~T}_{\mathrm{m}}$, $0.31 \mathrm{~T}_{\mathrm{m}}$, and $0.35 \mathrm{~T}_{\mathrm{m}}$; these have been described as representing recovery of specific types of defects (although which temperature refers to what type of defect is apparently

\footnotetext{
${ }^{15} \mathrm{~J}$. Moteff and J. P. Smith, "Recovery of Defects in Neutron-Irradiated Tungsten," ASTM STP-380, 1965, pp. $171-187$.
} 


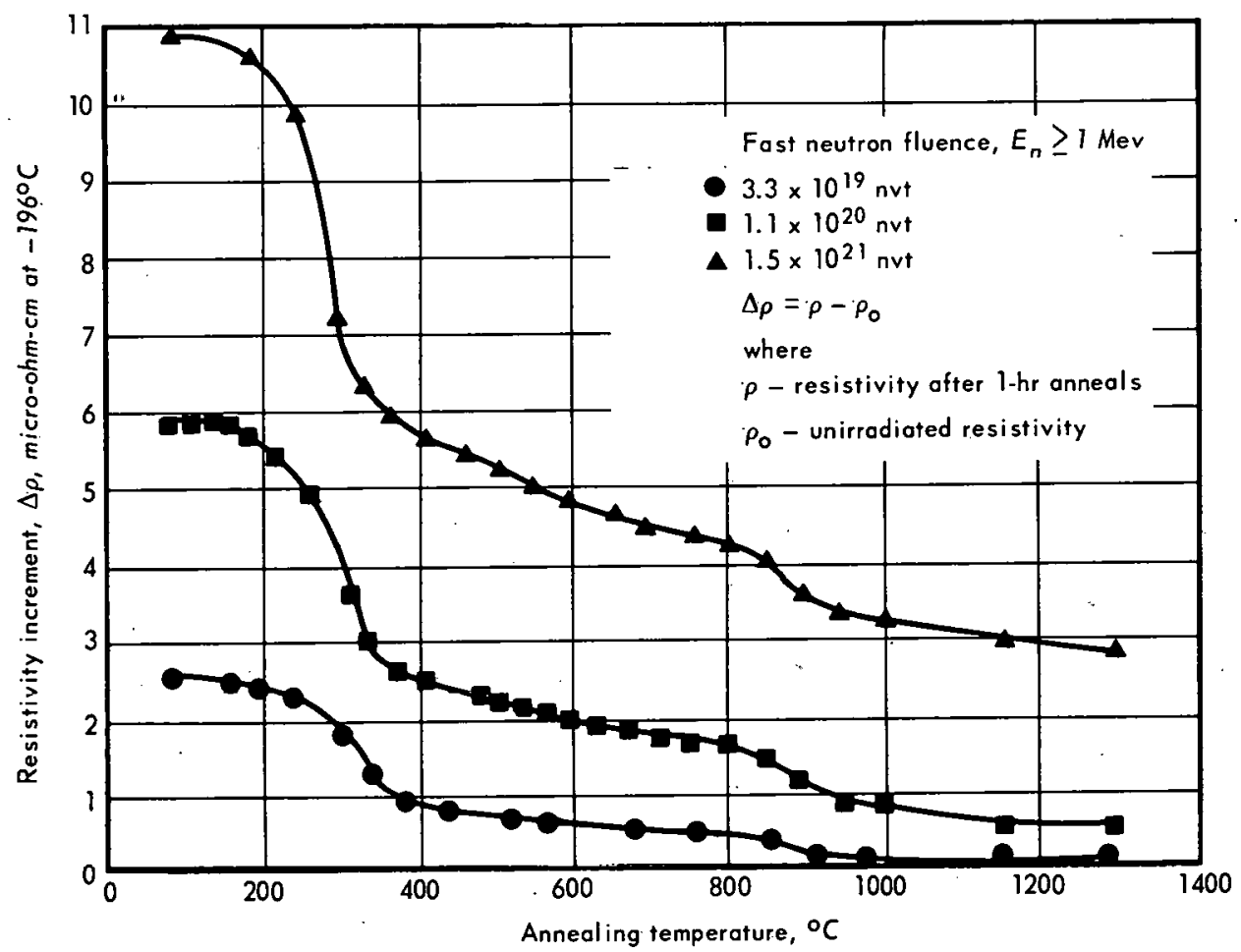

Fig. 2.20 - Isochronal resistivity recovery of neutron-irradiated, recrystallized tungsten as a function of annealing temperature

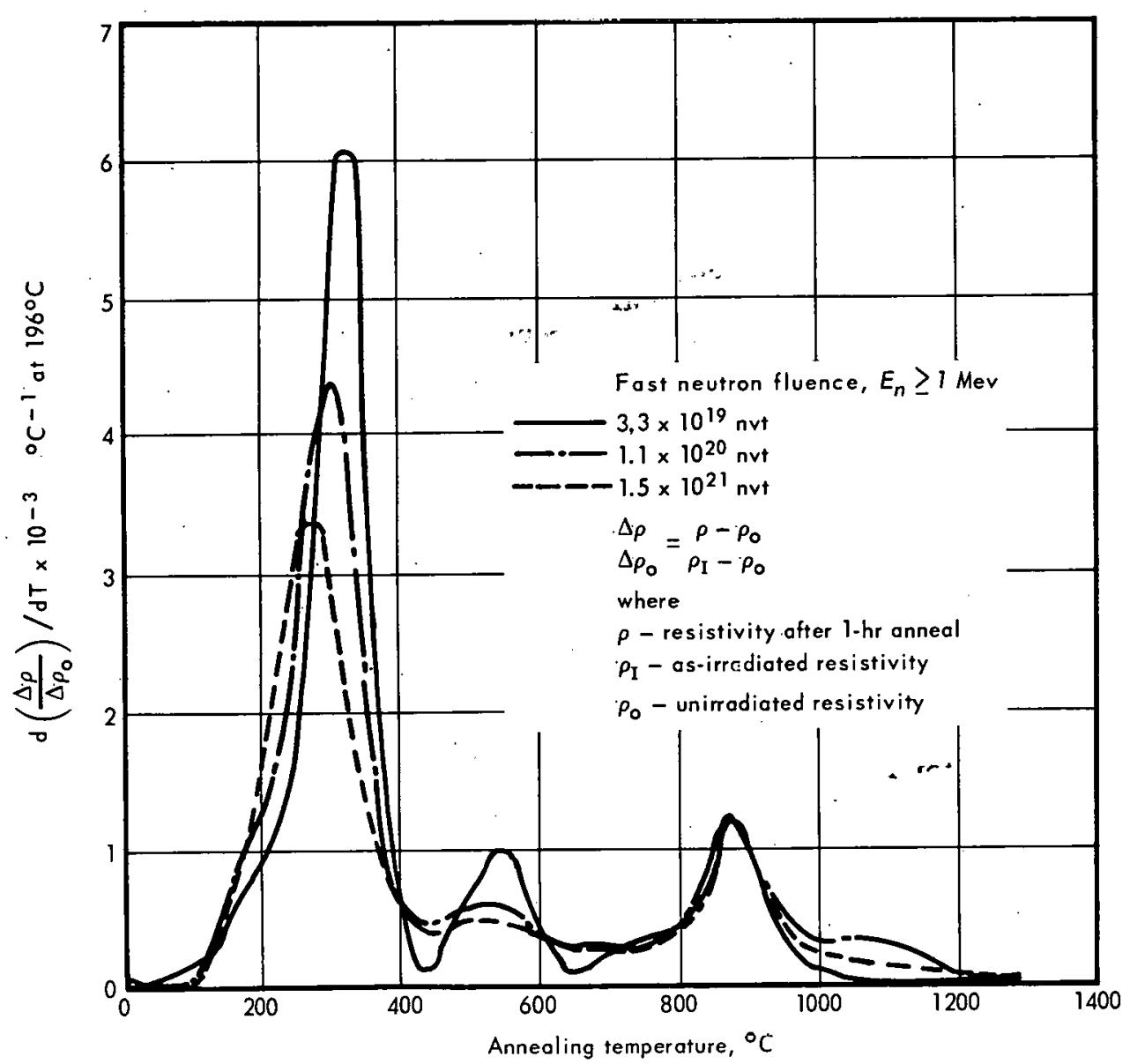

Fig. 2.21 - Derivative of the normalized isochronal resistivity recovery of neutron-irradiated, recrystallized fungsten as a function of annealing temperature 
still a controversy). These recovery regions have been called recovery stages and are referred to by numbers. In this section, the $0.15 \mathrm{~T}_{\mathrm{m}}$ peak is Stage $\mathrm{III}$ and the $0.31 \mathrm{~T}_{\mathrm{m}}$ peak Stage IV. The other peaks will not be referred to as specific stages at the present time.

It has been previously considered in this laboratory ${ }^{15}$ that $0.15 \mathrm{~T}_{\mathrm{m}}$ corresponds to interstitial migration or recovery; $0.22 \mathrm{~T}_{\mathrm{m}}$ corresponds to di-vacancy migration; $0.31 \mathrm{~T}_{\mathrm{m}}$ corresponds to vacancy migration; and $0.35 \mathrm{~T} m$ corresponds to polygonization. These may change as more experimental data is generated and evaluated. The exact temperature of recovery, listed according to its relative melting temperature fraction, for all the described recovery regions as well as the irradiation conditions employed are presented in Table 2.12. The temperature given for a particular recovery refers to the temperature at which the maximum in the recovery peaks in Figure 2.21 occurs. The stages in which a temperature is not presented result from lack of observation of a definite maximum in the recovery peaks.

The recovery observed at $0.35 \mathrm{~T}_{\mathrm{m}}$ appears to vary randomly with the fluence and gives an average value of about $1027^{\circ} \mathrm{C}$ which agrees very well with the predicted $0.35 \mathrm{~T}_{\mathrm{m}}$ of $1016^{\circ} \mathrm{C}$. The $0.31 \mathrm{~T}_{\mathrm{m}}$ recovery peak behaves in a manner similar to the $0.35 \mathrm{~T}_{\mathrm{m}}$ peak with an average temperature of $862^{\circ} \mathrm{C}$ which agrees favorably with the value of $869^{\circ} \mathrm{C}$ assumed for this peak. For the $0.22 \mathrm{~T}_{\mathrm{m}}$ peak, the assumed value of $537^{\circ} \mathrm{C}$ is in excellent agreement with the average observed recovery temperature for this stage of $536^{\circ} \mathrm{C}$. There does appear to be a possible shift of this peak to lower temperatures at the highest fluence, but a more quantitative discussion will require further study. The recovery observed for the $0.15 \mathrm{~T}_{\mathrm{m}}$ stage has been more quantitatively investigated and the corresponding temperature to this stage is $280^{\circ} \mathrm{C}$. As can be seen, only a few of the higher fluence specimens come close to this value while a much higher temperature is obtained at the lower fluences. A preliminary study of this effect was previously described ${ }^{16}$ as well as variation of the total resistivity recovery (area under the $0.15 \mathrm{~T}_{\mathrm{m}}$ recovery peak) with fluence. The changes in the $0.15 \mathrm{~T}_{\mathrm{m}}$ peak recovery temperature with the fast neutron fluence are shown in Figure 2.22 for all measured tungsten samples.

The initial high peak temperature required to recover this peak is believed to result from the presence of a defect trap or sink. Until a temperature of around $360^{\circ} \mathrm{C}$ is reached, the defect recovering at this stage is not freed from the defect trap. This trap is currently believed to be either rhenium or osmium produced by a transmutation resulting from thermal neutron $(n, \gamma)$ reactions with tungsten, in addition to the impurity atoms present in the material. At intermediate and high neutron fluences; the defect sink is most likely rhenium since it is directly formed from tungsten, whereas osmium forms secondarily from the resulting rhenium. As fast fluence increases, the temperature of this recovery peak shifts to a lower value of $312^{\circ} \mathrm{C}$ at a fast fluence of $9.8 \times 10^{19}$ neutrons $/ \mathrm{cm}^{2}$ and finally to $270^{\circ} \mathrm{C}$ at a fast neutron fluence of $1.5 \times 10^{21}$ neutrons $/ \mathrm{cm}^{2}$. It is tentatively believed that the peak shift in temperature is facilitated by other competing recovery mechanisms, arising from increased concentration of defects generated at the higher fast neutron fluences. ${ }^{16}$ In general, the total resistivity is seen to show evidence of saturation in a manner apparently related to the shift of the recovery peak temperature. The reasons for this saturation are quite complex and further investigation is necessary before a detailed explanation can be given. The saturation effect undoubtedly arises in this complex system from a number of competing recovery mechanisms. A few of the most likely are:

1. Annihilation of neighboring defects of opposite sign (Frenkel pairs).

2. Annihilation of distant defects of opposite sign after migration.

3. Migration of point defects to clusters of the same or opposite sign.

${ }^{16}$ GEMP-63, pp. 49-52. 
TABLE 2.12

DEFECT RECOVERY STAGES IN NEUTRON IRRADIATED TUNGSTEN DETERMINED FROM ISOCHRONAL RESISTIVITY STUDIES

\begin{tabular}{|c|c|c|c|c|c|c|c|c|c|c|c|c|c|}
\hline \multirow{3}{*}{$\begin{array}{l}\text { Sample } \\
\text { No. }\end{array}$} & \multirow[b]{3}{*}{ Rod } & \multirow[b]{3}{*}{ Capsule } & \multirow{2}{*}{\multicolumn{2}{|c|}{$\frac{\text { Irradiation Conditions }^{\mathrm{a}}}{\text { Fluence, nvt }}$}} & \multicolumn{9}{|c|}{$\begin{array}{c}\text { Maximum Rate of Recovery Temperature, }{ }^{\circ} \mathrm{C}^{\mathrm{b}} \text {, and Area Under Respective } \\
\text { Recovery Peak, micro-ohm-cm }\end{array}$} \\
\hline & & & & & \multirow[b]{2}{*}{$0.15 \mathrm{~T}_{\mathrm{m}}$} & \multirow[b]{2}{*}{ Area } & \multirow[b]{2}{*}{$0.22 \mathrm{~T}_{\mathrm{m}}$} & \multirow[b]{2}{*}{ Area } & \multirow[b]{2}{*}{$0.13 \mathrm{~T}_{\mathrm{m}}$} & \multirow[b]{2}{*}{ Area } & \multirow[b]{2}{*}{$0.35 \mathrm{~T}_{\mathrm{m}}$} & \multirow{2}{*}{ Area } & \multirow{2}{*}{$\begin{array}{l}\text { Residual Resistivity, } \\
\text { micro-ohm }-\mathrm{cm} \\
\pm 0.005\end{array}$} \\
\hline & & & Fast $\left(E_{n} \geq 1 \mathrm{Mev}\right)$ & Thermal & & & & & & & & & \\
\hline 354 & A & ORM -32 & $8.5 \times 10^{17}$ & $6.8 \times 10^{18}$ & 362 & 0.196 & $568^{\circ}$ & 0.021 & 867 & & 992 & - & - \\
\hline 101 & D & ORM-7 & $5.4 \times 10^{18}$ & $2.6 \times \cdot 10^{19}$ & 345 & 0.604 & 550 & 0.077 & - & - & - & - & - \\
\hline 355 & $A$ & ORM-33 & $5.9 \times 10^{18}$ & $4.1 \times 10^{19}$ & 333 & 0.816 & 519 & 0.132 & 855 & 0.103 & 1022 & - & 0.024 \\
\hline 175 & $\mathbf{E}$ & ORM-14 & $1.1 \times 10^{19}$ & $9.3 \times 10^{19}$ & 325 & 1.224 & 556 & 0.153 & 853 . & 0.209 & - & - & 0.046 \\
\hline 104 & $\bar{D}$ & ORM-11 & $3.3 \times 10^{19}$ & $1.2 \times 10^{20}$ & 819 & 1. 783 & 541 & 0.294 & 884 & 0.390 & - & - & 0.108 \\
\hline 356 & $\mathbf{A}$ & ORM-34 & $3.8 \times 10^{19}$ & $2.3 \times 10^{20}$ & 316 & 2.014 & 520 & 0.368 & 875 & 0.523 & 1021 & - & 0.205 \\
\hline 359 & $A$ & ORM-37 & $3.9 \times 10^{19}$ & $2.5 \times 10^{19}$ & 320 & 1. 722 & 484 & 0.291 & 873 & 0.452 & 1049 & - & 0.016 \\
\hline 337 & A & ORM-19 & $7.3 \times 10^{19}$ & $3.2 \times 10^{20}$ & 313 & 2. 388 & 540 & 0.263 & 877 & 0.781 & 1042 & - & 0.332 \\
\hline 348 & $A$ & MT-138 & $9.8 \times 10^{19}$ & $3.7 \times 10^{20}$ & 312 & 3. 161 & 532 & 0.431 & 873 & 0.788 & 1052 & - & 0.369 \\
\hline 2181 & $\mathbf{J}$ & ORM-38 & $1.1 \times 10^{20}$ & $5.2 \times 10^{20}$ & 307 & 3.384 & 534 & 0.434 & 875 & 1.025 & 1033 & - & 0.521 \\
\hline 2189 & $\mathbf{J}$ & MT 2-234 & $1.5 \times 10^{21}$ & 2. $6 \times 10^{21}$ & 270 & 7.4463 & 516 & 1. 1073 & 874 & 2. 1462 & - & - & 2. 843 \\
\hline
\end{tabular}

a The specimens were irradiated at reactor ambient temperatures in a water-moderated reactor.

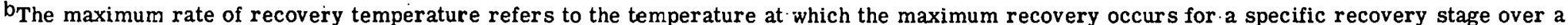

temperature region. This stage is related to the melting temperature, $T_{m}$, as shown. 


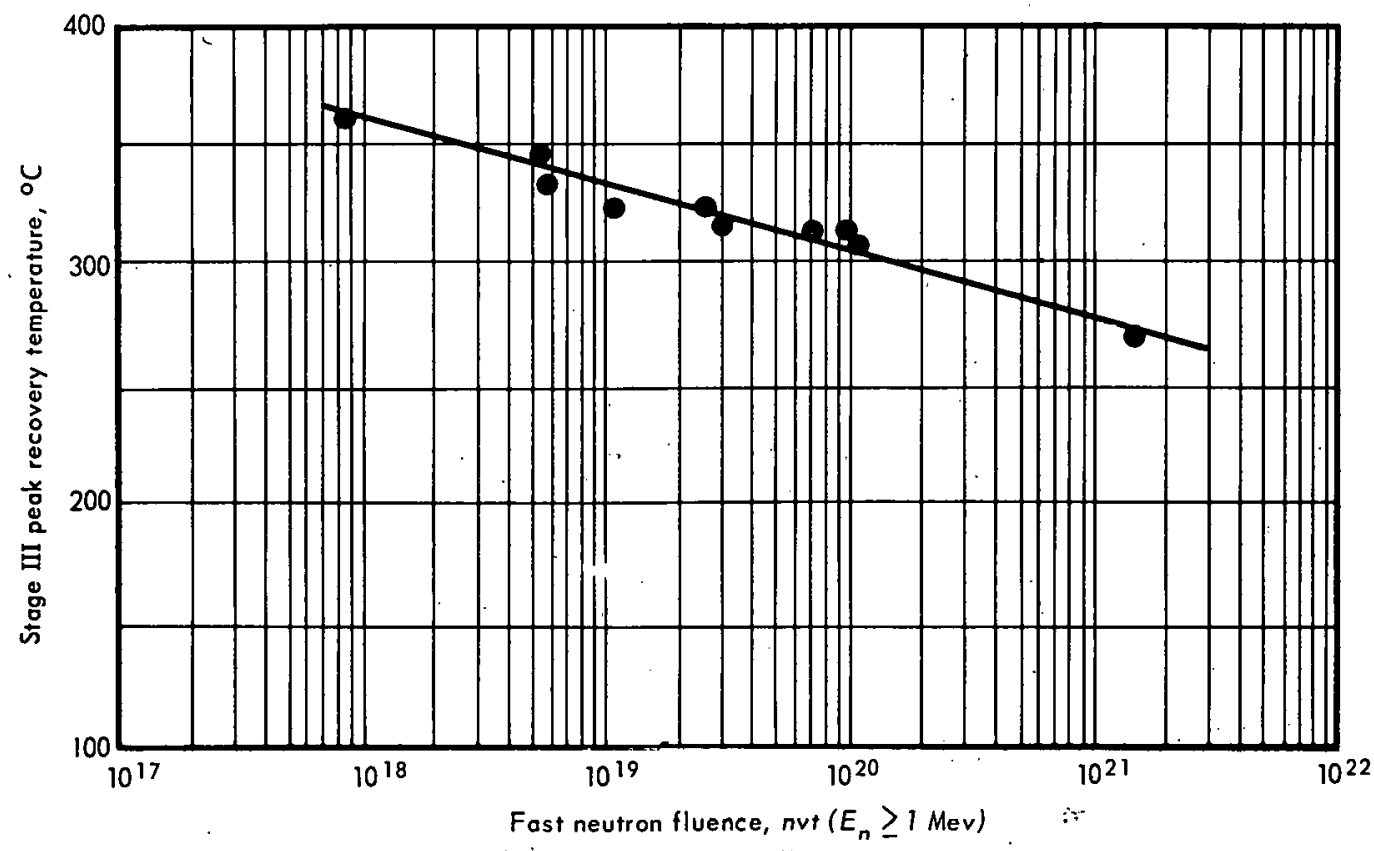

Fig. 2.22-Variation of Stage III peak recovery temperature as a function of fast neutron fluence

4. Freeing of point defects from point-defect traps. or sinks such as impurities, grain boundaries, dislocations, etc.

5. General increase in the fast fluence to thermal fluence ratio, indicating a larger defect-to-defect trap ratio with increasing fast fluence.

Many of these mechanisms will be affected by the magnitude of the neutron fluence since relative concentration of the various defects and some of the traps involved are similarly affected by this fluence. As indicated by Figure 2.20, the residual resistivity increment (that fraction which does not apparently anneal out), increases with the fast, or related thermal, neutron fluence. This is believed due to the increased concentration of rhenium (and osmium) produced by the higher thermal fluences. Residual resistivity as well as thermal neutron fluence can be used to calculate the rhenium concentration from previously established relations ${ }^{17,18}$ with the results shown in Table 2.13. Comparison between these two different measurements of the atom fraction of rhenium is good considering: (1) relative errors in thermal neutron fluence measurements; (2) small residual resistivities ini. volved for many of the specimens; (3) the assumption that the resistivity increases uniformly with increasing rhenium content from 0.00 to 0.04 atom fraction; and (4) the fact that the concentration of osmium is not significant below a thermal fluence of about $10^{21}$ neutrons $/ \mathrm{cm}^{2}$. The resistivity measurement is believed to give more accurate values than those calculated from thermal fluence data.

In addition to the "expected" recovery peaks given in Table 2.12, several other recovery peaks appeared at various fluences. These peaks appeared in the following samples at the reported temperatures: sample number 337 at $685^{\circ} \mathrm{C}$ and $493^{\circ} \mathrm{C}$; sample number 348 at $686^{\circ} \mathrm{C}$ and $473^{\circ} \mathrm{C}$; sample number 2181 at $698^{\circ} \mathrm{C}$ and $470^{\circ} \mathrm{C}$; and sample number 2189 at $663^{\circ} \mathrm{C}$. The recovery occurring at these two different temperature regions is not under stood at this time; however, it appears that the recovery at around $480^{\circ} \mathrm{C}$ is related to

${ }^{17}$ GEMP-334A, p. 77.

${ }^{18}$ GEMP-400A, p. 94 . 
TABLE 2.13

\begin{tabular}{|c|c|c|c|c|}
\hline \multirow[b]{2}{*}{$\begin{array}{l}\text { Specimen } \\
\text { No. }\end{array}$} & \multicolumn{2}{|c|}{ Experimental } & \multicolumn{2}{|c|}{ Calculated } \\
\hline & $\begin{array}{c}\text { Residual } \\
\text { Resistivity, } \\
\text { micro-ohm-cm }\end{array}$ & $\begin{array}{l}\text { Atom Fraction } \\
\text { Re } \\
\end{array}$ & $\begin{array}{c}\text { Thermal Fluence, } \\
\text { nvt }\end{array}$ & $\begin{array}{c}\text { Atom } \\
\text { Fraction } \\
\mathbf{R e} \\
\end{array}$ \\
\hline 175 & 0.0459 & 0.0007 & $9.3 \times 10^{19}$ & 0.0009 \\
\hline 152 & 0.0961 & 0.0014 & $1.1 \times 10^{20}$ & 0.0012 \\
\hline 104 & 0.1082 & 0.0016 & $1.2 \times 10^{20}$ & 0.0013 \\
\hline 356 & 0.2048 & 0.0031 & $2.3 \times 10^{20}$ & 0.0024 \\
\hline 337 & 0.3321 & 0.0049 & $3.2 \times 10^{20}$ & 0.0033 \\
\hline 358 & 0.3445 & 0.0051 & $4.9 \times 10^{20}$ & 0.0051 \\
\hline 348 & 0.3692 & 0.0055 & $3.7 \times 10^{20}$ & 0.0039 \\
\hline 2181 & 0.5210 & 0.0074 & $5.2 \times 10^{20}$ & 0.0054 \\
\hline 357 & 0.6357 & 0.0094 & $7 \times 10^{20}$ & 0.0075 \\
\hline 2189 & 2.8428 & 0.0420 & $2.6 \times 10^{21}$ & 0.0250 \\
\hline
\end{tabular}

that at $0.22 \mathrm{~T}_{\mathrm{m}}$ as these two peaks appear to coalesce in sample 2189 giving a resultant recovery at about $516^{\circ} \mathrm{C}$.

The dependence of total resistivity increment $(\Delta \rho)$, which is a measure of the total radiation effects, on fast neutron fluence for tungsten is given in Figure 2.23. The log of resistivity is seen to increase linearly with the $\log$ of fast fluence at low fluence levels. The slope obtained for this straight line is about 0.70 . At around 1020 neutrons $/ \mathrm{cm}^{2}$ the line shows considerable bending which is evidence of saturation (although it is still in doubt as to what saturation really is). Two possible causes of saturation are:

1. A greater degree of local point defect annealing at higher fluence levels (defect density by thermal spikes).

2. Formation of clusters from point defects as well as formation of fewer large clusters from many small clusters.

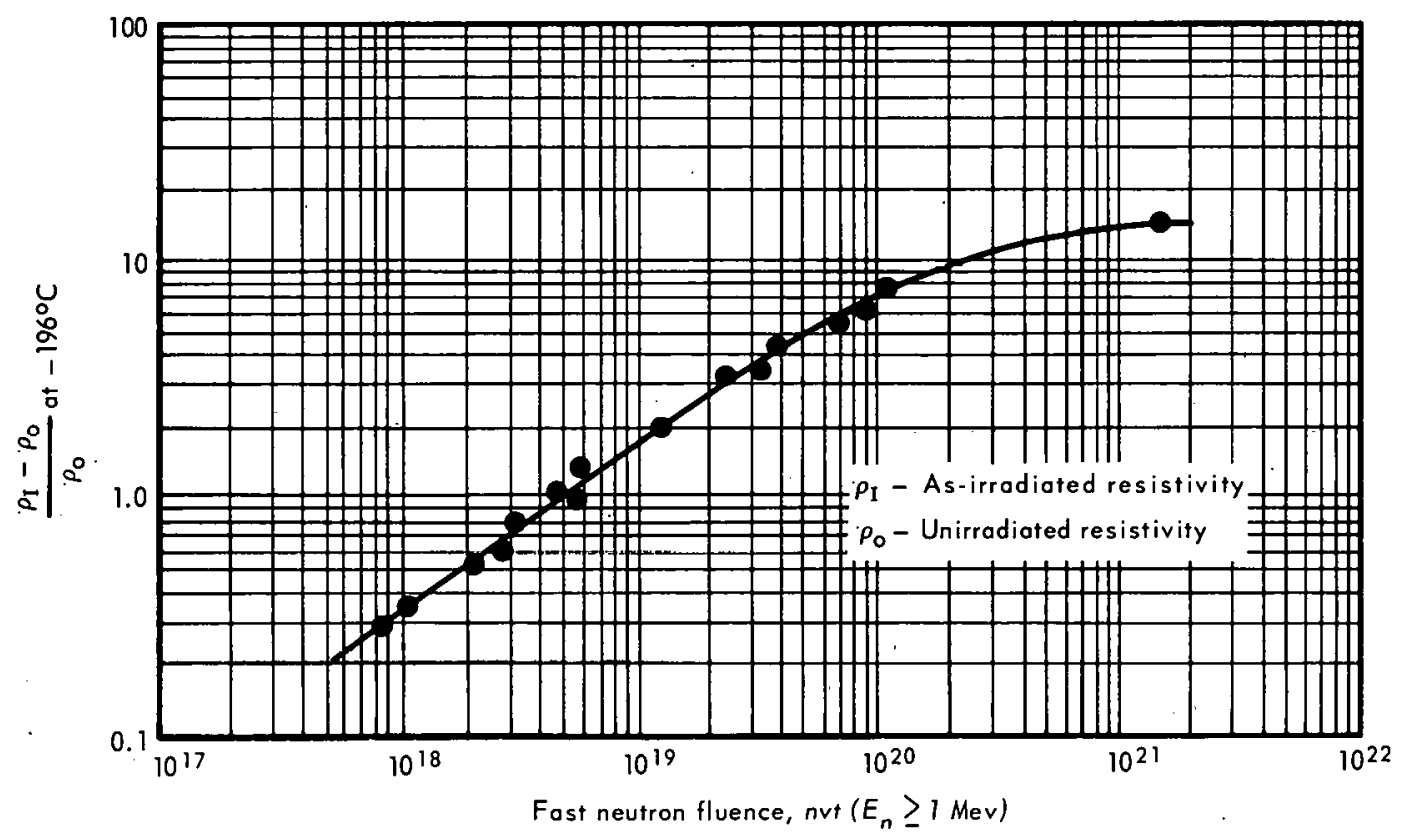

Fig. 2.23-Fractional increase in resistivity of recrystallized tungsten as a function of fost neutron fluence 
It was stated above that many of the tungsten specimens did not show complete recovery of the radiation-induced resistivity. Specimens irradiated at low fluence levels were found to completely recover the induced resistivity; however, as the fluence increased, residual resistivity after high-temperature anneals also increased. The total resistivity recovery found for the various stages $\left(0.15 \mathrm{~T}_{\mathrm{m}}, 0.22 \mathrm{~T}_{\mathrm{m}}\right.$, and $\left.0.31 \mathrm{~T}_{\mathrm{m}}\right)$ as well as the observed residual resistivities are shown as a function of fast neutron fluence in Figure 2.24. Although all the recovery stages show some saturation effects, residual resistivity continues to increase.

As previously noted, thermal neutrons can bring about a transmutation of $w^{187}$ to $W^{188}$ by the thermal neutron $(n, \gamma)$ reaction. ${ }^{19}$ The $W^{188}$ then decays to $\operatorname{Re}^{188}$ by $\beta^{-}$decay. There are other sources of transmutations to rhenium and possibly to osmium.

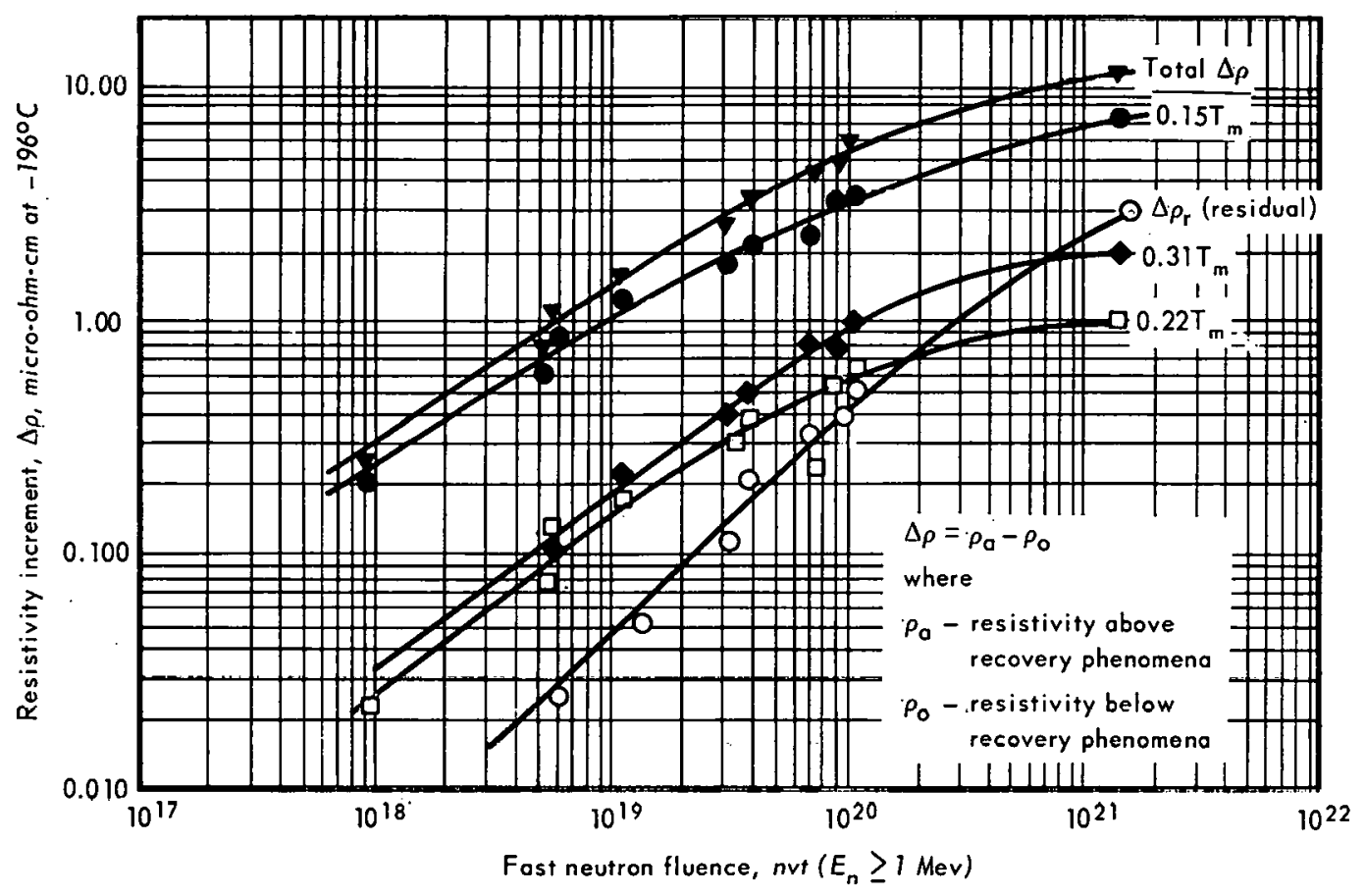

Fig. 2.24-Total radiation-induced resistivity, $\Delta \rho_{r}, 0.15 \mathrm{~T}_{\mathrm{m}}, 0.22 \mathrm{~T}_{\mathrm{m}}, 0.31 \mathrm{~T}_{\mathrm{m}}$ and residual resistivity increments as a function of fast neutron fluence

Quantitative measurements of residual resistivity are presented versus measured thermal neutron fluence in Figure 2, 25. The error in the residual resistivity measurement is shown by the vertical line through the respective point. This thermal neutron fluence dependence demonstrates the effect of transmutation products.

\section{Transmutation Effects}

To resolve the effects of tungsten transmutation reactions, further study was initiated which investigated the resistivity recovery of two tungsten specimens irradiated at about the same fast neutron fluence but different thermal neutron fluences. One specimen was in a cadmium shield to screen out some of the thermal neutrons. The unshielded specimen

${ }^{19}$ GEMP-400A, p. 93. 


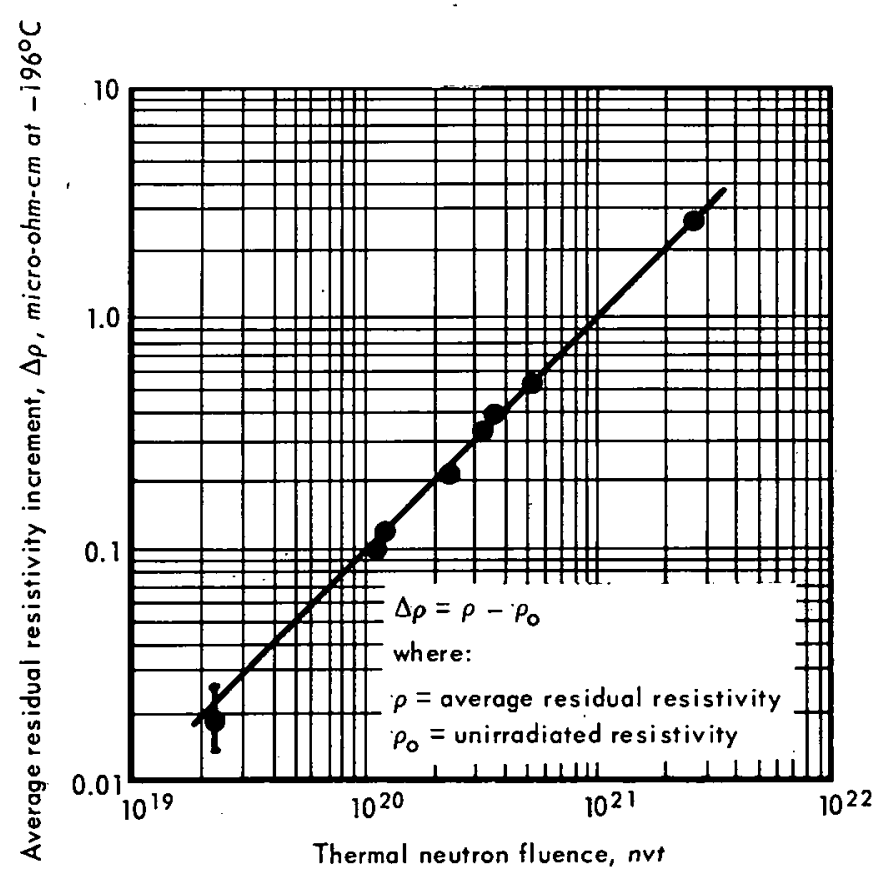

Fig. 2.25 - Average residual resistivity of recrystallized tungsten as a function of thermal neutron fluence

(ORM-34) was irradiated to a fast neutron fluence of $3.8 \times 10^{19}$ neutrons $/ \mathrm{cm}^{2}$ and a thermal neutron fluence of $2.3 \times 10^{20}$ neutrons $/ \mathrm{cm}^{2}$. The shielded specimen (ORM-37) was irradiated to a fast fluence of $3.9 \times 10^{19}$ neutrons $/ \mathrm{cm}^{2}$ and an effective thermal neutron fluence of only $2.5 \times 10^{19}$ neutrons $/ \mathrm{cm}^{2}$ due to the cadmium shield. The observed radiation-induced fractional resistivity $\left(\Delta \rho / \rho_{0}\right)$ of the nonshielded specimen was 4.34135 while that for the shielded specimen was about 20 percent smaller, 3.45910. After completion of the anneals, the residual resistivity fractions differed by only about 6 percent.

Results of this study are shown in Figure 2.26 in which the resistivity recovery is plotted versus annealing temperature for the two specimens; the difference between resistivity recovery of the two is plotted in Figure 2.27. The cadmium-shielded specimen recovers almost all its resistivity, whereas the nonshielded specimen recovers only about 94 percent of its resistivity. The actual contribution of transmutation products (foreign atoms) to the resistivity amounts to only about 6 percent of the resistivity measured. However, the effect of these foreign atoms as defect traps is about twice this value as shown by the initial resistivity difference of about 20 percent. This defect trapping ability is also evident from Table 2.14 which shows that the area under all the peaks considered is greater for the unshielded specimen than for the shielded specimen. Thus, the transmutation-produced foreign atoms apparently alter the recovery of many defects during irradiation. This trapping ability of the rhenium atom is believed to be a major cause of higher saturation fluence in tungsten.

W-25Re

Resistivity studies, similar to those described above for $\mathrm{W}$, were initiated to gain better understanding of the contribution of radiation-induced point defects to the mechanical properties of irradiated $\mathrm{W}-25 \mathrm{Re}$. This study was also undertaken to provide further information on the effects of Re on defect recovery in $\mathrm{W}$ as well as the effects of any subsequent $W$ or Re transmutation reactions resulting from thermal neutron irradiation. The results are presented in Figure 2.28 and Table 2.15. 


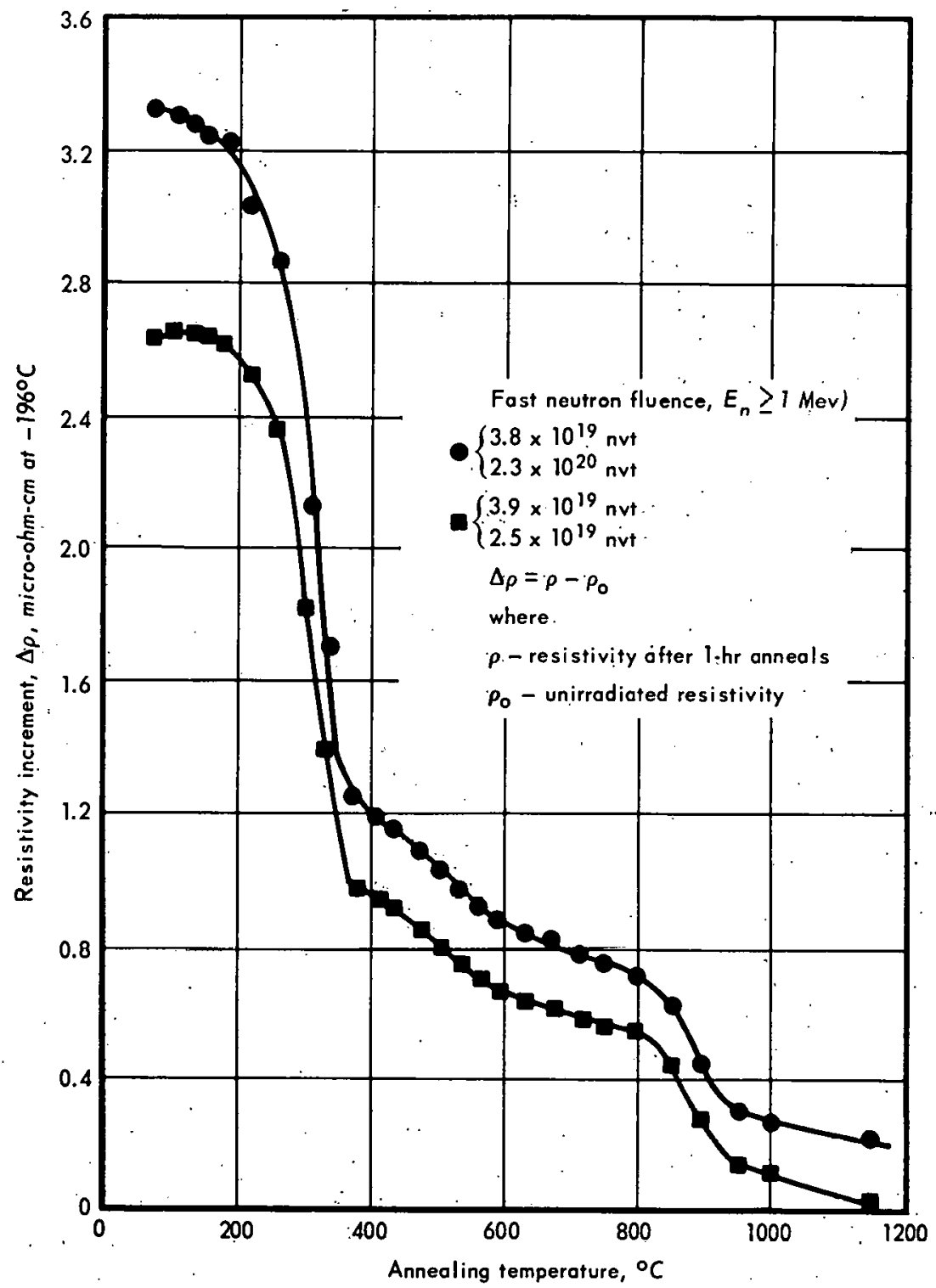

Fig. 2.26 - Isochronal resistivity recovery for neutron-irradiated, cadmiumshielded and unshielded, recrystallized fungsten as a function of annealing temperafure 


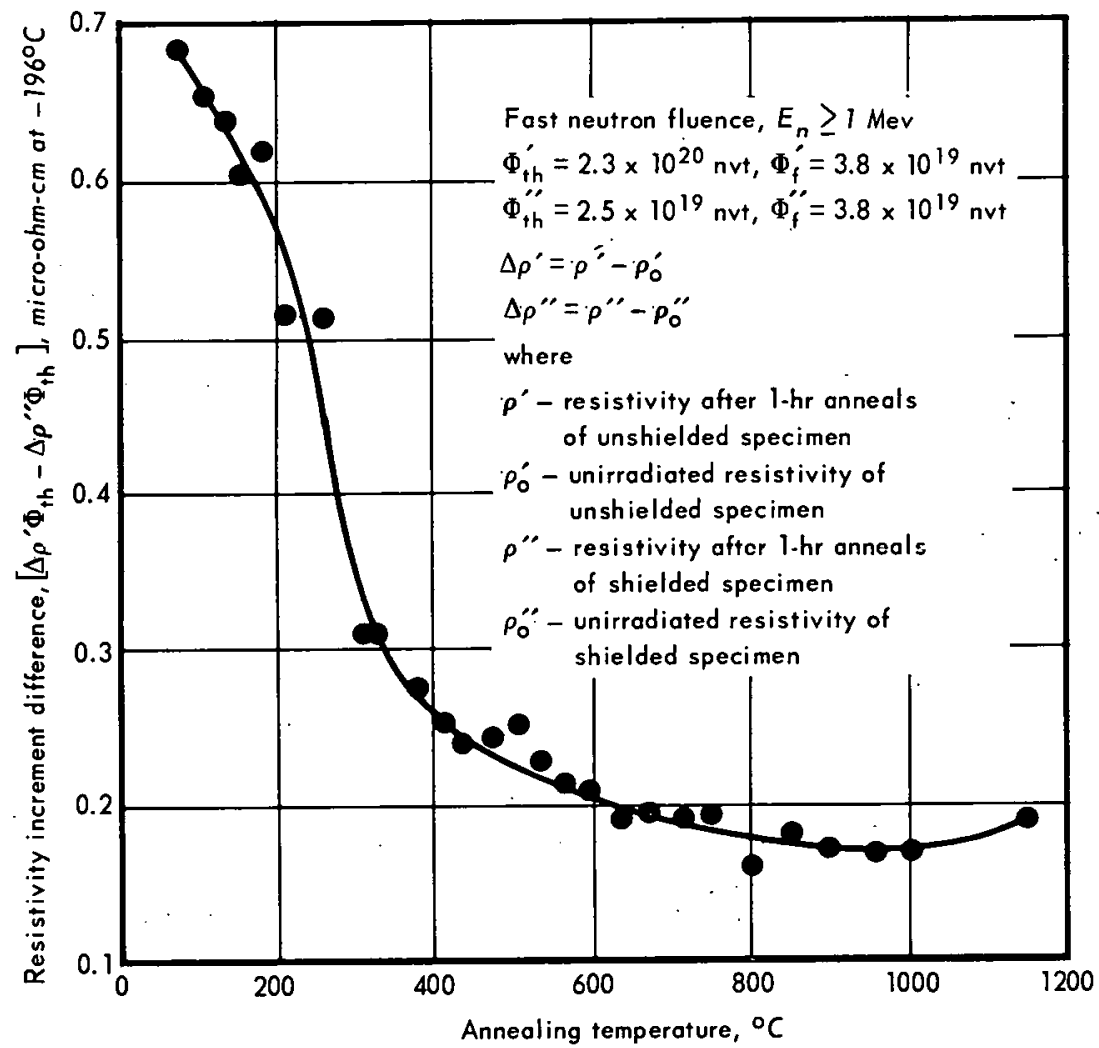

Fig. 2.27-Difference between the isochronal resistivity recovery of neutron-irradiated, unshielded and shielded, recrystallized tungsten as a function of annealing temperature

TABLE 2.14

COMPARISON OF THE AREA AND TEMPERATURE OF RECOVERY PEAKS FOR CADMIUM-SHIELDED AND UNSHIELDED TUNGSTEN SPECIMENS

\begin{tabular}{cccc}
\hline Specimen Condition & Stage & $\begin{array}{c}\text { Temperature of } \\
\text { Recovery Peak, }{ }^{\circ} \mathrm{C}\end{array}$ & Area, micro-ohm-cm \\
\hline Unshielded & $0.15 \mathrm{~T}_{\mathrm{m}}$ & 316 & 2.3319 \\
& $0.22 \mathrm{~T}_{\mathrm{m}}$ & 521 & 0.3929 \\
& $0.31 \mathrm{~T}_{\mathrm{m}}$ & 875 & 0.5360 \\
& $0.35 \mathrm{~T}_{\mathrm{m}}$ & 1021 & - \\
Shielded & $0.15 \mathrm{~T}_{\mathrm{m}}$ & 320 & 1.7223 \\
& $0.22 \mathrm{~T}_{\mathrm{m}}$ & 484 & 0.2910 \\
& $0.31 \mathrm{~T}_{\mathrm{m}}$ & 873 & 0.452 \\
& $0.35 \mathrm{~T}_{\mathrm{m}}$ & 1049 & -
\end{tabular}

a The area under the recovery peak represents the total resistivity recovery for that particular defect recovery stage. 


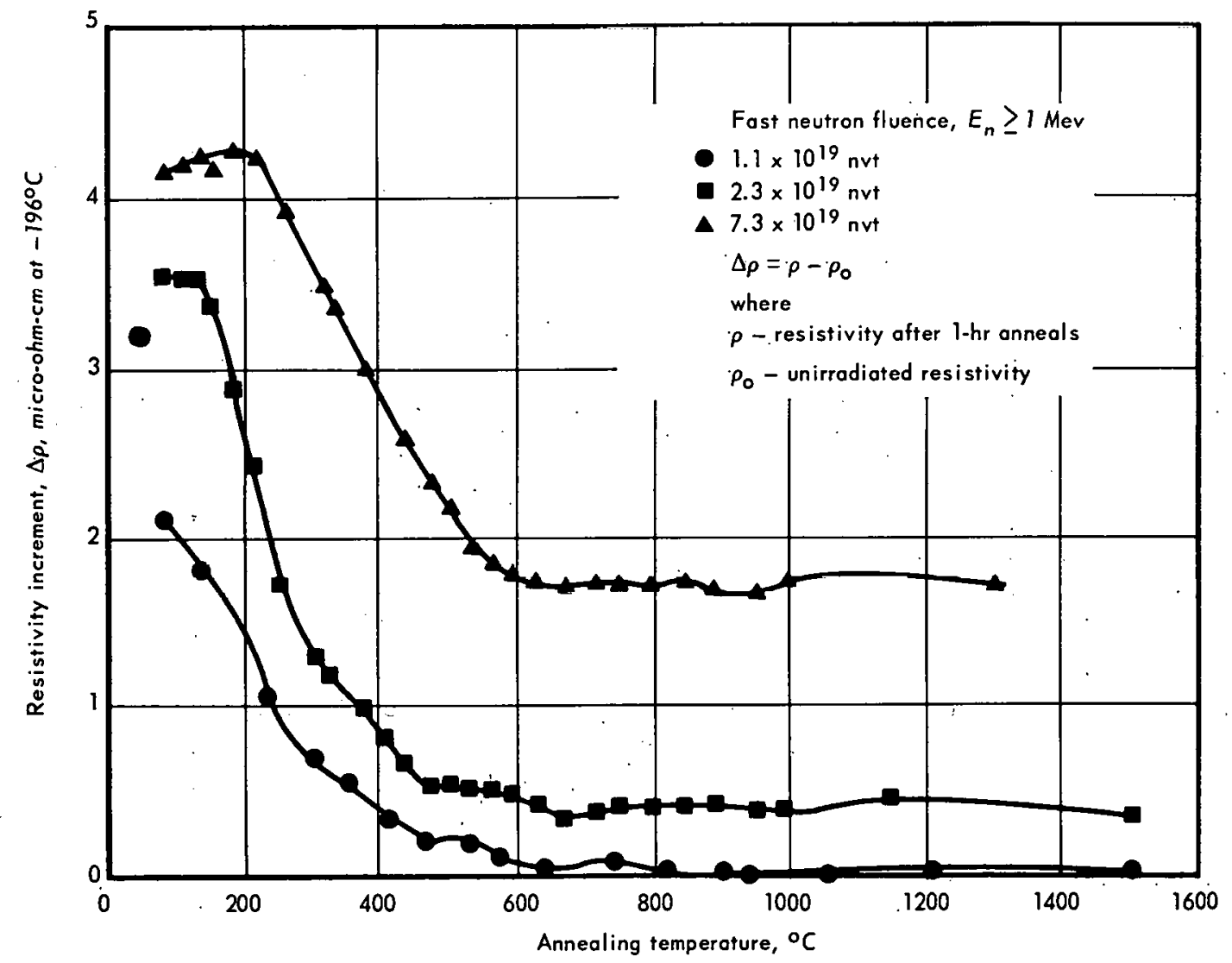

Fig. 2.28 - Isochronal resistivify recovery of neutron-irrodiated, recrystallized $W-25 R e$ as a function of annealing temperature

TABLE 2.15

DEFECT RECOVERY STAGES IN NEUTRON IRRADIATED W - 25Re, Mo, AND MO-TZM, DET ERMINED FROM ISOCHRONAL RESISTIVITY STUDIES

\begin{tabular}{|c|c|c|c|c|c|c|c|c|}
\hline \multirow{3}{*}{$\begin{array}{c}\text { Sample } \\
\text { No. }\end{array}$} & \multirow[b]{3}{*}{ Rod } & \multirow[b]{3}{*}{ Capsule } & \multicolumn{2}{|c|}{ Irradiation Conditions ${ }^{a}$} & \multicolumn{4}{|c|}{ Maximum Rate of Recovery } \\
\hline & & & \multicolumn{2}{|c|}{ Fluence, nut } & \multicolumn{4}{|c|}{ Temperature, ${ }^{\circ} \mathrm{C} b$} \\
\hline & & & Fast $\left(E_{n} \geq 1\right.$ Mev $)$ & Thermal & $0.15 \mathrm{~T}_{\mathrm{m}}$ & $0.22 \mathrm{~T}_{\mathrm{m}}$ & $0.31 \mathrm{~T}_{\mathrm{m}}$ & $0.35 \mathrm{~T}_{\mathrm{m}}$ \\
\hline \multicolumn{9}{|c|}{$W-25 \operatorname{Re}^{c}$} \\
\hline 700 & A & ORM-14 & $1.1 \times 10^{19}$ & $9.3 \times 10^{19}$ & 202 & - & 787 & - \\
\hline 764 & C & ORM-18 & $2.3 \times 10^{19}$ & $1.1 \times 10^{20}$ & 212 & 414 & 788 & 900 \\
\hline 765 & $\mathrm{C}$ & ORM-19 & $7 . \overline{3} \times 10^{19}$ & $3.2 \times 10^{20}$ & - & 450 & 776 & 880 \\
\hline \multicolumn{9}{|c|}{ Molybdenum } \\
\hline 520 & C & ORM-14 & $1.1 \times 10^{19}$ & $9.3 \times 10^{19}$ & 153 & $37 \%$ & 655 & - \\
\hline 527 & C & ORM-18 & $2.3 \times 10^{19}$ & $1.1 \times 10^{20}$ & 162 & 334 & 620 & 732 \\
\hline 909 & C & $\mathrm{MT}-138$ & $9.8 \times 10^{19}$ & $3.7 \times 10^{20}$ & 162 & 294 & 619 & 743 \\
\hline 923 & C & ORM-38 & $1.1 \times 10^{20}$ & $5.2 \times 10^{20}$ & 155 & 280 & 617 & 738 \\
\hline \multicolumn{9}{|c|}{ Mo-TZM } \\
\hline 966 & $S$ & ORM-18 & $2.3 \times 10^{19}$ & $1.1 \times 10^{20}$ & 169 & $398(284)^{d}$ & 615 & 773 \\
\hline 983 & S & MT-138 & $9.8 \times 10^{19}$ & $3.7 \times 10^{20}$ & 160 & $(267)^{\mathrm{d}}$ & 617 & 779 \\
\hline
\end{tabular}

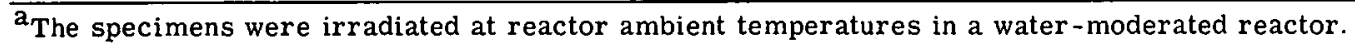

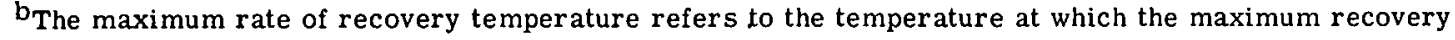
occurs for a specific recovery stage over a temperature region. This stage is related to the melting or solidus temperature, $\mathrm{T}_{\mathrm{m}}$ or $\mathrm{T}_{\mathrm{S}}$, as shown.

${ }^{C}$ Temperature fractions shown are based on solidus temperature $\left(3000^{\circ} \mathrm{C}\right)$.

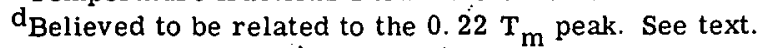


The recovery peaks presented in Table 2.15 refer only to related (by the previously defined melting or solidus) temperature fractions. In this analysis, a solidus temperature $\left(\mathrm{T}_{\mathrm{S}}\right)$ of $3000^{\circ} \mathrm{C}$ was used for the $\mathrm{W}-25 \mathrm{Re}$. The theoretical temperature expected for the $0.15 \mathrm{~T}_{\mathrm{S}}, 0.22 \mathrm{~T}_{\mathrm{S}}, 0.31 \mathrm{~T}_{\mathrm{S}}$, and $0.35 \mathrm{~T}_{\mathrm{S}}$ recoveries are $218^{\circ}, 447^{\circ}, 742^{\circ}$, and $873^{\circ} \mathrm{C}$, respectively. Both the residual resistivity and the increase of the low-temperature recovery peaks seem to indicate that the specimen irradiated at the higher fluence is exhibiting a considerable transmutation effect. This effect could presumably arise from additional $\mathrm{Re}$ formation; however, because of its definite difference from the other specimens and the already high Re concentration, it appears to support increased Os formation and its resulting defect trapping effects. Calculations have been made which yield the relative concentration of $\mathrm{W}, \mathrm{Re}$, and $\mathrm{Os}$ as a function of thermal neutron fluence in $\mathrm{W}-25 \mathrm{Re} .^{20}$ The Os concentration increases from about 0.001 atom fraction to almost 0.01 atom fraction over the range of thermal neutron fluence of this study. This 0.01 atom fraction of Os would be expected to represent a sufficient concentration to give a detectable contribution to the resistivity. Since $W-25 R e$ alloy could have an ordered $W_{3} R e$ arrangement of atoms, this large increase in the apparent residual resistivity could be due to radiation-induced atom disorder. It is possible that the slightly higher temperature of $212{ }^{\circ} \mathrm{C}$ for the $0.15 \mathrm{~T}_{\mathrm{m}}$ peak observed in specimen 764 , compared with the $202^{\circ} \mathrm{C}$ temperature observed in specimen 700 , represents an early indication of the growing importance in the effect of increased Os formation.

\section{MOLYBDENUM}

The recovery by annealing of defects produced by neutron irradiation of polycrystalline molybdenum specimens has been observed in a study of isochronal recovery of the radiation-induced resistivity increment. The various samples used and the pertinent irradiation conditions are shown in Table 2.15. The recovery of the radiation-induced resistivity increment for two of these specimens is presented in Figure 2.29. The recovery peaks are given in Figure 2.30.

The temperature of the $0.15 \mathrm{~T}_{\mathrm{m}}$ recovery peak is relatively constant over this neutron fluence region and agrees well with the resistivity studies by Peacock and Johnson, ${ }^{21}$ which were performed at much lower neutron fluences with a peak temperature of about $160^{\circ} \mathrm{C}$. This peak is also in good agreement with earlier studies by Kinchin and Thompson ${ }^{22}$ of irradiation damage and recovery in molybdenum by resistivity and stored energy measurements. A temperature of about $150^{\circ} \mathrm{C}$ was obtained for this recovery stage.

The $0.31 \mathrm{~T}_{\mathrm{m}}$ and $0.35 \mathrm{~T}_{\mathrm{m}}$ recovery peaks also remain relatively constant and are quite close to the expected values of $624^{\circ} \mathrm{C}$ and $740^{\circ} \mathrm{C}$, respectively. However, the $0.22 \mathrm{~T}_{\mathrm{m}}$ $\left(364^{\circ} \mathrm{C}\right)$ recovery peak appears to shift to lower temperatures, possibly as a result of saturation effects. Several other recovery peaks are also evident in Figure 2.30. One peak occurs in the range of $250^{\circ}$ to about $290^{\circ} \mathrm{C}$ and agrees with a peak reported by Peacock and Johnson ${ }^{21}$ at around $280^{\circ} \mathrm{C}$. There is also an additional peak at about $430^{\circ}$ to $460^{\circ} \mathrm{C}$ which has not been previously observed. These two peaks are believed at the present to arise as substages of the previously described recovery stages.

Kissinger, et al. ${ }^{23}$ indicated that interstitial point defects saturate in molybdenum at a fast neutron fluence of approximately $10^{19}$ neutrons $/ \mathrm{cm}^{2}$ and above this, they either

\footnotetext{
${ }^{20} \mathrm{GEMP}-400 \mathrm{~A}$, Figure 2.31, p. 95.

${ }^{21}$ D. R. Peacock and A. A. Johnson, "Stage III Recovery in Neutron Irradiated Molybdenum and Niobium," Philosophical Magazine, Vol. 8, 1963, pp. 563-577.

${ }^{22}$ G. H. Kinchin and M. W. Thompson, "Irradiation Damage and Recovery in Molybdenum and Tungsten," Journal of Nuclear Energy, Vol. 8, 1958, pp. 275-284.

${ }^{23} \mathrm{H}$ F. Kissinger, J. T. Rrimhall, and B, Masstell, "Physical Characterization of Molybdenum Single Crystals for Irradiation Experiments," International Conference on Characterization of Materials, Pennsylvania State University, November 16-18, 1966.
} 


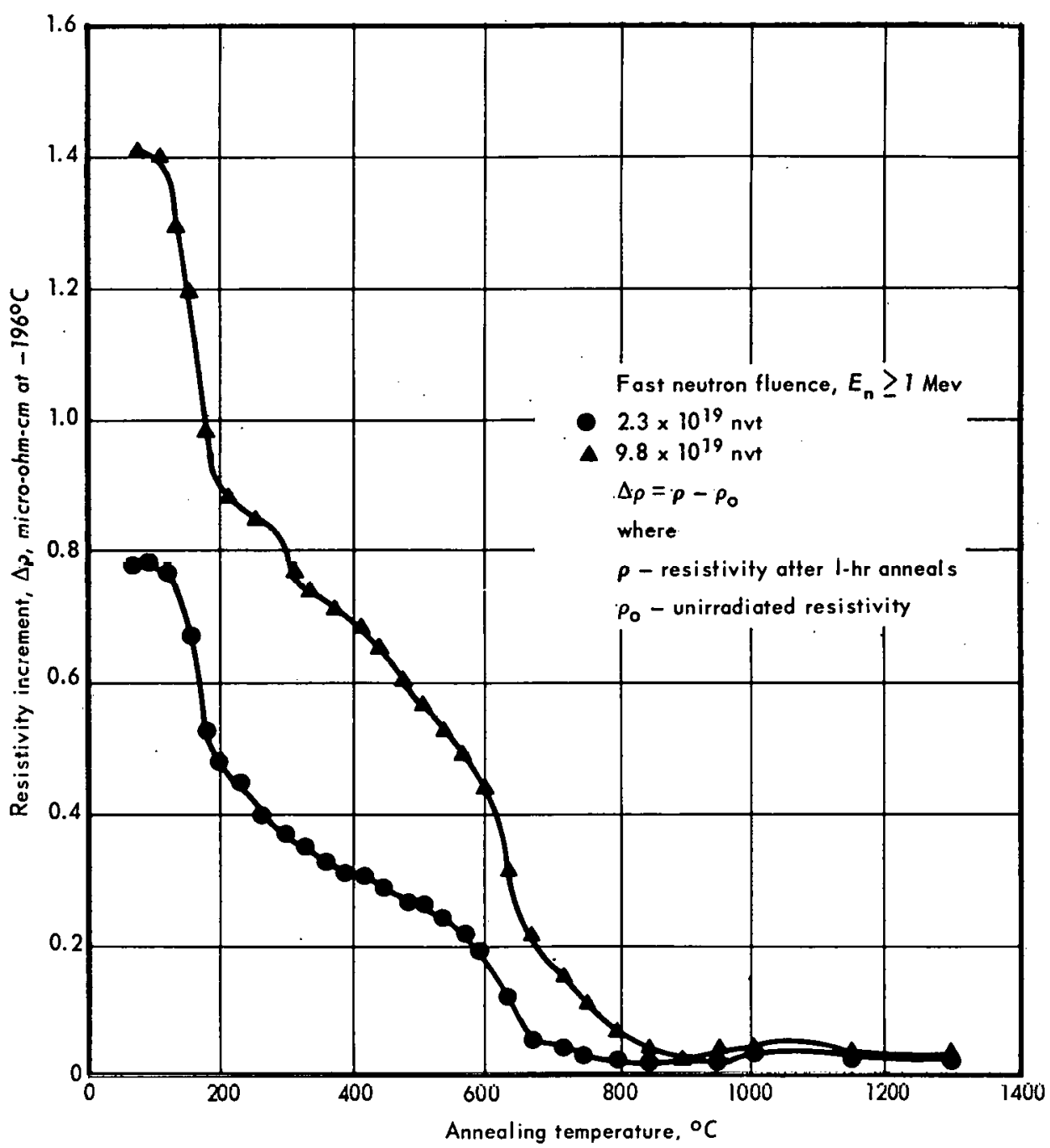

Fig. 2.29 ... Isochronal resistivity recovery for neutron-irradiated, recrystallized molybdenum os a function of annealing temperature

form clusters or are annihilated at vacancies. The vacancies, however, seem to remain isolated and do not give evidence of saturation until a neutron fluence of about $10^{20}$ neutrons $/ \mathrm{cm}^{2}$ is reached. These limited studies by resistivity of the effects of irradiation on molybdenum appear at first to be conflicting. If the interstitials, considered to migrate at about $160^{\circ} \mathrm{C}$ at high fluences, did saturate, this peak might then be expected to shift to a lower temperature as a first approximation. However, the temperature for this peak does not change. The lattice parameter measurements ${ }^{23}$ indicate that the interstitial recovery goes through a maximum at about a fast fluence of $10^{19}$ neutrons $/ \mathrm{cm}^{2}$ and then decreases to a value below the pre-irracution value. This is interpreted to support the migration of interstitials to form large clusters. The combination of these two facts seems to indicate that the interstitials, at least in the range of neutron fluence of $10^{18}$ to $10^{20}$ neutrons $/ \mathrm{cm}^{2}$ do not saturate but either migrate to vacancies or, more importantly, migrate to form interstitial clusters over this total range of fluence. Increasing the fluence from 1018 to 1019 neutrons $/ \mathrm{cm}^{2}$ increases the number of interstitials capable of migrating at about $160^{\circ} \mathrm{C}$ to form clusters, but does not appear to make it easier for clusters to form. Therefore, an interstitial saturation condition apparently does not arise in this fluence region. 


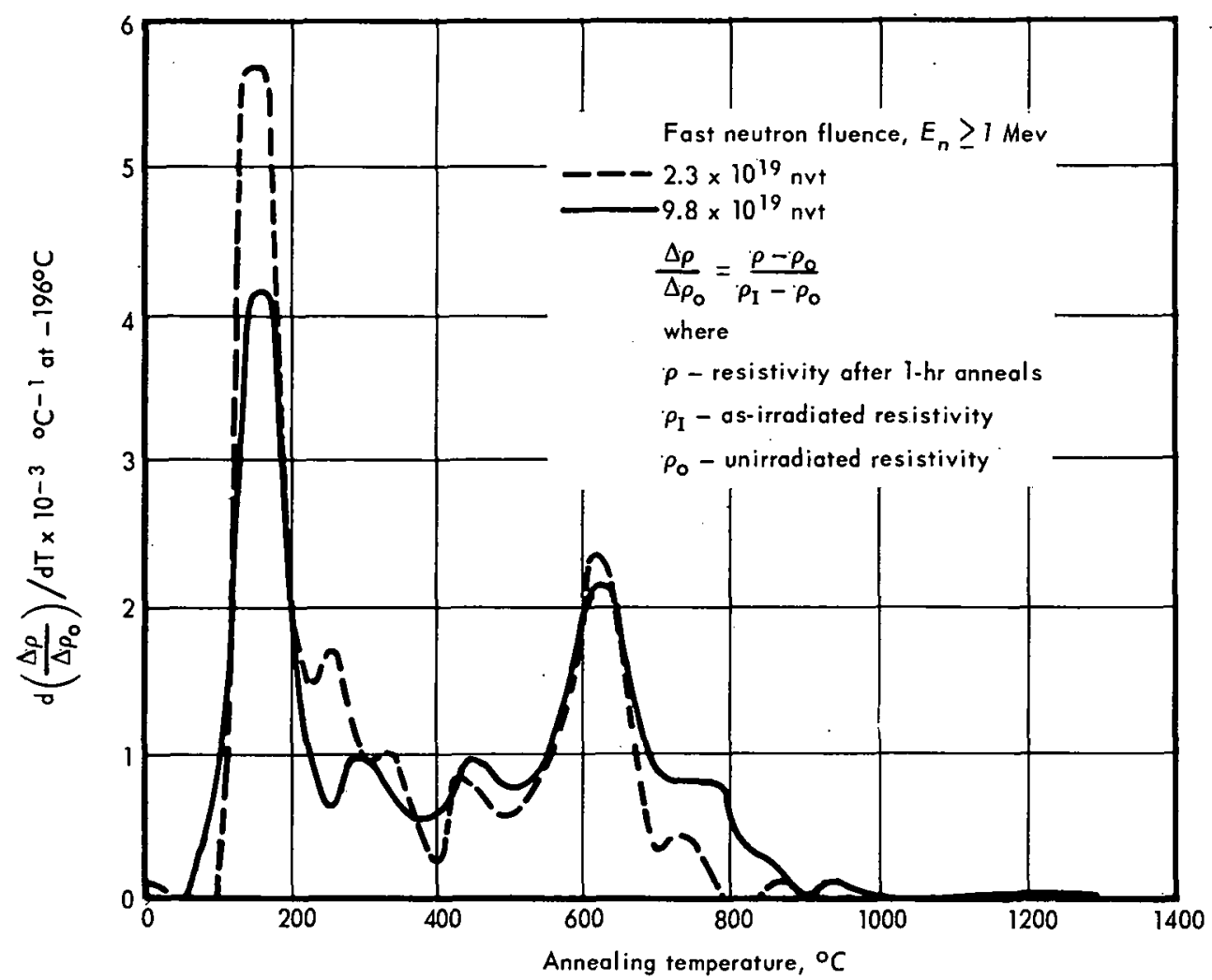

Fig. 2.30 - Derivative of the normalized isochronal resistivity recovery of neutron-irradiated, recrystallized molybdenum os a function of annealing temperature

As shown in Figure 2.29, some small residual resistivity is evident in molybdenum at high fast fluence levels. Although this is not well understood at the present, two possible explanations are: (1) some type of a transmutation reaction is occurring, but in a very minor manner as compared to tungsten; and (2) some higher temperature defect is occurring which is observable only at high concentrations (or high fast fluence levels).

The occurrence of saturation of radiation-induced defects has been described, with regard to specific defects, in numerous instances. However, measurements of the saturation by resistance studies of the total damage produced have been very limited. This fact is shown by the linearity of the plots of the logarithm of the total resistivity change (or its normalized counterpart) versus the logarithm of the fast or epithermal radiation fluence obtained in most experiments. This observation of saturation of the defects has been previously shown for tungsten but is more clearly demonstrated by molybdenum in Figure 2.31. In molybdenum, this saturation is seen to occur at a fast neutron fluence of about $10^{20}$ neutrons $/ \mathrm{cm}^{2}$. The resistivity change then decreases with inereasing fluence. The tungsten specimens appear to reach saturation at about $10^{21}$ neutrons $/ \mathrm{cm}^{2}$, but studies of higher fluences will be necessary to bear out this observation. The slope obtained for the linear portion of this plot is 0.58 which is in very good agreement with a slope of 0.54 (at lower fast neutron fluences) found by Peacock and Johnson. ${ }^{24}$

\footnotetext{
${ }^{24}$ Peacock and Johnson, loc. cit.
} 


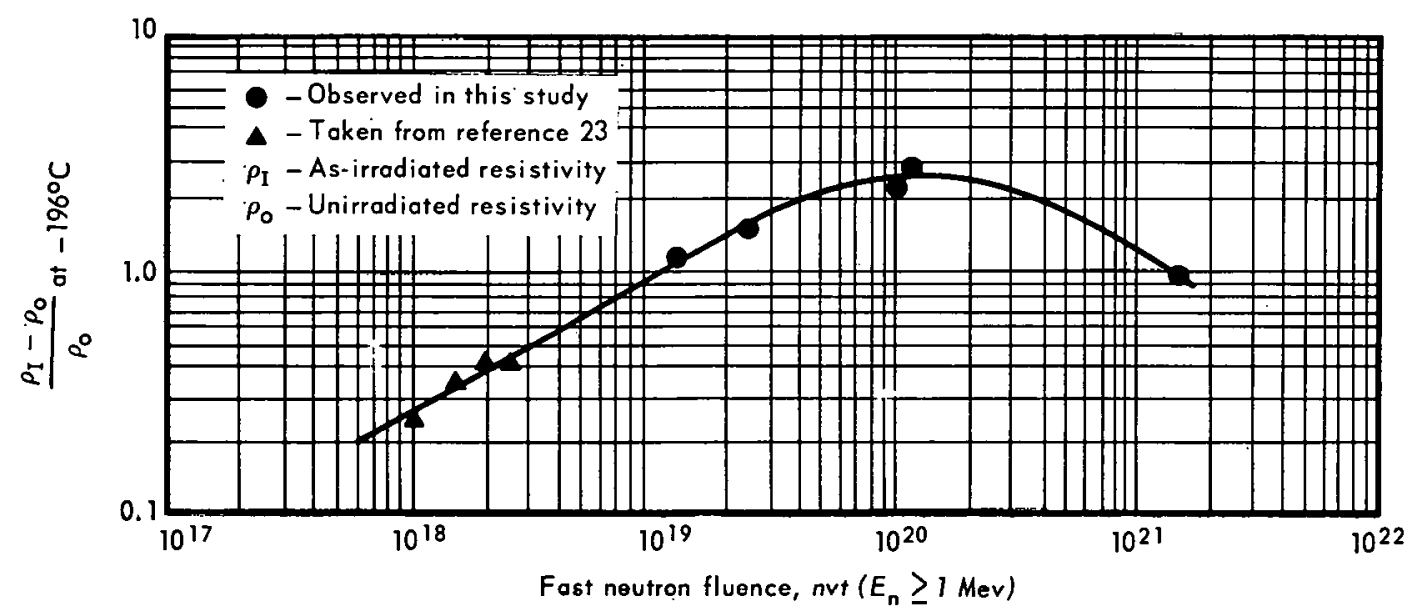

Fig. 2.31-Fractional increase in resistivity of recrystallized molybdenum as a function of fast neutron fluence

Mo-TZM. (Mo - 0.5Ti $-0.08 \mathrm{Zr})$

To further understand the effect of solute atoms on the isochronal recovery of defects in molybdenum and to generate defect recovery spectra of a class of structural alloys, two specimens of Mo-TZM were investigated after fast neutron irradiation to respective fluences of $2.3 \times 10^{19}$ and $9.8 \times 10^{19}$ neutrons $/ \mathrm{cm}^{2}$. The results are summarized in Table 2.15. The isochronal resistivity recovery increment is plotted ver sus the annealing tem perature in Figure 2.32, and the derivation of the normalized resistivity recovery increment is given in Figure 2.33. There appears to be a spreading and merging of the recovery peaks at the higher fluence. The recovery temperatures are comparable to appropriate fractional recovery temperatures found for molybdenum. The Mo-TZM specimen irradiated at $2.3 \times 10^{19}$ neutrons $/ \mathrm{cm}^{2}$ shows two additional peaks at $529^{\circ} \mathrm{C}$ and $920^{\circ} \mathrm{C}$ which are not yet understood. With the exception of the $160^{\circ} \mathrm{C}$ peak, all the recovery peaks are smaller for molybdenum than for Mo-TZM. Evidently, the solute atoms (titanium and zirconium) are more capable of trapping the defects recovering at higher temperatures than those at $160^{\circ} \mathrm{C}$; in fact, it appears that fewer defects recover in the Mo-TZM at $160^{\circ} \mathrm{C}$. The increased recovery at higher temperature for the Mo-TZM could be due to the freeing of the additional low-temperature $\left(160^{\circ} \mathrm{C}\right)$ point defects from foreign atom traps at higher temperatures.

\subsection{STRUCTURE STUDIES (R. C. Rau and R. L. Ladd)}

Structural studies using transmission electron microscopy are being conducted on neutron-irradiated tungsten, tensile and creep-rupture specimens to supplement the physical and mechanical property data obtained. The objective of these studies is to aid in the inter pretation of the observed irradiation effects and to elucidate the basic mechanism of radiation damage in refractory metals.

\section{ELECTROTHINNING}

A single-step technique was developed for rapid preparation of electron transparent disc foils from cylindrical test specimens. ${ }^{25}$ This method is based on immersion electropolish-

\footnotetext{
${ }^{25}$ R. L. Ladd and R. C. Rau, "A Single-Step Technique for Electrothinning Metal Disks for Transmission F.lectron Microscopy," GE-NMPO, GEMP-464, December 19, 1966. Submitted to Journal of Scientific Instruments.
} 


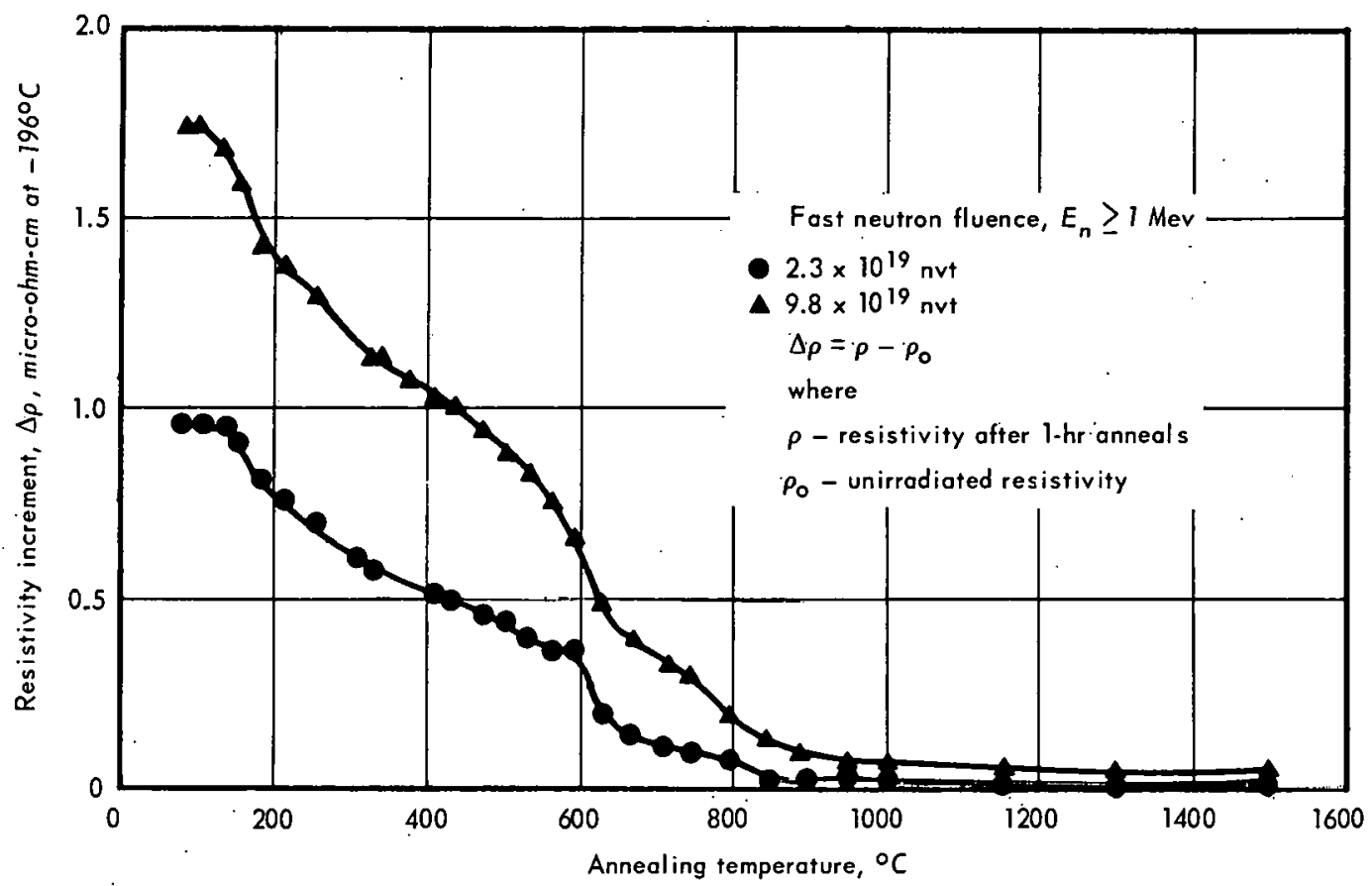

Fig. 2.32 - Isochronal resistivity recovery of neutron-irradiated, recrystallized Mo-TZM as a function of annealing temperature

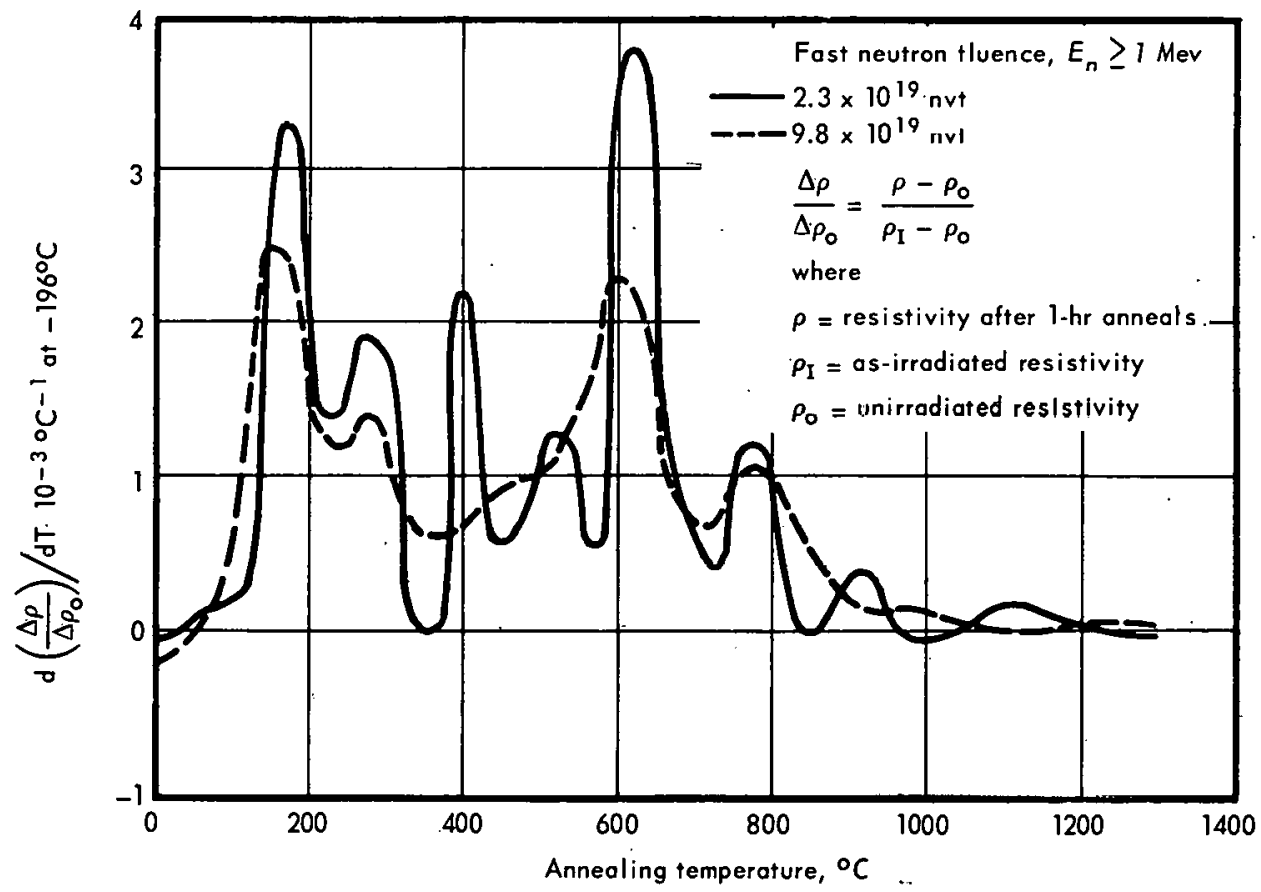

Fig. 2.33 - Derivative of the normalized isochronal resistivity recovery of neutronirradiated Mo-TZM as a function of annealing temperature 
ing and combines the advantages of a polytetra-fluoroethylene (PTFE) specimen holder ${ }^{26,27}$ with the double jet technique. ${ }^{28,} 29$

Initial preparation consists of slicing $0.5-\mathrm{mm}$-thick wafers from the test bars using a precision diamond cutoff wheel. One of these discs is then placed in the PTFE holder, shown in Figure 2.34, for electrothinning. To accommodate various disc diameters, interchangeable sets of PTFE inserts were made with counter-bored holes ranging from 1.9 to $5.0 \mathrm{~mm}$ in diameter. Positioning the disc in the properly sized insert masks its edges to prevent selective attack, and provides the means of making anodic contact through the platinum wire probe. The assembled holder is then lowered into position in the Pyrex polishing cell, also shown in Figure 2.34.

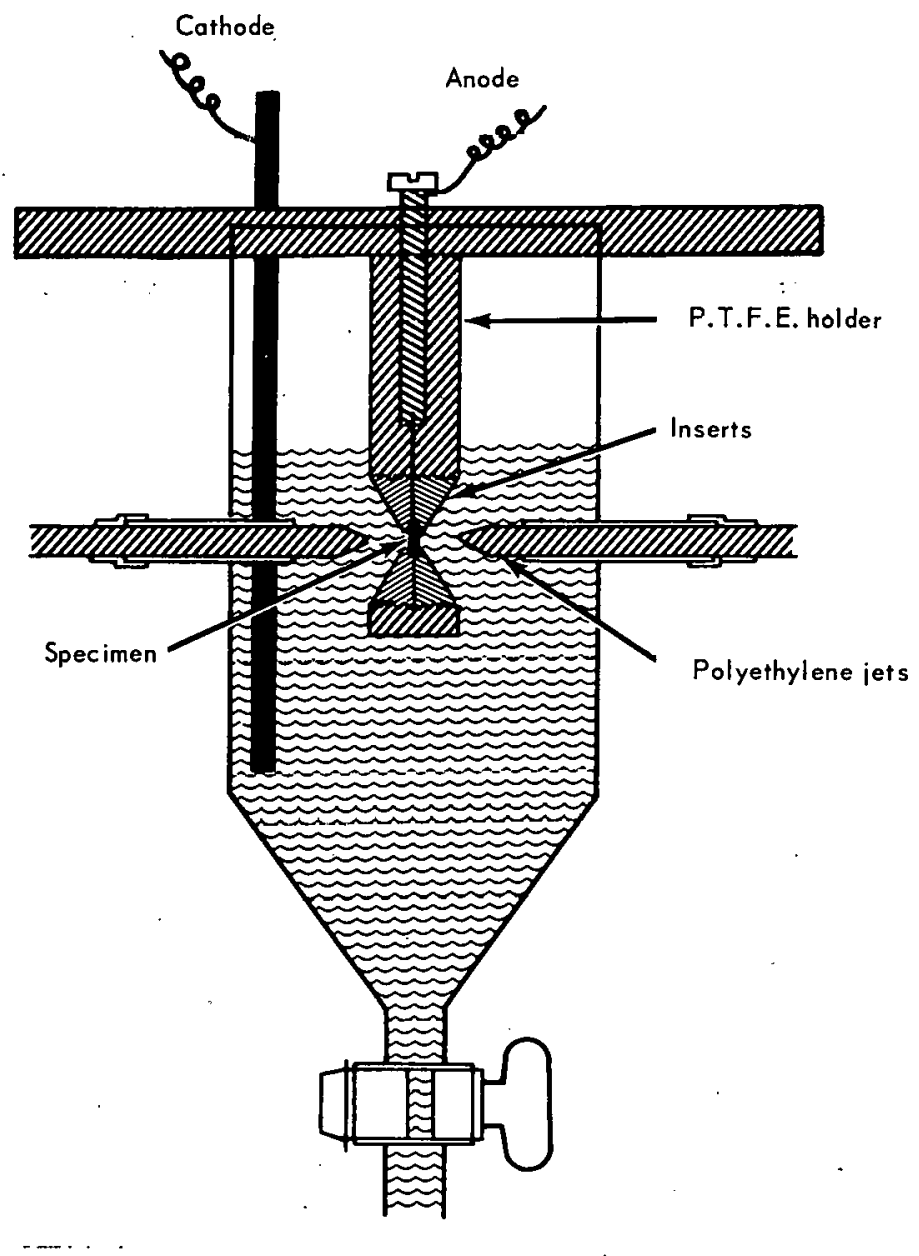

Fiio. 2.34 - Pyrox polishing eell and Polylelru=fluorethylene (P.T.F.E.) holder

${ }^{26}$ M. A. P. Dewey and T. G. Lewis, "A Holder for the Rapid Electrolytic Preparation of Thin Metal Foils for Transmission Electron Microscopy," Journal of Scientific Instruments, Vol. 40, August 1963, pp. 385-386.

${ }^{27}$ G. W. Briers, D. W. Dawe, M. A. P. Dewey, and I. S. Brammer, "A Technique for the Rapid Preparation of Thin Foils for Electron Microscopy from Bulk Materials," Journal of the Institute of Metals, Vol. 93, No. 3, 1964-65, pp. 77-80.

${ }^{28}$ R. C. Glenn and R. D. Schoone, "Electropolishing Unit for Rapid Thinning of Metallic Specimens for Transmission Electron Microscopy," Review of Scientific Instruments, Vol. 35, September 1964, pp. 1223-1224.

${ }^{29} \mathrm{~J}$. S. Hugo and V. A. Phillips, "A Twin-Jet Technique for Thinning Metals for Transmission Electron Microscopy," Journal of Scientifir. Instruments, Vol.42, May 1965, pp. 354-355. 
The cell consist of two opposing polyethylene jet nozzles mounted in glass guide tubes fused in the sides of the cell and a drain tube with stopcock. The assembly drains into a Buehler variable-speed pump unit which supplies electrolyte to the jet nozzles and continuously circulates fluid through the system. During operation, the stopcock is adjusted to maintain the electrolyte level in the cell to a depth of about $25 \mathrm{~mm}$ above the sample and jets. To avoid bending of the thin foil, a flow rate through the jets is chosen which is just sufficient to break up and carry away gas bubbles evolved by the electropolishing process.

Thinning of tungsten is carried out using an electrolyte of 1.5 percent $\mathrm{NaOH}$ in water with a regulated d-c voltage of 15 to 20 volts applied between the stainless steel cathode and sample. The specimen is strongly back-lighted and viewed continuously during thinning. As soon as penetration occurs (usually within 5 to 10 minutes) polishing is discontinued, and the sample and holder removed from the electrolyte. The perforated disc is rinsed in distilled water and then in ethanol prior to examination in the electron microscope. The method routinely produces foils with extensive electron transparent regions surrounding the periphery of the hole.

\section{TRANSMISSION ELECTRON MICROSCOPY RESULTS}

Three groups of irradiated polycrystalline tungsten specimens were studied by transmission electron microscopy. These include: Group I specimens which were irradiated to $1.6 \times 1019$ neutrons $/ \mathrm{cm}^{2}\left(\mathrm{E}_{\mathrm{n}} \geq 1 \mathrm{Mev}\right)$ and annealed at various temperatures prior to creeprupture testing at $900^{\circ} \mathrm{C}$; Group II specimens irradiated to various neutron fluences and tensile tested at $400^{\circ} \mathrm{C}$; and Group III specimens which were irradiated to various neutron fluences and creep-rupture tested at $1100^{\circ} \mathrm{C}$. All irradiations were carried out at reactor ambient temperature $\left(\sim 70^{\circ} \mathrm{C}\right)$.

Examinations were made in a JEM-6A electron microscope operating at $100 \mathrm{kv}$ and equipped with a tilting and rotating stage. To minimize contamination rate and thereby increase the useful lifetime of a thin foil in the intense electron beam, a liquid-nitrogen cooling device was used in the specimen chamber. For all specimens, thin foils were studied from both the unstressed button head and from the reduced section near the fracture.

\section{Group I Specimens}

Although both irradiation and subsequent annealing treatments produced changes in the mechanical properties of Group I specimens, no significant changes were evident by electron microscopy. These specimens are listed in Table 2.16. The microstructures of the as-irradiated as well as the various irradiated and annealed specimens remained similar to the unirradiated microstructures. ${ }^{30}$ However, this series of samples provided vivid evidence of the effect of stress on the microstructure.

Examination of the button heads of these and other specimens showed that the microstructure initially consisted of large tungsten grains divided into many small subgrains by elaborate geometric dislocation networks. As shown in Figure 2. 35a, several subgrain boundary dislocation networks were inclined at various angles to the foil surface and terminated on a grain boundary running diagonally across the photograph. Strain during testing causes a degradation of the dislocation networks into randomly tangled arrays as shown in Figure 2.35b. This photomicrograph shows dislocation tangles typical of the reduced sections of tested specimens.

Group II Specimens

The second group of specimens was irradiated to fast neutron fluences ranging from $4.0 \times 10^{18}$ to $1.2 \times 10^{20}$ neutrons $/ \mathrm{cm}^{2}$ and tensile tested at $400^{\circ} \mathrm{C}(0.18 \mathrm{~T} \mathrm{~m})$. During testing, the specimens were held at this temperature for about 1 hour.

30 ، “High-Temperature Materials Program Progress Report No. 61,"' GE-NMPO, GEMP-61, September 30, 1966, pp. 46-50. 


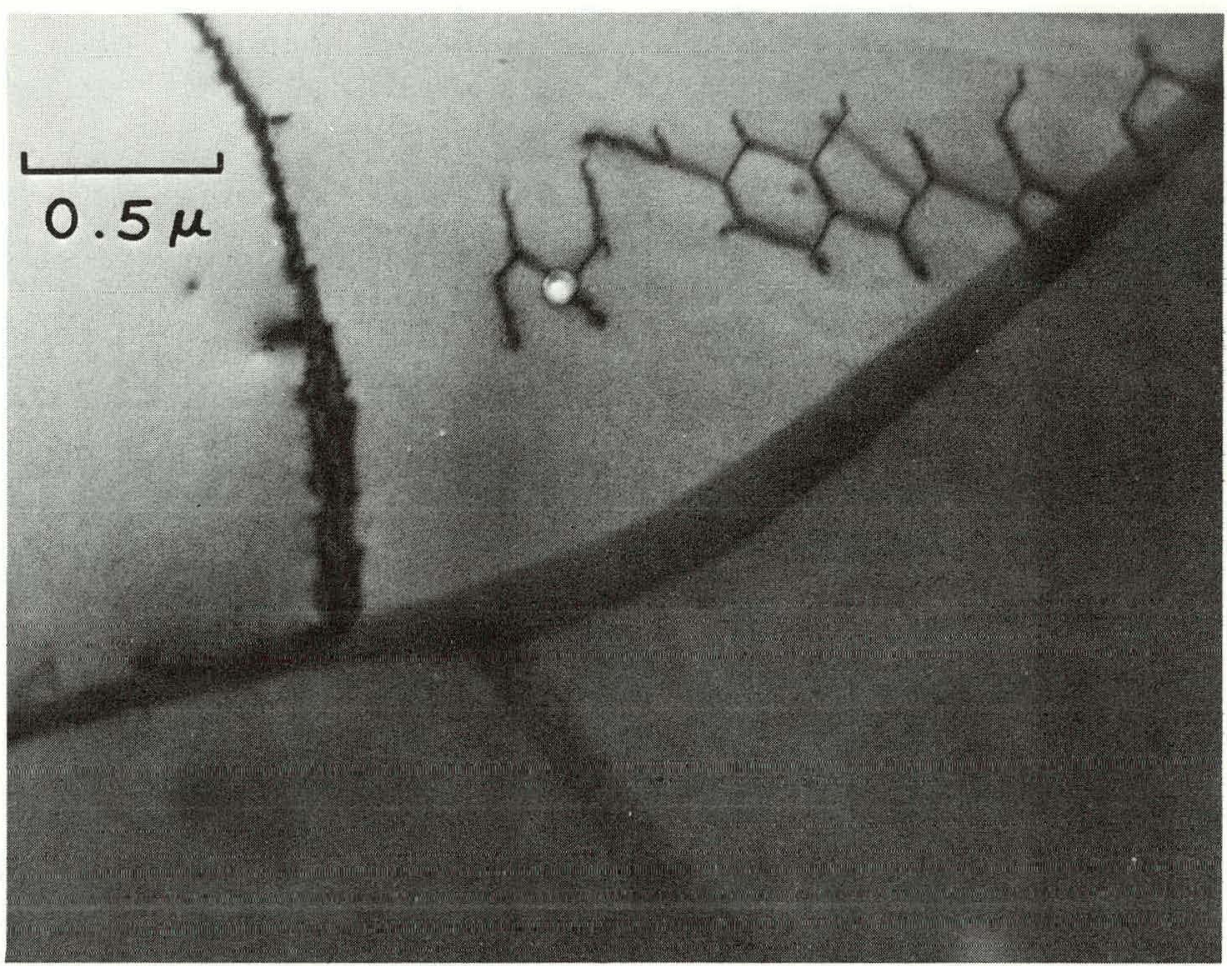

a. unstressed button head area (Neg. J.1233)

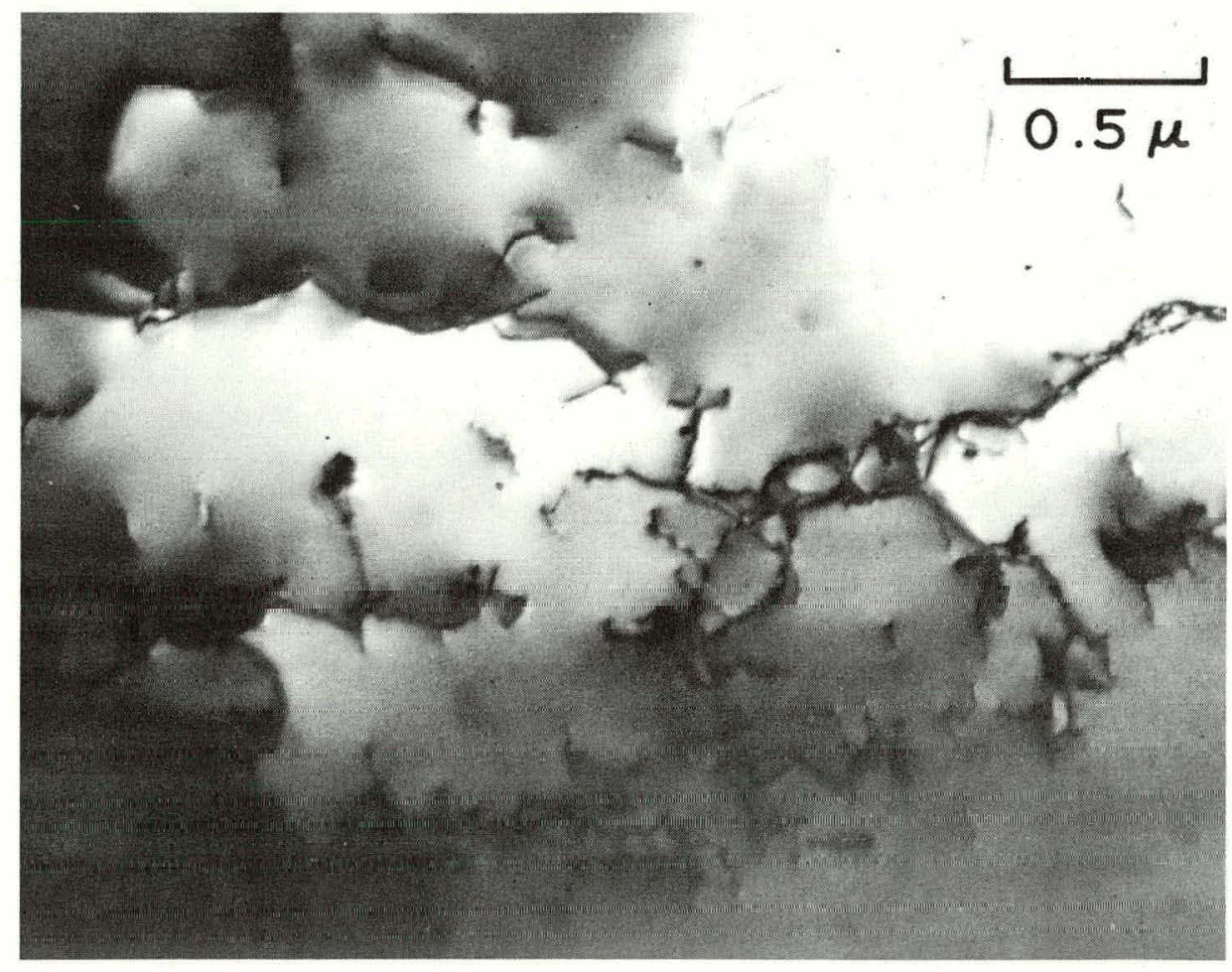

b. strained area near fracture (Neg. J-1238)

Fig. 2.35 - Transmission electron micrographs of unirradiated tungsten. 
TABLE 2.16

POST-IRRADIATION ANNEALED TUNGSTEN SPECIMENS FOR ELECTRON MICROSCOPY STUDIES

\begin{tabular}{|c|c|c|c|c|c|c|}
\hline Specimen $^{\mathrm{a}}$ & Capsule $^{\mathrm{b}}$ & $\begin{array}{c}\text { Annealing } \mathrm{c} \\
\text { Temperature, } \\
{ }^{\circ} \mathrm{C}\end{array}$ & $\begin{array}{c}\text { Creep Rate, } \\
\mathrm{sec}^{-1}\end{array}$ & $\begin{array}{c}\text { Rupture } \\
\text { Life, } \\
\text { hr }\end{array}$ & $\begin{array}{c}\text { Elongation } \\
\text { in } 2.54 \mathrm{~cm} \text {, } \\
\%\end{array}$ & $\begin{array}{c}\text { Reduction } \\
\text { in area, } \\
\%\end{array}$ \\
\hline 1265 & Control & - & $2.32 \times 10^{-6}$ & 12.45 & 36.2 & 96.6 \\
\hline 1268 & ORM-17 & as-irradiated & $5.46 \times 10^{-7}$ & 47.48 & 26.8 & 96.5 \\
\hline 1263 & ORM-17 & 1050 & $5.08 \times 10^{-7}$ & 77.04 & 32.5 & 96.8 \\
\hline 1271 & ORM-17 & 1200 & $1.96 \times 10^{-7}$ & 124.60 & 30.0 & 96.6 \\
\hline 1266 & ORM-17 & 1400 & $1.01 \times 10^{-6}$ & 32.20 & 35.3 & 93.7 \\
\hline 1267 & ORM-17 & 1700 & $1.26 \times 10^{-6}$ & 24.12 & 33.9 & 94.8 \\
\hline
\end{tabular}

a Creep-rupture tested at $900^{\circ} \mathrm{C}$ and $22.64 \mathrm{~kg} / \mathrm{mm}^{2}$.

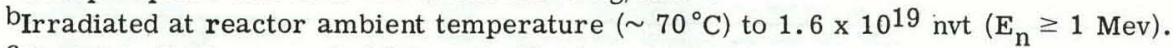

${ }^{c}$ Post-irradiation annealed 1 hour in $\mathrm{H}_{2}$ atmosphere.

This series of specimens, listed in Table 2.17, presented dramatic evidence of the buildup of defect clusters with increasing neutron fluence. The buildup is illustrated in Figures 2.36 and 2.37, which respectively show button heads and reduced sections. Figures $2.36 \mathrm{a}$ and $2.37 \mathrm{a}$ show typical unirradiated microstructures consisting of dislocation networks (Figure 2.36a) and tangles (Figure 2.37a) superimposed on a structureless matrix.

Specimens from the two lowest fluence levels, 4.0 and $5.9 \times 10^{18}$ neutrons $/ \mathrm{cm}^{2}$, showed microstructures basically similar to the unirradiated specimens; however, a population of very fine black dots was present in the matrix of the button heads. Figures $2.36 \mathrm{~b}$ and $2.37 \mathrm{~b}$ show typical low fluence specimens. The tiny black dots present in the button heads were estimated to be approximately 25 to $50 \AA$ in average size and were present in concentrations of about $1.4 \times 10^{16} / \mathrm{cm}^{3}$.

TABLE 2.17

TUNGSTEN TENSILE SPECIMENS TESTED AT $400^{\circ} \mathrm{C}$

\begin{tabular}{ccccccc}
\hline & & \multicolumn{2}{c}{ Fluence, ${ }^{\mathrm{a}} \mathrm{nvt}$} & \multicolumn{2}{c}{ Strength, $\mathrm{kg} / \mathrm{mm}^{2}$} & \\
\cline { 3 - 4 } Specimen & Capsule & Thermal & $\left(\mathrm{E}_{\mathrm{n}} \geq 1 \mathrm{Mev}\right)$ & Yield & Ultimate & $\begin{array}{c}\text { Elongation, } \\
\%\end{array}$ \\
\hline 1332 & Control & - & - & 21.9 & 39.8 & 45.6 \\
1325 & ORM-31 & $3.9 \times 10^{19}$ & $4.0 \times 10^{18}$ & 32.4 & 42.4 & 39.6 \\
1329 & ORM-33 & $4.1 \times 10^{19}$ & $5.9 \times 10^{18}$ & 35.9 & 39.8 & 37.2 \\
1331 & ORM-34 & $2.3 \times 10^{20}$ & $3.8 \times 10^{19}$ & 58.5 & 58.5 & 4.4 \\
1343 & ORM-37 & $2.5 \times 10^{19}$ & $3.9 \times 10^{19}$ & 54.8 & 54.8 & 0.3 \\
1340 & ORM-36 & $4.9 \times 10^{20}$ & $7.9 \times 10^{19}$ & 72.0 & 72.0 & Nil \\
1334 & ORM-35 & $7.0 \times 10^{20}$ & $1.4 \times 10^{20}$ & 82.7 & 82.7 & Nil \\
\hline
\end{tabular}

arradiated at reactor ambient temperature $\left(\sim 70^{\circ} \mathrm{C}\right)$.

b Specimen shielded with $0.63-\mathrm{mm}$-thick cadmium.

The four specimens from this group irradiated to fluence levels of $3.8 \times 10^{19}$ neutrons $/ \mathrm{cm}^{2}$ or greater showed appreciable buildup of defect clusters throughout the matrix. As shown in Figures $2.36 \mathrm{c}$ and $2.37 \mathrm{c}$, both button heads and reduced sections contained large numbers of enlarged dot clusters, probably about $100 \AA$ in diameter, and also occasionally contained resolvable loops of 200 to $300 \AA$ in diameter. This coarsening of the clusters was more noticeable the higher the neutron fluence. Cluster densities for all four specimens were estimated to be approximately 2 to $3 \times 1016 / \mathrm{cm}^{3}$, but these values are probably inaccurate 


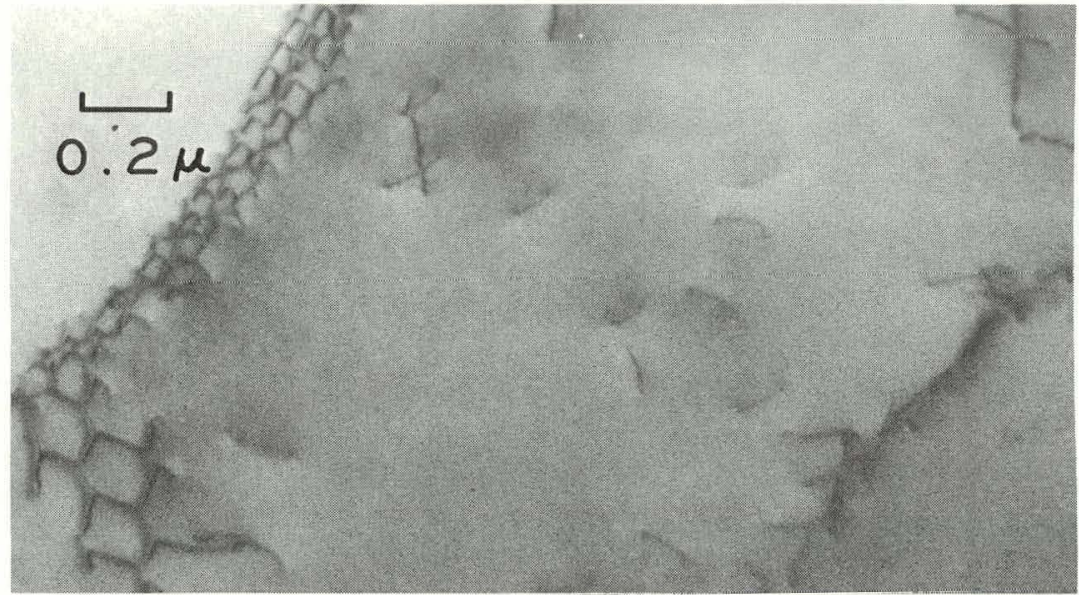

a. Unirradiated (Neg. J-1552)

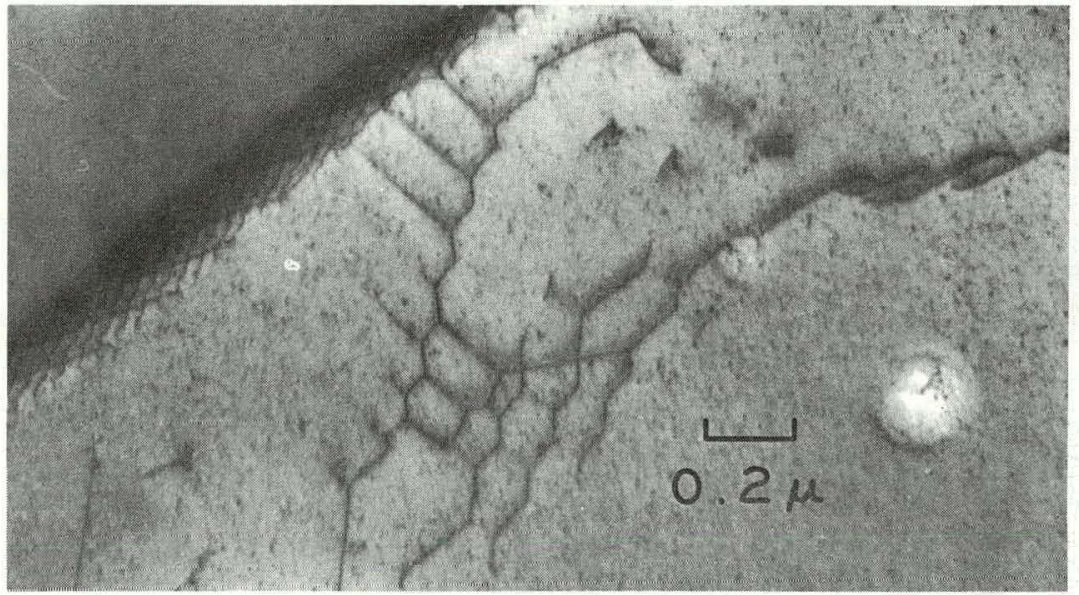

b. Irradiated to $5.9 \times 10^{18} \mathrm{nvt}$ $\left(E_{n} \geq 1 \mathrm{Mev}\right)$ (Neg. J-1527)

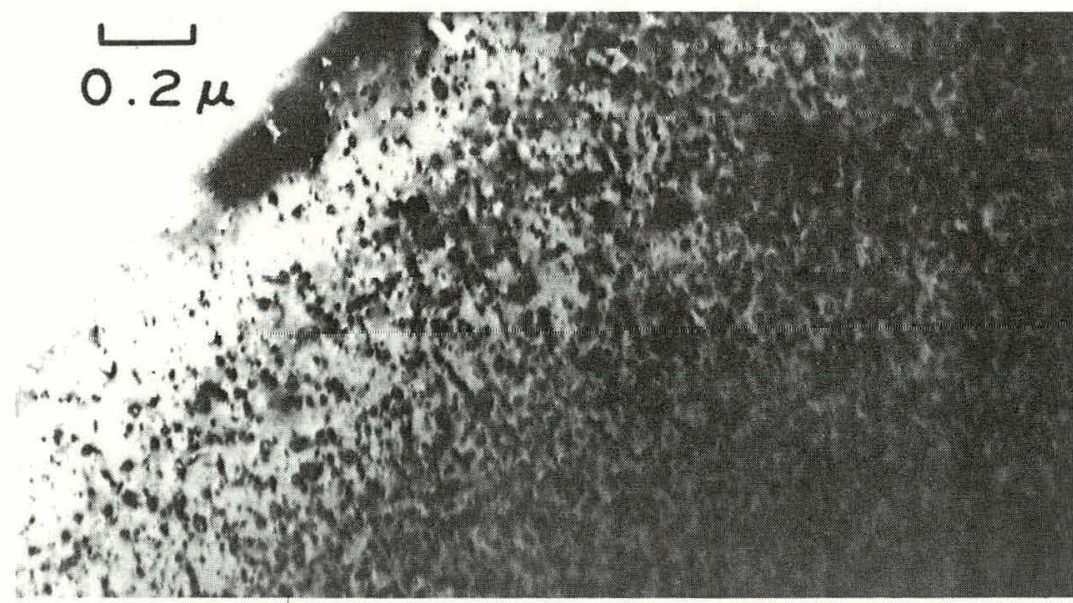

c. Irradiated to $1.2 \times 10^{20} \mathrm{nvt}$ $\left(E_{n} \geq 1 \mathrm{Mev}\right)$ (Neg. J-7449)

Fig. 2,36-Transmission electron micrographs of button heads of tungsten specimens tensile tested at $400^{\circ} \mathrm{C}$ 


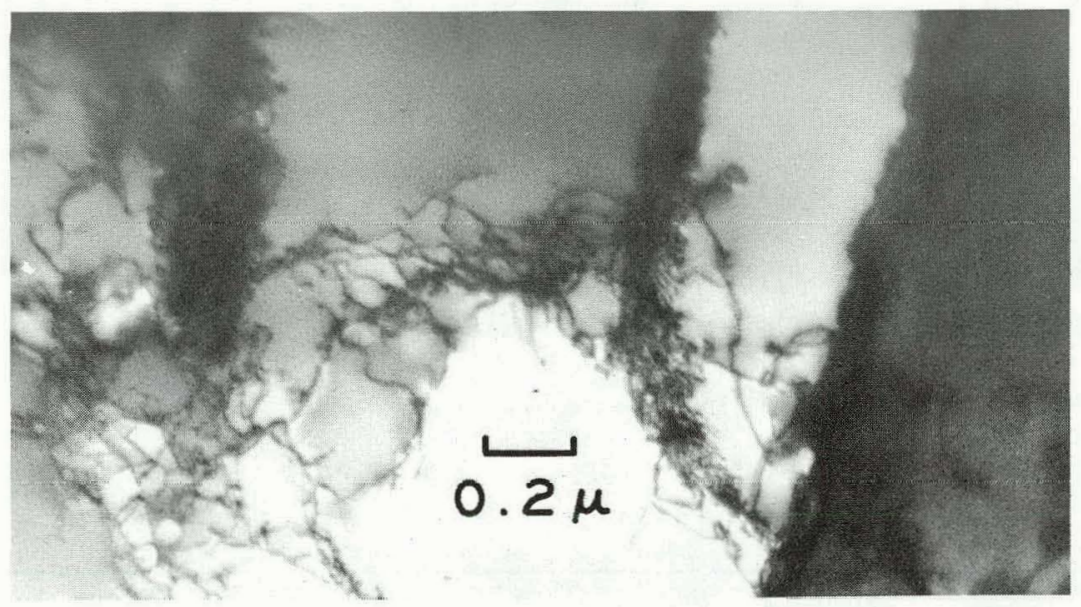

a. Unirradiated (Neg. J-1588)

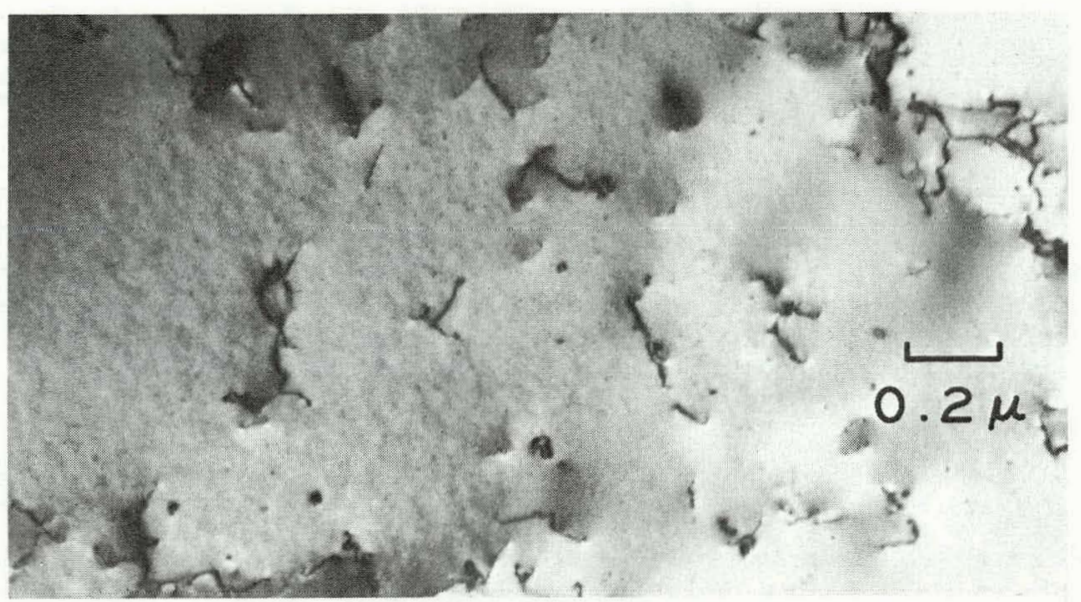

b. Irradiated to $5.9 \times 10^{18} \mathrm{nvt}$

$\left(E_{n} \geq 1 \mathrm{Mev}\right)$ (Neg.J-7605)

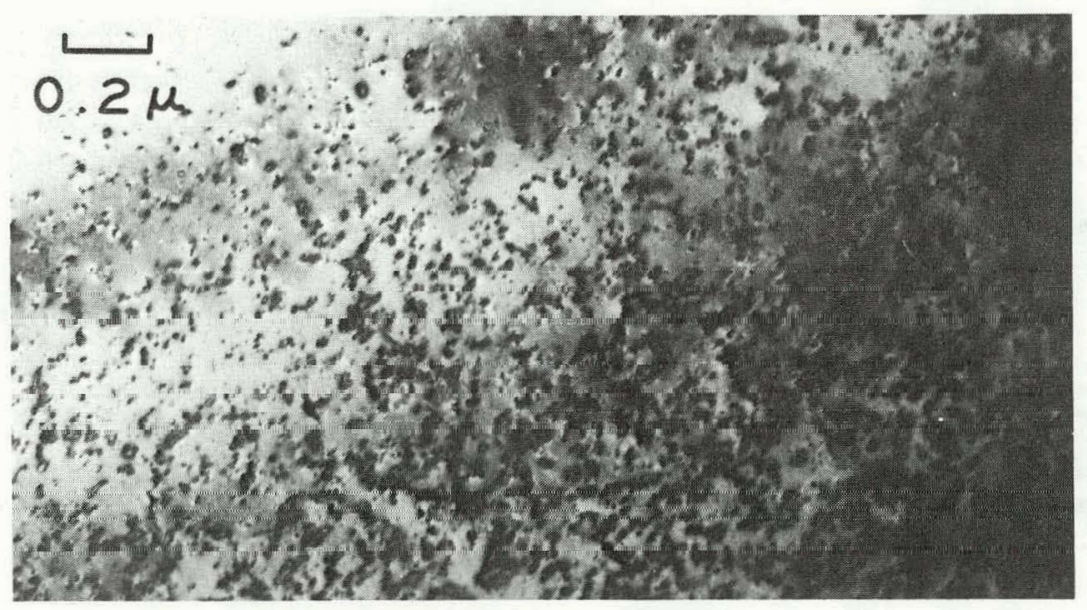

c. Irradiated to $1.2 \times 10^{20} \mathrm{nvt}$

$\left(E_{n} \geq 1 \mathrm{Mev}\right)$ (Neg. J.1659)

Fig. 2.37-Transmission electron micrographs of reduced areas near fracture of tungsten specimens tensile tested at $400^{\circ} \mathrm{C}$ 
and represent apparent saturation values arising from counting errors introduced by image overlap. ${ }^{31}$ The observation of broadening of diffraction spots and Kikuchi lines in the electron diffraction patterns as fluence level increased indicates that cluster. densities probably also continued to increase.

As indicated in Table 2.17, this group of samples contained a pair which received nearly identical fast neutron fluences ( 3.8 and $3.9 \times 10^{19}$ neutrons $/ \mathrm{cm}^{2}$ ), but which received thermal fluences differing by an order of magnitude. Although the decreased thermal fluence in the cadmium-shielded specimen resulted in greater embrittlement, no microstructural changes could be seen in the electron microscope. The photomicrographs in Figure 2.38 illustrate the similarity of the two specimens.

In addition to the foregoing effects, the subgrain boundary dislocation networks were much less evident in the higher fluence specimens. However, this effect is ascribed to overlap by the large number of cluster images rather than to an actual depletion of the networks, since tilting showed approximately the same subgrain distribution as in unirradiated or low fluence samples. No evidence of denudation of clusters near subgrain or grain boundaries was seen.

An initially surprising result of this study was the lack of observation of cleared pathways or channels through the defect clusters in specimens from the reduced areas near the fracture. Such channeling has been observed in molybdenum ${ }^{32,33}$ and occurs when glide dislocations move through the lattice and sweep up obstacles. However, the present lack can be explained by assuming that the high fluence specimens were apparently hardened by their high cluster content, and therefore failed by brittle fracture with little or no dislocation movement. This conclusion is substantiated by the two photomicrographs in Figure 2.38. Both of these show segments of dislocation networks which are unusually well preserved in comparison with the usual tangled arrays present after stressing.

Comparison of clustering in the present study with earlier work ${ }^{34}$ indicates that heating irradiated tungsten to $400^{\circ} \mathrm{C}\left(0.18 \mathrm{~T}_{\mathrm{m}}\right)$ produces observable effects in the microstructure. In particular, the presence of dot clusters in the lower dose specimens and loops in the higher dose specimens can be ascribed to this heating. Although the naturc of the clusters and loops was not determined, comparison with work on neutron-irradiated molybdenum ${ }^{35,36,37}$ suggests that they are probably interstitial. Future work will be directed toward an identification in tungsten.

\section{Group III Specimens}

The specimens in Group III were irradiated to fast ( $E \geq 1 \mathrm{Mev}$ ) neutron fluences ranging from $8.5 \times 10^{17}$ to $1.5 \times 10^{21}$ neutrons $/ \mathrm{cm}^{2}$ and then creep-rupture tested at $1100^{\circ} \mathrm{C}$

${ }^{31} \mathrm{~J}$. H. Chute and J. G. Napier, "Image Overlap in Transmission Electron Microscopy," Philosophical Magazine, Vol. 10, July 1964, pp. 173-176.

${ }^{32}$ B. Mastel, H. E. Kissinger, J. J. Laidler, and T. K. Bierlein, "Dislocation Channeling in Neutron-Irradiated Molybdenum," Journal of Applied Physics, Vol. 34, No. 12, December 1963, pp. 3637-3638.

${ }^{33} \mathrm{~J}$. L. Brimhall and B. Mastel, "The Effect of Prestrain and Subsequent Neutron Irradiation on Molybdenum," Acta Metallurgica, Vol. 14, No. 4, 1966, pp. 539-541.

${ }^{34}$ K. Lacefield, J. Moteff, and J. P. Smith, "Neutron Radiation Damage in Tungsten Single Crystals," Philosophical Magazine, Vol. 13, No. 125, May 1966, pp. 1079-1081.

${ }^{35}$ M. E. Downey and B. L. Eyre, "Neutron Irradiation Damage in Molybdenum," Philosophical Magazine, Vol. 11, No. 109, January 1965, pp. 53-70.

${ }^{36} \mathrm{~J}$. D. Meakin and I. G. Greenfield, "Interstitial Loops in Neutron Irradiated Molybdenum," Philosophical Magazine, Vol. 11, No. 110, February 1965, pp. 277-290.

${ }^{37}$ B. Mastel and J. L. Brimhall, "The Combined Effect of Carbon and Neutron Radiation on Molybdenum," Acta Metallurgica, Vol. 13, No. 1965, pp. 1109-1116. 


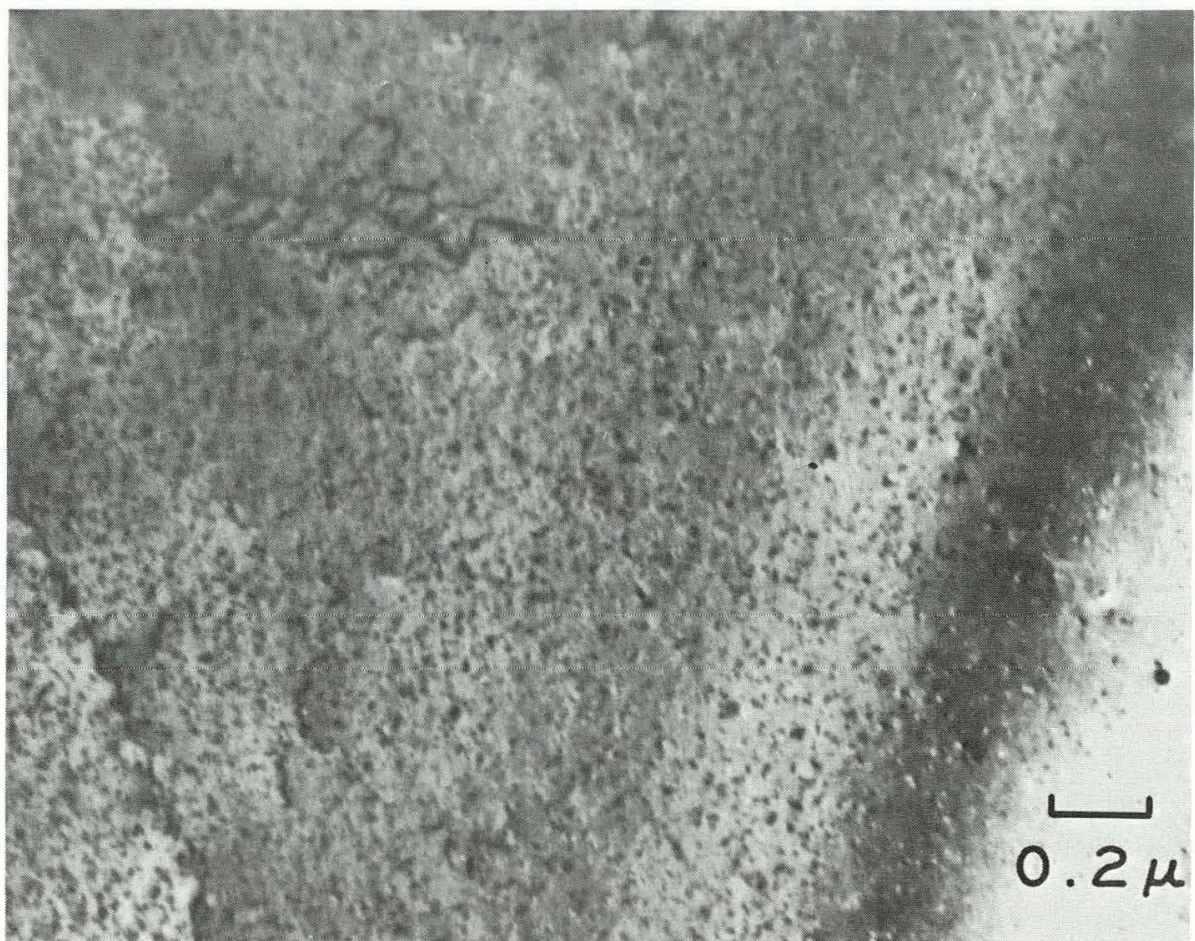

a. Unshielded; fast fluence $3.8 \times 10^{19} \mathrm{nvt;}$ thermal fluence $2.5 \times 10^{19} \mathrm{nvt}$ (Neg. J-1617)

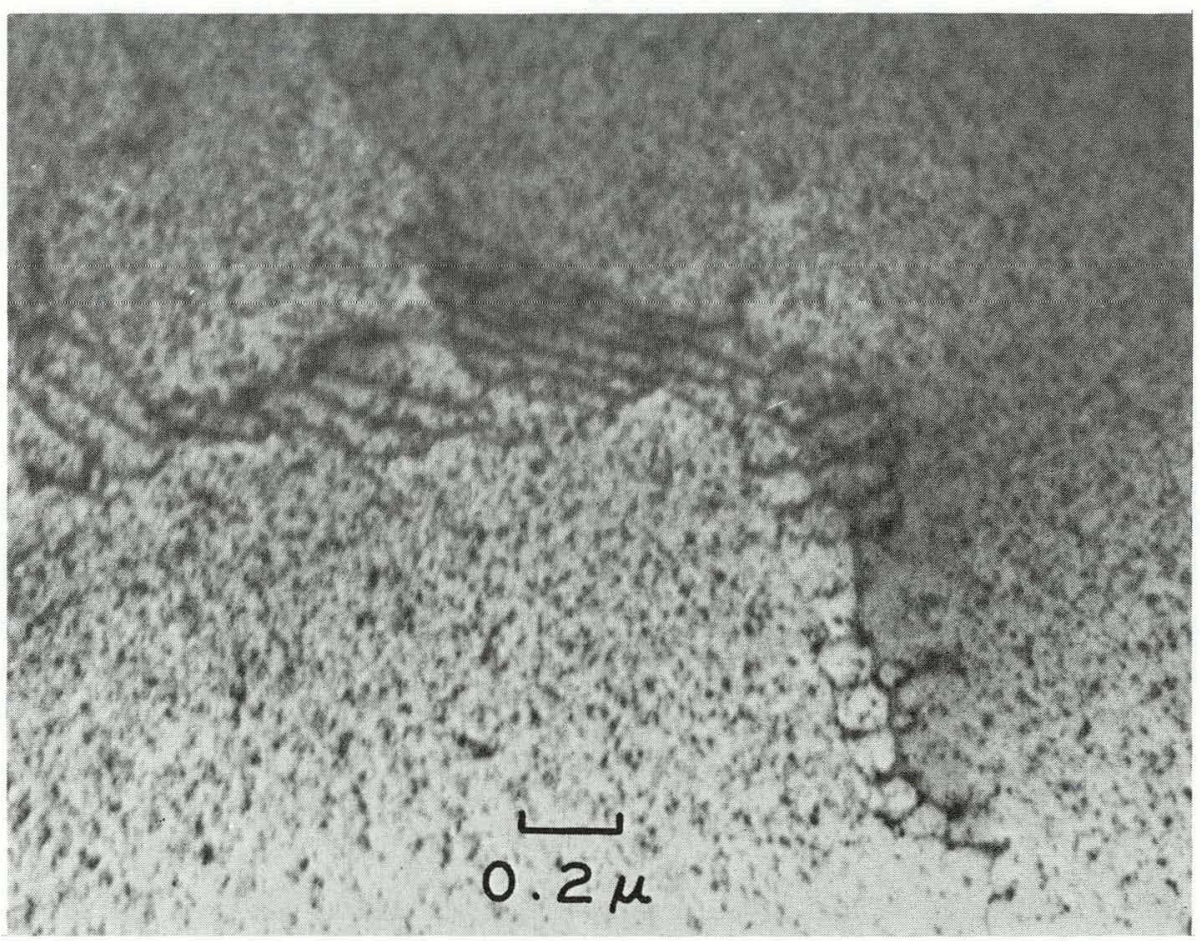

b. Shielded with $0.51-\mathrm{mm}$ cadmium; fast fluence $3.9 \times 10^{19} \mathrm{nvt}$; thermal fluence $2.3 \times 10^{20} \mathrm{nvt}$ (Neg. J-1637)

Fig. 2.38-Transmission electron micrographs of reduced sections of shielded and unshielded irradiated tungsten specimens tensıle tested at $400^{\circ} \mathrm{C}$ 
$\left(0.37 \mathrm{~T}_{\mathrm{m}}\right)$. Data for this group are presented in Table 2.18. Because of the heating during testing, this series of specimens basically illustrates the effects of high-temperature annealing on the radiation-produced microstructure. However, the results are probably also related to heating time since each specimen was held at the test temperature for a different period of time, depending upon its rupture life.

TABLE 2.18

TUNGSTEN CREEP-RUPTURE SPECIMENS TESTED AT $1100^{\circ} \mathrm{C}$ AND $18.28 \mathrm{~kg} / \mathrm{mm}^{2}$

\begin{tabular}{|c|c|c|c|c|c|c|c|}
\hline \multirow[b]{2}{*}{ Specimen } & \multirow[b]{2}{*}{ Capsule } & \multicolumn{2}{|c|}{ Fluence, ${ }^{a}$ nvt } & \multirow[b]{2}{*}{$\begin{array}{c}\text { Creep Rate, } \\
\text { sec }^{-1}\end{array}$} & \multirow{2}{*}{$\begin{array}{c}\text { Rupture } \\
\text { Life, } \\
\text { hr }\end{array}$} & \multirow[b]{2}{*}{$\begin{array}{c}\text { Elongation, } \\
\%\end{array}$} & \multirow[b]{2}{*}{$\begin{array}{c}\text { Reduction, } \\
\%\end{array}$} \\
\hline & & Thermal & $\begin{array}{c}\text { Fast } \\
\left(\mathrm{E}_{\mathrm{n}} \geq 1 \mathrm{Mev}\right)\end{array}$ & & & & \\
\hline 1391 & Control & - & - & $6.39 \times 10^{-6}$ & 6.23 & 30.3 & 98.7 \\
\hline 1384 & ORM-32 & $6.8 \times 10^{18}$ & $8.5 \times 10^{17}$ & $6.26 \times 10^{-6}$ & 6.87 & 33.9 & 95.9 \\
\hline 1383 & ORM-31 & $3.9 \times 10^{19}$ & $4.0 \times 10^{18}$ & $3.60 \times 10^{-6}$ & 12.61 & 28.0 & 90.0 \\
\hline 1385 & ORM-33 & $4.1 \times 10^{19}$ & $5.9 \times 10^{18}$ & $3.00 \times 10^{-6}$ & 15.92 & 32.2 & 95.1 \\
\hline 1345 & $U_{K M}-34$ & $2.3 \times 10^{20}$ & $3.8 \times 10^{19}$ & 1. U8 $\times 10^{-G}$ & 41.92 & 26.3 & บ2. 3 \\
\hline $1394^{b}$ & ORM-37 & $2.5 \times 10^{19}$ & $3.9 \times 10^{19}$ & $3.58 \times 10^{-6}$ & 14.64 & 28.0 & 90.0 \\
\hline 1388 & ORM-35 & $7.0 \times 10^{20}$ & $1.4 \times 10^{20}$ & $2.93 \times 10^{-7}$ & 194.9 & 33.5 & 92.4 \\
\hline 1403 & GEFP2-234 & $42.7 \times 10^{21}$ & $1.5 \times 10^{21}$ & $1.08 \times 10^{-8}$ & 315.41 & 6.6 & 32.5 \\
\hline
\end{tabular}

Irradiated at reactor ambient temperature $\left(\sim 70^{\circ} \mathrm{C}\right)$.

$\mathrm{b}_{\text {Shielded with } 0.51-\mathrm{mm} \text { cadmium. }}$

Typical microstructures are shown in Figures 2.39 and 2.40, which show button heads and reduced sections, respectively. Unirradiated and low fluence level $\left(5.9 \times 10^{18}\right.$ neutrons $/ \mathrm{cm}^{2}$ and below) specimens had similar microstructures, consisting of dislocation networks in the button heads (Figure 2.39a) and tangles in the reduced sections (Figure 2.40a). No evidence was seen of dot clusters in the matrix as occurred in the button heads of the $400^{\circ} \mathrm{C}$ tensile specimens.

Specimens irradiated to fluences of $3.8 \times 10^{19}$ neutrons $/ \mathrm{cm}^{2}$ or greater prior to testing showed clusters and resolvable dislocation loops in the matrix, but in quantities considerably below those of the $400^{\circ} \mathrm{C}$ tensile specimens irradiated to similar fluences. Button heads contained appreciably greater numbers of the defects than the reduced sections, as can be seen by comparing Figures $2.39 \mathrm{~b}$ and c with Figures $2.40 \mathrm{~b}$ and c. Defect concentrations in the button heads of the specimens irradiated in the $10^{19}$ and $10^{20}$ neutrons $/ \mathrm{cm}^{2}$ fluence range were estimated to be approximately $10^{14} / \mathrm{cm}^{3}$. The reduced sections and button head of the $10^{21}$ neutrons $/ \mathrm{cm}^{2}$ sample contained concentrations at least an order of magnitude lower.

The average size of the defects increased with neutron fluence. In the specimens irradiated to 3.8 and $3.9 \times 1019$ neutrons $/ \mathrm{cm}^{2}$, most of the defects appeared as dot clusters approximately $100 \AA$ in diameter, with some resolvable loops approaching $300 \AA$ diameter. In the specimen irradiated to $1.2 \times 10^{20}$ neutrons $/ \mathrm{cm}^{2}$, most of the defects appeared as loops averaging $200 \AA$ in diameter, with large loops approaching $500 \AA$. Finally, in the highest fluence specimen, $1.5 \times 10^{21}$ neutrons $/ \mathrm{cm}^{2}$, the average and maximum loop sizes were respectively $1000 \AA$ and $2000 \AA$.

Like the previous group, this group of specimens also contained a pair of cadmiumshielded/unshielded specimens which received similar fast neutron fluences but widely differing thermal fluences. Electron microscopy again failed to show any significant changes in microstructure, although the creep properties were different. 


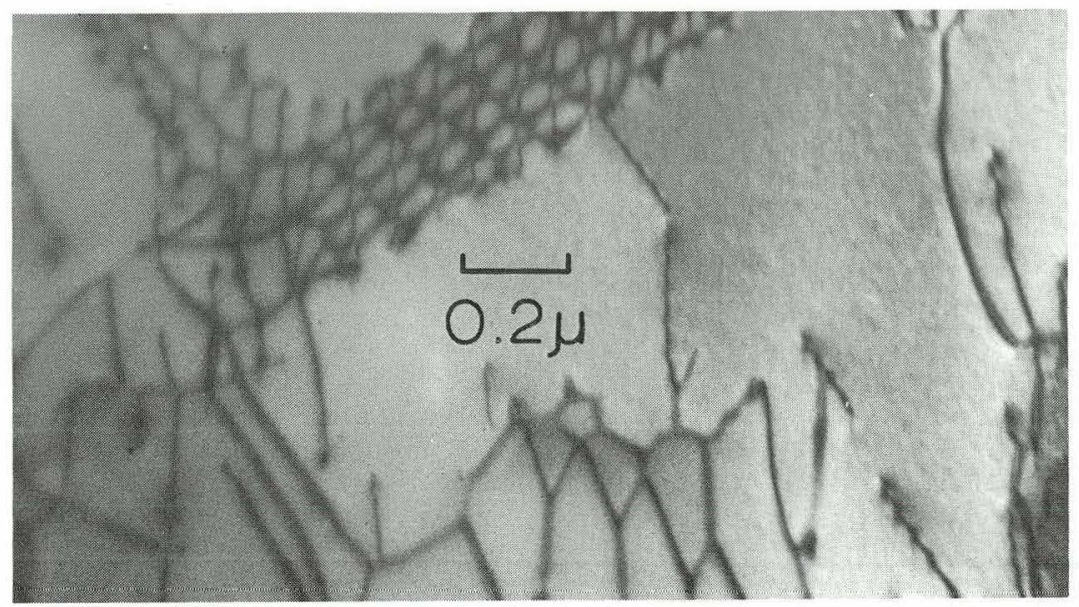

a. Irradiated to $4.0 \times 10^{18} \mathrm{nvt}$ $\left(E_{n} \geq 1 \mathrm{Mev}\right)(\mathrm{Neg} . J-1700)$

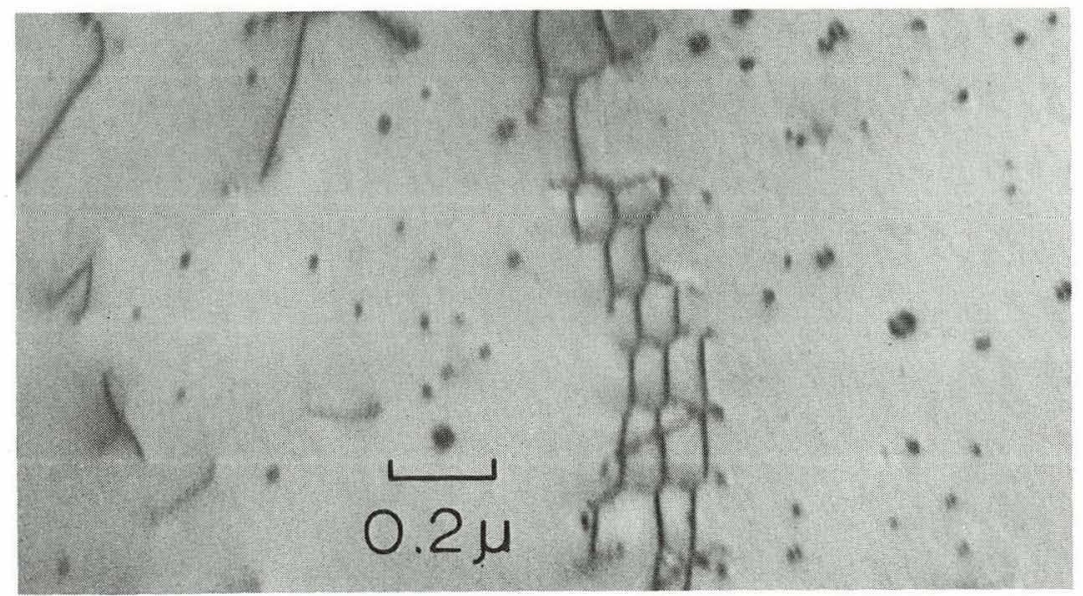

b. Irradiated to $1.2 \times 10^{20} \mathrm{nvt}$ $\left(E_{n} \geq 1\right.$ Mev) (Neg.J-1766)

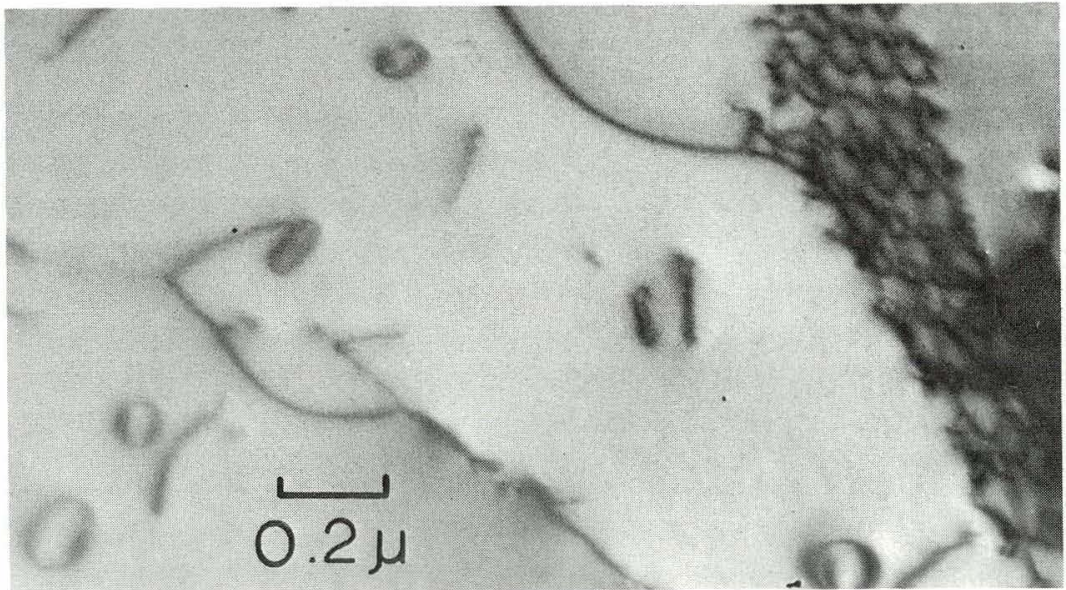

c. Irradiated to $1.5 \times 10^{21} \mathrm{nvt}$ $\left(F_{n} \geq 1 \mathrm{Mev}\right)(\mathrm{Neg} . J-1794)$

Fig. 2.39 - Transmission electron micrographs of button heads of tungsten specimens creep-rupture tested at $1100^{\circ} \mathrm{C}$ 


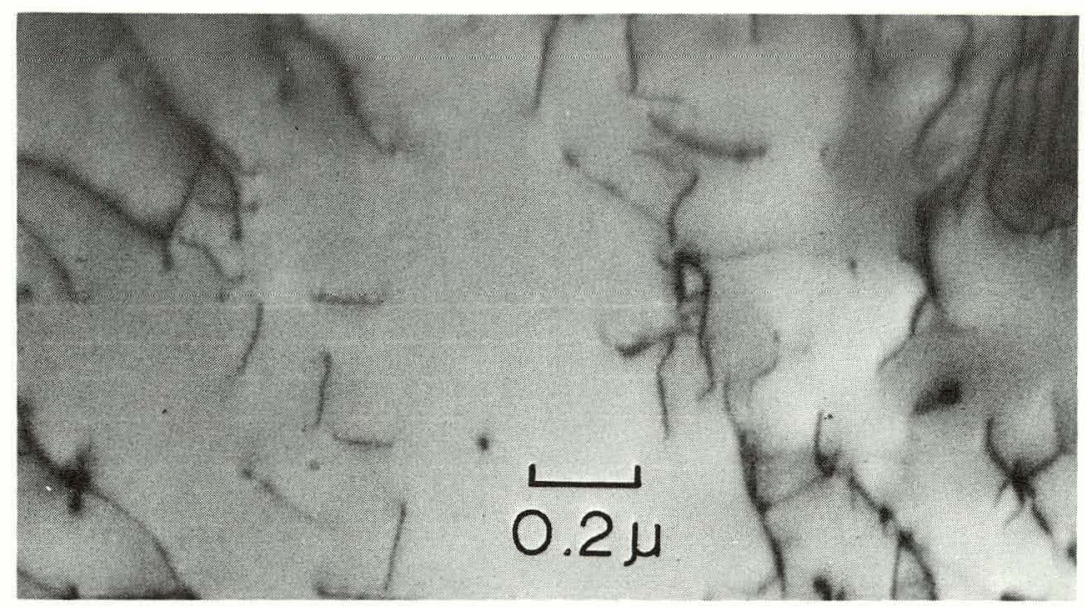

a. Irradıated to $4.0 \times 1 U^{10} \mathrm{nvt}$

$\left(E_{n} \geq 1 \mathrm{Mev}\right)$ (Neg. J-1836)

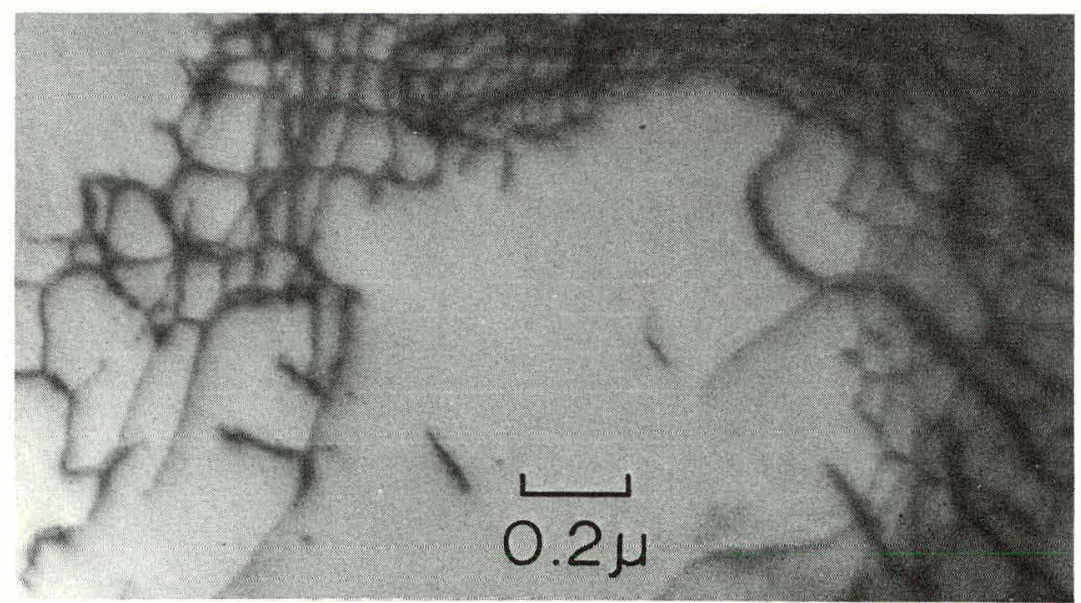

b. Irradiated to $1.2 \times 10^{20} \mathrm{nvt}$

$\left(E_{n} \geq 1 \mathrm{Mev}\right.$ ) (Neg. J-1906)

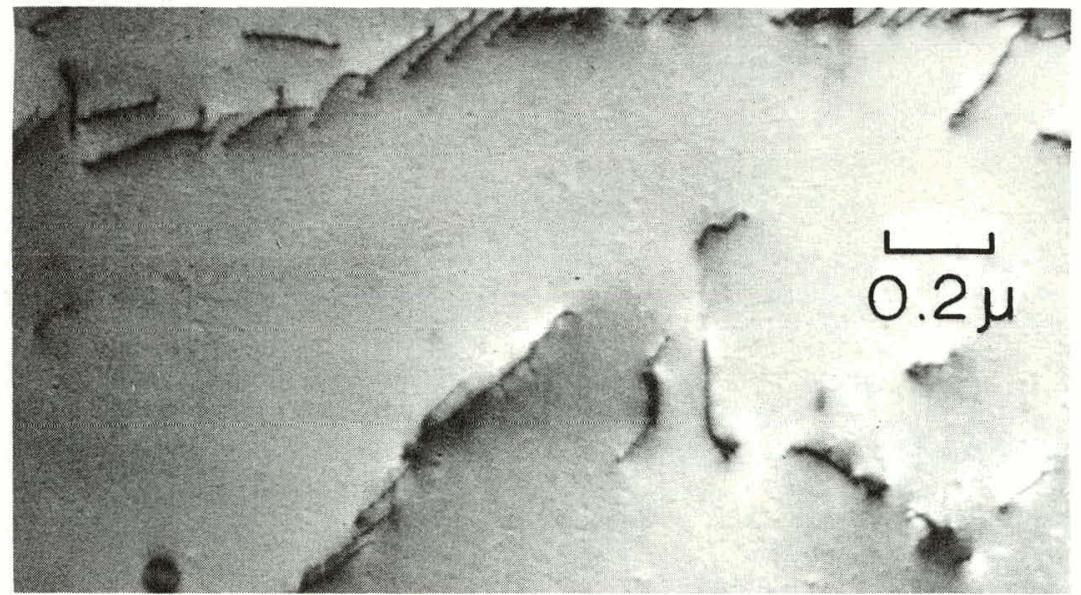

c. Irradiated to $1.5 \times 10^{21} \mathrm{nvt}$ $\left(E_{n} \geq 1 \mathrm{Mev}\right)$ (Neg. J-1921)

Fig. 2.40 - Transmission electron micrographs of reduced areas near fracture of tungsten specimens creep-rupture tested at $1100^{\circ} \mathrm{C}$ 
A noteworthy observation for all of the Group III samples was the rather high degree of retention of some relatively intact dislocation subgrain boundary networks in the reduced sections. Some of these retained networks appear to contain higher dislocation densities than networks in the button heads (see Figure 2.41). This is indicative of a rearrangement of the subgrains into orientations of greater lattice mismatch during high-temperature testing.

The observations of annealing of radiation-induced defects in the se specimens are in good agreement with previous results on irradiated, single-crystal tungsten annealed at $1090^{\circ} \mathrm{C} .{ }^{38}$ The lower loop densities in the reduced sections in comparison with the unstressed button heads can probably be ascribed to slightly higher temperatures in the gage lengths during creep-rupture or tensile tests, or to interaction of the defects with moving dislocations during reorientation of the subgrains. Although diffraction contrast analysis of the large loops found in the present study has not yet been carried out, their similarity to large interstitial loops formed on annealing irradiated molybdenum ${ }^{39,40} \mathrm{sug}$ gests that these loops also may be interstitial. Tilting experiments are planned to determine the nature and crystallography of loops in tungsten.

\section{7 SUMMARY AND CONCLUSIONS}

Creep-rupture tests on tungsten specimens irradiated to $1.4 \times 10^{20}$ neutrons $/ \mathrm{cm}^{2}$ $\left(E_{n} \geq 1 \mathrm{Mev}\right)$ at elevated temperatures $\left(1100^{\circ}\right.$ to $\left.1350^{\circ} \mathrm{C}\right)$ indicate that the ductility at fracture is a function of irradiation temperature and test temperature. Specimens irradiated at greater than $1250^{\circ} \mathrm{C}$ tended to show less ductility than specimens irradiated from $1100^{\circ}$ to $1250^{\circ} \mathrm{C}$. All irradiated specimens exhibited less ductility than control specimens at a given temperature in the $900^{\circ}$ to $1900^{\circ} \mathrm{C}$ range. The ductility of control and irradiated specimens decreased with increasing test temperature to $1700^{\circ} \mathrm{C}$ and then increased at $1900^{\circ} \mathrm{C}$. All specimens tested at $900^{\circ} \mathrm{C}$ and $1100^{\circ} \mathrm{C}$ failed by transgranular fracture; higher test temperatures produced predominantly intergranular fractures.

A series of tungsten specimens irradiated to fast fluence levels of $8.5 \times 10^{17}$ to 1. $5 \times 10^{21}$ neutrons $/ \mathrm{cm}^{2}(\mathrm{E} \geq 1 \mathrm{Mev})$ at reactor ambient temperature and creep tested at $1100^{\circ} \mathrm{C}$ have shown that the effect of different reactor spectra on the properties is mainly due to the production of rhenium from the $(n, \alpha)$ reaction with thermal neutrons. A log-log plot of thermal neutron fluence level versus creep rate did not show the discontinuities due to different reactor spectra that was observed in fast fluence plots.

The activation energy for creep of $\mathrm{W}-25 \mathrm{Re}$ in the $775^{\circ}$ to $930^{\circ} \mathrm{C}$ temperature range was found to be $112 \mathrm{kcal} / \mathrm{mole}$. It did not exhibit a stress dependency over the range studied.

Accelerated creep of irradiated molybdenum was observed at $580^{\circ} \mathrm{C}$ for low neutron levels ( $5 \times 10^{18}$ neutrons $/ \mathrm{cm}^{2}, \mathrm{E}_{\mathrm{n}} \geq 1 \mathrm{Mev}$ ) but not at a higher fluence level of $3 \times 10^{19}$ neutrons $/ \mathrm{cm}^{2}$. Delayed creep was observed in $600^{\circ} \mathrm{C}$ and $700^{\circ} \mathrm{C}$ tests on irradiated molybdenum but not in control specimens or in tests at $580^{\circ}, 850^{\circ}$, or $900^{\circ} \mathrm{C}$.

Tensile tests at $400^{\circ} \mathrm{C}$ of irradiated tungsten showed that the radiation-induced increase in yield strength is proportional to the square root of the fast neutron fluence. Saturation hardening had not been reached even at fast neutron values of $1.4 \times 10^{20}$ neutrons $/ \mathrm{cm}^{2}\left(E_{n} \geq 1 \mathrm{Mev}\right)$, although the ductility is seriously reduced at about $7.9 \times 10^{19}$ neutrons $/ \mathrm{cm}^{2}$. Annealing an irradiated specimen $\left(1.4 \times 10^{20}\right.$ neutrons $\left./ \mathrm{cm}^{2}\right)$ at $1200^{\circ} \mathrm{C}$

\footnotetext{
${ }^{38}$ Lacefield, Moteff, and Smith, loc. cit.

${ }^{39}$ Downey and Eyre, loc. cit.

${ }^{40}$ B. Mastel and J. L. Brimhall, "The Combined Effect of Carbon and Neutron Radiation on Molybdenum," Acta Metallurgica, Vol. 13, No. 1965, pp. 1109-1116.
} 


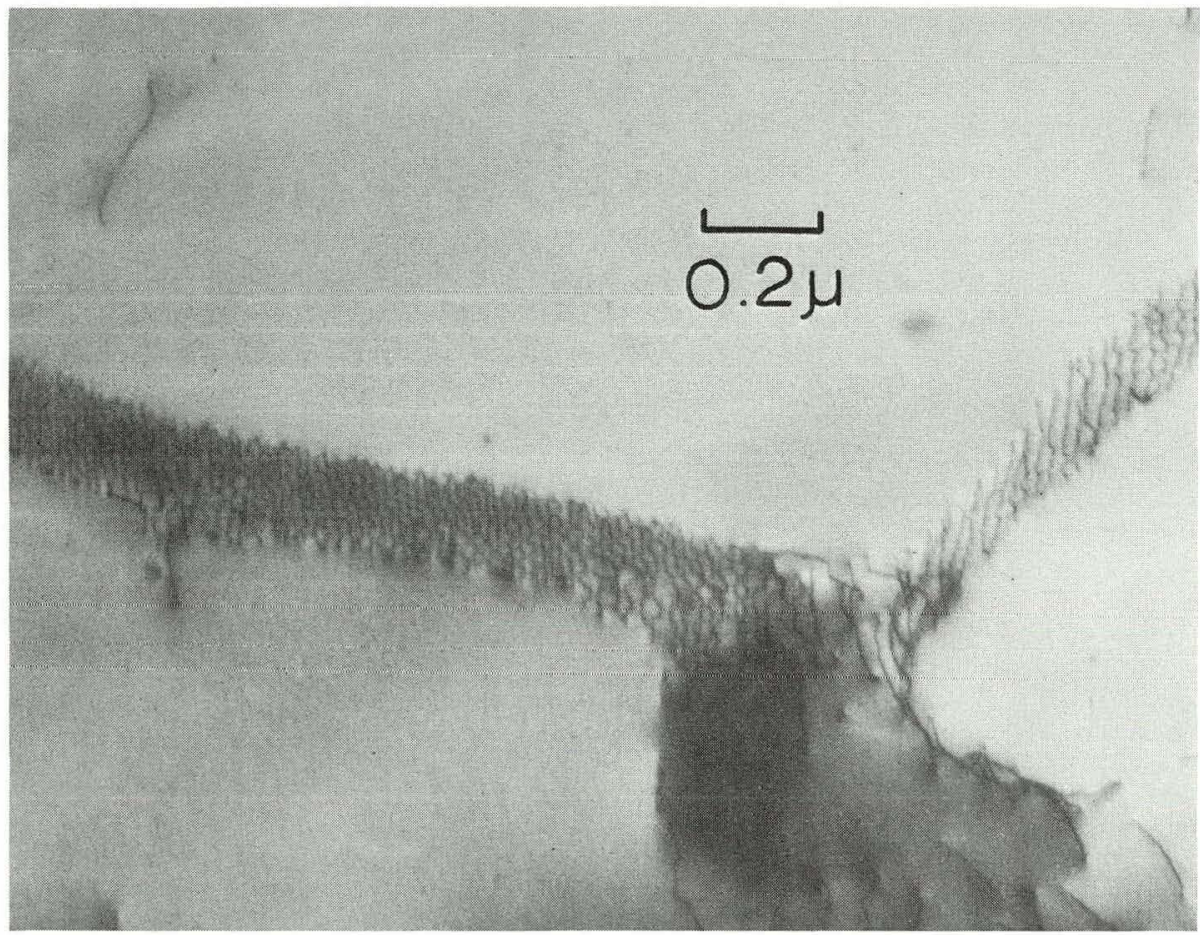

a. Irradiated to $8.5 \times 10^{17} \mathrm{nvt}$

$\left(E_{n} \geq 1 \mathrm{Mev}\right)(\mathrm{Neg} . J-1826)$

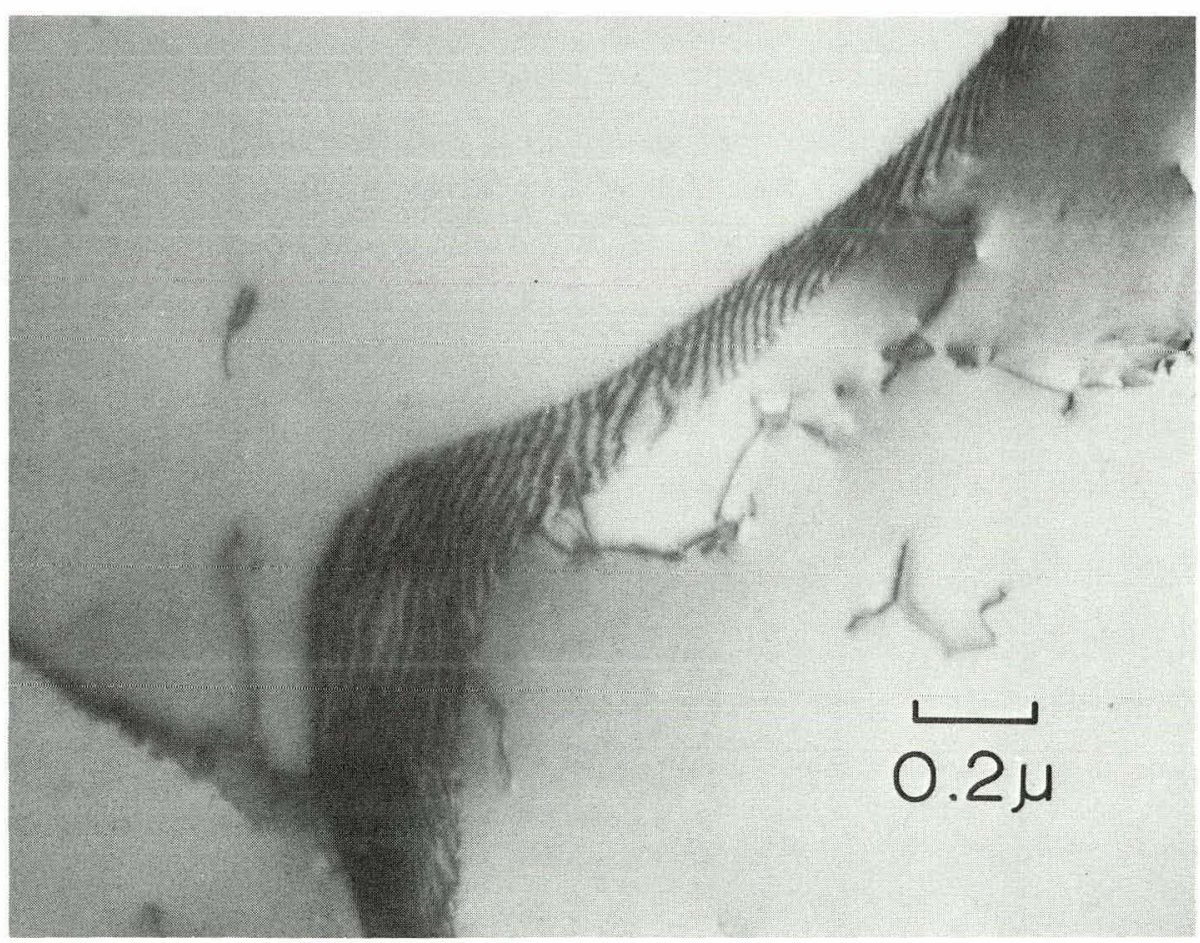

b. Irradiated to $3.8 \times 10^{19} \mathrm{nvt}$

$\left(E_{n} \geq 1 \mathrm{Mev}\right)(\mathrm{Neg} . \mathrm{J}-1870)$

Fig. 2.41 - Transmission electron micrographs showing retained dislocation networks in reduced sections of tungsten specimens creeprupture tested at $1100^{\circ} \mathrm{C}$ 
for 1 hour resulted in approximately 80-percent recovery of yield and ultimate strengths but very little recovery of ductility ( $1.2 \%$ elongation). Annealing specimens irradiated in the fast fluence range of 0.6 to $8 \times 10^{19}$ neutrons $/ \mathrm{cm}^{2}$ at $1300^{\circ} \mathrm{C}$ produced complete recovery of all strength and ductility characteristics.

The effect of anncaling temperature on the room-temperature tensile properties of ir radiated recrystallized molybdenum, $\mathrm{Mo}-50 \mathrm{Re}$, and $\mathrm{W}-25 \mathrm{Re}-30 \mathrm{Mo}$ were determined.

Recovery studies of hot-hardness and tensile properties of Mo, Mo-TZM, Mo - 50Re, $\mathrm{W}, \mathrm{W}-25 \mathrm{Re}$, and $\mathrm{W}-25 \mathrm{Re}-30 \mathrm{Mo}$ specimens irradiated at reactor ambient temperature showed that the properties are generally completely recovered at temperatures greater than $0.22 \mathrm{~T}_{\mathrm{m}}$ for the alloys and above $0.35 \mathrm{~T}_{\mathrm{m}}$ for the unalloyed metals. This implies that structural components fabricated from the alloys will have better properties under irradiation than the unalloyed material in the temperature range from 0.22 to $0.35 \mathrm{~T}_{\mathrm{m}}$.

The comprehensive investigation of the various recovery stages observed by resistivity measurements of isochronally annealed neutron-radiation-damaged $W, W-25 R e$, Mo, and Mo-TZM has been continued. These results show a number of important trends and effects:

1. The tungsten specimens appear to be saturating at a fast neutron fluence of about $1.5 \times 10^{21}$ neutrons $/ \mathrm{cm}^{2}$. This is the first resistivity evidence of saturation in tungsten as well as the highest neutron irradiation to be studied by resistivity. A residual resistivity, evident in most of the samples after the anneals, was found to increase with increasing thermal neutron fluence. This is attributed to a $W$ to $R e$ (and possibly some $R e$ to $O s$ ) transmutation reaction as a result of the thermal neutron bombardment. These transmutant products appear to act like defect traps, giving rise to a higher radiation-induced resistivity. These transmutation effects are also evident in neutron-irradiated $\mathrm{W}-25 \mathrm{Re}$. The $\mathrm{W}-25 \mathrm{Re}$ with the highest fast (and thermal) neutron fluence shows a considerable change in recovery and residual resistivity as compared to the other $\mathrm{W}-25 \mathrm{Re}$ specimens. This is believed due to an increase in the $R e$ to Os transmutation reaction.

2. The first resistivity evidence of saturation of neutron-irradiation damage in molybdenum was demonstrated. As the fast neutron fluence is increased, the induced resistivity passes through a maximum at about $10^{20}$ neutrons $/ \mathrm{cm}^{2}$ and then decreases. The effects of adding $\mathrm{Zr}$ and Ti to Mo (i. e., Mo-TZM) leads to a higher induced resistivity for the same neutron fluences for Mo-TZM than for Mo for all the temperatures above $0.15 \mathrm{~T}_{\mathrm{m}}$.

Transmission electron microscopy is being used to evaluate the microstructure of neutron-irradiated tungsten for subsequent correlation with physical and mechanical properties. A fluence threshold exists between $5.9 \times 10^{18}$ and $3.8 \times 10^{19}$ neutrons $/ \mathrm{cm}^{2}\left(E_{n} \geq 1 \mathrm{Mev}\right)$, above which distinct defect cluster formation occurs. The se clusters contribute to the hardness of the material, evidently by impeding dislocation movement, which leads to an observed embrittlement in tensile samples tested at $400^{\circ} \mathrm{C}$. The microstructure of ir radiated tungsten creep-rupture tested at $1100^{\circ} \mathrm{C}$ showed the presence of distinct dislocation loops, thought to result from interstitial aggregation. Evidence of subgrain reorientation during testing was seen in these specimens. The microstructural features observed in irradiated tungsten appear to be related to fast neutron flux $\left(E_{n} \geq 1 \mathrm{Mev}\right)$ rather than thermal flux.

\section{8 PLANS AND RECOMMENDATIONS}

Investigations will be continued to study the basic mechanisms of neutron irradiation damage in the refractory metals and alloys. Possible mechanisms will be identified utilizing current dislocation theories supported by analyses of transmission electron microscopy, creep, tensile, resistivity, and hot-hardness experimental studies. 
Mechanical testing of refractory materials based on specific temperature ranges indicated by recovery peaks demonstrated in resistivity and hot-hardness investigations will be performed. Additional emphasis will be placed on the analysis of fracture mechanism in the tensile and creep tests.

Utilization of fast reactor spectra will be emphasized in future irradiations to fully evaluate neutron-induced changes and form an accurate basis for damage theories applicable to various neutron spectra. Proposed fast reactor irradiations will include refractory metals and alloys not presently in the program.

The current investigations of the recovery mechanism of neutron-radiation-induced defects in various refractory metals and alloys by isochronal and isother mal resistivity studies will be continued. The isothermal studies in particular will be expanded to furnish migration energies and jump frequencies for the various defects exhibiting recovery at elevated temperatures. A more exhaustive study of molybdenum will be undertaken to match that already completed on tungsten.

In vlew of the possible significance of the accelerated creep observed in molybdenum . to other bcc metals, further study of neutron-induced changes in the creep properties of molybdenum under various conditions is planned.

To complement present studies, transmission electron microscopy studies will be performed on creep-tested molybdenum and tungsten specimens which were irradiated at elevated temperatures. In addition, quantitative studies on the type and the density of observable defects versus annealing temperature will be made.

Isothermal hot-hardness investigations are planned to study the various activation energies associated with the different stages of defect recovery in the irradiated materials. 


\title{
3. REFRACTORY-METAL ALLOY RESEARCH AND DEVELOPMENT
}

(57015)

\author{
E. S. Funston, *. 0. $\operatorname{Tarr}^{\dagger}$
}

The objective of this program is to further tne technology of refraci.ry metals, particularly the new refractory metals which have been developed under this task, to permit their early utilization in the many high-temperature reactor programs being sponsored by the AEC. In addition, a continuing research effort is being conducted to develop new refractory-metal alloys capable of markedly improving the temperature and life capabilities of nuclear power plants. Promising compositions identified during the research phase of this task are selected for advanced development to meet the specific requirements of various programs. Processing procedures are developed for the selected alloy; and tubing, sheet, and bars are then fabricated and submitted for evaluation of full-size test components.

A number of facets of the work performed under this task during CY -66 have not yet been reported. This covers such topics as several processing procedures, development of age hardening alloys and new alloy compositions elimination of microporosity, and the influence of addition of a fourth element to the W-Re-Mo ternary compositions. This work will be summarized following disclosure and filing procedures required by contract.

\section{1 DEVELOPMENT OF REFRACTORY-META:, PROCESSING PRCOCEDURES}

During CY-66, a complete technology was developed for fahricating W-Re and W-Re-Mo seamless tubing. Operational procedures were first selected and parameters established for each stage of the process; trial production runs were then performed to verify the adequacy of the overall procedure. Figure 3.1 gives a description of the major steps involved. This diagram shows the close correlation between basic procedures required for both sheet and seamless tubing fabrication. Originally, operational parameters such as powder-metallurgy processing technology, cold-working reductions, sintering cycles, and stress-relief temperatures were established for sheet processing. These procedures were then applied to the tubing process as required.

The basic purification procedure for deriving high-purity refractory-metal sheet is also delineated in Figure 3.1. Details of this procedure were previously reported. ${ }^{1} \mathrm{U} \cdot$ ing this method, large quantities of refractory-metal alloy sheet, rod, and tubing were piepared over the past year.

Results obtained from 36 extrusions of W-Re and W-Re-Mo alloys made during CY -66 are given in Tahle 3.1. W-30Re - 30Mo tubing of various sizes was prepared for refractory-metal tubing evaluation. After demonstrating that it was feasible to produce

\footnotetext{
*Project leader.

$\dagger_{\text {Principal investigator. }}$

1"Fourth Annual Report - High-Temperature Materials and Reactor Component Development Programs, Vol ume IMaterials," GE-NMPO, GEMP-334A, February 26, 1965, pp. 41-42.
} 
Basic Preparation Procedures

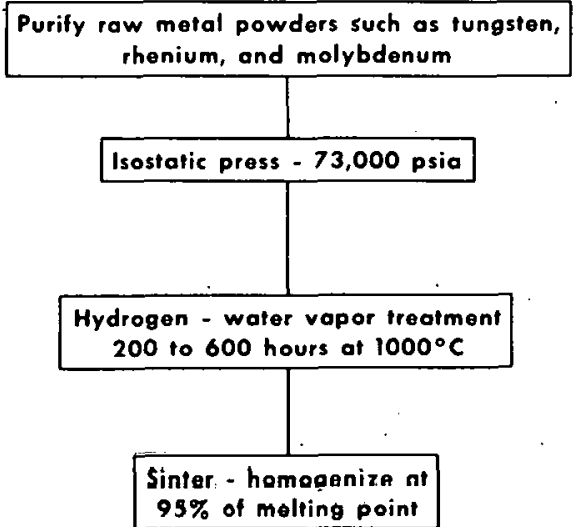

Metal Working Procedures

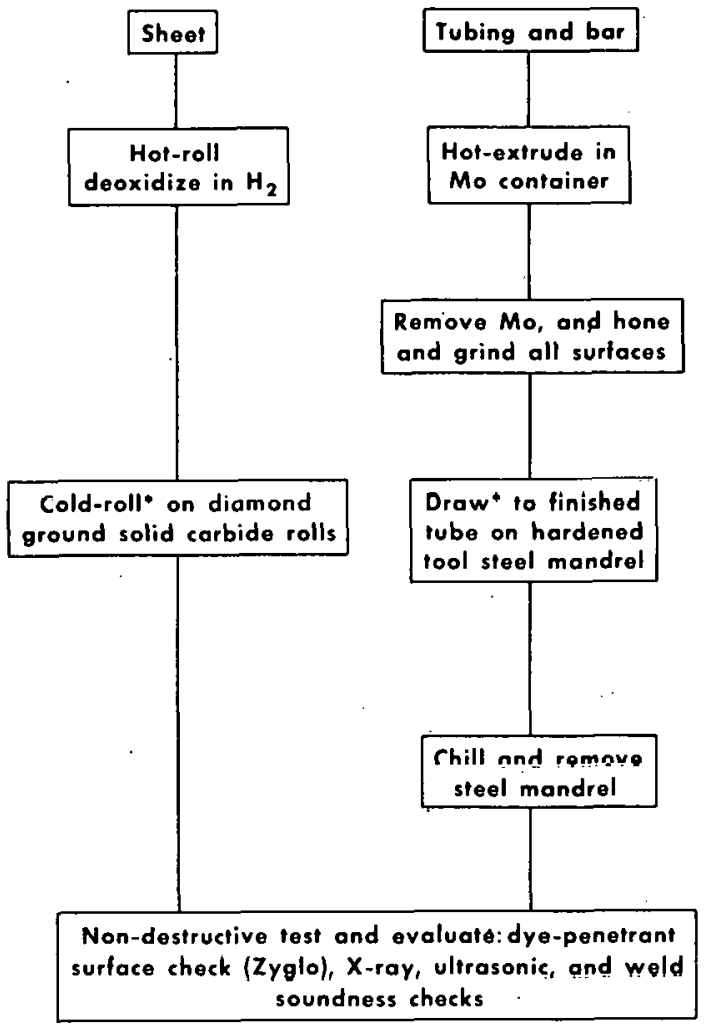

Key Points

Assures weld soundness in finished product.

Provides shope resulting in high yield of final product.

Lowers carbon content. Improves molybdenum ductility. Aids in weldability.

Dousplope a primary mofal ofruaturo frec of ijimuiiiled constituents.

Specifies $80 \%$ area reduction to establish required metal texture.

Results in good surface quality and assures concentricity.

Each working cycle includes a stress-relief treatment. Work conducted at $<200^{\circ} \mathrm{C}$ to avoid contamination from oir.

Steel shrints more then alloy during ehilling. Avoids cracks and other losses in freeing mandrel.

Non-destructive tests were selected to supplement onch othor. Emphacizo prosodures that evaluate density and detect internal defects. Weld soundness is a direct purity confirmation as impure materials yield unsound welds.

\footnotetext{
-Low speods and light reductions in working operotions. No lubricant
} used on internal surfaco of tubes to avoid contamination.

Fig. 3.1 - GE-NMPO refractory-metal production description 
TABLE 3. 1

RESULTS OF EXTRUSIONS MADE DURING CY -1966

\begin{tabular}{|c|c|c|c|c|c|c|c|c|c|c|}
\hline \multirow{2}{*}{$\begin{array}{c}\text { Extrusion } \\
\text { Number }\end{array}$} & \multirow[b]{2}{*}{ Alloy $^{a}$} & \multirow{2}{*}{$\begin{array}{l}\text { Objective of } \\
\text { Extrusion }\end{array}$} & \multicolumn{3}{|c|}{$\begin{array}{c}\text { Dimensions of Extrusion } \\
\text { Blank, } \mathrm{cm}\end{array}$} & \multirow{2}{*}{$\begin{array}{c}\text { Extrusion Blank } \\
\text { Weight, g }\end{array}$} & \multicolumn{2}{|c|}{$\begin{array}{c}\text { Dimensions of } \\
\text { Completed Extrusion, } \mathrm{cm} \\
\end{array}$} & \multirow{2}{*}{\multicolumn{2}{|c|}{$\begin{array}{c}\text { Ratio of Area } \\
\text { Reduction }\end{array}$}} \\
\hline & & & Length & $\mathrm{OD}$ & ID & & Length & OD at Center & & \\
\hline D 33 & $w-1$ Os & Solid & $\dot{9} .84$ & 2. 95 & - & 1153 & 35.56 & 0.97 & - & \\
\hline D 34 & 306 & Tube & 10.92 & 2.78 & 1. 89 & 600 & 229.87 & 0.64 & $15.2: 1$ & \\
\hline D 35 & 306 & Tube & 12.00 & 4.61 & 3.23 & 1642 & 224.79 & 1. 27 & 13. $1: 1$ & \\
\hline D 36 & 306 & Solid & 9.53 & 5.00 & - & 2769 & 19.05 & 2. 92 & 2. 5:1 & \\
\hline D 37 & 306 & Tube & 11.89 & 4.67 & 3.67 & 1282 & 210.82 & 1.63 & 11. 2:1 & \\
\hline D 38 & $250^{b}$ & Solid & 10.80 & 3. 87 & - & 2360 & 227.33 & 0.97 & 9. 3:1 & \\
\hline D 39 & 306 & Tube & 10.63 & 4. 37 & 3.12 & 1327 & 60.96 & 1.40 & 9. $8: 1$ & \\
\hline D 40 & 306 & Tube & 10.87 & 4. 41 & 3.28 & 1188 & 50.80 & 1. 37 & $10: 1$ & \\
\hline D 41 & 306 & Tube & 10.16 & 4. 39 & 3.18 & 1190 & 43.18 & 1. 37 & 9. $9: 1$ & \\
\hline D 42 & 306 & Tube & 11.22 & 5.07 & 3.56 & 1873 & - & - & 3. $6: 1$ & \\
\hline D 43 & $306^{b}$ & Tube & 20.29 & 4. 58 & 3.21 & 2663 & 204.47 & 1. 37 & 11. $1: 1$ & \\
\hline D 44 & $306^{b}$ & Tube & 20. 32 & 4.60 & 3.21 & 2720 & 187.96 & 1.37 & 11. $1: 1$ & \\
\hline D 45 & 306 & Tube & 12. 18 & 4. 44 & 3.75 & 880 & 58.42 & 1.98 & 5. 3:1 & \\
\hline D 46 & 306 & Tube & 12.28 & 5.03 & 3.92 & 1473 & 72.39 & 1.92 & 6. $8: 1$ & \\
\hline D 47 & 306 & Tube & 11.95 & 4. 52 & 3.27 & 1523 & 109.22 & 1. 47 & $10.46: 1$ & \\
\hline D 48 & 306 & Tube & 12.38 & 4. 89 & 3.28 & 2103 & 130.81 & 1.47 & $12: 1$ & \\
\hline D 49 & 306 & Tube & 12.00 & 4.89 & 3.59 & 1709 & 131.44 & 1.47 & 14. $8: 1$ & \\
\hline D 50 & 306 & Tube & 12. 01 & 4.64 & 3.43 & 1529 & 123.82 & 1.37 & 13. $4: 1$ & \\
\hline D 51 & 306 & Tube & 11. 81 & 4.79 & 3.57 & 1596 & 121.92 & 1. 42 & 13. $5: 1$ & \\
\hline D 52 & 306 & Tube & Hold ${ }^{c}$ & & & & & & & \\
\hline D 53 & 306 & Tube & 12.97 & 5.14 & 3. 37 & 2538 & 131. 44 & 1. 47 & $12: 1$ & \\
\hline D 54 & 306 & Tube & 12.32 & 4.65 & 3.82 & 1120 & 67.94 & 1.98 & 5. $8: 1$ & \\
\hline$D 55^{d}$ & 250 & Solid & 14. 25 & 6.63 & - & 9488 & 123.82 & 2.08 & $10: 1$ & \\
\hline D $56^{d}$ & $25 n \mathrm{~b}$ & Solid & 18. 50 & 2. 50 & - & 1909 & 50.80 & 3.05 & 4. $04: 1$ & \\
\hline D 57 Hold & $d^{c} 306$ & Tube & & & & & & & & \\
\hline D 58 & 306 & Tube & & & & & & & & \\
\hline D 59 & 306 & Tube & & & & & & & & \\
\hline D 60 & 306 & Tube & Hold $c$ & & & & & & & \\
\hline D 61 & 306 & Tube & & & & & & & & \\
\hline D 62 & 306 & Tube & & & & & & & & \\
\hline D 63 & 306 & Tube & & & & & & & & \\
\hline$D 64$ & 306 & Tube & 12.07 & 4.57 & 3.43 & 1414 & 58.42 & 1.88 & & \\
\hline D 65 & $\mathrm{w}-0.5 \mathrm{Os}$ & Solid & 10.17 & 2.68 & - & 2540 & 64.77 & 1. 32 & $12: 1$ & \\
\hline D 66 & 256 & Solid & - & 8.05 & - & - & - & - & $5: 1$ & - \\
\hline D 67 & 306 & Solid & 13.28 & 4.74 & - & 3859 & 118.11 & 1.32 & $12: 1$ & - \\
\hline D 68 & 256 & Tube & 12.18 & 4.72 & 3.50 & 1488 & 121. 92 & 1.47 & $8.16 \div 1$ & \\
\hline D 69 & 256 & Tube & 11.97 & 4.63 & 3.41 & 1518 & 107.95 & 1.52 & - & \\
\hline D 70 & 256 & Tube & 11.98 & 4.74 & 3.76 & 1302 & 62.23 & 1.98 & - & \\
\hline D 71 & 256 & Solid & 10.69 & 7.81 & - & 7809 & 48.26 & 3.81 & $5: 1$ & \\
\hline D 72 & 250 & Solid & 10.48 & 4. 44 & - & 2588 & Broke up & - & $12: 1$ & \\
\hline \multirow[t]{2}{*}{ D 73} & $250^{b}$ & Solid & 9.75 & 4.41 & - & 2724 & 140.97 & 12.19 & 12:1 & \\
\hline & & & 7. 16 & 4.41 & - & 1952 & - & - & & \\
\hline D 74 & 306 & Tube & 9.13 & 5.00 & 3.43 & 1583 & 45.08 & 1.98 & - & \\
\hline D 75 & Mo - 50Re & Tube & 9.24 & 5. 14 & 3.43 & 1450 & 74.93 & 1. 78 & - & \\
\hline
\end{tabular}

a 306 alloy is $\mathrm{W}-30 \mathrm{Re}-30 \mathrm{Mo}$ (at. \%)

256 alloy is $\mathrm{W}-25 \mathrm{Re}-30 \mathrm{Mo}$ (at. \%)

250 alloy is $W-25 R e$ (at. \%)

Mo - 50Re is the commercial alloy designation in weight percent.

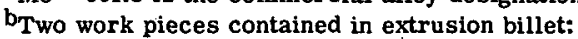

D-38 - also contained D-33

D-43 - contained two tubular extrusions of total length shown in fourth column

D-44 - contained two tubular extrusions of total length shown in fourth column

D-56 - contained two solid rods of 250 alloy

D-73 - contained two solid rods of 250 alloy

CPrepared, but not extruded. This action results from specifying purification treatments for all items processed.

dArc-cast process ingots; all: other materials were sintered metal powder processed ingots. 
this tubing by various techniques, thinner-walled tubes were made having a $0.393-\mathrm{cm}$ $\mathrm{OD}$ and a $0.343-\mathrm{cm}$ ID. As shown in Figure 3.2, tubing of excellent quality can be produced by drawing over a hardened steel mandrel; tubing processed without a hard-core filler (i.e., sinking of the tube) has an undesirably rough inner surface. This drawing technique not only improves the quality of the tubing, but also makes possible the production of tubing in greater lengths; a finished $45-\mathrm{cm}$-long tube is shown in Figure 3.3. Other variables investigated prior to adopting hardened steel mandrels included the use of lubricants, stress-relief temperatures, and drawing on removable core filler metals.

The drawing procedures developed for $0.421-\mathrm{cm}-\mathrm{OD}$ tubing have been applied to the drawing of larger tubing with a $0.025-\mathrm{cm}$-thick wall and an on of $1.27 \mathrm{~cm}$. Although the wall of this larger tubing is much thinner in relation to the OD than that of the smaller tubing, it was nevertheless processed without difficulty. Four sizes produced from a single starting extrusion are shown in Figure 3.4.

'I'o be of greatest use, tubing must be free of surface defects and must possess optimum mechanical strength, ductility, and weldability. The surface quality of a series of tubes processed from a single extrusion of $\mathrm{W}-30 \mathrm{Re}-30 \mathrm{Mo}$ alloy was evaluated. The methods of surface preparation in this series were:

1. Grinding and honing both the inside and outside surfaces before drawing.

2. Not grinding or honing before drawing.

3. Grinding only the outer or inner surface before drawing.

Results of this study showed that the first method produced the best results and eliminated minor laps, tears, and seams in the finished tubing. A particularly significant advantage of the grinding - honing approach is the good bore-to-outer-surface concentricity obtained. A section of a $\mathrm{W}-30 \mathrm{Re}-30 \mathrm{Mo}$ extrusion prepared by grinding and honing is shown in Figure 3.5.

\section{TUBE FORMING FROM SHEET STOCK}

It is often impractical to fabricate seamless rings or tubing in all the sizes required for performing the various research activities. This is especially true with rheniumcontaining alloys where the materials of interest are too expensive to consider large machine shop losses in fabricating a needed component from extruded bar stock. One of the most expedient ways of obtaining the required circular structure is to fabricate it from sheet stock by seam welding, but quite frequently, welding leaves the tube out of round or there is a highly recrystallized microstructure in the weld area which is extremely brittle. The seam-welded tubing is often dimensionally and structurally inferior to seamless tubing. To meet the variety of demands, processing techniques for producing sound tubes or rings to precise dimensions from sheet stock by roll forming and seam welding were developed. This technology is attractive from an economic standpoint since sheet can be rolled with a yield of over 90 percent of the starting materials. Other cost and quality advantages of this approach are that sheet can be inspected more stringently than tubing, and can readily be rolled to different thicknesses to achieve the variety of wall thicknesses required.

An example of the high quality obtained using these new procedures for producing seamwelded tubing is illustrated in Figure 3.6, which shows a welded tube before and after drawing; the cross section obtained is a true right circular cylinder. Figure 3.7 shows an arc-cast $\mathrm{W}-25 \mathrm{Re}$ sheet welded and drawn to tubing; the weld area is undetectable after working. 


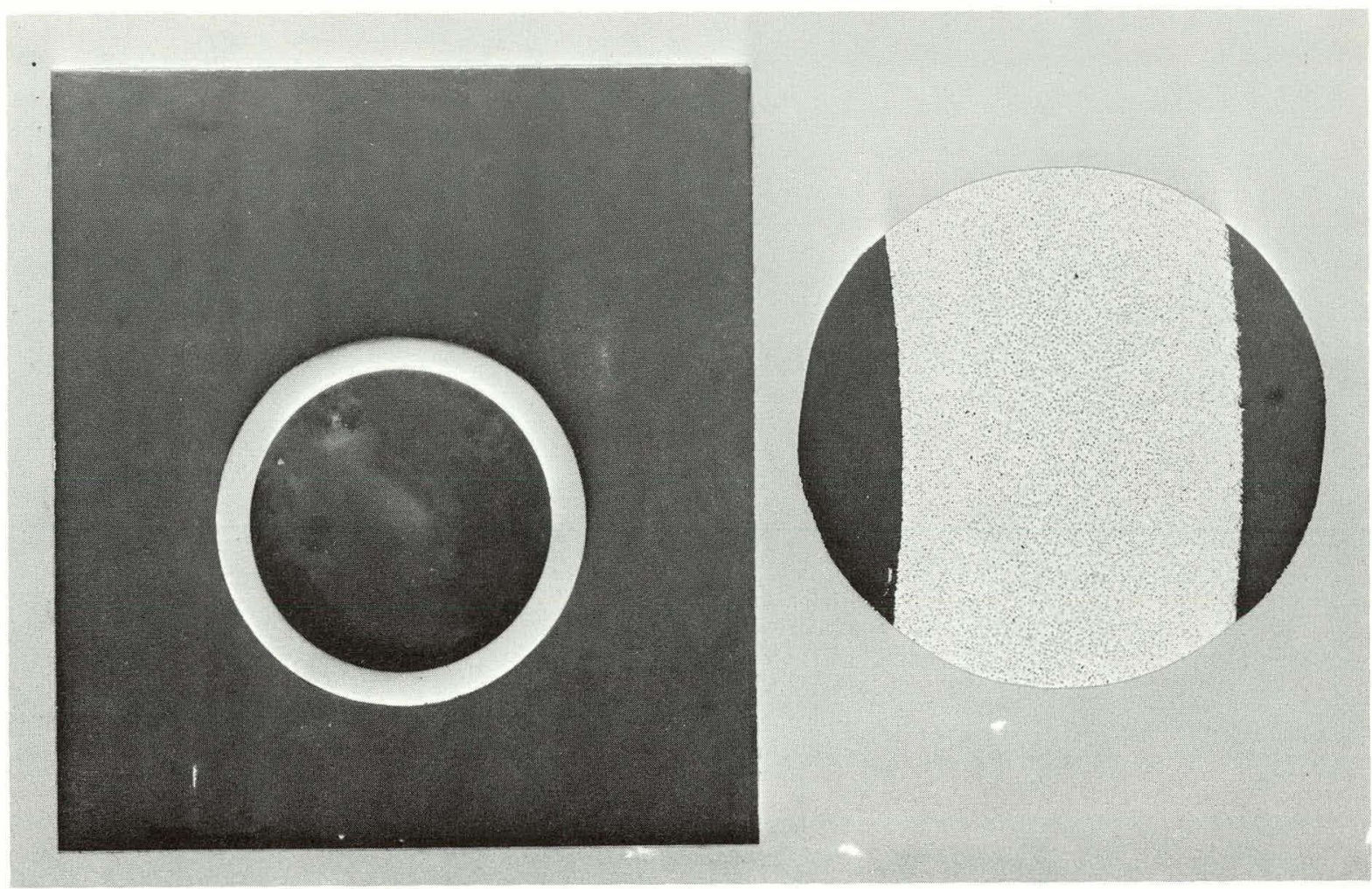

(Neg. 7479; 10X)

(Neg. 7480, 100X)

Cross section of a mandrel-drawn tube. As shown in the inset photomicrograph, concentricity, wall, and surface uniformity were good.
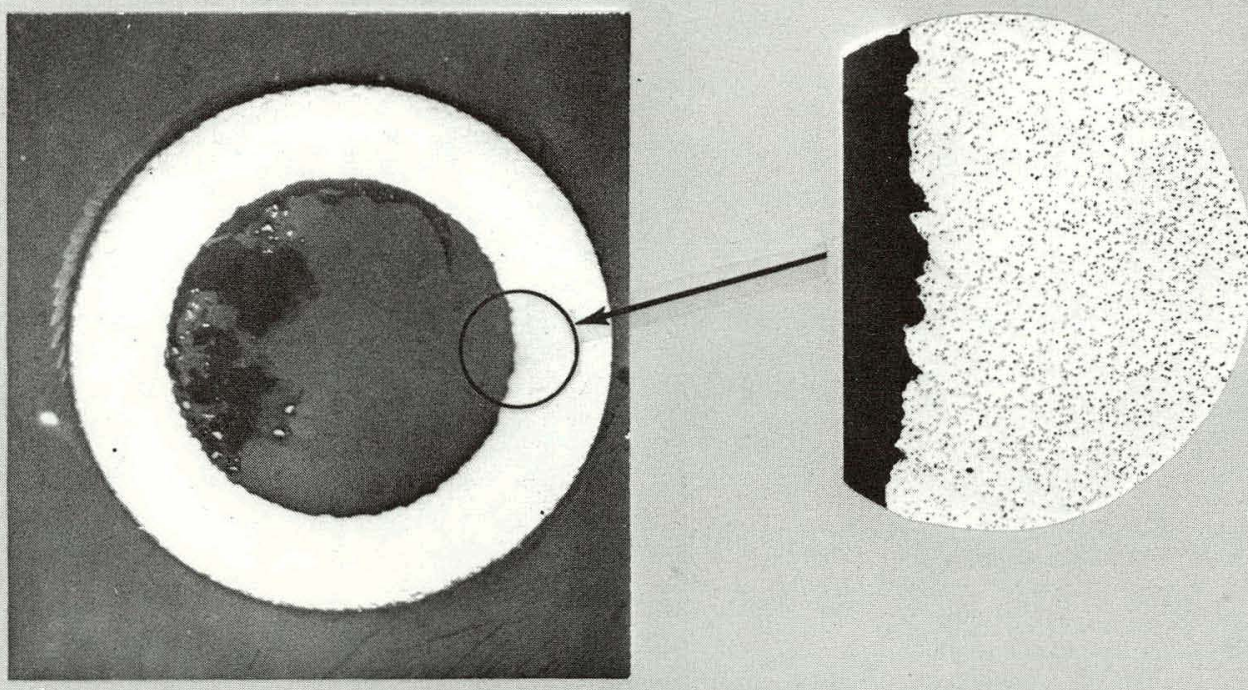

(Neg. 7485, 10X)

(Neg. 7417, 100X)

Cross section of a tube processed by sinking without a bore filler. Note irregularities of walls shown in the inset photomicrograph (Unetched)

Fig. 3.2-Comparison of $\mathrm{W}-30 \mathrm{Re}-30$ Mo tubing surfaces produced with and without $a$ hardened mandrel in the core during drawing 


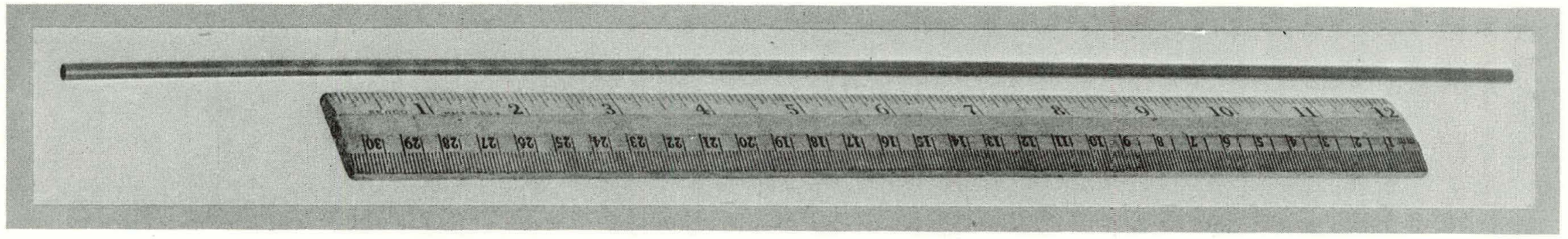

Fig. 3.3 - Finished W- 30Re - 30Mo tube; $45-\mathrm{cm}$ long by $0.425-\mathrm{cm}$ OD by 0.345-cm ID (Neg. P66-7-10) 


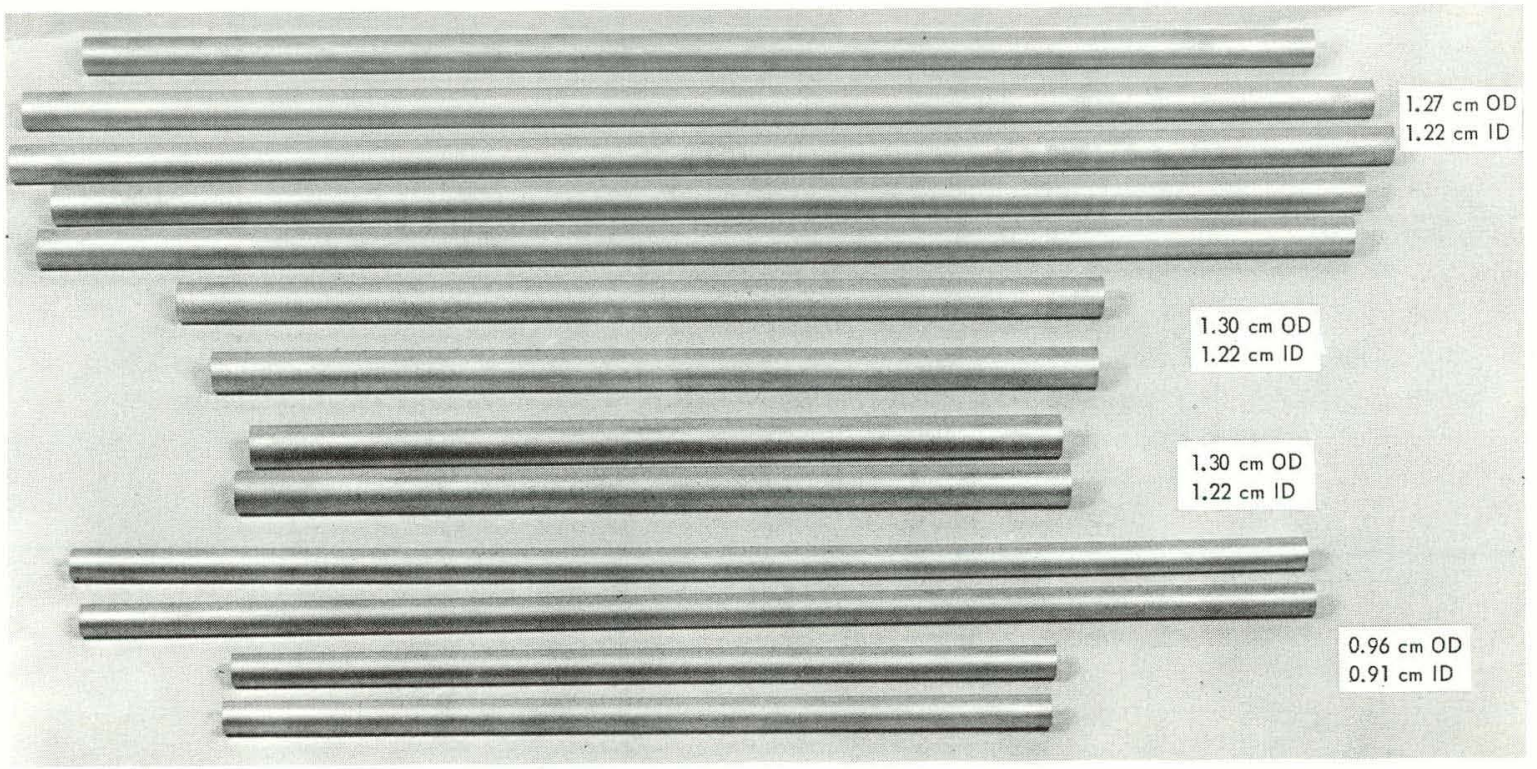

Fig. 3.4-Finished product obtained from extrusion D-46, W- 30Re - 30Mo. Longest tube is $47 \mathrm{~cm}$ long. (Neg. P66-10-57)

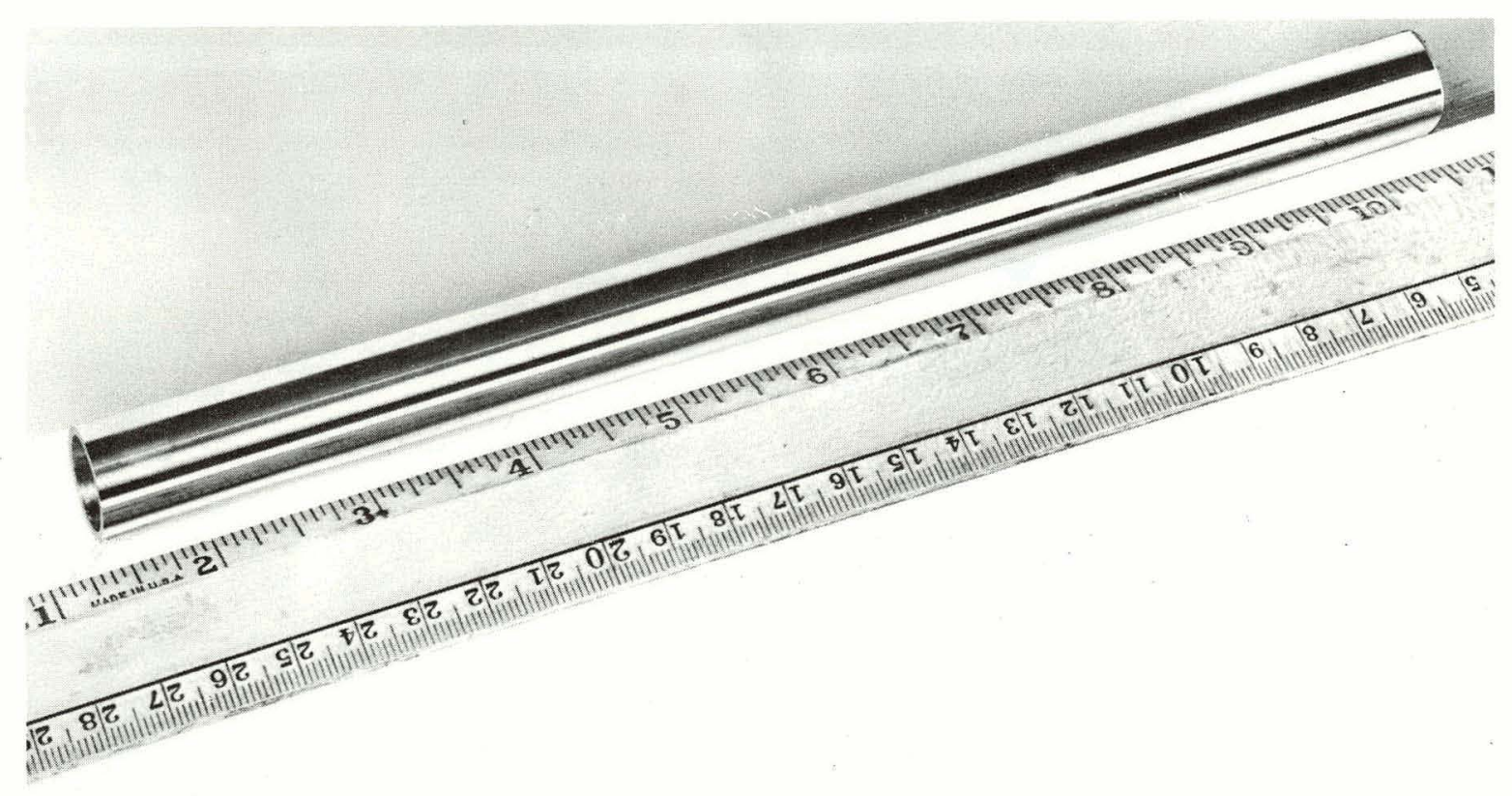

Fig. 3.5-Honed and ground segment of Extrusion D-46, W-30Re-30Mo alloy, as prepared for tube drawing. Approximately $152 \mathrm{~cm}$ of finished tubing drawn to $1.27-\mathrm{cm}$ diameter by $0.0254-\mathrm{cm}$ wall thickness was obtained from this tube. (Neg. P66-9-32D) 

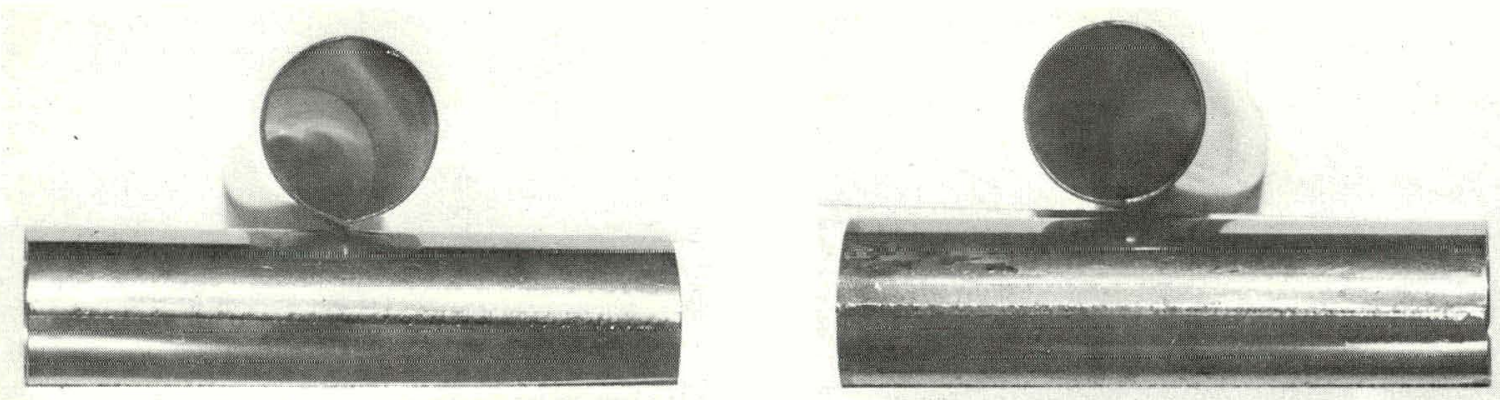

Fig. 3.6 - Formed and welded tube of W-30Re-30Mo alloy shown at left as-welded. The good circular quality obtained by drawing is shown on the right. (Neg. P66-9.32B)

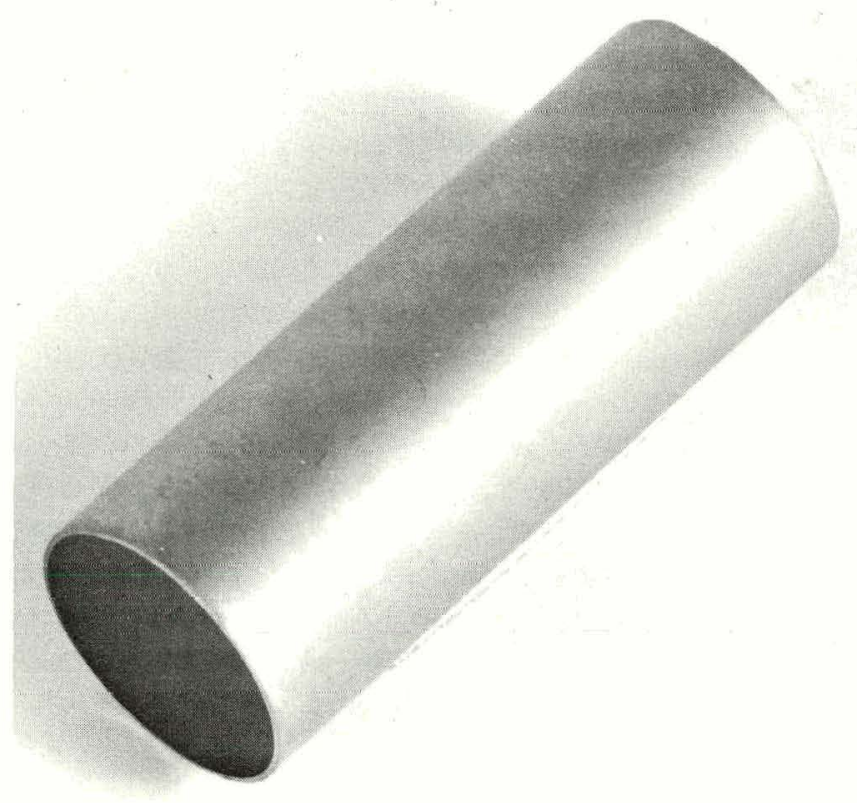

Fig. 3.7 - Tube obtained by drawing a formed and welded she ef arc-cast W-25Re alloy. Weld area cannot be detected by visual examination. (Neg.P66-9.17)

An application of the seam welding and drawing technique is in the fabrication of composite structures, that can be fitted together, such as the five-layer assembly shown in Figure 3.8. If the structure is autoclave bonded, a multiple layer component containing two or more metals or alloys can be fabricated. A typical structure, for example, would be comprised of a metal of suitable corrosion resistance for contact with one liquid metal as the inner surface, high-strength materials in the middle layers, and a second corrosionresistant metal as the outer layer. Since each layer can be separately inspected, quality could be assured before assembling and drawing to finished size. 


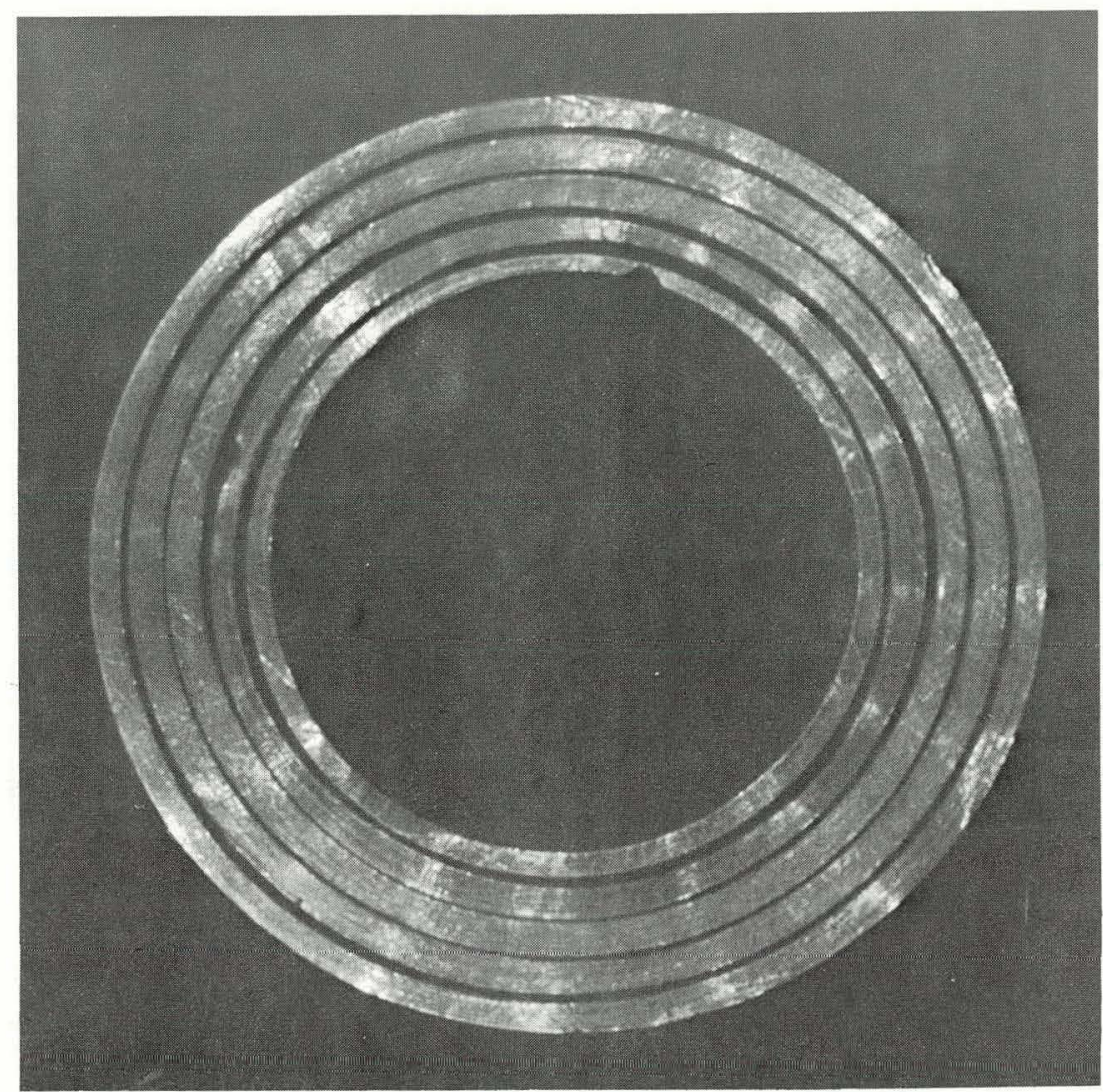

Fig. 3.8-Example of multilayer composite structure obtainable with GE-NMPO tube processing procedures. The five concentric tubes can be diffusion bonded into a single tube drawing blank and worked to a finished tube. (Neg. P64-5-27E)

\section{2 PURIFICATION OF MO AND Mo-BASE ALLOYS}

Joining molybdenum sheets and tubing is often characterized by an extremely brittle weld area. Brittleness is caused by recrystallization and weld porosity which greatly reduces the inherent strength of the molybdenum. The objective of this investigation has been to improve the quality of Mo and Mo-base alloys through process purification treatments. Specific goals were to improve weld soundness and toughness and to obtain lowtemperature ductility following short-time heating to high temperatures. This program has been conducted in two phases: (1) a program to develop purification procedures for Mo (and W), and (2) a program to apply the purification procedures to include Mo-base alloys containing Re.

\section{PURIFICATION OF UNALLOYED MO}

As shown in Figure 3.1, a key step in improving the room-temperature ductility of Mo sheet and also its weldability is to treat compacted metal powders for prolonged periods at $1000^{\circ} \mathrm{C}$ in a hydrogen - water vapor atmosphere; this treatment removes carbon. Additional treatments at $1000^{\circ} \mathrm{C}$ and $1450^{\circ} \mathrm{C}$ in dry hydrogen remove dissolved oxygen. The bend ductility of Mo sheet processed in this manner is compared with that of commercial arc-cast and powder-metallurgy process Mo in Table 3.2. This table shows that Mo sheet receiving these treatments is ductile after welding and after heating to $2400^{\circ} \mathrm{C}$. The bend ductility of welded specimens is given in Table 3.3. After stress relieving, full 90-degree bends were obtained as shown in Figure 3.9. 
TABLE 3.2

COMPARISON OF WELDABILITY AND BEND TESTS ON THREE TYPES OF MOLYBDENUM SHEET

\begin{tabular}{lcccc}
\hline & \multicolumn{3}{c}{ Room-Temperature Bend Tests } & \\
\cline { 2 - 4 } \multicolumn{1}{c}{ Material } & As-Received & $\begin{array}{c}\text { After 2 Hour Heat } \\
\text { Treatment at } 2400^{\circ} \mathrm{C}\end{array}$ & After Welding & Condition of Welds \\
\hline $\begin{array}{l}\text { Commercial powder- } \\
\text { metallurgy sheet }\end{array}$ & $90^{\circ}$ bends & $\begin{array}{l}90^{\circ} \text { bends (fine- } \\
\text { grained) }\end{array}$ & Not tested & $\begin{array}{l}\text { Large blow holes } \\
\text { (unweldable) }\end{array}$ \\
$\begin{array}{l}\text { Commercial arc-cast } \\
\text { sheet }\end{array}$ & $90^{\circ}$ bends & Brittle & Brittle & Excellent \\
$\begin{array}{l}\text { GE-NMPO powder- } \\
\text { metallurgy sheet }\end{array}$ & $90^{\circ}$ bends & $\begin{array}{l}90^{\circ} \text { bends (fine- } \\
\text { grained) }\end{array}$ & $45^{\circ}-90^{\circ}$ bends & Microporosity \\
\hline
\end{tabular}

${ }^{\text {a }}$ Coarsened to very large grains.

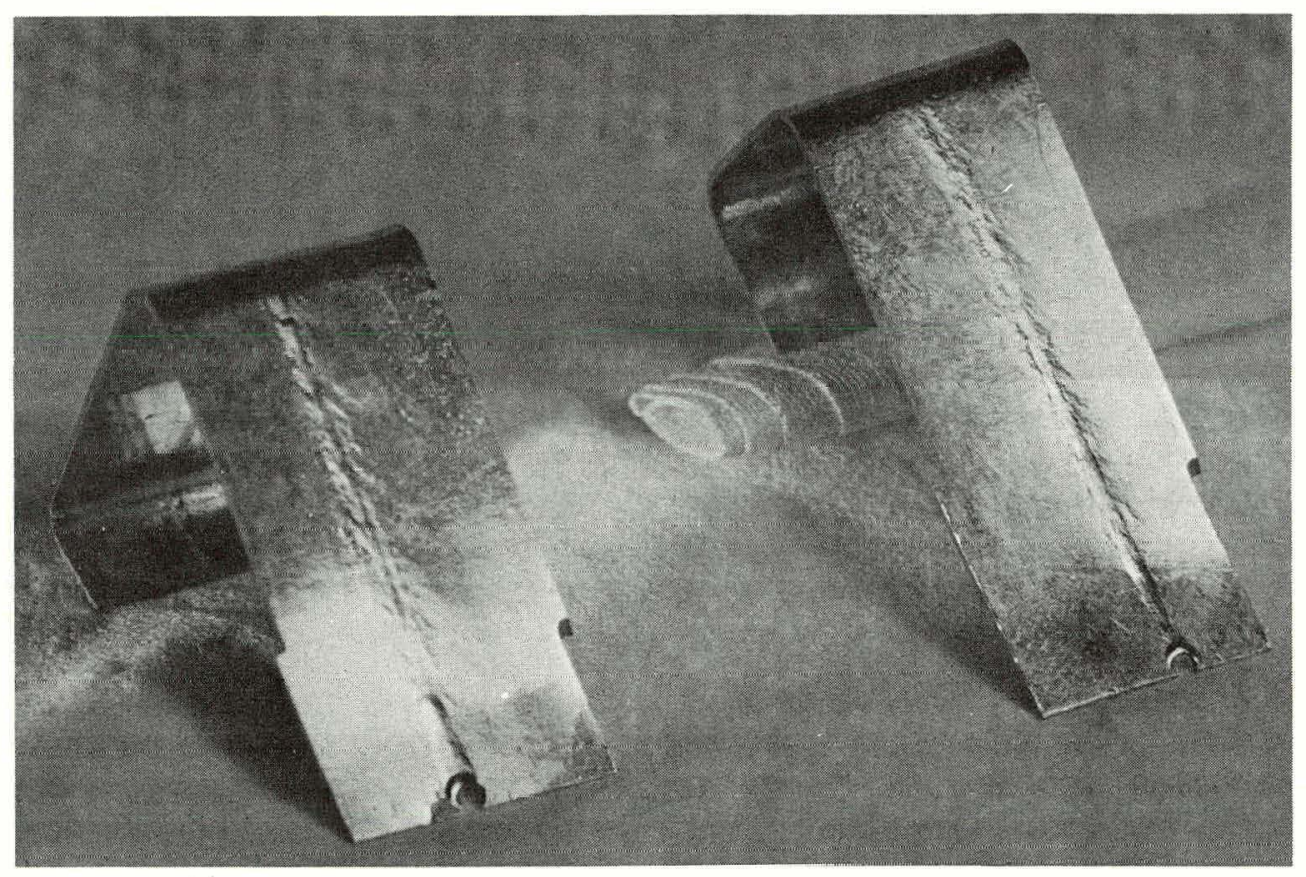

Fig. 3.9 - Bends completed at room temperature and at $-50^{\circ} \mathrm{C}$ on $0.050-\mathrm{cm}$ thick electron beam welded Mo sheet. Specimens were stressrelieved for 2 hours at $1450^{\circ} \mathrm{C}$ in hydrogen before bending. (Neg.P66-4-2) 
TABLE 3.3

DUCTILITY OF EB-WELDED PURIFIED MO SHEET ${ }^{\mathrm{a}}$

\begin{tabular}{cccc}
\hline $\begin{array}{c}\text { Sheet } \\
\text { Designation }\end{array}$ & $\begin{array}{c}\text { As-Welded } \\
\text { Room-Temperature } \\
\text { Bend, degrees }\end{array}$ & $\begin{array}{c}\text { As-Welded and Stress-Relieved } \\
\text { Room-Temperature } \\
\text { Bend, degrees }\end{array}$ & $\begin{array}{c}-50^{\circ} \text { C Bend, } \\
\text { degrees }\end{array}$ \\
\hline 3 & 10 & 50 & 30 \\
4 & 45 & 45 & 45 \\
5 & 10 & $>90$ & 70 \\
6 & $>90$ & $>90$ & $>90$ \\
7 & 30 & $>90$ & - \\
8 & 30 & $>90$ & $>90$ \\
9 & 45 & $>90$ & $>90$ \\
\hline
\end{tabular}

${ }^{a_{B}}$ dends conducted with $2 \mathrm{~T}$ radius punch in accordance with recommendations of the Materials Advisory Board for refractory sheet.

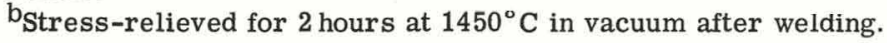

The purification treatment greatly improved both the weld ductility and weld porosity; however, there is still a tendency for some microporosity to form in the EB-welded area. This microporosity is not visible on the weld surface nor does it reduce weld ductility.

The improvements in ductility and weldability resulting from reducing the carbon and oxygen contents has been followed by an attempt to identify any other impurity or impurities which could be contributing to the internal microporosity observed in EB-weld zones. This work is incomplete, but several impurities have been identified for detailed studies.

To identify the trace impurity elements which might account for microporosity, a chemical analysis was performed for elements Li through Pu (Atomic No. 3 through 94) on an arc-cast process commercial Mo sheet with nonporous but brittle welds and Mo sheets processed by GE-NMPO, two with and two without weld porosity.

Chemical analyses were performed by the Union Carbide Nuclear Division, * using a spark-snurre mass spertrngraph. Twelve elements, consistently present in all specimens with markedly different concentrations, were selected from the overall analysis and are shown in Table 3.4. One or more of these elements having high vapor pressures (i. e., $\mathrm{Na}, \mathrm{Mg}, \mathrm{Al}, \mathrm{Si}, \mathrm{P}, \mathrm{K}, \mathrm{Ca}, \mathrm{Cr}, \mathrm{Mn}, \mathrm{N}, \mathrm{Cu}$, and $\mathrm{Sn}$ ) are believed to possibly contribute to the microporosity found in the EB-weld areas. The continuing program is intended to identify more positively the undesired constituents. Traces of alkaline elements have frequently been cited in the metallurgical literature as possible causes of weld porosity in refractory metals.

Another approach toward identifying the impurity elements responsible for weld porosity was through the weld evaluation of sheet stock fabricated from high-purity Mo obtained through the Mo fluoride dissociation process. A 500-gram batch of high-purity Mo was obtained from Union Carbide for this study. The spectrographic analysis (in ppm) on the powder reccived from Union Carbide was:

$$
\begin{array}{lll}
\mathrm{Ag}-<1 & \mathrm{Co}-<10 & \mathrm{Mn}-<1 \\
\mathrm{Al}-<1 & \mathrm{Cr}-<10 & \mathrm{Na}-<100 \\
\mathrm{~B}-<20 & \mathrm{Cu}-2 & \mathrm{Ni}-30 \\
\mathrm{Be}-<1 & \mathrm{~F}-113 & \mathrm{Si}-4 \\
\mathrm{C}-42 & \mathrm{Fe}-10 & \mathrm{Sn}-<10 \\
\mathrm{Cd}-<10 & \mathrm{Mg}-<1 & \mathrm{Ti}-15 \\
& & \mathrm{~V}-<20
\end{array}
$$

*Y-12 Plant, Oak Ridge, Tennessee. 
TABLE 3.4

TWELVE IMPURITY ELEMENTS SELECTED FROM SPARK SOURCE MASS SPECTROGRAPHIC ANALYSIS OF FIVE MO SHEETS ${ }^{a}$

\begin{tabular}{|c|c|c|c|c|c|}
\hline \multirow[b]{2}{*}{ Element } & \multicolumn{5}{|c|}{ Content, ppm } \\
\hline & $\begin{array}{l}\text { Weldable } \\
\text { Commercial } \\
\text { Arc-Cast } \\
\text { Mo Sheet }\end{array}$ & $\begin{array}{c}\text { GE-NMPO } \\
\text { Sheet C } \\
\text { (Weldable) }\end{array}$ & $\begin{array}{c}\text { Powder-Metallurgy } \\
\text { Sheet D } \\
\text { (Porous Welds) }\end{array}$ & $\begin{array}{c}\text { Process F } \\
\text { Sheet H } \\
\text { (Weldable) }\end{array}$ & $\begin{array}{c}\text { Purified Mo Sheet } \\
\text { Sheet P } \\
\text { (Porous Welds) }\end{array}$ \\
\hline $\mathrm{Na}$ & 0.69 & 0.23 & 0.75 & 2.1 & 2.2 \\
\hline $\mathrm{Mg}$ & 1.3 & 42 & 10 & 3.9 & 14 \\
\hline $\mathrm{Al}$ & 0.15 & 5.0 & 5.0 & 1.5 & 5. 0 \\
\hline $\mathrm{Si}$ & 7.0 & 35.0 & 35.0 & $32.0^{\mathrm{b}}$ & 11.2 \\
\hline $\mathbf{P}$ & 0.17 & 0.18 & 0.61 & 0.55 & 0.58 \\
\hline $\mathbf{K}$ & 0.06 & 0.39 & 1.3 & 1.2 & 1.2 \\
\hline $\mathrm{Ca}$ & $0.75^{b}$ & $0.81^{b}$ & $2.7^{b}$ & $2.5^{\mathrm{b}}$ & $7.7^{\mathrm{b}}$ \\
\hline $\mathrm{Cr}$ & 3.8 & 12.0 & 4.1 & 7.5 & 11. 7 \\
\hline Mn & 0.30 & 0.32 & 0.36 & 0.97 & 1.0 \\
\hline $\mathrm{Ni}$ & 0.34 & 5.7 & 5.7 & 15.7 & 16.2 \\
\hline $\mathrm{Cu}$ & 0.56 & 1.8 & 1.8 & 1.7 & 0.58 \\
\hline Sn & 0.66 & 7.0 & 7.1 & 2.2 & 2.2 \\
\hline $\begin{array}{l}\text { Total impurities, } \\
\text { ppm }\end{array}$ & 15.78 & 110.43 & 74.42 & 71.82 & 219. 36 \\
\hline $\begin{array}{l}\text { Total of } \\
\mathrm{Na}+\mathrm{K}+\mathrm{Mg}+\mathrm{Si}+\mathrm{Al}+\mathrm{Ca}\end{array}$ & 9.95 & 83.43 & 54.75 & 65.70 & 187.10 \\
\hline Total of $\mathrm{Si}+\mathrm{Mg}$ & 8. 30 & 77.00 & 45.0 & 35.90 & 121.00 \\
\hline $\begin{array}{l}\% \text { of Total for the } \\
\mathrm{Na}, \mathrm{K}, \mathrm{Mg}, \mathrm{Si}, \mathrm{Al}, \mathrm{Ca}\end{array}$ & 0.63 & 0.76 & 0.74 & 0.91 & 0.85 \\
\hline $\mathrm{Si}+\mathrm{Mg} \%$ of Total & 0.52 & 0.69 & 0.60 & 0.50 & 0.57 \\
\hline
\end{tabular}

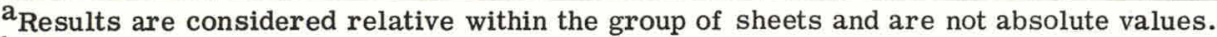

$b_{\text {Erratic. }}$

As can be seen, the fluoride impurity is high; however, it was expected that the subsequent purification treatment would greatly reduce this impurity.

Powder compacts were made into rectangular-shaped billets and treated for 600 hours at $1000^{\circ} \mathrm{C}$ in a hydrogen - water vapor atmosphere. This treatment is known to remove essentially all the carbon impurities and other volatiles. The purified compacts were fabricated into sheet by the usual hot- and cold-working techniques. The finished sheet made from the fluoride dissociated powders, when EB-welded, continued to show definite voids or pores in the weld areas, see Figures 3.10 and 3.11. Although porosity developed in the weld area, it is felt that work with the fluoride dissociated powder will give significant guidance for future work. The fluoride dissociation powders were lower in $\mathrm{Al}, \mathrm{Mg}$, and Si contents than that found in the GE-NMPO purified power which did not develop porosity in weld areas, but it did have higher $\mathrm{Na}$ and $\mathrm{Ni}$ impurities which may have led to weld porosity.

\section{PURIFICATION OF MO-BASE ALLOYS}

A group of tests was performed under Task 57005 to determine the long-time hightemperature stability of $\mathrm{UO}_{2}$-fuel-bearing cermet cores clad with $\mathrm{W}-30 \mathrm{Re}-30 \mathrm{Mo}$ alloy. The cladding had been prepared into small cylinder tubes by the seam welding and drawing technique previously described under this task. Welded $\mathrm{W}-30 \mathrm{Re}-30 \mathrm{Mo}$ capsules were held at $2500^{\circ} \mathrm{C}$ for several thousand hours. Microscopic examination of the cladding after testing revealed internal porosity throughout the microstructure except in the areas adjacent to the weld. It was tentatively assumed that the general porosity observed in the sheet stock was due to internal vapor pressure from the trace impurities. The nonporous 


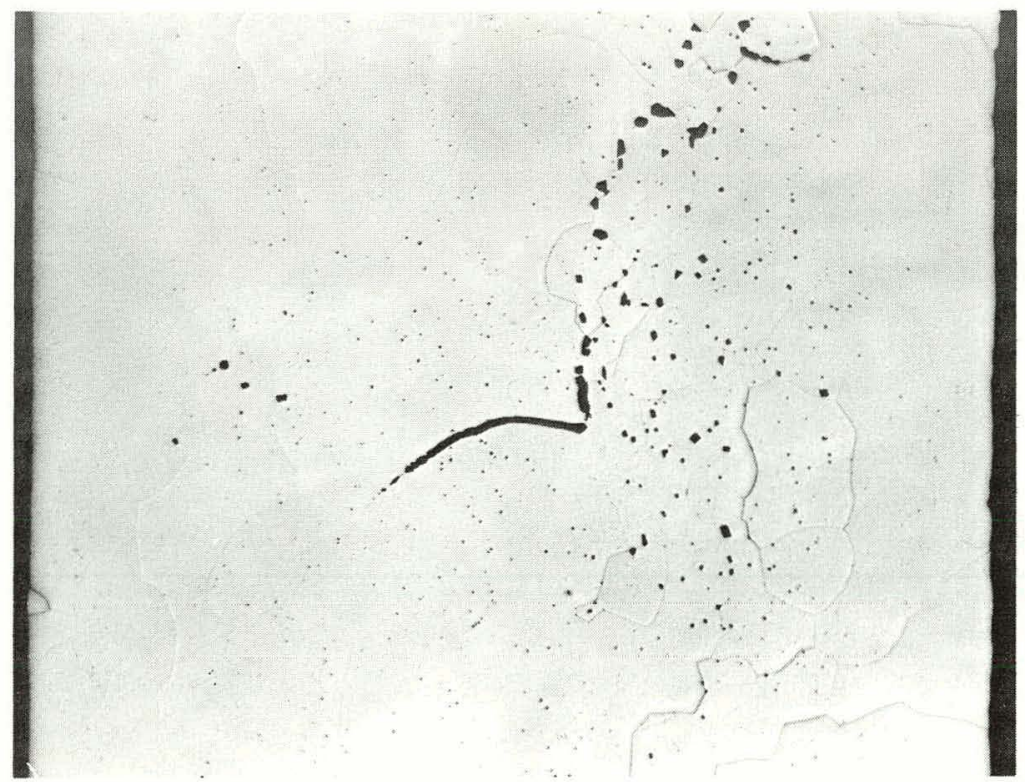

Fig. 3.10-Cross section of 0.100-cm-thick molybdenum sheet (hot-rolled and deoxidized) made from fluorine process Mo powder. Note long intergranular dark precipitant and numerous scattered small dark inclusions. (Neg. 7603, unetched, 100X)

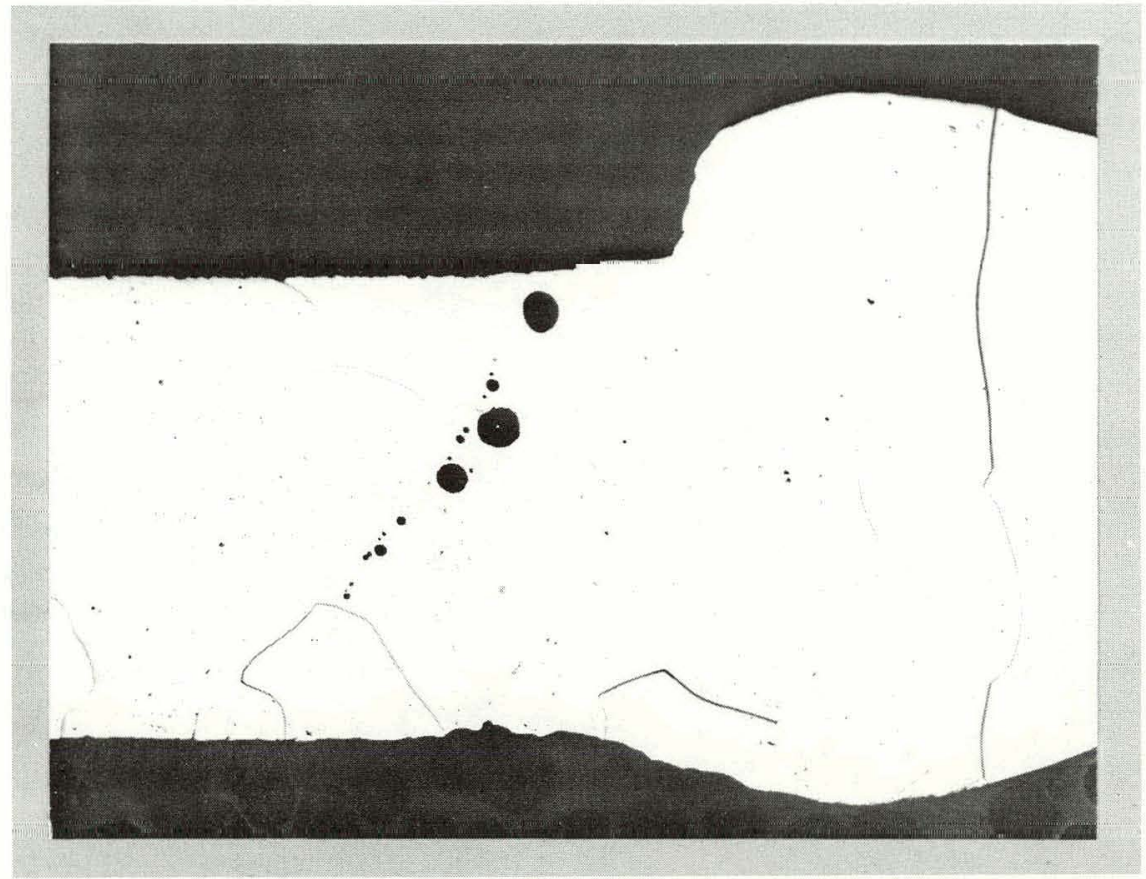

Fig. 3.11-Photomicrograph showing electron-weld-fused area in sheet made from fluorine process Mo powder. An undesired, large columnar structure is observed within the central portion of the weld (probably cracked), and there are numerous voids or pores in the weld to sheet interface area. (Neg. 7672, unetched, 50X) 
microstructure observed adjacent to the weld was assumed to be a result of a prior cleanup in the fused weld areas. Since considerable precautions are always taken to insure against any contamination by the inert gas used in the test furnace, contamination from the furnace atmosphere was considered to be improbable.

In preliminary studies directed toward solving the porosity problem and to developing Mo-base alloys of improved properties relative to those of commercial Mo-TZM and Mo-TZC, 0.054-cm-thick sheet was rolled from Mo $-5 \mathrm{Re}$, Mo $-3 \mathrm{Re}-5 \mathrm{~W}$, and Mo $-5 \mathrm{~W}$ compositions. The rolled sheets were given simulated EB welds and these areas were $\mathrm{X}$-rayed to inspect for porosity. Radiographs of the findings are shown in Figure 3.12. $\mathrm{X}$-rays of the welded alloyed Mo sheet showed the Mo $-5 \mathrm{Re}$ specimen contained internal porosity at the weld areas. Porosity was not noted in the Mo $-3 \mathrm{Re}-5 \mathrm{~W}$ alloy while there was some possible porosity in the Mo $-5 \mathrm{~W}$ alloy. Assuming the porosity was the result of impurities, an evaluation was made of the various raw materials used in the preparation of the alloys. Since prior alloy studies using $W$ as an alloying agent have shown it did not contribute to internal porosity, the indication was that the Re powder used might be contributing to the porosity found in the sheet.

\section{$\underline{\text { Raw Material Evaluation }}$}

Since impurities in the Re powder were believed to be a contributing factor for porosity in the finished sheet, the source of Re powder could be significant. To evaluate raw materials from different sources, 300-gram W-30Re - 30Mo powder metal compacts were prepared from American- and European-produced Re; the W and Mo powders were from the same source.

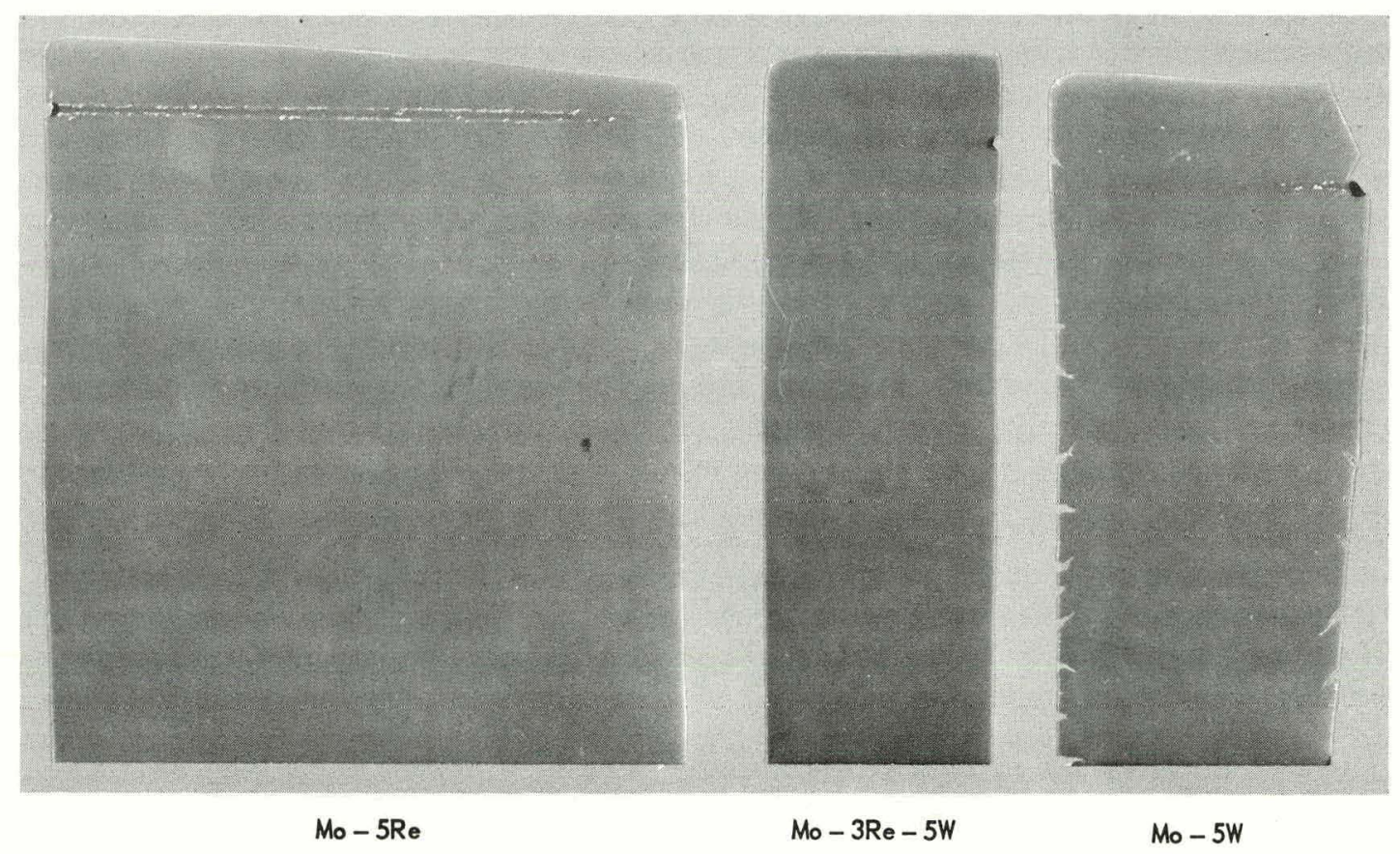

Fig. 3.12 - X-rays of welds in alloyed Mo sheet. White dots in the Mo-5Re specimen are internal porous areas not visually observed on the welded sheet. Pores are not noted in Mo $-3 R e-5 W$ alloy. Possible small pores in the Mo- $5 \mathrm{~W}$ alloy appear only at the starting end of the weld (right side). (Neg. 8079) 
The compacts were sintered, hot-rolled to $0.10-\mathrm{cm}$-thick sheet, and heated for 64 hours at $1400^{\circ} \mathrm{C}$ in hydrogen to remove oxygen absorbed during hot rolling. A simulated weld was made by electron-beam fusing an area along the length of the sheet. As shown in Figure 3.13, metallographic examination of the weld areas revealed undesirable porosity in the sheet processed from foreign $\mathrm{Re}$, while a sound weld was obtained in the sheet made using American-produced Re powder.

Evaluating metal powders from different sources will continue, especially since the American supplier emphasizes the use of purified ammonium perrhenate in the production of high-purity powder. Typical impurity analysis of the American Re was reported ${ }^{2}$ to be $2 \mathrm{ppm}$ or less of $\mathrm{Al}, \mathrm{Ca}, \mathrm{Cr}, \mathrm{Cu}, \mathrm{Fe}, \mathrm{Mg}, \mathrm{Ni}, \mathrm{Si}, \mathrm{Na}$, and $\mathrm{K}$. The foreign $\mathrm{Re}$ was analyzed at $7 \mathrm{ppm}-\mathrm{Na}_{2} \mathrm{O}, 5 \mathrm{ppm}-\mathrm{K}_{2} \mathrm{O}$, and $34 \mathrm{ppm}-\mathrm{SiO}_{2}$ as typical impurity levels; these values are considerably higher than were found for the same impurities in American-produced Re.

\section{3 AGING AND STRESS-RELIEF STUDIES OF W-Re-Mo ALLOYS}

The objective of the W-Re and W-Re-Mo alloy development programs is to provide useful, stronger metals with melting points above $2760^{\circ} \mathrm{C}$, for service primarily in the temperature range from $1900^{\circ}$ to $2600^{\circ} \mathrm{C}$. From this work, the $\mathrm{W}-25 \mathrm{Re}-30 \mathrm{Mo}$ and $\mathrm{W}-30 \mathrm{Re}-30 \mathrm{Mo}$ alloys have been selected for evaluation for service in the $1200^{\circ}$ to $1900^{\circ} \mathrm{C}$ range because of their inherent strength, ductility, and weldability. The W-Re-Mo alloy has a two-phase region consisting of a bcc solid solution plus a sigma phase in alloys containing more than 25 atomic percent rhenium. The sigma phase shows markedly increasing solubility in the bcc matrix with increasing temperature and is, therefore, potentially an age-hardening constituent.

To investigate solutioning temperature and aging temperature parameters, hardness tests were performed on a $\mathrm{W}-30 \mathrm{Re}$ alloy. For this program, the alloy was treated at $1650^{\circ} \mathrm{C}$ and $3000^{\circ} \mathrm{C}$ prior to cold-working to sheet. Specimens of the $\mathrm{W}-30 \mathrm{Re}$ alloy sheet were prepared for aging by solution-treating for 1 hour at $1800^{\circ}, 2000^{\circ}, 2200^{\circ}$, and $2400^{\circ} \mathrm{C}$ in vacuum. The specimens were then aged for 2,10 , and 100 hours by heating at $1000^{\circ}$, $1200^{\circ}, 1400^{\circ}, 1600^{\circ}$, and $1800^{\circ} \mathrm{C}$; a Rockwell "A" hardness value was obtained after each aging treatment. ${ }^{3}$

As shown in Figure 3.14, age hardening developed in the alloy at the $1400^{\circ}, 1600^{\circ}$, and $1800^{\circ} \mathrm{C}$ aging temperatures, but not at $1000^{\circ} \mathrm{C}$ and $1200^{\circ} \mathrm{C}$. Since the treatment at $1800^{\circ} \mathrm{C}$ produced the most positive change in hardness, the optimum aging temperature for maximum hardness may be higher than $1800^{\circ} \mathrm{C}$. Nucleation phenomena rather than precipitants may be responsible for age-hardening in these alloys. ${ }^{4}$

With the knowledge that the $\mathrm{W}-30 \mathrm{Re}$ alloy age-hardens at $1400^{\circ}$ to $1800^{\circ} \mathrm{C}$, the investigation was extended to include $\mathrm{W}-30 \mathrm{Re}$ alloy with 0 to 55 atomic percent Mo as a ternary addition. ${ }^{5}$ The specific compositions studied were:

$$
\begin{aligned}
& \text { W- }-30 R e \\
& \text { W }-30 R e-10 \mathrm{Mo}(\text { also } \mathrm{W}-20 \mathrm{Re}-10 \mathrm{Mo}) \\
& \mathrm{W}-30 \mathrm{Re}-20 \mathrm{Mo} \\
& \mathrm{W}-30 \mathrm{Re}-30 \mathrm{Mo} \\
& \mathrm{W}-30 \mathrm{Re}-40 \mathrm{Mo} \\
& \mathrm{W}-30 \mathrm{Re}-55 \mathrm{Mo}
\end{aligned}
$$

\footnotetext{
${ }^{2}$ J. H. Port, "Recent Developments in Rhenium and Rhenium Alloy Technology;" Plansee Proceedings, 1964, pp. 614-615.

3،'High-Temperature Materials Program Progress Report No. 55, Part A," GE-NMPO, GEMP-55A, January 21, 1966, p. 60.

${ }^{4}$ GEMP-55A, p. 63.

5،'High-Temperature Materials Program Progress Report No. 63," GE-NMPO, GEMP-63, December 30, 1966, p. 61.
} 

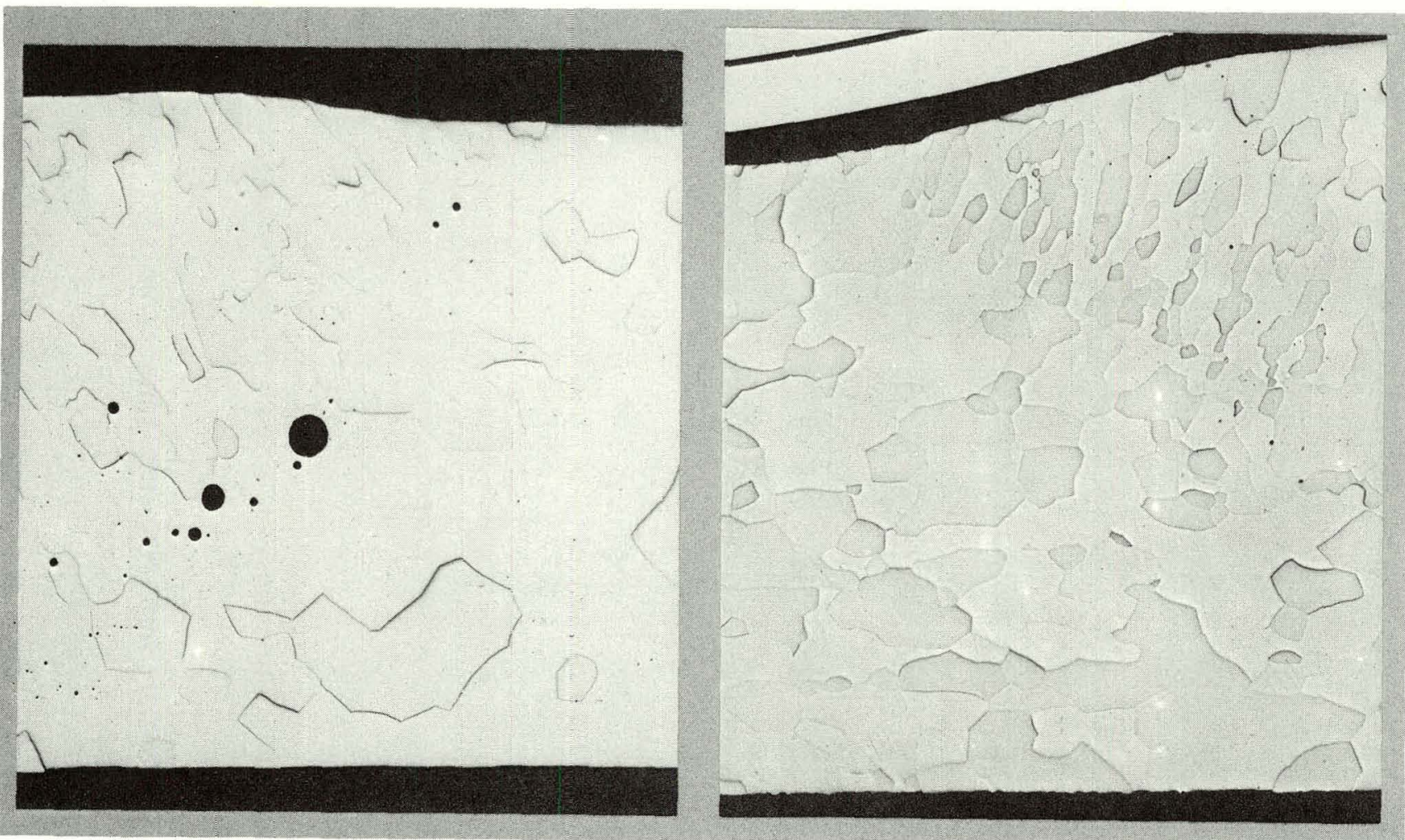

a. Porosity in weld-influenced area of $\mathrm{W}-30 \mathrm{Re}-30 \mathrm{Mo}$ sheet proces sed from European produced rheni sm

b. Sound metal in weld-influenced area in metal powder. (Neg. 7498) $W-30 R e-30 M 0$ sheet processed from U.S. produced rhenium. (Neg. 7497)

Fig. 3.13-Photomicrographs showing weld areas of hotrollet sheet produced from U.S. and European produced rhenium (Unetched, 75X) 

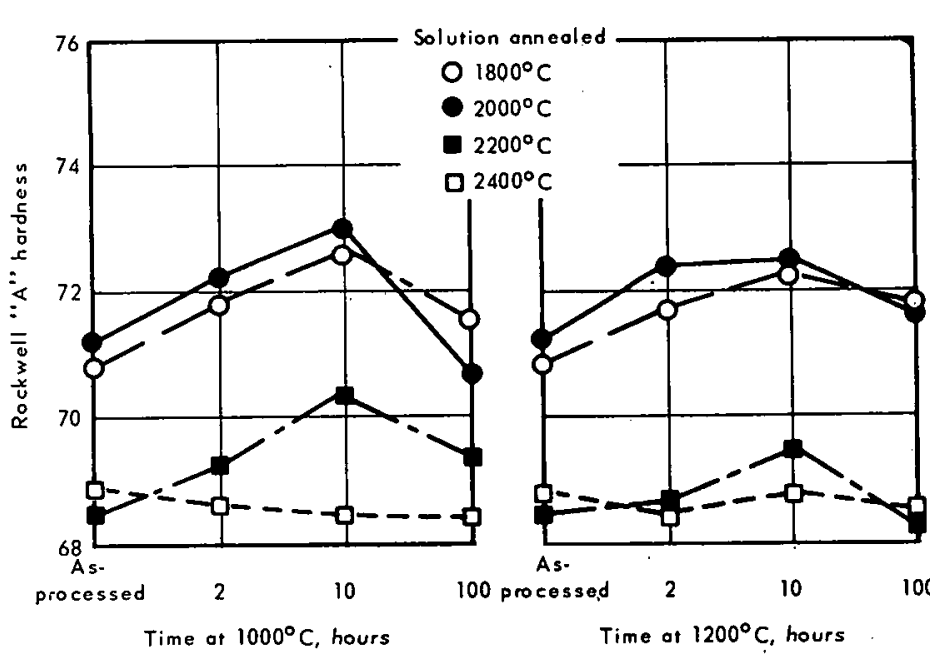

before cold-working
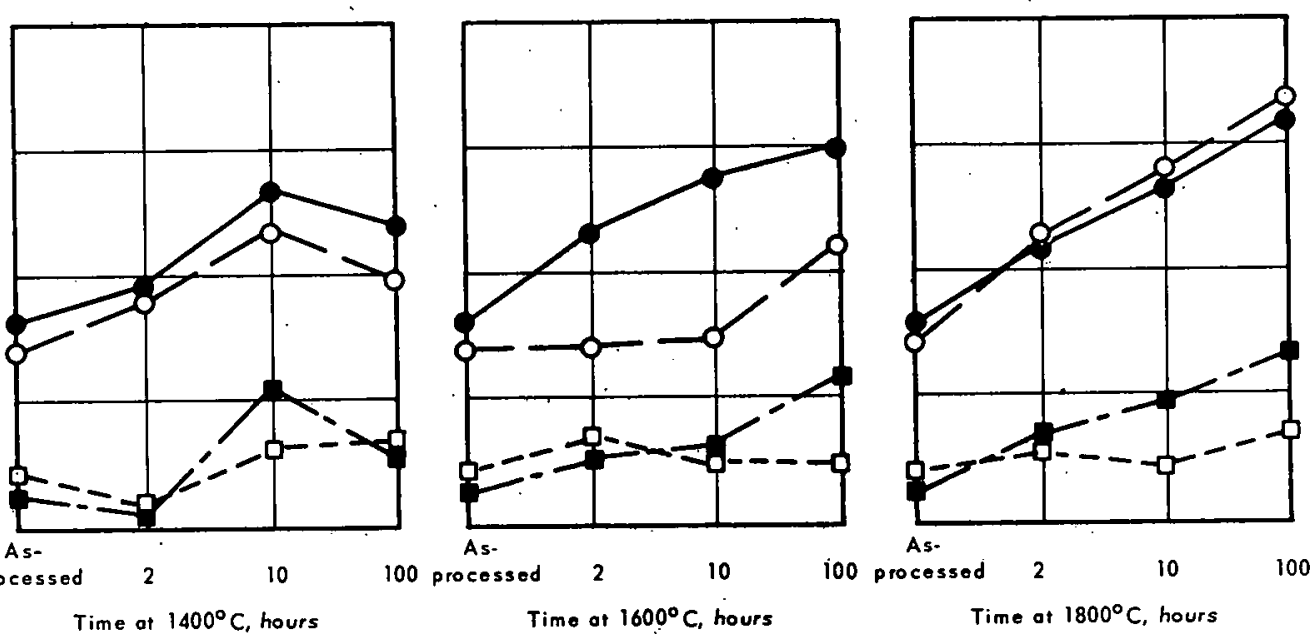

W- 30Re treated at $1650^{\circ} \mathrm{C}$ before cold-working
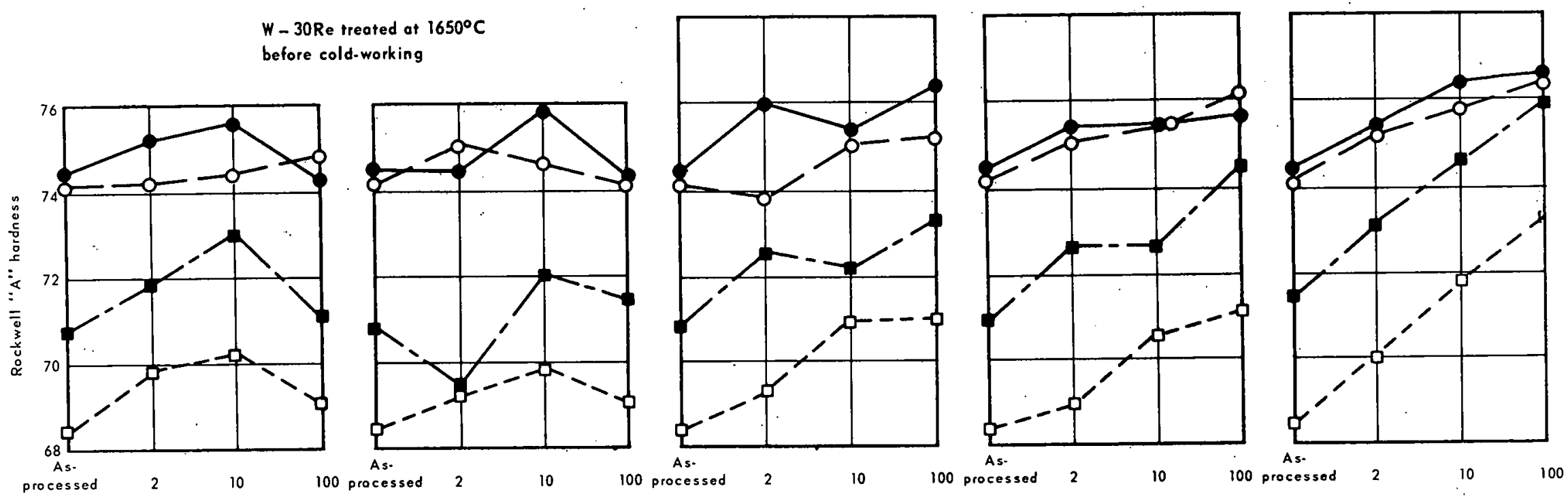

Time of $1000^{\circ} \mathrm{C}$, hours Time of $1200^{\circ} \mathrm{C}$, hours

Time of $1400^{\circ} \mathrm{C}$, hours

Time of $1600^{\circ} \mathrm{C}$, hours

Time at $1800^{\circ} \mathrm{C}$, hours

Fig. 3.14 - Influence of solution anneal and aging temperature on age-hardening of W-30Re 
These ternary alloys were solution-treated at $2400^{\circ} \mathrm{C}$ and aged for 2,10 , and 100 hours at $1400^{\circ} \mathrm{C}$ and $1600^{\circ} \mathrm{C}$. Supplementary test series included 16 -hour treatments at $1800^{\circ} \mathrm{C}$ and $2200^{\circ} \mathrm{C}$ prior to aging 100 hours at $1400^{\circ} \mathrm{C}$. Tentative conclusions derived from this investigation, in good accord with anticipated alloy behavior, were as follows:

1. The hardness level was reduced slightly with increasing Mo content.

2. There is slightly more aging response at $1400^{\circ} \mathrm{C}$ after the $2200^{\circ} \mathrm{C}$ solution treatment than after the $1800^{\circ} \mathrm{C}$ or $2400^{\circ} \mathrm{C}$ treatment.

Based on this work, the W-Re-Mo ternary alloy systems appear to have the potential of significant desirable aging characteristics at $1400^{\circ} \mathrm{C}$ and lower.

\subsection{SUMMARY AND CONCLUSIONS}

Various refractory-metal alloy systems are being investigated under this program, as well as new processing procedures and fabrication techniques. Two of the most significant accomplishments during CY-66 are the development of tube drawing techniques for W-Re-Mo alloys and purification procedures that have enhanced the ductility and weldability of unalloyed molybdenum.

A complete fabrication procedure was developed and confirmed for obtaining excellent quality seamless tubing of W-Re-Mo alloys. This process covers all phases of seamless tubing production from procuring the metal powders to demonstrating weldability of the finished tubing. $\mathrm{W}-25 \mathrm{Re}-30 \mathrm{Mo}$ and $\mathrm{W}-30 \mathrm{Re}-30 \mathrm{Mo}$ alloys were selected for first process confirmation and trial tubing production runs. Tube drawing parameters are being determined for other refractory-metal alloys, such as $\mathrm{W}-25 \mathrm{Re}$, in an effort to establish a source of high-quality tubing of these alloys.

Progress was made under a continuing research program directed oward improved ductility and weldability in unalloyed molybdenum. Purification procedur $\mathrm{S}$ s were developed that result in sheet of the desired ductility and weldability. Trial production runs of sheet for confirmation of the research results are underway, and tubing fabrication procedures are being developed.

These same purification procedures have also been extended to W-Re-Mo alloys in an effort to improve the quality of these ternary alloys. Among other things, this work revealed that high-purity rhenium produced in the United States has less tendency than rhenium acquired from foreign producers to cause weld porosity in finished W-Re-Mo alloys.

$\mathrm{W}-\mathrm{Re}-\mathrm{Mo}$ alloys containing 30 atomic percent rhenium exhibit significant age hardening at $1800^{\circ} \mathrm{C}$, and less hardening at $1600^{\circ} \mathrm{C}$ or lower. New compositions are being developed, therefore, in an effort to obtain strong alloys for service in the $1200^{\circ}$ to $1600^{\circ} \mathrm{C}$ temperature range.

\subsection{PLANS AND RECOMMENDATIONS}

Emphasis will be directed toward improving both the quality and the production rates of nuclear quality W-Re-Mo alloy sheet production and seamless tubing. Complete processing procedures will be established for producing acceptable sheet and tubing from other alloys such as $\mathrm{W}-25 \mathrm{Re}$.

Similarly, trial sheet and tubing production runs are scheduled for unalloyed Mo treated with the new purification techniques developed under this program. New or modified equipment will be installed to increase tube drawing capacity to $365-\mathrm{cm}$ lengths and sheet rolling capacity to $25-\mathrm{cm} \cdot$ widths by $120-\mathrm{cm}$ lengths. 
Investigation will be continued of the suitability of GE-NMPO tube working procedures of arc-cast material in the $\mathrm{W}-25 \mathrm{Re}-30 \mathrm{Mo}$ and $\mathrm{W}-30 \mathrm{Re}-30 \mathrm{Mo}$ compositions. The creep, tensile, recrystallization, and ductility characteristics of the arc-cast sheet materials will be compared to properties of powder-metallurgy sheet using the new purification treatments.

Several alloy development programs now underway should progress sufficiently to permit selection of specific compositions for advanced development. These programs include a Ta alloy, a Re-base alloy, a Mo-base alloy, and an age-hardening W-Re-Mo alloy. 
THIS PAGE

\section{WAS INTENTIONALLY \\ LEFT BLANK}




\title{
4. PHYSICAL METALLURGY OF REFRACTORY-METAL ALLOYS
}

\section{(57077)}

\author{
C. G. Collins*
}

The objective of this program is to define the physical metallurgy of refractory-metal alloys of the tungsten - rhenium - molybdenum system in terms of phase stability, composition variations, impurity concentrations, and effects resulting from self-diffusion and vaporization processes.

Initial studies under this program consisted of grain morphology, hardness, and bend ductility measurements of $\mathrm{W}-25 \mathrm{Re}-30 \mathrm{Mo}$ and $\mathrm{W}-30 \mathrm{Re}-30 \mathrm{Mo}$ (both at. \%) alloys aged for various periods at temperatures up to $2600^{\circ} \mathrm{C}$. Aging and recrystallization studies are in progress to compare "standard" powder-metallurgy W-30Re - 30Mo material with specially purified material. Studies of molybdenum vaporization from the $\mathrm{W}-30 \mathrm{Re}-30 \mathrm{Mo}$ alloy were also conducted.

4. 1 MOR PHOLOGY OF AGING OF W - 25Re - 30Mo AND W - 30Re - 30Mo ALLOYS (C. G. Collins, K. M. Bohlander)

Microstructural changes in as-processed sheet material of the $\mathrm{W}-25 \mathrm{Re}-30 \mathrm{Mo}$ and $\mathrm{W}-30 \mathrm{Re}-30 \mathrm{Mo}$ alloys were determined after aging treatments in hydrogen over the temperature range from $1200^{\circ}$ to $2600^{\circ} \mathrm{C}$ for periods up to 1000 hours. Both alloys were produced by powder metallurgy and were tested as wrought $0.05-\mathrm{cm}$-thick sheet, which was stress-relieved 15 minutes at $1400^{\circ} \mathrm{C}$ after the final reduction of 4.75 percent.

The morphological changes in both alloys indicated that the as-processed structure is relatively stable. The grain structure of the as-processed alloys consisted of grains elongated in the rolling direction and flattened normal to the rolled surface as shown in Tables 4.1 and $4: 2$. Upon aging at $1600^{\circ} \mathrm{C}$ or lower temperatures, the elongated grains grew toward a more equiaxed structure, but the elongated shape was comparatively little changed at $1200^{\circ} \mathrm{C}$ and was not completely eliminated even after 1000 hours at $1600^{\circ} \mathrm{C}$. At temperatures of $1800^{\circ} \mathrm{C}$ or higher, the materials recrystallized to an equiaxed grain structure in 2 hours or less although some difference in grain size between transverse and longitudinal sections persisted for the shorter aging times ( 2 and $10 \mathrm{hr}$ ) at $1800^{\circ} \mathrm{C}$ and $2000^{\circ} \mathrm{C}$. The recrystallized grain size was roughly the same as the average grain size in the as-processed condition, indicating that few recrystallization nuclei existed in the latter structure. Considering that the total cold work of 50 percent was attained in 4 - to 5 -percent reduction steps with annealing at $1400^{\circ} \mathrm{C}$ between reductions, it is apparent that the 4 to 5 percent reduction is the appropriate cold-work value for the asprocessed condition; hence, the $1400^{\circ} \mathrm{C}$ anneals prevent the accumulation of recrystallization nuclei.

*Project leader and principal investigator. 
TABLE 4.1

GRAIN SIZE, HARDNESS, AND BEND DUCTILITY OF 0.05-CM-THCK W - 25Re - 30MO SHEET AFT ER AGING IN HYDROGEN

\begin{tabular}{|c|c|c|c|c|c|c|c|c|c|c|c|c|c|c|c|}
\hline \multirow[b]{3}{*}{$\begin{array}{l}\text { Aging } \\
\text { Temp. , } \\
{ }^{\circ} \mathrm{C}\end{array}$} & \multirow{2}{*}{\multicolumn{3}{|c|}{2 Hours }} & \multirow{2}{*}{\multicolumn{3}{|c|}{10 Hours }} & \multirow{2}{*}{\multicolumn{3}{|c|}{$\frac{\text { Aging Time }}{100 \text { Hours }}$}} & \multirow{2}{*}{\multicolumn{3}{|c|}{500 Hours }} & \multirow{2}{*}{\multicolumn{3}{|c|}{1000 Hours }} \\
\hline & & & & & & & & & & & & & & & \\
\hline & $\begin{array}{l}\text { Grain Size, }{ }^{a} \\
\text { microns }\end{array}$ & $\begin{array}{c}\text { Hardness, } b \\
\text { DPH }\end{array}$ & $\begin{array}{c}\text { Bend } \\
\text { Angle, } \\
\text { degrees }\end{array}$ & $\begin{array}{l}\text { Grain Size, }{ }^{a} \\
\text { microns }\end{array}$ & $\begin{array}{c}\text { Kardne.ss, } \\
\text { DPH }\end{array}$ & $\begin{array}{c}\text { Bend } \\
\text { Angle, } \\
\text { degrees }\end{array}$ & $\begin{array}{l}\text { Grain Size, } \\
\text { microns }\end{array}$ & $\begin{array}{l}\text { Hardness, } \\
\text { DPH }\end{array}$ & $\begin{array}{c}\text { Bend } \\
\text { Angle, } \\
\text { degrees }\end{array}$ & $\begin{array}{c}\text { Grain Size, }{ }^{\mathrm{a}} \\
\text { microns }\end{array}$ & $\begin{array}{l}\text { Hardness, } \\
\text { DPH }\end{array}$ & $\begin{array}{c}\text { Bend } \\
\text { Angle, } c \\
\text { degrees }\end{array}$ & $\begin{array}{c}\text { Grain Size, }{ }^{\mathrm{a}} \\
\text { microns }\end{array}$ & $\begin{array}{c}\text { Hardness, } \\
\text { DPH }\end{array}$ & $\begin{array}{c}\text { Bend } \\
\text { Angle, } \mathrm{c} \\
\text { degrees }\end{array}$ \\
\hline $\begin{array}{l}\text { As- } \\
\text { processed }^{d}\end{array}$ & $\sim 150,20,55$ & 460 & $>90$ & & & & & & & & . & & & & \\
\hline 1200 & $190,24,58$ & 446 & $>90$ & $145,24,64$ & 450 & $>90$ & $65,27,55$ & 383 & $>90$ & $65,27,55$ & 409 & $>90$ & $69,29,53$ & 414 & $>90$ \\
\hline 1400 & $96,19,50$ & 439 & $>90$ & 38,51 & 401 & $>90$ & 40,53 & 387 & $>90$ & 42,50 & 401 & 45 & 43,53 & 409 & 30 \\
\hline 1600 & $100,21,50$ & 401 & $>90$ & 38,46 & 387 & $>90$ & 41,53 & 383 & $>90$ & - & - & - & 43,53 & 390 & $>90$ \\
\hline 1800 & 42,49 & 405 & $>90$ & 46,53 & 376 & $>90$ & 47 & 372 & $>90$ & 49 & 376 & $>90$ & 54 & 366 & $>90$ \\
\hline 2000 & 36,46 & 394 & $>90$ & 49 & 380 & $>90$ & 43 & 378 & $>90$ & 49 & 397 & $>90$ & - & - & - \\
\hline 2200 & 42 & 390 & $>90$ & 46 & 363 & $>90$ & 47 & 350 & $>90$ & 47 & 380 & $>90$ & 47 & 387 & $>90$ \\
\hline 2400 & 43 & 363 & $>90$ & 46 & 374 & $>90$ & - & - & - & - & - & - & - & - & - \\
\hline 2600 & 50 & 370 & $>90$ & 50 & 360 & $>90$ & 53 & 366 & $>90$ & 59 & 354 & $>90$ & 51 & 366 & $>90$ \\
\hline
\end{tabular}

${ }^{\mathrm{a}} \mathrm{Grain}$ sizes were deter mined by the linear intercept method. Where three values are given, these refer respectively to the length, height, and width of the grains as determined from longitudinal (parallel.to rolling direction) and transverse sections. Where two values are given, the values represent the average grain size in the transverse and longitudinal sections respectively, both sections exhibiting approximately equiaxed grain structure.

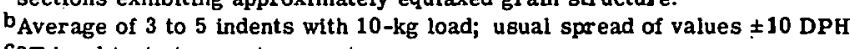

$\mathrm{c}_{2} \mathrm{~T}$ bend test at room temperature.

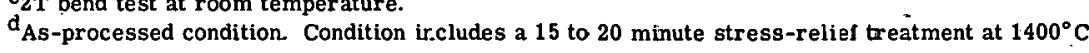

TABLE 4.2

GRAIN SIZE, HARDNESS, AND BEND DUCTILITY OF 0.05-CM-THICK W - 30Re - 30MO SHEET AFTER AGING IN HYDROGEN

\begin{tabular}{|c|c|c|c|c|c|c|c|c|c|c|c|c|c|c|c|}
\hline \multirow[b]{3}{*}{$\begin{array}{l}\text { Aging } \\
\text { Temp., } \\
{ }^{\circ} \mathrm{C}\end{array}$} & \multirow{2}{*}{\multicolumn{3}{|c|}{2 Hours }} & \multirow{2}{*}{\multicolumn{6}{|c|}{$\frac{\text { Aging Time }}{100 \text { Hours }}$}} & \multirow{2}{*}{\multicolumn{3}{|c|}{$5 \mathrm{C} 0$ Hours }} & \multirow{2}{*}{\multicolumn{3}{|c|}{1000 Hours }} \\
\hline & & & & & & & & & & & & & & & \\
\hline & $\begin{array}{c}\text { Grain Size, }^{\mathbf{a}} \\
\text { microns }\end{array}$ & $\begin{array}{c}\text { Hardness, } \\
\text { DPH }\end{array}$ & $\begin{array}{c}\text { Bend } \\
\text { Angle,c } \\
\text { degrees }\end{array}$ & $\begin{array}{c}\text { Grain Siże, }{ }^{a} \\
\text { microns }\end{array}$ & $\begin{array}{c}\text { Hardness; } ; \dot{b} \\
\text { DPH }\end{array}$ & $\begin{array}{c}\text { Bend } \\
\text { Angle, } \\
\text { degrees }\end{array}$ & 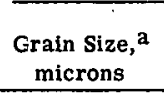 & $\begin{array}{c}\text { Hardness, } \\
\text { DPH }\end{array}$ & $\begin{array}{c}\text { Bend } \\
\text { Angie, } \\
\text { degrees } \\
\end{array}$ & $\begin{array}{c}\text { Grain Size, }^{a} \\
\text { microns }\end{array}$ & $\begin{array}{c}\text { Hardness, } \\
\text { DPH }\end{array}$ & $\begin{array}{c}\text { Bend } \\
\text { Angle, } \\
\text { degrees }\end{array}$ & $\begin{array}{c}\text { Grain Size, } \\
\text { microns }\end{array}$ & $\begin{array}{c}\text { Hardness, } \\
\text { DPH }\end{array}$ & $\begin{array}{c}\text { Bend } \\
\text { Angle, } \\
\text { degrees }\end{array}$ \\
\hline $\begin{array}{l}\text { As- } \\
\text { processed }^{d}\end{array}$ & $\sim 120,25,80$ & 460 & $>90$ & & 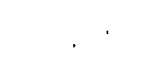 & & & & & & & & & & \\
\hline 1200 & $117,25,85$ & 454 & $>90$ & $112,25,75$ & 450 & $>90$ & $120,20,71$ & 429 & $>90$ & $130,21,67$ & 459 & 90 & $115,24,72$ & 488 & 20 \\
\hline 1400 & $82,29,56$ & 420 & $>90$ & $67,35,64$ & 424 & $>90$ & $77,42,78$ & 433 & $>90$ & $75,47,74$ & 468 & 20 & $80,51,80$ & 459 & $\sim 15$ \\
\hline 1600 & 59,78 & 380 & $>90$ & 63,64 & 383 & $>90$ & 52,68 & 416 & $>90$ & 50,61 & 409 & $>90$ & 65,74 & 397 & $>90$ \\
\hline 1800 & 57,63 & 370 & $>90$ & 67 & 342 & $>90$ & 67 & 363 & $>90$ & 70 & 354 & $>90$ & & & \\
\hline 2000 & 64 & 363 & $>90$ & 60 & 350 & $>90$ & 62 & 330 & $>90$ & & & & & & \\
\hline 2200 & 69 & 350 & $>90$ & 71 & 360 & $>90$ & 82 & 366 & $>90$ & & & & & & \\
\hline 2400 & 70 & 357 & $>90$ & 75 & 360 & $>90$ & & & & & & & & & \\
\hline 2600 & 68 & 348 & $>90$ & - & - & - & 75 & 333 & $>90$ & 86 & 327 & $>90$ & 92 & 333 & $>90$ \\
\hline
\end{tabular}

${ }^{a}$ Grain sizes were determined by the linear intercept method. Where three values are given, these refer respectively to the length, height, and width of the grains as determined from longitudin (parallel to rolling direction) and transverse sections. Where two values are given, the values represent the average grain size in the transverse and longitudinal sections respectively, both sections exhibiting approximately equiaxed grain structure.

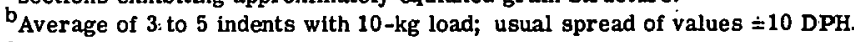

$c_{2} \mathrm{~T}$ bend test at room temperature.

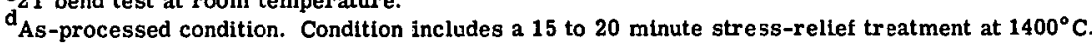


Surface hardness measurements on the aged samples indicated that annealing of the hardness was essentially complete in time periods ranging from a few minutes at $2600^{\circ} \mathrm{C}$ to 10 hours at $1600^{\circ} \mathrm{C}$. In the as-processed condition, the $\mathrm{W}-25 \mathrm{Re}-30 \mathrm{Mo}$ alloy had a diamond pyramid hardness (DPH) of 450 to 460 . Samples aged at temperatures up to $2000^{\circ} \mathrm{C}$ attained an apparent minimum DPH of about 380 , while those aged at higher temperatures dropped to roughly $350 \mathrm{DPH}$. The hardness changes in $\mathrm{W}-30 \mathrm{Re}-30 \mathrm{Modiffered}$ to some extent from those in $\mathrm{W}-25 \mathrm{Re}-30 \mathrm{Mo}$. At $1200^{\circ} \mathrm{C}$ and $1400^{\circ} \mathrm{C}$, the minimum hardness values attained in W-30Re - 30Mo were 420 to $430 \mathrm{DPH}$ compared to about $380 \mathrm{DPH}$ for $\mathrm{W}-25 \mathrm{Re}-30 \mathrm{Mo}$. In contrast, the hardness decrease in this alloy appeared somewhat larger after 2 hours at temperatures above $1800^{\circ} \mathrm{C}$, indicating more rapid recovery or recrystallization in the high-temperature region.

Presumably, the differences in grain growth and hardness changes in the two alloys stem from the presence of a sigma phase in the W-30Re - 30Mo alloy. The higher rhenium content is retained in solid solution only at temperatures greater than approximately $1700^{\circ} \mathrm{C}$; hence, during aging at lower temperatures, a rhenium-rich $(\sim 50 \%)$ phase precipitates in the sigma structure from solution-treated material. Thus, some sigma develops in the as-processed material as a result of the $1400^{\circ} \mathrm{C}$ anneals. There are-indications that the amount of sigma in the as-processed condition varies appreciably for different production sheets. Such variations are apparently influenced by both the starting powder materials and the purification procedures. The W-30Re - 30Mo sheet studied had sigma concentration in the as-processed condition amounting to 0.9 volume percent; this sigma phase was in the form of spheroidal particles, 1- to 2-microns in diameter, which were located predominantly in the grain boundaries. On aging at $1400^{\circ} \mathrm{C}$, the sigma particles attained lengths of 8 to 12 microns and widths of about 2 microns; at $1600^{\circ} \mathrm{C}$, although the length increased to 10 to 16 microns, the major difference was an increase in particle width to 6 to 10 microns. The general trend of the sigma precipitates with temperature thus ranged from the formation of numerous small particles at low temperatures to fewer and larger, nearly equiaxed particles at higher temperatures. Volume concentrations of the sigma phase appeared to be essentially constant after 500 hours at both $1400^{\circ} \mathrm{C}$ and $1600^{\circ} \mathrm{C}$; based on single determinations, equilibrium concentrations were 7.5 and 5.0 percent, respectively. After 1000 hours at $1200^{\circ} \mathrm{C}$, the sigma concentration was 7 percent but did not appear to have reached equilibrium. The increase in the amount of sigma-phase precipitates may be partly responsible for some reduction of the bend ductility in the $\mathrm{W}-30 \mathrm{Re}-30 \mathrm{Mo}$ after extended aging at $1200^{\circ} \mathrm{C}$ and $1400^{\circ} \mathrm{C}$; however, decreased ductility in the $\mathrm{W}-25 \mathrm{Re}-30 \mathrm{Mo}$ alloy at $1400^{\circ} \mathrm{C}$ in the absence of sigma precipitates indicates that other aging processes are also involved. The sigma phase formed at $1600^{\circ} \mathrm{C}$ did not appear to influence the room-temperature ductility.

\section{RECRYSTALLIZATION STUDIES}

Recrystallization annealing studies were begun on $\mathrm{W}-30 \mathrm{Re}-30 \mathrm{Mo}$ and $\mathrm{W}-25 \mathrm{Re}-30 \mathrm{Mo}$ to compare the effects of composition and purification treatments. Two $\mathrm{W}-30 \mathrm{Re}-30 \mathrm{Mo}$ materials, both prepared by powder metallurgy, were examined; one was processed by standard methods while the second was specially purified. Both alloys were initially of $0.051-\mathrm{cm}$ thickness obtained through 50-percent reduction by cold working in 4- to 5-percent reduction steps with intermediate anneals at $1400^{\circ} \mathrm{C}$. They were solution-treated for 2 hours at $2000^{\circ} \mathrm{C}$ in hydrogen and then cold-rolled at $200^{\circ} \mathrm{C}$ to obtain a range of reductions. Although subsequent work has shown that cold reductions of over 50 percent are attainable in both alloys in the solution-treated condition, the maximum reductions obtained with the particular rolling equipment employed were 19 percent in the $\mathrm{W}-30 \mathrm{Re}-30 \mathrm{Mo}$ alloys and 13 percent in the $\mathrm{W}-25 \mathrm{Re}-30 \mathrm{Mo}$. Reductions ranging up to these maximums were examined for recrystallization and grain growth behavior; studies at larger reductions are in progress. 
The recrystallization behavior of the alloys at these reductions was comparable to that in the as-processed condition. Although there was little evidence of the formation and growth of grains from new nuclei, more rapid grain growth occurred at the higher reductions. Following solution treatment, all three materials had equiaxed grains, a structure which was not significantly altered by the reductions. Evidence for some non-uniformity was apparent, however, in that grain size measurements after aging treatments at $1500^{\circ} \mathrm{C}$ and $1700^{\circ} \mathrm{C}$ (summarized in Table 4.3) showed considerable variation despite the fact that the sequential metallograplic specimens were taken from adjacent positions in areas of uniform thickness. Grain growth in the $\mathrm{W}-30 \mathrm{Re}-30 \mathrm{Mu}$ alloys ranged to more than 100 percent, appreciably larger than that in the as-processed condition. There was no clear evidence of greater grain growth with increasing amounts of cold work over the range 8.7to 19.4-percent reduction; hence, the difference in grain growth compared to the as-processed condition is probably attributable to the solution treatment. It also did not appear that the grain growth rates of the two $\mathrm{W}-30 \mathrm{Re}-30 \mathrm{Mo}$ materials differed appreciably, although the grain size of the specially purified material was roughly twice that of the standard material in the solution-treated and reduced conditions. Grain growth in the W-25Re - 30Mo alloy ranged from 5 to 20 percent, roughly comparable to that in the as-processed condition.

I'ABLE 4. 3

\section{RECRYSTALLIZED GRAIN SIZE OF W-Re-MO ALLOYS ${ }^{a}$}

\begin{tabular}{|c|c|c|c|c|c|c|c|c|c|c|c|}
\hline \multirow{2}{*}{$\begin{array}{c}\text { Aging } \\
\text { Time and } \\
\text { Temperature } \\
\end{array}$} & \multicolumn{3}{|c|}{$\begin{array}{c}\text { Specially Purified } \\
\text { W-30Re - 30Mo } \\
\text { Reduction, \% }\end{array}$} & \multicolumn{4}{|c|}{$\begin{array}{c}\text { Standard Process } \\
\begin{array}{c}\mathrm{W}-30 \mathrm{Re}-30 \mathrm{Mo} \\
\text { Reduction, } \%\end{array}\end{array}$} & \multicolumn{4}{|c|}{$\begin{array}{c}\begin{array}{c}\text { Standard Process } \\
\text { W-25Re }-30 \mathrm{Mo}\end{array} \\
\text { Reduction, } \% \\
\end{array}$} \\
\hline & 12.5 & 13.8 & 19.4 & 8.7 & 11.1 & 12.3 & 18.0 & 5.3 & 9.6 & 11.5 & 13.5 \\
\hline $\begin{array}{l}\text { As-reduced } \\
\text { grain size, } \mu\end{array}$ & 108 & 113 & 95 & 36 & 55 & 48 & 55 & 55 & 64 & 53 & 62 \\
\hline $\begin{array}{l}\text { Aged } 0.5 \mathrm{hr} \\
\text { at } 1500^{\circ} \mathrm{C}, \mu\end{array}$ & 125 & 119 & 110 & 40 & 62 & 57 & 55 & 50 & 63 & 60 & 74 \\
\hline $\begin{array}{l}\text { Aged } 2.5 \mathrm{hr} \\
\text { at } 1500^{\circ} \mathrm{C}, \mu\end{array}$ & 108 & 132 & 103 & 42 & 56 & 48 & 57 & 57 & 62 & 53 & 64 \\
\hline $\begin{array}{l}\text { Aged } 16 \mathrm{hr} \\
\text { at } 1500^{\circ} \mathrm{C}, \mu\end{array}$ & 163 & 108 & 132 & 33 & 69 & 56 & 71 & 57 & 59 & 60 & 59 \\
\hline $\begin{array}{l}\text { Aged } 0.5 \mathrm{hr} \\
\text { at } 1700^{\circ} \mathrm{C}, \mu\end{array}$ & 176 & 116 & 97 & 67 & 71 & 71 & 60 & 55 & 55 & 63 & 59 \\
\hline $\begin{array}{l}\text { Aged } 2.0 \mathrm{hr} \\
\text { at } 1700^{\circ} \mathrm{C}, \mu\end{array}$ & 139 & 135 & 226 & 132 & 113 & 128 & 125 & .59 & 67 & 66 & 74 \\
\hline
\end{tabular}

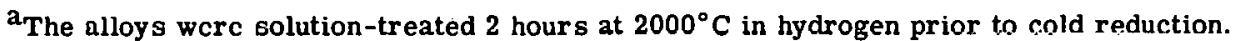
Initial materials were $0.051-\mathrm{cm}$-thick sheets.

A significant difference in sigma-phase formation was observed in the two $\mathrm{W}-30 \mathrm{Re}-30 \mathrm{Mo}$ alloys. Although the solution treatment $\left(2\right.$ hours at $\left.2000^{\circ} \mathrm{C}\right)$ given these alloys eliminated the sigma, it reappeared in the grain boundaries of the purified $\mathrm{W}-30 \mathrm{Re}-30 \mathrm{Mo}$ only after the 16 -hour aging at $1500^{\circ} \mathrm{C}$. During aging of the standard process $\mathrm{W}-30 \mathrm{Re}-30 \mathrm{Mo}$, sigma formation occurred as randomly dispersed spherical particles throughout the matrix after only 0.5 hour at $1500^{\circ} \mathrm{C}$ and $1700^{\circ} \mathrm{C}$. At longer aging times, the sigma formed predominantly in the grain boundaries but with additional particles dispersed through the grains, and the total sigma concentration appeared greater than that in the specially purified material.

\section{AGING STUDIES OF SPECIALLY PURIFIED W - 30Re - 30Mo ALLOY}

Studies are in progress to assess the aging characteristics of $\mathrm{W}-30 \mathrm{Re}-30 \mathrm{Mo}$ alloy prepared using four special purification techniques. ${ }^{*}$ Analyses indicate that these treat-

*Pending clarification of patent status, these purification treatments will be identified only by number, e.g., $1,2,3$, and 4 . 
ments lower the concentrations of carbon, nitrogen, and oxygen impurities, particularly carbon.

The aging treatments utilized included 2-hour pre-treatments at $1200^{\circ}, 1600^{\circ}, 2000^{\circ}$, $2200^{\circ}$, and $2400^{\circ} \mathrm{C}$ followed by isothermal aging at $1400^{\circ}, 1600^{\circ}$, and $1800^{\circ} \mathrm{C}$ for 2,10 , and 100 hours. Conceptually, the $1200^{\circ} \mathrm{C}$ and $1600^{\circ} \mathrm{C}$ pre-treatments provide different distributions for sigma-phase nuclei, whereas the pre-treatments at $2000^{\circ} \mathrm{C}$ and above are solution-treatment conditions. The $1400^{\circ} \mathrm{C}$ and $1600^{\circ} \mathrm{C}$ aging temperatures are conditions under which sigma-phase precipitation occurs. The $1400^{\circ} \mathrm{C}$ condition is of particular interest in that reduced bend ductility is first apparent at this temperature; for this reason, aging at $1400^{\circ} \mathrm{C}$ was extended to 500 hours. All material tested was in the form of 0.051 cm-thick sheet.

In general, hardness and bend ductility test results indicated that the special purification treatments did not improve the material in these respects, although improvement in the welding characteristics has been noted. ${ }^{1}$ Hardness data, summarized in Table 4. 4, show nearly identical changes in the four purified materials for all pre-treatment and aging conditions.

Comparisons of the hardness changes in the purified and standard materials are shown in Figure 4. 1 for isochronal annealing and in Figure 4.2 for isothermal aging at $1400^{\circ} \mathrm{C}$; some differences are apparent but, in general, the changes are comparable. The bend ductility of the materials was essentially identical. Materials aged at $1600^{\circ} \mathrm{C}$ and $1800^{\circ} \mathrm{C}$ gave 90 degree bends in $2 \mathrm{~T}$ bend tests irrespective of the pre-treatment. All materials aged 500 hours at $1400^{\circ} \mathrm{C}$ gave approximately 20 degree bends, also without respect to pre-treatment. Overall, the hardness and bend test results for the purified materials were comparable to those of the standard material.

TABLE 4. 4

HARDNESS ${ }^{a}$ OF $\mathrm{W}-30$ Re - 30MO ALLOY AFTER AGING IN HYDROGEN

\begin{tabular}{|c|c|c|c|c|c|c|c|c|c|c|c|c|}
\hline \multirow{3}{*}{$\begin{array}{l}\text { Pre-Treatment } \\
\text { Conditions }\end{array}$} & \multirow[b]{3}{*}{ Specimen $^{b}$} & \multirow{3}{*}{$\begin{array}{c}\text { Hardness After } \\
\text { Pre-Treatment, } \\
\text { DPH }\end{array}$} & \multicolumn{10}{|c|}{ Hardness After Aging, DPH } \\
\hline & & & \multicolumn{4}{|c|}{$1400^{\circ} \mathrm{C}$} & \multicolumn{3}{|c|}{$1600^{\circ} \mathrm{C}$} & \multicolumn{3}{|c|}{$1800^{\circ} \mathrm{C}$} \\
\hline & & & $2 \mathrm{Hr}$ & $10 \mathrm{Hr}$ & $100 \mathrm{Hr}$ & $500 \mathrm{Hr}$ & $2 \mathrm{Hr}$ & $10 \mathrm{Hr}$ & $100 \mathrm{Hr}$ & $2 \mathrm{Hr}$ & $10 \mathrm{Hr}$ & $100 \mathrm{Hr}$ \\
\hline \multirow{4}{*}{$\begin{array}{l}2 \mathrm{hr} \text { at } 1200^{\circ} \mathrm{C} \\
\text { in hydrogen }\end{array}$} & 1 & 418 & 409 & 394 & 424 & 454 & 397 & 382 & 397 & 363 & 360 & 342 \\
\hline & 2 & 429 & $\mathbf{4 1 1}$ & 403 & 424 & 441 & 394 & 380 & 397 & 370 & 366 & 360 \\
\hline & 3 & 420 & 407 & 405 & 429 & 446 & 416 & 387 & 373 & 373 & 357 & 360 \\
\hline & 4 & 397 & 405 & 401 & 433 & 450 & 424 & 397 & 397 & 360 & 366 & 370 \\
\hline \multirow{4}{*}{$\begin{array}{l}2 \mathrm{hr} \text { at } 1600^{\circ} \mathrm{C} \\
\text { in hydrogen }\end{array}$} & 1 & 387 & 420 & 397 & 394 & 444 & 418 & 387 & .390 & 376 & 373 & 354 \\
\hline & 2 & 409 & 405 & 405 & 433 & 450 & 413 & 376 & 401 & 363 & 372 & 373 \\
\hline & 3 & 416 & 408 & 420 & 428 & 446 & 387 & 394 & 409 & 394 & 376 & 348 \\
\hline & 4 & 384 & 401 & 405 & 409 & 446 & 405 & 394 & 405 & 373 & 366 & 373 \\
\hline \multirow{5}{*}{$\begin{array}{l}2 \mathrm{hr} \text { at } 2000^{\circ} \mathrm{C} \\
\text { in hydrogen }\end{array}$} & 1 & 387 & 354 & 390 & 370 & 407 & 376 & 370 & 370 & 380 & 370 & 357 \\
\hline & 2 & 361 & 373 & 383 & 383 & 409 & 387 & 390 & 401 & 368 & 370 & 363 \\
\hline & 3 & 368 & 366 & 376 & 416 & 409 & 370 & 360 & 397 & 366 ." & 373 & 376 \\
\hline & 4 & 380 & 363 & 373 & 387 & 405 & 376 & 357 & 390 & 376 & 382 & 380 \\
\hline & 5 & 333 & 342 & 362 & 380 & 416 & - & - & - & - & - & - \\
\hline \multirow{4}{*}{$\begin{array}{l}2 \mathrm{hr} \text { at } 2200^{\circ} \mathrm{C} \\
\text { in hydrogen }\end{array}$} & 1 & 352 & 376 & 366 & 380 & 397 & 370 & 380 & 387 & 363 & 373 & 354 \\
\hline & 2 & 387 & 354 & 376 & 386 & 380 & 383 & 363 & 380 & 376 & 366 & 373 \\
\hline & 3 & 394 & 344 & 354 & 366 & 401 & 392 & 354 & 390 & 357 & 370 & 380 \\
\hline & 4 & 381 & 380 & 375 & 389 & 383 & 383 & 380 & 380 & 376 & 357 & 380 \\
\hline \multirow{4}{*}{$\begin{array}{l}2 \mathrm{hr} \text { at } 2400^{\circ} \mathrm{C} \\
\text { in hydrogen }\end{array}$} & 1 & 368 & 383 & 360 & 363 & 375 & 357 & 354 & 383 & 357 & 376 & 342 . \\
\hline & 2 & 371 & 354 & 350 & 373 & 380 & 383 & 383 & 373 & 373 & 357 & 357 \\
\hline & 3 & 357 & 354 & 380 & 380 & 401 & 360 & 344 & 383 & 363 & 360 & 370 \\
\hline & 4 & 360 & 366 . & 350 & 372 & 401 & 387 & 360 & 380 & 368 & 350 & 373 \\
\hline
\end{tabular}

Average of 3 to 5 indents with $10-\mathrm{kg}$ load; usual spread of values $\pm 10 \mathrm{DPH}$.

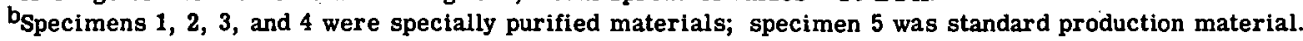

\footnotetext{
1،'High-Temperature Materials Program Progress Report No. 61,"'GE-NMPO, GEMP-61, September 30, 1966, p. 63.
} 

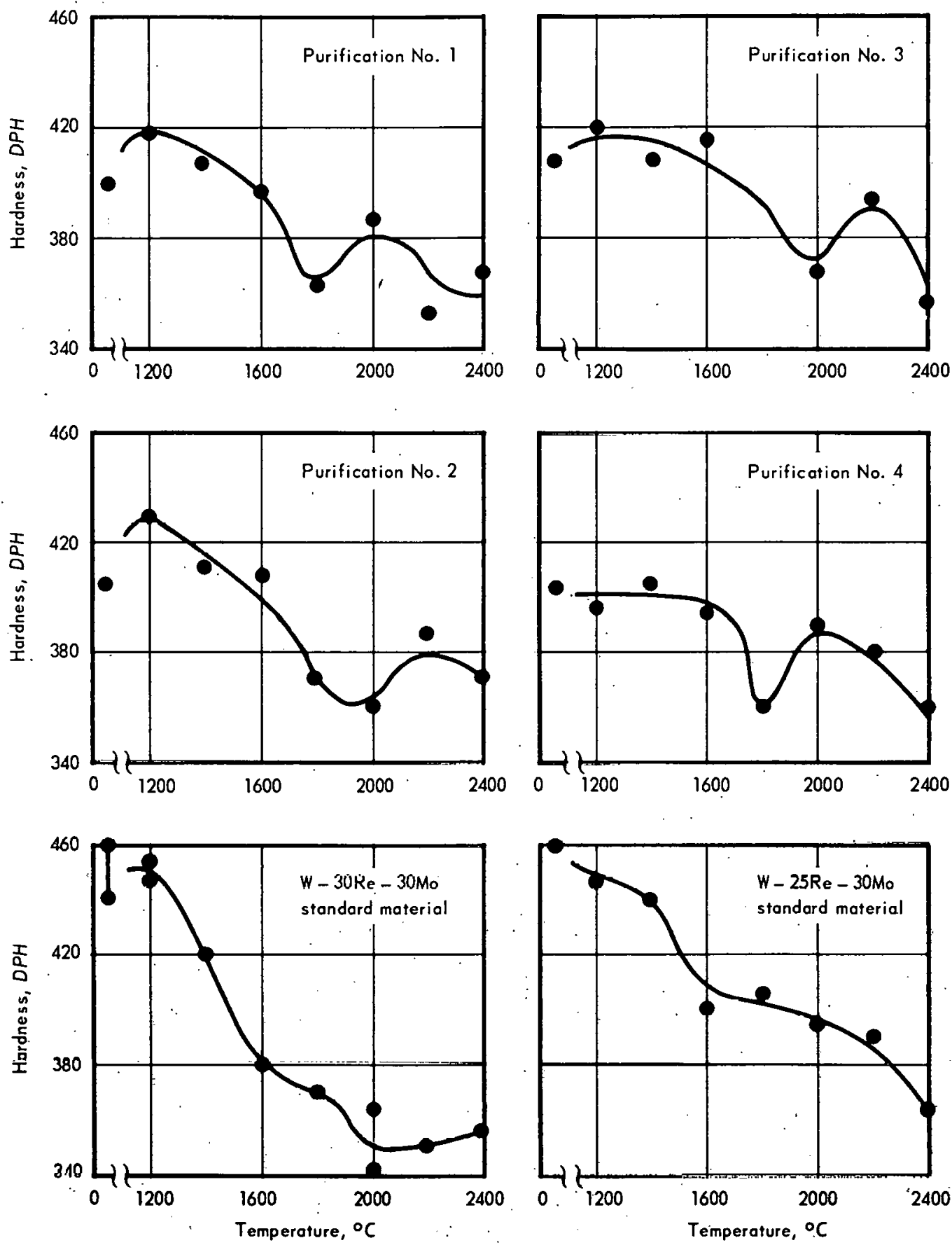

Fig. 4.1-Hardness changes in purified $W-30 R e-30 M_{0}$ alloys compared to standard $W-30 R e-30 M_{0}$ and $W-25 R e-30 M o$ alloys during 2 -hour anneals. Points of $1400^{\circ} \mathrm{C}$ and $1800^{\circ} \mathrm{C}$ were obfoined from data on aging 2 hours at these temperotures after pre-treatment for 2 hours of $1200^{\circ} \mathrm{C}$. 

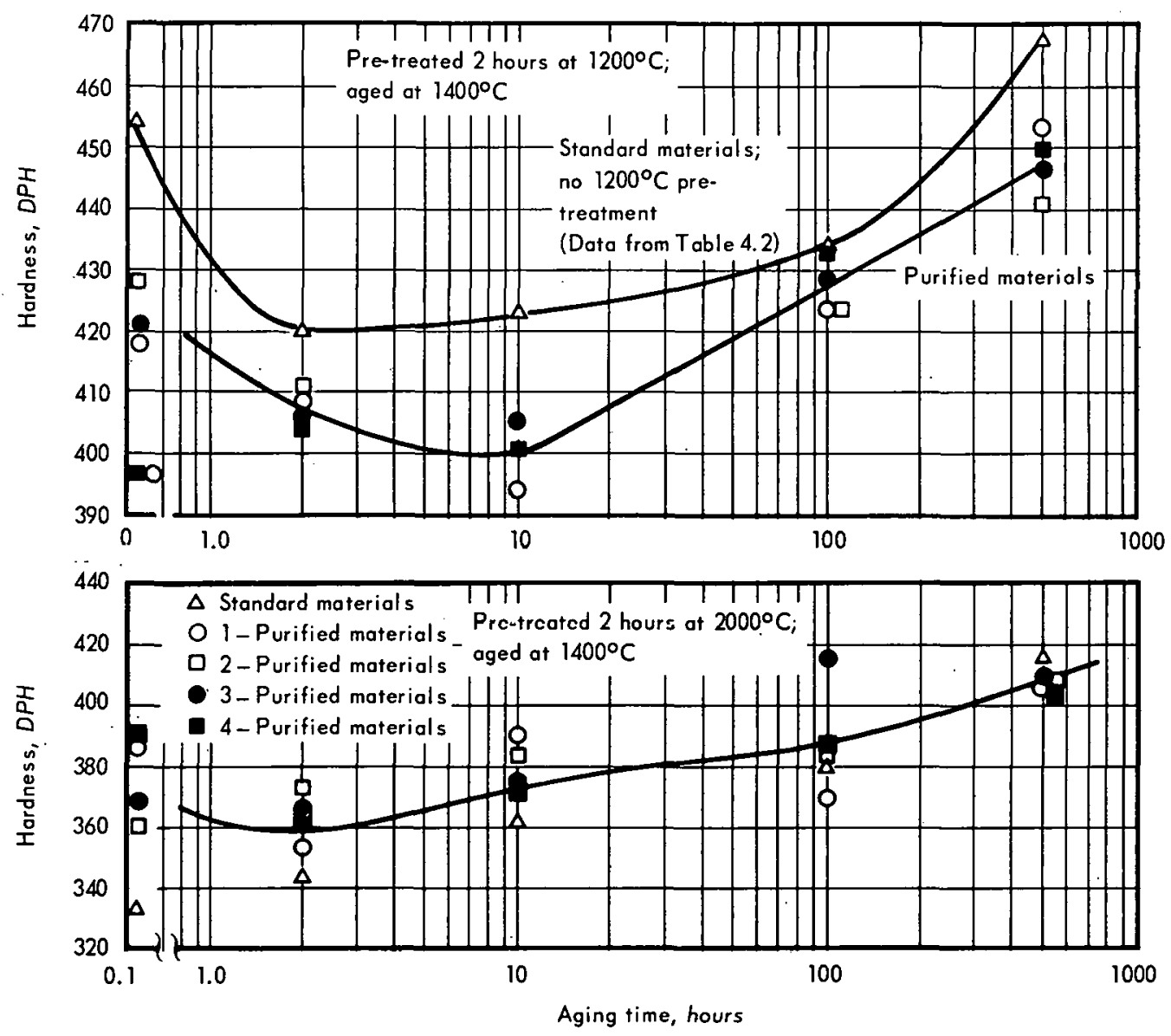

Fig. 4.2-Hardness changes in standard and specially purified $W-30 \mathrm{Re}-30 \mathrm{Mo}$ alloys aged of $1400^{\circ} \mathrm{C}$

VAPORIZATION OF MOLYBDENUM FROM W - 30Re - 30MO ALLOY

Measurements are being made of molybdenum loss from the surface of sheet material of the $\mathrm{W}-30 \mathrm{Re}-30 \mathrm{Mo}$ alloy following extended exposures in hydrogen at temperatures above $2000^{\circ} \mathrm{C}$. The molybdenum concentration is determined by $\mathrm{X}$-ray fluorescence using 70 -kilovolt $X$-rays. Based on the beam penetration, estimates indicate this method yields molybdenum concentration to a depth of 10 to 20 microns, less than one-half the grain diameter of the materials examined. Reproducibility of the measurements is about \pm 0.3 percent; however, the absolute molybdenum concentrations are probably uncertain by about \pm 1 percent due to variations in different areas of the same sample as well as other factors in the counting.

Results of measurements at $2200^{\circ} \mathrm{C}$ and $2600^{\circ} \mathrm{C}$ indicate that about one-third of the surface molybdenum is lost at these temperatures in time periods ranging up to 4500 hours. Curves of the surface molybdenum concentration versus time are shown in Figure 4.3. Apparently, this appreciable molybdenum loss causes the sigma-phase formation that has been observed in some materials aged at high temperatures. Measurements are being continued at other temperatures, and molybdenum concentration profiles are being obtained through the sheet thickness to define the vaporization behavior.

\section{2 SUMMARY AND CONCLUSIONS}

Aging studies of $\mathrm{W}-25 \mathrm{Re}-30 \mathrm{Mo}$ and $\mathrm{W}-30 \mathrm{Re}-30 \mathrm{Mo}$ (at. \%) alloys established that the as-processed structure is relatively stable with grain growth of only about 20 percent 


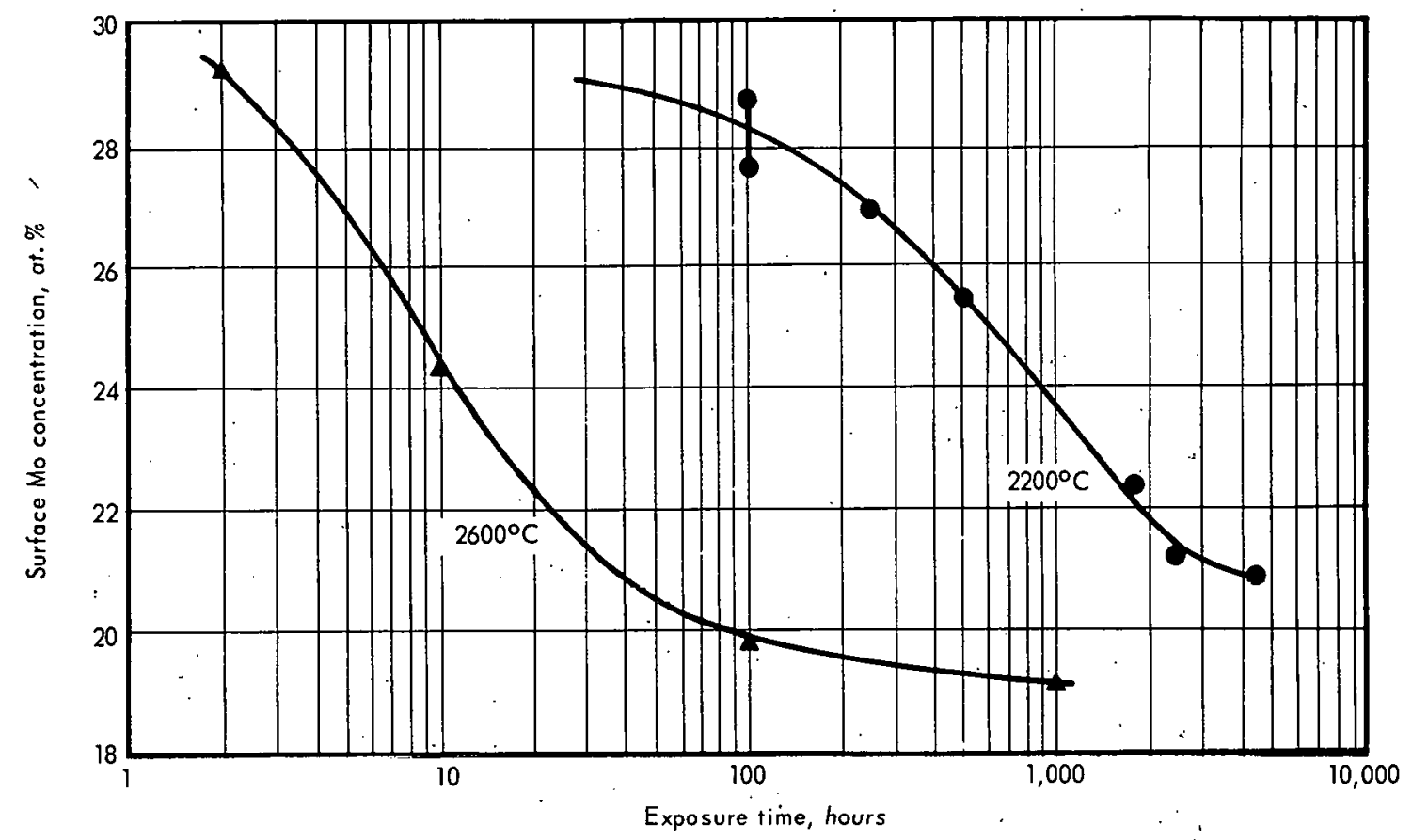

Fig. 4.3-Molybdenum loss from the surface of $W-30 R e-30$ Mo alloy in isothermal exposures in hydrogen

occurring after 1000 hours at $2600^{\circ} \mathrm{C}$. From an as-processed DPH of about 450, the hardness of $\mathrm{W}-25 \mathrm{Re}-30 \mathrm{Mo}$ dropped to 380 in varying times at $1200^{\circ}$ to $1600^{\circ} \mathrm{C}$ and to about 350 at higher temperatures. Similar hardness changes occurred in $\mathrm{W}-30 \mathrm{Re}-30 \mathrm{Mo}$; huwever, sigma-phase formation limited the decrease to a DPH of approximately 420 at $1200^{\circ} \mathrm{C}$ and $1400^{\circ} \mathrm{C}$. Both alloys increased in hardness after 500 hours at $1200^{\circ}$ to $1600^{\circ} \mathrm{C}$. Bend ductility in both alloys was about 90 degrees in $2 \mathrm{~T}$ bend tests at all aging conditions above $1600^{\circ} \mathrm{C}$. At temperatures of $1200^{\circ}$ to $1400^{\circ} \mathrm{C}$, the bend ductility dropped to 20 to 30 degrees aftcr several hundred hours.

Recrystallization studies on sheet spccimens of $\mathrm{W}-25 \mathrm{Re}-30 \mathrm{Mo}$ and $\mathrm{W}-30 \mathrm{Re}-30 \mathrm{Mo}$ indicated that cold reductions ranging from 5 to 19 percent did not promote extensive recrystallization. There was little or no evidence of the formation and growth of grains from new nuclei; the materials recrystallized with an average grain size approximately the same as the average grain size of the wrought structure. Relatively rapid grain growth occurred in the solution-treated $\mathrm{W}-30 \mathrm{Re}-30 \mathrm{Mo}$ at the higher reductions, the grain size doubling in 2 hours at $1700^{\circ} \mathrm{C}$.

Comparative aging studies completed on $\mathrm{W}-30 \mathrm{Re}-30 \mathrm{Mo}$ as prepared by standard processing and by four special purification treatments showed essentially the same behavior in hardness and ductility changes in all of the materials.

Molybdenum loss from the surface of the $\mathrm{W}-30 \mathrm{Re}-30 \mathrm{Mo}$ alloy was found to be appreciable in isothermal exposures at elevated temperatures. The surface molybdenum concentration decreased from 30 to 19 percent in 1000 hours at $2600^{\circ} \mathrm{C}$ and decreased to 21 percent in approximately 4500 hours at $2200^{\circ} \mathrm{C}$.

\section{3 PLANS AND RECOMMENDATIONS}

Recrystallization studies on $\mathrm{W}-25 \mathrm{Re}-30 \mathrm{Mo}$ and $\mathrm{W}-30 \mathrm{Re}-30 \mathrm{Mo}$ alloys will continue using materials reduced 30,40 , and 50 percent. Arc-cast, powder-metallurgy material will'be included in the materials examined. 
Molybdenum vaporization measurements will continue on the $\mathrm{W}-30 \mathrm{Re}-30 \mathrm{Mo}$ alloy at several temperatures above $1800^{\circ} \mathrm{C}$, and molybdenum concentration profiles through the sheet thickness will be determined in efforts to define the vapor loss behavior.

Lattice parameters as a function of composition will be determined for a range of compositions of W-Re-Mo alloys. 


\section{THIS PAGE \\ WAS INTENTIONALLY \\ LEFT BLANK}




\title{
5. ADVANCED LONG-LIFE REACTOR FUEL CLADDING AND STRUCTURAL MATERIALS DEVELOPMENT
}

\section{(57019)}

\author{
J. F. Collins, * F. C. Robertshaw ${ }^{\dagger}$
}

The objective of this program is to develop improved fuel element cladding and structural materials and to define their properties of importance for fast breeder reactor applications. This program was initiated at the start of FY-67; in addition to new work, it includes a continuation of some of the work conducted under Task 57001, "Oxidation-Resistant Fuel Element Materials Research," which was terminated at the end of FY-66. A summary of the unirradiated and the irradiated fuel element evaluations performed under Task 57001 during FY-66 is presented at the end of this section.

The program background and direction of Task 57019 were discussed in an earlier report. ${ }^{1}$ In summary, fuel cladding and structural material or materials are being sought that will be more suitable than the austenitic stainless steels for fast breeder reactor applications.

The three alloy systems selected for study under this program are shown in Table 5.1 together with an indication of their potential utility in various coolants. The factors considered in selecting these systems for study were economy, chemical stability, radiation stability, thermal stability, strength, and nuclear cross section.

TABLE 5. 1

ALLOY SYSTEMS SELECTED FOR STUDY AS FAST BREEDER REACTOR CLADDING MATERIALS

\begin{tabular}{|c|c|}
\hline Alloy System and Type & Applicable Coolant Systems \\
\hline $\begin{array}{l}\text { Fe-Cr-Base } \\
\text { 1. Dispersion strengthened (DS) } \\
\text { Fe-Cr-Al-Y alloys } \\
\text { 2. Standard wrought } \mathrm{Fe}-\mathrm{Cr}-\mathrm{Al}-\mathrm{Y} \\
\text { 3. Developmental wrought } \mathrm{Fe}-\mathrm{C}\end{array}$ & $\begin{array}{l}\mathrm{Na} \text {, steam, } \mathrm{CO}_{2} \text {, inert gases, } \\
\text { air }\end{array}$ \\
\hline $\begin{array}{l}\frac{\text { Fe-Base }}{\text { 1. Binary alloys }} \\
\text { 2. Multi-component alloys }\end{array}$ & $\mathrm{Na}$, inert gases \\
\hline $\mathrm{Cr}$-Base & $\mathrm{Na}$, inert gases \\
\hline
\end{tabular}

*Project leader.

†Principal investigator.

1“'High-Temperature Materials Program Progress Report No. 61," GE-NMPO, GEMP-61, September 30, 1966, pp. 111-113. 
In the $\mathrm{Fe}-\mathrm{Cr}$ system, the $\mathrm{Fe}-\mathrm{Cr}-\mathrm{Al}-\mathrm{Y}$ alloys have been under study at GE-NMPO for a number of years (Task 57001). They have shown excellent oxidation resistance in air, steam, and $\mathrm{CO}_{2}$. Being iron-rich, they are also nuclearly attractive. In tests conducted during the past year, they show signs of being quite resistant to irradiation damage. In their present form, these alloys are not as strong at elevated temperatures as AISI Type 304 stainless steel, at least in terms of ultimate strength. Accordingly, steps are being taken to improve their strength using two approaches: (1) dispersion strengthening, and (2) alloying for solution strengthening and precipitation hardening. In addition, the currently available alloys are being characterized in the temperature range of interest.

Oxidation resistance has been the major problem in developing Fe-base alloys for hightemperature applications. However, assuming compatibility with liquid sodium or inert gases, alloys of this type should be quite acceptable in a fast breeder reactor. Accordingly, Fe-base alloys are being developed in which the major additives are included to impart hightemperature strength rather than oxidation resistance. Four primary additives, $\mathrm{Al}, \mathrm{Be}, \mathrm{Ti}$, and $\mathrm{V}$, are being studied to suppress allotropic transformation and to form vasle systems to which further additions can be made to effect strengthening by various mechanisms.

Of the three alloy systems being considered, the one based on chromium inherently possesses the highest strength; it is also excellent from a nuclear standpoint. While chromium readily absorbs interstitials such as oxygen and nitrogen when heated in air with resulting low-temperature embrittlement, this aspect has been inhibited by alloying additions. In any case, this should not rule out the chromium-base alloys for consideration in environments which contain minute quantities or none of these elements. Moreover, chromium-base alloys can be made quite ductile within and even below the temperature range $\left(\sim 200^{\circ}\right.$ to $\left.750^{\circ} \mathrm{C}\right)$ of primary interest in fast breeder reactor applications.

\subsection{IRON-CHROMIUM-BASE ALLOYS}

\section{MATERLAL PREPARATION}

The first five compositions listed in Table 5.2 were vacuum-induction-melted and cast into 12.7-cm-diameter tapered ingots weighing approximately $45.4 \mathrm{~kg}$. The ingots were cut in half and the bottom half of each (approximately $15.9 \mathrm{~kg}$ ) was extruded to $3.18-\mathrm{cm}-$ diameter rod. This rod was then converted to $0.076-\mathrm{cm}$-thick sheet and $2.22-\mathrm{cm}$-diameter rod for tensile, creep, bend, and impact test specimens. In addition to the five heats, a previously melted $1541^{*}$ alloy, also listed in Table 5.2, was similarly processed to sheet and rod.

The top halves of these five ingots were reserved for use in atomizing and preparing dispersion-strengthened versions of each composition. The dispersion-strengthened material is made from atomized powder prepared by a commercial producer from ingots prealloyed at GE-NMPO. The 0561* alloy was sent to an outside vendor for remelting in vacuum and atomizing in an argon stream. Because of equipment difficulties, the vendor was able to process only about $2.3 \mathrm{~kg}$ of powder; further production has been delayed indefinitely. The powder thus far produced has been returned to GE-NMPO for further processing to rod and sheet in accordance with procedures previously described. ${ }^{2}$

Four new developmental heats weighing $5.4 \mathrm{~kg}$ each were melted, cast, and extruded, after heating to $1000^{\circ} \mathrm{C}$, to $3.18-\mathrm{cm}$-diameter rod. These will be processed to sheet and rod stock for property studies.

\footnotetext{
*Designation for $\mathrm{Fe}-\mathrm{Cr}-\mathrm{Al}-\mathrm{Y}$ alloy. The first two digits designate $\mathrm{Cr}$ content; the third, $\mathrm{Al}$; and the fourth, $\mathrm{Y}$; i.e., 0561 is $\mathrm{Fe}-5 \mathrm{Cr}-6 \mathrm{Al}-1 \mathrm{Y}, 2541$ is $\mathrm{Fe}-25 \mathrm{Cr}-4 \mathrm{Al}-1 \mathrm{Y}$, etc.

${ }^{2}$ GEMP-61, p. 117.
} 
TABLE 5.2

ANALYSES OF IRON-CHROMIUM-BASE ALLOYS

\begin{tabular}{|c|c|c|c|c|c|c|c|c|c|}
\hline \multirow[b]{3}{*}{ Alloy } & \multirow{3}{*}{$\begin{array}{c}\text { Heat } \\
\text { No. }\end{array}$} & \multicolumn{8}{|c|}{ Analyses } \\
\hline & & \multicolumn{6}{|c|}{ wt $\%$} & \multicolumn{2}{|c|}{$\mathrm{ppm}$} \\
\hline & & $\mathrm{Cr}$ & $\overline{\mathrm{Al}}$ & $\bar{Y}$ & C & Si & Mo & $\mathrm{O}_{2}$ & $\mathbf{N}_{2}$ \\
\hline $\mathrm{Fe}-5 \mathrm{Cr} \div 6 \mathrm{Al}-1 \mathrm{Y}(0561)$ & MS59 & 4. 75 & 5. 96 & 1.02 & 0.05 & - & - & 9 & 1 \\
\hline $\mathrm{Fe}-10 \mathrm{Cr}-4 \mathrm{Al}-1 \mathrm{Y}(1041)$ & MS60 & .9 .82 & 3. 86 & 0.82 & 0.05 & 0.03 & - & 36 & 4 \\
\hline $\mathrm{Fe}-13 \mathrm{Cr}-6 \mathrm{Al}-1 \mathrm{Y}(1361)$ & MS61 & 11. 87 & 5. 89 & 1. 07 & 0.03 & 0.04 & - & 239 & 39 \\
\hline $\mathrm{Fe}-25 \mathrm{Cr}-4 \mathrm{Al}-1 \mathrm{Y}(2541)$ & MS62 & 24. 55 & 3. 83 & 1.23 & 0.04 & 0.15 & - & 11 & 6 \\
\hline \multicolumn{10}{|c|}{$\mathrm{Fe}-5 \mathrm{Cr}-6 \mathrm{Al}-1 \mathrm{Y}-3 \mathrm{Mo}$} \\
\hline$(0561+3 \mathrm{Mo})$ & MS64 & 5. 34 & 5. 87 & 1.46 & 0.04 & 0.09 & 3.42 & 65 & 12 \\
\hline $\mathrm{Fe}-15 \mathrm{Cr}-4 \mathrm{Al}-1 \mathrm{Y}(1541)$ & MS51 & 15. 11 & 4. 01 & 0.77 . & - & - & - & 16 & $\cdot 2$ \\
\hline
\end{tabular}

\section{MATERIAL EVALUATION}

\section{Environmental Compatibility}

Annealed sheet specimens from earlier heats of a number of $\mathrm{Fe}-\mathrm{Cr}-\mathrm{Al}-\mathrm{Y}$ alloys were exposed to metallic sodium (containing $22 \mathrm{ppm} \mathrm{O}_{2}$ ) at $750^{\circ} \mathrm{C}$ for 1000 hours. Details of specimen and capsule preparation and testing were previously described. ${ }^{3}$ Weight change data are shown in Figure 5.1 along with similar data on representatives of other alloy systems. Dimensional changes were negligible. Some surface discoloration occurred on the $\mathrm{Fe}-\mathrm{Cr}-\mathrm{Al}-\mathrm{Y}$ specimens, as shown in Figure 5.2.

With the exception of the 2541 alloy, all specimens were bent successfully 90 degrees over a $2 \mathrm{~T}$ radius at $-78^{\circ} \mathrm{C}$. The 2541 alloy specimen broke at a bend angle of 80 degrees. This is not believed to be due to the sodium exposure but, rather, to some precipitation of alpha prime or sigma phase during heating or cooling. In the as-annealed condition, all of these alloys bent 90 degrees without fracture at $-78^{\circ} \mathrm{C}$. Metallographic examination has not been completed.

The oxidation resistance of several previously prepared $\mathrm{Fe}-\mathrm{Cr}-\mathrm{Al}-\mathrm{Y}$ alloys, including the 1361 dispersion-strengthened (DS) alloy, was determined for periods up to 3000 hours in air at temperatures ranging from $450^{\circ}$ to $1100^{\circ} \mathrm{C}$. The resulting weight changes are presented in Table 5.3. All of the alloys possess excellent oxidation resistance up to $1100^{\circ} \mathrm{C}$.

TABLE 5. 3

WEIGHT GAIN OF Fe-Cr-Al-Y ALLOYS ${ }^{\mathrm{a}}$ AFTER 3000 HOURS IN AIR AT $450^{\circ}$ TO $1100^{\circ} \mathrm{C}$

\begin{tabular}{|c|c|c|c|c|c|}
\hline \multirow{2}{*}{$\begin{array}{c}\text { Alloy } \\
\text { Designation }\end{array}$} & \multicolumn{5}{|c|}{$\begin{array}{c}\text { Weight Gain }\left(\mathrm{mg} / \mathrm{cm}^{2}\right) \text { versus } \\
\text { Test Temperature }\end{array}$} \\
\hline & $450^{\circ} \mathrm{C}$ & $550^{\circ} \mathrm{C}$ & $730^{\circ} \mathrm{C}$ & $900^{\circ} \mathrm{C}$ & $1100^{\circ} \mathrm{C}$ \\
\hline 0561 & 0.15 & -0.2 & 0.14 & 0.62 & 2. 00 \\
\hline 1041 & -0.07 & 0.01 & 0.06 & 0.48 & 1.78 \\
\hline 1361 DS & 0.01 & 0.06 & 0.20 & 0.48 & 1.39 \\
\hline 1541 & 0.07 & 0.10 & 0.22 & 0.73 & 2.05 \\
\hline 2541 & 0.06 & 0.06 & 0.12 & 0.66 & 2. 18 \\
\hline
\end{tabular}

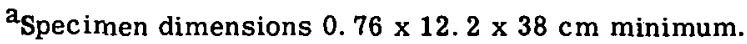




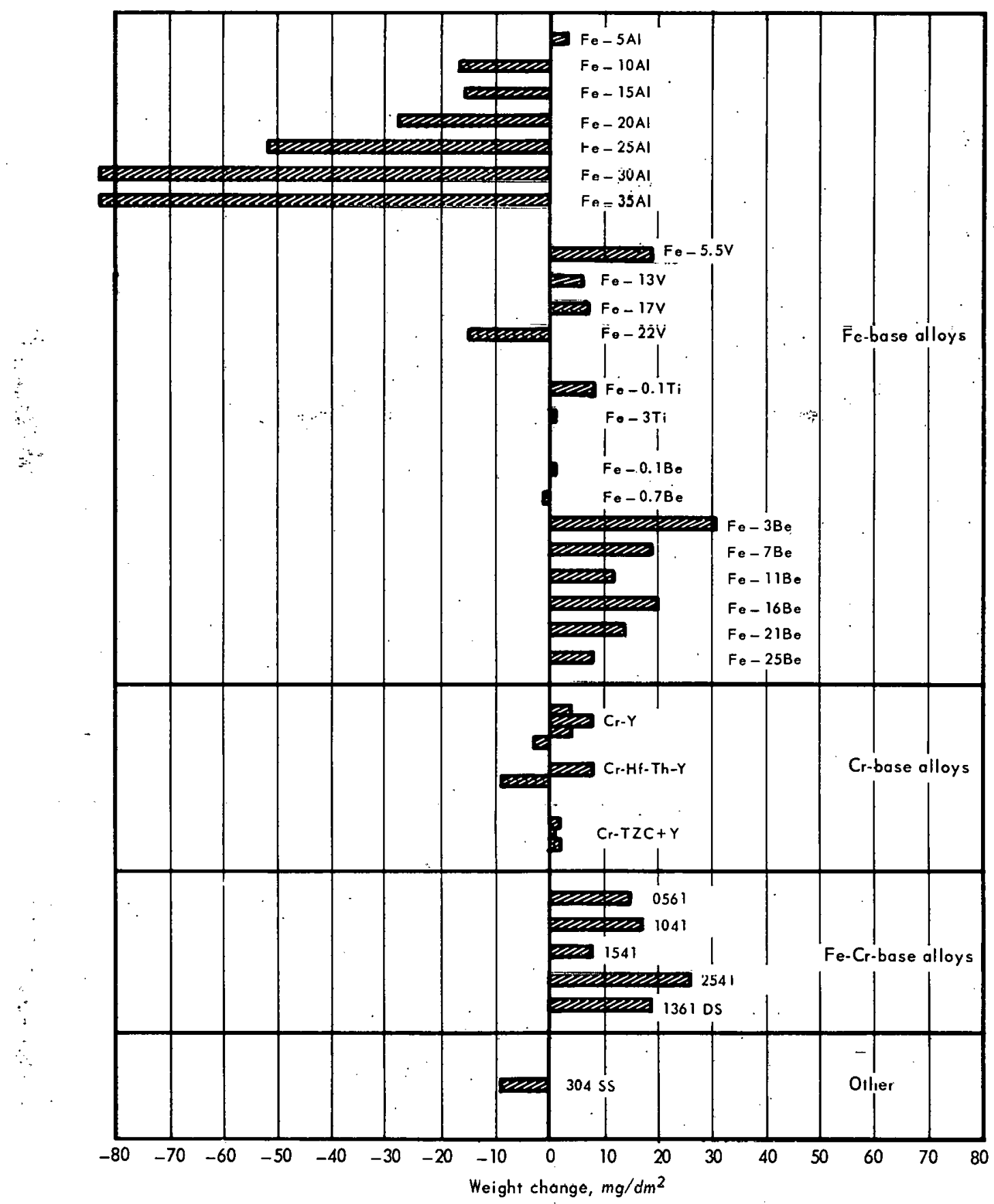

Fig. 5.1 - Compatibility of cladding alloys with static sodium of $750^{\circ} \mathrm{C}$ 


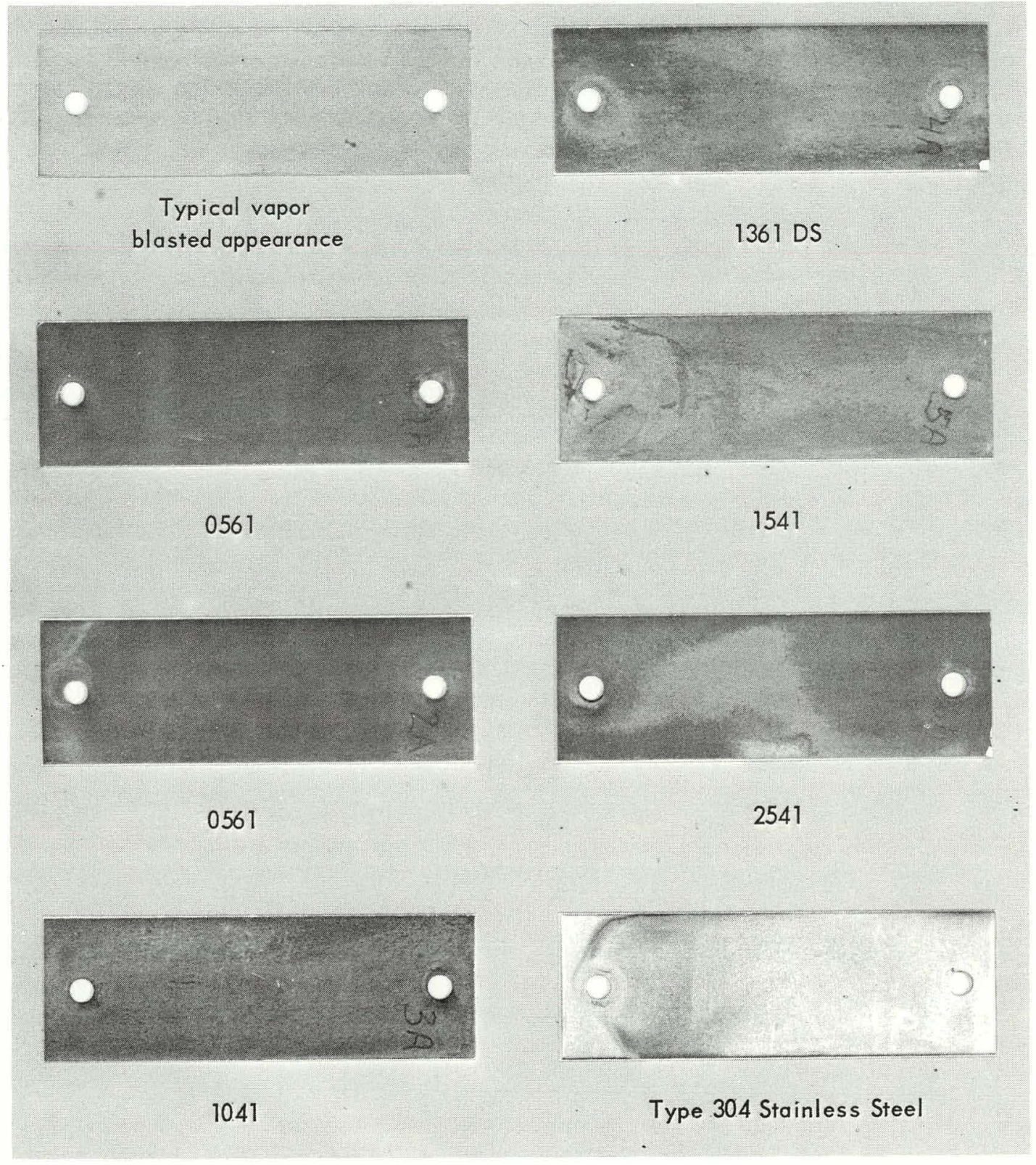

Fig. 5.2 - Coupons of $\mathrm{Fe}-\mathrm{Cr}$-base alloys after heating in sodium for 1000 hours at $750^{\circ} \mathrm{C}$ ( Neg. P66-11-35) 
Strength and Ductility

Tensile Data - The results of tensile tests performed in air on previously prepared 1361 DS sheet material $\left(0.076 \mathrm{~cm}\right.$ thick) at $24^{\circ}, 550^{\circ}$, and $750^{\circ} \mathrm{C}$ are presented in Table 5.4 which includes data on conventionally prepared 2541 and 1541 alloys as reported by Harwell. ${ }^{4}$ These data and data on Types 304 and 316 stainless steel are plotted in Figure 5.3.

The dispersion-strengthened alloy is much stronger at the lower temperatures; with increasing temperature, the strength advantage decreases and becomes marginal at $750^{\circ} \mathrm{C}$. This may be because the weakness of the matrix material at the higher temperatures renders the dispersant ineffective as a strengthener. It is for this reason that the $0561+3$ weight percent Mo alloy (Heat No. MS-64 in Table 5.2) is being investigated. Previous experience indicated that a 3 weight percent Mo addition should increase the matrix strength significantly.

During tensile testing, the 1361 DS material seemed to be notch sensitive, fracturing at the indents made by the extensometer knife edges. This was particularly obvious from the data at $550^{\circ} \mathrm{C}$ in Table 5.4 in which a specimen tested without an extensometer showed signiticantly higher strength and ductility. This behavior is not consistent with impact and bend data, discussed subsequently, which indicate the $1361 \mathrm{DS}$ alloy to be relatively tough.

Impact Strength - Cylindrical notched impact specimens $(5.6 \mathrm{~mm}$ diameter) of the previously prepared 1361 DS alloy were tested in a small Izod machine in the annealed condition $\left(1000^{\circ} \mathrm{C}\right.$ for 0.5 hour and water quenched) after heating in air for 50 hours at $450^{\circ}, 550^{\circ}$, and $800^{\circ} \mathrm{C}$. As indicated in Figure 5.4, there was a substantial difference in the results for the specimens heated at $450^{\circ} \mathrm{C}$. It is postulated that this was caused by fine precipitation at $450^{\circ} \mathrm{C}$ of alpha prime, the chromium-rich ferrite phase. This suggests that a somewhat lower chromium level than the 13.11 weight percent contained in the 1361 DS alloy may be necessary to insure structural stability on long-time heating in the alpha-prime precipitation range.

TABLE 5.4

TENSILE DATA ${ }^{\mathrm{a}}$ FOR Fe-Cr-Al-Y ALLOYS

\begin{tabular}{|c|c|c|c|c|c|c|}
\hline \multirow{2}{*}{$\begin{array}{c}\text { Alloy } \\
\text { Designation } \\
\end{array}$} & \multirow{2}{*}{$\begin{array}{l}\text { Test Temperature, } \\
{ }^{\circ} \mathrm{C} \\
\end{array}$} & \multicolumn{2}{|c|}{ Yield Strength } & \multicolumn{2}{|c|}{ Ultimate Strength } & \multirow[b]{2}{*}{ Elongation, \% } \\
\hline & & psi & $\mathrm{kg} / \mathrm{cm}^{2}$ & psi & $\mathrm{kg} / \mathrm{cm}^{2}$ & \\
\hline \multirow[t]{9}{*}{$1361 \mathrm{DS}^{\mathrm{b}}$} & RT & 114,620 & 8060 & 118,180 & 8310 & 1.1 \\
\hline & RT & 115,450 & 8120 & 120,520 & 8480 & 2. 8 \\
\hline & RT & 116,440 & 8190 & 120,470 & 8470 & 2.4 \\
\hline & RT & - & - & 122,300 & 8600 & 2. 8 \\
\hline & 550 & 32,500 & 2290 & 53,840 & 3790 & 6.0 \\
\hline & 550 & 35,520 & 2500 & 50,070 & 3520 & 6. 8 \\
\hline & 550 & c & - & 64,750 & 4550 & 190 \\
\hline & 750 & 6,270 & 440 & 11,470 & 810 & 50.3 \\
\hline & 750 & - & - & 12,720 & 900 & 44.2 \\
\hline \multirow[t]{3}{*}{1541} & $\mathrm{RT}^{\mathrm{d}}$ & 56,000 & 3940 & 77,000 & 5480 & 23.0 \\
\hline & $650^{\mathrm{d}}$ & 17,000 & 1200 & 18,300 & 1290 & 71.2 \\
\hline & $750^{\mathrm{d}}$ & 10,000 & 750 & 10,600 & 750 & $10 \% .0$ \\
\hline \multirow[t]{3}{*}{2541} & RT & 51,200 & 3600 & 75,300 & 5290 & - \\
\hline & $650^{d}$ & 16,600 & 1170 & 20,000 & 1410 & 70.0 \\
\hline & $750^{\mathrm{d}}$ & 9,600 & 680 & 9,600 & 680 & 110.7 \\
\hline
\end{tabular}

a All tests conducted in air.

$b_{1361}$ DS data at crosshead speed of $0.005 \mathrm{~cm} / \mathrm{cm}-\mathrm{min}$.

$\mathrm{c}_{\text {No extensometer. }}$

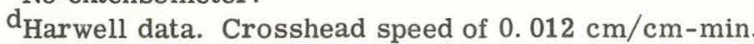

${ }^{4} \mathrm{~J}$. Antill, private communication. 

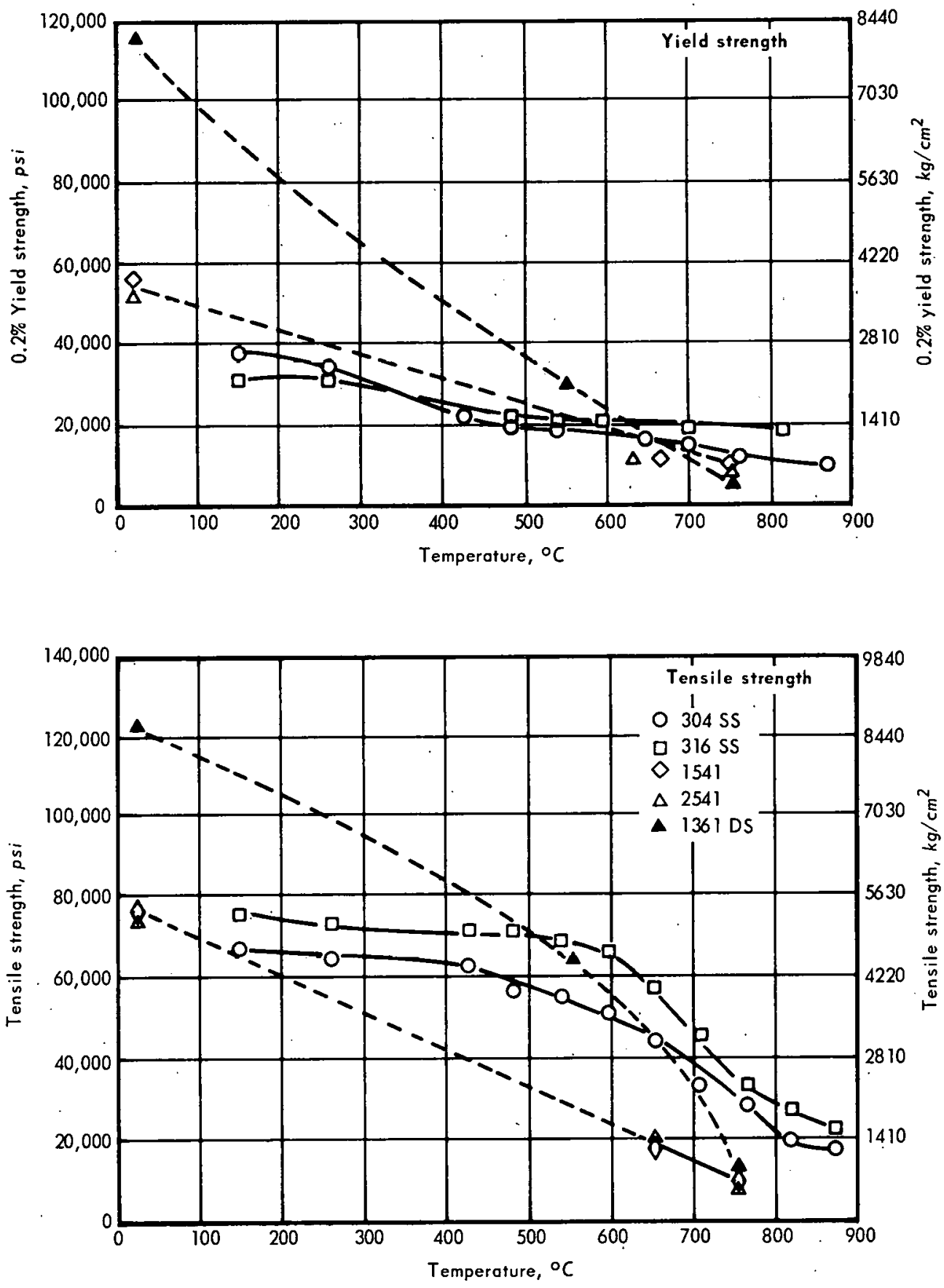

Fig. 5.3 - Tensile and 0.2-percent yield strength of $\mathrm{Fe}-\mathrm{Cr}$-Al-Y alloys 


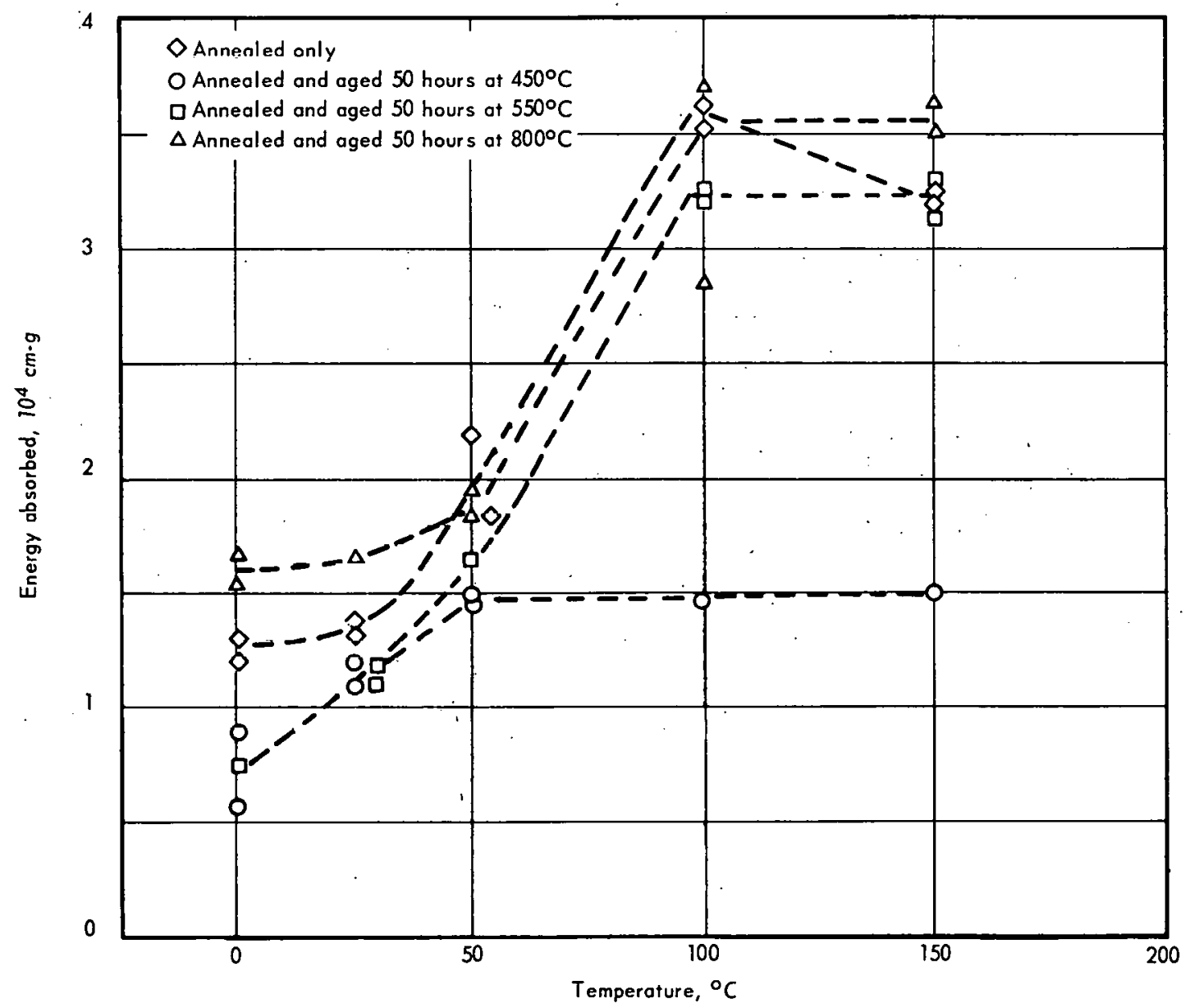

Fig. 5.4-Impact strength of 1361 DS alloy

A comparison of the impact strength of the $1361 \mathrm{DS}$ alloy and the conventionally prepared 1541 and 2541 allo: s (see Figure 5.5), all in the annealed condition, indicates the significant improvement in the ductile-to-brittle transition temperature (DBTT) in impact tests. The 1361 DS material also evidenced useful ductility in sheet form as two specimens were successfully bent 90 degrees over a $2 \mathrm{~T}$ radius at $-78^{\circ} \mathrm{C}$.

Creep Rupture - Initial creep-rupture tests on annealed 1361 DS alloy sheet specimens were made in air at $550^{\circ} \mathrm{C}$ and $7500^{\circ} \mathrm{C}$ to determine 1 percent creep strength and rupture strength. The data obtained are presented in Table 5.5.

$\mathrm{YFe}_{9}$ Dispersant - In an attempt to characterize the $\mathrm{YFe}_{9}$ dispersant believed to be responsible for strengthening the 1361 DS material, an arc-melted button was made from a stoichiometric mixture of yttrium and iron in a partial pressure of helium. The roomtemperature hardness of the as-cast. button exceeded $600 \mathrm{DPH}$. Hot-hardness tests will be made at $550^{\circ} \mathrm{C}$ and $750^{\circ} \mathrm{C}$ for comparison with standard 1541 material. The structure of the button alloy contained two phases, one arranged in a dendritic pattern within a matrix phase. The hardness of both phases was about the same. A $\dot{Y} \mathrm{Fe}_{9}$ phase was confirmed in $X$-ray diffraction analysis but the second phase was not identified. It is tentatively believed to be $\mathrm{YFe}_{4}: \cdots$ 


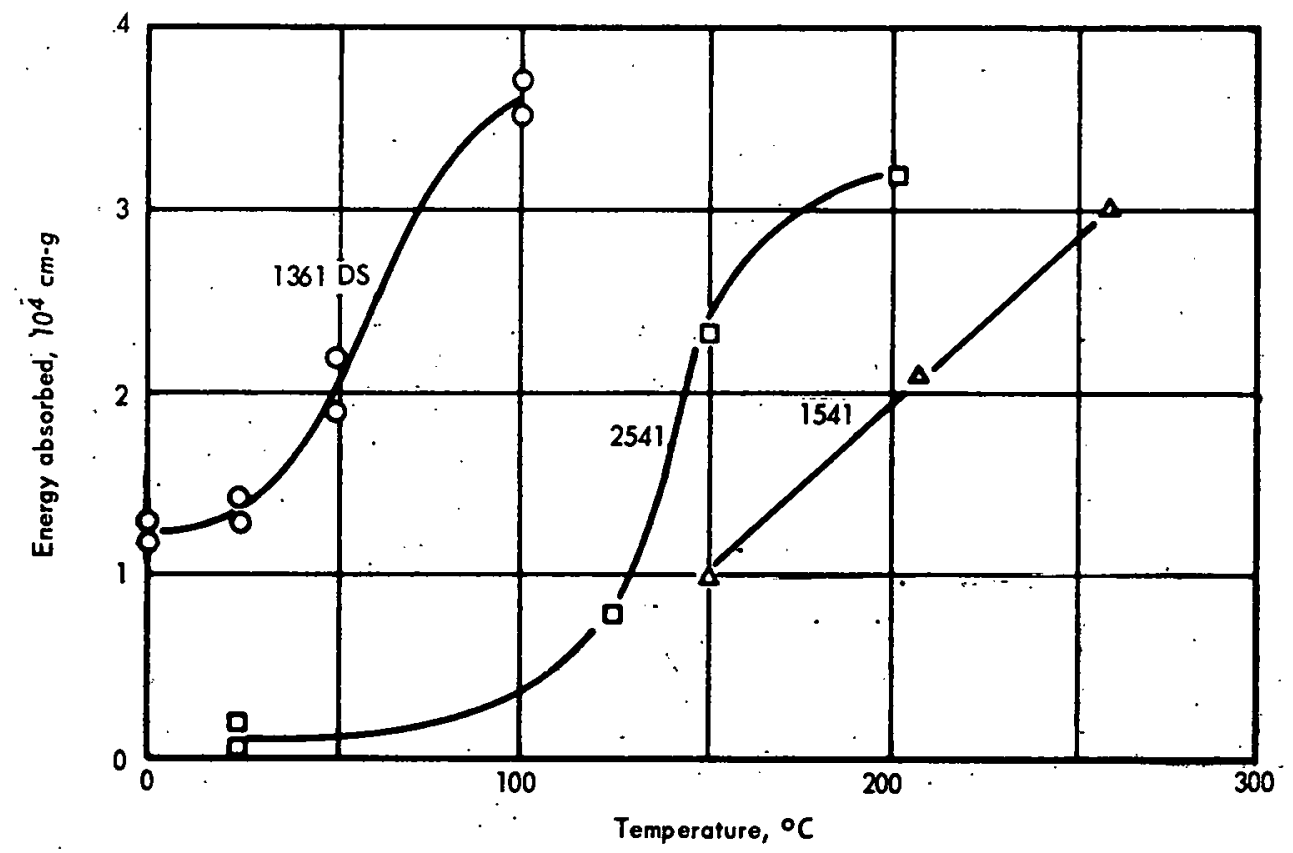

Fig. 5.5 - Impact strength of 1361 DS alloy compared to those of 2541 and 1.541 alloys

TABLE 5.5

CREEP-RUPTURE DATA FOR ANNEALED 1361 .DS SHEET

\begin{tabular}{|c|c|c|c|c|c|c|c|c|}
\hline \multirow{2}{*}{$\begin{array}{l}\text { Specimen } \\
\text { No. }\end{array}$} & \multirow{2}{*}{\multicolumn{2}{|c|}{$\begin{array}{c}\text { Test Temperature, } \\
{ }^{\circ} \mathrm{C}\end{array}$}} & \multicolumn{2}{|c|}{ Stresg } & \multirow{2}{*}{$\begin{array}{l}\text { Time to } 1 \% \\
\text { Elongation, } \mathrm{hr}\end{array}$} & \multirow{2}{*}{$\begin{array}{c}\text { Test Time, } \\
\text { hr }\end{array}$} & \multirow{2}{*}{$\begin{array}{c}\text { Total } \\
\text { Elongation, } \%\end{array}$} & \multirow{2}{*}{ Test Status } \\
\hline & & & psi & $\mathrm{kg} / \mathrm{cm}^{2}$ & & & & \\
\hline 11 & & 550 & 15,000 & 1050 & 3.8 & 111.0 & 40.3 & Ruptured \\
\hline 17 & & 550 & $10,-000$ & 700 & 11.5 & 458.1 & 6.4 & Terminated \\
\hline 12 & & 550 & 6,000 & 420 & 47.5 & 2125.6 & - & $\mathbf{a}$ \\
\hline 15 & & 550 & 6,000 & 420 & 180.0 & 561.6 & 1.4 & Terminated \\
\hline 16 & & 750 & 3,000 & 210 & 1172.2 & 1317.4 & 1.4 & Terminated \\
\hline 18 & & 750 & 3,000 & 210 & 1146.0 & 1221: 9 & 1.1 & Terminated \\
\hline
\end{tabular}

${ }^{a}$ Removed from creep stand at 1 -percent elongation and continued testing in a rupture stand. Specimen stlll intact at 2125.6 hours.

Structural Stability

Effect of Aging - The influence of aging on the hardness and structure of the 1361 DS material was studied using specimens cut from previously prepared $0.635-\mathrm{cm}$-diameter rod stock. Prior to specimen preparation, the rod stock was annealed at $1000^{\circ} \mathrm{C}$ for 0.5 hour and water quenched. The specimens were heated in air at $450^{\circ}, 550^{\circ}, 730^{\circ}, 900^{\circ}$, $1000^{\circ}$, and $1100^{\circ} \mathrm{C}$ and water quenched from each temperature after being aged for 1,5 , 25, 50, and 100 hours. Three diamond pyramid hardness measurements made on each specimen showed no significant change in hardness for any of the treatments. Preliminary observation of the aged specimens under the light microscope revealed no change in microstructure, no apparent change in the size or distribution of the $\mathrm{YFe}_{9}$ particles, and no evidence of alpha prime or sigma precipitation. The apparent absence of these phases and no change in hardness is somewhat surprising in view of the effect of aging at $450^{\circ} \mathrm{C}$ on impact strength which was discussed previously.

Studies are in progress to more accurately define the aging characteristics of compositions within the $\mathrm{Fe}-\mathrm{Cr}-\mathrm{Al}-\mathrm{Y}$ system at $450^{\circ} \mathrm{C}$. Fifteen arc-melted, 80 -gram buttons were 
fabricated and processed to $0.076-\mathrm{cm}$-thick strips. Hardness (DPH) and DBTT in bending will be established as a function of aging time. The following compositions are included in the study.

Composition, nominal weight percent

\begin{tabular}{|c|c|c|c|c|c|c|c|c|c|}
\hline & $\mathrm{Cr}$ & $\mathrm{Al}$ & $\mathbf{Y}$ & $\mathrm{Fe}$ & & $\mathrm{Cr}$ & $\underline{\mathrm{Al}}$ & $\mathbf{Y}$ & Fe \\
\hline 1 & 5 & 0 & 1 & Bal & 9 & 10 & 6 & 1 & Bal \\
\hline 2 & 5 & 4 & 1. & Bal & 10 & 12 & 0 & 1 & $\mathrm{Bal}$ \\
\hline 3 & 5 & 6 & 1 & Bal & 11 & 12 & 4 & 1 & Bal \\
\hline 4 & 7.5 & 0 & 1 & Bal & 12 & 12 & 0 & 1 & Bal \\
\hline 5 & 7.5 & 4 & 1 & Bal & 13 & 15 & 0 & 1 & Bal \\
\hline 6 & 7.5 & 6 & 1 & Bal & 14 & 15 & 4 & 1 & $\mathrm{Bal}$ \\
\hline 7 & 10 & 0 & 1 & Bal & 15 & 15 & 6 & 1 & Bal \\
\hline 8 & 10 & 4 & 1. & Bal & & & & & \\
\hline
\end{tabular}

Radiation Stability

Creep-rupture and bend test specimens of five $\mathrm{Fe}-\mathrm{Cr}-\mathrm{Al}-\mathrm{Y}$ compositions, along with chromium-base alloy specimens, were encapsulated for irradiation at a maximum temperature of $150^{\circ} \mathrm{C}$ in helium. The irradiation capsule, ORM-53, will be inserted in the A-2 facility of the ORR on February 2, 1967. It is scheduled to be removed on or about April 30, 1967, by which time the specimens will have experienced an estimated dosage of $1.5 \times 10^{20} \mathrm{nvt}\left(\mathrm{E}_{\mathrm{n}} \geq 1 \mathrm{Mev}\right)$.

\section{2 IRON-BASE ALLOYS}

\section{MATERIAL PREPARATION}

Fifty- and 80-gram drop castings were made of 26 binary compositions within the systems $\mathrm{Fe}-\mathrm{Be}, \mathrm{Fe}-\mathrm{Ti}, \mathrm{Fe}-\mathrm{Al}$, and $\mathrm{Fe}-\mathrm{V}$. Nominal compositions are presented in Table 5.6. Processing details were previously described. ${ }^{6}$ All of the 80 -gram castings were successfully converted to $0.076-\mathrm{cm}$-thick sheet with the exception of the four $\mathrm{Fe}-\mathrm{Al}$ alloys containing 25 to $\mathbf{4 0}$ atomic percent aluminum.

Based on the initial data obtained for the binary alloys, six multi-component alloys were designed. Pending clarification of patent status, these six multi-component alloys will be identified only as compositions $A$ through $F$. These six compositions were prepared in the form of 80-gram drop castings and converted to $0.076-\mathrm{cm}$-thick sheet. In addition, a 5.4$\mathrm{kg}$ vacuum-induction-melted heat was made of each alloy. These ingots were extruded to $2.86-\mathrm{cm}$-diameter rod, part of which was successfully hot-rolled at $1040^{\circ} \mathrm{C}$ to $0.076-\mathrm{cm}$ thick sheet as shown in Figure 5. 6. Attempts to cold-roll compositions A and D from 0.191 $\mathrm{cm}$ to final thickness were unsuccessful (which accounts for the splitting shown in 2 sections of heat M-327 in Figure 5.6). Therefore, all subsequent sheet was hot-rolled to final size. Other portions of the extruded rods of the multi-component alloys will be reduced to 1.27and $0.635-\mathrm{cm}$-diameter rod for varlous sodium compatibility and impact test specimens.

TABLE 5.6

\begin{tabular}{|c|c|c|}
\hline Alloy No. & Addition Element & Additions, at. $\%$ \\
\hline $1-8$ & $\mathrm{Al}$ & $5,10,15,20,25,30,35,40$ \\
\hline $9-14$ & Va & $1,3.5,5.5,13,17,22$ \\
\hline $16-19$ & $\mathbf{T i}$ & $0.1,0.5,3,5$ \\
\hline $20-27$ & $\mathrm{Be}$ & $0.1,0.75,3,7,11,16,21,25$ \\
\hline
\end{tabular}

5 GEMP-63, p. 88. 


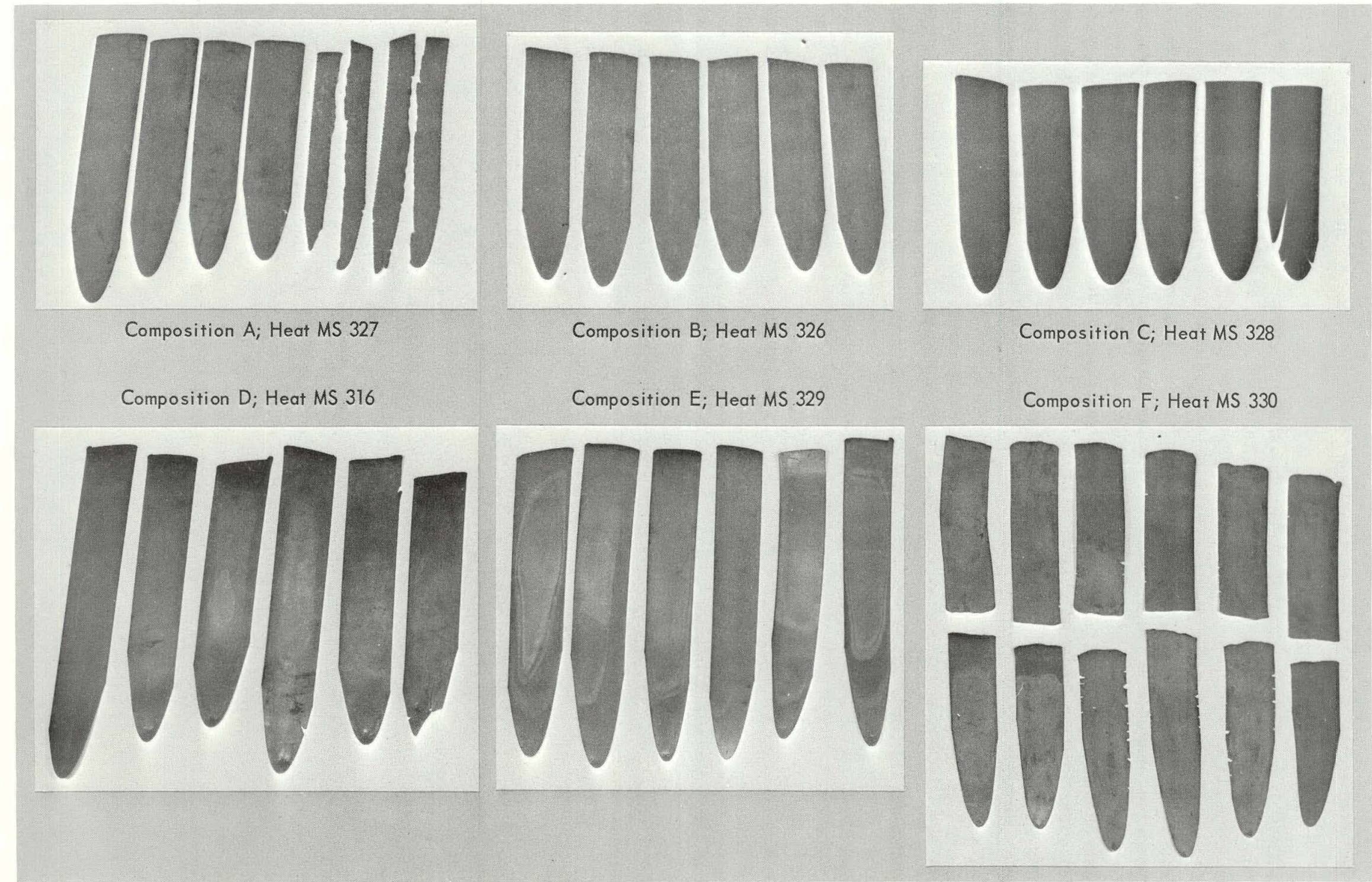

Fig. 5.6-Hot-rolled 0.076-cm-thick sheet of multi-component compositions $A$ through $F$ 


\section{MATERIAL EVALUATION}

Environmental Compatibility

Static sodium compatibility tests were run using $0.1-\mathrm{cm}$-thick wafers cut from the drop castings of most of the binary compositions. As previously described ${ }^{6}$ these specimens were placed in an evacuated stainless steel capsule containing sodium $\left(22 \mathrm{ppm} \mathrm{O}_{2}\right)$ and heated for 1029 hours at $750^{\circ} \mathrm{C}$. The appearance of the specimens following sodium exposure is shown in Figure 5.7. The weight change data for these compositions are shown in Figure 5.1 compared with other candidate materials. Insignificant dimensional changes were observed. Metallographic examination and surface and internal DPH hardness measurements on the low and high additive element compositions indicated no apparent surface attack. Two exceptions to this were $\mathrm{Fe}-35 \mathrm{Al}$ and $\mathrm{Fe}-22 \mathrm{~V}$. Fairly extensive intergranular voids on the surface of the $\mathrm{Fe}-35 \mathrm{Al}$ alloy can be seen in Figure 5.8. A less well defined, though definite, surface effect was also observed in the $\mathrm{Fe}-22 \mathrm{~V}$ specimen, also shown in Figure 5.8. These results suggest that high aluminum and, probably, high vanadium compositions may be impractical for long-time operation in sodium at $750^{\circ} \mathrm{C}$.

Strength and Ductility

The results of hardness studies on the binary alloys in various conditions were previously reported. ${ }^{7}$ These data indicate the strengthening effect at room temperature of each of the additive elements. In Figure 5.9, hardness is plotted as a function of alloying addition for some of the binary iron alloys in the form of hot-rolled sheet. As can be seen, Be appears to be the best strengthener followed in order by $\mathrm{Ti}, \mathrm{Al}$, and $\mathrm{V}$.

Tensile test results for sheet specimens of the binary alloys at room temperature in air and at $750^{\circ} \mathrm{C}$ in an argon-filled capsule are presented in Table 5. 7. Data obtained in the same equipment at $750^{\circ} \mathrm{C}$ for $\mathrm{Fe}$ and Type 304 stainless steel are included for comparison. The $750^{\circ} \mathrm{C}$ yield strength values are only approximate since strain measurements are based on deflectometer measurements of crosshead movement rather than an extensometer attached to the specimen.

The results obtained for the Fe-Be alloys are particularly interesting in terms of both room-temperature and high-temperature strength and ductility. Titanium seems to be second only to beryllium in imparting hot strength. Vanadium and aluminum appear to be much less effective in strengthening iron.

Hot tensile data obtained on sheet specimens from the button heats of the multi-component alloys at $550^{\circ} \mathrm{C}$ and $750^{\circ} \mathrm{C}$ indicate that several compositions, particularly $\mathrm{A}$ and $\mathrm{E}$, possess useful strength levels and may be suited for high-temperature application in sodium or inert gas. These data are presented in Table 5.8. The Fe and Type 304 stainless steel data at $750^{\circ} \mathrm{C}$ are repeated for comparison.

Preliminary bend tests were conducted at $-78^{\circ} \mathrm{C}$ on sheet specimens from the button heats of a number of the binary alloys and the multi-component alloys. The specimens were bent in a tensile machine at a crosshead speed of $0.076 \mathrm{~cm} / \mathrm{min}$ over a $2 \mathrm{~T}$ radius. The data are presented in Table 5.9. Most of the binary alloys appear to be ductile down to $-78^{\circ} \mathrm{C}$. The exceptions were $\mathrm{Fe}-20 \mathrm{Al}, \mathrm{Fe}-22 \mathrm{~V}$ which broke at an angle of 20 degrees, and $\mathrm{Fe}-25 \mathrm{Be}$ which broke at an angle of 50 degrees. Of the multi-component alloys, only composition $\mathrm{F}$ bent 90 degrees at $-78^{\circ} \mathrm{C}$. In the manual bends at room temperature, all compositions bent 90 degrees except compositions A and D.

\footnotetext{
${ }^{6}$ GEMP-63, pp. 88-90.

${ }^{7}$ GEMP-63, Figure 8.5, p. 91.
} 


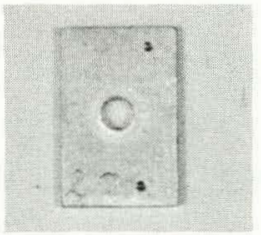

$\mathrm{Fe}-0.1 \mathrm{Be}$

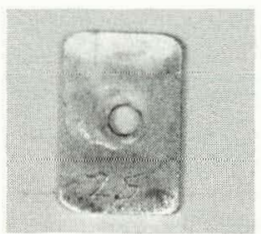

$\mathrm{Fe}-16 \mathrm{Be}$

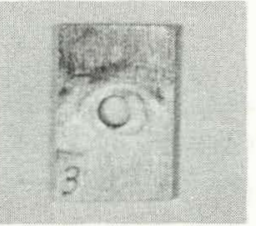

$F e-15 A I$

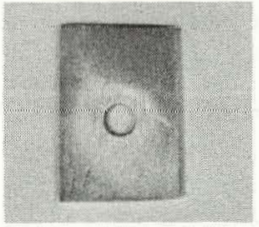

$F e-5.5 \mathrm{~V}$

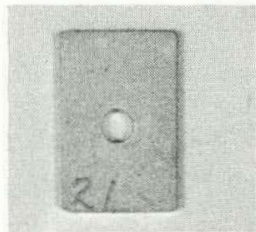

$\mathrm{Fe}-0.75 \mathrm{Be}$

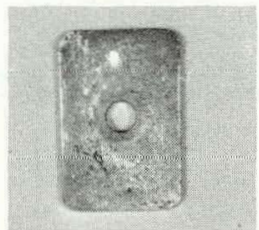

$\mathrm{Fe}-21 \mathrm{Be}$

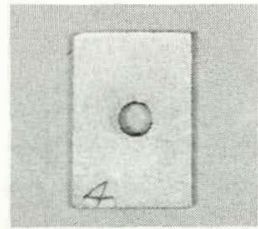

$\mathrm{Fe}-20 \mathrm{Al}$

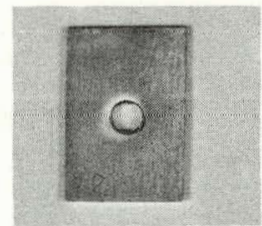

$\mathrm{Fe}-13 \mathrm{~V}$

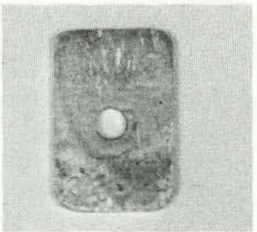

$\mathrm{Fe}-3 \mathrm{Be}$

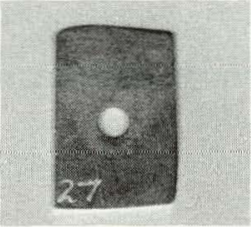

$\mathrm{Fe}-25 \mathrm{Be}$

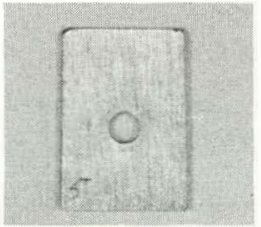

$\mathrm{Fe}-25 \mathrm{Al}$

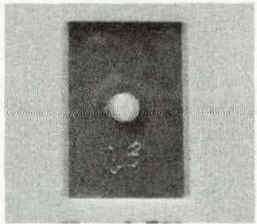

$\mathrm{Fe}-17 \mathrm{~V}$

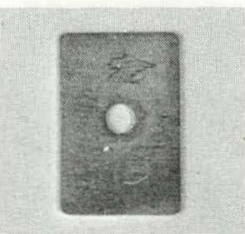

$\mathrm{Fe}-7 \mathrm{Be}$

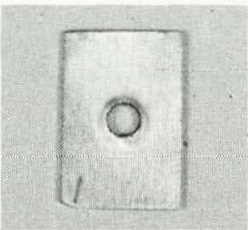

$F e-5 A$

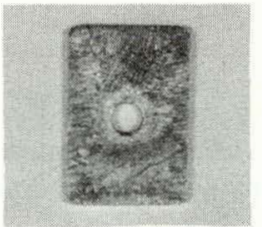

$\mathrm{Fe}-30 \mathrm{Al}$

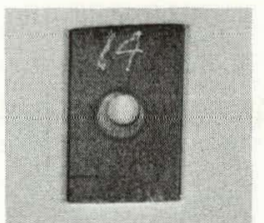

$\mathrm{Fe}-22 \mathrm{~V}$

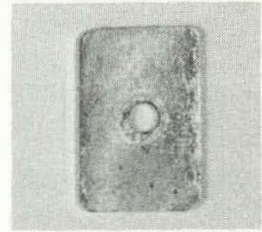

$\mathrm{Fe}-11 \mathrm{Be}$

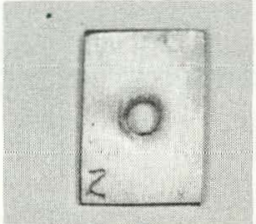

$\mathrm{Fe}-10 \mathrm{Al}$

Fig. 5.7 - Coupons of binary iron alloys after heating in sodium for 1029 hours at $750^{\circ} \mathrm{C}$ (Neg. P66-17-50)

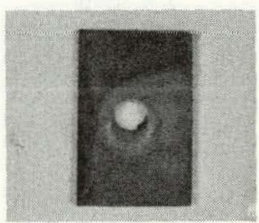

$\mathrm{Fe}-3 \mathrm{Ti}$ 


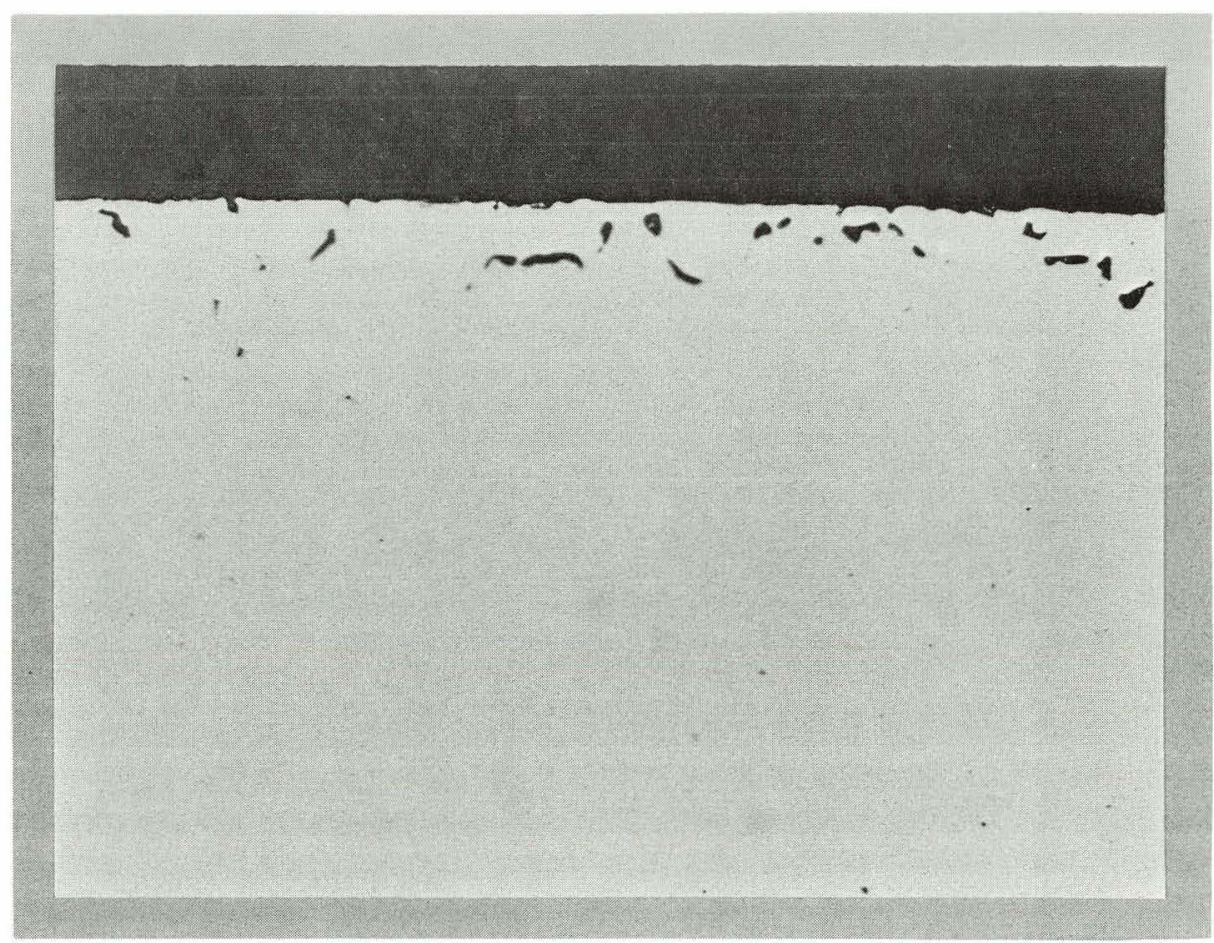

a. $\mathrm{Fe}-35 \mathrm{Al}(\mathrm{Neg} .8494)$

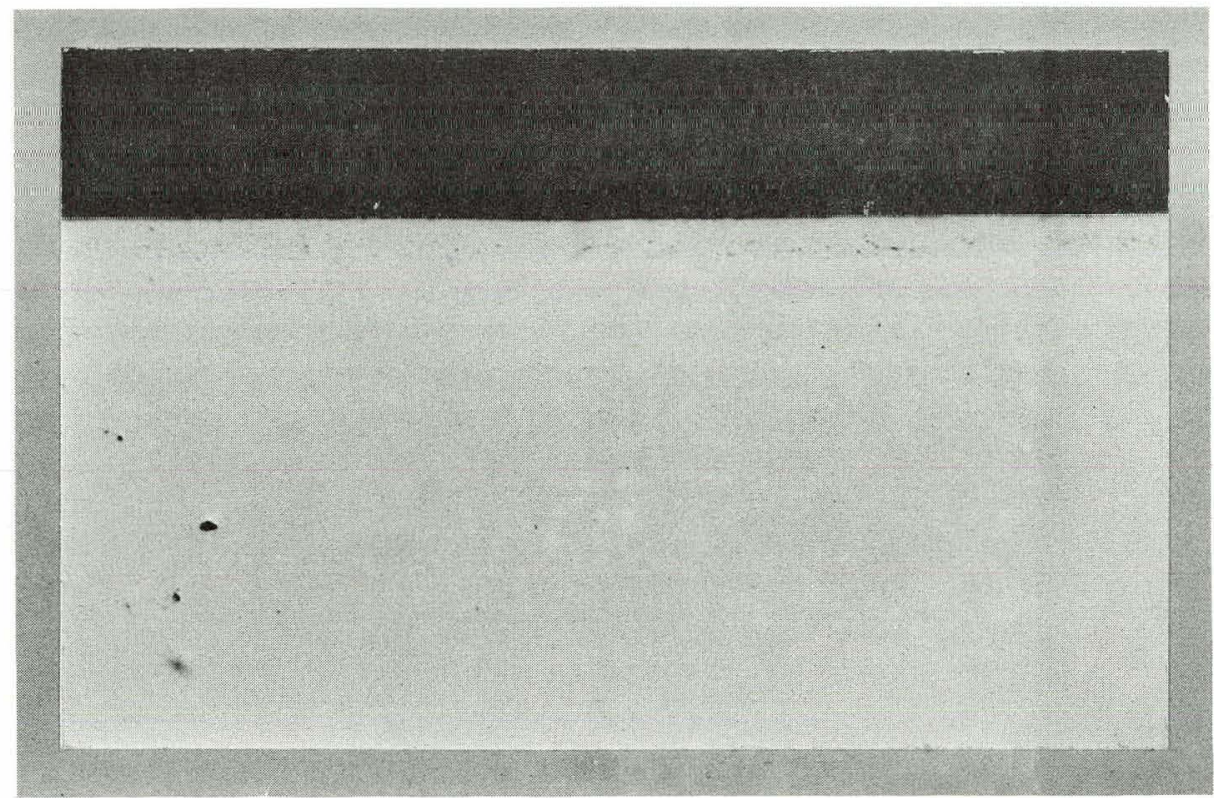

b. $\mathrm{Fe}-22 \mathrm{~V}(\mathrm{Neg} .8495)$

Fig. 5.8 - Longitudinal section at surface of $\mathrm{Fe}-35 \mathrm{Al}$ and $\mathrm{Fe}-22 \mathrm{~V}$ coupons after heating in sodium for 1029 hours at $750^{\circ} \mathrm{C}$ (As-polished, 250X) 
TABLE 5.7

TENSILE DATA FOR BINARY IRON-BASE ALLOYS

\begin{tabular}{|c|c|c|c|c|c|c|}
\hline \multirow{2}{*}{$\begin{array}{l}\text { Composition, } \\
\text { at. } \% \\
\end{array}$} & \multirow{2}{*}{$\begin{array}{c}\text { Test Temperature, } \\
{ }^{\circ} \mathrm{C}\end{array}$} & \multicolumn{2}{|c|}{ Yield Strength } & \multicolumn{2}{|c|}{ Tensile Strength } & \multirow{2}{*}{$\begin{array}{c}\text { Elongation in } \\
2.54 \mathrm{~cm}, \%\end{array}$} \\
\hline & & psi & $\mathrm{kg} / \mathrm{cm}^{2}$ & psi & $\mathrm{kg} / \mathrm{cm}^{2}$ & \\
\hline $\mathrm{Fe}-5 \mathrm{Al}$ & RT & 19,000 & 1340 & 36,900 & 2,590 & 14.8 \\
\hline $\mathrm{Fe}-10 \mathrm{Al}$ & RT & 32,800 & 2310 & 50,100 & 3,520 & 14.4 \\
\hline $\mathrm{Fe}-15 \mathrm{Al}$ & RT & 49,900 & 3520 & 61,700 & 4,340 & 13.5 \\
\hline $\mathrm{Fe}-20 \mathrm{Al}$ & RT & - & - & 63,800 & 4,490 & 1.8 \\
\hline $\mathrm{Fe}-5.5 \mathrm{~V}$ & RT & 22,500 & 1580 & 47,000 & 3,300 & 28.8 \\
\hline $\mathrm{Fe}-13 \mathrm{~V}$ & $\mathbf{R T}$ & 34,200 & 2410 & 57,100 & 4,020 & 27.3 \\
\hline $\mathrm{Fe}-17 \mathrm{~V}$ & RT & 51,600 & 3630 & 71,400 & 5,020 & 18.8 \\
\hline $\mathrm{Fe}-0.1 \mathrm{Ti}$ & $\mathbf{R T}$ & 18,200 & 1280 & 37,800 & 2,660 & 34.3 \\
\hline $\mathrm{Fe}-3 \mathrm{Ti}$ & RT & 29,000 & 2040 & 52,300 & 3,680 & 26.1 \\
\hline $\mathrm{Fe}-5 \mathrm{Ti}$ & $\mathbf{R T}$ & 35,900 & 2520 & 58,700 & 4,130 & 25.6 \\
\hline $\mathrm{Fe}-0.1 \mathrm{Be}$ & $\mathbf{R T}$ & 25,200 & 1770 & 29,200 & 2,050 & 31.0 \\
\hline $\mathrm{Fe}-0.75 \mathrm{Be}$ & $\mathbf{R T}$ & 21,500 & 1510 & 41,000 & 2,880 & 23.3 \\
\hline $\mathrm{Fe}-3 \mathrm{Be}$ & $\mathbf{R T}$ & 49,700 & 3490 & 74,700 & 5,250 & 25.6 \\
\hline $\mathrm{Fe}-11 \mathrm{Be}$ & RT & 77,400 & 5440 & 151,100 & 10,620 & 21.0 \\
\hline $\mathrm{Fe}-16 \mathrm{Be}$ & RT & 82,400 & 5790 & 163,400 & 11,490 & 14.8 \\
\hline $\mathrm{Fe}-5 \mathrm{Al}$ & 750 & 4,200 & 300 & 6,000 & 420 & 62.4 \\
\hline $\mathrm{Fe}-10 \mathrm{Al}$ & 750 & 6,200 & 440 & 7,800 & 550 & 101.4 \\
\hline $\mathrm{Fe}-15 \mathrm{Al}$ & 750 & 4,800 & 340 & 5,900 & .410 & 75.1 \\
\hline $\mathrm{Fe}-20 \mathrm{Al}$ & $750^{\mathrm{b}}$ & - & - & 6,400 & 450 & 52.7 \\
\hline $\mathrm{Fe}-3.5 \mathrm{~V}$ & 750 & 3,700 & 260 & 5,600 & 390 & 39.8 \\
\hline $\mathrm{Fe}-5.5 \mathrm{~V}$ & 750 & 4,000 & 280 & 5,900 & 410 & 50.3 \\
\hline $\mathrm{Fe}-13 \mathrm{~V}$ & 750 & 6,200 & 440 & 9,400 & 660 & 66.0 \\
\hline $\mathrm{Fe}-17 \mathrm{~V}$ & 750 & 9,200 & 650 & 11,300 & 790 & 50.3 \\
\hline $\mathrm{Fe}-22 \mathrm{~V}$ & 750 & - & - & 10,600 & 750 & 54.9 \\
\hline $\mathrm{Fe}-0.1 \mathrm{Ti}$ & 750 & 3,400 & 240 & 5,200 & 370 & 26.0 \\
\hline $\mathrm{Fe}-3 \mathrm{Ti}$ & 750 & 13,600 & 960 & 15,400 & 1,080 & 17.8 \\
\hline $\mathrm{Fe}-5 \mathrm{Ti}$ & 750 & 14,000 & 980 & 15,500 & 1,090 & 32.4 \\
\hline $\mathrm{Fe}-0.75 \mathrm{Be}$ & $750^{\mathrm{C}}$ & 3,900 & 270 & 6,400 & 450 & 31.7 \\
\hline $\mathrm{Fe}-3 \mathrm{Be}$ & $750^{\mathrm{d}}$ & 6,300 & 440 & 12,500 & 880 & 46.3 \\
\hline $\mathrm{Fe}-11 \mathrm{Be}$ & $750^{\mathrm{e}}$ & 14,000 & 980 & 19,400 & 1,360 & 6.9 \\
\hline $\mathrm{Fe}-.16 \mathrm{Be}$ & 750 & 12,900 & 910 & 19,400 & 1,360 & 63.4 \\
\hline $\mathrm{Fe}$ & 750 & 1,000 & 70 & 1,600 & 110 & 14.5 \\
\hline 304 Stainless & 750 & 15,100 & 1060 & 26,700 & 1,880 & 51.0 \\
\hline
\end{tabular}

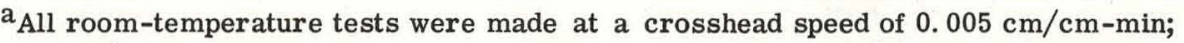
all $750^{\circ} \mathrm{C}$ tests were made at a crosshead speed of $0.072 \mathrm{~cm} / \mathrm{min}$ with the exception of $b, c$, and $d$.

${ }^{b}$ Crosshead speed of $0.216 \mathrm{~cm} / \mathrm{min}$.

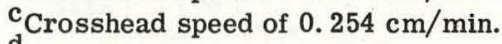

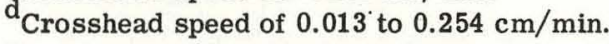

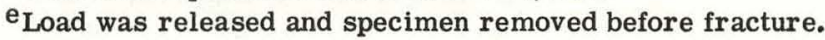




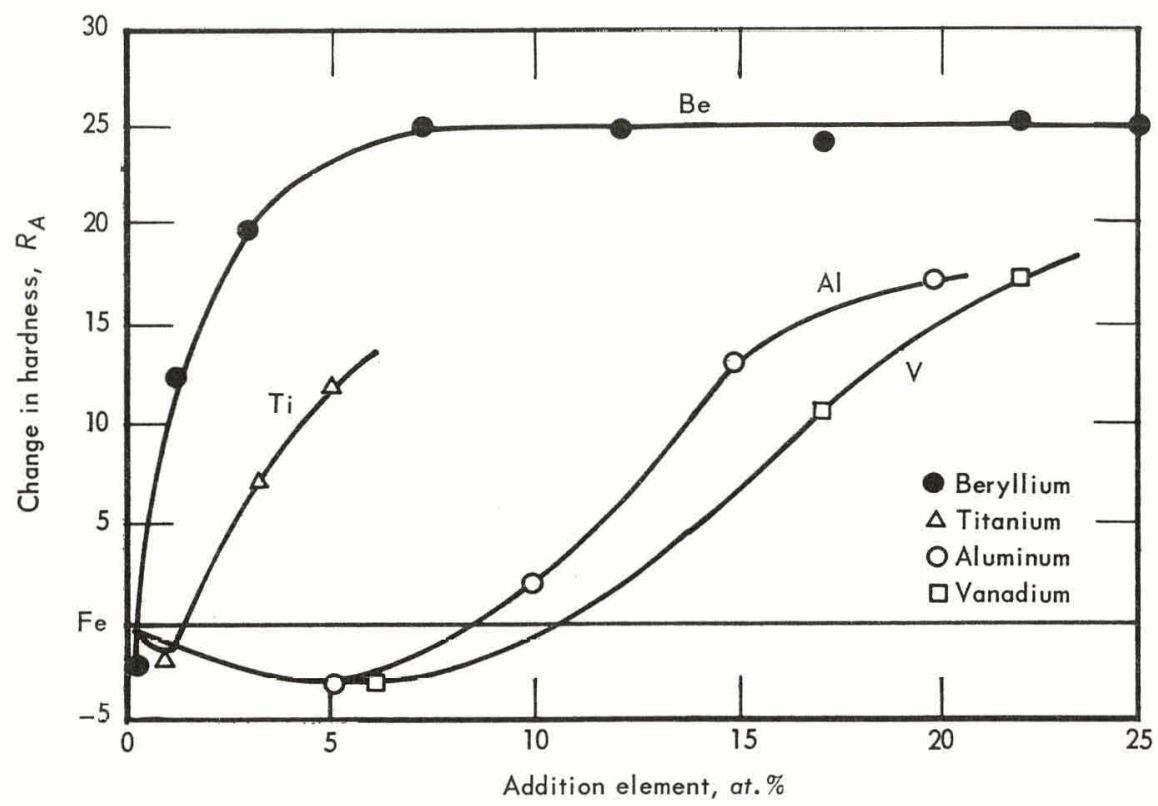

Fig. 5.9 - Change in room-temperature hardness of alpha iron as a function of alloy additions of $\mathrm{Be}, \mathrm{Ti}, \mathrm{Al}$, and $\mathrm{V}$. Hardness measured after hot-rolling to sheet.

\section{3 CHROMIUM-BASE ALLOYS}

\section{MATERIAL PREPARATION}

Three chromium-base alloys (Table 5.10) were selected for initial study. Sheet and rod were prepared from existing stocks of the three alloys for preliminary evaluation. The principal material for evaluation, however, will be provided by a $5.4-\mathrm{kg}$ induction heat which was made of each of the three compositions. The ingots were extruded to rod and converted to $0.076-\mathrm{cm}$-thick sheet and small diameter bar for property studies.

Two separate procedures were used to fabricate the sheet material. One procedure involved hot rolling from $1100^{\circ} \mathrm{C}$ to finish thickness. After the final pass, the sheet was annealed for 15 minutes at $1100^{\circ} \mathrm{C}$. The other procedure involved hot working from $1100^{\circ} \mathrm{C}$ to $0.865 \mathrm{~cm}$ thickness, reducing the temperature to $1000^{\circ} \mathrm{C}$ for rolling to $0.254 \mathrm{~cm}$ thickness, and then to $850^{\circ} \mathrm{C}$ for rolling to $0.076 \mathrm{~cm}$ thickness. In general, a 10 -percent reduction per pass was used. In both procedures, heating was performed in a hydrogen atmosphere. In the discussion that follows, the sheet produced by the first procedure is referred to as hot-rolled sheet; that produced by the second procedure as warm-rolled sheet.

\section{MATERIAL EVALUATION}

\section{Environmental Compatibility}

Sheet specimens made from existing stocks of the three primary compositions and two additional compositions, $\mathrm{Cr}-2 \mathrm{~V}-1 \mathrm{Y}$ and unalloyed $\mathrm{Cr}$, were sealed in an evacuated stainless steel capsule containing sodium $\left(22 \mathrm{ppm} \mathrm{O}_{2}\right)$ and heated at $750^{\circ} \mathrm{C}$ for 1000 hours. Specimen and capsule preparation were described previously. ${ }^{8}$ The appearance of the specimens after test is illustrated in Figure 5.10. With the exception of the $\mathrm{Cr}-20 \mathrm{~V}-1 \mathrm{Y}$ alloy, which shows a slight discoloration, no change occurred in surface appearance. Weight changes were quite low as shown by the data in Figure 5.1. From these preliminary data, it appears that chromium-base alloys will be compatible with sodium.

\footnotetext{
${ }^{8}$ GEMP-63, p. 90.
} 
TABLE 5.8

TENSILE DATA FOR MULTI-COMPONENT ALLOYS

\begin{tabular}{|c|c|c|c|c|c|c|}
\hline \multirow{2}{*}{ Composition } & \multirow{2}{*}{$\begin{array}{c}\text { Test Temperature, }{ }^{a} \\
{ }^{\circ} \mathrm{C}\end{array}$} & \multicolumn{2}{|c|}{ Yield Strength } & \multirow{2}{*}{$\frac{\text { Tensile }}{\text { psi }}$} & \multirow{2}{*}{$\frac{\text { Strength }}{\mathrm{kg} / \mathrm{cm}^{3}}$} & \multirow{2}{*}{$\begin{array}{c}\text { Elongation in } \\
2.54 \mathrm{~cm}, \% \\
\end{array}$} \\
\hline & & psi & $\mathrm{kg} / \mathrm{cm}^{2}$ & & & \\
\hline A & 750 & 26,700 & 1880 & 28,900 & 2030 & 94.7 \\
\hline \multirow[t]{2}{*}{ B } & 550 & 54,600 & 3840 & 65,100 & 4580 & 9.8 \\
\hline & 750 & 19,000 & 1340 & 23,600 & 1660 & 41.1 \\
\hline \multirow[t]{2}{*}{$\mathrm{C}$} & RT & 113,600 & 7990 & 132,900 & 9340 & 3.2 \\
\hline & $750^{b}$ & 9,000 & 630 & 16,900 & 1190 & 49.6 \\
\hline \multirow[t]{2}{*}{ D } & 550 & 58,300 & 5000 & 76,100 & 5350 & 18.4 \\
\hline & 750 & 23,100 & 1620 & 25,100 & 1770 & 60.4 \\
\hline \multirow[t]{3}{*}{$\mathbf{E}$} & 550 & 73,800 & 5190 & 96,200 & 6760 & 13. 7 \\
\hline & 750 & 21,100 & 1480 & 25,500 & 1790 & 77.3 \\
\hline & 750 & 25,400 & 1790 & 30,400 & 2140 & 62.1 \\
\hline \multirow[t]{2}{*}{$F$} & RT & 34,300 & 2410 & 68,100 & 4790 & 26.8 \\
\hline & 750 & 13,900 & 980 & 16,100 & 1130 & 38.1 \\
\hline $\mathrm{Fe}$ & 750 & 1,000 & 70 & 1,600 & 110 & 14. 5 \\
\hline 304 Stainless & 750 & 15,100 & 1060 & 26,700 & 1880 & 51.0 \\
\hline
\end{tabular}

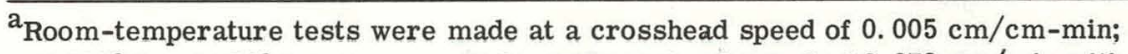
all $550^{\circ} \mathrm{C}$ and $750^{\circ} \mathrm{C}$ tests were made at a crosshead speed of $0.072 \mathrm{~cm} / \mathrm{min}$ with the exception of $b$.

${ }^{b}$ Crosshead speed of 0.071 to $0.254 \mathrm{~cm} / \mathrm{min}$.

TABLE 5.9

BEND TEST RESULTS AT $-78^{\circ} \mathrm{C}$ FOR BINARY AND MULTI-COMPONENT ALLOYS

\begin{tabular}{ccc}
\hline Composition & Bend Angle, ${ }^{\mathrm{a}}$ degrees & Comments \\
\hline $\mathrm{Fe}-5 \mathrm{Al}$ & 90 & No fracture \\
$\mathrm{Fe}-10 \mathrm{Al}$ & 90 & No fracture \\
$\mathrm{Fe}-15 \mathrm{Al}$ & 90 & No fracture \\
$\mathrm{Fc}-20 \Lambda \mathrm{l}$ & $\mathrm{b}$ & No fracture \\
$\mathrm{Fe}-1 \mathrm{~V}$ & 90 & No fracture \\
$\mathrm{Fe}-3.5 \mathrm{~V}$ & 90 & No fracture \\
$\mathrm{Fe}-5.5 \mathrm{~V}$ & 90 & No fracture \\
$\mathrm{Fe}-13 \mathrm{~V}$ & 90 & No fracture \\
$\mathrm{Fe}-17 \mathrm{~V}$ & 90 & No fracture \\
$\mathrm{Fe}-22 \mathrm{~V}$ & 20 & Fractured \\
$\mathrm{Fe}-5 \mathrm{Ti}$ & 90 & No fracture \\
$\mathrm{Fe}-25 \mathrm{Be}$ & 50 & \\
$\mathrm{~A}$ & & Fractured \\
$\mathrm{B}$ & $\mathrm{b}$ & Fractured \\
$\mathrm{C}$ & 30 & Fractured \\
$\mathrm{D}$ & 40 & Fractured \\
$\mathrm{E}$ & $\mathrm{b}$ & Fractured \\
$\mathrm{F}$ & 25 & Fractured \\
\hline
\end{tabular}

${ }^{\mathrm{a}} 0.076 \mathrm{~cm} / \mathrm{min}$ over $2 \mathrm{~T}$ radius.

$\mathrm{b}_{\mathrm{In}}$ manual bends at room temperature, the $\mathrm{Fe}-20 \mathrm{Al}$ alloy and compositions $\mathrm{A}$ and D fractured; compositions $\mathrm{B}, \mathrm{C}, \mathrm{E}$, and $\mathrm{F}$ all bent 90 degrees. 
TABLE 5.10

CHEMICAL ANALYSIS OF CHROMIUM-BASE ALLOYS

\begin{tabular}{|c|c|c|c|c|c|c|c|c|c|c|c|c|c|c|}
\hline \multirow[b]{3}{*}{ Alloy } & \multirow[b]{3}{*}{ Heat No. } & \multicolumn{13}{|c|}{ Composition } \\
\hline & & \multicolumn{5}{|c|}{ wt $\%$} & \multicolumn{8}{|c|}{ ppm } \\
\hline & & $\mathbf{Y}$ & Th & $\mathrm{Hf}$ & $\mathrm{Zr}$ & $\mathrm{Ti}$ & $\mathrm{C}$ & $\mathrm{O}_{2}$ & $\mathrm{~N}_{2}$ & $\mathrm{H}_{2}$ & $\mathbf{S}$ & $\mathrm{Si}$ & $\mathrm{Ca}$ & $\overline{\mathbf{P}}$ \\
\hline $\mathrm{Cr}-\mathrm{Y}$ & $\mathrm{M}-313$ & 0.097 & - & - & 0.001 & - & 413 & 18 & 77 & 5 & $<10$ & 200 & 10 & 39 \\
\hline $\mathrm{Cr}-\mathrm{Hf}-\mathrm{Th}-\mathrm{Y}$ & $\mathrm{M}-314$ & 0.13 & 0.074 & 0.24 & 0.007 & - & 160 & 15 & 90 & 6 & $<10$ & 70 & 10 & 8 \\
\hline $\mathrm{Cr}-\mathrm{TZC}+\mathrm{Y}$ & $M-315$ & 0.12 . & - & - & 0.37 & 0.12 & 349 & 12 & 26 & 7 & $<10$ & 10 & 10 & 3 \\
\hline
\end{tabular}

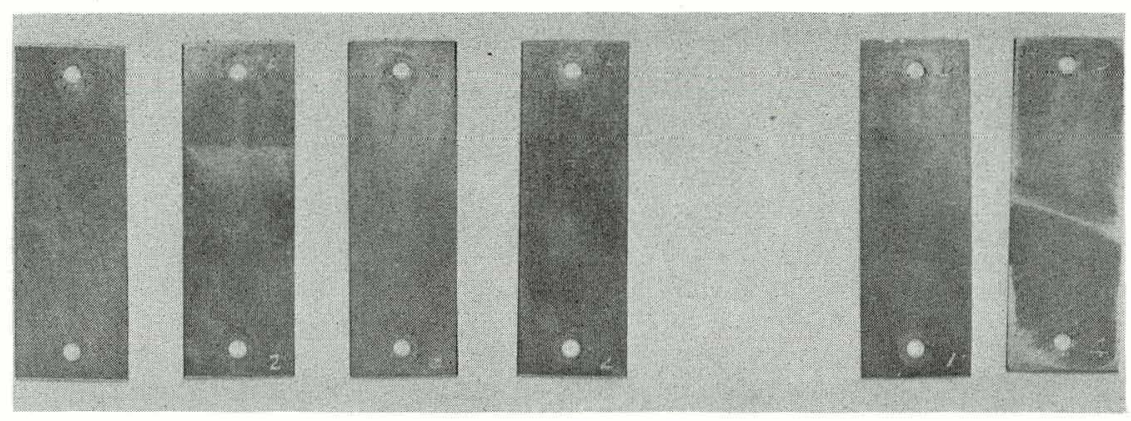

Cr-Y

Cr-Hf-Th-Y

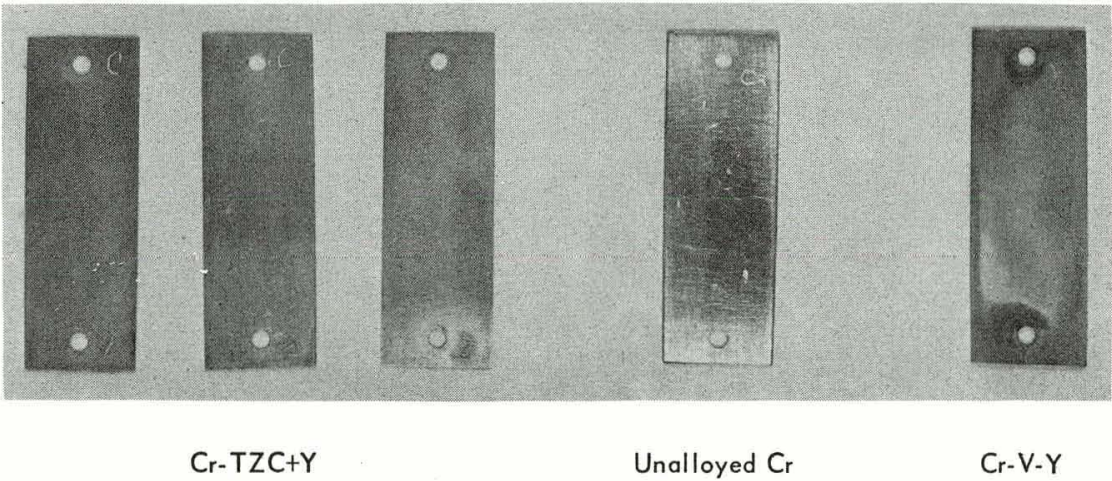

Fig. 5.10 - Coupons of $\mathrm{C}_{\mathrm{r}}$-base alloys after heating in sodium for 1000 hours at $750^{\circ} \mathrm{C}$

(Neg. P67-7-39E)

\section{Strength and Ductility}

Tensile tests were conducted on hot-rolled $0.076-\mathrm{cm}$-thick sheet specimens made from existing stock. The tests were conducted in an argon-filled capsule at $550^{\circ} \mathrm{C}$ and $750{ }^{\circ} \mathrm{C}$ at a crosshead speed of $0.071 \mathrm{~cm} / \mathrm{min}$. The results are presented in Table 5.11 . Attempts to conduct tests at room temperature were unsuccessful as all specimens broke prematurely at support pin holes due to a combination of stress concentration at these points and low specimen ductility.

Bend tests over a $2 \mathrm{~T}$ radius were conducted at varied temperatures and loading rates on $\mathrm{Cr}-\mathrm{Y}$ alloy specimens made from existing stock. The results are presented in Figure 5.11. The DBTT in bending increased $50^{\circ} \mathrm{C}$ for approximately a 30 -fold increase in loading rate. 
TABLE 5.11

TENSILE DATA ${ }^{\mathrm{a}}$ FOR CHROMIUM-BASE ALLOYS

\begin{tabular}{|c|c|c|c|c|c|c|c|c|c|}
\hline \multirow[b]{2}{*}{ Alloy } & \multirow[b]{2}{*}{ Heat No. } & \multirow[b]{2}{*}{ Temperature, ${ }^{\circ} \mathrm{C}$} & \multicolumn{2}{|c|}{ Yield Strength ${ }^{\mathrm{b}}$} & \multicolumn{2}{|c|}{$\begin{array}{l}\text { Ultimate } \\
\text { Strength }\end{array}$} & \multirow{2}{*}{$\begin{array}{c}\text { Elongation in } \\
2.54 \mathrm{~cm}, \%\end{array}$} & \multicolumn{2}{|c|}{$\begin{array}{c}\text { Hardness, DPH } \\
(2.5-\mathrm{kg} \text { load })\end{array}$} \\
\hline & & & psi & $\mathrm{kg} / \mathrm{cm}^{2}$ & psi & $\mathrm{kg} / \mathrm{cm}^{2}$ & & Before & After \\
\hline $\mathrm{Cr}-\mathrm{Hf}-\mathrm{Th}-\mathrm{Y}$ & M-191 & 550 & 19,100 & 1340 & 31,500 & 2220 & 16. 3 & 140 & 138 \\
\hline $\mathrm{Cr}-\mathrm{TZC}+\mathrm{Y}$ & M-298 & 550 & 10,700 & 750 & 30,900 & 2170 & 15.2 & 134 & 149 \\
\hline $\mathrm{Cr}-\mathrm{Y}$ & M-216 & 750 & 12,600 & 890 & 20,100 & 1410 & 28.4 & 119 & 128 \\
\hline $\mathrm{Cr}-\mathrm{Hf}-\mathrm{Th}-\mathrm{Y}$ & M-191 & 750 & 21,200 & 1490 & 27,700 & 1950 & 6.5 & 170 & 162 \\
\hline $\mathrm{Cr}-\mathrm{TZC}+\mathrm{Y}$ & M-298 & 750 & 8,300 & 580 & 26,900 & 1890 & 35.4 & 131 & 151 \\
\hline 304 Stainless & & 750 & 15,100 & & 26,700 & & 51.0 & 188 & 181 \\
\hline
\end{tabular}

${ }^{\mathrm{a}}$ Crosshead speed of $0.071 \mathrm{~cm} / \mathrm{min}$.

${ }^{b}$ Approximate values as strain measurements are based on extensometer attached to lead bars.

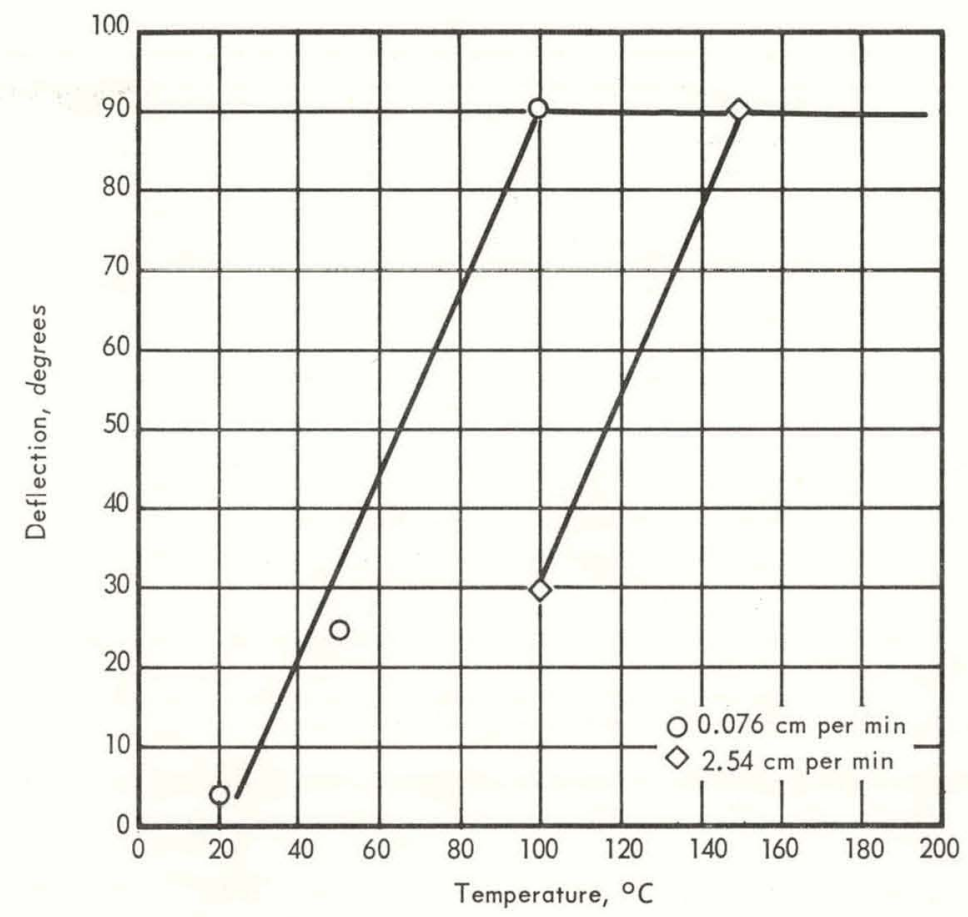

Fig. 5.11 - Bend test results on $\mathrm{Cr}_{-} \mathrm{Y}$ alloy

Subsize, cylindrical, notched impact specimens of the three primary alloys were prepared by hot-swaging material, at $1100^{\circ} \mathrm{C}$ in hydrogen, from existing stocks to $0.636-\mathrm{cm}-$ diameter rod. The specimens were centerless ground to $2.84 \mathrm{~cm}$ long by $0.559 \mathrm{~cm}$ diameter with a 60 degree $\mathrm{V}$-notch $(0.0254 \mathrm{~cm}$ radius) located at the midpoint. Diameter at the base of the notch was $0.381 \mathrm{~cm}$.

The results, Figure 5.12, show that the $\mathrm{Cr}-\mathrm{Y}$ alloy has the lowest DBTT, about $300^{\circ} \mathrm{C}$. The toughness in impact of a $\mathrm{Cr}-\mathrm{Y}$ specimen tested at $350^{\circ} \mathrm{C}$ can be seen in Figure 5.13 which shows plastic deformation at the notch. With alternate working procedures (e.g., warm finishing) and selected heat treatments, it should be possible to lower the DBTT of all chromium-base alloys. 


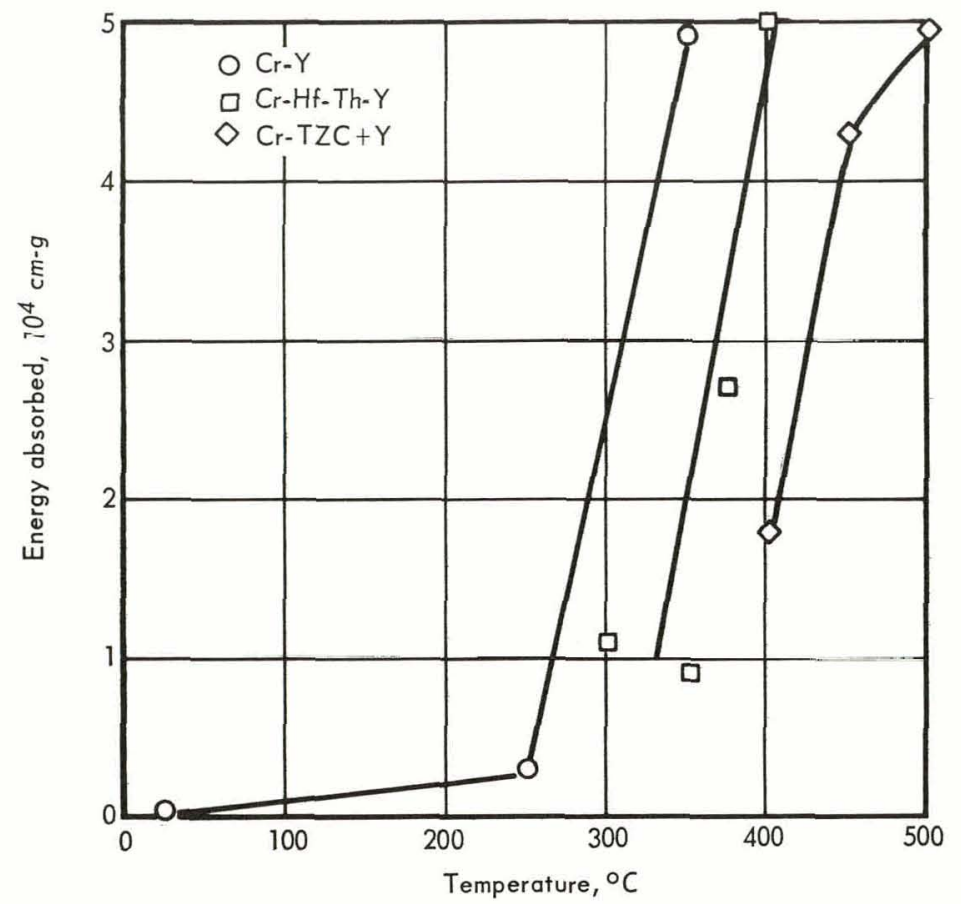

Fig. 5.12-Impact strength of $\mathrm{Cr}$-base alloys

\section{Structural Stability}

Annealing studies were conducted on both hot-rolled and warm-rolled $\mathrm{Cr}-\mathrm{Y}$ sheet, and on warm-rolled $\mathrm{Cr}-\mathrm{TZC}+\mathrm{Y}$ and $\mathrm{Cr}-\mathrm{Th}-\mathrm{Hf}-\mathrm{Y}$ sheet, all from the new 5.4-kg heats. Four bend specimens were prepared from $0.076-\mathrm{cm}$-thick sheet of each alloy for each condition, wrapped in tantalum foil, and annealed for 2 hours in vacuum at temperatures of $750^{\circ}$, $870^{\circ}, 980^{\circ}$, and $1090^{\circ} \mathrm{C}$. Figure 5.14 is a plot of hardness versus annealing temperature for these alloys.

The warm-rolled sheet was much harder than the recrystallized hot-rolled sheet. Annealing the warm-rolled sheet at $750^{\circ} \mathrm{C}$ did not change the hardness level and no significant recrystallization occurred. Annealing at $870^{\circ} \mathrm{C}$ produced a slight decrease in hardness and recrystallization began $(\sim 5 \%)$. Annealing at $980^{\circ} \mathrm{C}$ and $1090^{\circ} \mathrm{C}$ resulted in softening and complete recrystallization. Only a few of the specimens have been bent at $100^{\circ} \mathrm{C}$ thus far, Table 5.12.

\section{Processability}

Exploratory efforts are underway to fabricate the $\mathrm{Cr}-\mathrm{Y}$ alloy into tubing. In preliminary experiments, the alloy, in rod form, was drawn through wire dies on a draw bench with varying drawing speed, drawing temperature, and percent reduction. Drawing force in pounds was determined for each procedure. The data obtained are shown in Table 5.13. Fluorescent penetrant and radiographic inspection disclosed no cracking, regardless of procedure. These data were used to establish tentative tube drawing procedures.

A Cr-Y alloy tube blank was machined from existing rod stock. Initial dimensions were $1.245 \mathrm{~cm}$ by $0.305 \mathrm{~cm}$ wall thickness by $6.509 \mathrm{~cm}$ long, Figure 5.15 . For drawing, the tube blank was placed on a $0.633-\mathrm{cm}$-diameter mandrel which was coated with a petroleumbase lubricant STP. A tungsten-disulphide-base lubricant was then sprayed on the outside of the tube blank and the tube was drawn at $350^{\circ} \mathrm{C}$ at a drawing speed of $5.08 \mathrm{~cm} / \mathrm{min}$ to 


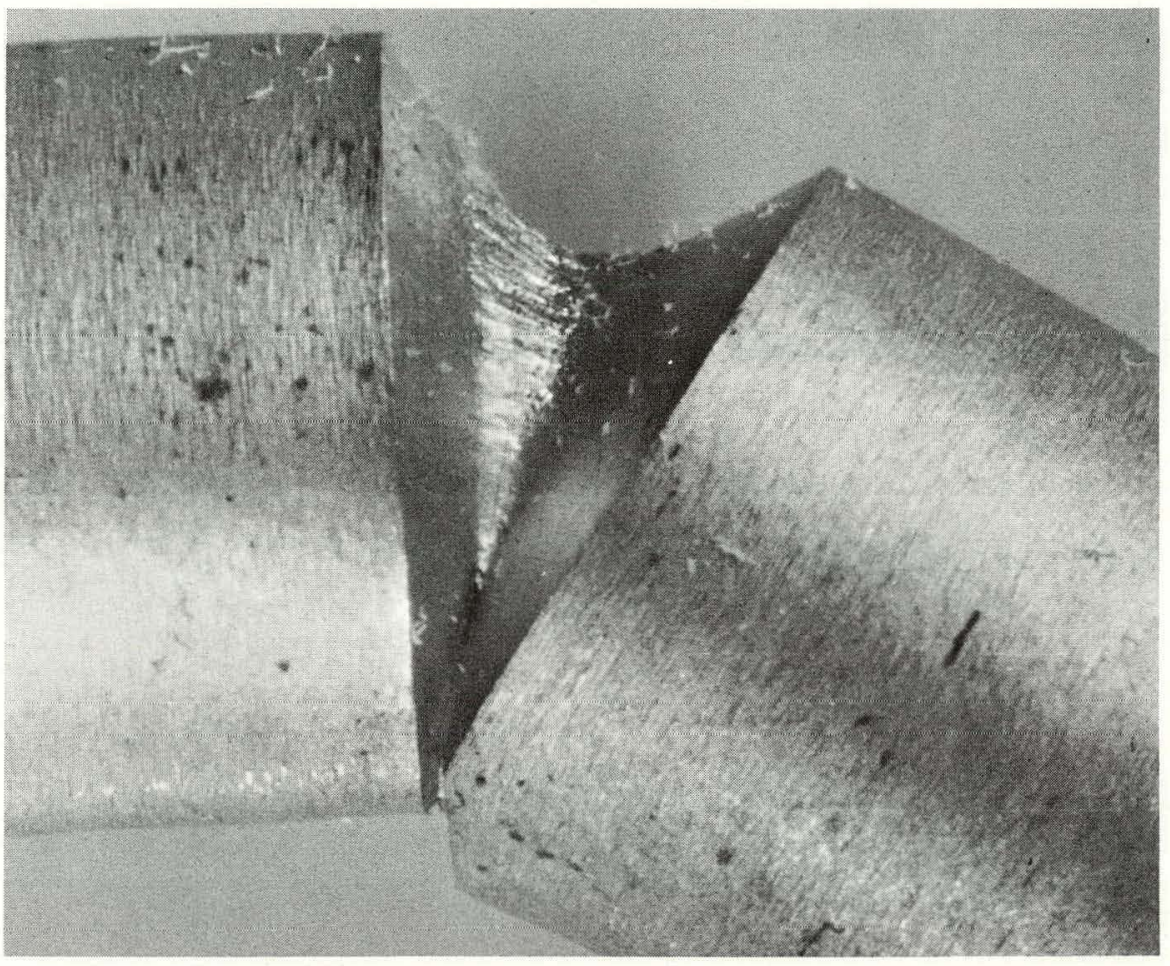

(Neg.P67.1.39A)

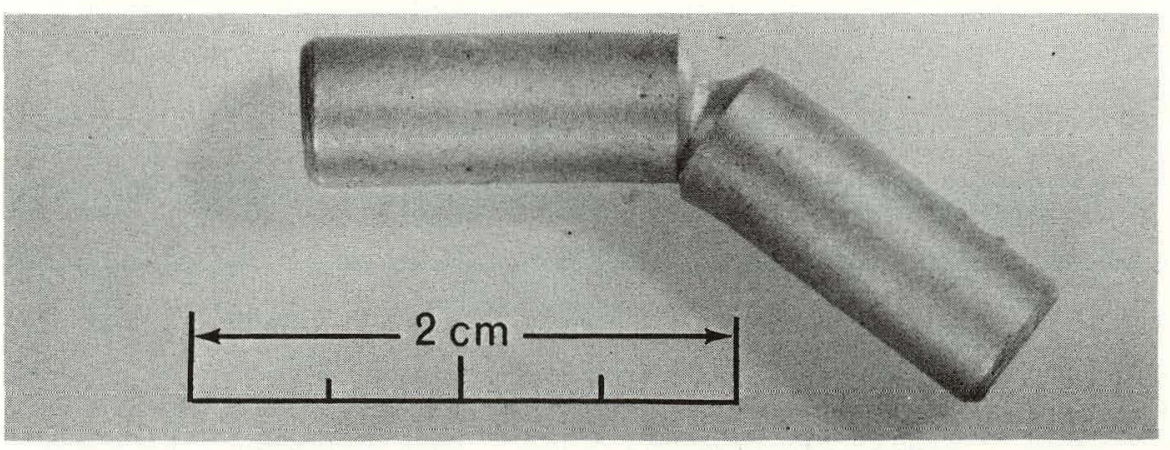

(Neg. P67-1-39B)

Fig. $5.13-\mathrm{Cr}_{\mathrm{r}} \mathrm{Y}$ impact specimen after $350^{\circ} \mathrm{C}$ test 


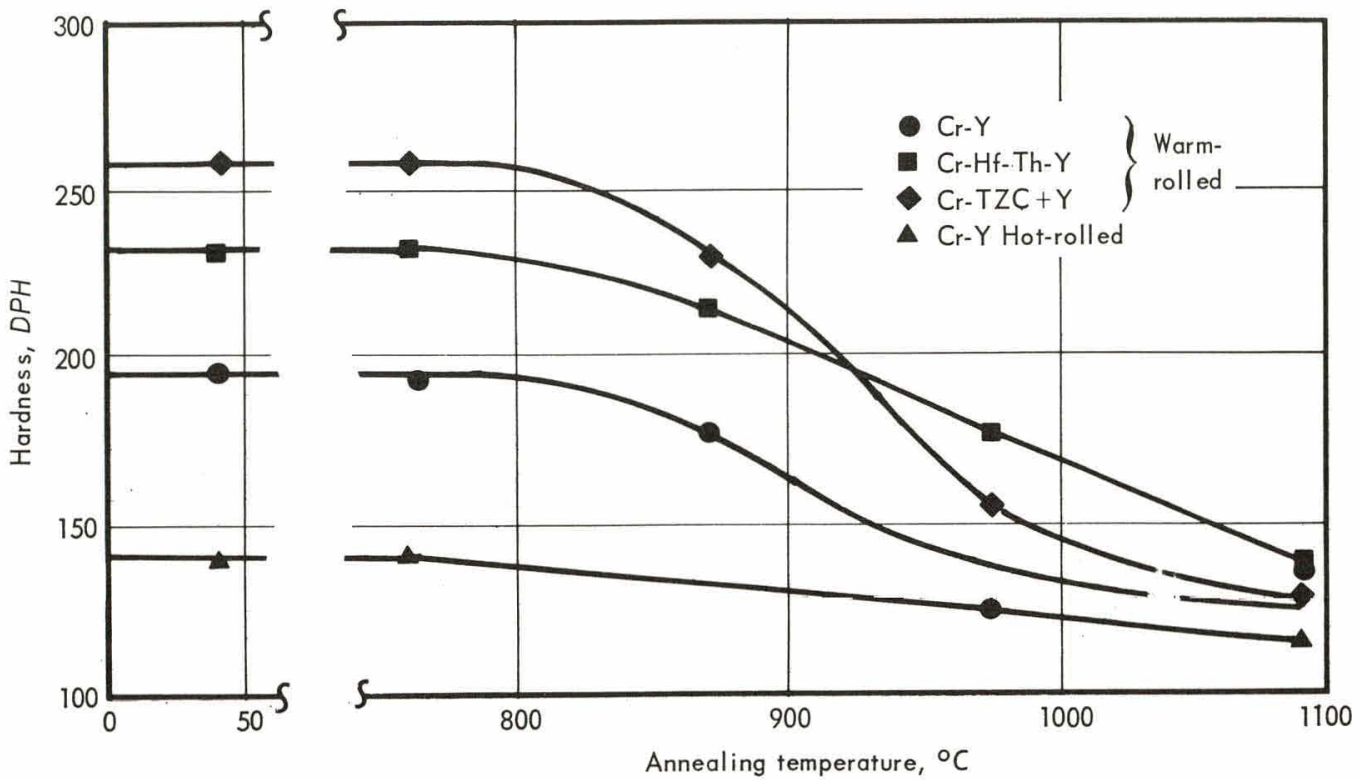

Fig. 5.14-Room-temperature hardness versus annealing temperature for Cr-base alloys

TABLE 5.12

BEND TEST RESULTS AT $100^{\circ} \mathrm{C}$ FOR CHROMIUM-BASE ALLOYS

\begin{tabular}{lclccc}
\hline \multicolumn{1}{c}{ Alloy } & Heat No: & \multicolumn{1}{c}{ Condition } & $\begin{array}{c}\text { Hardness, } \\
\text { DPH }\end{array}$ & $\begin{array}{c}\text { Bend Angle, } \\
\text { degrees }\end{array}$ & Comment \\
\hline $\mathrm{Cr}-\mathrm{Y}$ & $\mathrm{M}-313$ & Warm-rolled & 195 & 90 & No fracture \\
$\mathrm{Cr}-\mathrm{Y}$ & $\mathrm{M}-313$ & $\begin{array}{l}\text { Warm-rolled } \\
\text { plus } 750^{\circ} \mathrm{C} \text { anneal }\end{array}$ & 195 & 90 & No fracture \\
$\mathrm{Cr}-\mathrm{Y}$ & $\mathrm{M}-313$ & $\begin{array}{l}\text { Hot-rolled } \\
\text { plus 750 }\end{array}$ & 140 & 5 & Fractured \\
$\mathrm{Cr}-\mathrm{Hf}-\mathrm{Th}-\mathrm{Y}$ & $\mathrm{M}-314$ & $\begin{array}{l}\text { Warm-rolled } \\
\text { plus } 750^{\circ} \mathrm{C} \text { anneal }\end{array}$ & 232 & 9 & Fractured \\
$\mathrm{Cr}-\mathrm{TZC}+\mathrm{Y}$ & $\mathrm{M}-315$ & $\begin{array}{l}\text { Warm-rolled } \\
\text { plus 750 }\end{array}$ & 259 & 12 & Fractured \\
\hline
\end{tabular}

TABLE 5.13

WARM DRAWING EXPERIMENTS ON Cr-Y RODS

\begin{tabular}{ccccc}
\hline Rod No. & $\begin{array}{c}\text { Reduction } \\
\text { in Area, } \%\end{array}$ & $\begin{array}{c}\text { Temperature, } \\
{ }^{\circ} \mathrm{C}\end{array}$ & $\begin{array}{c}\text { Drawing Speed, } \\
\mathrm{cm} / \mathrm{min}\end{array}$ & Force, lb \\
\hline 1 & 23 & 430 & 61.0 & $500-550$ \\
2 & 23 & 350 & 61.0 & 550 \\
3 & 23 & 430 & 30.5 & 350 \\
4 & 9 & 440 & 30.5 & 300 \\
5 & 9 & 350 & 30.5 & 300 \\
6 & 23 & 430 & 5.08 & 350 \\
7 & 9 & 440 & 5.08 & 300 \\
8 & 9 & 370 & 5.08 & 250 \\
\hline
\end{tabular}




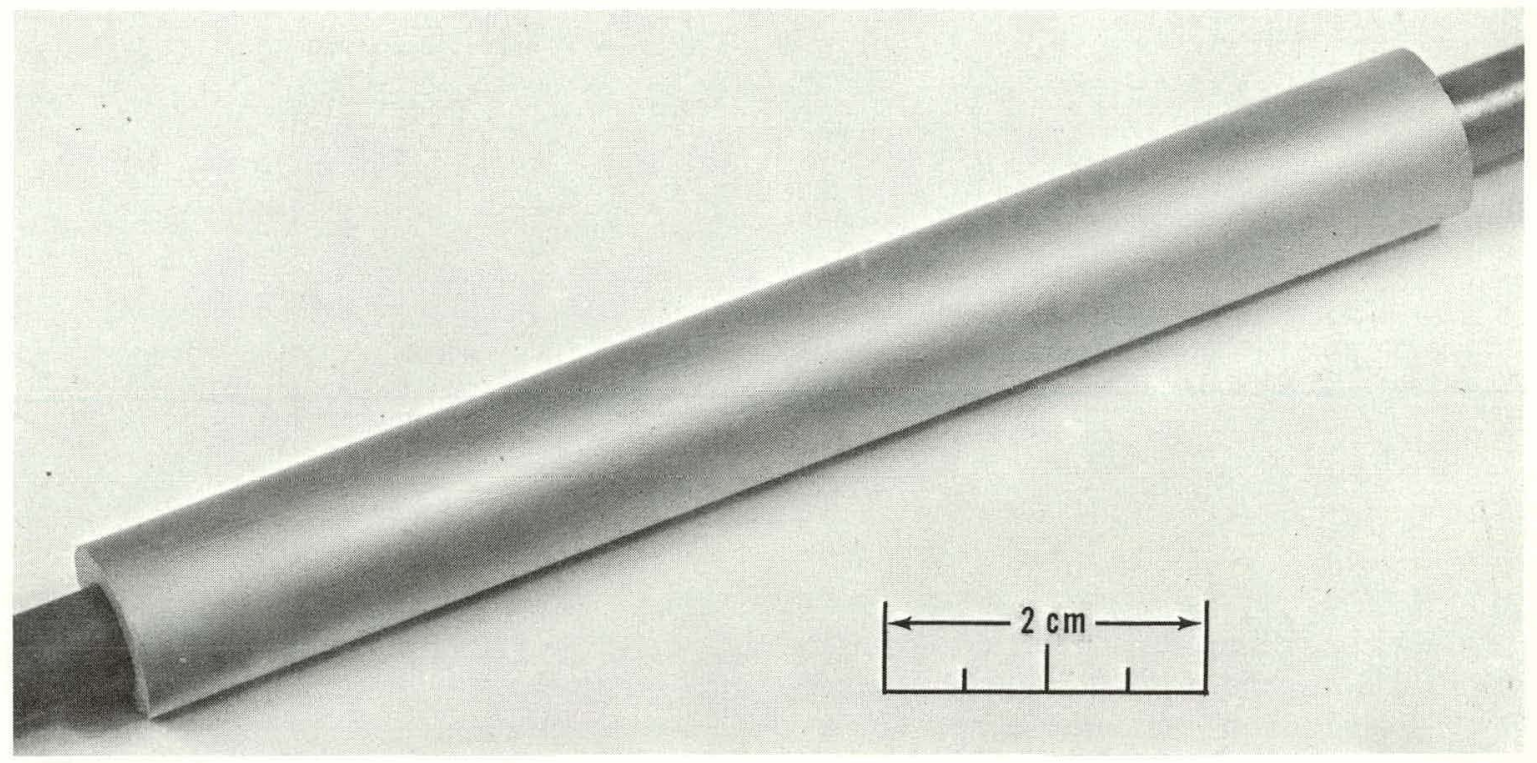

After one drawing pass (21.5\% reduction in area) (Neg. P67-1-39C)

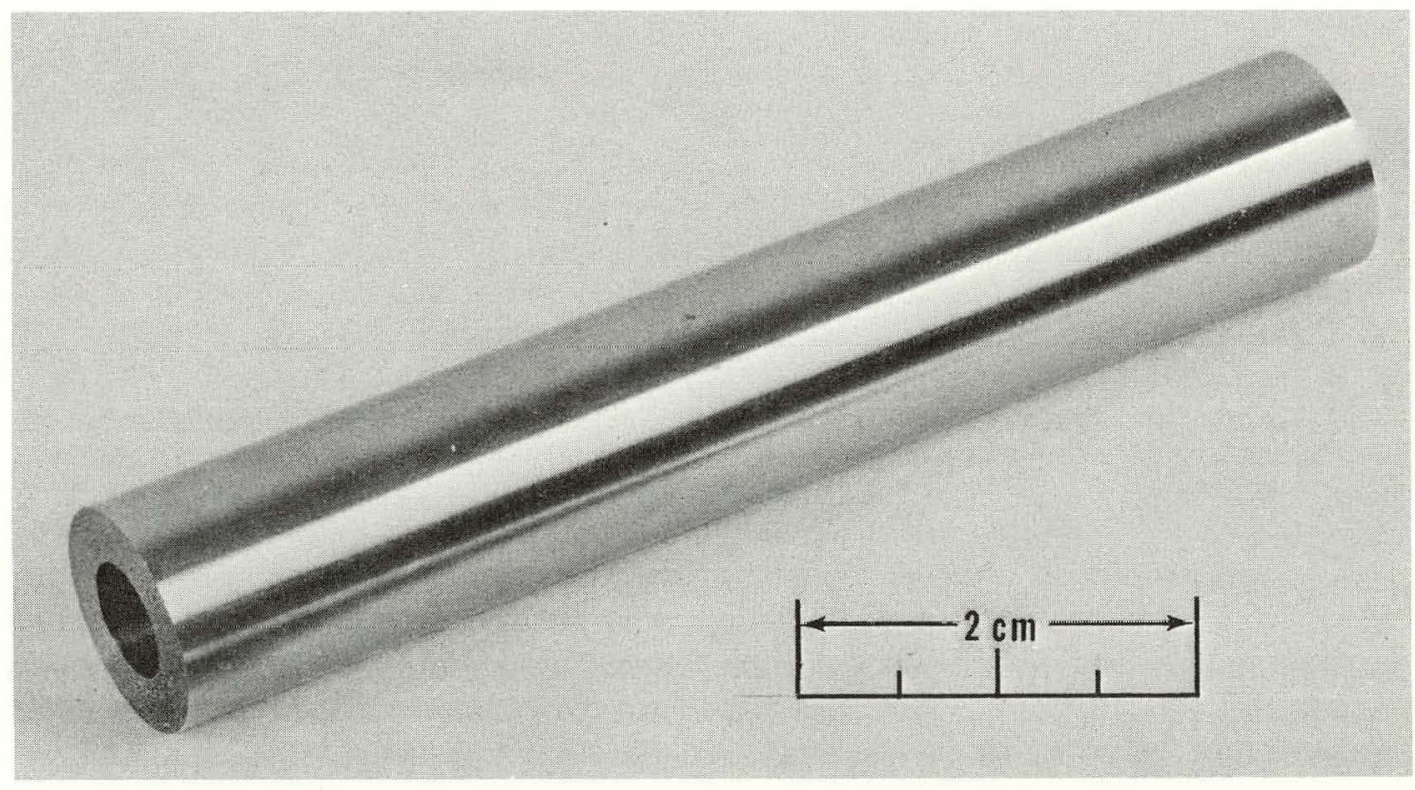

Original tube blank (Neg. P66-17-38)

Fig. $5.15-\mathrm{Cr}_{\mathrm{r}} \mathrm{Y}$ tube blank and tube after warm drawing 
$1.143-\mathrm{cm}$ OD, a 21.5 -percent reduction in area. The force required was 1800 pounds. After vapor blasting, the tube was free of visible defects. Radiographic inspection revealed three small radial cracks, originating at the inside surface of the tube. These experiments are continuing.

Radiation Stability

Creep-rupture specimens of the three primary chromium-base alloys and $\mathrm{Cr}-\mathrm{Y}$ alloy bend test specimens, all made from hot-rolled sheet, are included in irradiation experiment ORM-53, mentioned previously. The data obtained from these specimens will be among the first relating to the effects of neutron radiation on the mechanical behavior of chromium-base alloys.

\section{4 SUMMARY AND CONCLUSIONS}

A quantity of vacuum-induction-melted ingots, sheet, and bar of various $\mathrm{Fe}-\mathrm{Cr}-\mathrm{Al}-\mathrm{Y}$ alloys was prepared. Preliminary static $750^{\circ} \mathrm{C}$ sodium compatibility tests on these materials are favorable. Their oxidation resistance in air is outstanding up to at least $1100^{\circ} \mathrm{C}$. The strength of the standard compositions (2541 and 1541) is relatively low. Dispersion strengthening was found to effect significant short-time strength improvement at room temperature and $550^{\circ} \mathrm{C}$, but not at $750^{\circ} \mathrm{C}$. Efforts are being made to characterize the $\mathrm{YFe}_{9}$ phase responsible for dispersion strengthening. A study of the effect of composition on alpha-prime precipitation is underway. An irradiation experiment was initiated to establish, on a preliminary basis, the effect of neutron radiation on the tensile, creep, and bend properties of several of the standard compositions. Other experimental alloys designed for higher strength are being processed for evaluation. Two standard (2541 and 1541) and one dispersion-strengthened composition (1361 DS) possess DBTT (in notched impact tests) ranging from $50^{\circ}$ to $200^{\circ} \mathrm{C}$.

Both $5.4-\mathrm{kg}$ vacuum-induction-melted heats and/or arc-melted button heats were made of a number of binary and multi-component $\mathrm{Fe}$-base alloys. Most are alpha-stabilized and contain one or more $\mathrm{Al}, \mathrm{V}, \mathrm{Be}$, or $\mathrm{Ti}$ additions. The heats were successfully converted to sheet and rod. Room-temperature hardness measurements versus alloy additions for the binary compositions identified $\mathrm{Be}$ as the most potent strengthener followed in order by $\mathrm{Ti}, \mathrm{Al}$, and V. Favorable results were achieved for binary compositions of $\mathrm{Fe}-\mathrm{Ti}, \mathrm{Fe}-\mathrm{Be}$, and $\mathrm{Fe}-\mathrm{V}$ in preliminary compatibility tests at $750{ }^{\circ} \mathrm{C}$ in static sodium. Most of the $\mathrm{Fe}-\mathrm{Al}$ alloys and a high vanadium binary composition were less favorable, with an $\mathrm{Fe}-35 \mathrm{Al}$ composition showing definite surface degradation. Tensile data on the binary compositions showed the $\mathrm{Fe}-\mathrm{Be}$ and $\mathrm{Fe}-\mathrm{Ti}$ alloys to possess promising strength levels. Outstanding tensile properties at $550^{\circ} \mathrm{C}$ and $750^{\circ} \mathrm{C}$ were determined for several multi-component alloys in initial tests. Ductile-to-brittle transition temperatures (in sheet bending tests) were found to be near or below room temperature for the compositions tested, including all of the multi-component and many of the binary compositions.

Vacuum-induction-melted heats $(5.4 \mathrm{~kg})$ of the three primary $\mathrm{Cr}$-base compositions, $\mathrm{Cr}-\mathrm{Y}, \mathrm{Cr}-\mathrm{Hf}-\mathrm{Th}-\mathrm{Y}$, and $\mathrm{Cr}-\mathrm{TZC}+\mathrm{Y}$, were prepared and converted into sheet and rod. Previous stocks of these alloys were also converted and used for study. All three compositions possessed excellent compatibility with sodium in preliminary static tests at $750^{\circ} \mathrm{C}$. Encouraging strength levels and excellent ductility were found in tensile tests at $550^{\circ} \mathrm{C}$ and $750^{\circ} \mathrm{C}$. The DBTT (in sheet bending tests) for the $\mathrm{Cr}-\mathrm{Y}$ alloy in the hot-rolled $\left(1100^{\circ} \mathrm{C}\right)$ and recrystallized condition was found to increase with bending rate to a value of approximately $150^{\circ} \mathrm{C}$. The DBTT (in notched impact tests) for the three primary compositions in the as-swaged $\left(1100^{\circ} \mathrm{C}\right)$ condition ranged from approximately $300^{\circ}$ to $450^{\circ} \mathrm{C}$. Warm-rolled sheet $\left(870^{\circ} \mathrm{C}\right.$ ) appears to possess a significantly lower DBTT (in bending) than hot-rolled $\left(1100^{\circ} \mathrm{C}\right)$, recrystallized sheet. Studies are in progress of the annealing characteristics 
of warm-rolled sheet of the three primary compositions in terms of hardness and recrystallization. The results to date indicate that warm rolling significantly increases as-rolled hardness and that all alloys fully recrystallize after 2 hours at $975^{\circ} \mathrm{C}$. Initial experiments were begun to fabricate $\mathrm{Cr}-\mathrm{Y}$ alloy tubing with encouraging results.

It is premature to cite more than tentative general conclusions in a program this new, but it appears that compositions from all three alloy systems are processable to useful shapes and are compatible with static sodium at $750^{\circ} \mathrm{C}$. The $\mathrm{Fe}$-base and $\mathrm{Cr}$-base compositions exhibited short-time strengths comparable to austenitic stainless steels at $750^{\circ} \mathrm{C}$ and, in several cases, far exceed them at lower temperatures. From the standpoint of economy, the $\mathrm{Fe}$-base alloys are most attractive. The $\mathrm{Cr}$-base alloys must prove to be very attractive technically to warrant their added cost. The aspects of structural stability, low-temperature ductility, and creep-rupture properties require definition and their determination will be intensified.

\subsection{PLANS AND RECOMMENDATIONS}

Preparation and conversion of experimental alloy heats in all three systems will be continued. Additional sodium compatibility studies will be initiated. Tensile, bend, and impact studies will continue on alloys from all three systems. Creep-rupture studies will be initiated on $\mathrm{Fe}$-base and $\mathrm{Cr}$-base alloys. Structural stability experiments for $\mathrm{Fe}-\mathrm{Cr}$ base and $\mathrm{Fe}$-base alloys will continue. More extensive fabrication studies will be conducted on $\mathrm{Fe}-\mathrm{Cr}$-base and $\mathrm{Cr}$-base alloys, including fabrication of tubing and preliminary welding experiments.

\section{6 SUMMARY OF TASK 57001, "OXIDATION-RESISTANT FUEL ELEMENT MATERIALS RESEARCH"}

The objective of this research was to develop and evaluate oxidation-resistant fuel element materials markedly superior to presently available fuel materials in terms of hightemperature capabilities, long-time service life, and containment of fission products in environments of steam, air, carbon dioxide or other oxidizing coolants.

The need for such materials was reduced by the de-emphasis of the Superheat Reactor Program and a shift in emphasis to the Fast Breeder Reactor Program. Therefore, the work directly related to oxidation-resistant fuel element materials was terminated.

This section summarizes the significant findings on the $\mathrm{Fe}-\mathrm{Cr}-\mathrm{Al}-\mathrm{Y}$ cladding alloys and their compatibility with fueled cores.

\section{FUEL ELEMENT EVALUATIONS}

The laboratory test program was completed on $\mathrm{Fe}-\mathrm{Cr}-\mathrm{Al}-\mathrm{Y}-\mathrm{clad} \mathrm{Fe}-\mathrm{UO}_{2}$ specimens tested at $750^{\circ}, 950^{\circ}$, and $1100^{\circ} \mathrm{C}$ in air for times up to 14,600 hours. Four in-pile tests of $\mathrm{Fe}-\mathrm{Cr}-\mathrm{Al}-\mathrm{Y}-\mathrm{clad} \mathrm{Fe}-\mathrm{UO}_{2}$ fuel element specimens in flowing air demonstrated the excellent stability and fission product retention capabilities of the system at temperatures from $750^{\circ}$ to $1100^{\circ} \mathrm{C}$ under high-burnup conditions.

Fueled Capsule Testing

A laboratory test program was conducted to demonstrate the time - temperature capabilities in air of both 2541 - and 1541-clad $\mathrm{Fe}-40 \mathrm{UO}_{2}$ fuel element specimens for times in excess of 10,000 hours. Thermal stability test data were obtained on various cladding core combinations using cylindrical capsule specimens $1.05 \mathrm{~cm}$ in diameter by $2.54 \mathrm{~cm}$ in length with a cladding thickness of $0.50 \mathrm{~mm}$. The cladding was bonded to the sintered core by autoclaving in helium gas pressure at $1100^{\circ} \mathrm{C}$ which resulted in a core density of about 98 percent of theoretical. During testing, non-destructive analyses were made periodically using $\mathrm{X}$-ray fluorescence analysis for uranium diffusion through the cladding. At 
the completion of scheduled test periods, one specimen of each group of five or more specimens was sectioned and studied metallographically for fuel - cladding compatibility and depth of surface oxidation.

One 2541 -clad $\mathrm{Fe}-50 \mathrm{UO}_{2}$ specimen tested for 14,662 hours at $950^{\circ} \mathrm{C}$ in air had surface oxidation to a depth of only 6 microns, some intergranular and internal oxidation of the cladding at the surface and near the core - cladding interface, and a small amount of discontinuous oxide at the interface. The microstructure of a section through the core, interface, and cladding of this specimen is shown in Figure 5.16. This is typical of the excellent thermal stability and fuel compatiblity demonstrated by most of the fueled specimens tested in this program for periods of 5,000 to 10,000 hours.

Metallographic examination was performed on ten other specimens which represented different fuel forms (spheroidized versus agglomerated $\mathrm{UO}_{2}$ particles), different core compositions ( $\mathrm{Fe}$ versus $\mathrm{Fe}-25 \mathrm{Cr}$ matrix), different cladding alloys (2541 versus 1541) and three test temperatures. ${ }^{9}$ In all specimens tested at $750^{\circ} \mathrm{C}$ or $950^{\circ} \mathrm{C}$ for periods up to 7350 hours, the cladding alloy showed an oxide layer of less than 5 microns thickness, no evidence of fuel instability at the core - cladding interface, and generally, a good bond -between the core and cladding. Specimens tested at $1100^{\circ} \mathrm{C}$ for 7300 hours had considerably more surface oxide (14 microns) on the 2541 alloy cladding and some oxide formation around the fuel particles and at the core - cladding interface. ${ }^{10}$ Either spheroidized $\mathrm{UO}_{2}$ particles or the agglomerated fuel particles (Figure 5.16) make a good dispersion-type fuel core and appear to have equal stability in isothermal testing.

The relative intensity of uranium concentration on the cladding surface as analyzed periodically by $\mathrm{X}$-ray fluorescence was generally higher for specimens tested at $1100^{\circ} \mathrm{C}$ than for specimens tested at $750^{\circ} \mathrm{C}$ or $950^{\circ} \mathrm{C}$.

In the course of this fueled capsule test program, the X-ray fluorescence technique was used at regular intervals to detect surface concentration of $\mathrm{U}^{238}$ on tested specimens. Initial values were reported in terms of "relative uranium intensity" ent percent uranium. "12 While such methods of reporting allowed the arrangement of specimens in the order of increasing or decreasing uranium concentration on the cladding surface, it did not give a quantitative measure of the uranium that had diffused through the cladding.

To measure quantitative values, it was necessary to determine the location of the diffused uranium in the cladding. This was accomplished by sectioning a specimen and subjecting it to electron microprobe analysis. This examination showed that uranium diffused through the cladding and deposited under a thin film of $\mathrm{Al}_{2} \mathrm{O}_{3}$ that normally forms on the surface of $\mathrm{Fe}-\mathrm{Cr}-\mathrm{Al}-\mathrm{Y}$ alloys. Several specimens were then analyzed by $\mathrm{X}$-ray fluorescence after which the surface layer was removed in $0.05-\mathrm{mm}$ increments, and the shavings obtained were chemically analyzed for uranium. A plot of X-ray fluorescence (counts/second) versus micrograms of uranium per fixed area was constructed. From the uranium contents found at various depths it was determined that the lower limit of uranium detection by Xray fluorescence was approximately $32 \mathrm{micrograms} / \mathrm{cm}^{2}$ to $150 \mathrm{micron}$ depth when an effective counting area of $0.25 \mathrm{~cm}^{2}$ was used. Greater sensitivity would be expected if a larger counting area were employed.

\footnotetext{
${ }^{9}$ GEMP-61, pp. 94-95.

10 “Fifth Annual Report - High-Temperature Materials Programs, Part A," GE-NMPO, GEMP-400A, February 28, 1966, p. 140.

${ }^{11}$ GEMP-400A, p. 137 .

12، “High-Temperature Materials Program Progress Report No. 49, Part A,” GE-NMPO, GEMP-49A, July 28, 1965, pp. $14-15$.
} 
$\mathrm{Fe}-25 \mathrm{Cr}-4 \mathrm{Al}-1 \mathrm{Y}$ cladding (Neg. 7558)

$\mathrm{Fe}-50 \mathrm{UO}_{2}$ Core (Neg. 7557)

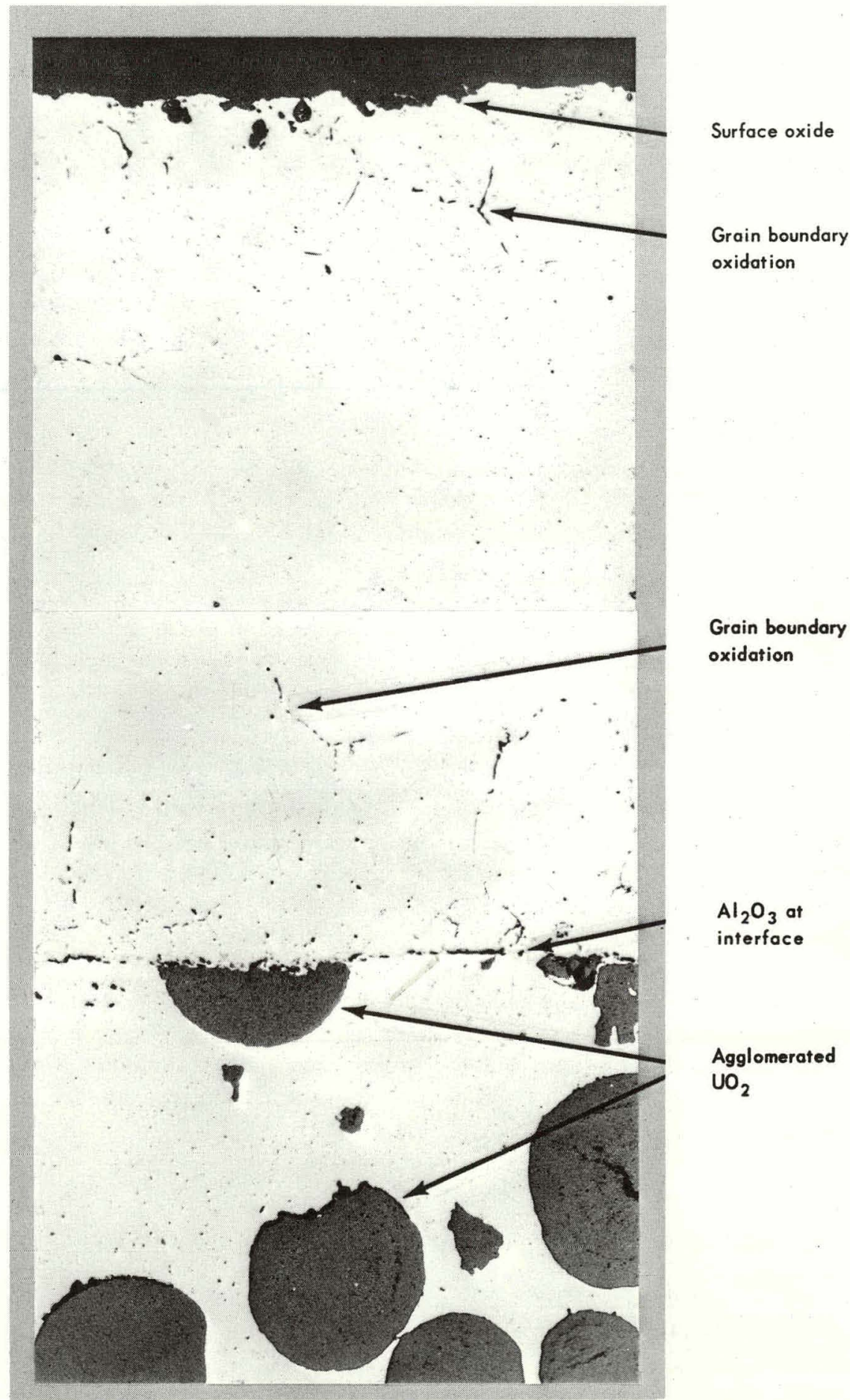

Fig. 5.16-Photomicrographs of core-cladding interface of 2541-clad $\mathrm{Fe}-50 \mathrm{UO}_{2}$ specimen after 14,662 hours at $950^{\circ} \mathrm{C}$ in air (250X) 
The following equations permit conversion of previously reported data to surface uranium concentration to 150 micron depth expressed in micrograms $/ \mathrm{cm}^{2}$. Previous data reported as "Relative Intensity": $\mu \mathrm{g} \mathrm{U} / \mathrm{cm}^{2}=($ R. I. $\times 9.4)+31.6$. Previous data reported as "Percent Uranium": $\mu \mathrm{g} \mathrm{U} / \mathrm{cm}^{2}=(\% \mathrm{U} \times 57)+31.6$. X-ray fluorescence analyses of all fuel element test specimens were rerun and reported in terms of the absolute measure described above. The highest value recorded was 46 micrograms $/ \mathrm{cm}^{2}$ in a specimen which was tested at $1100^{\circ} \mathrm{C}$ for 10,035 hours. Most of the specimens analyzed less uranium than the lower detectable limit of $32 \mathrm{micrograms} / \mathrm{cm}^{2}$ which is not detrimental to the oxidation resistance of the $\mathrm{Fe}-\mathrm{Cr}-\mathrm{Al}-\mathrm{Y}$ cladding.

These evaluations of $\mathrm{Fe}-\mathrm{Cr}-\mathrm{Al}-\mathrm{Y}-\mathrm{clad} \mathrm{Fe}-\mathrm{UO}_{2}$ specimens and the data obtained from more than 80 specimens tested in the past year show that for long-time service in the temperature range from $750^{\circ}$ to $950^{\circ} \mathrm{C}$ the 2541 - or 1541 -clad $\mathrm{Fe}-\mathrm{UO}_{2}$ fuel element has excellent stability. Their performance at $1100^{\circ} \mathrm{C}$ in air may be limited by fuel - cladding interaction and reduced thermal stability of the cladding structure.

In-Pile Testing

Three in-pile tests of the $\mathrm{Fe}-\mathrm{Cr}-\mathrm{Al}-\mathrm{Y}$-clad $\mathrm{Fe}-\mathrm{UO}_{2}$ system were completed in the LITR and one in the ORR which demonstrated the ability of the cladding alloys to contain fission products under relatively high-burnup conditions at $750^{\circ}, 950^{\circ}$, and $1100^{\circ} \mathrm{C}$.

Details of the specimen and cartridge design were described previously. ${ }^{13}$ Essentially, the LITR specimen was of an annular design of $1.4-\mathrm{cm}$ OD and $0.78-\mathrm{cm}$ ID containing a fueled core $1.26-\mathrm{cm}$ OD by $3.8-\mathrm{cm}$ long with a ring thickness of $0.15 \mathrm{~cm}$. The overall length was $9.5 \mathrm{~cm}$ which included $2.5 \mathrm{~cm}$ of reduced diameter stem on each end the specimen. ${ }^{14}$

The specimen was contained in a stainless steel capsule with provision for air cooling of the fuel element specimen. Instrumentation consisted of five thermocouples (Pt / Pt $\mathrm{Rh}$ ) located in the center tube of the specimen and held in place by a solid ceramic plug. With this plug in place, the air coolant removed heat only from the outer surface of the specimen. Sampling of the exit air for fractional release of fission products was performed periodically during each test, using charcoal traps.

A summary of the test condition, calculated burnup, fission product release and posttest dimensional changes for all four tests is given in Table 5.14. Since all specimens were similar in composition, the series of four tests affords a good comparison of the effects of temperature and burnup on the stability of the $\mathrm{Fe}-\mathrm{Cr}-\mathrm{Al}-\mathrm{Y}-\mathrm{clad} \mathrm{Fe}-\mathrm{UO}_{2}$ fuel element system over a range of test conditions.

TABLE 5.14 SUMMARY OF IN-PILE TEST DATA FROM Fe-Cr-Al-Y FUEL ELEMENT SPECIMENS TESTED IN LITR OR ORR

\begin{tabular}{|c|c|c|c|c|c|c|c|c|c|}
\hline \multirow[b]{2}{*}{$\begin{array}{l}\text { Experiment } \\
\text { No. }\end{array}$} & \multicolumn{2}{|c|}{ Specimen Composition } & \multicolumn{4}{|c|}{$\begin{array}{r}\text { Test Conditions } \\
\end{array}$} & \multirow{2}{*}{$\begin{array}{l}\text { Cadculated } \\
\text { Durnup, } \\
\text { fissions } / \mathrm{em}^{3}\end{array}$} & \multirow{2}{*}{$\begin{array}{c}\text { Maximum } \\
\text { Fission Gas } \\
\text { Release }(R / B), \\
\mathrm{Xe}^{133}\end{array}$} & \multirow{2}{*}{$\begin{array}{c}\text { Diametric } \\
\text { Growth, } \\
\text { percent }\end{array}$} \\
\hline & Cladding & $\begin{array}{l}\text { Core, } \\
\text { vol } \%\end{array}$ & $\begin{array}{c}\overline{\text { Temperature, }} \\
{ }^{\circ} \mathrm{C}\end{array}$ & $\begin{array}{c}\text { Time, } \\
\text { hr }\end{array}$ & Cycles & $\begin{array}{c}\text { Airflow, } \\
\text { liters/min }\end{array}$ & & & \\
\hline LT FC-1 & 2541 & $\mathrm{Fe}-40 \mathrm{UO}_{2}$ & 1100 & 1007 & 12 & 680 & $4.8 \times 10^{19}$ & $3 \times 10^{-7}$ & $0.2-0.7$ \\
\hline LTFC-2 & 1541 & $\mathrm{Fe}-40 \mathrm{UO}_{2}$ & 950 & 2000 & 18 & 790 & $9.0 \times 10^{19}$ & $4 \times 10^{-7}$ & Nil \\
\hline LTFC-3 & 1541 & $\mathrm{Fe}-40 \mathrm{UO}_{2}$ & 950 & 2406 & 19 & 1700 & $1.8 \times 10^{20}$ & $2 \times 10^{-7}$ & Nil \\
\hline ORFC-1 & 1541 & $\mathrm{Fe}-25 \mathrm{UO}_{2}$ & 750 & 731 & 5 & 4800 & $1.9 \times 10^{20}$ & $2 \times 10^{-3}$ & - \\
\hline
\end{tabular}

13،'High-Temperature Materials Program Progress Report No. 47, Part A,'” GE-NMPO, GEMP-47A, May 28, 1965 , pp. $18-19$. ${ }^{14}$ GEMP-400A, pp. $144-145$. 
LTFC-1 - Test LTFC-1 was operated at the highest temperature $\left(1100^{\circ} \mathrm{C}\right)$ and the lowest burnup $\left(4.8 \times 10^{19}\right.$ fissions $\left./ \mathrm{cm}^{3}\right)$ of the series. ${ }^{15},{ }^{16}$ The 2541 alloy cladding appeared in good condition, the diametric growth was a maximum of 0.7 percent and the $\mathrm{Fe}-\mathrm{UO}_{2}$ core microstructure was unaffected by the irradiation. Intergranular oxidation at the surface of the outer cladding was greater than that observed for subsequent specimens tested at lower temperature.

LTFC-2 - Test LTFC-2 differed from LTFC-1 only in the cladding composition (1541) and the lower test temperature $\left(950^{\circ} \mathrm{C}\right) .{ }^{17}$ The burnup was double that of the first test, yet the fuel and core microstructure showed no evidence of damage or deterioration. No measurable growth in diameter occurred and the oxidation resistance of the 1541 cladding alloy was excellent.

LTFC-3 - Test LTFC-3 duplicated LTFC-2 except it was positioned in a higher flux where twice the burnup of $\mathrm{U}^{235}$ occurred $\left(1.8 \times 10^{20}\right.$ fissions $\left./ \mathrm{cm}^{3}\right)$ in the 2406 hours of operation at $950^{\circ} \mathrm{C}$. The power generation in this fuel element specimen was calculated as $204,000 \mathrm{Btu} / \mathrm{hr}-\mathrm{ft}^{2}$ and required an airflow rate of 1700 liter $\mathrm{s} / \mathrm{min}$ over the specimen to hold the temperature at $950^{\circ} \mathrm{C}$. The fractional release of fission gases as measured by $\mathrm{Xe}^{133}$ did not exceed $8 \times 10^{-7}(\mathrm{R} / \mathrm{B})$ at any time during the test. ${ }^{18}$ The slight release resulted from a thermal diffusion mechanism of $\mathrm{U}^{235}$ through the cladding rather than direct diffusion of fission products. The specimen had a light-gray coating over most of the fueled portion similar to the protective oxide film that forms on $\mathrm{Fe}-\mathrm{Cr}-\mathrm{Al}-\mathrm{Y}$ alloys at high temperature in air. No weight change was detected, no diametric growth occurred, and only a slight increase in hardness of the cladding was noted (67 Rockwell $15 \mathrm{~N} \mathrm{scale}$ ). The microstructure of the fueled specimen after test showed no deterioration of fuel particles or matrix as shown in Figure 5.17.

ORFC-1 - The fourth in-pile experiment, ORFC-1, was conducted in the ORR where a higher flux density was obtained and a more rapid burnup occurred than in the previous LITR tests. A 1541 -clad $\mathrm{Fe}-25 \mathrm{UO}_{2}$ specimen of annular design and dimensions similar to the above described LITR specimens was irradiated for 731 hours at $750{ }^{\circ} \mathrm{C}$, cooled by an air flow of 4800 liters/minute. The fission density was calculated to be $1.9 \times 10^{20}$ fissions $/ \mathrm{cm}^{3}$. The test was terminated prematurely when a sudden release of fission gas occurred indicating a rupture of the cladding. ${ }^{19}$

The fuel element specimen had small blisters on the surface at the downstream-end indicating localized over-temperature occurred during the test. When the specimen was sectioned, a small spot was found on the ID cladding at the downstream end where oxidation had penetrated the cladding and extended into the core. This localized oxidation was caused by the $\mathrm{Al}_{2} \mathrm{O}_{3}$ insert used to hold thermocouples in place reacting with the 1541 alloy cladding in the over-temperature area. The remaining two-thirds of the specimen which did not exceed the $750^{\circ} \mathrm{C}$ test temperature was not affected by the cladding failure at the hottest end. The transverse section shown in the photomicrograph of Figure 5.18 is typical of the excellent condition of the fuel and cladding after the high-burnup test. This is good evidence that the 1541-clad $\mathrm{Fe}-\mathrm{UO}_{2}$ fuel element system is capable of long-time operation in an oxidizing environment of fission densities greater than $2 \times 10^{20}$ at temperatures of $750^{\circ} \mathrm{C}$ and higher without deterioration.

\footnotetext{
${ }^{15}$ GEMP-400A, pp. 143-145.

${ }^{16}$ GEMP-49A, p. 18.

17 “High-Temperature Materials Program Progress Report No. 53, Part A," GE-NMPO, GEMP-53A, November 26, 1965 , p. 19.

18 ، 'High-Temperature Materials Program Progress Report No. 59, Part A," GE-NMPO, GEMP-59A, May 31, 1966, pp. $14-15$.

${ }^{19}$ GEMP-59A, pp. $14-15$.
} 


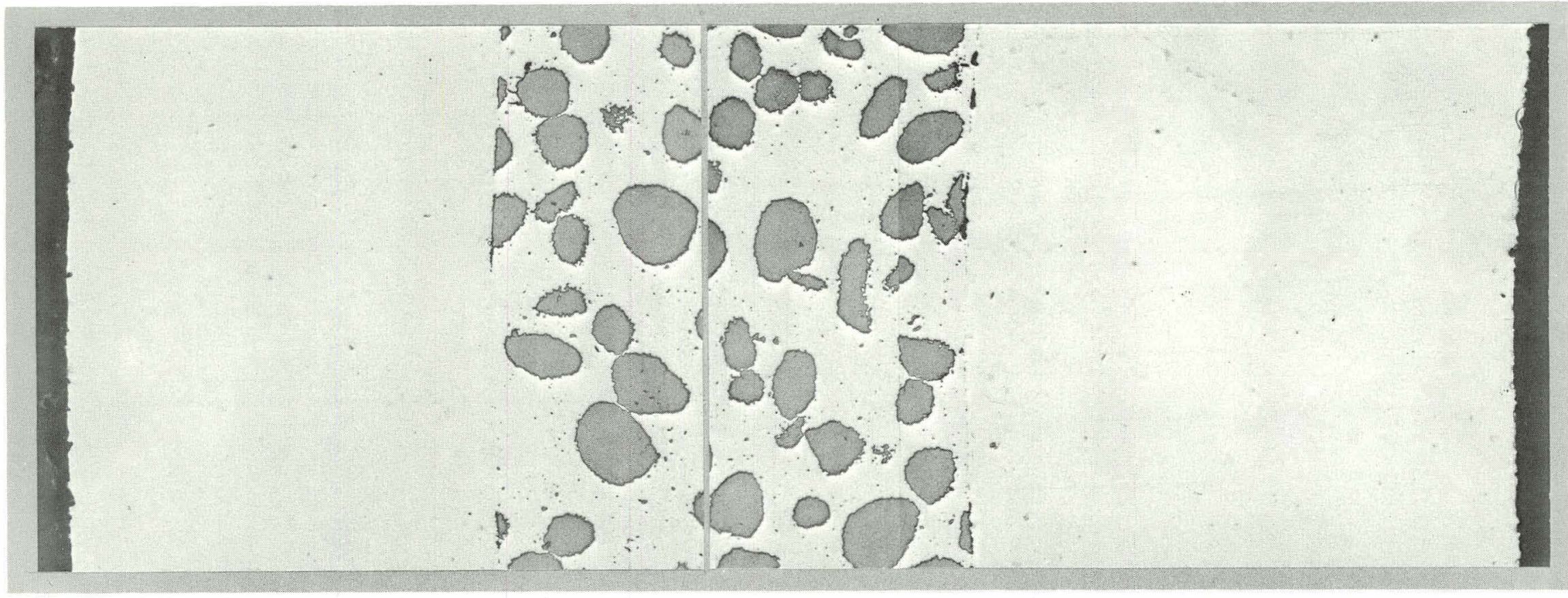

Outer cladding

Fueled core

Inner cladding

(Neg. R.1630)

(Neg. R.1628)

(Neg. R-1627)

Fig. 5.17 - Photomicrographs of transverse section of 154l-clad $\mathrm{Fe}-40 \mathrm{UO}_{2}$ specimen from LITR test LTFC. 3 after 2406 hours at $950^{\circ} \mathrm{C}$ in

flowing air with fission density of $1.8 \times 10^{20}$ fissions $/ \mathrm{cm}^{3}$

(100X) 


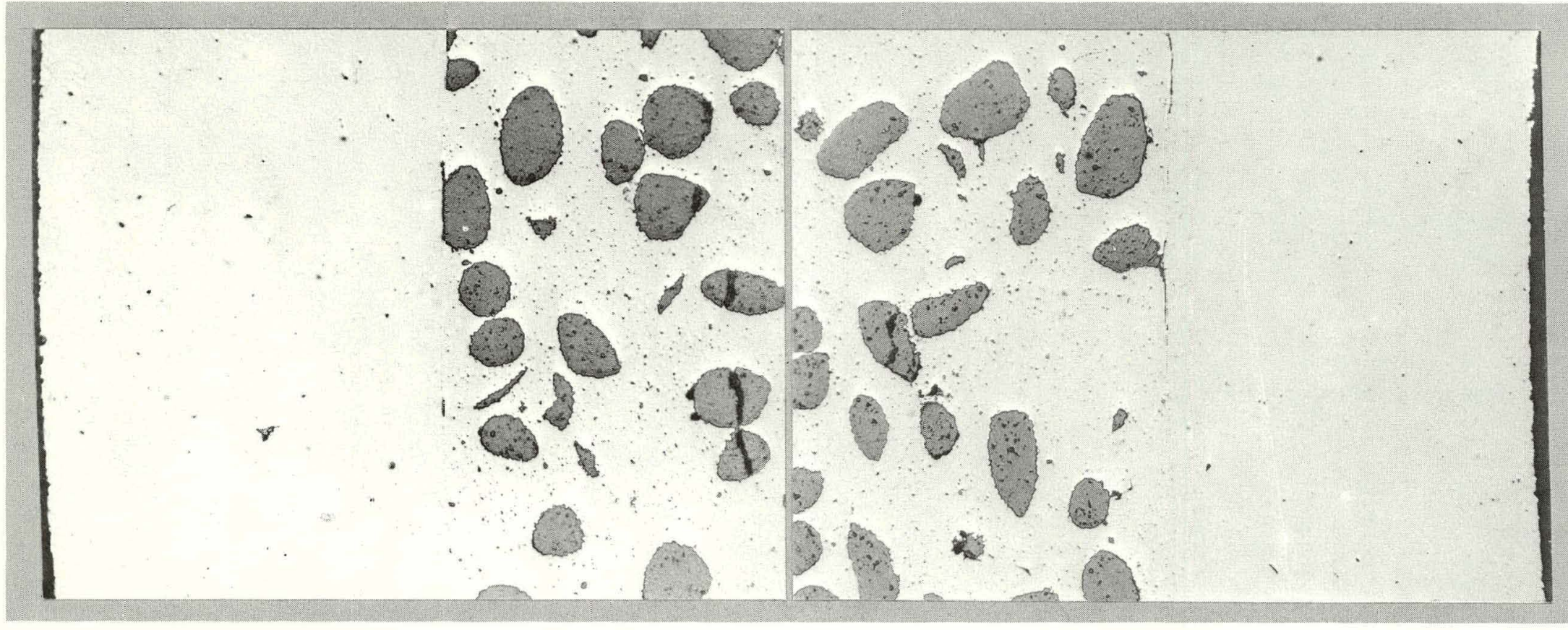

Outer cladding

Fueled core

Inner cladding

(Neg, R.1604)

(Neg. R-1603)

Fig. 5.18-Photomicrographs of 1541-clad $\mathrm{Fe}-25 \mathrm{UO}_{2}$ specimen from ORR experiment ORFC-1 after 731 hours at $750^{\circ} \mathrm{C}$ in flowing air with fission density of $1.9 \times 10^{20}$ fissions $/ \mathrm{cm}^{3}$. The power density at the outer cladding surface was approximately 387,000 Btu/hr-ft 2. (100X) 


\section{4}

The power generation in the ORR test specimen was calculated to be $387,000 \mathrm{Btu} / \mathrm{hr}-\mathrm{ft}^{2}$, which is four times that of many operating gas-cooled or boiling water reactor fuel elements. The excellent performance of these experimental fuel element specimens under these conditions suggests that additional tests should be made under fast breeder reactor conditions.

\section{SUMMARY AND CONCLUSIONS}

The 10, 000-hour thermal stability test program was completed for a series of $\mathrm{Fe}-\mathrm{Cr}-\mathrm{Al}-\mathrm{Y}-$ clad $\mathrm{Fe}-\mathrm{UO}_{2}$ fueled specimens. Specimens clad with 1541 alloy tested at $750^{\circ} \mathrm{C}$ or $950^{\circ} \mathrm{C}$ for times up to 7350 hours had cladding oxidation of less than 5 microns, no fuel instability at core - cladding interfaces and generally a good bond between core and cladding. One specimen tested at $950^{\circ} \mathrm{C}$ for 14,662 hours showed excellent thermal stability.

A nondestructive analytical procedure for quantitative measurement of surface uranium concentration based on $\mathrm{X}$-ray fluorescence techniques indicated uranium diffusion through the cladding at $1100^{\circ} \mathrm{C}$ did not exceed 46 micrograms $/ \mathrm{cm}^{2}$ after 10,000 hours.

Four in-pile experiments demonstrated that the 1541-clad fueled system is capable of operation in an oxidizing environment at $950^{\circ} \mathrm{C}$ for at least 2400 hours or to a fission density of $1.8 \times 10^{20}$ fissions $/ \mathrm{cm}^{3}$ without deterioration or loss of fission products. Under these conditions, minor dimensional changes occurred and no fuel deterioration was detected. 


\title{
6. PHYSICO-CHEMICAL STUDIES OF Fe-Cr-Al-CLAD FUEL SYSTEMS
}

\section{(57076)}

\author{
H. S. Edwards, ${ }^{*}$ K. M. Bohlander ${ }^{\dagger}$
}

The objective of this program is to define and to understand the reactions which can occur between oxidation-resistant $\mathrm{Fe}-\mathrm{Cr}-\mathrm{Al}$ alloys and $\mathrm{UO}_{2}$ in the temperature region from $500^{\circ}$ to $1200^{\circ} \mathrm{C}$.

In early attempts to apply the $\mathrm{Fe}-\mathrm{Cr}-\mathrm{Al}$ alloys as claddings for $\mathrm{UO}_{2}$ or metal $-\mathrm{UO}_{2}$ cermet cores, an undesirable result was the appearance of uranium as surface contamination during elevated-temperature testing. The tentative explanation was that reduction of $\mathrm{UO}_{2}$ by aluminum produced uranium which diffused to the surface. The present program, aimed at quantitative understanding of the problem, is divided into four parts: phase studies, diffusion studies, thermodynamic investigations, and fueled capsule tests.

\subsection{PHASE STUDIES}

A clear understanding of the mechanism of U production is critical in these studies. Although available thermodynamic information indicates that the reaction of pure $\mathrm{Al}$ with $\mathrm{UO}_{2}$ to give $\mathrm{Al}_{2} \mathrm{O}_{3}$ and free $\mathrm{U}$ is not favored, any reliable prediction must take into account the chemical potentials of the reactants and products. Essentially, the oxides $\mathrm{Al}_{2} \mathrm{O}_{3}$ and $\mathrm{UO}_{2}$ are mutually insoluble at the temperatures under consideration (up to $1200^{\circ} \mathrm{C}$ ); thus, it is assumed that their potentials are those of the pure compounds. The chemical potential of $\mathrm{Al}$ in $\mathrm{Fe}-\mathrm{Cr}-\mathrm{Al}$ alloys has not yet been measured; but in the cladding compositions of interest, the potential of dissolved $\mathrm{Al}$ must be considerably lower than that of pure $\mathrm{Al}$. These considerations indicate that $\mathrm{U}$ in the $\mathrm{U}$-bearing product of $\mathrm{UO}_{2}$ reduction must also have a chemical potential considerably lower than that of pure U. This low chemical potential could be maintained either by rapid diffusion of $U$ away from the reaction zone or by formation of a stable U-bearing phase.

Since a thorough investigation of the $\mathrm{Fe}-\mathrm{Cr}-\mathrm{Al}-\mathrm{U}-\mathrm{O}$ system would require a major effort, a simplified approach was first attempted which involved forming diffusion couples between various $\mathrm{Fe}-\mathrm{Cr}-\mathrm{Al}$ alloys and $\mathrm{U}$ metal. Nine $\mathrm{Fe}$-base ternary alloys were chosen for study with nominal compositions containing 5,15 , and 25 weight percent $\mathrm{Cr}$ and $\mathrm{Al}$ contents of 4,7 , and 10 percent at each $\mathrm{Cr}$ level. Capsules of the $\mathrm{Fe}-15 \mathrm{Cr}-4 \mathrm{Al}$ alloy were fabricated with $0.478-\mathrm{cm}$-thick walls and were fitted with $\mathrm{U}$ cores. They were sealed by electron-beam welding, autoclaved, and heat-treated at $600^{\circ}, 800^{\circ}, 1000^{\circ}$, and $1200^{\circ} \mathrm{C}$. After 300 to 750 hours at $600^{\circ} \mathrm{C}$, there were traces of core - cladding interaction, and extensive core - cladding reactions had occurred after 150 to 1000 hours at $800^{\circ} \mathrm{C}$ or $1000^{\circ} \mathrm{C}$. Within 80 hours at $1200^{\circ} \mathrm{C}$, the cladding thickness was completely penetrated by the U-bearing core material. Electron-microprobe examination of the specimens showed the formation of two or more new compositions in the original $U$ core area at each test temperature.

*Project leader.

${ }^{\dagger}$ Principal investigator. 
The specimens also failed to show a continuous gradient of U concentration. Based on these results, this simplified approach apparently will not yield the desired information for the phase studies nor will it be satisfactory for measurement of $U$ diffusion coefficients.

A survey of the low-U portion of the $\mathrm{Fe}-\mathrm{Cr}-\mathrm{Al}-\mathrm{U}$ phase diagram was begun. Two alloys of $\mathrm{Fe}-25 \mathrm{Cr}-10 \mathrm{Al}$ plus 1- and 5-percent $\mathrm{U}$, and two of $\mathrm{Fe}-5 \mathrm{Cr}-4 \mathrm{Al}$ plus 1- and 5-percent $\mathrm{U}$, were prepared by multiple arc-melting to insure homogeneity. Specimens from these melts were aged in vacuum for 150 hours and 500 hours at $600^{\circ}, 800^{\circ}, 1000^{\circ}$, and $1200^{\circ} \mathrm{C}$ and then quenched. Post-test metallographic examination disclosed no significant differences due to time or $\mathrm{Fe}-\mathrm{Cr}-\mathrm{Al}$ composition. In the specimens heated at $600^{\circ} \mathrm{C}$ and $800^{\circ} \mathrm{C}$, the amount and appearance of the U-bearing phase appeared similar to that in the as-cast specimens. At $1000^{\circ} \mathrm{C}$, most of the original as-cast stringer-like $U$ phase had segregated, while at $1200^{\circ} \mathrm{C}$, the $\mathrm{U}$ phase was no longer visible in the matrix up to $600 \mathrm{X}$ magnification; however, small spheroids had appeared on the lower surfaces of the latter specimens.

Electron-microprobe examination of the specimens after heat treatment revealed no significant composition changes in the $\mathrm{Fe}-\mathrm{Cr}-\mathrm{Al}$ alloys, and $\mathrm{U}$ solubilities smaller than the 0.1 -percent detection limit. Analysis of the insoluble U-bearing phase in the heat-treated specimens showed this phase contains about 50-percent $\mathrm{U}$ with the balance being $\mathrm{Fe}, \mathrm{Cr}$, and $\mathrm{Al}$. The spheroids, which formed on the surface of the specimens heat-treated at $1200^{\circ} \mathrm{C}$, proved to be nonhomogeneous; the outer periphery analyzed 93 -percent $\mathrm{U}$ and the $\mathrm{Fe}-\mathrm{Cr}-\mathrm{Al}$ interior less than 0.1-percent $\mathrm{U}$. These analyses suggest extensive solubility of the cladding constituents in $U$, but less than 0.1 -percent $U$ solubility in the cladding alloy. At $1200^{\circ} \mathrm{C}$, a liquid phase, containing the major portion of the $\mathrm{U}$ originally dispersed throughout the matrix, was formed and was rapidly expelled from the matrix.

As noted above, the extremely low $\mathrm{U}$ solubilities in $\mathrm{Fe}-\mathrm{Cr}-\mathrm{Al}$ alloys were at or below the detection limit of the electron microprobe, thus rendering this instrument useless in accurately determining solubility limits and U diffusion coefficients in these alloys. To provide such information, the feasibility of using a spark-source mass spectrograph was then investigated since, under favorable conditions, this instrument is capable of analyses in the low parts per million range. Through the cooperation of Union Carbide Nuclear Division, several mass-spectrographic analyses were made on both sides of a solid $\mathrm{Fe}-$ $\mathrm{Cr}-\mathrm{Al}-\mathrm{U}$ versus $\mathrm{Fe}-\mathrm{Cr}-\mathrm{Al}$ diffusion couple containing 5 -percent $\mathrm{U}$ on one side and less than 0.1 -percent $U$ on the other. The initial mass-spectrographic analyses indicated 1-percent $\mathrm{U}$ on the $\mathrm{Fe}-\mathrm{Cr}-\mathrm{Al}-\mathrm{U}$ side and $500-\mathrm{ppm} \mathrm{U}$ (relative) on the other. The variation between the spectrographic and wet-chemical analyses (respectively $1-$ and $5-\% \mathrm{U}$ ) indicated that additional developmental work was necessary to perfect the spark-source mass-spectrographic technique for the specimen being used; however, after further difficulties were encountered in measuring concentration gradients (discussed in Section 6.2), it was concluded that additional work with this technique was not warranted.

\section{2 DIFFUSION STUDIES}

The program for determining $\mathrm{U}$ diffusion coefficients in $\mathrm{Fe}-\mathrm{Cr}-\mathrm{Al}$ alloys has been hampered by lack of an accurate and sensitive method to measure very small concentrations of $U$ in these alloys. Since the electron microprobe is not accurate below 0.1 percent, the capabilities of the spark-source mass spectrograph to measure U concentration gradients were investigated. This technique entailed the preparation of specimens designed to obtain maximum accuracy and sensitivity from the instrument.

Diffusion couples of $\mathrm{Fe}-\mathrm{Cr}-\mathrm{Al}$ versus $\mathrm{Fe}-\mathrm{Cr}-\mathrm{Al}-\mathrm{U}$ were sealed within evacuated capsules, heat-treated at $1000^{\circ} \mathrm{C}$ for 500 - and 1000 -hour periods, and air cooled. The microstructure of a diffusion couple heat-treated for 500 hours is shown in Figure 6.1. The insoluble U- 


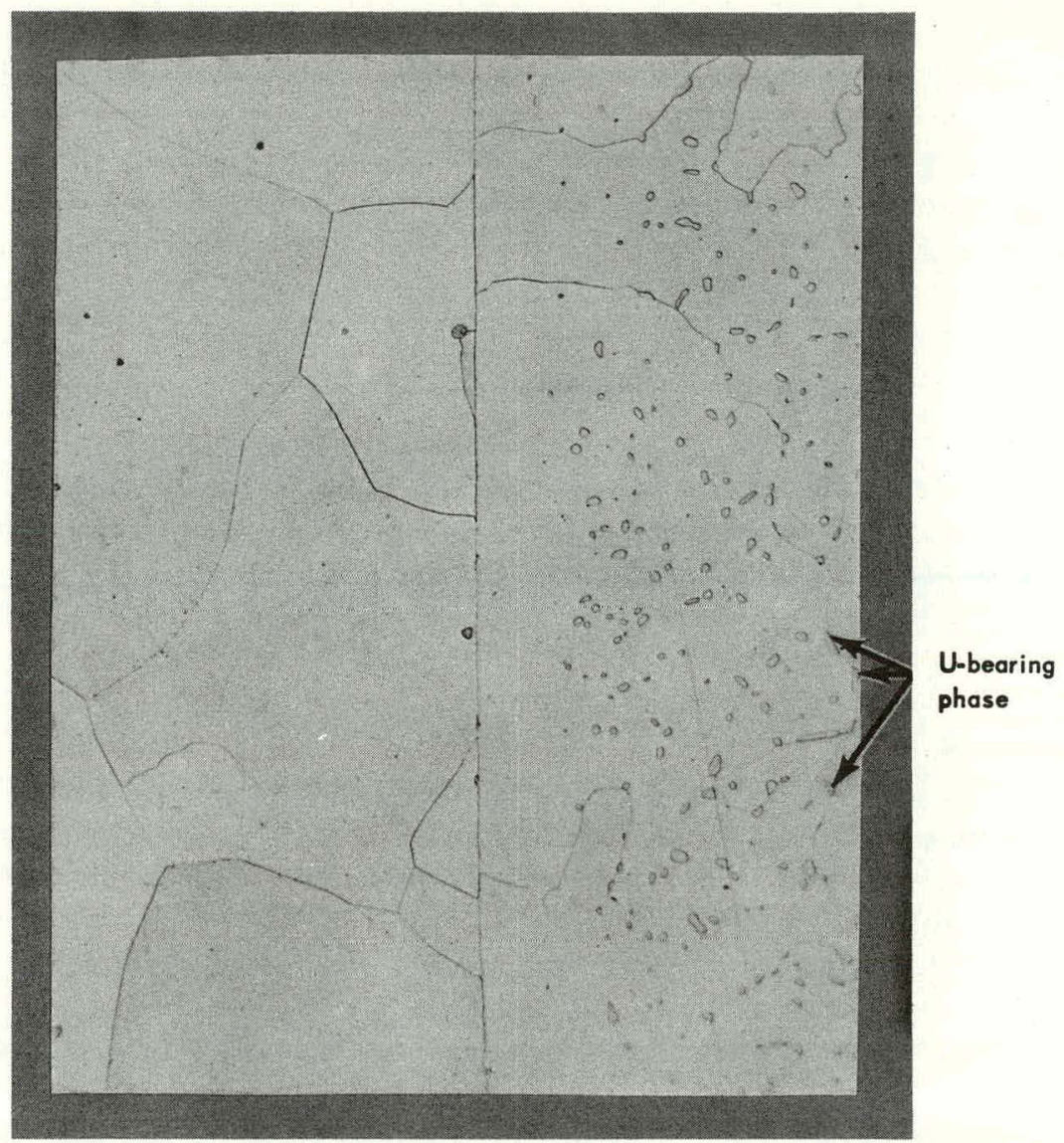

Fig. 6.1-Photomicrograph of interface area showing $\mathrm{Fe}-5 \mathrm{Cr}-4 \mathrm{Al}$ and $\mathrm{Fe}-5 \mathrm{Cr}-4 \mathrm{Al}-5 \mathrm{U}$ after heat treating for 500 hours at $1000^{\circ} \mathrm{C}$ (Neg. 7704, Etched, 250X)

bearing phase is evenly dispersed throughout the original U-containing portion of the couple, except at the interface where none is visible in an area approximately 50 microns wide; no U-bearing phases are discernable in the other portion of the couple. Electron-microprobe step-scan analyses detected trace amounts of soluble $U$ (possibly as high as $0.3 \%$ ) within 9 microns of individual, insoluble U-bearing particles in the $\mathrm{Fe}-\mathrm{Cr}-\mathrm{Al}-\mathrm{U}$ portion of the couple; $\mathrm{U}$ is also present in minute amounts at the couple interface. If soluble $U$ was present in the $\mathrm{Fe}-\mathrm{Cr}-\mathrm{Al}$ portion of the couple, it was below the limit of detection of the microprobe (approximately $0.1 \%$ ). The appearance of the $U$-depleted zone adjacent to the interface suggests that $\mathrm{U}$ diffusion coefficients are high in $\mathrm{Fe}-\mathrm{Cr}-\mathrm{Al}$ alloys and $\mathrm{U}$ solubility is low.

As discussed in Section 6.1, several spark-source mass-spectrographic analyses were made along the central axis perpendicular to the interface. In addition to the discrepancies in $\mathrm{U}$ content noted above, it was found that this technique was not suitable for measuring concentration gradients due to the low resolution of the arc. When the arc was adjusted to cover a small area of about 50 microns diameter, the sensitivity was low. Adjusting the instrument for maximum sensitivity necessitated a greatly enlarged and non-uniform arc diameter, which nullified the possibility of calculating diffusion coefficients unless the length of the concentration gradient was extreme. The degree of importance attached to obtaining $U$ diffusion coefficients has decreased since the results from the fueled capsule tests, discussed in Section 6.4, show that the rate of $\mathrm{U}$ diffusion through the cladding is not the limiting step in the processes leading to surface $U$. 
Consideration was given to the possible need to correlate $\mathrm{Al}$ or $\mathrm{Cr}$ diffusion in $\mathrm{Fe}-\mathrm{Cr}-\mathrm{Al}$ alloys with the gradient of chemical potential rather than with the gradient of concentration. Studies were performed on diffusion couples of $\mathrm{Fe}-10 \mathrm{Al}$ versus $\mathrm{Fe}-5 \mathrm{Cr}-10 \mathrm{Al}, \mathrm{Fe}-10 \mathrm{Al}$ versus $\mathrm{Fe}-25 \mathrm{Cr}-10 \mathrm{Al}, \mathrm{Fe}-25 \mathrm{Cr}$ versus $\mathrm{Fe}-25 \mathrm{Cr}-4 \mathrm{Al}$, and $\mathrm{Fe}-25 \mathrm{Cr}$ versus $\mathrm{Fe}-$ $25 \mathrm{Cr}-10 \mathrm{Al}$ (all in wt \%); in addition to ascertaining other results, these investigations were to determine whether there is preferential migration leading to a discontinuity of $\mathrm{Al}$ or $\mathrm{Cr}$ concentration at the couple interface. After periods up to 1000 hours at $1000^{\circ} \mathrm{C}$, microprobe traverses revealed no evidence of unequal $\mathrm{Al}$ or $\mathrm{Cr}$ concentration. Apparently, the concentration gradient is an adequate approximation of the gradient of chemical potential, and no further investigation of this point is planned.

Diffusion couples of $\mathrm{Fe}-\mathrm{Cr}-\mathrm{Al}$ versus $\mathrm{Fe}$ and $\mathrm{Fe}-\mathrm{Cr}-\mathrm{Al}$ versus $\mathrm{Cr}$ are being studied to determine the rate of $\mathrm{Al}$ influx into the core area, normally a cermet of $\mathrm{Fe}-\mathrm{UO}_{2}$ or $\mathrm{Cr}-\mathrm{UO}_{2}$. If this process was slow, it might be the rate controlling step in U production and might also show an observable induction period. In this investigation, diffusion couples were fabricated from $1.27-\mathrm{cm}$-diameter $\mathrm{Fe}-\mathrm{Cr}-\mathrm{Al}$ rods with a $0.32-\mathrm{cm}$-diameter opening drilled parallel to the $2.54-\mathrm{cm}$ length. The core material (usually $\mathrm{Fe}$ or $\mathrm{Cr}$ ) was fitted into the opening in the cladding, and the capsule was then evacuated, sealed by welding, and autoclaved for 2 hours at $1000^{\circ} \mathrm{C}$ and $700 \mathrm{~kg} / \mathrm{cm}^{2}$ gas pressure. Sufficient couples were placed on test at $1000^{\circ} \mathrm{C}$ so that a complete set of couples could be removed for destructive analysis after 100, 300, and 1000 hours. Electron-microprobe traverses were made on each transverse section from a distance in the cladding where analyses indicated constant composition, across and perpendicular to the interface and then into the core material to a distance where constant composition again was reached. The instrument recorded $\mathrm{Fe}, \mathrm{Cr}$, and $\mathrm{Al}$ compositions simultaneously. The traverses of $\mathrm{Al}$ content were affected by a considerable amount of statistical variation in the instantaneous rate meter readout system, and efforts to smooth out the data were not successful. For this reason, it was not possible to calculate diffusion coefficients from the existing data, and it will be necessary to re-examine the diffusion couples using the electron microprobe in the step-scan scaling mode.

For accurate results, the raw microprobe data must be corrected for matrix effects such as absorption and fluorescence. Two correction programs, originally coded by J. D. Brown ${ }^{1,2}$ of the U.S. Bureau of Mines, were adapted for use on a shared-time computer system.

The results of the electron-microprobe analyses, shown in Table 6.1, cannot be considered quantitatively accurate, but trends in the data do suggest certain conclusions. While cladding materials containing greater quantities of $\mathrm{Al}$ will increase the distance $\mathrm{Al}$ diffuses into Fe cores, this effect is far less evident when the core material is $\mathrm{Cr}$. Apparently, $\mathrm{Cr}$ most effectively prevents diffusion of cladding constituents into the core. The present data for $\mathrm{Cr}$ cores do not show increases in diffusion distance with time in contrast to the data from the Fe cores. Since the rate of traverse of the sample beneath the electron beam limited determinations of individual elements to 48 -micron intervals, it is probable that the true diftusion distances in Cr cores are significantly shorter than the values indicated in Table 6.1. In addition, data from the $\mathrm{Fe}$-base core diffusion couples indicate that $\mathrm{Al}$ diffuses at a higher rate into the core when the $\mathrm{Cr}$ cladding constituent is increased from 5 percent to 25 percent.

\footnotetext{
${ }^{1}$ J. D. Brown, "A Computer Program for Electron Probe Microanalysis," Report of Investigation RI-6648. United States Department of the Interior, Bureau of Mines, 1965.

${ }^{2}$ J. D. Brown, "Comprehensive Computer Program for Electron Probe Microanalysis," Analytical Chemistry, Vol. 38, June 1965, pp. 890-894.
} 
TABLE 6.1

\begin{tabular}{|c|c|c|c|c|c|}
\hline \multirow{2}{*}{$\begin{array}{c}\text { Core } \\
\text { Material }\end{array}$} & \multirow[b]{2}{*}{ Cladding } & \multirow{2}{*}{$\begin{array}{l}\text { Diffusing } \\
\text { Species }\end{array}$} & \multicolumn{3}{|c|}{$\begin{array}{l}\text { Extent of Diffusion into } \\
\text { Core at } 1000^{\circ} \mathrm{C},{ }^{a} \text { microns } \\
\end{array}$} \\
\hline & & & $100 \mathrm{hr}$ & $300 \mathrm{hr}$ & $1000 \mathrm{hr}$ \\
\hline $\mathrm{Fe}$ & $\mathrm{Fe}-5 \mathrm{Cr}$ & $\mathrm{Cr}$ & 100 & 50 & 190 \\
\hline $\mathbf{F e}$ & $\mathrm{Fe}-25 \mathrm{Cr}$ & $\mathrm{Cr}$ & 160 & 80 & 225 \\
\hline Fe & $\mathrm{Fe}-4 \mathrm{Al}$ & $\mathrm{Al}$ & 290 & 460 & 730 \\
\hline $\mathbf{F e}$ & $\mathrm{Fe}-10 \mathrm{Al}$ & $\mathrm{Al}$ & 375 & 530 & 1200 \\
\hline $\mathrm{Fe}$ & $\mathrm{Fe}-5 \mathrm{Cr}-4 \mathrm{Al}$ & $\mathrm{Cr}, \mathrm{Al}$ & 180 & 440 & 730 \\
\hline $\mathbf{F e}$ & $\mathrm{Fe}-25 \mathrm{Cr}-4 \mathrm{Al}$ & $\mathrm{Cr}, \mathrm{Al}$ & 240 & 440 & 960 \\
\hline $\mathbf{F e}$ & $\mathrm{Fe}-5 \mathrm{Cr}-10 \mathrm{Al}$ & $\mathrm{Cr}, \mathrm{Al}$ & 360 & 570 & 900 \\
\hline $\mathbf{F e}$ & $\mathrm{Fe}-25 \mathrm{Cr}-10 \mathrm{Al}$ & $\mathrm{Cr}, \mathrm{Al}$ & 540 & 660 & 1530 \\
\hline $\mathrm{Cr}$ & $\mathbf{F e}-5 \mathrm{Cr}$ & $\mathrm{Fe}$ & 28 & 80 & 240 \\
\hline $\mathrm{Cr}$ & $\mathrm{Fe}-25 \mathrm{Cr}$ & $\mathbf{F e}$ & 65 & 140 & $150^{\circ}$ \\
\hline $\mathrm{Cr}$ & $\mathrm{Fe}-4 \mathrm{Al}$ & $\mathrm{Fe}, \dot{\mathrm{Al}}$ & $<40$ & 30 & 140 \\
\hline $\mathrm{Cr}$ & $\mathrm{Fe}-10 \mathrm{Al}$ & $\mathrm{Fe}, \mathrm{Al}$ & 70 & 70 & - \\
\hline $\mathrm{Cr}$ & $\mathrm{Fe}-5 \mathrm{Cr}-4 \mathrm{Al}$ & $\mathrm{Fe}, \mathrm{Al}$ & $<50$ & $<20$ & $<60$ \\
\hline $\mathrm{Cr}$ & $\mathrm{Fe}-25 \mathrm{Cr}-4 \mathrm{Al}$ & $\mathrm{Fe}, \mathrm{Al}$ & 60 & 40 & $<50$ \\
\hline $\mathrm{Cr}$ & $\mathrm{Fe}-5 \mathrm{Cr}-10 \mathrm{Al}$ & $\dot{\mathrm{Fe}}, \mathrm{Al}$ & 100 & 25 & 16 \\
\hline $\mathrm{Cr}$ & $\mathrm{Fe}-25 \mathrm{Cr}-10 \mathrm{Al}$ & $\mathrm{Fe}, \mathrm{Al}$ & - & 30 & 80 \\
\hline $\mathrm{Fe}-25 \mathrm{Cr}$ & $\mathrm{Fe}-25 \mathrm{Cr}-4 \mathrm{Al}$ & $\mathrm{Al}$ & 430 & 660 & 520 \\
\hline $\mathrm{Fe}-25 \mathrm{Cr}$ & $\mathrm{Fe}-25 \mathrm{Cr}-10 \mathrm{Al}$ & $\mathrm{Al}$ & 360 & - & 1175 \\
\hline $\mathrm{Fe}-10 \mathrm{Al}$ & $\mathrm{Fe}-5 \mathrm{Cr}-10 \mathrm{Al}$ & $\mathrm{Cr}$ & - & - & 1580 \\
\hline $\mathrm{Fe}-10 \mathrm{Al}$ & $\mathrm{Fe}-25 \mathrm{Cr}-10 \mathrm{Al}$ & $\mathrm{Cr}$ & 450 & - & 1640 \\
\hline
\end{tabular}

a Distance perpendicular to the interface and from it into the core until the electron microprobe indicated constant composition was reached.

\section{3 THERMODYNAMIC INVESTIGATIONS}

Measuring the emf of electrochemical cells with molten salt electrolytes was chosen as the most promising method for determining the chemical potential of $\mathrm{Al}$ in solid $\mathrm{Fe}-\mathrm{Cr}-\mathrm{Al}$ alloys. An apparatus similar to that described by Radcliffe, et al.,$^{3}$ was fabricated and assembled. Measurements were made at low temperature $\left(420^{\circ} \mathrm{C}\right)$ with $\mathrm{LiCl}-\mathrm{KCl}$ electrolyte to verify that the fused salt was sufficiently free of electro-active elements and the equipment and procedures were adequate to prevent electrolyte contamination. ${ }^{4}$ Modifications were made to the electrolytic cell and similar verification measurements were made at $700^{\circ} \mathrm{C}$ using an electrolyte of an equimolar mixture of $\mathrm{KCl}-\mathrm{NaCl}$ and then $\mathrm{KCl}-\mathrm{NaCl}$ containing 0.05 mole fraction of $\mathrm{AlCl}_{3} .^{5}$

The experimental procedure of Radcliffe, et al., was used with two $\mathrm{Fe}-\mathrm{Al}$ alloys ( $\mathrm{Fe}-4 \mathrm{Al}$ and $\mathrm{Fe}-10 \mathrm{Al}$, both wt $\%$ ) to further test the reliability of the electrolytic cell before measuring the series of $\mathrm{Fe}-\mathrm{Cr}-\mathrm{Al}$ alloys. A diagram of the assembled cell ready for operation is shown in Figure 6.2. The cell was heated to $800^{\circ} \mathrm{C}$, allowed to stand overnight, and the emf measured at intervals of $20^{\circ}$ to $30^{\circ} \mathrm{C}$ in the temperature range from $875^{\circ}$ to $1000^{\circ} \mathrm{C}$ on heating and cooling. To insure equilibrium conditions, the temperature was maintained constant for about 1 hour before each measurement.

Emf measurements made during this checkout phase were not reproducible when a molten Al reference electrode was used. They did show negligible emf (less than 0.02 volt) when

${ }^{3}$ S. V: Radcliffe, B. L. Averbach, and M. Cohen, "Relative Thermodynamic Properties of Solid Iron-Aluminum

Alloys," Acta Metallurgica, Vol. 9, March 1961, pp. 169-176.

4،"High-Temperature Materials Program Progress Report No. 61," GE-NMPO, GEMP-61, September 30, 1966, p. 108.

5“'High-Temperature Materials Program Progress Report No. 63," GE-NMPO, GEMP-63, December 30, 1966, pp. 78-79. 


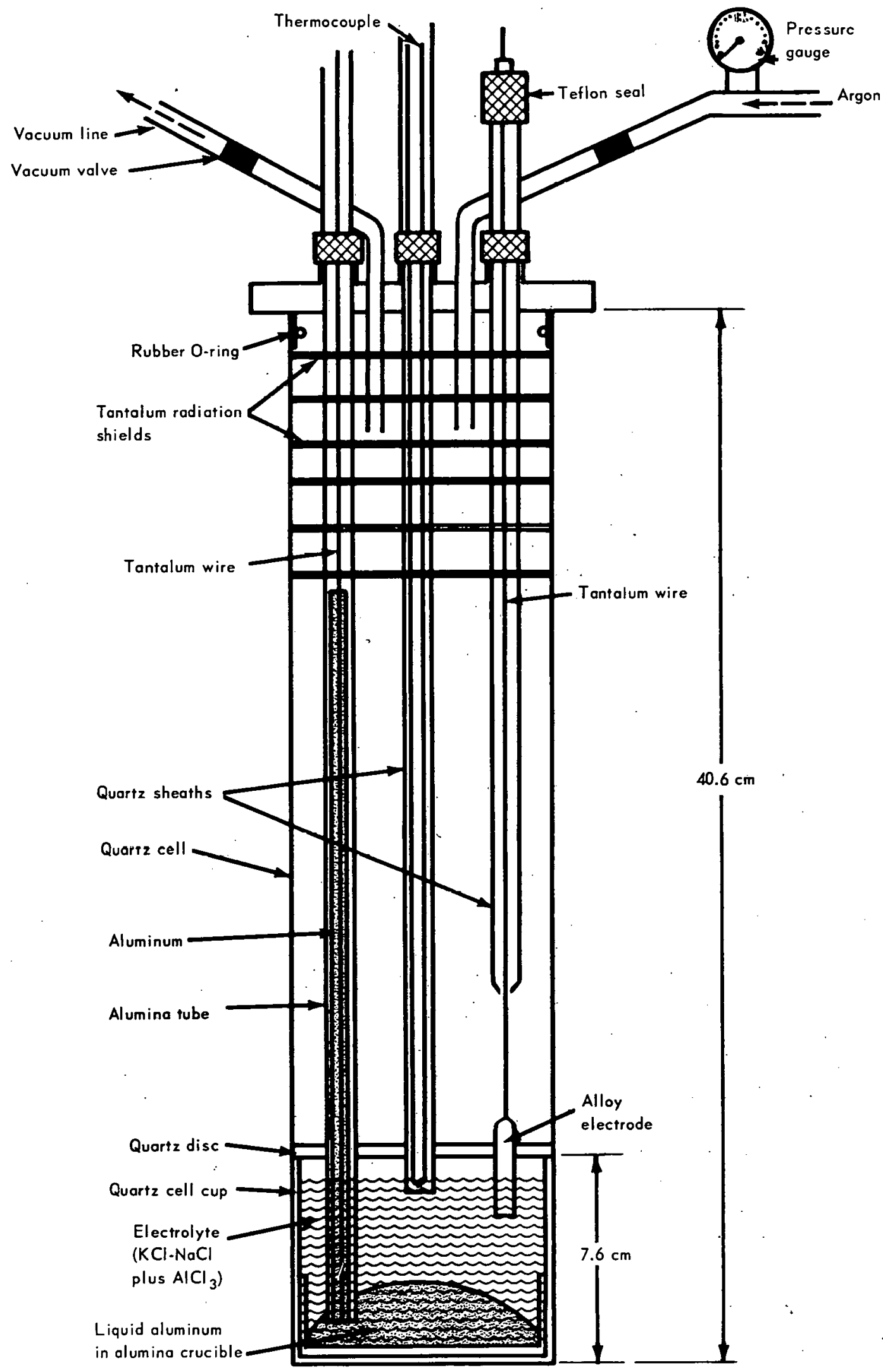

Fig. 6.2-Fused salt electrolytic cell 
two identical $\mathrm{Fe}-\mathrm{Al}$ alloy electrodes were compared. The erratic results were explained by a detailed examination of the $\mathrm{Al}$ reference electrode. $\mathrm{An} \mathrm{Al}_{2} \mathrm{O}_{3}$-sheathed $\mathrm{Ta}$ lead wire was used to make contact with the pool of molten Al. The Al-Ta combination produced a brittle $\mathrm{TaAl}_{3}$ section. which either broke or was dissolved by the $\mathrm{Al}$, thus destroying electrical continuity. Larger diameter Ta wires expanded, cracked the $\mathrm{Al}_{2} \mathrm{O}_{3}$ sheath, and effectively produced a Ta-Al reference electrode of unknown composition.

A substitute lead was prepared by suction casting 99.99-percent pure $\mathrm{Al}$ into an $\mathrm{Al}_{2} \mathrm{O}_{3}$ tube with a $0.051-\mathrm{cm}$-diameter $\mathrm{Ta}$ wire cast into the sheath to maintain electrical contact. Preliminary measurements indicated that this new type of lead will be satisfactory.

\subsection{FUELED CAPSULE TESTS}

Capsule tests are aimed at quantitative determination of the rate of $U$ accumulation on a specimen surface as a function of the cladding and core compositions. Over wide composition ranges, such tests should provide additional insight into the mechanism of U production as well as supply experimental data for comparison with predictions from the thermodynamic and kinetic studies also being conducted.

Specimen design was dictated by the requirement for a flat, $2.5-\mathrm{cm}$-diameter cladding. surface which was necessary to obtain the greatest accuracy in analyzing for surface $U$ by $\mathrm{X}$-ray fluorescence techniques. This nondestructive method has been correlated with wet-chemical $U$ analysis ${ }^{6}$ to provide accurate values in spite of extraneous surface Fe-, $\mathrm{Cr}$-, and $\mathrm{Al}$-oxide films. The $\mathrm{Fe}-\mathrm{Cr}-\mathrm{Al}$ cladding alloys being used in this study contain Cr levels of 5, 15, and 25 percent and $\mathrm{Al}$ levels of 4, 7, and 10 percent; the $\mathrm{Fe}$-base binary alloys contain $\mathrm{Cr}$ levels of 5 and 25 percent and $\mathrm{Al}$ levels of 4 and 10 percent. All of the alloys were vacuum-induction-melted, extruded, hot-forged, and rolled to $0.76-\mathrm{cm}$ and $0.38-\mathrm{cm}$-thick sheet stock before deep drawing to form cup-shaped receptacles. The $\mathrm{UO}_{2}, \mathrm{UO}_{1.989}$, and $\mathrm{Fe}-40 \mathrm{UO}_{2}$ (vol \%) fueled cores to be tested were sintered to densities in excess of 95 percent of theoretical, then cut and ground to form disc-shaped specimens of approximately $2.5-\mathrm{cm}$ diameter and $0.25-\mathrm{cm}$ thickness. The cores were fitted within the cladding so that each capsule was composed of a $0.038-\mathrm{cm}$-thick side and a $0.076-\mathrm{cm}$ thick side to increase the possibilities of obtaining accurate rate data during testing. The capsules were evacuated, sealed by electron-beam welding, and autoclaved at $600^{\circ} \mathrm{C}$ and $140 \mathrm{~kg} / \mathrm{cm}^{2}$ gas pressure to achieve uniform core - cladding contact during test.

To perfect test procedures, an exploratory test at $1200^{\circ} \mathrm{C}$ was performed on clad capsules with $\mathrm{Fe}-40 \mathrm{UO}_{2}$ cores. It was found suitable to test under 2 atmospheres of argon gas containing 3 volume percent oxygen; this insured sufficient oxidation of any $U$ diffusing to the surface without subjecting some of the low-oxidation-resistant claddings to weld failure by severe oxidation. It was also necessary to separate individual capsules with $\mathrm{Al}_{2} \mathrm{O}_{3}$ spacers to prevent cross-contamination.

This exploratory test was continued for 1000 hours with intermediate analyses for surface $U$ after: $100,200,400$, and 700 hours. The analyses showed that the first evidence of surface $U, 7$ to 9 micrograms per $\mathrm{cm}^{2}$, occurred within 100 hours on both the $0.038-\mathrm{cm}$ - and $0.076-\mathrm{cm}$-thick sides of the capsule claddings containing 7 - and 10-percent $\mathrm{Al}$; capsule claddings containing 0 - and 4-percent $\mathrm{Al}$ did not show surface $\mathrm{U}$ contamination within 1000 hours. After testing, the specimens were examined metallographically. No significant changes were observed in the fuel distribution.

Currently, two series of clad specimens are being simultaneously tested at $1200^{\circ} \mathrm{C}$ in the same furnace muffle; one series contains $\mathrm{UO}_{2.0}$ cores and the other $\mathrm{UO}_{1.989}$ cores.

6“"Fifth Annual Report-High-Temperature Materials Programs, Part A," GE-NMPO, GEMP-400A, February 28, 1966, p. 142. 
After 6 hours, both surfaces were analyzed for U. All capsules containing substoichiometric $\mathrm{UO}_{1.989}$ cores measured 300 to 700 micrograms of $U$ per $\mathrm{cm}^{2}$ on the $0.038-\mathrm{cm}$-thick, $\mathrm{Fe}-\mathrm{Cr}-\mathrm{Al}$ alloy cladding. The capsules clad with $\mathrm{Fe}-5 \mathrm{Cr}$ and $\mathrm{Fe}-25 \mathrm{Cr}$ measured 7 and 90 micrograms of $U$ per $\mathrm{cm}^{2}$, respectively. To date, these capsules have accumulated 400 hours, and claddings containing no $\mathrm{Al}$ have less surface $\mathrm{U}$ contamination by a factor of 2 or higher. Apparently, the free $U$ present in the cores prior to testing diffuses rapidly through the cladding since $U$ contamination was also found on the $0.076-\mathrm{cm}$-thick side after 6 hours; however, the quantity measured was significantly lower than that on the thinner side. $U$ diffusing into the cladding appears to have a detrimental effect on the cladding. or the core - cladding interface as radial cracks were observed in many claddings after 10 hours and two thermal cycles. These cladding cracks appeared only in the capsule series containing $\mathrm{UO}_{1.989}$ cores tested at $1200^{\circ} \mathrm{C}$. Testing at $1200^{\circ} \mathrm{C}$ is continuing.

The capsule series containing $\mathrm{UO}_{2.0}$ cores required over 6 but less than 55 hours of test time before the first evidence of surface $\mathrm{U}$ could be detected on the thin $\mathrm{Fe}-\mathrm{Cr}-\mathrm{AI}$ cladding. The capsules clad with $\mathrm{Fe}-5 \mathrm{Cr}$ and $\mathrm{Fe}-25 \mathrm{Cr}$ showid no surface $U$ after 400 hours. Most of the claddings measured only 9 to 20 micrograms of $U$ per $\mathrm{cm}^{2}$ after 400 hours at $1200^{\circ} \mathrm{C}$; consequently, additional testing will be required to establish any definite data trends.

A series of capsules containing $\mathrm{Fe}-40 \mathrm{UO}_{2}$ cores and $\mathrm{UO}_{1.989}$ cores completed 1000 hours at $600^{\circ} \mathrm{C}$ with no trace of surface $\mathrm{U}$ on any cladding. Rer ${ }^{\top}$ ced on test at $800^{\circ} \mathrm{C}$, these capsules showed no surface $U$ after 400 hours of a test that is continuing. The absence of surface $U$ on the capsules containing substoichiometric $\mathrm{UO}_{1.989}$ is unexpected, since work described in Section 6.1 indicated that extensive core - cladding reactions would occur at $800^{\circ} \mathrm{C}$.

\subsection{SUMMARY AND CONCLUSIONS}

The limit of $\mathrm{U}$ solubility in the $\mathrm{Fe}-\mathrm{Cr}-\mathrm{Al}$ alloys tested is about 0.1 weight percent in the temperature range from $600^{\circ}$ to $1200^{\circ} \mathrm{C}$; however, there is extensive solubility of $\mathrm{Fe}, \mathrm{Cr}$, and $\mathrm{Al}$ in $\mathrm{U}$.

Fueled capsule tests at $1200^{\circ} \mathrm{C}$ show that free $U$ from substoichiometric $\mathrm{UO}_{1.989}$ cores will diffuse through $0.076-\mathrm{cm}$-thick $\mathrm{Fe}-\mathrm{Cr}-\mathrm{Al}$ cladding and appear on the surface within 6 hours. For stoichiometric cores, the appearance time is approximately 30 hours. At this temperature, $U$ diffusion through these alloys is not the rate-limiting step which controls accumulation of $U$ on the surface of unirradiated clad fuel elements. In lower temperature tests with substoichiometric cores, no surface $U$ was found after 1000 hours at $600^{\circ} \mathrm{C}$ or after an additional 400 hours at $800^{\circ} \mathrm{C}$.

The rate of accumulation of surface $\mathrm{U}$ on $\mathrm{UO}_{1.989}$ fueled capsules clad with $\mathrm{Fe}-\mathrm{Cr}-\mathrm{Al}$ or $\mathrm{Fe}-\mathrm{Al}$ was approximately double the rate for $\mathrm{Fe}-\mathrm{Cr}$-clad specimens tested at $1200^{\circ} \mathrm{C}$. On stoichiometric $\mathrm{UO}_{2}$ fueled capsules. clad with $\mathrm{Fe}-\mathrm{Cr}-\mathrm{Al}$ or $\mathrm{Fe}-\mathrm{Al}$, the accumulation of surface $U$ was in the range from 8 to 60 micrograms of $U$ per $\mathrm{cm}^{2}$ during 400 hours at $1200^{\circ} \mathrm{C}$. No surface $U$ above the detection limit of 7 to 9 micrograms of $U$ per $\mathrm{cm}^{2}$ appeared on the $\mathrm{Fe}-\mathrm{Cr}$-clad specimens in the same test.

Preliminary results from diffusion couples of $\mathrm{Fe}-\mathrm{Cr}-\mathrm{Al}$ versus $\mathrm{Fe}$ or $\mathrm{Cr}$ indicate that the diffusion coefficient of $\mathrm{Al}$ in these alloys is greater than $5 \times 10^{-12} \mathrm{~cm}^{2} / \mathrm{sec}$ at $1000^{\circ} \mathrm{C} .^{7}$ In this temperature region, the gradient of concentration is an adequate approximation of the gradient of chemical potential in diffusion studies.

A significantly lower penetration of $\mathrm{Al}$ and other cladding components into pure $\mathrm{Cr}$ was observed in contrast to penetration into pure $\mathrm{Fe}$. Chromium appears to be a superior choice over $\mathrm{Fe}$ or $\mathrm{Fe}$-base alloys as the metallic component in $\mathrm{UO}_{2}$ cermet cores clad with $\mathrm{Fe}-\mathrm{Cr}-\mathrm{Al}$ alloys.

${ }^{7}$ GEMP-63, p. 78. 


\subsection{PLANS AND RECOMMENDATIONS}

In the phase studies, alternative analytical methods such as X-ray fluorescence will be evaluated for the determination of $\mathrm{U}$ at its solubility limit in $\mathrm{Fe}-\mathrm{Cr}-\mathrm{Al}$.

The diffusion studies will attempt to identify whether $U$ diffusion proceeds by grain boundary or volume diffusion. The diffusion coefficient of $\mathrm{Al}$ in $\mathrm{Fe}-\mathrm{Cr}-\mathrm{Al}, \mathrm{Fe}$, and $\mathrm{Cr}$ will be measured.

In the thermodynamic investigations, determination of the chemical potential of $\mathrm{Al}$ in $\mathrm{Fe}-\mathrm{Cr}-\mathrm{Al}$ alloys will be completed.

Fueled capsule tests extending to at least 1000 hours at $800^{\circ}, 1000^{\circ}$, and $1200^{\circ} \mathrm{C}$ will be completed. 
THIS PAGE

\section{WAS INTENTIONALLY \\ LEFT BLANK}




\title{
7. EFFECT OF RADIATION ON HEAT-RESISTANT METALS AND ALLOYS
}

(57018)

\author{
J. Moteff,* J.P. Smith ${ }^{\dagger}$
}

The objective of this program is to determine the effect of radiation on the time-, temperature-, and stress-dependent properties of heat-resistant metals and alloys at elevated temperatures, to identify the causes of any observed changes in these properties, and to develop remedial measures.

Materials to be investigated in this program include A-286, Hastelloy $X$, Hastelloy $N$ (INOR-8), Hastelloy R-235, Fe-Cr-Al-Y alloys, AISI 304 Stainless Steel, ASTM-A302B and A350-LF3 pressure vessel steels, and various Inconel and Incoloy alloys.

\subsection{STATUS OF IRRAdIATIONS (J. P. Smith, W. S. Chenault)}

A summary of irradiations of current interest is shown in Table 7.1. During the current year, capsules GEFP2-144, -145 , and -158 were irradiated in the ETR; capsules ORM-49-1 through 49-6, ORM-50, and ORM-51 were irradiated in the ORR; and test assembly NRL-1 was irradiated at the Industrial Reactor Laboratory (IRL). The latter was a cooperative effort with the Naval Research Laboratory (NRL) to study the effects of radiation on pressure vessel steels. A total of 73.creep-rupture, 28 resistivity, and 10 hardness specimens were irradiated at temperatures ranging from reactor ambient to $760^{\circ} \mathrm{C}$. Materials included Hastelloy $\mathrm{R}-235, \mathrm{Fe}-15 \mathrm{Cr}-4 \mathrm{Al}-1 \mathrm{Y}$, pressure vessel steels (A302B and A350-LF3), and stainless steels $(304,310$, and 348). Irradiation atmospheres included air, air - helium, and NaK.

In addition to these materials, specimens of Hastelloy $X$, IN-102, Incoloy 800, and Inconel 625 were received from GE-NL (G. E.'s Nucleonics Laboratory). These specimens had been irradiated in EBR-II and in the GETR to a fluence of approximately $10^{20}$ to $10^{21}$

neutrons $/ \mathrm{cm}^{2}\left(E_{\mathrm{n}} \geq 1 \mathrm{Mev}\right)$. These and unirradiated control specimens will be creep-rupture tested primarily to determine the effect of neutron spectrum on the creep-rupture properties of high-temperature alloys. These studies will also permit extending some earlier data ${ }^{1}$ on Hastelloy $\mathrm{X}$ into a much higher dose range.

\section{2 CREEP-RUPTURE TESTING (A. J. Lovell, J. P. Smith, J. Moteff)}

\section{HASTELLOY N}

Fifty-nine of the 69 irradiated Hastelloy $N$ specimens listed in Table 7.1 were creeprupture tested at temperatures of $650^{\circ}, 760^{\circ}$, and $815^{\circ} \mathrm{C}$. Most of the specimens were irradiated in the as-received (mill-annealed at $1175^{\circ} \mathrm{C}$ for 0.5 hour followed by rapid air

\footnotetext{
*Project leader.

†Principal investigator.

1" Second Annual Report - High-Temperature Materials and Reactor Component Development Programs, Volume IMaterials," GE-NMPO, GEMP-177A, February 28, 1963, pp. 75-85.
} 
TABI.E 7.1

IRRADIATION DATA FOR HIGH-TEMPERATURE ALLOY CAPSULES

\begin{tabular}{|c|c|c|c|c|c|c|c|c|c|c|}
\hline \multirow[b]{3}{*}{ Capsule } & \multirow[b]{3}{*}{ Material } & \multirow{3}{*}{\multicolumn{2}{|c|}{ pecimen Data }} & \multirow[b]{3}{*}{ Quantity } & \multicolumn{6}{|c|}{ Irradiation Conditions } \\
\hline & & & & & \multicolumn{4}{|c|}{ Neutron Data } & \multicolumn{2}{|c|}{ Temperature Data } \\
\hline & & & & & Facility & $\begin{array}{l}\text { Exposure, } \\
\text { Mwd }\end{array}$ & $\begin{array}{c}\text { Thermal, } \\
\text { nvt }\end{array}$ & $\begin{array}{c}\text { Fast, nvt } \\
\left(E_{\mathrm{n}} \geq 1 \mathrm{Mev}\right)\end{array}$ & $\begin{array}{c}\text { Time, } \\
\mathbf{h r}\end{array}$ & $\begin{array}{c}{ }^{\circ} \mathrm{C} \\
\text { Temperature, }\end{array}$ \\
\hline ORM-39 & $A-302 B$ & & $\begin{array}{l}\text { Res } \\
\text { H }\end{array}$ & $\begin{array}{l}1 \\
1\end{array}$ & ORR-Rabbit & & $3.3 \times 10^{18}$ & $4.1 \times 10^{17}$ & 5 & $\overline{\text { Reactor amblent }}$ \\
\hline NRL-1 & $\begin{array}{l}\text { A-302B } \\
\text { A-302B } \\
310 \text { SS } \\
\text { Tungsten }\end{array}$ & Rod $J$ & $\begin{array}{l}\text { Res } \\
\text { H } \\
\text { Res } \\
\text { Res }\end{array}$ & $\begin{array}{l}5 \\
3 \\
5 \\
5\end{array}$ & $\mathbf{I R L}^{\mathbf{b}}$ & & & $9 \times 10^{17}$ to $6 \times 10^{18^{c}}$ & & Reactor ambient \\
\hline $33 \mathrm{MT}-99$ & $\begin{array}{l}\mathrm{A}-286+0.010 \mathrm{~B} \\
\mathrm{~A}-286+0.0043 \mathrm{~B} \\
\mathrm{~A}-286+0.0008 \mathrm{~B} \\
\mathrm{~A}-286+0.0065 \mathrm{~B}\end{array}$ & $\begin{array}{l}\text { RV }-403-5 C \\
\text { RV-403-5B } \\
\text { RV-403-5A } \\
\text { RV }-451\end{array}$ & $\begin{array}{l}\text { CR } \\
\text { CR } \\
\text { CR } \\
\text { CR }\end{array}$ & $\begin{array}{l}7 \\
7 \\
7 \\
7\end{array}$ & ETR-K3 & 7910 & $6.5 \times 10^{20}$ & $4.8 \times 10^{19}$ & & Reactor ambient \\
\hline GEFP2-128 & Hastelloy $\mathrm{N}$ & 5081 & CR & 18 & ETR-E5-NW & 5154 & $5.0 \times 10^{20}$ & $8.8 \times 10^{19}$ & d & d \\
\hline GEFP2-139 & $\begin{array}{l}\text { Hastelloy N } \\
A-286+0.010 B \\
A-286+0.0043 B \\
\Lambda-386+0.0008 D \\
A-286+0,0065 B\end{array}$ & $\begin{array}{l}5081 \\
R V-403-5 C \\
R V-403-5 B \\
R V-4 n 3-5 A \\
R V-451\end{array}$ & $\begin{array}{l}\mathrm{CR} \\
\mathrm{CR} \\
\mathrm{CR} \\
\mathrm{CR} \\
\mathrm{CR}\end{array}$ & $\begin{array}{l}6 \\
3 \\
1 \\
4 \\
4\end{array}$ & ETR-E5-NW & 2920 & $2.4 \times 10^{20}$ & $7.2 \times 10^{19}$ & e & e \\
\hline GEFP2-144 & $\begin{array}{l}\text { Hastelloy } \\
\text { R-235 }\end{array}$ & - & $\mathbf{C R}$ & 18 & ETR & - & - & $5 \times 10^{19^{c}}$ & & 760 \\
\hline GEFP2-145 & $\begin{array}{l}\text { Hastelloy } \\
\text { R-235 }\end{array}$ & - & CR & 18 & ETR & - & - & $1 \times 10^{20^{c}}$ & & $\begin{array}{l}760+ \\
\text { Reáctor amblent }\end{array}$ \\
\hline GEFP2-148 & $\begin{array}{l}\text { Hastelloy } N \\
\text { Hastelloy } N \\
A-286+0.010 B \\
A-286+0.0043 B \\
A-286+0.0008 B\end{array}$ & $\begin{array}{l}5081 \\
5085 \\
\text { RV-403-5C } \\
\text { RV }-403-5 B \\
\text { RV-403-5A }\end{array}$ & $\begin{array}{l}\mathrm{CR} \\
\mathrm{CR} \\
\mathrm{CR} \\
\mathrm{CR} \\
\mathrm{CR}\end{array}$ & $\begin{array}{l}3 \\
6 \\
3 \\
3 \\
3\end{array}$ & ETR-N14-SE & 3348 & $2.4 \times 10^{20}$ & $4.6 \times 10^{19}$ & 376 & $\sim 650$ \\
\hline GEFP2-151 & $\begin{array}{l}\text { Hastelloy N } \\
\text { Hastelloy N }\end{array}$ & $\begin{array}{l}5065,5067 \\
5081\end{array}$ & CR(W) & 12 & ETR-N14-SE & 3920 & $2.5 \times 10^{20}$ & $4.4 \times 10^{19}$ & 440 & $\sim 650$ \\
\hline GE FP2 -152 & Hastelloy $\mathbf{X}$ & $E-9500$ & CR & 18 & ETR-N14-SE & 1847 & $9.6 \times 10^{19}$ & $1.9 \times 10^{19}$ & & 650 \\
\hline GEFP2-155 & Hastelloy $\mathrm{N}$ & 5081 & CR & 18 & ETR-N14-NW & 3735 & $2.4 \times 10^{20}$ & $1.4 \times 10^{20}$ & & 760 \\
\hline GEFP2-158 & $\begin{array}{l}304 \mathrm{SS} \\
348 \mathrm{SS}\end{array}$ & 55697 & CR & $\begin{array}{r}6 \\
12\end{array}$ & ETR & - & - & $5 \times 10^{19^{c}}$ & & 650 \\
\hline ORM-49-1 & $\begin{array}{l}\text { A-302B } \\
\text { A 350-LF3 }\end{array}$ & & $\begin{array}{l}\text { Res } \\
\text { H, Res }\end{array}$ & $\begin{array}{l}1 \\
1\end{array}$ & ORR-A2 & & & $6 \times 10^{17^{c}}$ & & Reactor ambient \\
\hline ORM $-49-2$ & $\begin{array}{l}A-302 B \\
A 350-L F 3\end{array}$ & & Res & $\begin{array}{l}1 \\
1\end{array}$ & ORR-A2 & & & $1 \times 10^{18^{c}}$ & & Reactor amblent \\
\hline ORM-49-3 & $\begin{array}{l}A-302 B \\
A 350-L F 3\end{array}$ & & $\begin{array}{l}\text { Res } \\
\text { H, Res }\end{array}$ & $\begin{array}{l}1 \\
1\end{array}$ & ORR-A2 & . & & $4 \times 10^{18^{c}}$ & & Reactor amblent \\
\hline ORM-49-4 & $\begin{array}{l}\text { A-302B } \\
\text { A 350-LF3 }\end{array}$ & & $\begin{array}{l}\text { Res } \\
\text { H, Res }\end{array}$ & $\begin{array}{l}1 \\
1\end{array}$ & ORR-A2 & & & $1 \times 10^{19^{c}}$ & & Reactor amblent \\
\hline ORM-49-5 & $\begin{array}{l}\text { A-302B } \\
\text { A 350-LF3 }\end{array}$ & & $\begin{array}{l}\text { Res } \\
\text { H, Res }\end{array}$ & $\begin{array}{l}1 \\
1\end{array}$ & ORR-A2 & & & $4 \times 10^{19^{c}}$ & & Reactor ambient \\
\hline ORM-49-6 & $\begin{array}{l}\text { A-302B } \\
\text { A 350-LF3 }\end{array}$ & & $\begin{array}{l}\text { Res } \\
\text { H, Res }\end{array}$ & 1 & ORR-A2 & & & $1 \times 10^{20^{c}}$ & & Reactor ambient \\
\hline ORM-50 & $\begin{array}{l}\text { Hastelloy } \\
\mathbf{R}-235^{h}\end{array}$ & & CR & 12 & ORR & - & $1.6 \times 10^{20}$ & $5.5 \times 10^{19}$ & & Reactor amblent \\
\hline ORM-51 & $\mathrm{Fe}-15 \mathrm{Cr}-4 \mathrm{Al}-1$ & IY MS-51 & CR & 7 & ORR & - & - & $1 \times 10^{20^{c}}$ & ' & $\begin{array}{l}\text { Reuctor amblent } \\
\text { in NaK }\end{array}$ \\
\hline 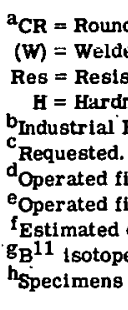 & $\begin{array}{l}\text { d creep-rupture sp } \\
\text { ed specimen (flller } \\
\text { tivity } \\
\text { ness } \\
\text { Reactor Laborator } \\
\text { irst } 5 \text { hours at } \sim 65 \\
\text { irst } 80 \text { hours at } \sim 6 \\
\text { dose. } \\
\text { contain } 50 \text { ppm na }\end{array}$ & $\begin{array}{l}\text { metal is fro } \\
\text { (Painsboro } \\
50^{\circ} \mathrm{C} \text { and the } \\
350^{\circ} \mathrm{C} \text { and the }\end{array}$ & $\begin{array}{l}\text { om heat } \\
\text { o, New J } \\
\text { remaind } \\
\text { e remair }\end{array}$ & $\begin{array}{l}\text { 5101) } \\
\text { Jer sey). } \\
\text { inder (702 } \\
\text { inder }(320\end{array}$ & $\begin{array}{l}\text { hours) of the cy } \\
\text { hours) of the } \\
\text {. }\end{array}$ & $\begin{array}{l}\text { le at } \mathbf{r} \\
\text { cle at }\end{array}$ & $\begin{array}{l}\text { ambient } t \\
\mathrm{r} \text { ambient }\end{array}$ & $\begin{array}{l}\text { perature. } \\
\text { nperature. }\end{array}$ & & . \\
\hline
\end{tabular}


cooling). Some, however, were given a pre-irradiation heat treatment at $870^{\circ} \mathrm{C}$ which is the normal "stress-relief" treatment for Hastelloy N. Unirradiated specimens given comparable heat treatments were tested to establish a control line for evaluating the degree of radiation damage in specimens subjected to the various heat treatments and test conditions. The majority of the specimens were tested in the as-irradiated condition; however, selected samples were post-irradiation-annealed at $870^{\circ} \mathrm{C}$ prior to testing.

The results of all tests at $650^{\circ}, 760^{\circ}$, and $815^{\circ} \mathrm{C}$ of specimens in the mill-annealed (solutioned) condition are shown in Figures 7.1, 7.2, and 7.3, respectively. The curves were obtained from a least squares fit of the data points shown for a given condition. One of the more significant features of the three plots is the general tendency for the line through the points from as-irradiated material to approach the unirradiated control line for lowstress (long-time) tests; this indicates possible annealing of radiation-induced damage during tests. Note also that, as the test temperatures increase, the predicted time for convergence becomes less. Assuming no change in stress dependency, the control and irradiated curves would be expected to meet at 50,000 hours at $650^{\circ} \mathrm{C}$ but only after 1000 hours at $815^{\circ} \mathrm{C}$. Actual convergence has been observed in at least one other nickel-base solution-strengthened alloy, Hastelloy $\mathrm{X} .^{1}$

The scatter at $650^{\circ} \mathrm{C}$ is somewhat higher than desirable and also higher than obtained at the other temperatures. This increased scatter is probably caused by a combination of the following factors:

1. Four separate irradiations were involved; hence, minor differences due to factors such as capsule location and flux become significant.

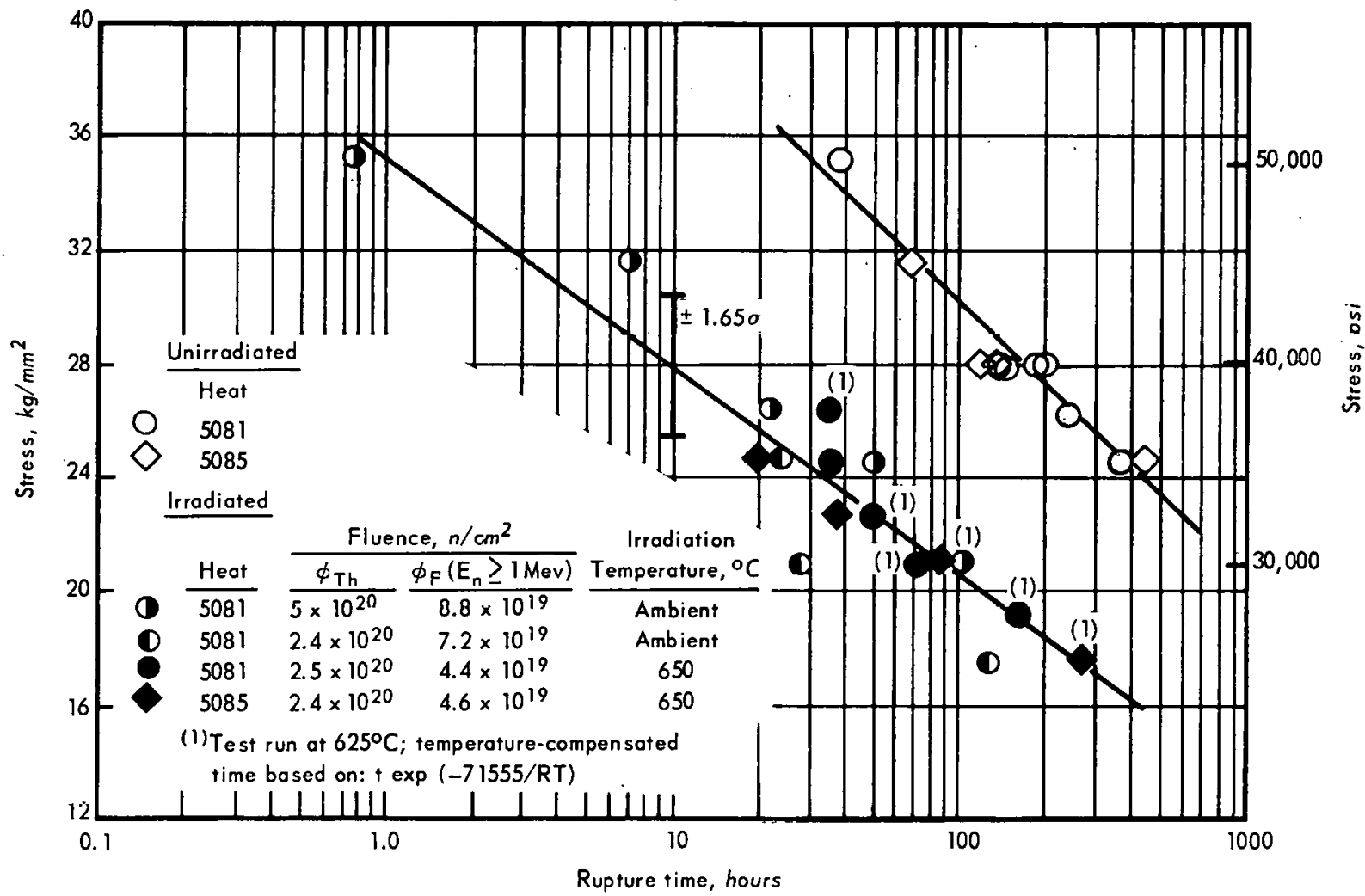

Fig. 7.1 - Stress-rupture properties of Hastelloy $\mathrm{N}$ at $650^{\circ} \mathrm{C}$ in the solution-treated condition 


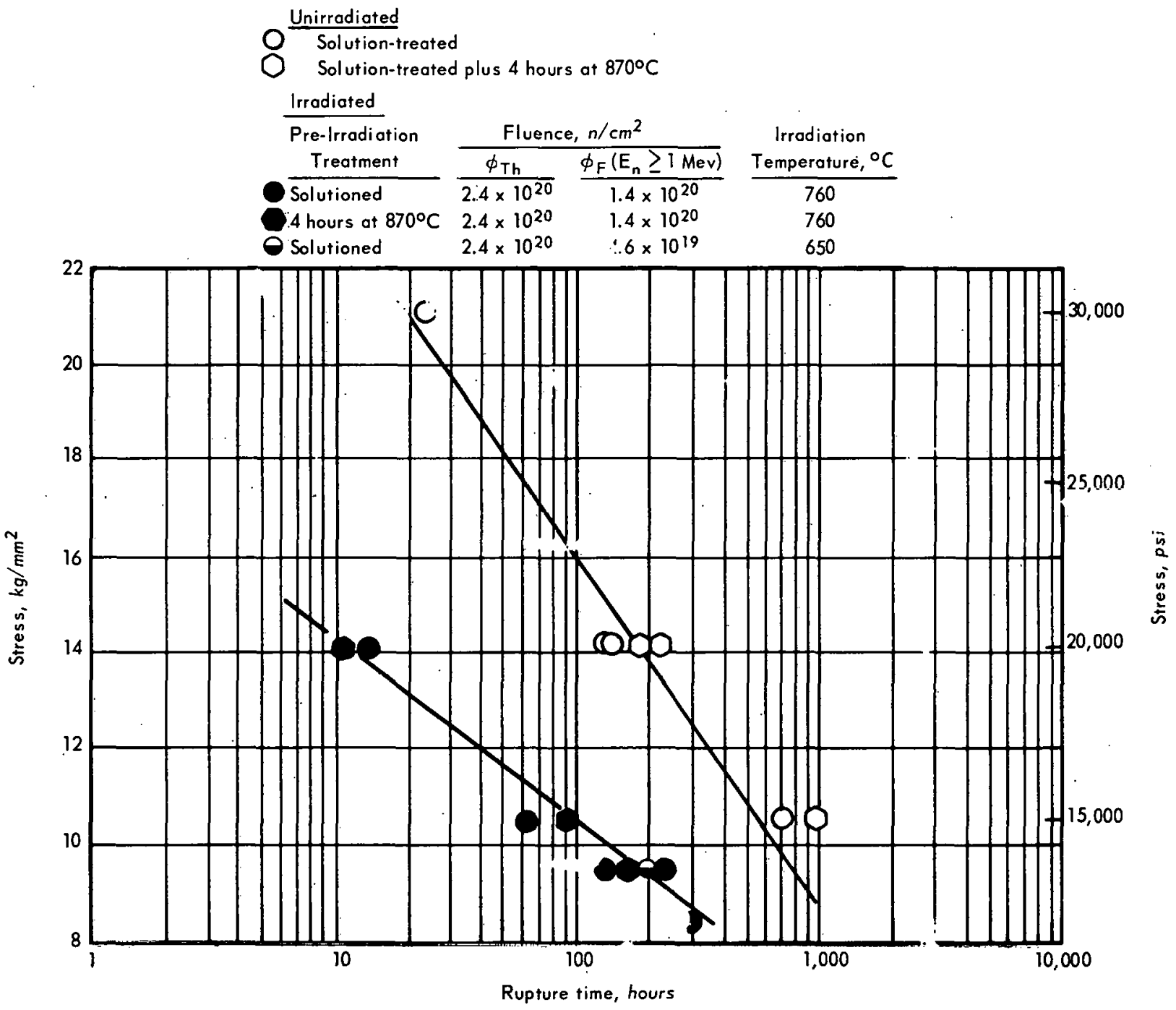

Fig. 7.2 - Stress-rupture properties of Hostelloy $\mathrm{N}$ at $760^{\circ} \mathrm{C}$

2. Residual stresse $s$ may vary since specimens were machined by c'ifferent vendors, and since two different heats of material were involved.

3. Pre-irradiation specimen history may be more significant at low test temperatures where different fracture modes art predominant than at the higher temperatures.

It should also be pointed out that a temperature-compensated time correction was applied to several of the GEFP2-148 and -151 (inradiation temperature, $650^{\circ} \mathrm{C}$ ) shown in Figure 7.1. This was necessitated by a shift in thermccouple calibration in one of the rupture machines. The thermocouple was recalibrated after close examination of ine data indicated a shift from the previously determined base line. This check showed that the output of the thermocouple was in error by as much as $54^{\circ} \mathrm{C}$. Visual examination of the thermocouple in the area of the hot junction showed that about 1 inch of one leg had deteriorated.

The temperature-compensated time was determined from the relationship:

$$
\frac{\mathrm{t}_{1}}{\mathrm{t}_{2}}=\exp \left[\frac{\Delta \mathrm{H}}{1.987}\left(\frac{1}{\mathrm{~T}_{1}}-\frac{1}{\mathrm{~T}_{2}}\right)\right]
$$

using the value of $\Delta \mathrm{H}=71,555 \mathrm{cal} / \mathrm{mole}$ (as derived later in this section). 


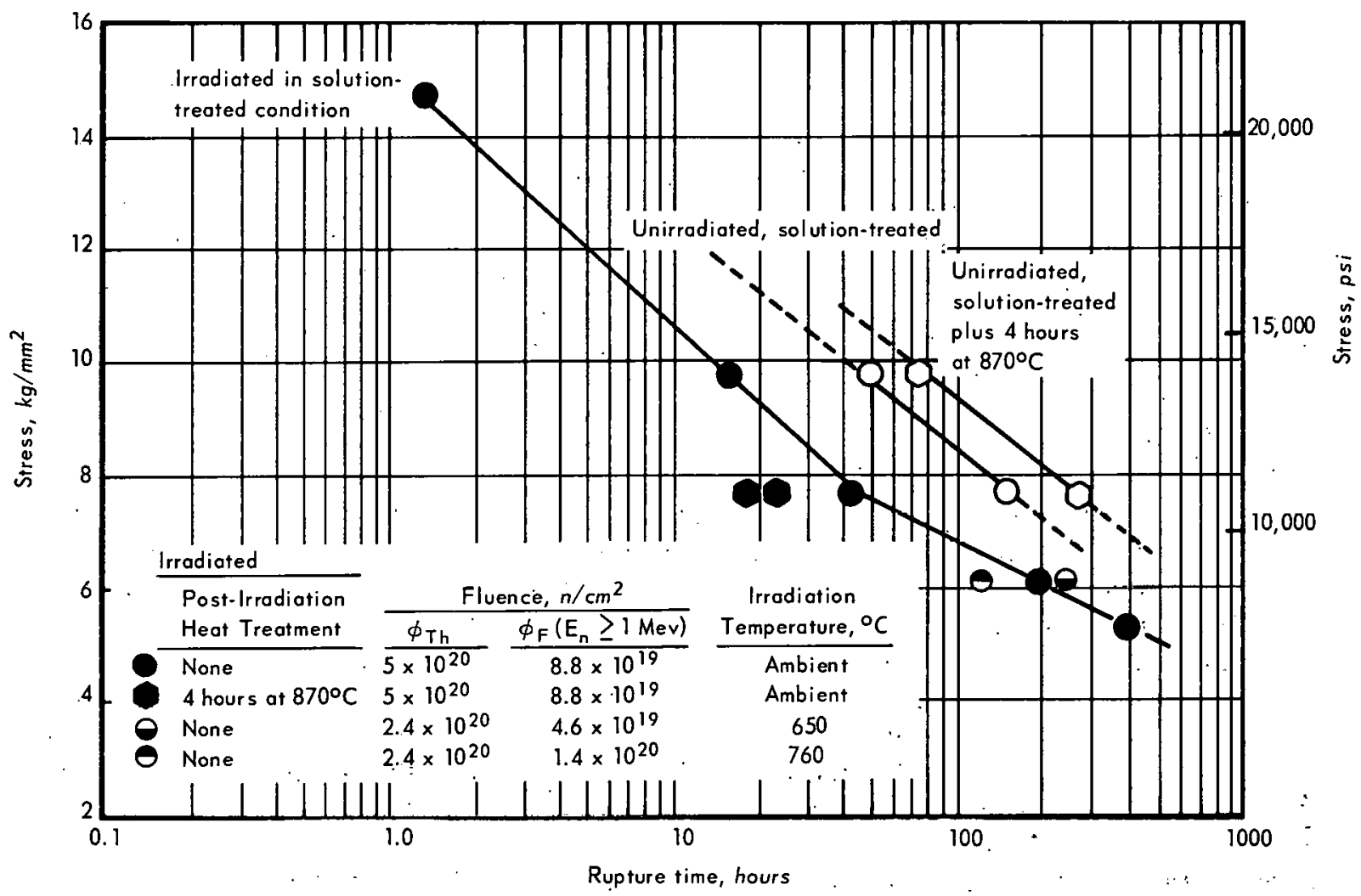

Fig. 7.3 - Stress-rupture properties of Hostelloy $\mathrm{N}$ at $815^{\circ} \mathrm{C}$

"Parameter" techniques were employed to obtain a somewhat clearer picture of the trends observed in the above mentioned isothermal creep-rupture plots. Two parameters were analyzed: :

Larson-Miller: $P=T(C+\log t) \times 10^{3}=a+b \log \sigma+c(\log \sigma)^{2}$

Garofalo: $\operatorname{Ln}(\theta)=\ln [t \exp (-\Delta \dot{H} / R T)]=A+n \ln [\operatorname{Sinh}(\alpha \sigma)]$

where:

$$
\begin{aligned}
\mathrm{T} & =\text { temperature (absolute) } \\
\mathrm{t} & =\text { time to rupture } \\
\sigma & =\text { applied stress } \\
\mathbf{n} & =\text { slope } \\
\Delta \mathrm{H} & =\text { activation energy for creep } \\
\mathbf{R} & =\text { gas constant }
\end{aligned}
$$

.C, A, $\alpha=$ material constants

$\mathrm{a}, \mathrm{b}, \mathrm{c}=\mathrm{constant}$ s

The Larson-Miller parameter was employed because of its widespread use and familiaritj in engineering. The Garofalo relationship is useful because it yields a straight line over a fairly wide range of stresses and temperatures even when assuming that $\Delta \mathrm{H}$ and $\alpha$ are constant with changing temperature and has a form similar to equations derived from dislocation theory. Other relationships which may represent a closer tie-in with the dislocation theory, such as the Weertman equation ${ }^{2}$ will be investigated to more fully explain the creep

${ }^{2}$ J. Weertman, "Steady State Creep Through Dislocation Climb," Journal of Applied Physics, Vol. 28, 1957, pp. 362-364. 
behavior. To use either equation (7.1) or (7.2), the material constants $\mathrm{C}, \Delta \mathrm{H}$, and $\alpha$ must be determined for a given material; this is best done with a large amount of data over a fairly wide range of temperatures and stresses. Since only a small amount of unirradiated control data was available at GE-NMPO, the constants were derived from $\mathrm{ORNL}^{3}$ data from the same heat of material. Separate computer programs were written to solve equations (7.1) and (7.2). For a given set of data, these programs determine the optimum value of $\mathrm{C}, \Delta \mathrm{H}$, and $\alpha$ (also the other unknown constants); print out the equation of the line of best fit as determined by a least squares analysis; and also print tabulator values of the dependent and independent variables to simplify subsequent plotting. Using the ORNL data, the following constants were derived for unirradiated mill-annealed Hastelloy $N$ (Heat 5081):

$$
\begin{aligned}
\mathrm{C} & =14.25 \\
\Delta \mathrm{H} & =71,555 \mathrm{cal} / \mathrm{mole} \\
\alpha & =0.0492 \mathrm{~mm}^{2} / \mathrm{kg}
\end{aligned}
$$

The parameter curves are shown in Figures 7.4 and 7.5 for the ORNL and GE-NMPO unirradiated mill-annealed material. The GE-NMPO curves were obtained using the above constants to calculate the curve of best fit as determined by a least squares analysis. Note the slight difference between the data from the two sites. The increased curvature of the GE-NMPO curve at the low stresses in Figure 7.4 is probably not real and is presumably caused by insufficient quantity of data in this area; nevertheless, it is the least squares line. These differences are considered insignificant in the final analysis. ${ }^{4}$ Since the constants derived from the ORNL data proved to be applicable to the GE-NMPO unirradiated data, these same constants were used to compute a Larson-Miller and a Garofalo curve for data from irradiated samples. The data from the mill-annealed irradiated specimens, along with the above calculated control curves, are shown in Figures 7.6 and 7.7. The Larson-Miller plot shown in Figure 7.6 is presented for its engineering application. It is rather difficult to analyze since it is not a linear relationship; it will not be discussed further. Because of the linear relationship of the Garofalo plot, Figure 7.7, observation and analysis are somewhat simplified. Note that in the Garofalo plots (Figures 7.4 and 7.6) the stress function is plotted on the abscissa (independent variable) and the time function is plotted on the ordinate. This is consistent with the usual mathematical and dislocation theory treatment of these functions. Two features are particularly significant:

1. The general tendency for convergence at low-stress, long-time conditions as discussed in connection with the isotherms (Figures 7.1, 7.2, and 7.3).

2. All the data for the irradiated specimens generally fall on a single straight line. This indicates that the activation energy $(\Delta \mathrm{H})$ and the constant $\alpha$ are not changed by irradiation. Note especially that the $815^{\circ} \mathrm{C}$ tests were run on specimens irradiated at reactor ambient temperature. The fact that these data points fall on the same straight line with the other specimens (especially the $650^{\circ} \mathrm{C}$ and $760^{\circ} \mathrm{C}$ irradiated specimens) implies that irradiation temperature is not the critical factor in determining the as-irradiated properties. If it were, there would probably be a step in the curve between the $815^{\circ} \mathrm{C}$ tests and the other tests. The minor role of irradiation temperature was implied in connection with the $650^{\circ} \mathrm{C}$ isothermals (Figure 7.1 ) and appears to be confirmed in this parameter plot. To further determine the role of radiation and test temperatures, specimens which were irradiated at $650^{\circ} \mathrm{C}$ were tested at $760^{\circ} \mathrm{C}$ and $815^{\circ} \mathrm{C}$; also, specimens which were irradiated at $760^{\circ} \mathrm{C}$ were tested at $650^{\circ} \mathrm{C}$ and $815^{\circ} \mathrm{C}$. The results of these tests are included in Figures 7.2, 7.3, and 7.8. These results show that the $650^{\circ} \mathrm{C}$ irradiated points are exactly as predicted from the previously established base lines at $760^{\circ} \mathrm{C}$ and $815^{\circ} \mathrm{C}$ tests, as shown in Figures 7.2 and 7.3. Likewise, the $760^{\circ} \mathrm{C}$ irradiated specimen ruptured at $815^{\circ} \mathrm{C}$ at the same point as would

3ORNL-TM-1017, Table 5.

4،'High-Temperature Materials Program Progress Report No. 63," GE-NMPO, GEMP-63, Decem ber 30, 1967, pp. $101-102$. 


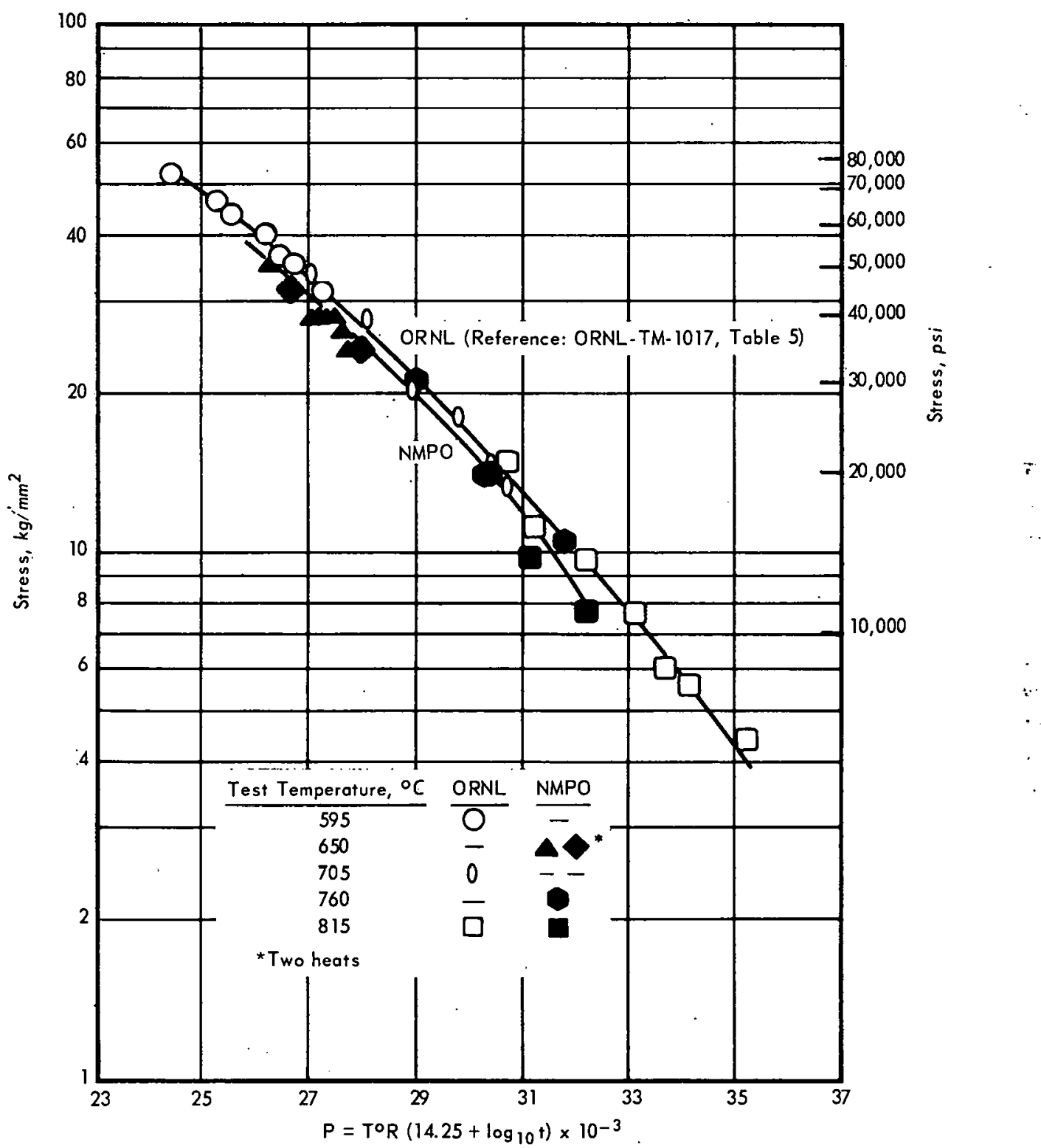

Fig. 7.4-Variation of Larson-Miller parameter, $P$, as a function of stress for unirradiated Hastelloy $\mathrm{N}$ 


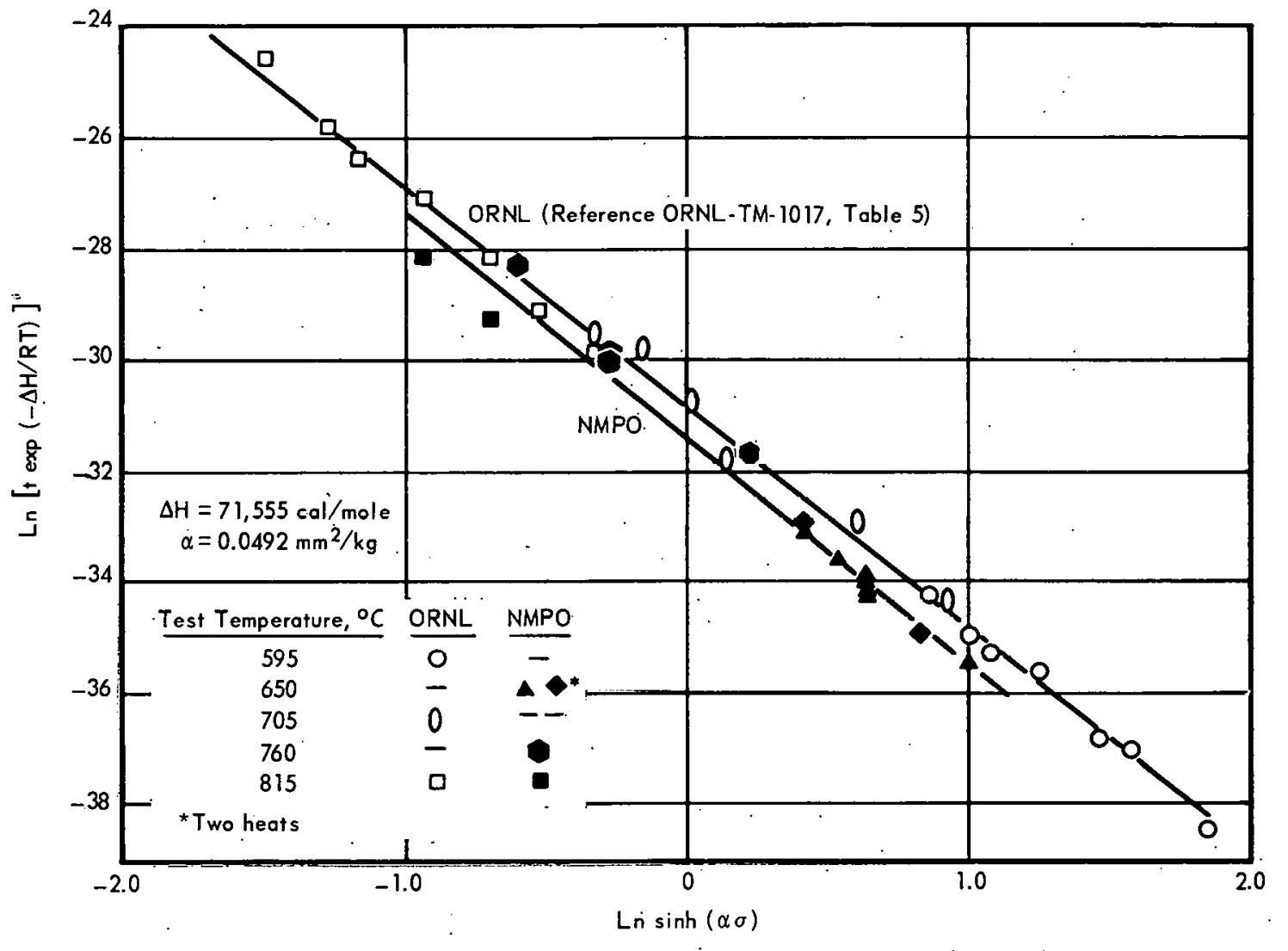

Fig. 7.5 - Variation of "Dorn Temperature-Compensated Time" as a function of $\sinh (\alpha \sigma)$ for unirradiated Hastelloy N (Garafalo relationship).

have been predicted from either ambient or $650^{\circ} \mathrm{C}$ irradiated specimens, as shown in Figure 7.3. On the other hand, the $760^{\circ} \mathrm{C}$ irradiated specimens which were tested at $650^{\circ} \mathrm{C}$ showed considerably improved properties compared to specimens irradiated at ambient temperature or at $650^{\circ} \mathrm{C}$, as shown in Figure 7.8.

The conclusion arising from this series of experiments is that, in the $650^{\circ}$ to $815^{\circ} \mathrm{C}$ test range, as-irradiated properties are entirely a function of the maximum temperature that the specimen has been exposed to, regardless of whether the maximum temperature occurred during irradiation or during testing. (Post-1rradiation annealing, discussed below, tends to change this observation especially for a test temperature of $815^{\circ} \mathrm{C}$.) The implication of these results is that the loss in rupture life (ductility ranged from 1 to $4 \%$ at all test temperatures after irradiation) is probably controlled by a point defect - impurity atom complex which is annealed at high temperatures. Since all test temperatures were above 0.5 $\mathbf{T}_{\mathrm{m}}$ of the alloy, simple atom displacements were essentially eliminated. Hence, the remaining damage state must be fairly complex to be stable at these relatively high temperatures. The possible interaction of helium (from $\mathrm{B}^{10}$ transmutation) atoms with dislocations and displacement spikes should also be considered. Transmission electron microscopy will undoubtedly be needed to verify which mechanism is predominant. 


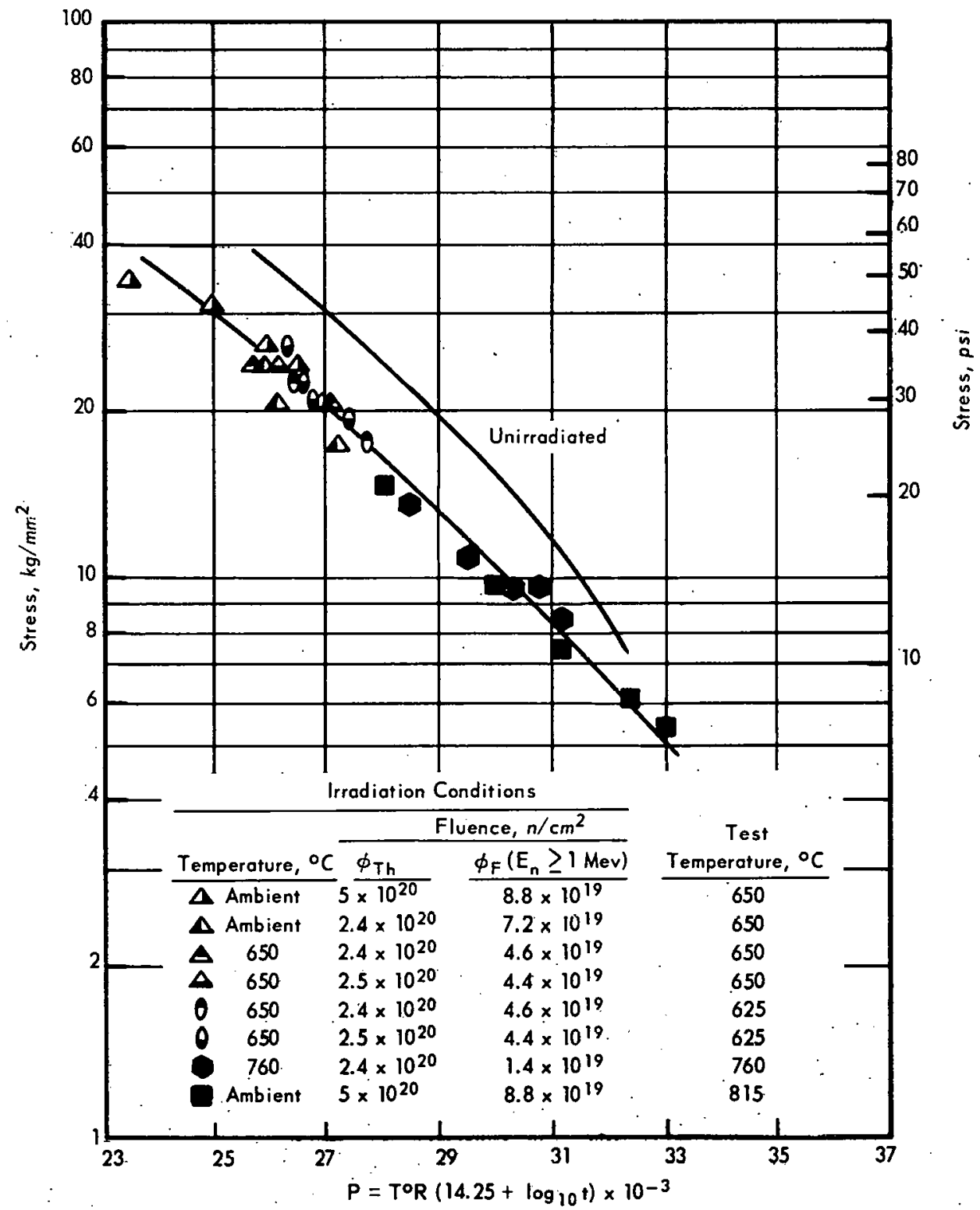

Fig. 7.6 - Variation of Larson-Miller parameter, $P$, as a function of stress for unirradioted and irradiated Hostelloy $N$ 


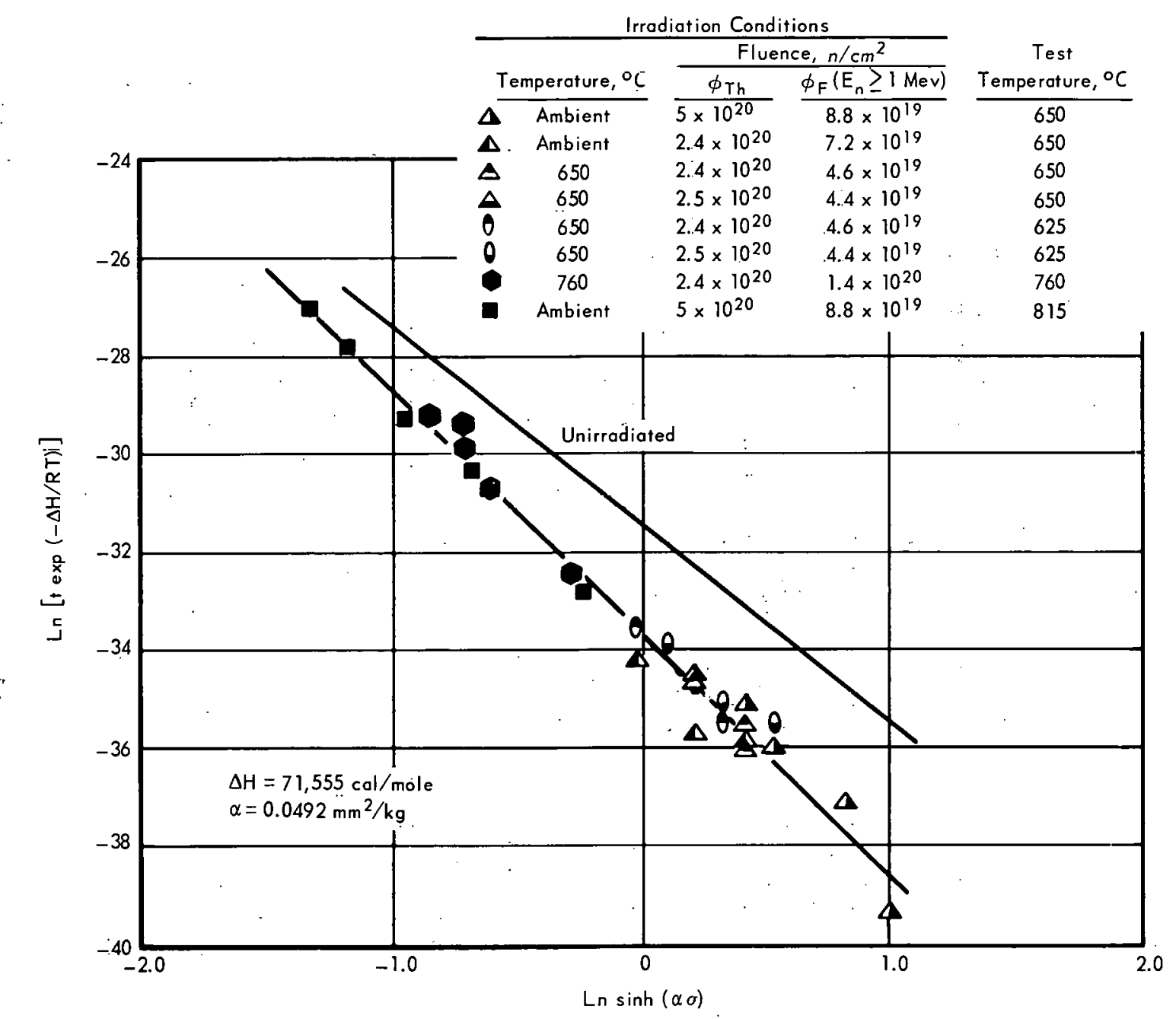

Fig. 7.7-Variation of "Dorn Temperature-Compensated Time" as a function of sinh $(\alpha \sigma)$ for unirradiated and irradiated Hastelloy $\mathrm{N}$ (Gorafalo relationship)

\section{Effects of Pre- and Post-Irradiation Annealing}

To determine the effect of annealing (aging) at $870^{\circ} \mathrm{C}$ for 4 hours on the post-irradiation properties, several specimens were irradiated at $650^{\circ} \mathrm{C}$ and $760^{\circ} \mathrm{C}$ in the annealed condition. The results of the $650^{\circ} \mathrm{C}$ tests (Figure 7.9) show that the pre-annealed material has considerably improved properties compared to material that was solutioned prior to irradiation. However, Figure 7.9 also shows that the control curve for the unirradiated annealed material also indicates improved rupture life. The net effect is, therefore, to merely raise the base line for reference since the ratio of unirradiated to irradiated data is essentially the same for both conditions. Figure 7.2 shows that pre-irradiation annealing had no effect on the specimens irradiated and tested at $760^{\circ} \mathrm{C}$.

Post-irradiation annealing prior to testing at $650^{\circ} \mathrm{C}$ resulted in very slight $(\sim 15 \%)$ improvement in properties compared to those of the as-irradiated material. ${ }^{5}$ Post-irradiation annealing prior to $815^{\circ} \mathrm{C}$ tests resulted in a reduction in rupture life compared to that of the as-irradiated material. ${ }^{5}$

5"Fifth Annual Report - High-Temperature Materials Programs, Part A," GE-NMPO, GEMP-400A, February 28, 1966, pp. 172,-1.73. 


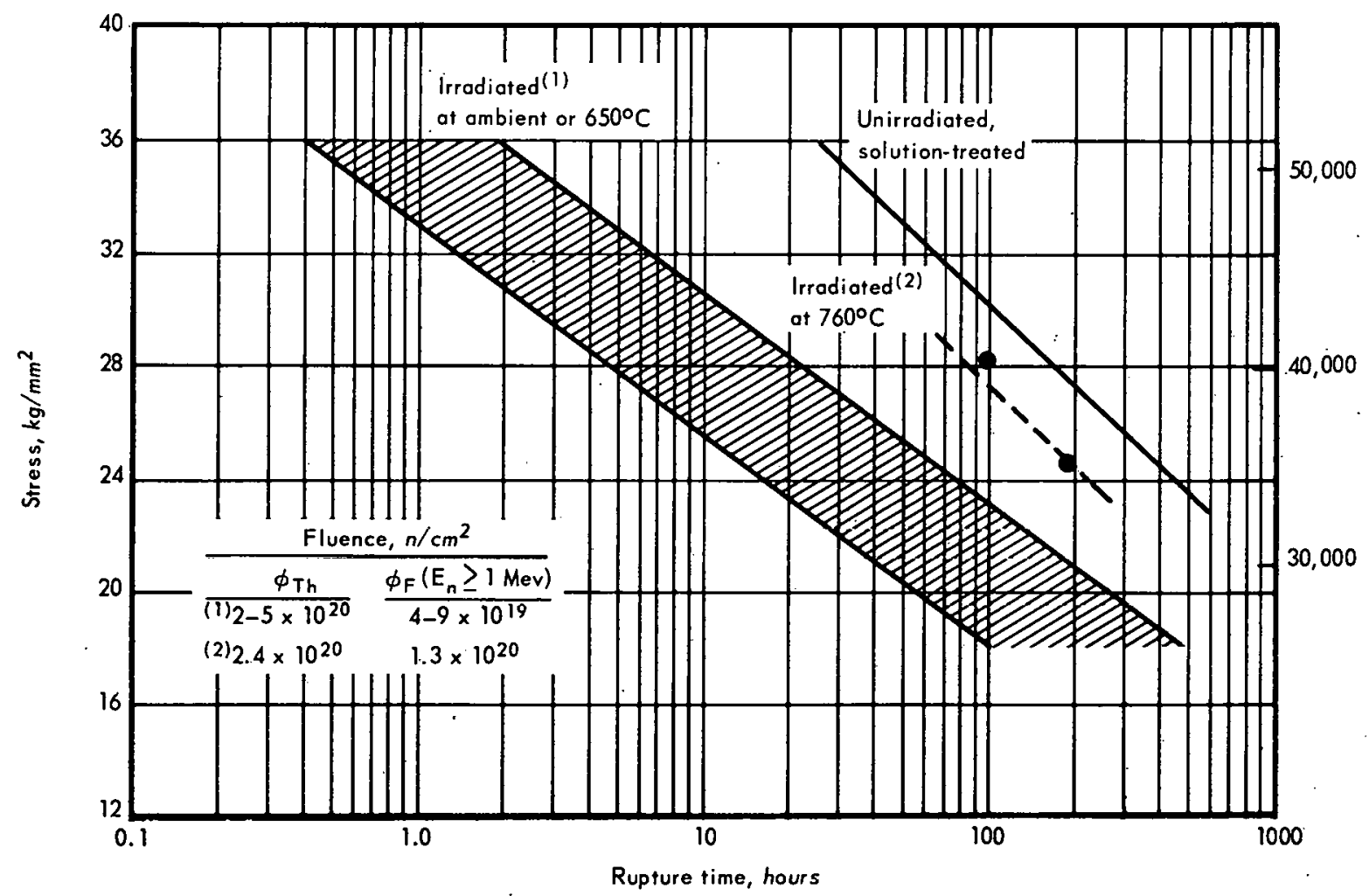

$\bar{n}$
2
$\bar{s}$
$\bar{n}$
$\bar{n}$

Fig. 7.8 - Effect of $760^{\circ} \mathrm{C}$ irradiation on $650^{\circ} \mathrm{C}$ stress-rupture properties of solution-treated Hastelloy $\mathrm{N}$

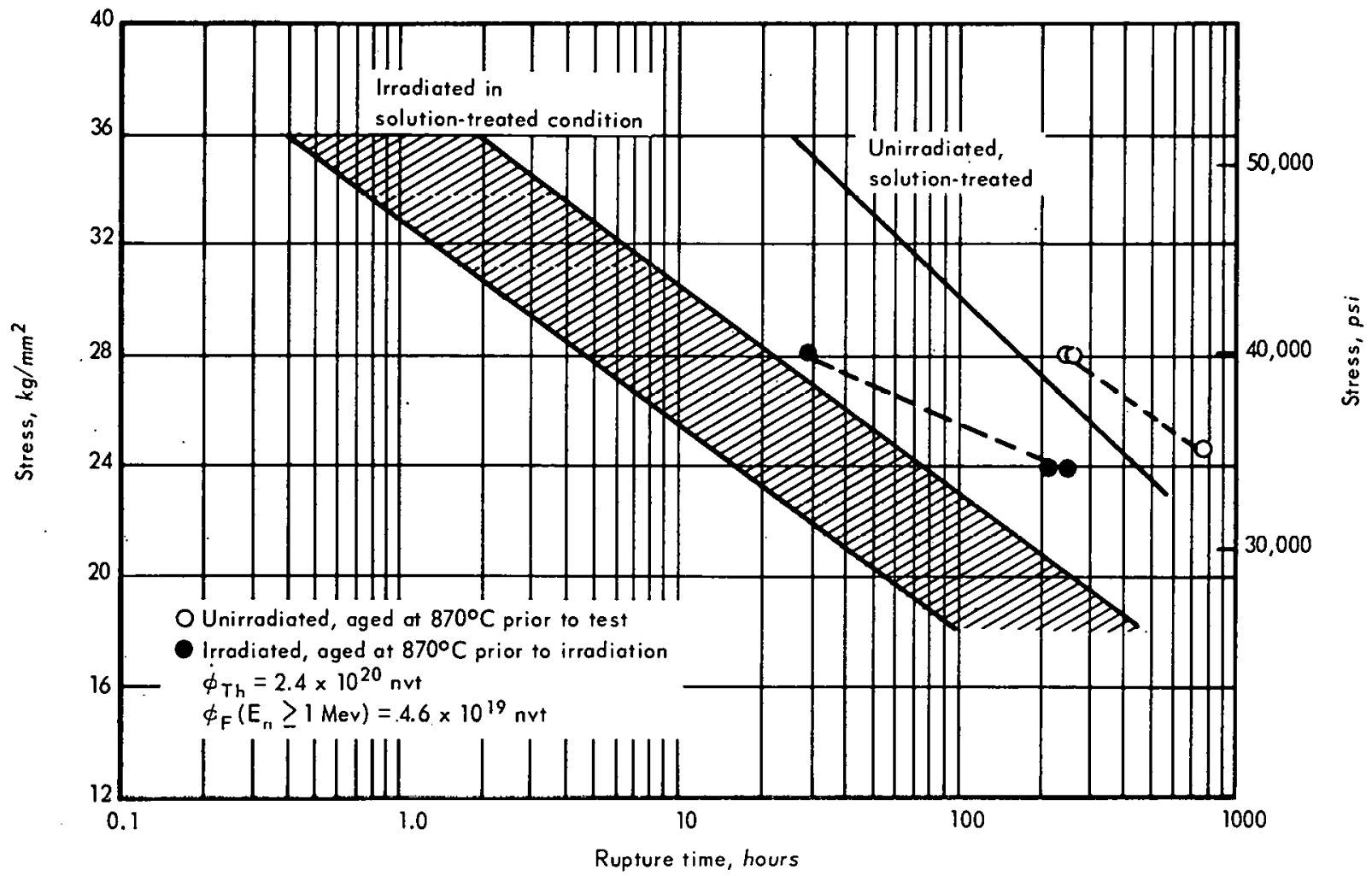

Fig. 7.9 - Effect of aging of $870^{\circ} \mathrm{C}$ on the $650^{\circ} \mathrm{C}$ stress-rupture properties of unirradiated and irradiated Hastelloy $\mathrm{N}$ 


\section{Effect of Radiation on Rupture Ductility}

As discussed above, the loss in rupture life due to irradiation appears to be almost entirely recoverable under proper conditions. On the other hand, no heat treatment has yet resulted in a significant recovery of rupture ductility. The general behavior of rupture ductility with heat treatment, annealing, and irradiation is summarized in Table 7.2.

\section{Weldments}

An effort was made to determine the effect of radiation at $650^{\circ} \mathrm{C}$ on the $650^{\circ} \mathrm{C}$ creep-rupture properties of as-welded plate. The results, Figure 7.10, show that welding itself causes a significant drop in rupture life and that subsequent irradiation causes no further reduction. Elongation of both the unirradiated and irradiated weldment specimens ranged from 1 to 2 percent.

TABLE 7.2

EFFECT OF IRRADIATION ON RUPTURE DUCTILITY OF HASTELLOY N

\begin{tabular}{ll}
\hline Condition & \multicolumn{1}{c}{ Elongation } \\
\hline Solution treatnient (control) & -7 to $10 \%$ at $650^{\circ} \mathrm{C}$ \\
& 25 to $40 \%$ at $760^{\circ} \mathrm{C}$ \\
& $12 \%$ at $815^{\circ} \mathrm{C}$
\end{tabular}

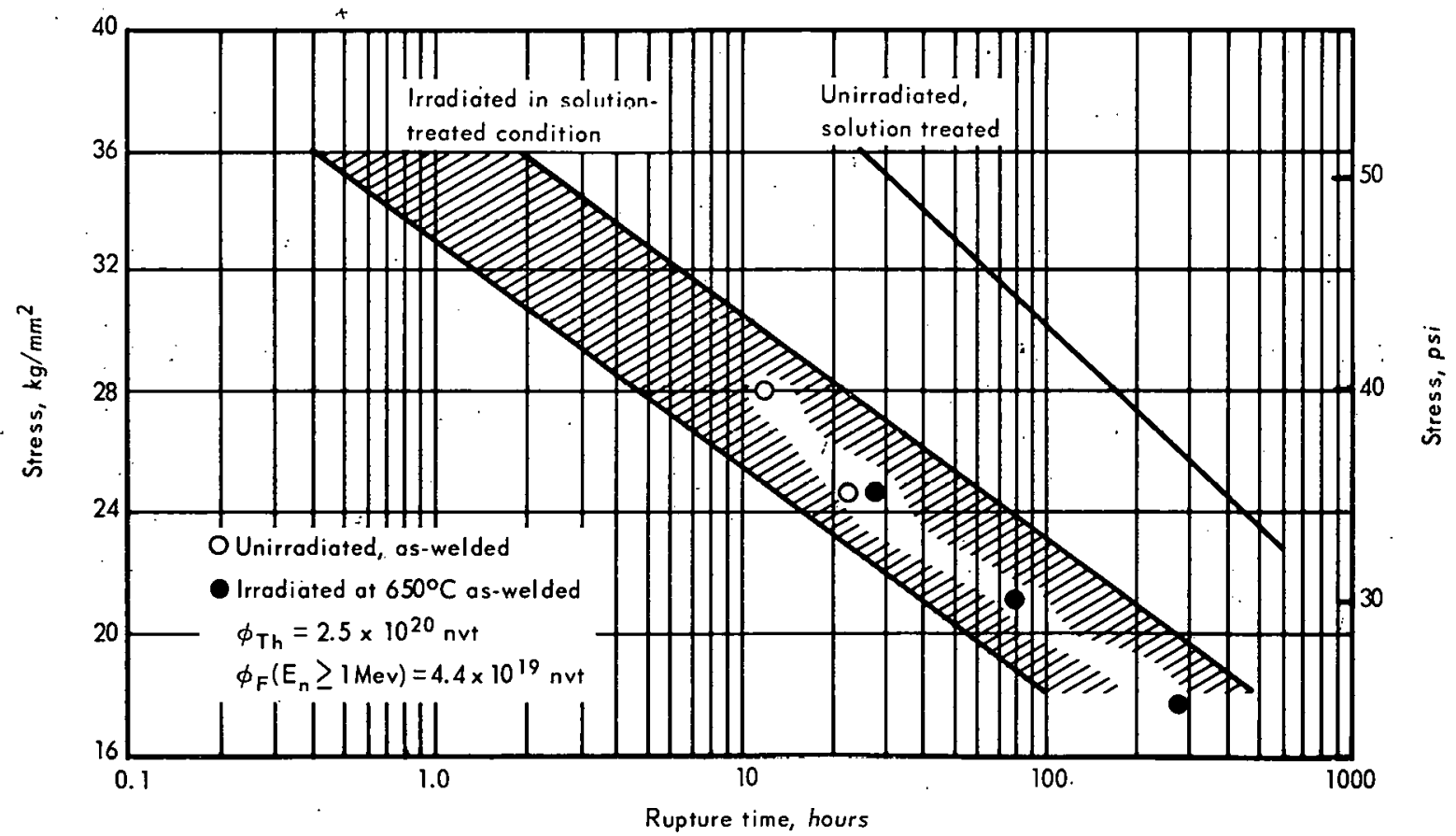

t. Fig. 7.10-Stress-rupture properties of welded Hastelloy $\mathrm{N}$ at $650^{\circ} \mathrm{C}$ 
Metallographic Study (J. P. Smith, R. C. Rau)

Metallographic techniques were employed to assess more directly the effects of the various heat treatments described above, especially the 4-hour anneal at $870^{\circ} \mathrm{C}$. As discussed previously, ${ }^{6}$ the annealing treatment tends to produce a predominantly grain boundary precipitate; however, a significant amount of matrix precipitate is also observed. Because these particles have a rather strong effect on the creep-rupture properties, a more thorough study of the morphology and identity of the particles was undertaken. Techniques utilized were electrolytic digestion, carbon extraction replication, X-ray diffraction and fluorescence, and electron diffraction? The extraction replicas were particularly fruitful, and appear to provide a very useful means for future examination of microstructures. The results of these studies showed only the presence of $(\mathrm{Mo}, \mathrm{Ni})_{6} \mathrm{C}$ precipitate. Typical extraction replicas from annealed specimens are shown in Figure 7.11. Note the presence of at least three types of prccipitates - particulate, blocky, and cellular. Selected area diffraction proved that all three were of the $\mathrm{M}_{6} \mathrm{C}$ type with a lattice parameter of $11.0 \AA$. Extraction replicas of the solutioned material showed the presence of the blocky-type precipitate; it too was identified as $\mathrm{M}_{6} \mathrm{C}$ with an $11.0 \AA$ lattice parameter. The cellular precipitate in the annealed specimens is quite unusual and interesting since the annealing treatment doubles the ductility at all test temperatures (see Table 7.2). One possible explanation is that, although a fairly large quantity was observed, its deleterious effects are masked by the beneficial effects discussed below. The reason for the ductilizing effects of the precipitate may be that the $(\mathrm{Mo}, \mathrm{Ni})_{6} \mathrm{C}$ depletes adjacent matrix areas of the hardening agents, making these depleted zones ductile enough for rather large plastic strains before failure.

A final observation with regard to the morphology is that the precipitate observed on the incoherent twin boundaries ${ }^{6}$ is almost always of the cellular type.

Metallographic analysis of fractured areas was undertaken in an effort to develop a better understanding of the effects of the 4 -hour anneal at $870^{\circ} \mathrm{C}$ on the rupture properties. Fractures of unirradiated specimens tested at $650^{\circ} \mathrm{C}$ were observed to be transgranular, whereas intergranular cracking was observed at $815^{\circ} \mathrm{C}$ (Figure 7.12). On comparing the millannealed versus the $870^{\circ} \mathrm{C}$ aged for the $650^{\circ} \mathrm{C}$ test (Figures $7.12 \mathrm{a}$ and b) more grain deformation is observed in the annealed material consistent with the softening effect discussed in the previous paragraph. Another interesting feature of these photographs is the significance of the large blocky carbides in initiating fractures; a high percentage of these particles have either started cracks or are separated from the matrix. The direction of crack propagation in the vicinity of the carbides is always perpendicular to the stress axis.

TESTING OF A-286 WITH VARIABLE B ${ }^{10}$ CONTENT (A. J. Lovell, J. Moteff)

Creep-Rupture

A special split heat of A-286 containing three different natural boron levels was fabricated $^{8}$ to cietermine the role of boron on post-irradiation creep-rupture properties. The natural boron contents were $0.0010,0.0040$, and 0.0100 weight percent. Pertinent results from a detailed discussion ${ }^{9}$ are shown in Figure 7.13. The general indications are that the helium formation from the $\mathrm{B}^{10}(\mathrm{n}, \alpha) \mathrm{Li}$ reaction is not directly the cause of the

${ }^{6}$ GEMP-400A, pp. 176-177.

7 “'High-Temperature Materials Program Progress Report No. 61," GE-NMPO, GEMP-61, September 30, 1966, pp. $128-131$.

8“"Third Annual Report - High-Temperature Materials and Reactor Component Development Programs, Volume IMaterials,"' GE-NMPO, GEMP-270A, p. 78.

${ }^{9}$ A. J. Lovell, J. Moteff, F. Kingsbury, and J. P. Smith, "The Influence of Boron on the Creep-Rupture Properties of a Neutron Irradiated Precipitation Hardening Iron Base Alloy," to be published in Proceedings of 1966 ASTM Symposium on Irradiation Effects to Metals, Atlantic City, New Jersey. 


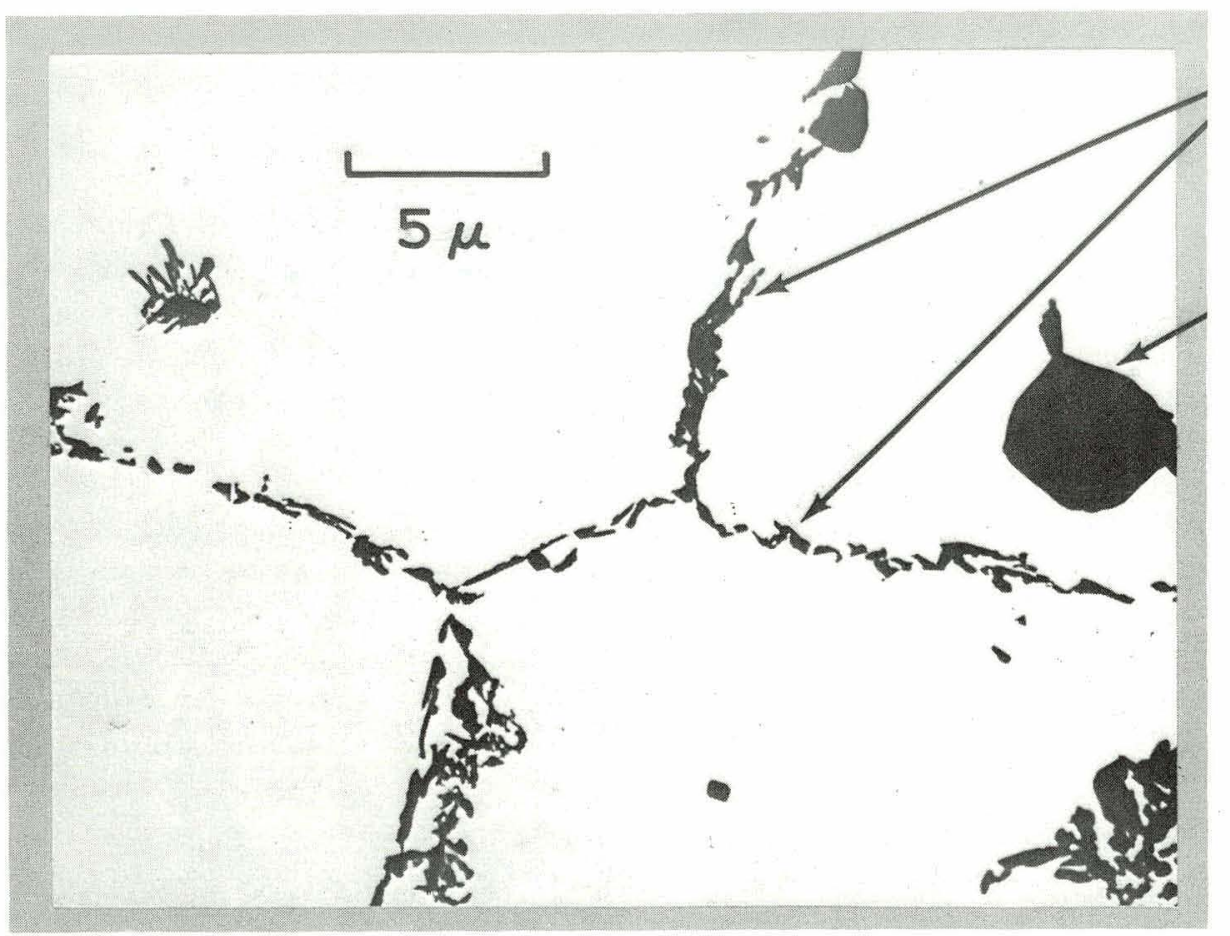

Grain boundary

Blocky particle

a. Fine grain boundary particles and large blocky particles (Neg. 987E)

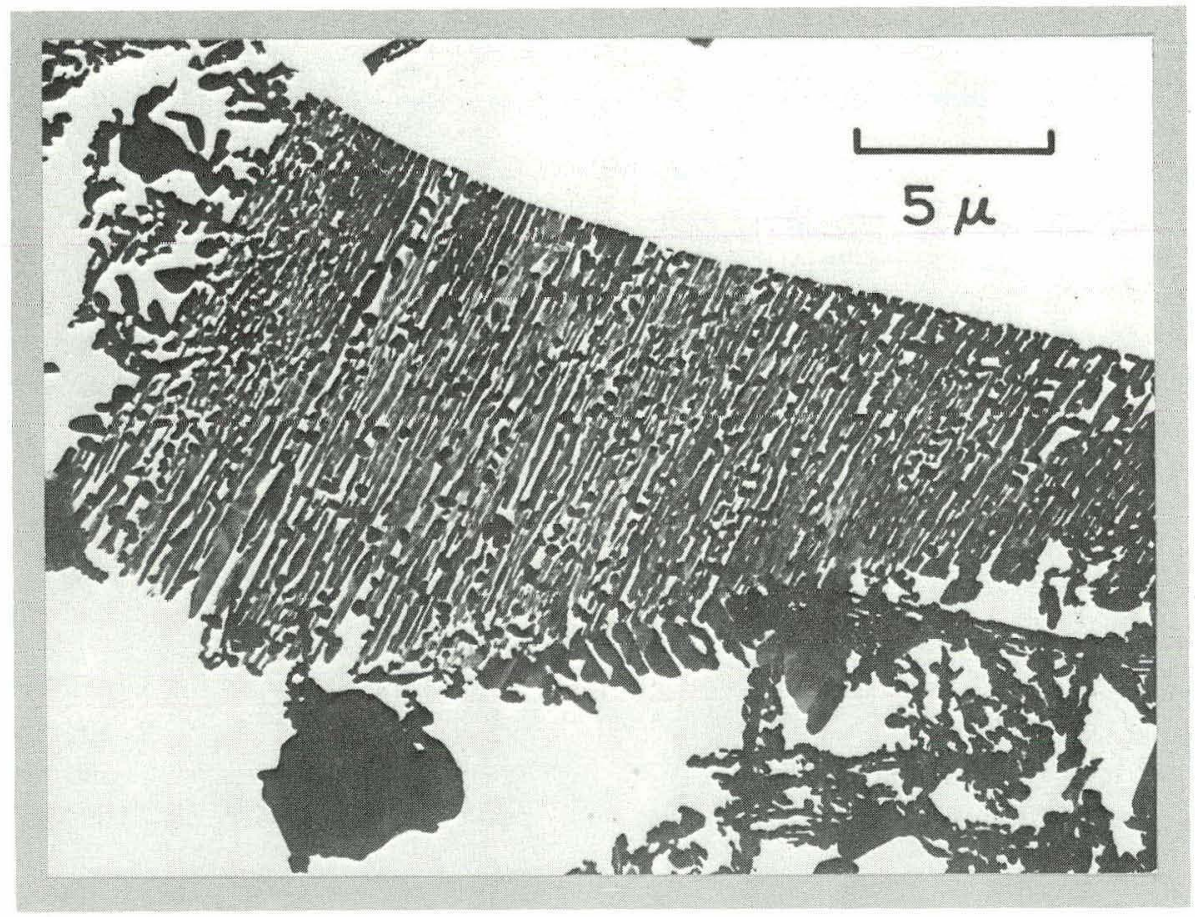

b. Cellular grain boundary precipitate (Neg. 987A)

Fig. 7.11 - Electron micrographs showing typical $\mathrm{M}_{6} \mathrm{C}$ morphology in Hastelloy $\mathrm{N}$ aged 4 hours at $870^{\circ} \mathrm{C}(\mathrm{HCl}$ - alcohol extraction replica) (4000X) 


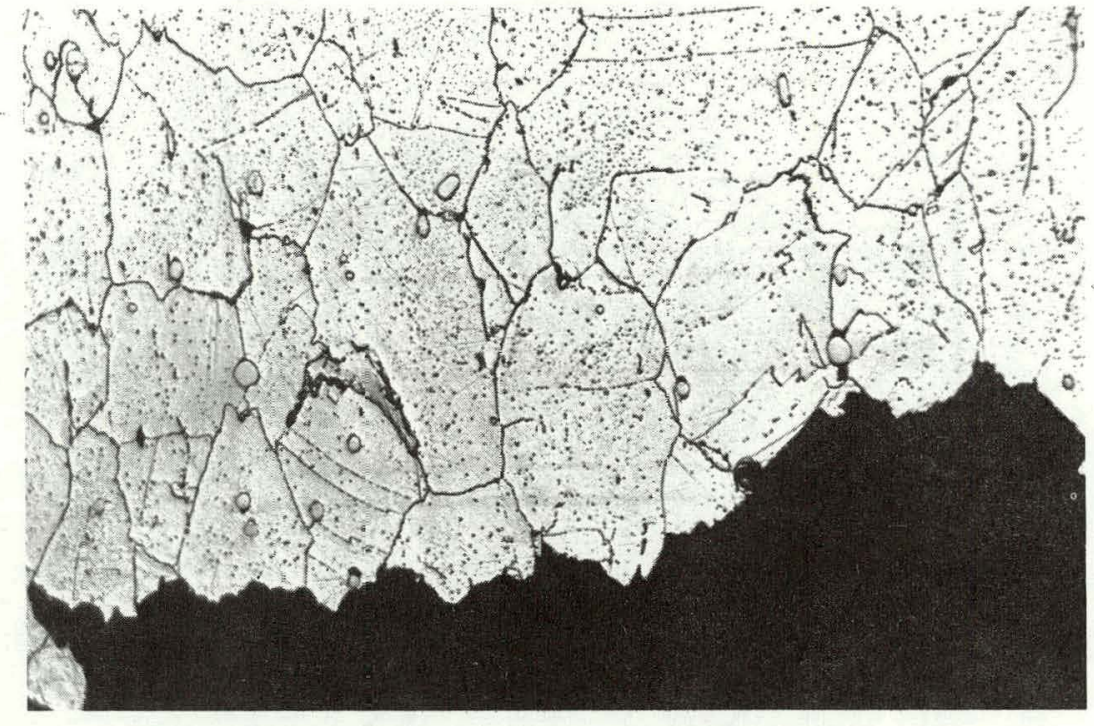

a. $650^{\circ} \mathrm{C}$ frocture

Mill-annealed

(Neg.R-1706)

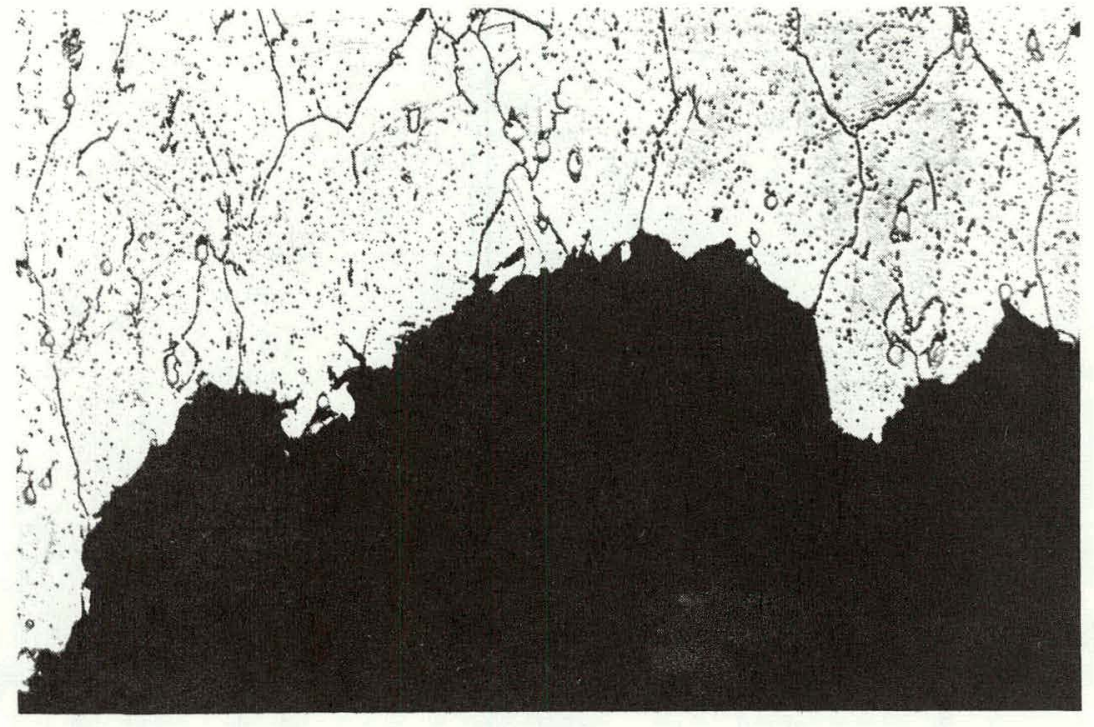

b. $650^{\circ} \mathrm{C}$ fracture

Mill-annealed plus $870^{\circ} \mathrm{C}$ for 4 hours (Neg. R-1711)

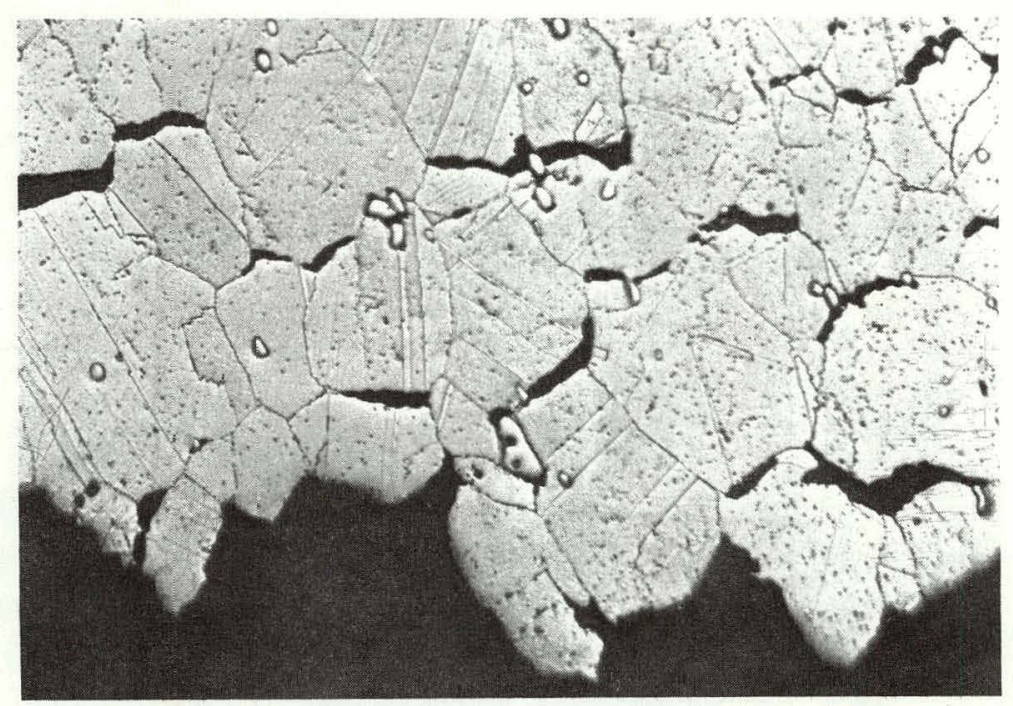

c. $815^{\circ} \mathrm{C}$ fracture

Mill annealed

(Neg.R-1514)

Fig. 7.12 - Fracture appearance of unirradiated Hastelloy $\mathrm{N}$ stress-rupture specimens (Marbles etchant, 250X) 


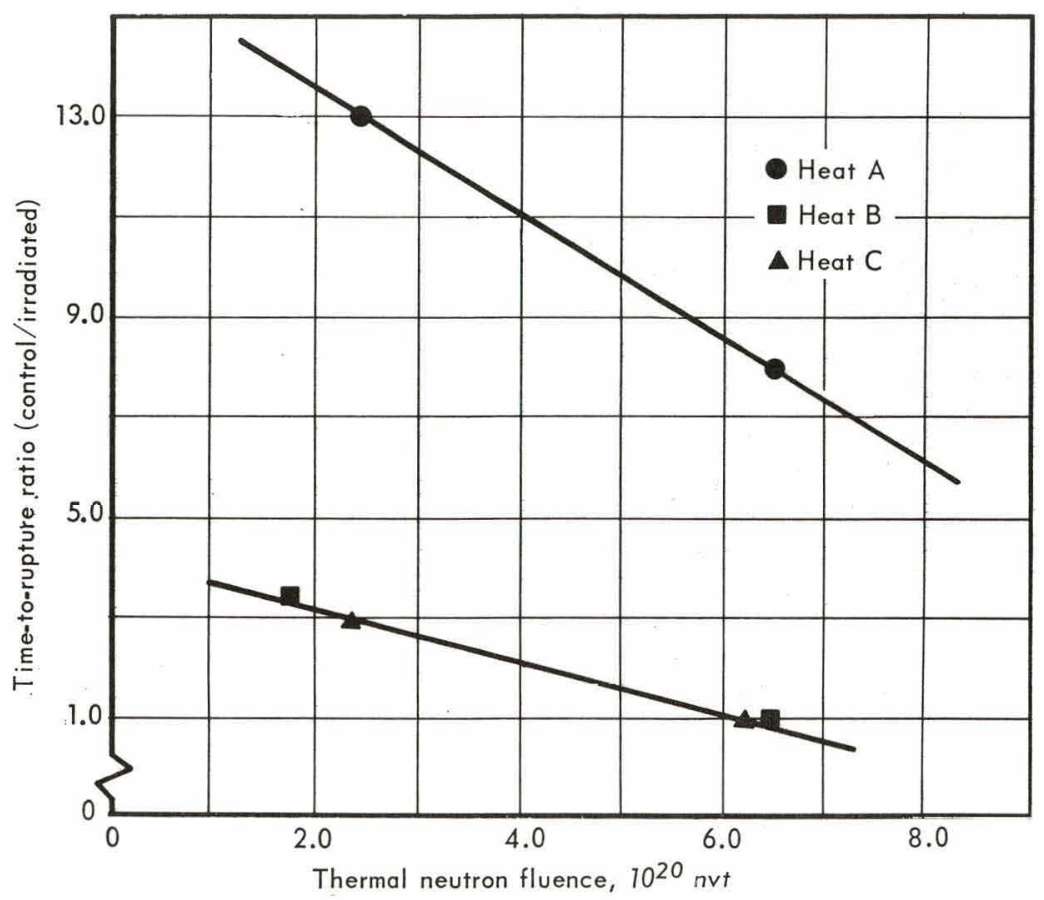

a. As a function of thermal neutron fluence level

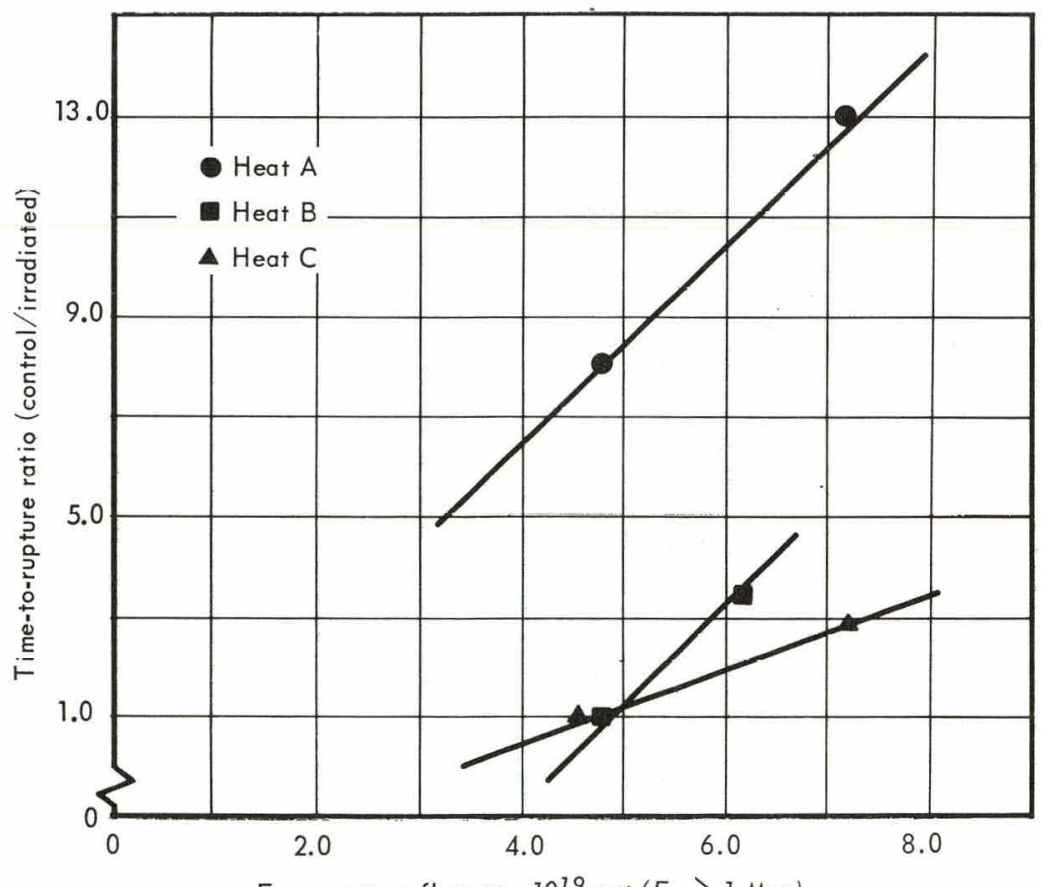

Fast neutron fluence, $10^{19} \mathrm{nvt}\left(E_{n} \geq 1 \mathrm{Mev}\right)$

b. As a function of fast neutron fluence level

Fig. 7.13-Time-to-rupture ratio of the control to the irradiated A-286 tested at $650^{\circ} \mathrm{C}\left(\sigma=42.19 \mathrm{~kg} / \mathrm{mm}^{2}\right)$ 


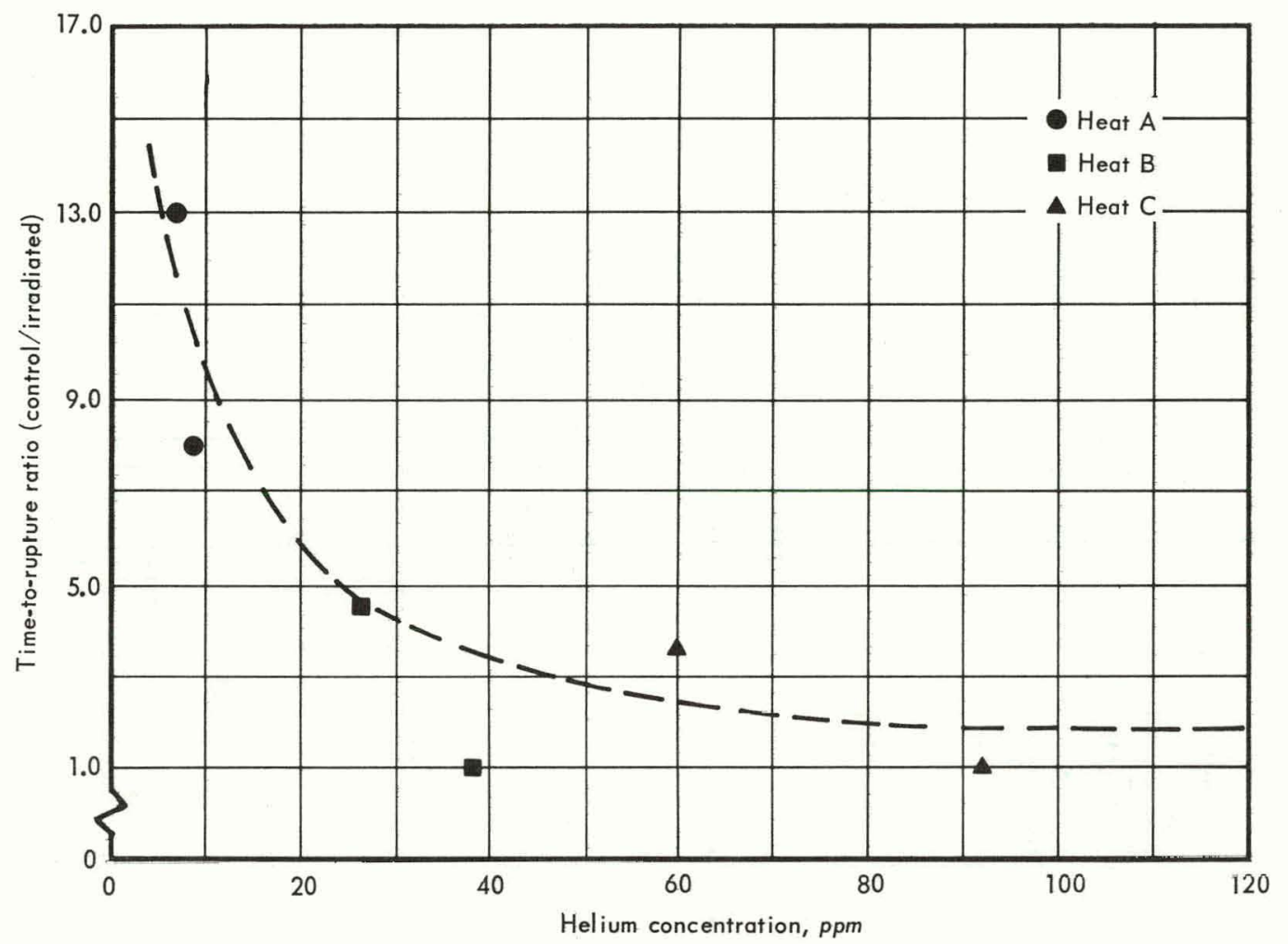

c. As a function of helium concentration

Fig. 7.13 (Cont.) - Time-to-rupture ratio of the control to the irradiated A-286 tested at $650^{\circ} \mathrm{C}\left(\sigma=42.19 \mathrm{~kg} / \mathrm{mm}^{2}\right)$

loss of rupture life. However, it probably contributes indirectly by acting as an effective pinning point for mobile dislocations. Thus, by preventing the normal movement to the grain boundaries within each grain, the tendency for grain boundary sliding is reduced and embrittlement results.

Transmission Microscopy (D. A. Woodford, ${ }^{*}$ J. P. Smith, J. Moteff)

Transmission electron microscopy work initiated last year was extended to more fully determine the role of helium in the above discussed A-286 specimens. Specimens cut from the unstressed buttonhead portion of irradiated samples of the low- and high-boron heat were aged at $760^{\circ}, 845^{\circ}$, and $955^{\circ} \mathrm{C}$ for 3 hours to grow helium bubbles large enough to be readily studied in the electron microscope. All six specimens showed the presence of well-defined helium bubbles whose average diameter increased as the annealing temperature was increased. Also, the high-boron specimen yielded a larger bubble size than the corresponding low-boron specimen for a given heat treatment. The histograms in Figure 7.14 summarize these results. No bubbles were observed in unirradiated control specimens given heat treatments simultaneously with the irradiated specimens.

A study of numerous photomicrographs of the annealed specimens yielded these conclusions:

The helium bubbles tend to form preferentially on dislocations rather than at the gamma prime $\left(\gamma^{\prime}\right)$ particle - matrix interfaces. This is illustrated in Figures $7.15 \mathrm{a}$ and b. Figure 7.15a shows that virtually all the bubbles lie on dislocation lines ( $\gamma^{\circ}$ particles, being out of contrast in this picture, are not visible). Figure $7.15 \mathrm{~b}$ shows the 


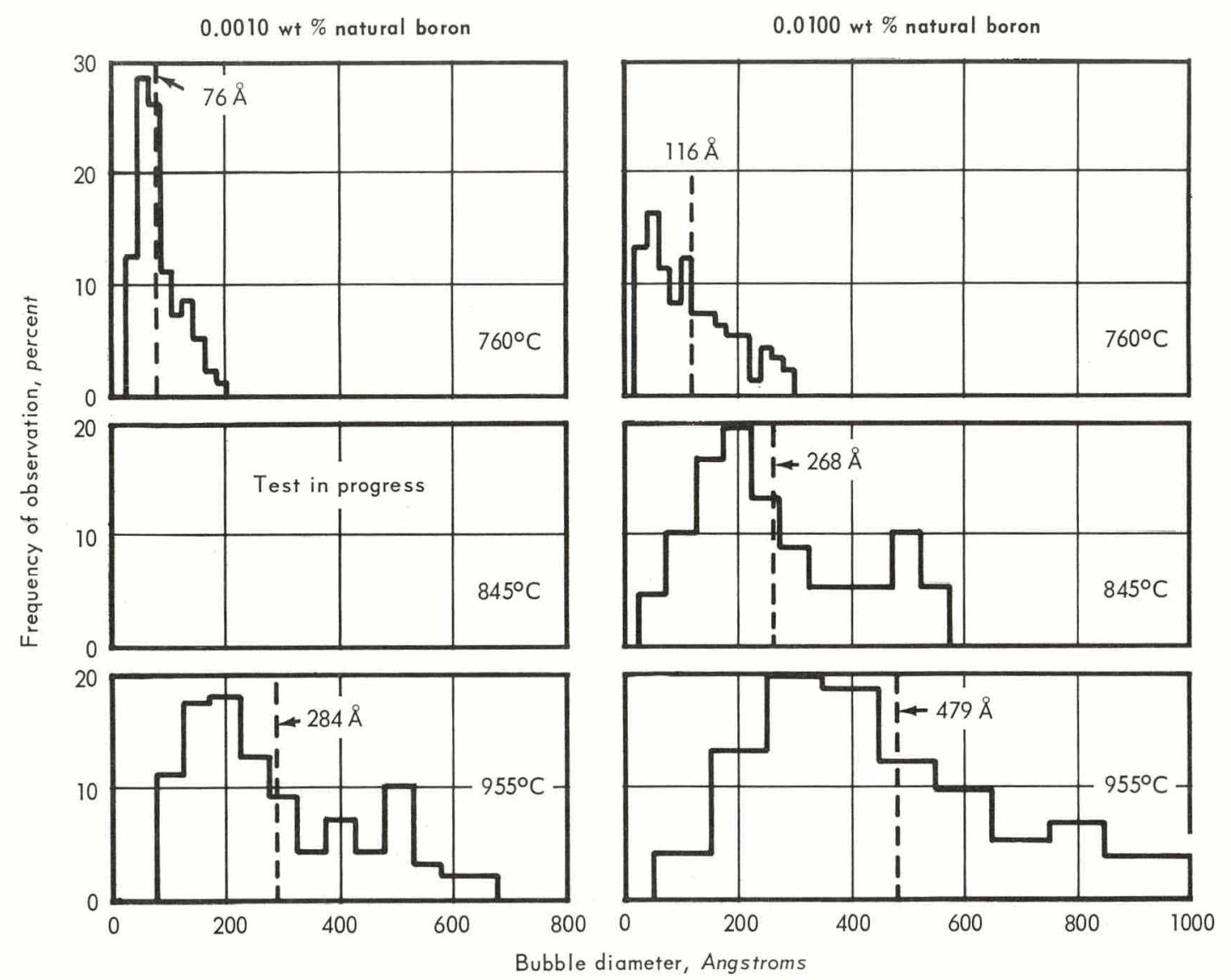

Fig. 7.14 - Variation of helium bubble diameter with boron concentration and postirradiation annealing temperature in unstressed irradiated A-286

presence of $\gamma^{\prime}$ strain fields as well as dislocations (the $\gamma^{\prime}$ itself is too small to be visible). Note that, although some small bubbles are present at the $\gamma^{\prime}$ strain fields, most of them (and virtually all the largest ones) lie on the dislocation lines.

The preference of dislocation sites for bubble formation is not surprising since the effective cross section exposed to a recoiling helium atom traveling through the matrix is much larger for a dislocation line than for a $\gamma^{\prime}$ particle. Also, a helium atom has a much better diffusion path when attached to a dislocation line. Figure $7.15 \mathrm{~b}$ confirms this condition, showing that, in general, the bubbles associated with $\gamma^{\prime}$ particles are much smaller than the bubbles on the dislocations.

Another significant conclusion is that the helium does not tend to migrate to the grain boundaries, possibly because the elevated-temperature heat treatment was performed on unstressed samples. Heat treatment of samples from stressed specimens is currently underway. This is illustrated in Figure $7.15 \mathrm{c}$ which shows a high density of bubbles near the boundary but only a few on the boundary itself. Note again that all the bubbles are associated with dislocation lines.

The results discussed above tend to indicate that radiation-induced embrittlement may be caused by bubbles pinning dislocations, especially in areas adjacent to grain boundaries. This prevents the dislocations from moving to the boundaries - a necessary condition for grain boundary sliding. 


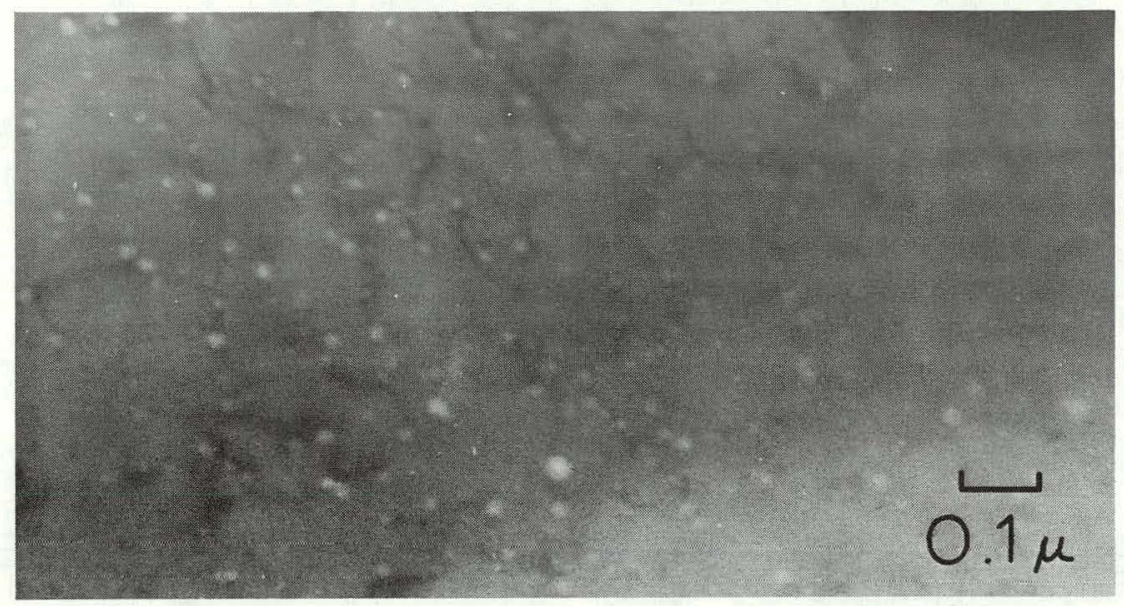

a. Bubbles on dislocations

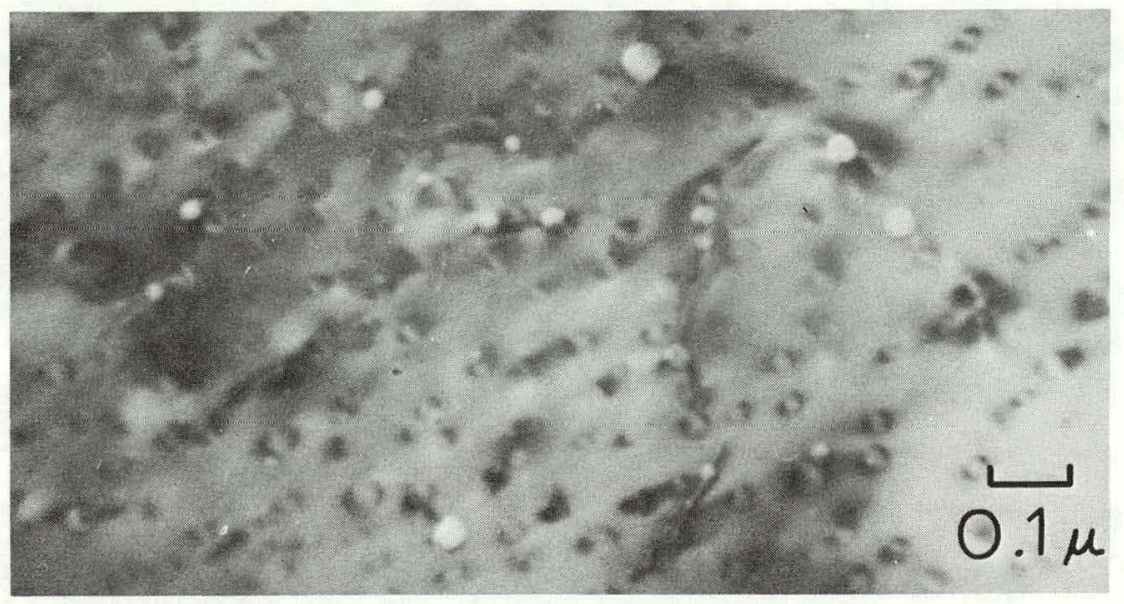

b. Bubbles on dislocations and gamma prime particles

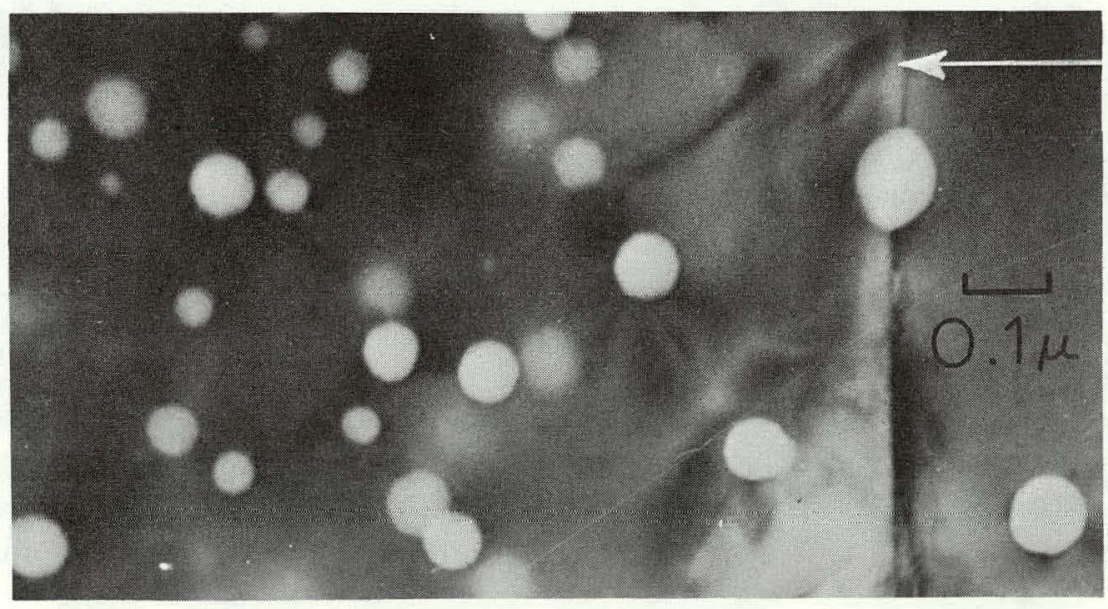

Grain

boundary

c. Bubbles on dislocations and grain boundaries

Fig. 7.15-Transmission electron micrographs showing precipitation of helium bubbles in irradiated A-286 
Another interesting observation was made on the high-boron specimen annealed at $955^{\circ} \mathrm{C}$, illustrated in Figure 7.16, which shows an impurity particle (TiC) surrounded by a "shell" of bubbles. The radius of this shell and of others that have been observed is approximately 2 to 3 microns. The normal range of an $\alpha$ particle in an iron matrix is approximately 4 microns..$^{10}$ It appears that a fair amount of boron may be soluble in the TiC particles or at the particle - matrix interface and that these particles may be surrounded by a sphere of helium atoms.

Another possible explanation for this shell may be that a strain field exists around the impurity particle in such a manner that dislocations present in or about this field are effective sinks for mobile helium atoms.

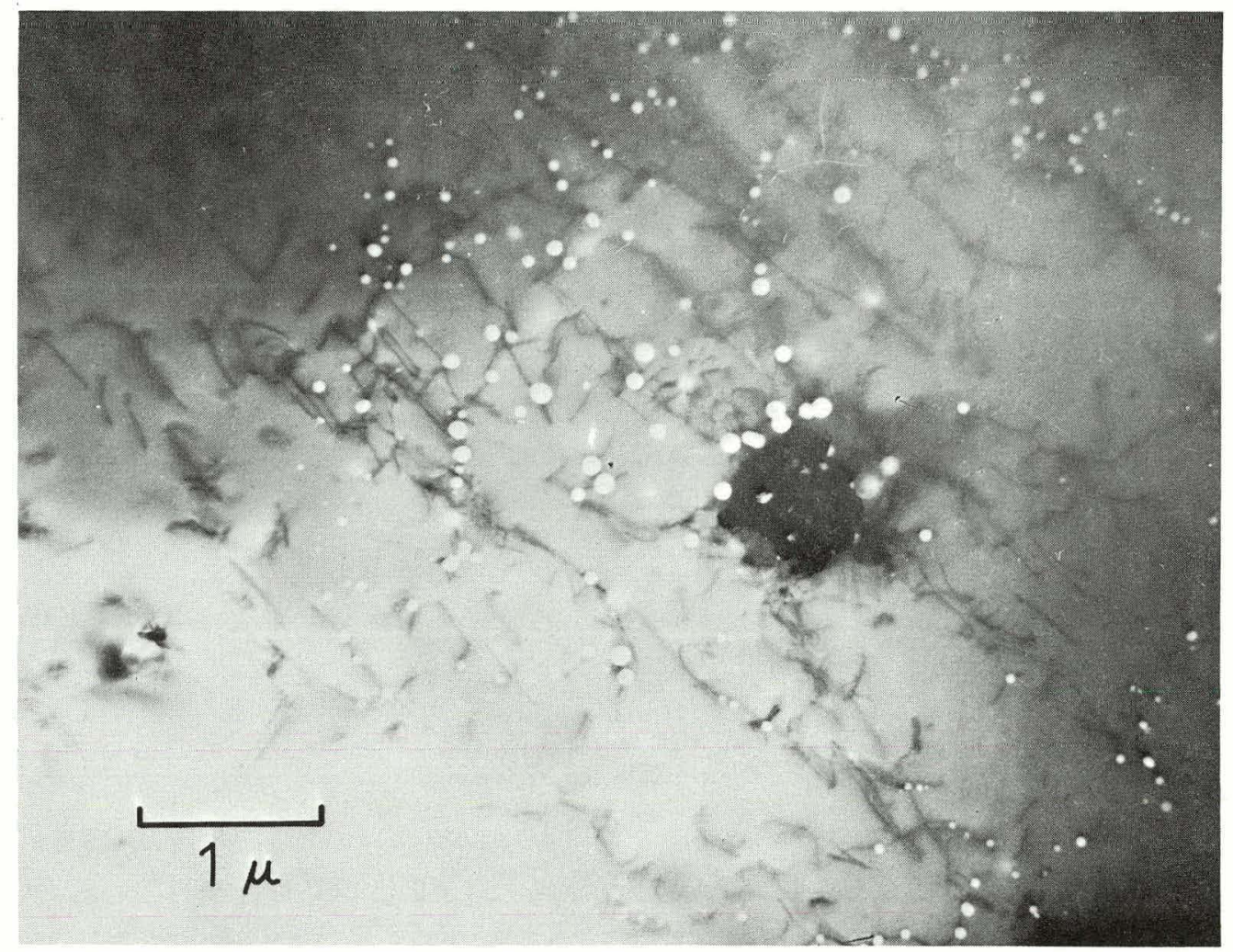

Fig. 7.16 - Shell of helium bubbles surrounding an impurity particle in irradiated A-286. Shell radius $\sim 2.5$ microns.

\section{CREEP-RUPTURE TESTING OF HASTELLOY R-235 WITH VARIABLE B 10 CONTENT}

The first series of creep-rupture tests was completed on the special split heat of Hastelloy R-235 described previously. ${ }^{11}, 12$ This heat consisted of four ingots containing different boron isotopes: (1) $2 \mathrm{ppm}$ natural boron, (2) $50 \mathrm{ppm}$ boron enriched to $98 \% \mathrm{~B}^{10}$, (3) $50 \mathrm{ppm}$ boron enriched to $98 \% \mathrm{~B}^{11}$, and (4) $50 \mathrm{ppm}$ natural $\mathrm{B}$. Specimens from each of

${ }^{10} \mathrm{~J}$. Moteff, F. Robertshaw, and F. Kingsbury, "Effects of Neutron Irradiation on the Stress-Rupture Properties of High-Temperature Precipitation Hardening Alloys," Journal of Nuclear Materials, Vol. 17, 1965, pp. 245-258.

11،"High-Temperature Materials Program Progress Report No. 58, Part A," GE-NMPO, GEMP-58A, Apri1 29, 1966, pp. $34-35$.

${ }^{12}$ GEMP-63, p. 104. 
the four ingots in both the unirradiated and irradiated ambient temperature conditions were creep-rupture tested at $14 \mathrm{~kg} / \mathrm{mm}^{2}$ at $870^{\circ} \mathrm{C}$. The results are plotted in Figure 7.17 and show:

1. The unirradiated materials containing $50 \mathrm{ppm}$ boron all exhibit essentially identical rupture properties.

2. Boron enhances the rupture properties of the unirradiated alloy and appears to be a necessary additive for obtaining optimum properties.

3. The loss in rupture life following irradiation is clearly related to $\mathrm{B}^{10}$ concentration: the more $B^{10}$ present, the larger the loss in rupture life.

4. Both the low-boron and the $\mathrm{B}^{11}$-enriched materials contain essentially the same amount of $\mathrm{B}^{10}(\sim 1 \mathrm{ppm})$ and each lost approximately 50 percent of its rupture life due to radiation.

Further tests are being performed at other stress levels; meanwhile, the above specimens will be examined metallographically and by means of transmission electron microscopy.

\section{Fe-Cr-Al-Y ALLOYS}

A cooperative effort between GE-NMPO and Harwell to determine the effects of radiation on the properties of $\mathrm{Fe}-\mathrm{Cr}-\mathrm{Al}-\mathrm{Y}$ alloys (primarily $\mathrm{Fe}-15 \mathrm{Cr}-4 \mathrm{Al}-1 \mathrm{Y}$ ) is producing promising results. Saruples of this material were also sent to ORNL and GE-NL to be used in radiation effects studies. To date, ORNL, Harwell, and GE-NL have performed tensile tests at various strain rates up to $1000^{\circ} \mathrm{C}$. GE-NMPO creep tests are underway but results are not yet available. Results on the $1541^{*}$ alloy at Harwell on ambient-ir radiated material show essentially no loss in ductility at temperatures up to about $800^{\circ} \mathrm{C}$, and only a small loss between $800^{\circ}$ and $1000^{\circ} \mathrm{C}$. There was only a slight loss in ductility in the $1540^{*}$ alloy at $600^{\circ} \mathrm{C}$ and $700^{\circ} \mathrm{C}$, whereas at $850^{\circ} \mathrm{C}$ the ductility of irradiated 1540 alloy was only about one-half that of the unirradiated material. Irradiation of the 1541 alloy at $700^{\circ} \mathrm{C}$ in the GETR by GE-NL showed no loss in ductility at $600^{\circ} \mathrm{C}$ and only a drop from 61 to 52 percent at $700^{\circ} \mathrm{C}$. Strain rate sensitivity tests on the 1541 alloy at ORNL ${ }^{13}$ after ambient temperature irradiation showed some signs of strain rate sensitivity at very high strain rates $(20 \% / \mathrm{min})$ in the $500^{\circ}$ to $870^{\circ} \mathrm{C}$ temperature range. In general, however, the ir radiated ductility did not vary significantly from unirradiated ductility for strain rates ranging from 0.2 to 20 percent per minute in the $500^{\circ}$ to $800^{\circ} \mathrm{C}$ temperature range.

\section{3 RESISTIVITY STUDIES (J. Moteff, J. P. Smith)}

\section{PRESSURE VESSEI STEELS}

A cooperative program was initiated with the Naval Research Laboratory in an effort to develop a better understanding of the nature of radiation embrittlement observed in ASTM-A302B and A350-LF3 pressure vessel steels. GE-NMPO resistivity specimens of A302B were irradiated simultaneously with NRL tensile and impact samples in a pressure vessel mockup. The correlation between change in resistivity and shift in ductile-to-brittle transition temperatures (DBTT) is shown in Figure 7.18. The impact data are from data reported by NRL. ${ }^{14}$ It should be pointed out that the fluence range involved $-4 \times 10^{17}$ to $3 \times 1018$ nvt $\left(E_{n} \geq 1 \mathrm{Mev}\right)$ - is below the normally accepted saturation level; it is not yet

*1541 is the designation for $\mathrm{Fe}-15 \mathrm{Cr}-4 \mathrm{Al}-1 \mathrm{Y} .1540$ is the same composition without yttrium.

13، Annual Progress Report for Period Ending June 30, 1966," Oak Ridge National Laboratory, Metals and Ceramics Division, ORNL-3970, Table 20.3, p. 116.

${ }^{14}$ C. 2 . Serpan and L. E. Steele, "Damaging Neutron Exposure Criteria for Evaluating the Embrittlement of Reactor Pressure Vessel Steels in Different Neutron Spectra," NRL-6415, July 28, 1966, p. 15. 

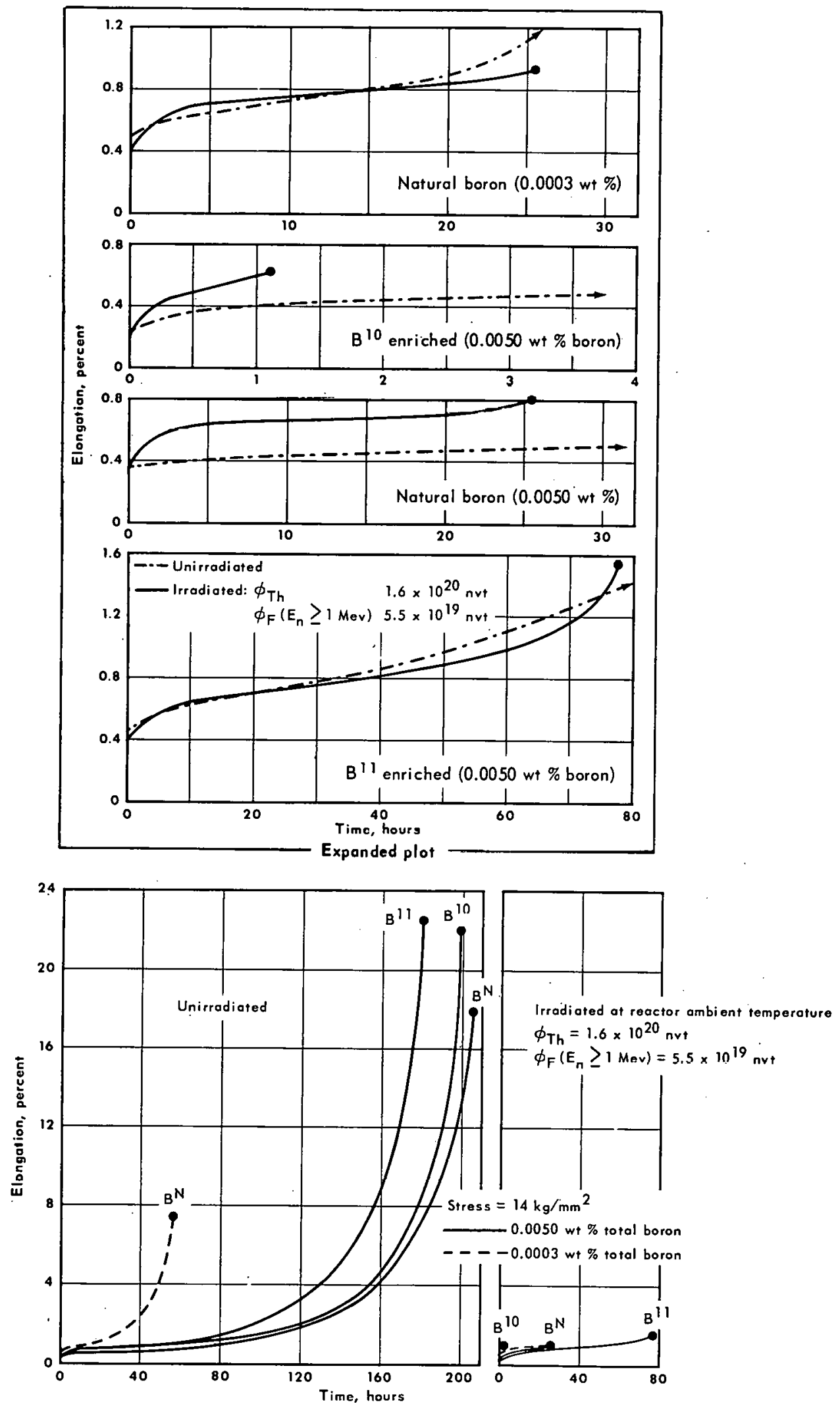

Fig. 7.17 - Effect of boron isotopic concentration on creep of irradiated Hastelloy R-235 at $870^{\circ} \mathrm{C}$ 


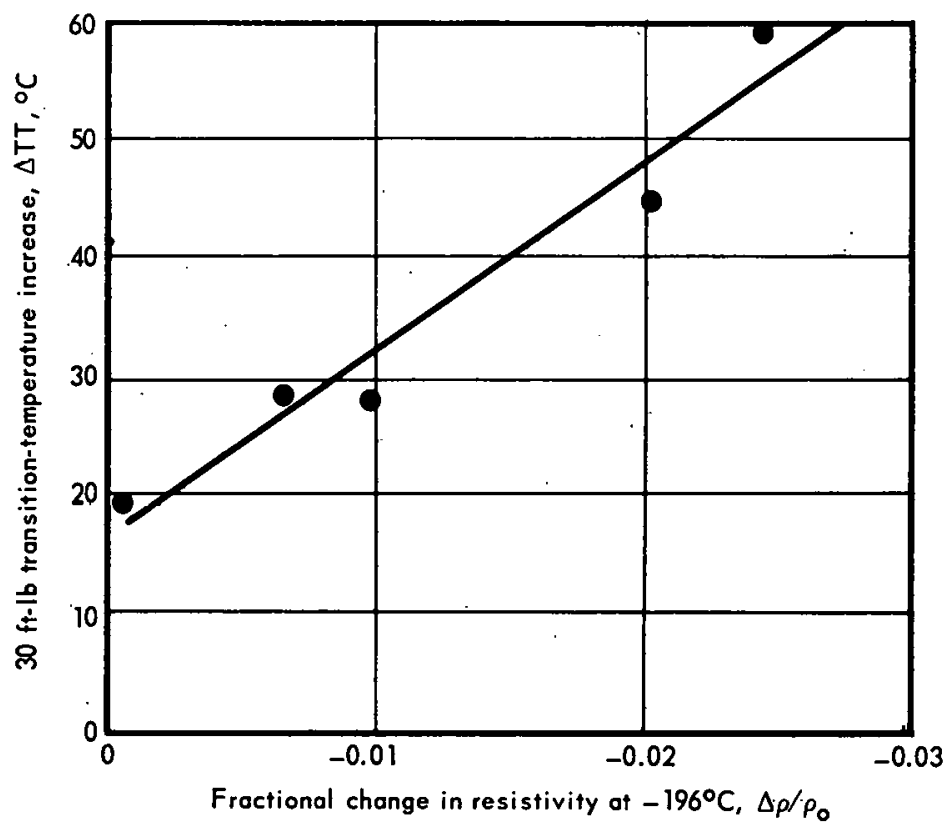

Fig. 7.18-Fractional change in resistivity versus transitiontemperature increase for irradiated ASTM-A302-B steel

known whether this apparently linear relationship between the two properties would persist into the neutron fluence range above saturation. The resistivity data of Figure 7.18 are plotted in Figure 7.19 as a function of distance within the pressure vessel mockup. Note that the fluence decreases with increasing thickness.

Resisitivity change as a function of time for A302B and A350-LF3 specimens irradiated simultancously in the ORR is shown in Figure 7.20. Note that the A350-LF3 is somewhat more susceptible to radiation damage than the A302B. This greater sensitivity has also been observed in impact tests performed at NRL. ${ }^{14}$

Two observations of particular significance can be derived from these data:

1. The resistivity changes are relatively small compared to the changes observed in pure metals irradiated to fluence levels within this same range (see section 2 of this report)

2. The resistivity is reduced by radiation: the greater the fluence level, the greater the reduction in resistivity. This is in marked contrast to the increases in resistivity normally experienced in irradiated unalloyed metals (also described in section 2 of this report).

No attempt should be made to correlate the A302B data from the two irradiation series (i. e., ORR and IRL) unless correction factors are applied for the completely different spectra in the two facilities as well as for the differences in ambient temperatures. Ambient temperature for these facilities can probably vary from $20^{\circ}$ to $100^{\circ} \mathrm{C}$ or more and occurs in a very sensitive temperature region for point defect (including impurity atom) migration; as discussed below, this is an extremely critical temperature range for iron and alloys of iron. 

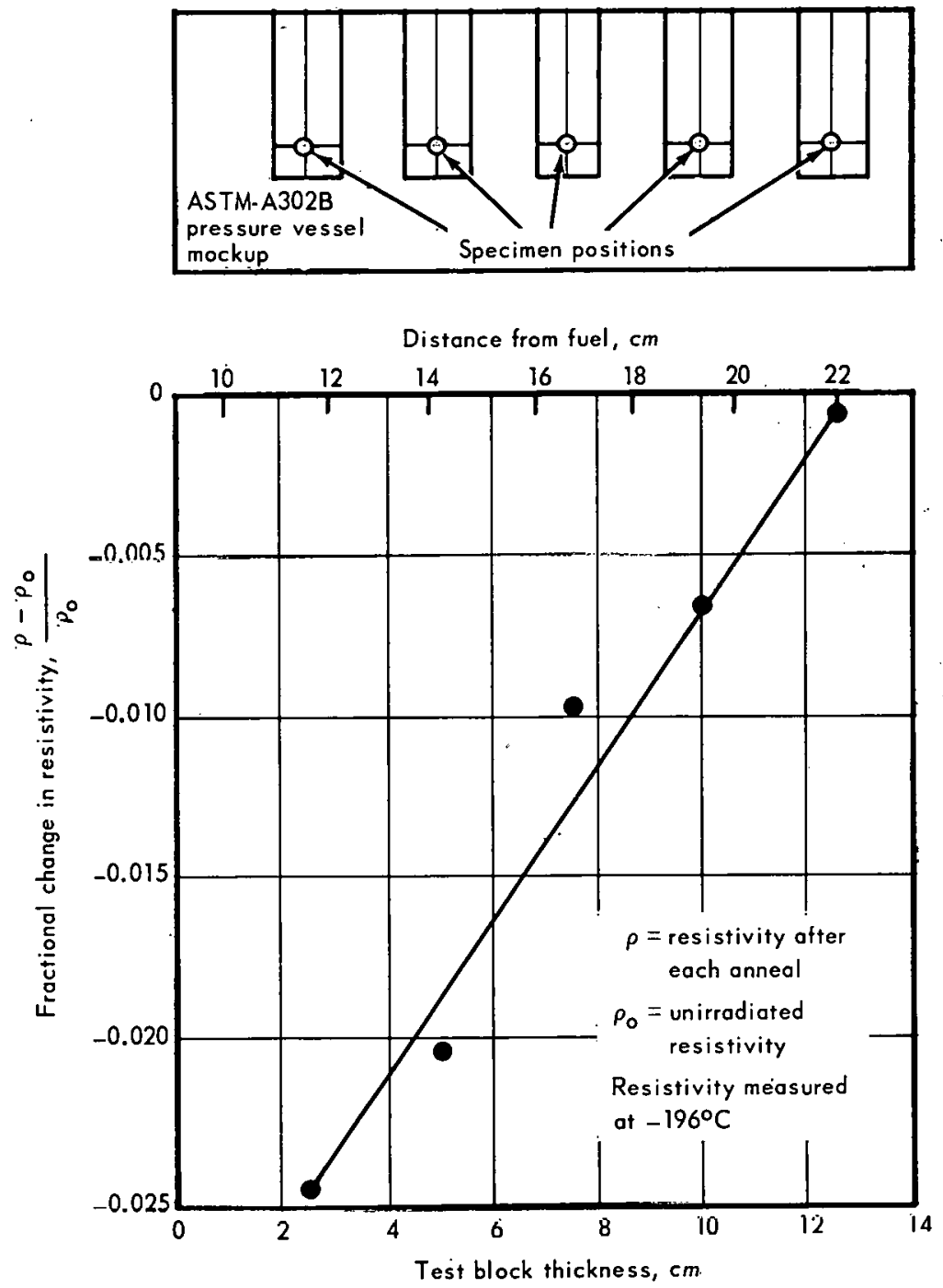

Fig. 7.19 - Fractional resistivity change in irrodiated ASTM-A302B as a function of distance within a pressure vessel mockup

Removal of carbon from solution by precipitation is known to cause a decrease in resistivity, whereas displacement damage generally causes an increase in resistivity. Therefore, carbon (or nitrogen) precipitation in the form of a defect cluster is probably the predominant factor in irradiated $\mathrm{A} 302 \mathrm{~B}$, although the observed result is probably the sum of the two separate processes (defect production and carbon precipitation). In an effort to determine the mechanism of the radiation-induced change in the resistivity, an isochronal anneal was performed on the specimens irradiated to the lowest and highest fluences in the IRL. The results, shown in Figure 7.21, reveal the presence of two important temperature regions. The first anneal (at $100^{\circ} \mathrm{C}$ ) on both specimens increased the resistivity compared to the as-irradiated value. This coincides quite well with the region in which thermal hardening has been observed by other investigator $s^{15,16}$ on similar low-alloy steels and may

${ }^{15}$ D. R. Harries, A: F. Ardy, and A. F. Bartlett, "Radiation Hardening in Mild and Low Alloy Steels," Journal of the lron and Steel Institute, Vol. 202, Part 6, June 1964, pp. 518-522.

${ }^{16}$ N. Milasin, "Contribution a L'Etude du Durcissement Par Irradiation d'un Acier Faiblement Allie Destine Au Caisson de Reacteurs," Journal of Nuclear Materials, Vol. 19, No. 3, June 1966. 


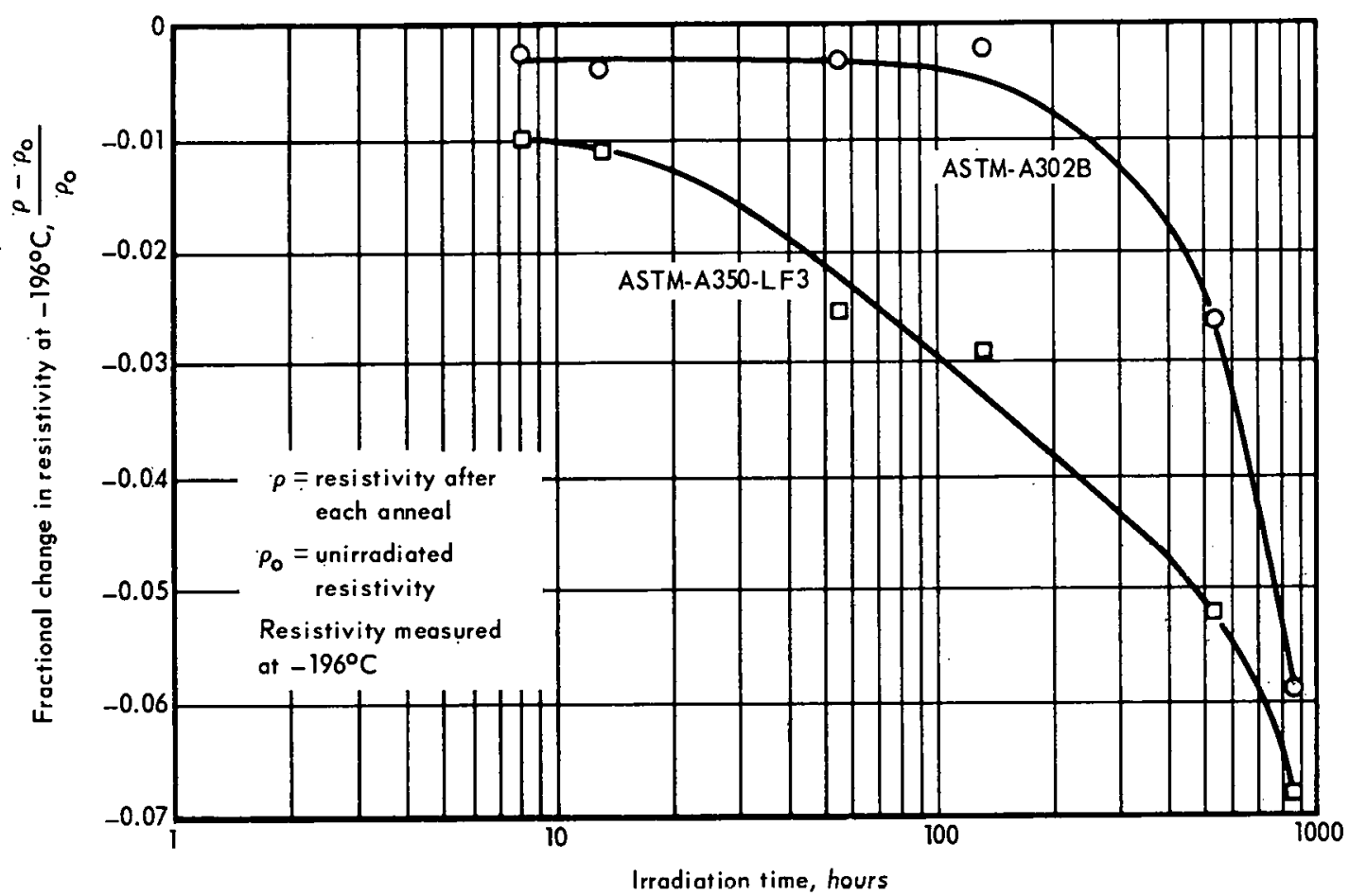

Fig. 7.20 - Fractional change in resistivity of ASTM-A302B and A350-LF3 as a function of neutron exposure in the ORR

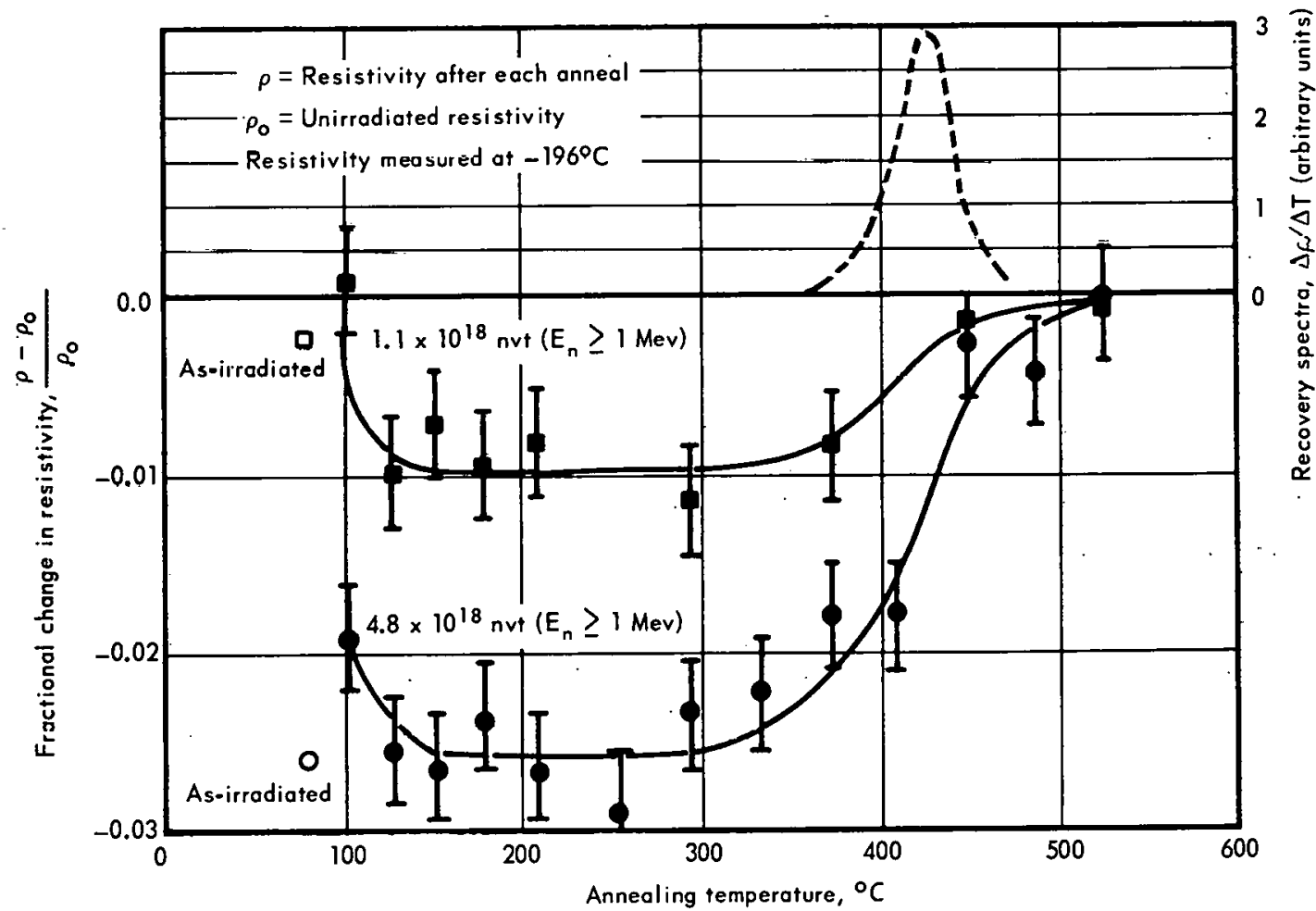

Fig. 7.21 - Isochronal resistivity recovery of ir radiated ASTM-A302B 
be due to agglomeration or clustering of radiation-induced point defects. Further annealing above $100^{\circ} \mathrm{C}$ caused a reduction in resistivity. The exact mechanism is not known but it may be related to the defect ${ }^{17}$ observed in many metals heated to about $0.22 \mathrm{~T}_{\mathrm{m}}$.

Annealing in the temperature range of $150^{\circ}$ to about $300^{\circ} \mathrm{C}$ has little effect on the resistivity, but annealing between $300^{\circ}$ and $500^{\circ} \mathrm{C}$ removes essentially all the remaining negative resistivity change. This is presumably caused by dissociation of the radiationinduced carbon-defect clusters. Further annealing (not shown) at temperatures above $600^{\circ} \mathrm{C}$ increased the resistivity of both irradiated specimens and of an unirradiated control. At about $720^{\circ} \mathrm{C}$ (the solution temperature of carbon in iron) a sharp increase in resistivity was observed in all three specimens.

\section{4 SUMMARY AND CONCLUSIONS}

Creep-rupture life of irradiated Hastelloy $\mathrm{N}$ is reduced by approximately 20 to 30 at $650^{\circ} \mathrm{C}$ and 2 to 3 at $815^{\circ} \mathrm{C}$. The loss in rupture life appears to be controlled by the maximum exposure temperature, regardless of whether it occurred during irradiation or during subsequent testing. Also, the activation energy for creep in the $650^{\circ}$ to $815^{\circ} \mathrm{C}$ range does not appear to be affected by radiation.

At $650^{\circ} \mathrm{C}$, pre-irradiation annealing at $870^{\circ} \mathrm{C}$ tends to improve post-irradiation rupture life compared to mill-annealing plus irradiation. This is not the case at $760{ }^{\circ} \mathrm{C}$. Post-irradiation annealing at $870^{\circ} \mathrm{C}$ is beneficial when the test temperature is $650^{\circ} \mathrm{C}$, but deleterious at a test tomperature of $815^{\circ} \mathrm{C}$. Although recovery of rupture life appears to be possible, efforts to appreciably improve post-irradiation ductility have been unsuccessful. The rupture properties at $650^{\circ} \mathrm{C}$ of as-welded Hastelluy $\mathrm{N}$ irradiated at $650^{\circ} \mathrm{C}$ appear to be unchanged. Welding, per se, produces significant loss in rupture life and ductility.

The fracture of unirradiated Hastelloy $\mathrm{N}$ is transgranular at $650^{\circ} \mathrm{C}$ but intergranular at $815^{\circ} \mathrm{C}$. Metallographic and X-ray diffraction studies have shown that (Mo, Ni) ${ }_{6} \mathrm{C}$ is the only precipitate present in Hastelloy $\mathrm{N}$.

Creep-rupture tests and transmission electron microscopy studies on irradiated A-286 indicate that the radiation-induced embrittlement is not caused by coalescence of helium bubbles on grain boundaries. Rather, the helium atoms are apparently pinning dislocations, thereby preventing the dislocations from moving to grain boundaries where they would promote grain boundary sliding.

Creep-rupture testing of Hastelloy R-235 containing a fixed total boron content but varying a mounts of $\mathrm{B}^{10}$ showed that the loss in rupture life at $870^{\circ} \mathrm{C}$ increases with increasing $\mathrm{B}^{10}$ concentration.

$\mathrm{Fe}-15 \mathrm{Cr}-4 \mathrm{Al}-1 \mathrm{Y}$ alloys irradiated at reactor ambient temperatures or at $700^{\circ} \mathrm{C}$ showed essentially no radiation-induced tensile embrittlement at test temperatures up to $1000^{\circ} \mathrm{C}$.

Embrittlement in ASTM-A302B and A350-LF3 pressure vessel steels appears to be caused by the formation of a defect-carbon type of precipitate (cluster) which is completely annealed out in the $300^{\circ}$ to $500^{\circ} \mathrm{C}$ temperature range. Resistivity tests on these materials correlate quite well with changès and recovery of mechanical properties.

\subsection{PLANS AND RECOMMENDATIONS}

Investigations will be continued to find the basic cause of radiation damage in high-temperature alloys. The approach will be based on current dislocation theories; the techniques to be used are analysis of creep data, transmission electron microscopy, and resistivity and hot-hardness studies.

${ }^{17} \mathrm{~J}$. Moteff and J. P. Smith, "Recovery of Defects in Neutron-Irradiated Tungsten," ASTM STP-380. 
High-strength irradiated cladding and structural alloys will be creep-rupture tested, with emphasis shifted to evaluating fracture modes and analyzing creep data.

Alloys irradiated in a fast reactor spectrum will be tested and evaluated. These data are needed to determine if current theories with regard to radiation embrittlement are applicable to fast spectrum irradiations.

The special split heats of A-286 and Hastelloy R-235 containing various boron contents will be studied, primarily through continuing transmission electron microscopy and creeprupture testing.

Creep-rupture facilities will be expanded and up-dated to permit more precise measurement of strain - time relationships needed for the intensive creep analyses to be performed under this task. 


\section{THIS PAGE}

WAS INTENTIONALLY

\section{LEFT BLANK}




\title{
8. EVALUATIONS OF THE PLASTIC FATIGUE PROPERTIES OF HEAT-RESISTANT ALLOYS
}

\section{(57016)}

\author{
J. Moteff, ${ }^{*}$ T. Slot ${ }^{\dagger}$
}

The objective of this program is to determine the parameters affecting low-cycle fatigue life of metals and alloys at elevated temperatures and to generate low-cycle fatigue data for use in the design of structural components of high-performance nuclear reactor systems.

Materials currently being considered in this program are the AISI stainless steels 304, 316 , and 348. Test parameters under investigation are temperature, strain amplitude, strain rate, and the length of hold times at peak strain in each cycle.

Fatigue test resuits presented in progress reports to date were identified as pertaining to Type 304 stainless steel from controlled heat No. 55697; however, it was recently established that the material received also included rods of Type 348 stainless steel from controlled heat No. $55700 .{ }^{1}$ Since subsequent inspection of tested fatigue specimens has shown that almost all results were applicable to Type 348 stainless steel, only the data for this material are summarized in this report. The test results for Type 304 stainless steel will be reported at a later date when additional tests have been completed to permit a direct comparison with Type 348 stainless steel data.

\subsection{FATIGUE TFSTING EQUIPMENT}

Experimental procedures developed for low-cycle fatigue experiments on pressure vessel steels at elevated temperatures have been reported previously. ${ }^{2}$ These discussions included the choice of a push - pull test specimen with an hourglass-shaped gage section, the method of specimen loading and heating, the technique of diametral strain measurement, and the performance of a general-purpose hydraulic fatigue machine shown in Figure 8.1.

During the past year, three additional fatigue machines were acquired, ${ }^{3}$ which are specialpurpose in the sense that they were developed for use in fatigue tests with closed-loop control of the diametral strain in push - pull specimens. However, with minor modifications, it will be possible to operate the machines with control of load or actuator displacement. One of these machines is shown in Figure 8.2.

\footnotetext{
*Project leader.

${ }^{\dagger}$ Principal investigator.

${ }^{1}$ T. T. Clandson, "Fabrication History of Alloys Used in the Irradiation Effects on Reactor Structural Materials Program," Pacific Northwest Laboratory, BNWL-CC-236, Richland, Washington, October 1965.

2"Fifth Annual Report - High-Temperature Materials Program, Part A," GE-NMPO, GEMP-400A, February 28, 1966, pp. 186-198.

3“'High-Temperature Materials Program Progress Report No. 61," GE-NMPO, GEMP-61, September 30, 1966, pp. $133-139$.
} 


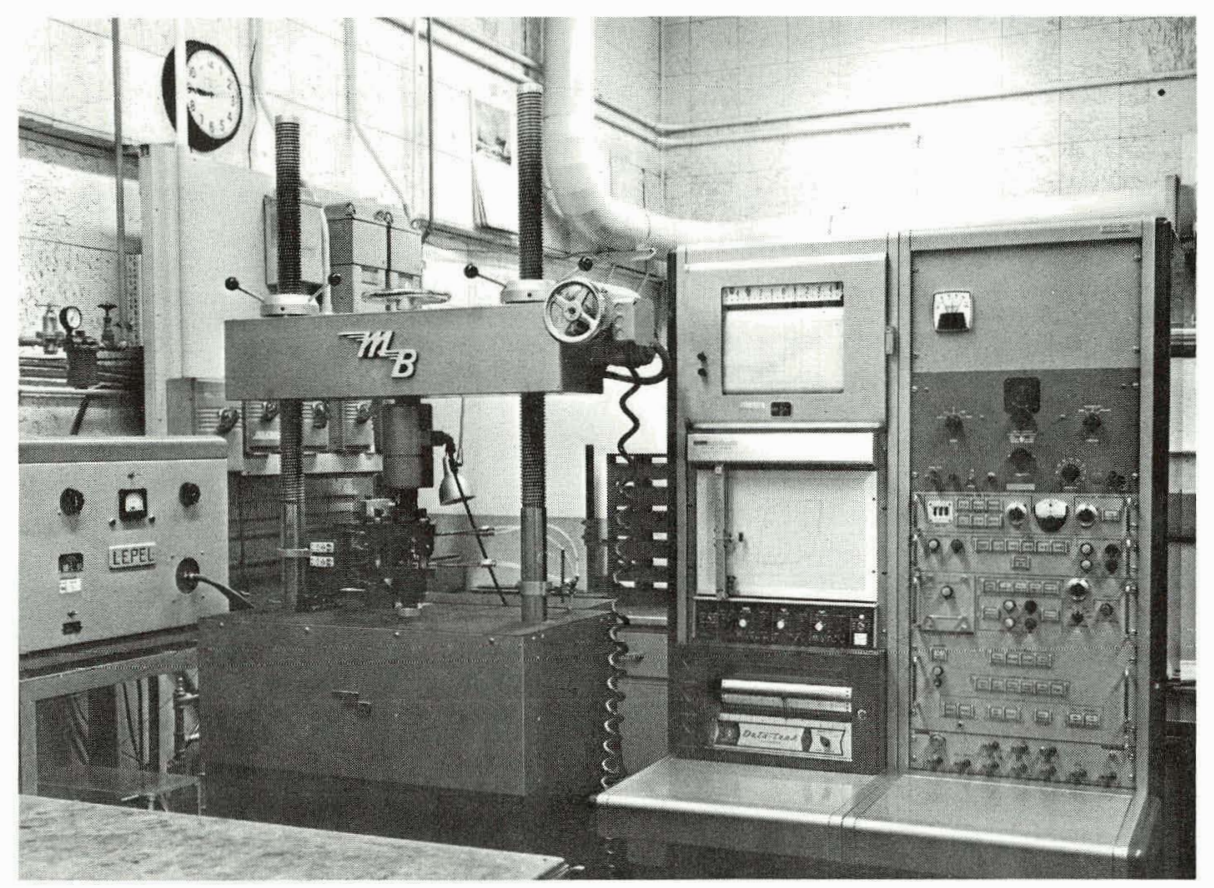

Fig. 8.1 - Servocontrolled hydraulic materials testing machine (Neg. P66-6-2)

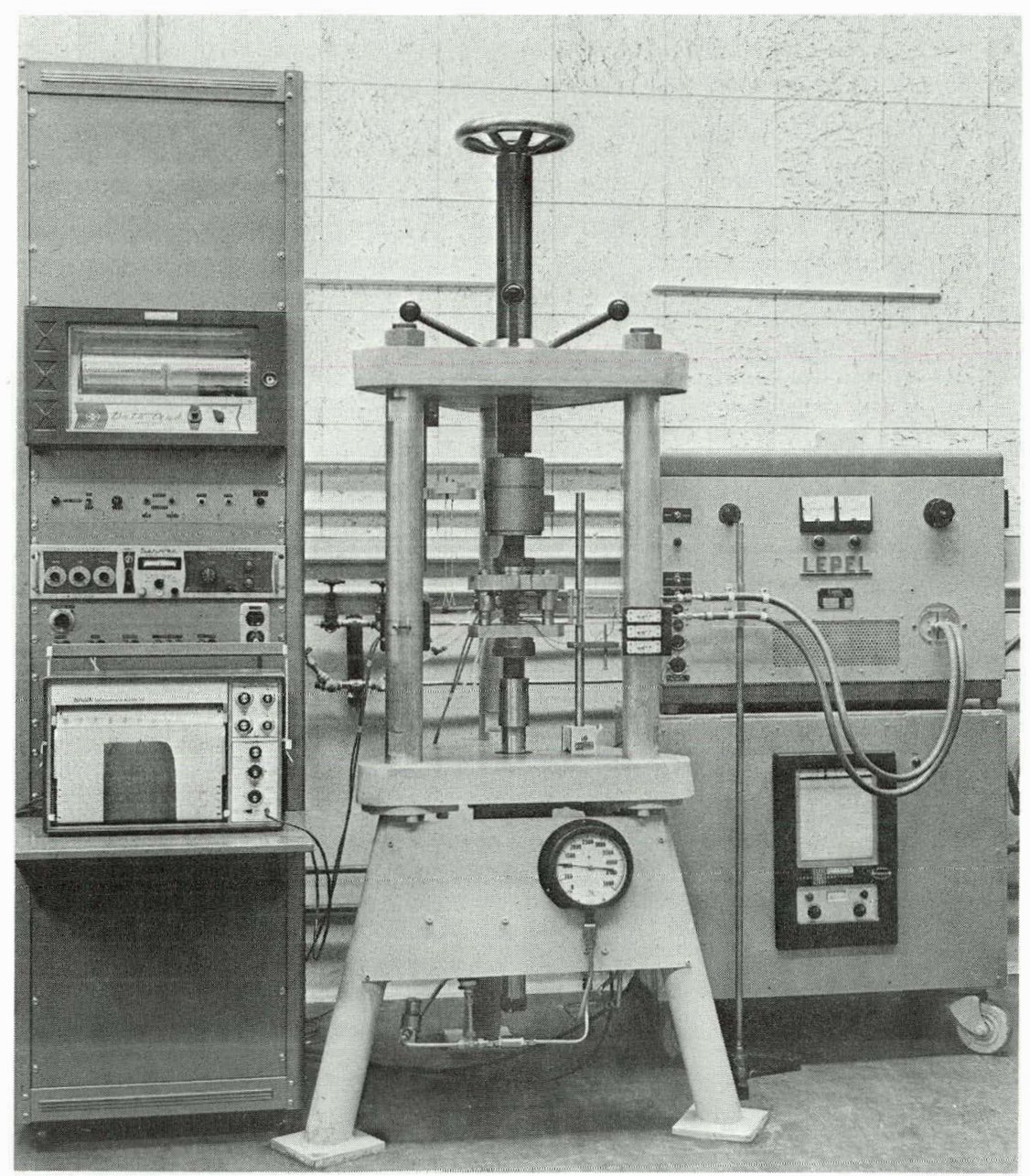

Fig. 8.2 - Servocontrolled hydraulic fatigue machine (Neg. P66-5-27B) 
A typical example of the performance obtained with these machines is shown in Figure 8. 3. On the left, stress in a Type 348 stainless steel specimen is recorded versus diametral strain, the controlled parameter in the test conducted at $430^{\circ} \mathrm{C}$. (To obtain the hysteresis loops in their familiar form, the stress was actually plotted against the negative of the diametral strain.) While it is evident that the total diametral strain range was maintained, the plastic portion of the strain range, taken to be the width of the hysteresis loop at zero stress, diminished somewhat with successive cycles. This behavior is due to cyclic hardening of the material, which is also apparent from the load history shown on the right.

Material: Annealed Type 348 stainless steel
Temperature: $430^{\circ} \mathrm{C}$
Control mode: Diametral strain
Cyclic mode: Triangular, zero mean strain
Frequency: 4.44 cycles $/$ minute
$\Delta \epsilon_{\mathrm{d}}=1.34 \% ; \Delta \sigma=76 \mathrm{~kg} / \mathrm{mm}^{2}$ (afte: 15 cycles)

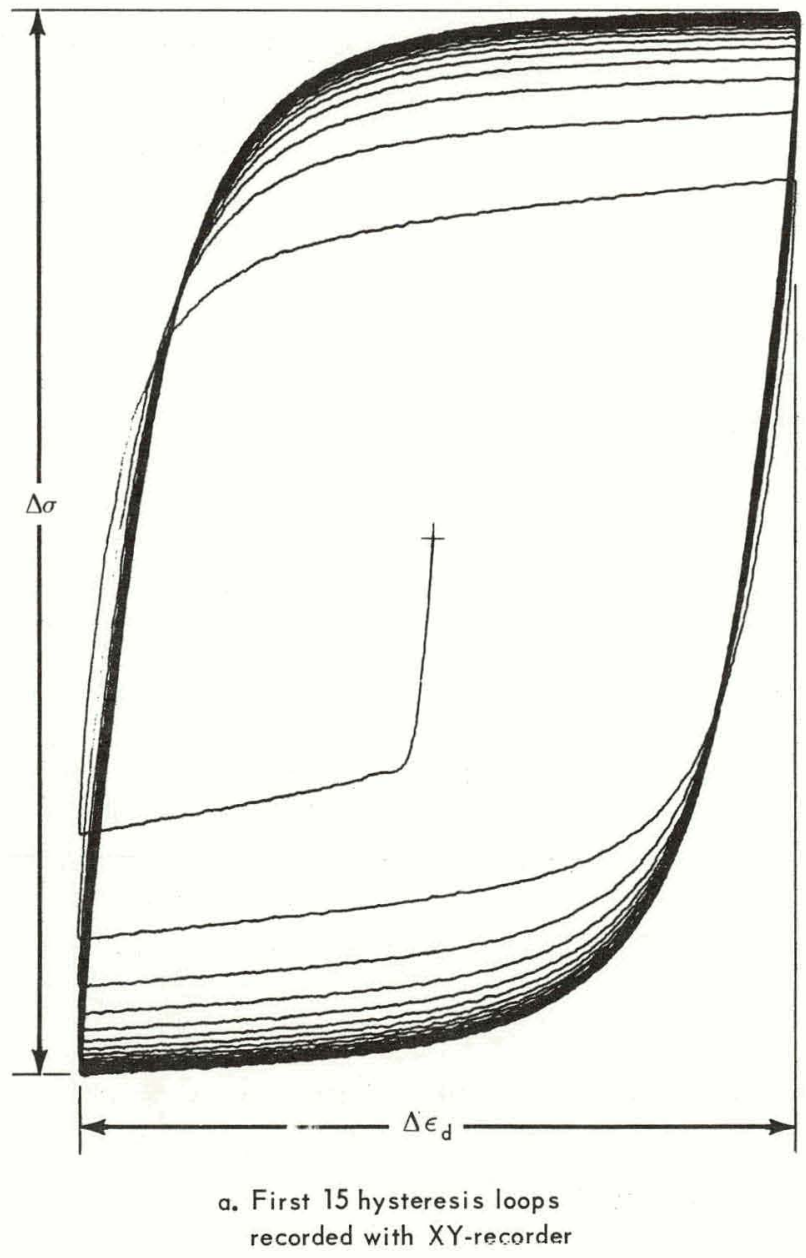

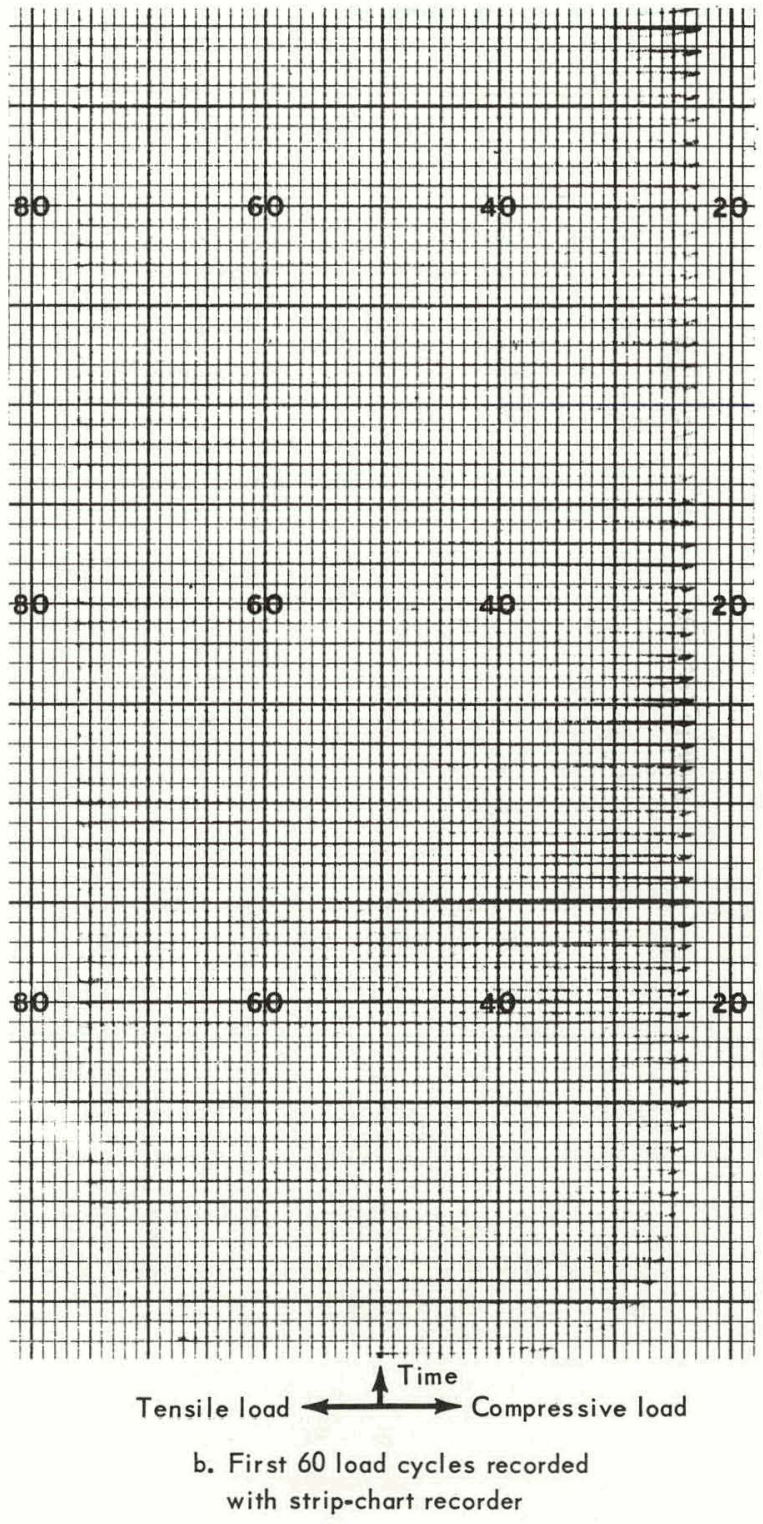

Fig. 8.3-Test records illustrating strain-hardening of Type 348 stainless steel specimen during initial portion of strain-cycling test performed at $430^{\circ} \mathrm{C}$ 
A more detailed discussion of equipment development and system performance may be found in two topical reports issued during the year., 5

\subsection{LOW-CYCLE FATIGUE TEST RESULTS FOR TYPE 348 STAINLESS STEEL}

Fatigue tests completed to date were performed primarily on Type 348 stainless steel from a controlled heat, Heat No. $55700 .^{6}$ The diametral strain was varied in a triangular cyclic mode about a zero mean value, and the frequency of loading was generally selected to give a nominal diametral strain rate of $0.002 \mathrm{sec}^{-1}$. All tests were started in compression. In computing axial strain components from diametral strain components, a Poisson's ratio of 0.3 and 0.5 was used to. relate elastic and plastic components, respectively. ${ }^{?}$

\section{EFFECT OF TEMPERATURE ON FATIGUE LIFE - FIXED STRAIN AMPLITUDE}

Fatigue tests were performed on Type 348 stainless steel at temperatures ranging from $24^{\circ}$ to $816^{\circ} \mathrm{C}$ and at approximately the same strain amplitude and strain rate. The results are summarized in Table 8.1. These tests werc performed to examine the effect of temperature on the fatigue life of the material and to determine suitable operating conditions for the testing machines in relation to the temperature-dependent mechanical behavior of the specimen.

A plot of the number of cycles to fracture as a function of test temperature is shown in Figure 8.4. The value of the stress range at the half-life point in the fatigue test is plotted versus test temperature in Figure 8.5. For most tests, this value was also the steadystate or saturation value of the stress range attained following the initial strain-hardening phase of the test.

\section{EFFECT OF STRAIN AMPLITUDE ON FATIGUE LIFE AT TEMPERATURES OF $430^{\circ}$,} $650^{\circ}$, AND $816^{\circ} \mathrm{C}$

In Table 8.2, the results are summarized for fatigue tests at $430^{\circ} \mathrm{C}$ in which the total axial strain range varied from a low of 0.5 percent to a high of 3.4 percent. Figure 8. 6 shows graphically the relationship between the logarithm of the plastic strain range, $\Delta \epsilon_{\mathrm{p}}$, and the logarithm of the number of cycles to fracture, $\mathrm{N}_{\mathrm{f}}$. The apparent linearity is in accord with the Coffin-Manson relation, $\Delta \epsilon_{\mathrm{p}}=\mathrm{cN}_{\mathrm{f}}-\mathrm{m}$, where $\mathrm{c}$ and $\mathrm{m}$ are material constants. The validity of this relation has been demonstrated for many materials tested at temperatures below the creep range. To obtain an accurate estimate of the values of $c$ and $\mathrm{m}$, a least squares analysis was performed on the results from the first 22 tests in Table 8. 2. An analysis with $\Delta \epsilon_{\mathrm{p}}$ as the independent variable and $\mathrm{N}_{\mathrm{f}}$ as the dependent variable yielded $\Delta \epsilon_{\mathrm{p}}=43.4 \mathrm{~N}_{\mathrm{f}}-0.461$, where $\Delta \epsilon_{\mathrm{p}}$ is in percent. In Figure 8.4, the straight line drawn through the data points corresponds to this relation. The value of $c$ furnished a predicted value for the reduction of area, RA, which is normally obtained from a tensile test, i. e., RA $=56$ percent. ${ }^{8}$ Actual tensile tests furnished a value of 66 percent when approximately the same strain rate was used.

A plot of the total strain range versus fatigue life at $430^{\circ} \mathrm{C}$ is presented in Figure 8.7, while Figure 8.8 shows the cyclic relationship between stress and strain. The data points shown as open circles in Figure 8.8 correspond to the values of $\Delta \epsilon$ and $\Delta \sigma$ given in Table

\footnotetext{
${ }^{4}$ T. Slot, "Experimental Developments in Low-Cycle Fatigue Research on Pressure Vessel Steels at Elevated Temperatures," GE-NMPO, GE-TM 66-6-11, June 1966.

${ }^{5}$ R. H. Stentz, "The Development and Operation of Low-Cycle Fatigue Testing Machines," GE-NMPO, GEMP-465, December 1966.

${ }^{6}$ Clandson, loc. cit.

${ }^{7}$ GEMP-61, pp. 133-139.

8‘'High-Temperature Materials Program Progress Report No. 63," GE-NMPO, GEMP-63, December 30, 1966, pp. $107-110$.
} 
TABLE 8.1

LOW-CYCLE FATIGUE TEST ${ }^{2}$ RESULTS FOR ANNEALED TYPE 348 STAINLESS STEEL IN TEMPERATURE RANGE FROM $24^{\circ}$ TO $816^{\circ}{ }^{\circ} \mathrm{C}$ (HEAT NO. 55700)

\begin{tabular}{|c|c|c|c|c|c|c|c|c|c|c|c|}
\hline \multirow{3}{*}{\multicolumn{2}{|c|}{$\begin{array}{c}\text { Test } \\
\text { Identification }\end{array}$}} & \multirow{4}{*}{$\begin{array}{c}{ }^{\circ} \mathrm{C} \\
\text { Temperature, }\end{array}$} & \multicolumn{3}{|c|}{ Axial Strain } & \multicolumn{3}{|c|}{ Diametral Strain } & \multirow{4}{*}{$\begin{array}{c}\text { Axial Stress } \\
\text { Stress Range } \\
\text { at } \mathrm{N}_{\mathrm{f}} / 2 \\
(\Delta \sigma), \mathrm{kg} / \mathrm{mm}^{2}\end{array}$} & \multirow{2}{*}{\multicolumn{2}{|c|}{ Fatigue Life }} \\
\hline & & & \multirow{3}{*}{$\begin{array}{l}\text { Total } \\
\text { Strain } \\
\text { Range } \\
(\Delta \in), \%\end{array}$} & \multirow{3}{*}{$\begin{array}{c}\text { Plastic } \\
\text { Strain } \\
\text { Range } \\
\left(\Delta \epsilon_{\mathrm{p}}\right), \%\end{array}$} & \multirow{3}{*}{$\begin{array}{c}\text { Blastic } \\
\text { Strain } \\
\text { Range } \\
\left(\Delta \epsilon_{\mathrm{e}}\right), \%\end{array}$} & \multirow{3}{*}{$\begin{array}{c}\text { Total } \\
\text { Strain } \\
\text { Range } \\
\left(\Delta \epsilon_{\mathrm{d}}\right), \%\end{array}$} & \multirow{3}{*}{$\begin{array}{c}\text { Plastic } \\
\text { Strain } \\
\text { Range } \\
\left(\Delta \epsilon_{\mathrm{dp}}\right), \%\end{array}$} & \multirow{3}{*}{$\begin{array}{c}\text { Elastic } \\
\text { Strain } \\
\text { Range } \\
\left(\Delta \epsilon_{\mathrm{de}}\right), \%\end{array}$} & & & \\
\hline & & & & & & & & & & \multirow{2}{*}{$\begin{array}{l}\text { Cycles to } \\
\text { Fracture } \\
\left(\mathrm{N}_{\mathrm{f}}\right)\end{array}$} & \multirow{2}{*}{$\begin{array}{l}\text { Cycles to } 5 \% \\
\text { Load Reduction } \\
\text { Point }\left(\mathrm{N}_{5}\right)\end{array}$} \\
\hline $\begin{array}{l}\text { Test } \\
\text { No. }\end{array}$ & $\begin{array}{l}\text { Specimen } \\
\text { No. }\end{array}$ & & & & & & & & & & \\
\hline 1 & $8-6$ & 150 & 1.72 & 1.32 & 0.40 & 0.78 & 0.66 & 0.12 & 7.3 .9 & 2984 & 2984 \\
\hline 2 & $8-2$ & 150 & 1.72 & 1.32 & 0.40 & 0.78 & 0.66 & 0.12 & 71.4 & 4696 & 4665 \\
\hline 3 & $8-7$ & 300 & 1.72 & 1. 32 & 0.40 & 0.78 & 0.66 & 0.12 & 64.5 & 2408 & 2390 \\
\hline 4 & $8-9$ & 300 & 1.73 & 1.36 & 0.37 & 0.79 & 0.68 & 0.11 & 63.1 & 2575 & 2540 \\
\hline 5 & $8-8$ & 400 & 1.74 & 1.34 & 0.40 & 0.79 & 0.67 & 0.12 & 68.8 & 2496 & 2430 \\
\hline 6 & $8-4$ & 400 & 1.72 & 1.32 & 0.40 & 0.78 & 0.66 & 0.12 & 67.8 & 2732 & 2690 \\
\hline 7 & 269 & 500 & 1.73 & 1.29 & 0.44 & 0.78 & 0.65 & 0.13 & 63.6 & 1910 & 1910 \\
\hline 8 & 267 & 500 & 1. 74 & 1. 27 & 0.47 & 0.78 & 0.64 & 0.14 & 67.6 & 1912 & 1840 \\
\hline 9 & 268 & 500 & 1.74 & 1.29 & 0.45 & 0.78 & 0.65 & 0.13 & 62.3 & 2160 & 2160 \\
\hline 10 & 250 & 600 & 1.70 & 1. 31 & 0.39 & 0.77 & 0.65 & 0.12 & 66.3 & 870 & 820 \\
\hline 11 & 252 & 600 & 1. 71 & 1. 35 & 0.36 & 0.77 & 0.66 & 0.11 & 63.0 & 1002 & 950 \\
\hline 12 & $8-5$ & 600 & 1.73 & 1. 34 & 0.37 & 0.79 & 0.68 & 0.11 & 62.7 & 1304 & 1260 \\
\hline 13 & 311 & 650 & 1.74 & 1.35 & 0.39 & 0.80 & $0.6 \mathrm{~B}$ & 0.12 & 57.4 & 834 & 815 \\
\hline 14 & 312 & 650 & 1.76 & 1.36 & 0.40 & 0.80 & $0.6 \mathrm{~B}$ & 0.12 & 58.1 & 895 & 841 \\
\hline 15 & 283 & 650 & 1.68 & 1.28 & 0.40 & 0.76 & 0.64 & 0.12 & 57.7 & 1024 & 980 \\
\hline 16 & 317 & 700 & 1. 72 & 1. 32 & 0.40 & 0.79 & 0.66 & 0.13 & 54.4 & 740 & 660 \\
\hline 17 & 270 & 700 & 1.70 & 1. 33 & 0.37 & 0.78 & 0.67 & 0.11 & 52.4 & 768 & 730 \\
\hline 18 & 316 & 750 & 1. 73 & 1. 40 & 0.33 & 0.80 & 0.70 & 0.10 & 50.9 & 531 & 420 \\
\hline 19 & 276 & 750 & 1.68 & 1. 36 & 0.32 & 0.77 & 0.68 & 0.09 & 48.4 & 538 & 420 \\
\hline 20 & 275 & 750 & 1.67 & 1. 36 & 0.31 & 0.77 & 0.68 & 0.09 . & 45.6 & 576 & 520 \\
\hline $21^{\mathrm{b}}$ & 48 & 816 & 1.63 & 1.41 & 0.22 & 0.77 & 0.70 & 0.07 & 39. 1 & 290 & 230 \\
\hline 22 & 59 & 816 & 1. 6.3 & 1.43 & 0.20 & 0.78 & 0.72 & 0.06 & 37.8 & 304 & 220 \\
\hline $23^{b}$ & 52 & 816 & 1.63 & 1.41 & 0.22 & 0.77 & 0.70 & 0.07 & 41.1 & 304 & 230 \\
\hline
\end{tabular}

Control mode: Diametral strain

Mode shape: Triangular with zero mean strain

Diametral strain range: $0.78 \%$ (nominal value)

Cyclic rate: 400 cycles/hour

Starting condition: Compression first

${ }^{b}$ Cyclic rate: 356 cycles/hour 
Material: Annealed Type 348 stainless steel - heat No. 55700

Temperature: $24^{\circ} 10816^{\circ} \mathrm{C}$

Control mode: Diametral strain

Cyclic mode: Triongular, with zero mean stroin

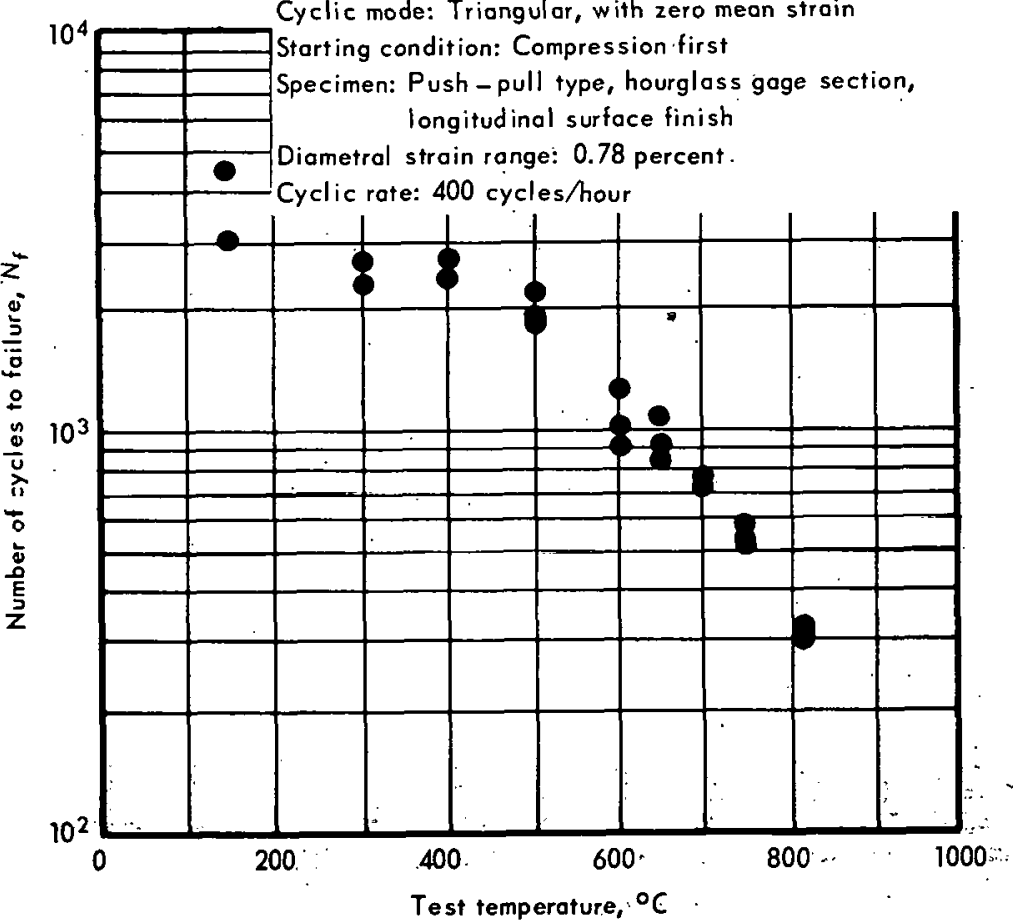

Fig. 8.4 - Low-cycle fatigue test results for Type 348 stainless steel in temperature range from $24^{\circ}$ to $816^{\circ} \mathrm{C}$

Material: Annealed Type $348^{\prime}$ stainless steel. - heat No: 55700

Temperature: $24^{\circ}$ to $816^{\circ} \mathrm{C}$

Control mode: Diametral strain. .

Cyclic mode: Triangular, with zero me an strain

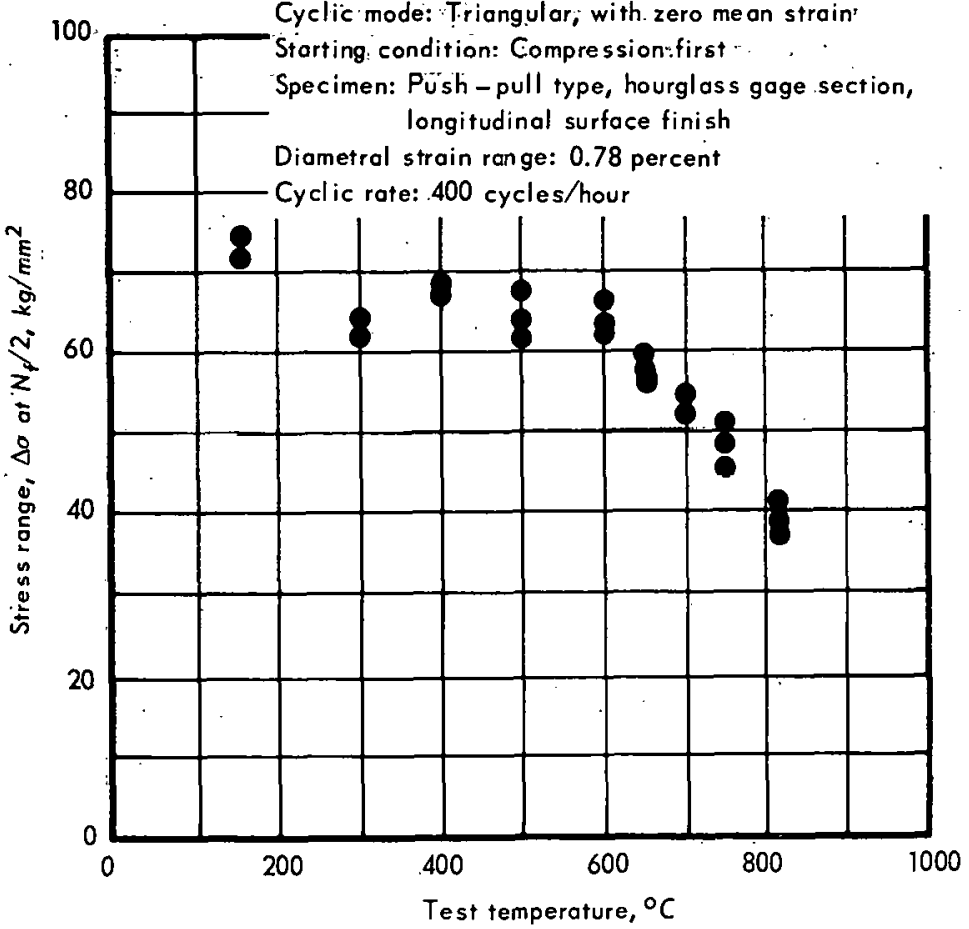

Fig. 8:5- Low-cycle fatigue test results for Type 348 stainless steel in temperature range from $24^{\circ}$ to $816^{\circ} \mathrm{C}$ 
TABLE 8.2

LOW-CYCLE FATIGUE TEST RESULTS FOR TYPE 348 STAINLESS STEEL AT $430^{\circ} \mathrm{C}^{\circ}$ (HEAT NO. 55700)

\begin{tabular}{|c|c|c|c|c|c|c|c|c|c|c|c|c|c|}
\hline & & & \multicolumn{3}{|c|}{ Axial Strain } & \multicolumn{3}{|c|}{ Diametral Strain } & \multirow{4}{*}{$\begin{array}{c}\frac{\text { Axial Stress }}{\text { Stress Range }} \\
\text { at } \mathrm{N}_{\mathrm{f}} / 2 \\
(\Delta \sigma), \mathrm{kg} / \mathrm{mm}^{2}\end{array}$} & \multirow{2}{*}{\multicolumn{2}{|c|}{ Cyclic Rate }} & \multirow{2}{*}{\multicolumn{2}{|c|}{$\begin{array}{l}\text { Fatigue Life } \\
\end{array}$}} \\
\hline \multirow{2}{*}{\multicolumn{3}{|c|}{ Test Identification }} & \multirow{3}{*}{$\begin{array}{l}\text { Total } \\
\text { Strain } \\
\text { Range } \\
(\Delta \epsilon), \%\end{array}$} & \multirow{3}{*}{$\begin{array}{l}\text { Plastic } \\
\text { Strain } \\
\text { Range } \\
\left(\Delta \epsilon_{\mathrm{p}}\right), \%\end{array}$} & \multirow{3}{*}{$\begin{array}{l}\text { Elastic } \\
\text { Strain } \\
\text { Range } \\
\left(\Delta \epsilon_{\mathrm{e}}\right)_{2} \%\end{array}$} & \multirow{3}{*}{$\begin{array}{l}\text { Total } \\
\text { Strain } \\
\text { Range } \\
\left(\Delta \epsilon_{\mathrm{d}}\right): \%\end{array}$} & \multirow{3}{*}{$\begin{array}{l}\text { Plastic } \\
\text { Strain } \\
\text { Range } \\
\left(\Delta \epsilon_{\mathrm{dp}}\right), \%\end{array}$} & \multirow{3}{*}{$\begin{array}{l}\text { Elastic } \\
\text { Strain } \\
\text { Range } \\
\left(\Delta \epsilon_{\mathrm{de}}\right), \%\end{array}$} & & & & & \\
\hline & & & & & & & & & & Frequency of & Axial Strain & Cycles to & Cycles to $5 \%$ \\
\hline $\begin{array}{l}\text { Test } \\
\text { No. }\end{array}$ & $\begin{array}{l}\text { Test } \\
\text { Stand }\end{array}$ & $\begin{array}{l}\text { Specimen } \\
\text { No. }\end{array}$ & & & & & & & & $\begin{array}{l}\text { Loading } \\
\text { (f), cycles/min }\end{array}$ & $\begin{array}{c}\text { Rateb }^{\mathrm{b}} \\
(\dot{\epsilon}), \mathrm{sec}^{-1}\end{array}$ & $\begin{array}{l}\text { Fracture } \\
\left(\mathrm{N}_{\mathrm{f}}\right)\end{array}$ & $\begin{array}{l}\text { Load Reduction } \\
\text { Point }\left(\mathrm{N}_{5}\right)\end{array}$ \\
\hline 1 & 1 & 329 & 3.39 & 2.88 & 0.51 & 1.59 & 1.44 & 0.15 & 80.3 & 3.33 & $3.8 \times 10^{-3}$ & 348 & 325 \\
\hline 2 & 1 & 314 & 3.43 & 2.90 & 0.53 & 1.61 & 1.45 & 0.16 & 81.7 & 3.33 & 3.8 & 430 & 425 \\
\hline 3 & 1 & 327 & 3.41 & 2.88 & 0.53 & 1.60 & 1.44 & 0.16 & 82.5 & 3. 33 & 3.8 & 490 & 490 \\
\hline 4 & 3 & 336 & 2.84 & 2.34 & 0.51 & 1.32 & 1.17 & 0.15 & 83. 2 & 4.44 & 4.2 & 417 & 417 \\
\hline 5 & 3 & 331 & 2.89 & 2. 38 & 0.51 & 1.34 & 1.19 & 0.15 & 80.3 & 4.44 & 4.3 & 607 & 592 \\
\hline 6 & 1 & 326 & 2.59 & 2.12 & 0.47 & 1.20 & 1.06 & 0.14 & 78.2 & 4. 44 & 3.8 & 680 & 657 \\
\hline 7 & 1 & 325 & 2. 56 & 2.12 & 0.44 & 1.19 & 1.06 & 0.13 & 82.5 & 4.44 & 3.8 & 538 & 510 \\
\hline 8 & 3 & 342 & 2.63 & 2. 15 & 0.48 & 1.22 & 1.08 & 0.14 & 81.7 & 4. 44 & 3.9 & 762 & 762 \\
\hline 9 & 2 & 340 & 2. 35 & 1.92 & 0.43 & 1.09 & 0.96 & 0.13 & 78.2 & 5. 33 & 4.2 & 690 & 690 \\
\hline 10 & 1 & 334 & 1.97 & 1.56 & 0.41 & 0.90 & 0.78 & 0.12 & 74.6 & 5. 93 & 3.9 & 1182 & 1152 \\
\hline 11 & 1 & 324 & 1.75 & 1.34 & 0.41 & 0.79 & 0.67 & 0.12 & 69.5 & 6.67 & 3.9 & 1724 & 1724 \\
\hline 12 & 1 & 323 & 1.76 & 1.37 & 0.39 & 0.80 & 0.68 & 0.12 & 71.7 & 6.67 & 3.9 & 1875 & 1848 \\
\hline 13 & 3 & 321 & 1.80 & 1.40 & 0.40 & 0.82 & 0.70 & 0.12 & 68.1 & 6.00 & 3. 6 & 2000 & 1990 \\
\hline 14 & 2 & 349 & 1.35 & 1.02 & 0.33 & 0.61 & 0.51 & 0.10 & 60.2 & 9.00 & 4.0 & 2945 & 2890 \\
\hline 15 & 1 & 338 & 1.35 & 0.98 & 0.37 & 0.60 & 0.49 & 0.11 & 57.4 & 8.89 & 4.0 & 4007 & 3980 \\
\hline 16 & 1 & 322 & 1.33 & 1.00 & 0.33 & 0.60 & 0.50 & 0.10 & 62.4 & 8.89 & 3.9 & 4776 & 4635 \\
\hline 17 & 2 & 341 & 0.94 & 0.62 & 0.32 & 0.41 & 0.31 & 0.10 & 48.8 & 13.7 & 4.3 & $982 \leq$ & 9824 \\
\hline 18 & 1 & 339 & 0.93 & 0.62 & 0.31 & 0.40 & 0.31 & 0.09 & 48.0 & 13.3 & 4.1 & 11440 & 11440 \\
\hline 19 & 2 & 346 & 0.73 & 0.44 & 0.29 & 0.31 & 0.22 & 0.09 & 45.9 & 18.0 & 4.4 & 20329 & 20329 \\
\hline 20 & 1 & 343 & 0.71 & 0.42 & 0.29 & 0.30 & 0.21 & 0.09 & - & 17.8 & 4.2 & 20663 & 20663 \\
\hline 21 & 1 & 345 & 0.72 & 0.44 & 0.28 & 0.30 & 0.22 & 0.08 & 43.0 & 17.8 & 4.3 & 21157 & 21157 \\
\hline 22 & 1 & 337 & 0.72 & 0.44 & 0.28 & 0.30 & 0.22 & 0.08 & 45.2 & 17.8 & 4. 3 & 24126 & 24126 \\
\hline 23 & 1 & 347 & 0.51 & 0.24 & 0.27 & 0.20 & 0.12 & 0.08 & 45.2 & 26. 7 & $4.5 \times 10^{-3}$ & 104250 & 104250 \\
\hline
\end{tabular}

Montrol mode: Diametral strain

Starting conditions: Compression first

$\mathbf{b}_{\dot{\mathbf{E}}}=(\mathrm{f})(\Delta \epsilon) / 30$ 


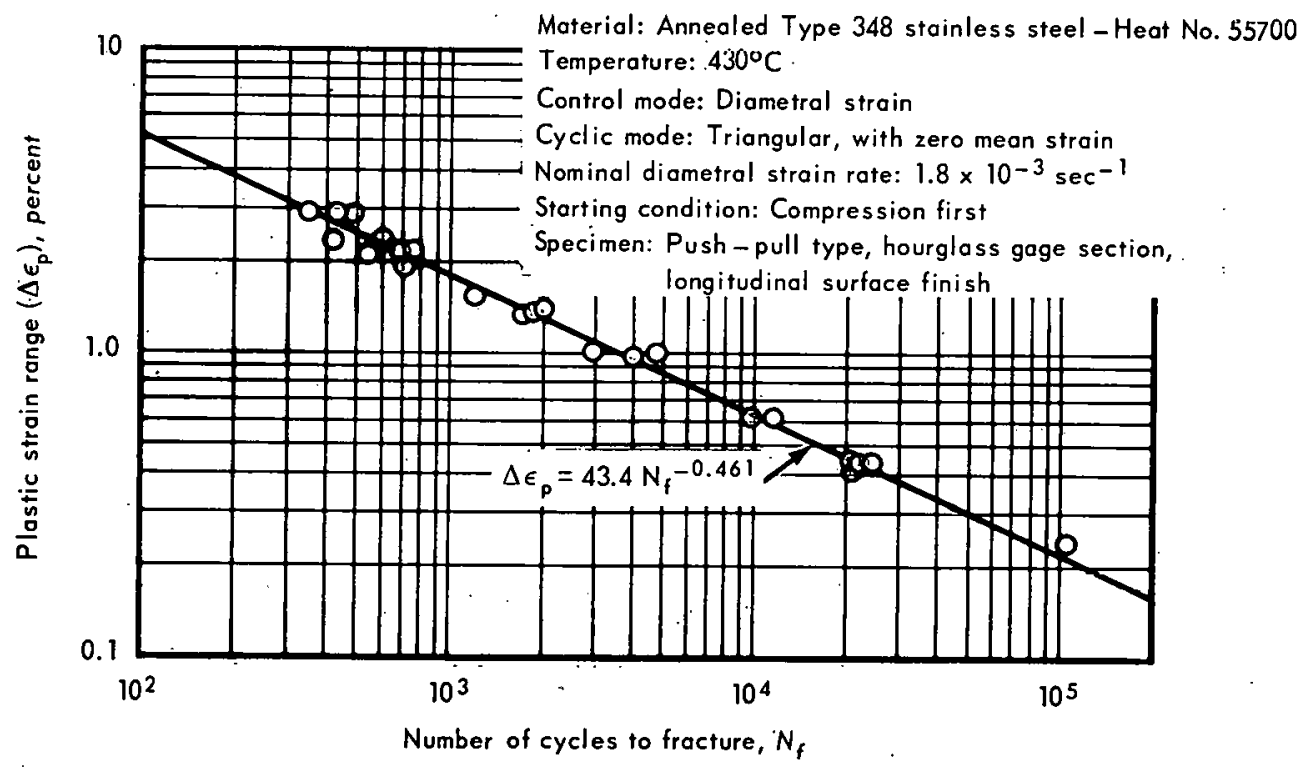

Fig. 8.6 - Low-cycle fatigue test results for Type 348 stainless steel at $430^{\circ} \mathrm{C}$

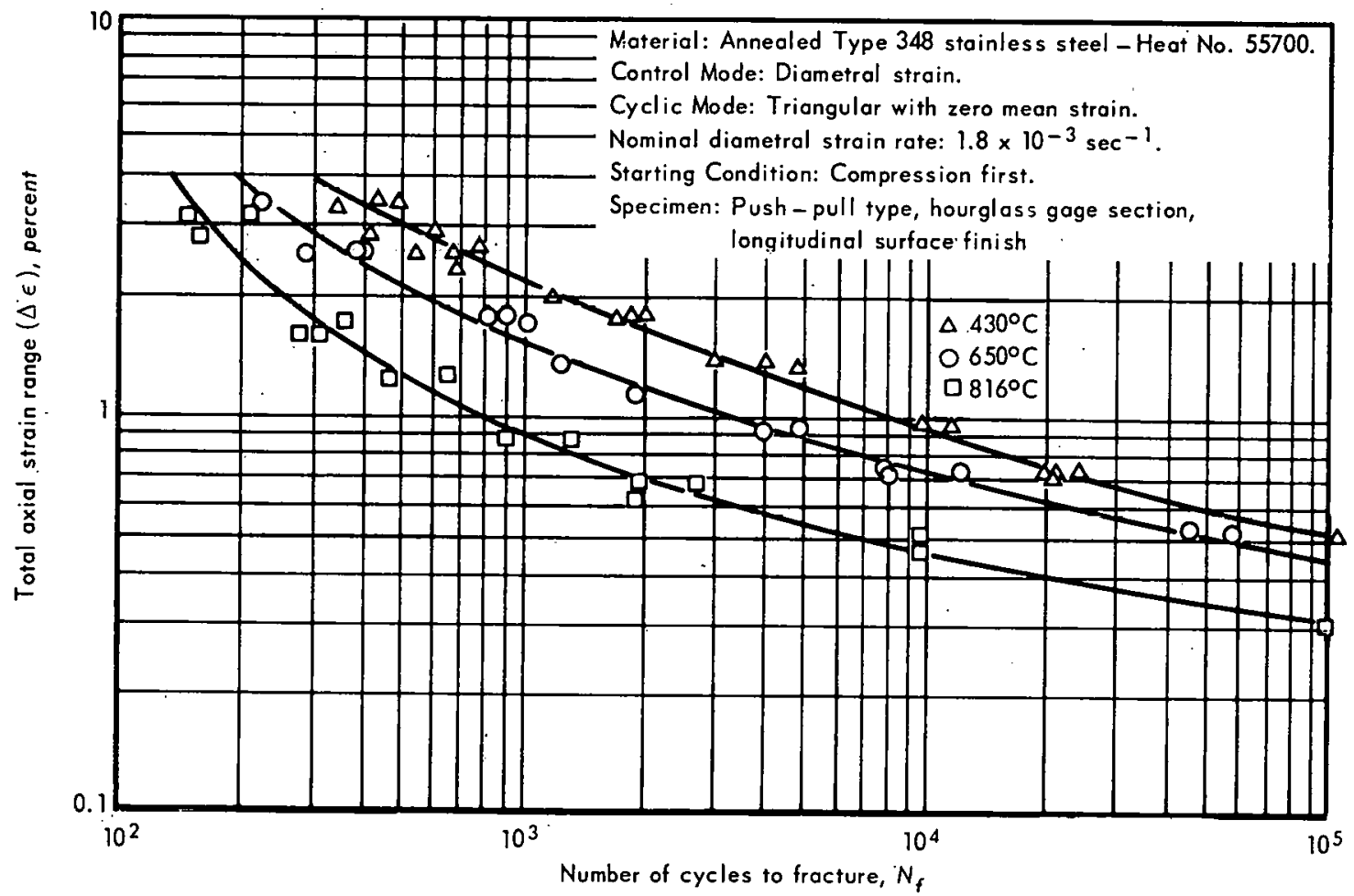

Fig. 8.7 - Low-cycle fotigue test results for Type 348 stainless steel at $430^{\circ}, 650^{\circ}$, and $816^{\circ} \mathrm{C}$ 
8. 2. Also shown is a cyclic stress - strain diagram obtained with a single specimen which was cyclically loaded for short periods at successively higher strain levels. Each datum point shown as a closed circle defines the stress range measured after approximately 100 cycles at the indicated strain range. The frequency of loading was 6.67 cycles per minute. The rather close correspondence between the two sets of data is indicative of the relatively few cycles required to reach a steady-state or saturation condition for the stress range at this temperature.

Results from fatigue tests at $650{ }^{\circ} \mathrm{C}$ were reported previously. ${ }^{9}$ It was indicated, however, that the results were not quite satisfactory because of equipment problems experienced during the test series and because the specimens were not identical in regard to heat treatment and surface finish. A new set of experiments has since been performed with the results given in Table 8. 3. The total strain range versus fatigue life at this temperature is shown in Figure 8.7.

The fatigue test results obtained for $816^{\circ} \mathrm{C}$ are given in Table 8.3. Most of this information was presented in the previous annual report, ${ }^{10}$ but two tests have been added (Specimens 333 and 2-10). In Figure 8.7, the results for this temperature are compared with the corresponding results for $430^{\circ} \mathrm{C}$ and $650^{\circ} \mathrm{C}$.

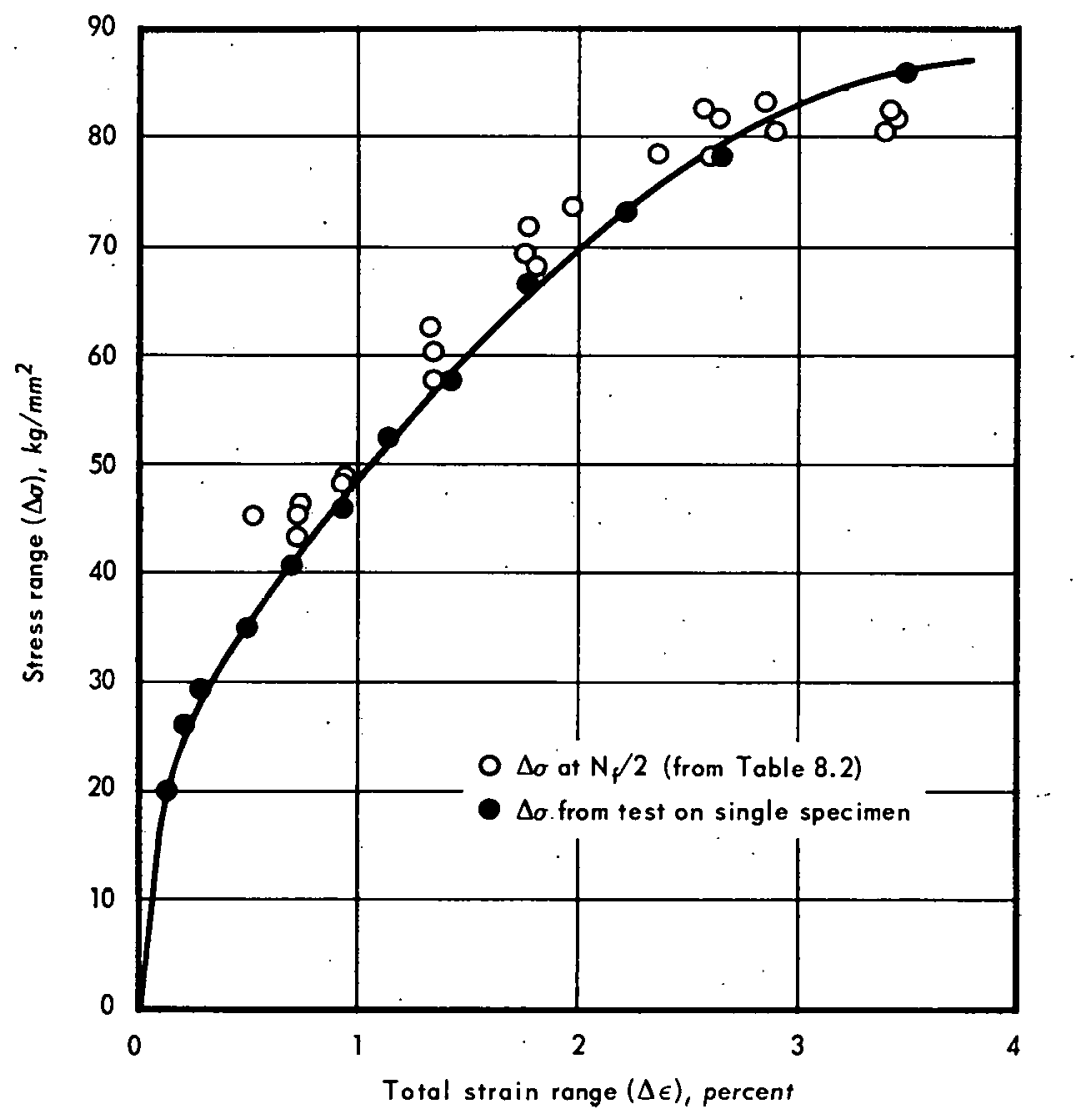

Fig. 8.8 - Cyclic stress - strain characteristics of Type 348 stainless steel at $430^{\circ} \mathrm{C}$

\footnotetext{
9 “'High-Temperature Materials Program Progress Report No. 58, Part A," GE-NMPO, GEMP-58A, April 29, 1966, pp. $25-29$.

${ }^{10}$ GEMP-400A, pp. 198-199.
} 
TABLE 8.3

LOW-CYCLE FATIGUE TEST RESULTS FOR TYPE 348 STAINLESS STEEL AT $650^{\circ} \mathrm{C}$ AND $816^{\circ} \mathrm{C}^{\mathrm{a}}$ (HEAT NO. 55700)

\begin{tabular}{|c|c|c|c|c|c|c|c|c|c|c|c|c|c|}
\hline \multirow{3}{*}{\multicolumn{3}{|c|}{ Test Identification }} & \multicolumn{3}{|c|}{ Axial Strain } & \multicolumn{3}{|c|}{ Diametral Strain } & \multirow{4}{*}{$\begin{array}{c}\text { Axial Stress } \\
\text { Stress Range } \\
\text { at } \mathrm{N}_{\mathrm{f}} / 2 \\
(\Delta \sigma), \mathrm{kg} / \mathrm{mm}^{2}\end{array}$} & \multicolumn{2}{|c|}{ Cyclic Rate } & \multirow{2}{*}{\multicolumn{2}{|c|}{ Fatigue Life }} \\
\hline & & & \multirow{3}{*}{$\begin{array}{l}\text { Total } \\
\text { Strain } \\
\text { Range } \\
(\Delta \epsilon), \% \\
\end{array}$} & \multirow{3}{*}{$\begin{array}{l}\text { Plastic } \\
\text { Strain } \\
\text { Range } \\
\left(\Delta \epsilon_{p}\right), \%\end{array}$} & \multirow{3}{*}{$\begin{array}{l}\text { Elastic } \\
\text { Strain } \\
\text { Range } \\
\left(\Delta \epsilon_{\mathrm{e}}\right), \%\end{array}$} & \multirow{3}{*}{$\begin{array}{c}\text { Total } \\
\text { Strain } \\
\text { Range } \\
\left(\Delta \epsilon_{d}\right), \%\end{array}$} & \multirow{3}{*}{$\begin{array}{l}\text { Plastic } \\
\text { Strain } \\
\text { Range } \\
\left(\Delta \epsilon_{\text {dp }}\right), \%\end{array}$} & \multirow{3}{*}{$\begin{array}{l}\text { Elastic } \\
\text { Strain } \\
\text { Range } \\
\left(\Delta \epsilon_{\mathrm{de}}\right), \%\end{array}$} & & \multirow{3}{*}{$\begin{array}{l}\text { Frequency of } \\
\text { Loading (f), } \\
\text { cycles/min }\end{array}$} & \multirow{3}{*}{$\begin{array}{c}\text { Axial } \\
\text { Sțrain } \\
\text { Rate }^{\mathrm{b}} \\
(\dot{\epsilon}), \mathrm{sec}^{-1}\end{array}$} & & \\
\hline & & & & & & & & & & & & \multirow{2}{*}{$\begin{array}{l}\text { Cycles to } \\
\text { Fracture } \\
\left(\mathbf{N}_{\mathbf{f}}\right)\end{array}$} & \multirow{2}{*}{$\begin{array}{l}\text { Cycles to 5\% } \\
\text { Load Reduction } \\
\text { Point }\left(\mathrm{N}_{5}\right)\end{array}$} \\
\hline $\begin{array}{l}\text { Test } \\
\text { No. }\end{array}$ & $\begin{array}{l}\text { Test } \\
\text { Stand }\end{array}$ & $\begin{array}{c}\text { Specimen } \\
\text { No. }\end{array}$ & & & & & & & & & & & \\
\hline \multicolumn{14}{|c|}{$650^{\circ} \mathrm{C}$} \\
\hline 1 & 2 & 351 & 3.43 & 3.00 & 0.43 & 1.63 & 1.50 & 0.13 & 71.7 & 3.33 & $3.8 \times 10^{-3}$. & 226 & 216 \\
\hline 2 & 2 & 356 & 2.59 & 2.16 & 0.43 & 1.21 & 1.08 & 0.13 & 68.8 & 4.44 & 3.8 & 286 & 268 \\
\hline 3 & 1 & 2-6 & 2. 57 & 2.14 & 0.43 & 1.20 & 1.07 & 0.13 & 63.1 & 4.44 & 3.8 & 398 & 377 \\
\hline 4 & 1 & $2-4$ & 2. 61 & 2.18 & 0.43 & 1.22 & 1.09 & 0.13 & 64.5 & 4.44 & . 3.9 & 412 & 381 \\
\hline 5 & 1 & 311 & 1. 74 & 1.35 & 0.39 & 0.80 & 0.68 & 0.12 & 57.4 & 6.67 & 3.8 & 834 & 815 \\
\hline 6 & 1 & 312 & 1.76 & 1.36 & 0.40 & 0.80 & 0.68 & 0.12 & 58.1 & 6.67 & 3.9 & 895 & 841 \\
\hline 7 & 1 & 283 & 1.68 & 1.28 & 0.38 & 0.76 & 0.64 & 0.12 & 57.7 & 6.67 & 3.7 & 1024 & 980 \\
\hline 8 & 2 & 354 & 1.37 & 0.99 & 0.38 & 0.61 & 0.50 & 0.11 & 57.4 & 8. 89 . & 4.1 & 1244 & 1229 \\
\hline 9 & 1 & $1-10$ & 1.14 & 0.79 & 0.35 & 0.50 & 0.40 & 0.10 & 52.3 & 10.67 & 4.1 & 1926 & 1850 \\
\hline 10 & 2 & $1-6$ & 0.93 & 0.61 & 0.32 & 0.40 & 0.31 & 0.09 & 53.1 & 13.3 & 4.1 & 4040 & 3770 \\
\hline 11 & 2 & $1-8$ & 0.93 & $0: 61$ & 0.32 & 0.40 & 0.30 & 0.10 & 52.3 & 13.3 & 4.1 & 4830 & 4630 \\
\hline 12 & 2 & $2-8$ & 0.75 & 0.48 & 0.27 & 0.32 & 0.24 & 0.08 & 50.2 & 17.8 & 4.4 & .8010 & 7310 \\
\hline 13 & 2 & $2-9$ & 0.71 & 0.45 & 0.26 & 0.30 & 0.22 & 0.08 & 51.6 & 17.8 & 4.2 & 8254 & 7490 \\
\hline 14 & 1 & 357 & 0.72 & 0.43 & 0.29 & 0.31 & 0.22 & 0.09 & - & 17.8 & 4. 3 & 12305 & - \\
\hline 15 & 1 & 1-2 & 0.53 & 0.24 & 0.29 & 0.21 & 0.12 & -0.09 & 43.0 & 26.7 & 4. 7 & 46140 & 44320 \\
\hline 16 & 1 & $2-11$ & $: 0.51$ & 0.24 & 0.27 & 0.20 & 0.12 & 0.08 & 44.5 & 26.7 & 4. 5 & 57650 & 55750 \\
\hline \multicolumn{14}{|c|}{$816^{\circ} \mathrm{C}$} \\
\hline 1 & 1 & 33 & 3. 26 & 3. 04 & 0.22 & 1.59 & 1.52 & 0.07 & 40.8 & 3.33 & $3.6 \times 10^{-3}$ & 214 & 140 \\
\hline 2 & 1 & 37 & 2.93 & 2. 74 & 0.19 & 1.42 & 1.36 & 0.06 & 41.0 & 3.33 & 3. 3 & 158 & 125 \\
\hline 3 & 1 & 57. & .3 .11 & 2.89 & 0.22 & 1.47 & 1.40 & 0.07 & 38.9 . & 3.33 & 3.4 & 150 & 122 \\
\hline 4 & 1 & 48 & 1.63 & 1.41 & 0.22 & 0.77 & 0.70 & 0.07 & 38.9 & 5.93 & 3. 2 & 290 & 230 \\
\hline 5 & 1 & 52 & $: 1.63$ & 1.41 & 0.22 & 0.77 & 0.70 & 0.07 & 40.8 & 5.93 & 3.2 & 304 & 230 \\
\hline 6 & 1 & 59 & 1.63 & 1.43 & 0.20 & 0.78 & 0.72 & 0.06 & 37.9 & 6.67 & 3.6 & 304 & 220 \\
\hline 7 & 2 & 333 & 1.71 & 1.47 & 0.24 & 0.81 & 0.74 & 0.07 & 36.9 & 6.67 & 3.8 & 358 & 283 \\
\hline 8 & 1 & 46 & 1.26 & 1.04 & 0.22 & 0.58 & 0.52 & 0.06 & 38.2 & 8. 89 & 3.7 & 477 & 380 \\
\hline 9 & 1 & 31 & 1.28 & 1.06 & 0.22 & 0.59 & 0.53 & 0.06 & 37.8 & 8. 89 & 3: 8 & 662 & 390 \\
\hline 10 & 1 & 51 & 0.88 & 0.69 & 0.19 & 0.40 & 0.34 & 0.06 . & 36.1 & 13.3 & 3.9 & 922 & 600 \\
\hline 11 & 1 & 56 & 0.88 & 0.68 & 0.20 & 0.40 & 0.34 & 0.06 & 32.6 & $13: 3$ & 3.9 & 1335 & 860 \\
\hline 12 & 1 & 55 & 0.69 & 0.50 & 0.19 & 0.31 & 0.25 & 0.06 & 32.4 & 17.8 & 4.1 & 2690 & 2210 \\
\hline 13 & 1 & 41 & 0.68 & 0.49 & 0.19 & 0.30 & 0.24 & 0.06 & 28.9 & 17.8 & 4.0 & 1974 & 1820 \\
\hline 14 & 1 & 42 & 0.64 & 0.46 & 0.18 & 0.28 & 0.23 & 0.05 & 33. 9 & 17.8 & 3.8 & .1956 & 1700 \\
\hline 15 & 1 & 49 & 0.50 & 0.36 & 0.14 & 0.22 & 0.18 & 0.04 & 31.0 & 26.7 & 4. 4 & 9874 & 9610 \\
\hline 16 & 1 & 43 & 0.46 & 0.32 & 0.14 & 0.20 & 0.16 & 0.04 & 29.6 & 26.7 & 4. 1 & 9772 & $\mathbf{9 2 8 0}$ \\
\hline 17 & 1 & $2-10$ & 0.31 & 0.16 & 0.15 & 0.12 & 0.08 & 0.04 & 23.7 & 26.7 & 2.7 & 98130 & - \\
\hline
\end{tabular}

Control mode: Diametral strain

Mode shape: Triangular with zero mean strain

Starting condition: Compression first

$\mathbf{b}_{\dot{\boldsymbol{\epsilon}}}=(\mathbf{f})(\Delta \epsilon) / 30$ 


\section{3 ANALYTICAL DETERMINATION OF STRESS DISTRIBUTION IN NOTCHED SHEET} SPECIMENS OF FINITE LENGTH

Notched test specimens are frequently used to investigate the effect of stress (or strain) concentration on material behavior under cyclic loading conditions. Whenever such specimens are employed, precise knowledge of the elastic stress distribution is important, even if plastic deformation occurs in the actual experiment. Both the maximum stress and the stress gradient in the notch, which characterize the severity of the stress concentration in the specimen, are usually of particular interest. However, it is also often desirable to know how short a specimen can be made without significantly affecting the distribution of stresses and strains in the notch region.

For sheet specimens, boundary collocation methods have proven useful in accurately predicting elastic stress distributions in specimens of finite length. Gross, et al. ${ }^{11}$ used such a method to obtain the stresses in a tensile specimen with a single-edge crack; Kobayashi, et al. ${ }^{12}$ performed a similar analysis for a tensile specimen with an interior crack. A cumputer program, developed at GE-NMPO for the analysis of perforated plates, ${ }^{13}$ was used to compute the stresses in sheet specimens with holes or semi-circular notches. Presented below are partial results for a short specimen with a pair o: semi-circular notches subjected to: (1) uniform extension, (2) uniform tension, and (3) pure bending.

The geometry and the loading conditions considered are defined in Figure 8.9. Because of the symmetry about two axes, it is sufficient in the mathematical analysis to consider only one quadrant of the structure, as indicated in Figure 8.10. The computer program mentioned above permits boundary conditions to be satisfied exactly along the notch and along the horizontal axis. For the other parts of the boundary (BC, $C D, D E$ ), stresses and displacements can be specified for a finite number of discrete points. Stresses may also be specified by their average value between two points on the boundary. Table 8.4 summarizes the conditions that were specified to obtain the sclutions for the problems considered here. With reference to Figure 8.10, the notation used in the table is apparent from the following examples:

$\sigma_{X}(7) \quad=$ normal stress in the $x$-direction at point 7

$\tau_{x y}(3)=$ shear stress in the $x$ - or $y$-direction at point 3

$\bar{\sigma}_{y}(9,11)=$ average value of the normal stress in the $y$-direction between points 9 and 11

$\mathrm{U}_{\mathrm{X}}(5)=$ displacement in the $\mathrm{x}$-direction at point 5

Stresses and displacements were determined for points along the entire boundary in Figure 8.10. For example, the stresses along the minimum cross section are given in Table 8.5. It is interesting to note that in spite of the short length of the specimen, the stresses obtained at the notch are very close to the stresses reported for very long specimens. ${ }^{14,15}$ With minor changes in the computer program, it will also be possible to obtain the stress gradient at a point as well as corresponding information in terms of strain.

\footnotetext{
${ }^{11}$ B. Gross, J. E. Strawley, and W. F. Brown, "Stress-Intensity Factors for a Single-Edge-Notch Tension Specimen by Boundary Collocation of a Stress Function," NASA TN D-2395, August 1964.

${ }^{12}$ A. S. Kobayashi, R. D. Cherepy, and W. C. Kinsel, "A Numerical Procedure for Estimating the Stress Intensity Factor of a Crack in a Finite Plate," Journal of Busic Engineering, Transactions of the ASME, Vol.84, 1964, pp. 681-684.

${ }^{13}$ T. Slot and J. P. Yalch, "Stress Analysis of Plane Perforated Structures by Point-Wise Matching of Boundary Conditions," Nuclear Engineering and Design, Vol. 4, 1966, pp. 163-176.

${ }^{14}$ A. Atsumi, "Stress Functions for an Infinite Strip with Semi-Circular Notches," 'Trans. Japan Soc. Mech. Engrg., Vol. 20, 1954, pp. 699-706 (in Japanese).

${ }^{15}$ C. B. Ling, "On the Stresses in a Notched Strip," Journal of Applied Mechanics, Vol. 19, 1952, pp. 141-146.
} 

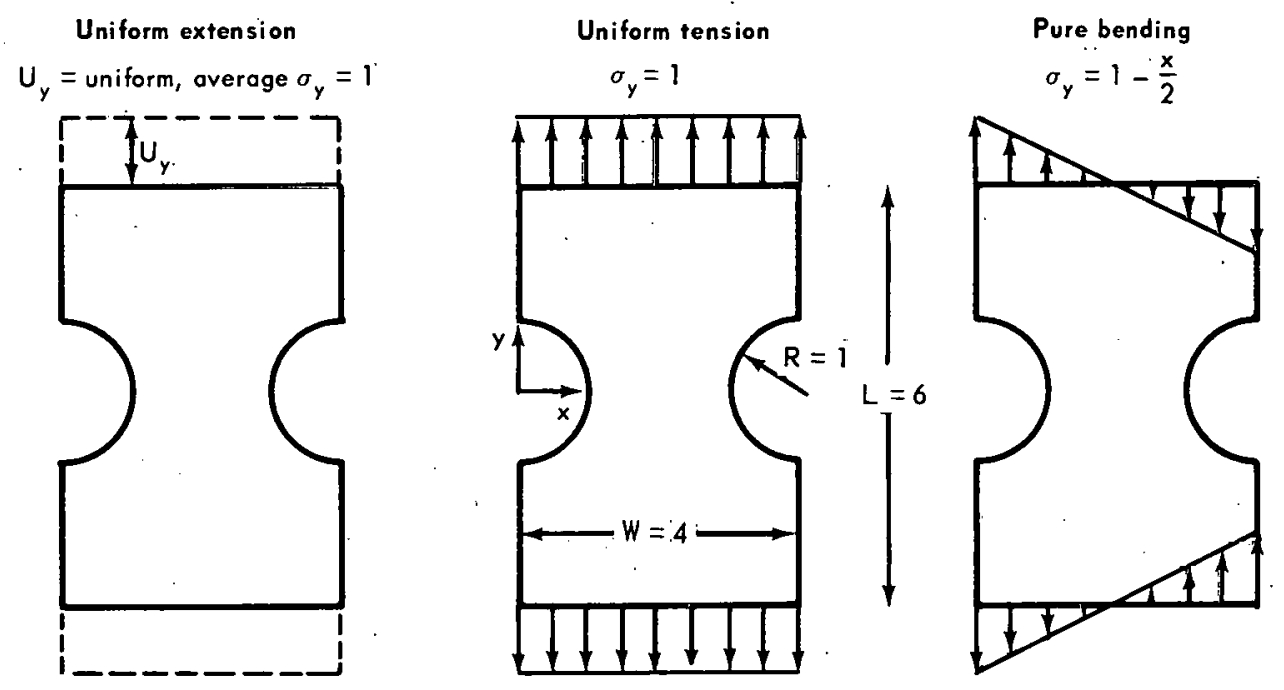

Fig. 8.9 - Short, notched sheet specimen subjected to three loading conditions

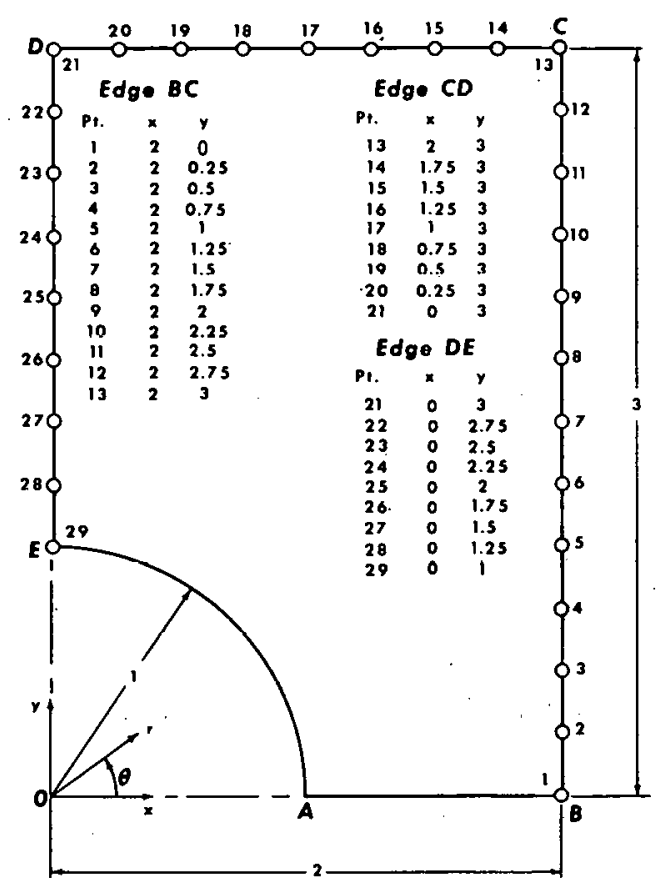

Fig. 8.10-Basic element considered in analysis of notched strip problems 
TABLE 8.4

BOUNDARY CONDITIONS SPECIFIED FOR SECTIONS BC, CD, AND DE

Problem 1

$$
\begin{aligned}
& \bar{\tau}_{x y}(1,3)=\bar{\tau}_{x y}(3,5)=\bar{\tau}_{x y}(5,7)=\bar{\tau}_{x y}(7,9)=\bar{\tau}_{x y}(9,11)=\bar{\tau}_{x y}(11,13)=0 \\
& U_{x}(1)=U_{x}(3)=U_{x}(5)=U_{x}(7)=U_{x}(9)=U_{x}(11)=U_{x}^{\prime}(13) \\
& \bar{\tau}_{\mathrm{xy}}(13,15)=\bar{\tau}_{\mathrm{xy}}(15,17)=\bar{\tau}_{\mathrm{xy}}(17,19)=\bar{\tau}_{\mathrm{xy}}(19,21)=0 \\
& \mathrm{U}_{\mathrm{y}}(13)=\mathrm{U}_{\mathrm{y}}(14)=\mathrm{U}_{\mathrm{y}}(15)=\mathrm{U}_{\mathrm{y}}(16)=\mathrm{U}_{\mathrm{y}}(17)=\mathrm{U}_{\mathrm{y}}(18)=\mathrm{U}_{\mathrm{y}}(19)=\mathrm{U}_{\mathrm{y}}(20)=\mathrm{U}_{\mathrm{y}}(21) \\
& \bar{\sigma}_{\mathrm{y}}(13,21)=1 \\
& \bar{\tau}_{x y}(21,23)=\bar{\tau}_{x y}(23,25)=\bar{\tau}_{x y}(25,27)=\bar{\tau}_{x y}(27,29)=0 \\
& \bar{\sigma}_{x}(21,23)=\bar{\sigma}_{x}(23,25)=\bar{\sigma}_{x}(25,27)=\bar{\sigma}_{x}(27,29)=0 \\
& \tau_{X y}(13)=\tau_{X y}(21)=\sigma_{x}(21)=\sigma_{x}(29)=0
\end{aligned}
$$

Problem 3

$$
\begin{aligned}
& \bar{\sigma}_{x}(1,3)=\bar{\sigma}_{x}(3,5)=\bar{\sigma}_{x}(5,7)=\bar{\sigma}_{x}(7,9)=\bar{\sigma}_{x}(9,11)=\bar{\sigma}_{x}(11,13)=0 \\
& U_{y}(3)=U_{y}(5)=U_{y}(7)=U_{y}(9)=U_{y}(11)=U_{y}(13)=0 \\
& \bar{\tau}_{x y}(13,15)=\bar{\tau}_{x y}(15,17)=\bar{\tau}_{x y}(17,19)=0 \\
& \bar{\sigma}_{y}(13,14)=0.06248, \bar{\sigma}_{y}(14,15)=0.18752, \bar{\sigma}_{y}(15,16)=0.31248, \bar{\sigma}_{y}(16,17)=0.43752, \\
& \bar{\sigma}_{y}(17,18)=0.56248, \bar{\sigma}_{y}(18,19)=0.68752, \bar{\sigma}_{y}(19,20)=0.81248, \bar{\sigma}_{y}(20,21)=0.93752 \\
& \bar{\tau}_{x y}(21,23)=\bar{\tau}_{x y}(23,25)=\bar{\tau}_{x y}(25,27)=\bar{\tau}_{x y}(27,29)=0 \\
& \bar{\sigma}_{x}(21,23)=\bar{\sigma}_{x}(23,25)=\bar{\sigma}_{x}(25,27)=\bar{\sigma}_{x}(27,29)=0 \\
& \tau_{x y}(13)=\sigma_{y}(13)=\tau_{x y}(21)=\sigma_{x}(21)=\sigma_{x}(29)=0, \sigma_{y}(21)=1
\end{aligned}
$$


TABLE 8. 5

STRESSES IN MINIMUM CROSS SECTION $(y=0)$

\begin{tabular}{|c|c|c|c|c|c|c|}
\hline \multirow{2}{*}{$\overline{\frac{X}{R}}$} & \multicolumn{2}{|c|}{ Problem 1} & \multicolumn{2}{|c|}{ Problem 2} & \multicolumn{2}{|c|}{ Problem 3} \\
\hline & $\sigma_{\mathrm{x}}$ & $\sigma_{y}$ & $\sigma_{\mathbf{x}}$ & $\sigma_{y}$ & $\sigma_{x}$ & $\sigma_{\mathrm{y}}$ \\
\hline 1 & 0.000 & 3.256 & 0.000 & 3.259 & 0.001 & 5.381 \\
\hline 1.1 & 0.247 & 2.722 & 0.251 & 2.736 & 0.373 & 4.090 \\
\hline 1.2 & 0.385 & 2. 364 & 0.398 & 2. 378 & 0.526 & 3.187 \\
\hline 1.3 & 0.463 & 2.117 & 0.485 & 2.128 & 0.565 & 2.515 \\
\hline 1.4 & 0.506 & 1.945 & 0.535 & 1.950 & 0.540 & 1.988 \\
\hline 1.5 & 0.529 & 1.822 & 0.565 & 1.821 & 0.480 & 1.555 \\
\hline 1.6 & 0.541 & 1.735 & 0.582 & 1.729 & 0.399 & 1.186 \\
\hline 1.7 & 0.546 & 1.674 & 0.591 & 1.664 & 0.307 & 0.858 \\
\hline 1.8 & 0.548 & 1.634 & 0.596 & 1.621 & 0.208 & 0.558 \\
\hline 1.9 & 0.549 & 1.612 & 0.599 & 1.597 & 0.105 & 0.275 \\
\hline 2 & 0.549 & 1.604 & 0.599 & 1.589 & 0.001 & -0.001 \\
\hline
\end{tabular}

The accuracy of the solutions obtained by boundary collocation depends on how well the boundary conditions are approximated all along the boundary. Inspection of the stresses and displacements listed in Table 8.6 for the points identified in Figure 8.10 shows that boundary conditions for the three problems of interest were satisfied in good approximation. The numbers listed are the deviations from a true value of zero and those with absolute values less than 0.0005 were rounded off to 0 . These deviations should not significantly affect the stress field in the notch region.

It should be noted that the even nur:bsred points in Figure 8.10 were not used in prescribing displacement boundary conditions, except in Problem 1 where both the odd and even number ed points along $C D$ were used. For this problem, Table 8.6 does not provide information on the vertical displacements at intermediate points on $C D$, but the computer solutions showed that these displacements multiplied by $\mathbf{E}$ did not deviate by more than 0.002 from the value for point 13, where $\mathrm{EU}_{\mathrm{y}}=4.317$.

\subsection{SUMMARY AND CONCLUSIONS}

During CY -66 , the fatigue laboratory was expanded by the addition of three test stands. In all, four stands, each consisting of a hydraulic fatigue machine and an induction-heating system, are now available for the evaluation of fatigue properties of heat-resistant alloys.

Fatigue data generated to date for Type 348 stainless steel are summarized herein. The information furnishes insight into the fatigue life of laboratory specimens as a function of strain amplitude and temperature. A distinction was made between $N_{f}$, the number of cycles to complete fracture, and $N_{5}$, the number of cycles to the point in the test where the load range has decreased 5 percent from its steady value due to a propagating crack: Whereas the data presented are for a strain rate of approximately 0.2 percent per second, similar data are being generated at this time with strain rates smaller by factors of 10 and 100.

\subsection{PLANS AND RECOMMENDATIONS}

A technique will be perfected that will permit the axial strain to be controlled in conjunction with diametral strain measurement. This technique is based on electronic computation of the axial strain from the signals generated by the load cell and the diametral strain extensometer. While retaining the advantages of hourglass specimens and diametral strain sensing, the axial strain will be the test parameter programmed in the fatigue test. Initial experience with this technique has been quite favorable. 
TABLE 8. 6

INSPECTION OF BOUNDARY CONDITIONS ${ }^{a}$

\begin{tabular}{|c|c|c|c|c|c|c|}
\hline \multirow[b]{2}{*}{ Point } & \multicolumn{2}{|c|}{ Problem 1} & \multicolumn{2}{|c|}{ Problem 2} & \multicolumn{2}{|c|}{ Problem 3} \\
\hline & ${ }^{\tau} \mathrm{xy}$ & $\mathbf{E U}_{\mathbf{X}}{ }^{\prime}$ & $\tau_{x y}$ & $E U_{x}^{\prime}$ & $\sigma_{\mathbf{x}}$ & $\mathrm{EU}_{\mathrm{y}}$ \\
\hline$\overline{1}$ & 0 & 0 & 0 & 0 & 0 & 0 \\
\hline 2 & 0 & 0 & 0 & 0 & -0.001 & 0 \\
\hline 3 & 0 & 0 & 0 & 0 & -0.001 & -0.001 \\
\hline 4 & 0 & 0 & 0 & 0 & -0.001 & -0.001 \\
\hline 5 & 0 & 0 & 0 & 0 & 0 & -0.001 \\
\hline 6 & 0 & 0 & 0 & 0 & 0 & -0.001 \\
\hline 7 & 0 & 0 & 0 & 0 & 0 & -0.001 \\
\hline 8 & 0 & 0 & 0 & 0 & 0.001 & -0.001 \\
\hline 9 & -0.001 & 0 & 0.001 & 0 & 0.001 & 0 \\
\hline 10 & -0.002 & 0 & 0 & 0.001 & -0.001 & -0.001 \\
\hline 11 & -0.001 & 0 & -0.006 & 0 & -0.012 & -0.001 \\
\hline 12 & 0 & 0 & -0.006 & -0.005 & 0 & -0.015 \\
\hline \multirow[t]{2}{*}{13} & 0 & 0 & 0 & 0 & 0 & -0.001 \\
\hline & $\tau_{\mathrm{xy}}$ & $\mathrm{EU}_{\mathrm{y}}^{\prime}$ & $\sigma_{y^{-1}}$ & $\tau_{\mathbf{x y}}$ & $\sigma_{y}-\left(1-\frac{x}{2}\right)$ & $\tau_{x y}$ \\
\hline 13 & 0 & 0 & -0.040 & 0 & 0.001 & 0 \\
\hline 14 & -0.001 & 0 & 0.012 & -0.001 & -0.001 & 0.001 \\
\hline 15 & 0.006 & 0 & 0.002 & -0.009 & -0.004 & -0.025 \\
\hline 16 & 0 & 0 & 0 & 0.003 & -0.003 & -0.002 \\
\hline 17 & -0.005 & 0 & 0 & 0.006 & -0.005 & 0.033 \\
\hline 18 & 0 & 0 & -0.002 & 0 & -0.002 & 0.006 \\
\hline 19 & 0.004 & 0 & 0.004 & -0.005 & 0.002 & -0.045 \\
\hline 20 & -0.001 & 0 & 0 & 0.001 & -0.005 & 0.001 \\
\hline \multirow[t]{2}{*}{21} & 0 & 0 & 0 & 0 & 0 & 0 \\
\hline & $\sigma_{\mathbf{x}}$ & $\tau_{\mathrm{xy}}$ & $\sigma_{\mathrm{x}}$ & $\tau_{x y}$ & $\sigma_{\mathbf{x}}$ & $\tau_{\mathrm{xy}}$ \\
\hline 21 & 0 & 0 & 0 & 0 & 0 & 0 \\
\hline 22 & -0.002 & -0.002 & -0.001 & 0 & 0.009 & 0.005 \\
\hline 23 & 0.008 & 0.003 & 0 & 0.007 & -0.028 & 0.025 \\
\hline 24 & 0 & 0.001 & 0.001 & 0.001 & 0.004 & -0.005 \\
\hline 25 & -0.008 & -0.008 & -0.003 & -0.009 & 0.019 & -0.007 \\
\hline 26 & 0 & -0.003 & 0 & -0.004 & -0.003 & -0.001 \\
\hline 27 & 0.007 & 0.019 & 0.003 & 0.022 & -0.008 & 0.016 \\
\hline 28 & -0.005 & 0.005 & -0.005 & 0.006 & -0.0004 & 0.011 \\
\hline 29 & 0 & 0 & 0 & 0 & 0 & 0 \\
\hline
\end{tabular}

${ }^{a} U_{x}^{\prime}=U_{x}-U_{x}(1) ; U_{y}^{\prime}=U_{y}-U_{y}(13) ; E=$ modulus of elasticity; absolute values smaller than 0.0005 entered in table as 0 .

The ability to control axial strain will especially enhance the quality of strain-controlled tests with hold times. Tests conducted at temperatures in the creep range exhibited considerable stress relaxation during the hold periods. This results in an increase of plastic strain accompanied by a decrease in elastic strain. Consequently, the relationship between diametral and axial strain varies so that a hold in diametral strain will not produce a hold in the axial strain. As long as the plastic strain is large relative to the elastic strain, the effect is not so important, but when this is not the case, the axial strain should preferably be programmed since it is the test parameter correlated with fatigue life.

Another advantage of programming the axial strain is that cyclic hardening or softening does not affect the amplitude of the axial strain variation, which it does when the diametral strain is programmed. In addition, modifications of the control equipment will make it possible to program the plastic portion of the strain range in the specimen. 
A test program is in progress on Type 348 stainless steel in which the effect of strain rate on fatigue life is being investigated. Tests completed to date show that there is a significant decrease in fatigue life with a decrease in strain rate at $816^{\circ} \mathrm{C}$. This work will continue at temperatures of $650^{\circ} \mathrm{C}$ and $816^{\circ} \mathrm{C}$.

Testing with hold times has been suspended pending the development of axial strain programming capability. It is expected that such testing will be resumed during the next quarter.

Metallographic and fractographic analyses of fractured fatigue specimens is underway and will be continued.

A limited number of Type 304 stainless steel specimens will be tested to augment fatigue data already generated for Type 348 stainless steel.

Type 316 stainless steel has been received and will be tested in the same way as the Types 348 and 304 stainless steels. 


\section{ADVANCED PRESSURE VESSEL MATERIALS}

\section{(57021)}

\section{F. C. Robertshaw, ${ }^{*}$ H. R. Stephan}

The objective of this program is to determine the applicability of high-strength steels and alloys to nuclear reactor pressure vessels. The program results from a need to exploit high-strength materials for pressure vessels to achieve improved safety and to fulfill other criteria, and from a Naval Research Laboratory (NRL) finding that two highstrength alloys, a $12 \mathrm{Ni}-5 \mathrm{Cr}-3 \mathrm{Mo}$ maraging steel and a $7.5 \mathrm{Ni}-\mathrm{Cr}-\mathrm{Mo}$ steel, possess significant radiation resistance. ${ }^{1}$

A review of the materials which are presently approved for Class $A$ pressure vessels under Section III of the ASME Boiler and Pressure Vessel Code disclosed that, at room temperature, only a few have minimum tensile strengths in excess of $7032 \mathrm{~kg} / \mathrm{cm}^{2}(100,000$ psi) and minimum yield strengths in excess of $3516 \mathrm{~kg} / \mathrm{cm}^{2}(50,000 \mathrm{psi})$. Design stress intensity values, based on the lower of one-third minimum tensile strength or two-thirds minimum yield strength, do not exceed $3164 \mathrm{~kg} / \mathrm{cm}^{2}(45,000 \mathrm{psi})$ at any temperature from $38^{\circ}$ to $371^{\circ} \mathrm{C}$ inclusive. Although allowable stress levels for the almost universally used A-212B and A-302B materials do not exceed $1877 \mathrm{~kg} / \mathrm{cm}^{2}(26,700 \mathrm{psi})$, a number of highstrength steels and alloys could attain two to three times the level for A-302B." Using such materials would permit the wall thickness of a vessel based on A-302B to be reduced from, for example, $30 \mathrm{~cm}$ to $15 \mathrm{~cm}$ or even $10 \mathrm{~cm}$. In summary, the use of stronger materials than those currently used would permit one or more of the following to be achieved:

1. Greater reliability and safety.

2. Reduced weight and section size leading to more compact construction and ease in handling and assembly. (In certain instances, this may make on-site fabrication practicable.)

3. Improved reactor performance resulting from higher attainable pressure and/or temperatures. (This would appear to apply particularly to new concepts for gas-cooled reactors and super-critical pressurized water reactors.)

The foregoing advantages make it desirable, if not mandatory, to examine carefully the many special steels and alloys which possess far greater strength levels than those which are Code-approved. While these materials will necessitate greater unit costs for materials and processing, it is believed that overall reactor economics may disclose an acceptable cost balance, particularly in view of such intangibles as greater safety or equal safety with less weight.

\footnotetext{
*Project leader and principal investigator.

${ }^{1}$ L. E. Steele, J. R. Hawthome, and K. A. Gray, Jr., "Neutron .Irradiation Embrittlement of Several High-Strength Steels," Naval Research Laboratory, Washington, D.C., NRL-6419, September 7, 1966.
} 


\subsection{EXPERIMENTAL PROGRAM}

\section{MATERIAL SELECTION}

A preliminary review of potential materials, including discussions with NRL, alloy vendors, and others, has led to the selection of four high-strength alloys for evaluation. All are capable of achieving nominal 0.2 percent yield and tensile strengths of about 10,550 $\mathrm{kg} / \mathrm{cm}^{2}(150,000 \mathrm{psi})$ and $11,950 \mathrm{~kg} / \mathrm{cm}^{2}(170,000 \mathrm{psi})$, respectively, or greater. Properly heat-treated, all possess favorable ductile-to-brittle fracture transition characteristics. Three of the alloys, a $12 \mathrm{Ni}-5 \mathrm{Cr}-3 \mathrm{Mo}$ maraging steel, a precipitation-hardening stainless steel designated $\mathrm{PH} 13-8 \mathrm{Mo}$, and a $7.5 \mathrm{Ni}-\mathrm{Cr}-\mathrm{Mo}$ high-strength steel, are developmental while the fourth is the commercial Inconel alloy 718. Among these four, the Inconel alloy 718 offers the greatest potential for significantly increased pressure vessel operating temperatures since its properties at $480^{\circ} \mathrm{C}$ are more than 90 percent of the room-temperature values. A comparison of the room-temperature mechanical properties of these alloys and selected pressure vessel steels is presented in Table 9.1.

TABLE 9.1

ROOM-TEMPERATURE MECHANICAL PROPERTIES OF VARIOUS STEELS AND CANDIDATE MATERIALS FOR PRESSURE VESSELS

\begin{tabular}{|c|c|c|c|c|c|c|c|c|c|c|}
\hline \multirow[b]{2}{*}{ Mąterial } & \multirow{2}{*}{$\begin{array}{l}\text { Form and } \\
\text { Heat Treatment }\end{array}$} & \multicolumn{2}{|c|}{$\begin{array}{c}0.2 \% \\
\text { Yield Strength, }\end{array}$} & \multicolumn{2}{|c|}{$\begin{array}{r}\text { Tensile } \\
\text { Strength, }\end{array}$} & \multirow{2}{*}{$\underset{\%}{\text { Elongation; }}$} & \multirow{2}{*}{$\begin{array}{c}\text { Reduction } \\
\text { Area, } \\
\% .\end{array}$} & \multicolumn{2}{|c|}{ CHARPY VEE } & \multirow[b]{2}{*}{ Reference } \\
\hline & & psi & $\mathrm{kg} / \mathrm{cm}^{2}$ & psi. : & $\mathrm{kg} / \mathrm{cm}^{2}$ & & & ft-lbs & kg-meters- & \\
\hline A212-B & $\dot{2} .54 \mathrm{~cm} \mathrm{plate}^{\mathrm{a}}$ & $34: 1$ & 2,400 & 67.1 & 4,710 & 33.0 & 64.0 & 35 & 4.84 & 1 \\
\hline A302-B & $17.8 \mathrm{~cm}$ plate $\mathrm{b}$. & 53.1 & 3,720 & 79.0 & 5,510 & 25.2 & 58.1 & 40 . & 5.53 & 2 \\
\hline $7.5 \mathrm{NI}-\mathrm{Cr}-\mathrm{Mo}$ & $2.54 \mathrm{~cm}$ platec & 148.8 & 10,400 & 169.4 & 11,800 & 19.0 & 68.7 & $60^{\circ}$ & 8. 32 & 3 \\
\hline $12-5-3$ & $1.27 \mathrm{~cm}$ plate & 169.0 & 11,850 & 174.4 & 12,250 & 16.4 & 72.0 & 75 & 10.40 . & 4 \\
\hline \multicolumn{11}{|l|}{ Maraging } \\
\hline PH13-8Mo & $\begin{array}{l}7.6 \times 20.3 \mathrm{~cm} \\
\text { billete }\end{array}$ & 187.0 & 13,070 & 195.0 & 13,600 & 14.7 & 69.0 & 110 & 15.20 & 5 \\
\hline $\begin{array}{l}\text { Inconel } \\
\text { alloy } 718\end{array}$ & barf & 172.0 & 11,050 & 208.0 & 14,600 & 21.0 & - & - & - & 6 \\
\hline
\end{tabular}

a615 ${ }^{\circ} \mathrm{C}$ for $2 \mathrm{hr}-$ air cooled.

biven a complex heat treatment to simulate fabrication of a large pressure vessel.

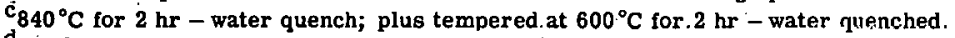

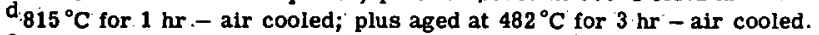

$1000^{\circ} \mathrm{C}$ for $0.5 \mathrm{hr}$ - air cooled; plus aged at $570^{\circ} \mathrm{C}$ for $1 \mathrm{hr}$ - air cooled.

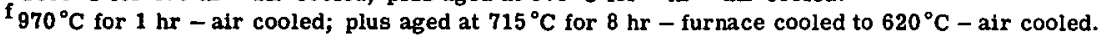

REFERENCES

1. "Studies of Welding Procedures-Part III", Supplement to Welding Journal, May 1966, pp. 193s-201s.

2. E. T. Wessel and Witt Pryle, "Brittle Fracture Characteristics of a Reactor Prcssure-Vessel Steel", Welding Journal, Vol. 40, No. 1, January 1961, pp. 41s-48s.

3. L. E. Steele, J. R. Hawthorne, and K. A. Gray,Jr., "Neutron Irradiation Embrittlement of Several Higher Strength Steels", Naval Research Laboratory, Washington, D.C., NRL-Report 6419, Sept. 7, 1966.

4. R. J. Knoth and W. A. Petersen; "The Welding of $12 \%$ Nickel Maraging Steels", Welding Journal, Vol. 44, No. 1, Welding Res. Supplement, 1965, pp. 21s-26s.

5. A. F. Hoence and D. B. Roach, "New Developments in High-Strength Stainless Steels", BMT Defense Information Center, DMIC-223, January 3, 1966.

6. Bulletin- "High-Temperature High Strength Nickel Base Alloys", International Nickel Co., 1964.

In addition to strength, the selected materials may possess certain other advantages. For example, the $12 \mathrm{Ni}-5 \mathrm{Cr}-3 \mathrm{Mo}$, $\mathrm{PH} 13-8 \mathrm{Mo}$, and Inconel alloy 718 : may require only relatively low-temperature aging after welding instead of a more complex heat treatment. It is also probable that the latter two materials are sufficiently corrosion resistant that they may not require "buttering" on internal surfaces with stainless steel.

\section{MATERLAL EVALUATION}

Although procurement of the $7.5 \mathrm{Ni}-\mathrm{Cr}-\mathrm{Mo}$ steel must await completion of further development by the vendor, the other three selected alloys were procured in plate form and weld filler metal was also obtained for each. These test materials are described in Table 9.2. 
TABLE 9.2

DESCRIPTION OF TEST MATERIALS

\begin{tabular}{|c|c|c|c|c|c|c|c|c|c|c|c|c|c|c|c|c|c|c|c|}
\hline \multirow[b]{2}{*}{ Material } & \multirow[b]{2}{*}{ Heat No. } & \multirow{2}{*}{$\begin{array}{c}\text { Melting } \\
\text { Procedure }\end{array}$} & \multirow[b]{2}{*}{ Size, $\mathrm{cm}$} & \multirow[b]{2}{*}{ Condition } & \multicolumn{15}{|c|}{ Vendor's Chemical Aralysis, wt \% } \\
\hline & & & & & $\bar{C}$ & $\mathrm{Mn}$ & $\mathbf{P}$ & $\mathrm{S}$ & $\mathbf{S i}$ & $\mathrm{Cr}$ & $\mathrm{Ni}$ & $\mathbf{T i}$ & Al & Mo & $\mathrm{Nb}+\mathrm{Ta}$ & Co & $\mathrm{Cu}$ & B & $\mathrm{Fe}$ \\
\hline \multirow[t]{2}{*}{$\begin{array}{l}12-\bar{\nu}-3 \\
\text { Maraging }\end{array}$} & 01378 & $A M+V C E M$ & 2. $7 \times 61 \times 61$ & $\begin{array}{l}815^{\circ} \mathrm{C} \text { for } 1 \mathrm{hr}- \\
\text { air cool }\end{array}$ & 0.02 & 0.06 & 0.006 & 0.006 & 0.06 & 5.00 & 11.90 & 0.13 & 0.37 & 3.08 & - & - & - & - & Bal \\
\hline & 01434 & $A M+V C E M$ & $\begin{array}{l}\text { 0.32 Dia. } \times \text { spool } \\
\text { (filler metail) }\end{array}$ & & 0.02 & 0.01. & 0.005 & 0.008 & 0.02 & 2. 75 & 11.97 & 0.33 & 0.39 & 2.63 & - & - & - & - & Bal \\
\hline \multirow[t]{2}{*}{ PH13-8Mo } & VC-5281-1A & IVM+VCEM & $1.27 \times 30.5 \times 183$ & $\begin{array}{l}1000^{\circ} \mathrm{C} \text { for } 0.5 \mathrm{hr}- \\
\text { air cool }\end{array}$ & 0.042 & 0.02 & 0.003 & 0.004 & 0.02 & 12.58 & 8. 07 & - & 1.11 & 2. 06 & - & - & - & - & Bal \\
\hline & VC -5178 & IVM+VCEM & $\begin{array}{l}0.155 \text { Dia. } x \text { spool } \\
\text { (filler meta } 2 \text { ) }\end{array}$ & $\begin{array}{l}\text { Overaged and } \\
\text { cold drawn. }\end{array}$ & 0.044 & - & 0.002 & 0.003 & 0.016 & 12.74 & 8. 58 & - & 0.76 & 2. 20 & - & - & - & - & Bal \\
\hline \multirow{2}{*}{$\begin{array}{l}\text { Inconel } \\
\text { df } 718\end{array}$} & O2AOES & IVM & $2.54 \times 96 \times 140$ & As-hot-rolled & 0.02 & 0.10 & 0.02 & 0.007 & 0.18 & 18.27 & 53.28 & 1.01 & 0.54 & 3.07 & 5.10 & 0.06 & 0.04 & 0.0032 & 18.30 \\
\hline & $4878 \mathrm{E}$ & IVM & $\begin{array}{l}0.32 \text { Dia. } \times 91 \\
\text { (filler metai) }\end{array}$ & As-cold-drawn & 0.04 & 0.30 & 0.011 & 0.007 & 0.18 & 18.39 & 52.95 & 0.84 & 0.14 & 3.11 & 4.76 & 0.05 & 0.03 & 0.0023 & 18. 95 \\
\hline
\end{tabular}

a IVM - Induction vacuum melt

VCEM - Vacuum consumable electrode melt

AM - Air melt. 
All of the materials were subjected to non-destructive inspection using fluorescent penetrant, radiographic, and ultrasonic techniques, and were found to be essentially sound.

For each of the materials, specimens are being prepared to ascertain base-metal tensile and impact properties versus temperature as a function of rolling direction. In addition, experimental welds are being made on each material to determine weldability as evidenced by weld soundness, ductility, and weld strength efficiencies. Thermal stability studies are in progress to identify maximum use temperature. Test specimens from a section of each plate are also being prepared for NRL for determination of irradiation effects on tensile and impact properties; a total of 135 impact specimens and 14 tensile blanks are involved.

Four Inconel alloy 718 weldments in $2.54-\mathrm{cm}$-thick plate were completed; two were for preparation of all-weld tensile test specimens and two were for weld-joint tensile and impact tests. The two weld-joint designs shown in Figure 9.1 were used in the preparation of the weldments. Joint No. 1 was used for the all-weld test specimens but could not be used for joint test specimens due to excessive distortion caused by shrinkage of the weld which available fixtures could not prevent. Accordingly, joint No. 2 was used for weldjoint tests.

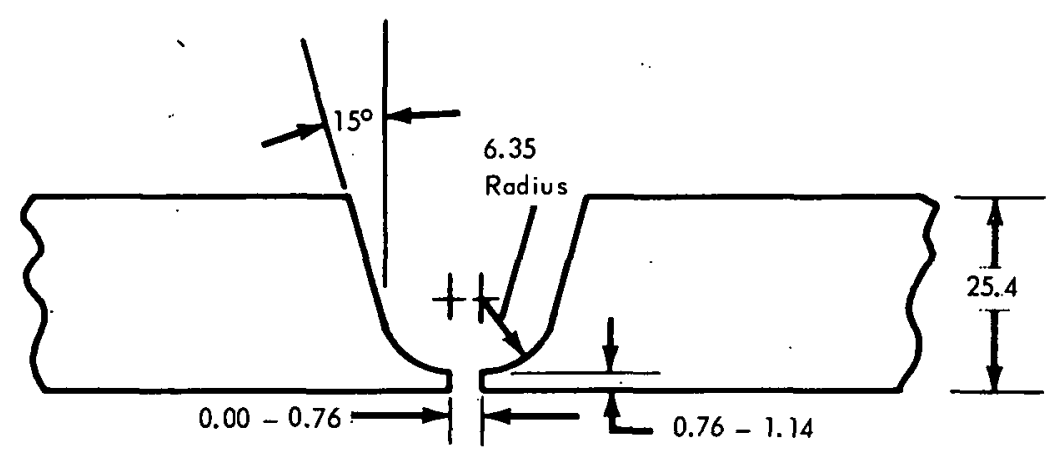

Joint No. 1 - "U' preparation

All dimensions in millimeters

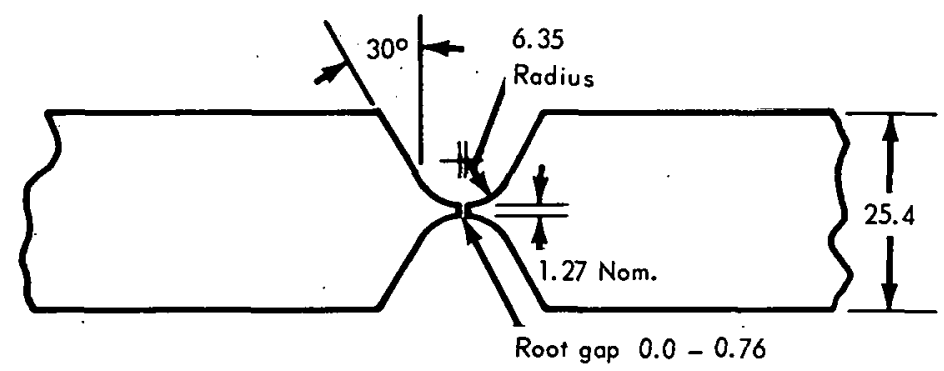

Joint No. 2 - Double "U" preparation

Fig. 9.1 - Weld joint designs used for Inconel 718 plote 
The manual tungsten inert gas arc-welding method was employed and $0.32-\mathrm{cm}$-diameter Inconel alloy 718 bare rod served as filler metal. After machining, the parts for the weldments were cleaned, degreased, and vapor-blasted. Two matching blanks were then clamped to a copper block that provided for an argon gas backup during the root pass. The prepared surfaces were again cleaned with acetone just prior to making the root pass which was desighned to give a full penetration weld. As indicated above, the size of the parts and the massiveness of the weld in the "U" preparation of joint No. 1 made it impossible to clamp the parts firmly enough to prevent heavy distortion due to shrinkage of weld metal (see Figure 9.2).

A set of machined parts for joint No. 2 before and after welding is shown in Figure 9.3. With the double $U$ preparation, the Inconel alloy 718 weldment evidences no distortion. The

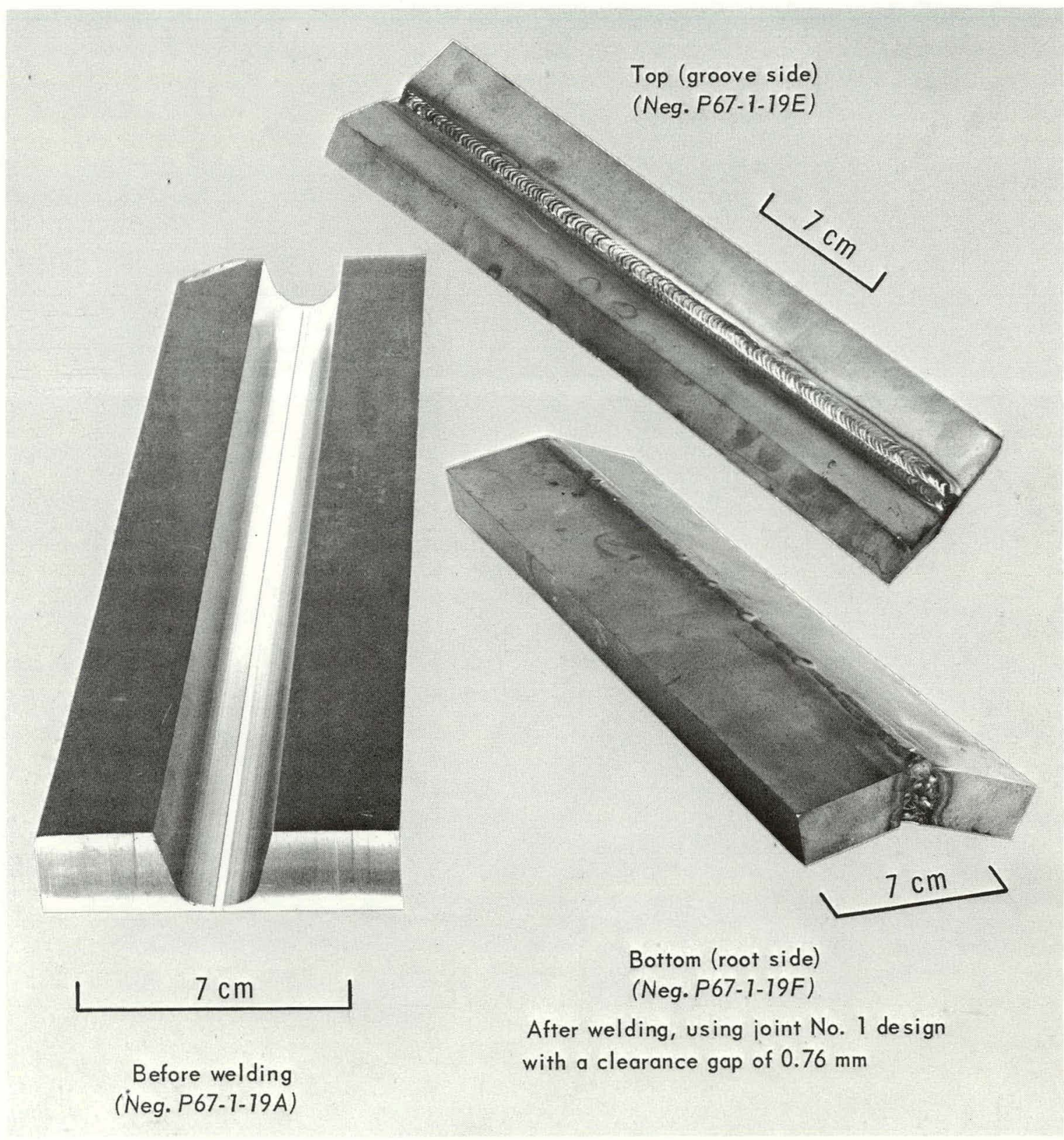

Fig. 9.2 - Inconel 718 plate for tensile specimen, before and after welding 


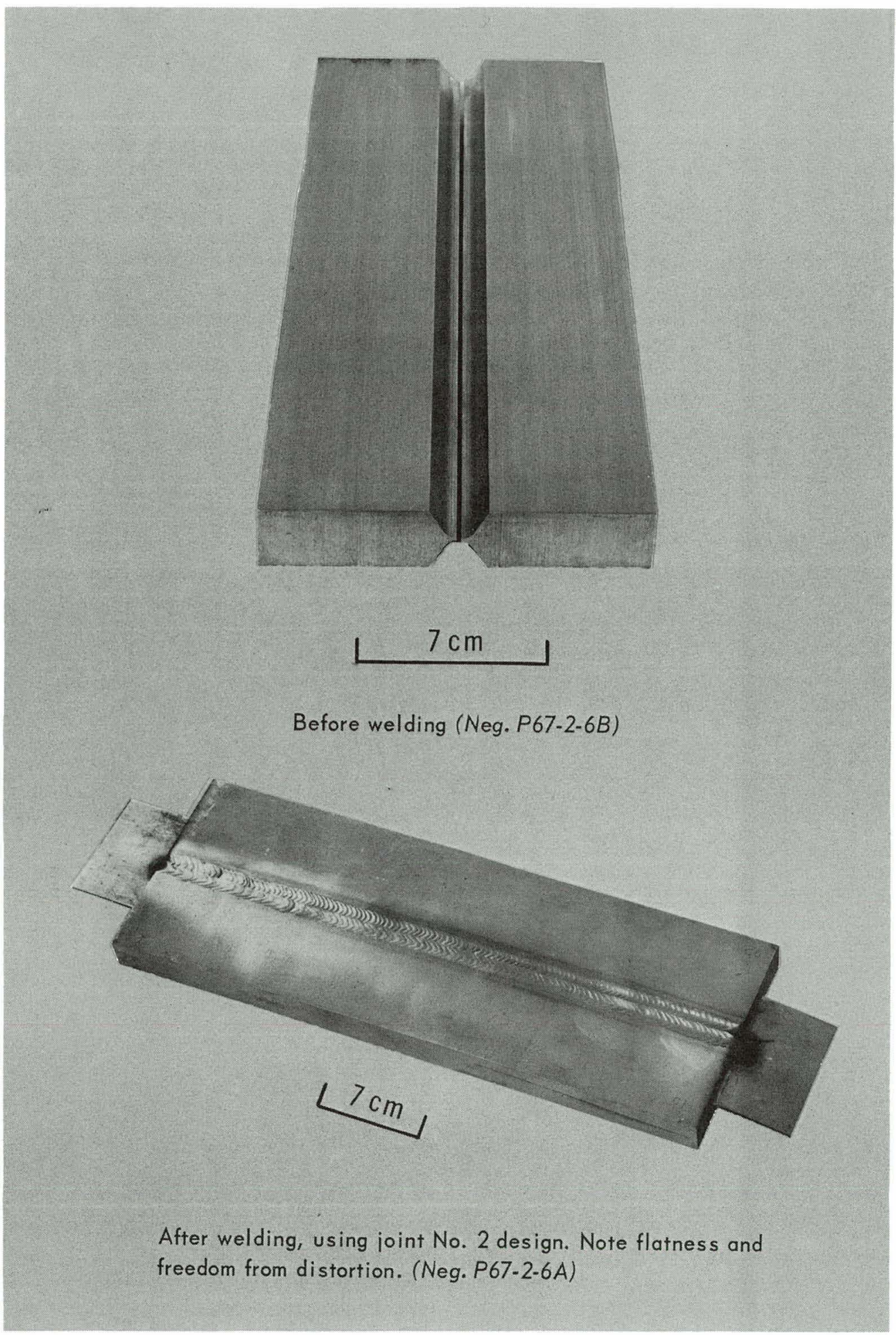

Fig. 9.3-Inconel 718 plate for joint tensile and impact specimens, before and after welding 
tabs on the ends are stainless steel run-off and starter plates to aid in carrying the weld to the ends of the weldment.

Tables 9.3 and 9.4 show the typical operations and conditions for the preparation of the two types of Inconel alloy 718 weldments. Inspection of the rough ground weldments by

TABLE 9.3

TYPICAL OPERATIONS AND CONDITIONS FOR INCONEL ALLOY 718 WELDMENTS WITH "U" JOINT PREPARATION ${ }^{\mathrm{a}, \mathrm{b}}$

\begin{tabular}{|c|c|c|c|c|}
\hline \multirow[b]{2}{*}{ Sequence } & \multicolumn{3}{|c|}{ Argon Gas } & \multirow[b]{2}{*}{ Remarks } \\
\hline & $\begin{array}{l}\text { Torch Speed, } \\
\mathrm{cm} / \mathrm{min}\end{array}$ & $\begin{array}{l}\text { Flow, } \\
\text { liter/min }\end{array}$ & $\begin{array}{l}\text { Approximate } \\
\text { Amperes }\end{array}$ & \\
\hline Tack weld & Both ends & & & \\
\hline Root pass & 10 & 9.3 & 180 & $\begin{array}{l}2.3 \text { liters } / \mathrm{min} \text {, backup purge of } \\
\text { argon; wire brush rọot pass }\end{array}$ \\
\hline 2 Cover passes & 13 & 9.3 & 180 & $\begin{array}{l}\text { SS wire brush between passes; } \\
\text { grind on finish pass }\end{array}$ \\
\hline 2 Layers of 3 passes each & 13 & 9.3 & 180 & $\begin{array}{l}\text { SS wire brush between passes; } \\
\text { grind on finish pass }\end{array}$ \\
\hline 2 Layers of 3 passes each & 13 & 9.3 & 200 & $\begin{array}{l}\text { Shrinkage distortion heavy; } \\
\text { SS wire brush between passes; } \\
\text { grind on finish pass }\end{array}$ \\
\hline 2 Layers of 3 passes each & 13 & 9.3 & 240 & $\begin{array}{l}\text { Shrinkage distortion heavy; } \\
\text { SS wire brush between passes; } \\
\text { grind on finish pass }\end{array}$ \\
\hline 2 Layers of 3 passes each & 13 & 9.3 & 240 & $\begin{array}{l}\text { Shrinkage distortion heavy; } \\
\text { SS wire brush between passes; } \\
\text { grind on finish pass }\end{array}$ \\
\hline 2 Layers of 3 passes each & 13 & 9.3 & 240 & $\begin{array}{l}\text { Shrinkage distortion heavy; } \\
\text { SS wire brush between passes; } \\
\text { grind on finish pass }\end{array}$ \\
\hline
\end{tabular}

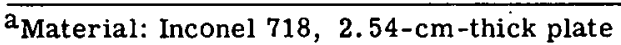

Filler metal: Inconel $718,0.32-\mathrm{cm}$ diameter

Joint type: No. 1

Weldments: $\mathrm{W}-1$ and $\mathrm{W}-4$

$b_{\text {Post-welding operation }}$

1. Smooth grind, penetration-dye check.

2. Smooth grind cover layer, dye check.

3. X-ray inspection.

4. Zyglo inspection.

5. Heat treatment.

6. Sectioning and test specimen fabrication.

cone small crack, noted in root pass near spot where tungsten stuck, was ground out and repaired.

visual, dye check, black light, and X-ray have shown that they are sound. Further inspection will be made following heat treatment and/or sectioning.

\section{2 SUMMARY AND CONCLUSIONS}

Four alloys have been initially selected for study: a $7.5 \mathrm{Ni}-\mathrm{Cr}-\mathrm{Mo}$ steel, a $12 \mathrm{Ni}-5 \mathrm{Cr}-3 \mathrm{Mo}$ maraging steel; a martensitic, precipitation-hardening stainless steel, PH 13-8Mo; and Inconel alloy 718. Plate and welding rod of the latter three materials have been obtained, and test specimen preparation and thermal stability studies are in process. Sound TIG. weldments of Inconel alloy 718 have been completed. 
TABLE 9.4

TY PICAL OPERATIONS AND CONDITIONS FOR INCONEL ALLOY 718

\begin{tabular}{|c|c|c|c|c|}
\hline Sequence & $\begin{array}{l}\text { Torch Speed, } \\
\mathrm{cm} / \mathrm{min}\end{array}$ & $\begin{array}{c}\text { Argon Gas Flow, } \\
\text { liter } / \mathrm{min}\end{array}$ & Amperes & Remarks \\
\hline Tack weld. & Both ends & & & \\
\hline Root pass & 10 & 9.3 & 200 & $\begin{array}{l}3 \text { liters } / \mathrm{min} \text {, backup argon, } \\
\text { wire brush }\end{array}$ \\
\hline 2 Cover passes & 13 & 9.3 & 200 & \\
\hline $\begin{array}{l}\text { Turn over, clean, } \\
\text { make } 3 \text { passes }\end{array}$ & 13 & 9.3 & 240 & $\begin{array}{l}\text { Grind before weld; SS wire } \\
\text { brush between passes }\end{array}$ \\
\hline $\begin{array}{l}\text { Turn over, clean, } \\
\text { make } 3 \text { passes }\end{array}$ & 13 & 9.3 & 240 & $\begin{array}{l}\text { Grind before weld; SS wire } \\
\text { brush between passes }\end{array}$ \\
\hline $\begin{array}{l}\text { Turn over, clean, } \\
\text { make } 3 \text { passes }\end{array}$ & 13 & 9.3 & 240 & $\begin{array}{l}\text { Grind before weld; SS wire } \\
\text { brush between passes }\end{array}$ \\
\hline $\begin{array}{l}\text { Turn over, clean, } \\
\text { make } 3 \text { passes }\end{array}$ & 13 & 9.3 & 240 & $\begin{array}{l}\text { Grind before weld; SS wire } \\
\text { brush between passes }\end{array}$ \\
\hline $\begin{array}{l}\text { Turn over, clean, } \\
\text { make } 3 \text { passes }\end{array}$ & 13 & 9.3 & 240 & $\begin{array}{l}\text { Grind before weld; SS wire } \\
\text { brush between passes }\end{array}$ \\
\hline
\end{tabular}

${ }^{\mathrm{a}}$ Material: Inconel 718, 2.54-cm-thick plate

Filler metal: $0.76-\mathrm{cm}$-diameter Inconel 718 bare rod

Joint type: No. 2

Weldments: $\mathrm{W}-2$ and $\mathrm{W}-3$.

${ }^{b} \mathrm{PC}$ : $t$-welding operations:

1. Wire brush

2. Grind and dye check

3. X-ray inșpection

4. Zyglo inspection

5. Heat treatment

6. Sectioning and test specimen fabrication.

\section{3 PLANS AND RECOMMENDATIONS}

The-determination of-parent-metal tensile and impact-properties will begin. All weldments will be completed.

Impact specimens and tensile blanks will be sent to the Naval Research Laboratory for radiation effects studies. Thermal stability tests will continue.

A critique, presently in draft form, will be completed which considers a large number of available high-strength materials in terms of their applicability to nuclear pressure vessels. 


\title{
10. PHYSICO-CHEMICAL STUDIES OF CLAD UO $\mathrm{U}_{2}$ IN POTENTIAL MELTDOWN ENVIRONMENTS
}

(57075)

\author{
J. F. White*
}

The objective of this program is to determine the behavior of Zircaloy-and stainless steel-clad $\mathrm{UO}_{2}$ fuel elements in steam and steam plus air from about $1200^{\circ} \mathrm{C}$ to the melting point of $\mathrm{UO}_{2}$, and includes measurement, where necessary, of the physical and mechanical properties of the claddings, the oxidized cladding, and $\mathrm{UO}_{2}$ to their respective melting points.

The behavior of zirconium-alloy-clad and stainless steel-clad $\mathrm{UO}_{2}$ fuel elements during temperature excursions to the melted condition in the presence of steam or steam plus air has not been studied in sufficient detail to allow suitable hazard analyses when loss of coolant occurs. Consequently, this program is being conducted to investigate the reactions that occur during meltdown in these atmospheres at heating rates which approximate those likely to be encountered in nuclear afterheat temperature excursions when the coolant has been lost. These investigations include the following studies:

1. Dynamic testing to determine the behavior of clad $\mathrm{UO}_{2}$ when oxidized by steam, reactions between the various reactor core components, internal pressure effects, hydrogen release by the metal - water reactions, and flow aspects of the molten constituents.

2. Measurements of the rates of metal - water reactions, oxidation of $\mathrm{UO}_{2}$ by steam, and reactions between core constituents.

3. Property measurements, including the thermal properties of $\mathrm{UO}_{2}$, Zircaloy -4 , and Type 304 SS, and the mechanical properties of Zircaloy-4 and Type 304 SS.

10.1 REACTION MECHANISMS AND KINETICS (J. T. Bittel, L. H. Sjodahl, J. F. White) DYNAMIC TESTING OF ZIRCALOY-4-CLAD UO 2

Studies of the corrosion of Zircaloy-4 were begun to explore its behavior in steam when used as a cladding on $\mathrm{UO}_{2}$. Dynamic heating rates in these tests were limited to the range between $0.3^{\circ}$ and $3^{\circ} \mathrm{C}$ per second. Test samples were $1.26-\mathrm{cm}$-diameter $\mathrm{UO}_{2}$ rods of about 96 percent of theoretical density encapsulated in Zircaloy -4 tubes, $1.27-\mathrm{cm} \mathrm{W}$ by 0.8-mm wall thickness with vacuum welded 0.8-mm-thick Zircaloy-4 end caps. The assembled samples were $7.6 \mathrm{~cm}$ long.

The samples were heated in a $450 \mathrm{kc}, 50 \mathrm{kw}$ induction heating unit shown in Figure 10.1. Figure 10.2 shows the programmed heating control schematic for this unit. The current concentrator (see Figure 10.1) can uniformly heat about an $8-\mathrm{cm}$ length of sample. The sample's surface temperature is read optically through a small hole in both the induction coil and the current concentrator. The temperature sensor controls the power demand so that the desired heating rate is maintained.

*Project leader and principal investigator. 


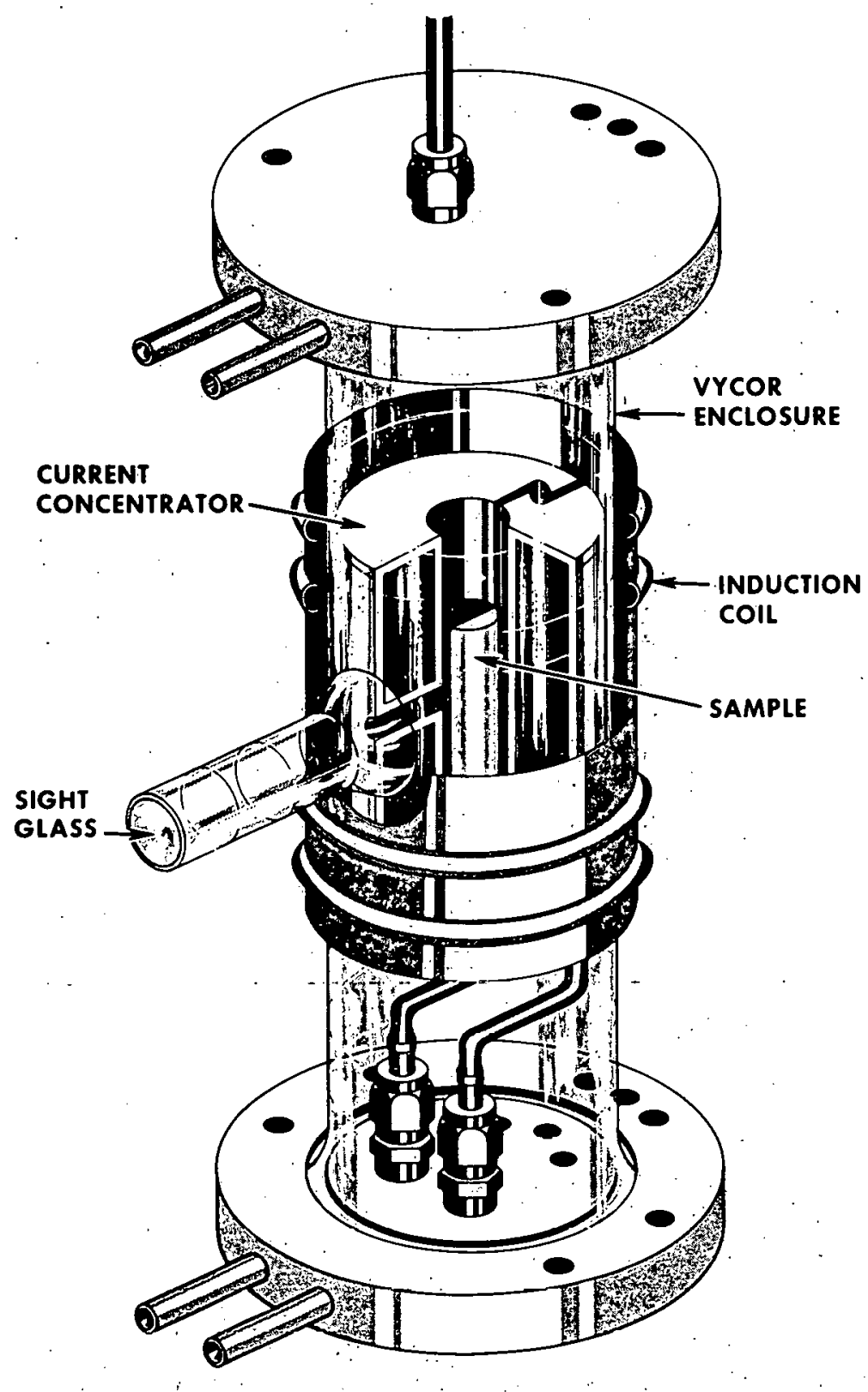

Fig. 10.1 - Dynamic steam corrosion test rig (Neg. AS-525) 


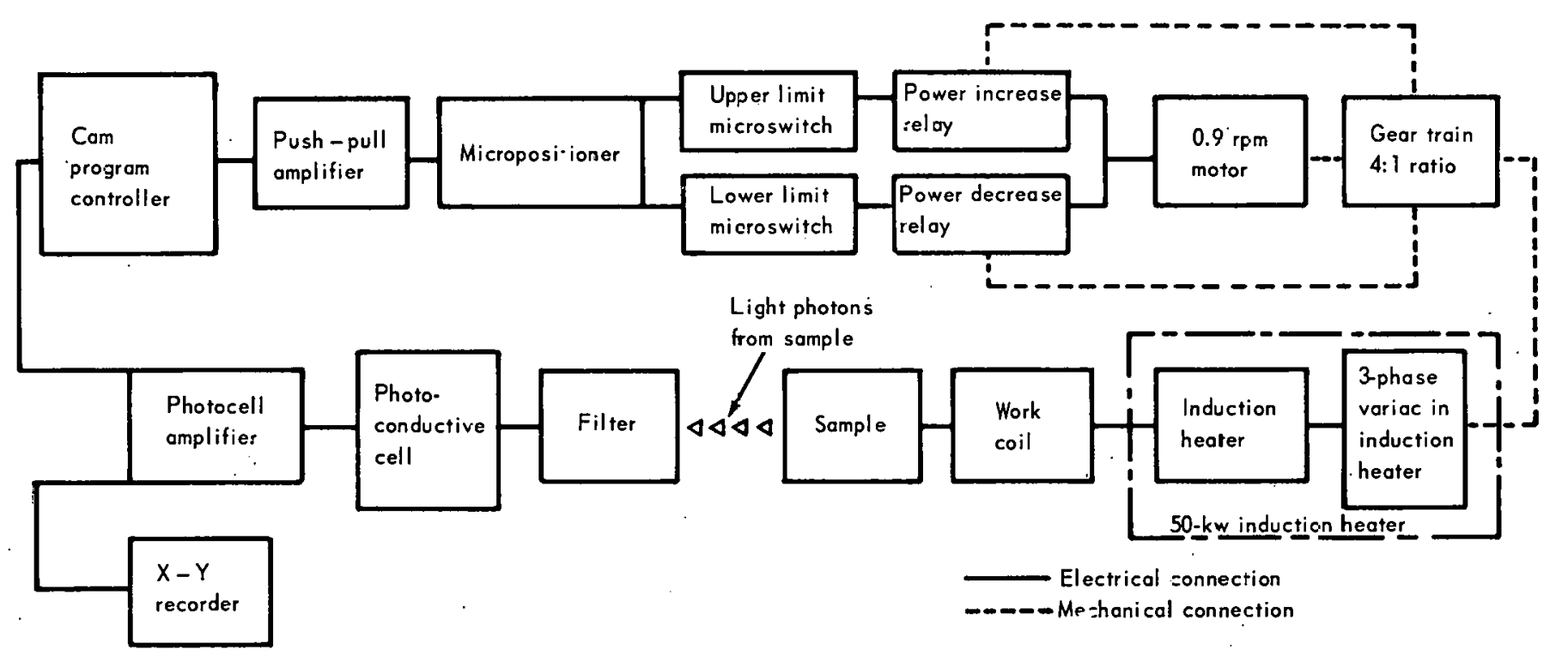

Fig. 10.2-Block diagram of 50-kw induction heater control 
Temperature measurements are made by an optical pyrometer and are accurate to $\pm 10^{\circ} \mathrm{C}$ from $1000^{\circ}$ to $1400^{\circ} \mathrm{C}$ and $\pm 20^{\circ} \mathrm{C}$ from $1400^{\circ}$ to $1850^{\circ} \mathrm{C}$. The pyrometer temperature readings were checked by observing the melting of Type 304 SS and Zircaloy-4 in an inert atmosphere and by a Pt/Pt-10Rh thermocouple in a steam atmosphere in which samples were resistively heated to $1200^{\circ} \mathrm{C}$. Circumferential temperatures have varied as much as $100^{\circ} \mathrm{C}$ at the melting point of Zircaloy -4 because of inaccurately centered samples in the current concentrator. Errors this great should be rare, however, since the samples are centered as carefully as possible for each run. The longitudinal temperature variation was less than the circumferential variation as evidenced by relatively uniform melting of both Zircaloy-4 and Type 304 SS in the longitudinal direction.

During the heating of a sample in steam, its temperature is assumed to be the same as its surface temperature. This introduces an obvious error due to the thickening oxide film on the sample; the relatively low rate of heat transfer through this oxide film results in a temperature gradient, of unknown magnitude, across the film.

Figure 10.3 shows the microstructure of Zircaloy-4-clad $\mathrm{UO}_{2}$ after heating at $0.3^{\circ} \mathrm{C}$ per second to $1600^{\circ} \mathrm{C}$ in steam, resulting in complete oxidation of the cladding. This figure also shows the general composition of the specimen as determined by electron-microprobe analyses.

Zircaloy-4-clad $\mathrm{UO}_{2}$ samples were partially. oxidized by heating in steam at $0.3^{\circ}, 0.6^{\circ}$, $1^{\circ}$, and $3^{\circ} \mathrm{C}$ per second to temperatures of $1200^{\circ}$ to $1600^{\circ} \mathrm{C}$, and then quenching. The cladding was examined under polarized light and thickness measurements were made of the oxide film, of the metal which had absorbed oxygen and was the alpha phase at the final test temperature, and of the alpha phase metal quenched from the beta phase. These data are given in Table 10.1. A photomicrograph of a typical sample after test is shown in Figure 10.4. The results from the $0.3^{\circ} \mathrm{C} / \mathrm{sec}$ heating rate are compared in a later section ("Comparison of Dynamic and Isothermal Corrosion Rates").

TABLE 10.1

STEAM OXIDATION OF ZIRCALOY -4 CLADDING AT DIFFERENT HEATING RATES

\begin{tabular}{|c|c|c|c|c|c|c|c|c|}
\hline \multirow{3}{*}{$\begin{array}{c}\text { Maximum } \\
\text { Temperature, } \\
{ }^{\circ} \mathrm{C} \\
\end{array}$} & \multicolumn{8}{|c|}{ Thickness, microns } \\
\hline & \multicolumn{2}{|c|}{$3^{\circ} \mathrm{C} / \mathrm{sec}$} & \multicolumn{2}{|c|}{$1^{\circ} \mathrm{C} / \mathrm{sec}$} & \multicolumn{2}{|c|}{$0.6^{\circ} \mathrm{C} / \mathrm{sec}$} & \multicolumn{2}{|c|}{$0.3^{\circ} \mathrm{C} / \mathrm{sec}$} \\
\hline & $\alpha$ Phase & Oxide & $\alpha$ Phase & Oxide & $\alpha$ Phase & Oxide & $\alpha$ Phase & Oxide \\
\hline 1200 & - & - & - & - & - & - & 37 & 36 \\
\hline 1300 & 57 & 17 & 71 & 42 & 84 & $60^{\circ}$ & 136 & 98 \\
\hline 1400 & 83 & 33 & 106 & 75 & 143 & 94 & 206 & 200 \\
\hline 1500 & 124 & 50 & 158 & 145 & 177 & 127 & 590 & 316 \\
\hline 1600 & 177 & 161 & 483 & 308 & 519. & 297 & - & - \\
\hline
\end{tabular}

\section{OXIDATION OF ZIRCONIUM ALLOYS BY STEAM}

Isothermal tests ${ }^{1}$ of steam reaction with zirconium alloys were extended to $1600^{\circ} \mathrm{C}$, using the thermobalance apparatus shown previously. ${ }^{2}$

\footnotetext{
1“"Fifth Annual Report-High-Temperature Materials Programs, Part A," GE-NMPO, GEMP-400A, February 28, 1966, p. 208.

2،"High-Temperature Materials Program Progress Report No. 61," GE-NMPO, GEMP-61, September 30, 1966, Figure 13.3, p. 146.
} 


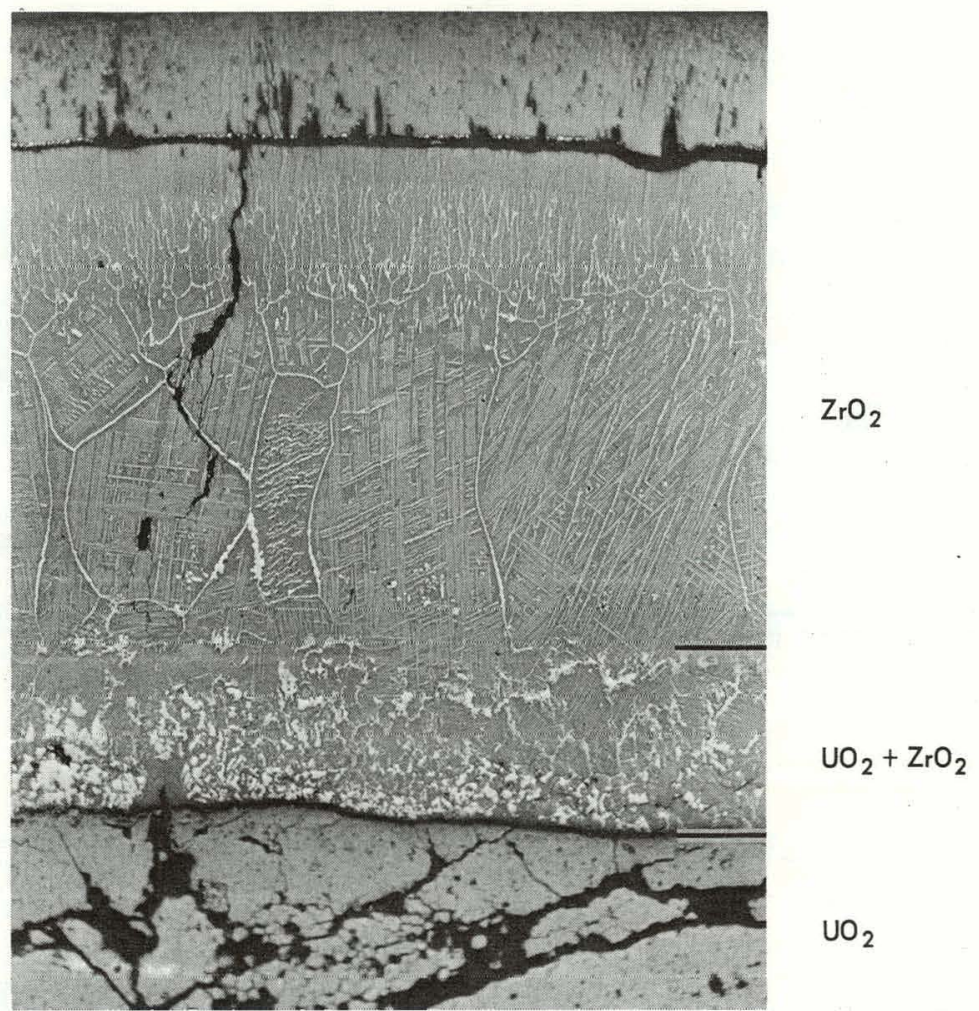

Fig. 10.3 - Zircaloy-4-clad $\mathrm{UO}_{2}$ heated to $1600^{\circ} \mathrm{C}$ in 1 atmosphere of steam at $0.3^{\circ} \mathrm{C}$ per second $(\mathrm{Neg} .7053,75 \mathrm{X})$

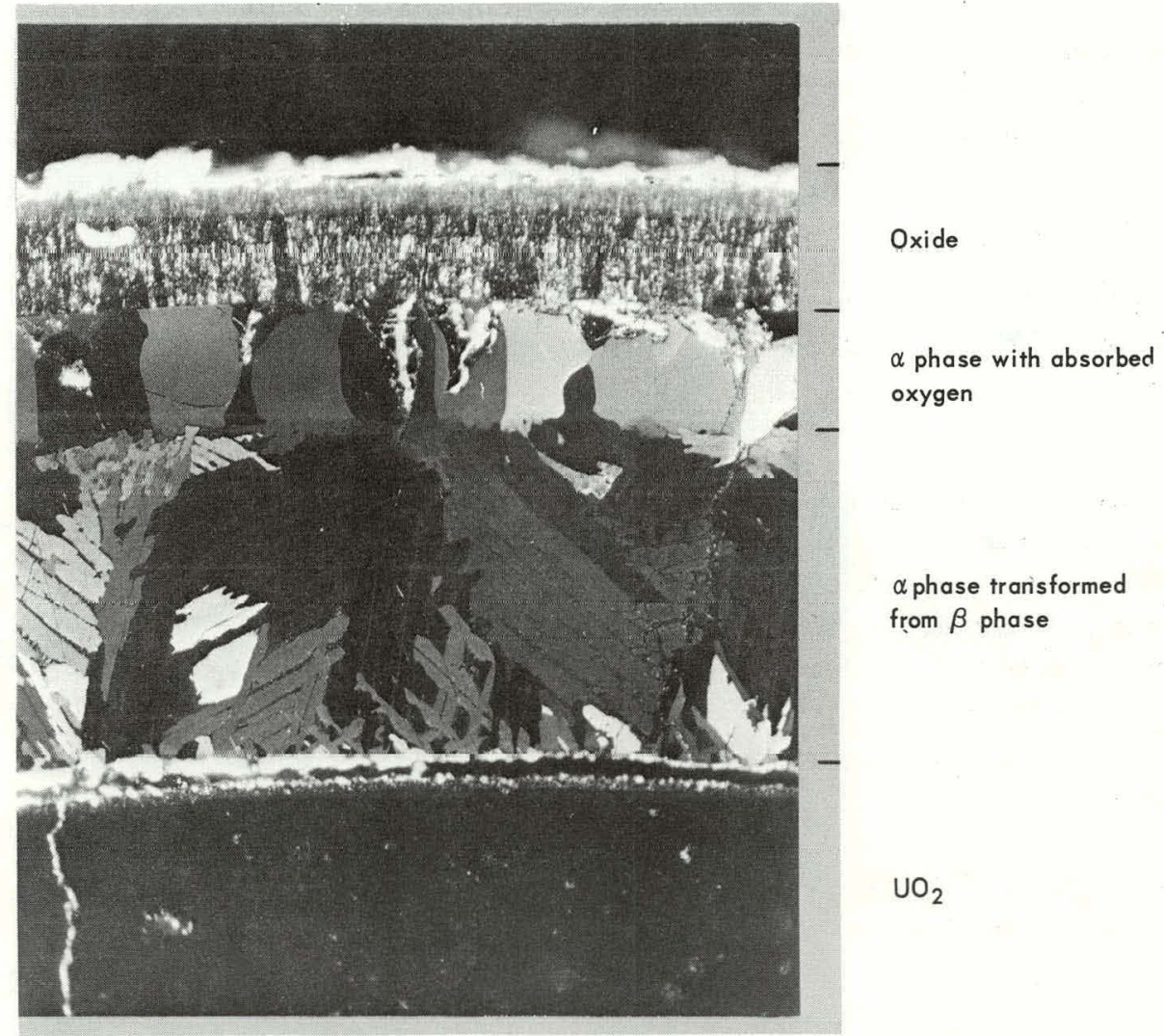

Fig. 10.4 - Phases present in Zircaloy-4 cladding after heating to $1600^{\circ} \mathrm{C}$ in steam at $3{ }^{\circ} \mathrm{C}$ per second (Neg. 7713,75X) 
A Zircaloy-2 ball was tested at $1600^{\circ} \mathrm{C}$; Zircaloy-4 discs were tested at $1250^{\circ} \mathrm{C}$ and at $1600^{\circ} \mathrm{C}$; and discs of a zirconium alloy (Valoy ${ }^{*}$ ) were tested at $1200^{\circ}, 1400^{\circ}$, and $1615^{\circ} \mathrm{C}$. The microstructure of the Valoy sample tested at $1200^{\circ} \mathrm{C}$ is shown in Figure 10.5.

Parabolic rate constants determined from these test results are shown in Table 10.2 together with previous Zircaloy ${ }^{1}$ results and with pertinent published data. ${ }^{3,4}{ }^{4}{ }^{5}$ These data are plotted in Figure 10.6 and the results show that within experimental error, Zircaloy-4 and Valoy oxidize at the same rates in the temperature range $1200^{\circ}$ to $1600^{\circ} \mathrm{C}$. While the data for the Zircaloy ball-shaped samples are slightly lower, they are believed to agree within experimental error with the data for the disc-shaped samples. Examination of the data by least squares fit yields the following equations:

$$
\begin{aligned}
& \text { GE-NMPO }
\end{aligned}
$$

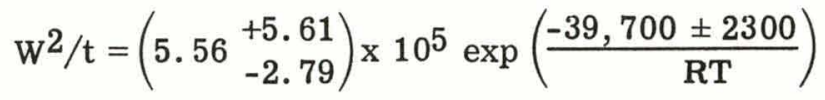

$$
\begin{aligned}
& \text { GE-NMPO + Lemmon low } \\
& \text { temperature }\left(1000^{\circ}\right. \text { to } \\
& 1300^{\circ} \mathrm{C} \text { ) }
\end{aligned}
$$

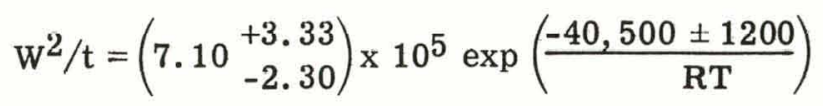

$$
\begin{aligned}
& \text { GE-NMPO + Lemmon + } \\
& \text { Bostrum } \\
& \mathrm{W}^{2} / \mathrm{t}=\left(\begin{array}{r}
5.77+7.54 \\
-3.27
\end{array}\right) \times 10^{5} \exp \left(\frac{-40,000 \pm 2700}{\mathrm{RT}}\right) \\
& \mathrm{W}^{2} / \mathrm{t}=\left(\begin{array}{r}
8.58+6.50 \\
-4.66
\end{array}\right) \times 10^{5} \exp \left(\frac{-41,200 \pm 2600}{\mathrm{RT}}\right)
\end{aligned}
$$

where $\mathrm{W}=$ weight gain, $\mathrm{mg}\left(\mathrm{O}_{2}\right) / \mathrm{cm}^{2}$ of exposed area ${ }^{\dagger}$

$\mathrm{R}=$ gas constant, cal $/ \mathrm{mole}-{ }^{\circ} \mathrm{K}$

$\mathrm{T}=$ absolute temperature, ${ }^{\circ} \mathrm{K}$

$\mathrm{t}$ = time, seconds

The four equations agree very closely and, based on this analysis, it appears that the oxidation rate (by steam) of $\mathrm{Zr}$, Zircaloy-2, Zircaloy-4, and Valoy can be adequately expressed by equation (10.2). This equation is plotted on Figure 10.6 along with broken lines to show the 95-percent confidence limits for these data.

\section{COMPARISON OF DYNAMIC AND ISOTHERMAL CORROSION RATES}

The equations derived above for isothermal tests can be used to evaluate the extent of corrosion under dynamic conditions of increasing temperature. The general form of this equation is:

$$
\mathrm{W}^{2} / \mathrm{t}=\mathrm{K}_{\mathrm{O}} \exp (\Delta \mathrm{H} / \mathrm{RT})
$$

where $\mathrm{W}=$ weight gain, $\mathrm{mg}\left(\mathrm{O}_{2}\right) / \mathrm{cm}^{2}$ of area

$$
\begin{aligned}
\mathrm{K}_{\mathrm{O}} & =\text { a constant, } \mathrm{mg}^{2} / \mathrm{cm}^{4}-\mathrm{sec} \\
\Delta \mathrm{H} & =\text { activation energy of the reaction, cal } / \mathrm{mole} \\
\mathrm{R} & =\text { gas constant, cal } / \mathrm{mole}-{ }^{\circ} \mathrm{K} \\
\mathrm{T} & =\text { absolute temperature },{ }^{\circ} \mathrm{K} \\
\mathrm{t} & =\text { time, seconds }
\end{aligned}
$$

*General Electric Company trademark applied for. Composition: $\mathrm{Cr}, 2.0$ at. \%; Fe, 0.16 at. \%; Ni, <70 ppm; Sn, <100 ppm; balance $Z$ r.

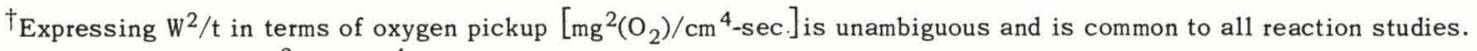
For conversion to $\mathrm{mg}^{2}(\mathrm{Zr}) / \mathrm{cm}^{4}$-sec, multiply by 8.126 .

${ }^{3}$ L. Baker and L. C. Just, "Studies of Metal-Water Reactions at High Temperatures, III. Experimental and Theoretical Studies of the Zirconium-Water Reactions," Argonne National Laboratory, ANL-6548, 1962.

${ }^{4}$ A. W. Lemmon, "Studies Relating to the Reaction Between Zirconium and Water at High Temperatures," Battelle Memorial Institute, BMI-1154, January 1957.

5W. A. Bostrum, "The High Temperature Oxidation of $\mathrm{Zr}-2$ in $\mathrm{H}_{2} \mathrm{O}$," Westinghouse-APD, WAPD-104, March 19, 1954. 


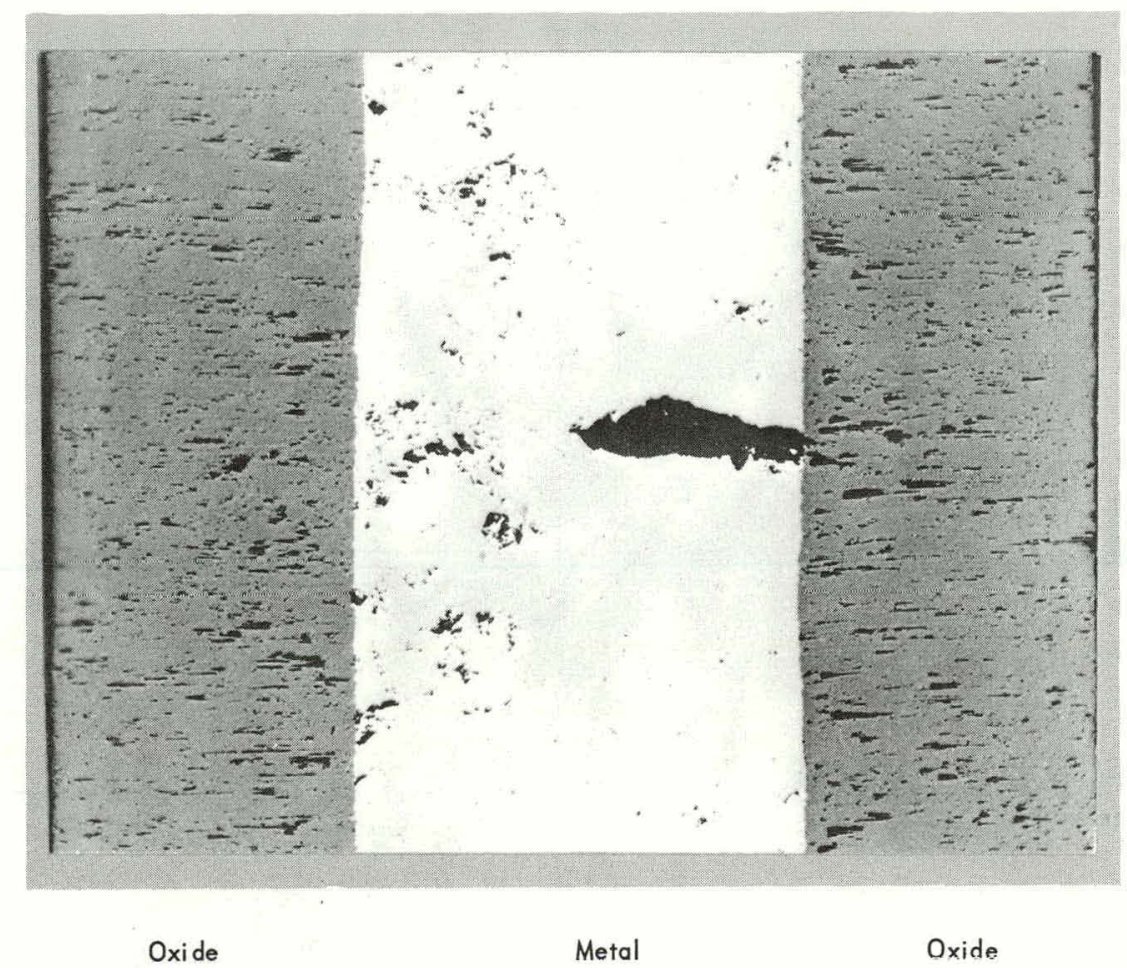

Fig. 10.5 - Photomicrograph showing the microstructure of zirconium alloy "Valoy" heated for 60 minutes at $1200^{\circ} \mathrm{C}$ in steam (Neg. 7349, as-polished, 100X)

TABLE 10. 2

RESULTS OF OXIDATION OF ZIRCONIUM ALLOYS BY STEAM

\begin{tabular}{llcc}
\hline Investigator & Material & Temperature, ${ }^{\circ} \mathrm{C}$ & $\begin{array}{c}\text { Parabolic Rate, } \\
\mathrm{mg}^{2}\left(\mathrm{O}_{2}\right) / \mathrm{cm}^{4} \text {-sec }\end{array}$ \\
\hline NMPO (balls) & Zircaloy-4 & 1200 & 0.602 \\
& Zircaloy-4 & 1400 & 2.95 \\
& Zircaloy-2 & 1600 & 10.6 \\
NMPO (disks) & Zircaloy-4 & 1250 & 1.43 \\
& Zircaloy-4 & 1600 & 13.54 \\
& Valoy & 1200 & 0.742 \\
Lemmon & Valoy & 1400 & 4.25 \\
(Low Temperature) & Zaloy & 1615 & 16.98 \\
& Zircaloy-2 & 1000 & 0.073 \\
& Zircaloy-2 & 1100 & 0.255 \\
Lemmon & Zircaloy-2 & 1200 & 0.765 \\
(High Temperature) & Zircaloy-2 & 1300 & 1.78 \\
& Zircaloy-2 & 1400 & 1.87 \\
& Zircaloy-2 & 1600 & 2.98 \\
Zircaloy-2 & 1700 & 5.11 \\
Bostrum & Zircaloy-2 & 1300 & 12.80 \\
& Zircaloy-2 & 1450 & 1.97 \\
Baker & Zircaloy-2 & 1600 & 6.65 \\
\hline & Zircaloy-2 & 1750 & 30.8 \\
& Zirconium & $1852(\mathrm{MP})$ & 62.3 \\
& & & 85.5 \\
\hline
\end{tabular}




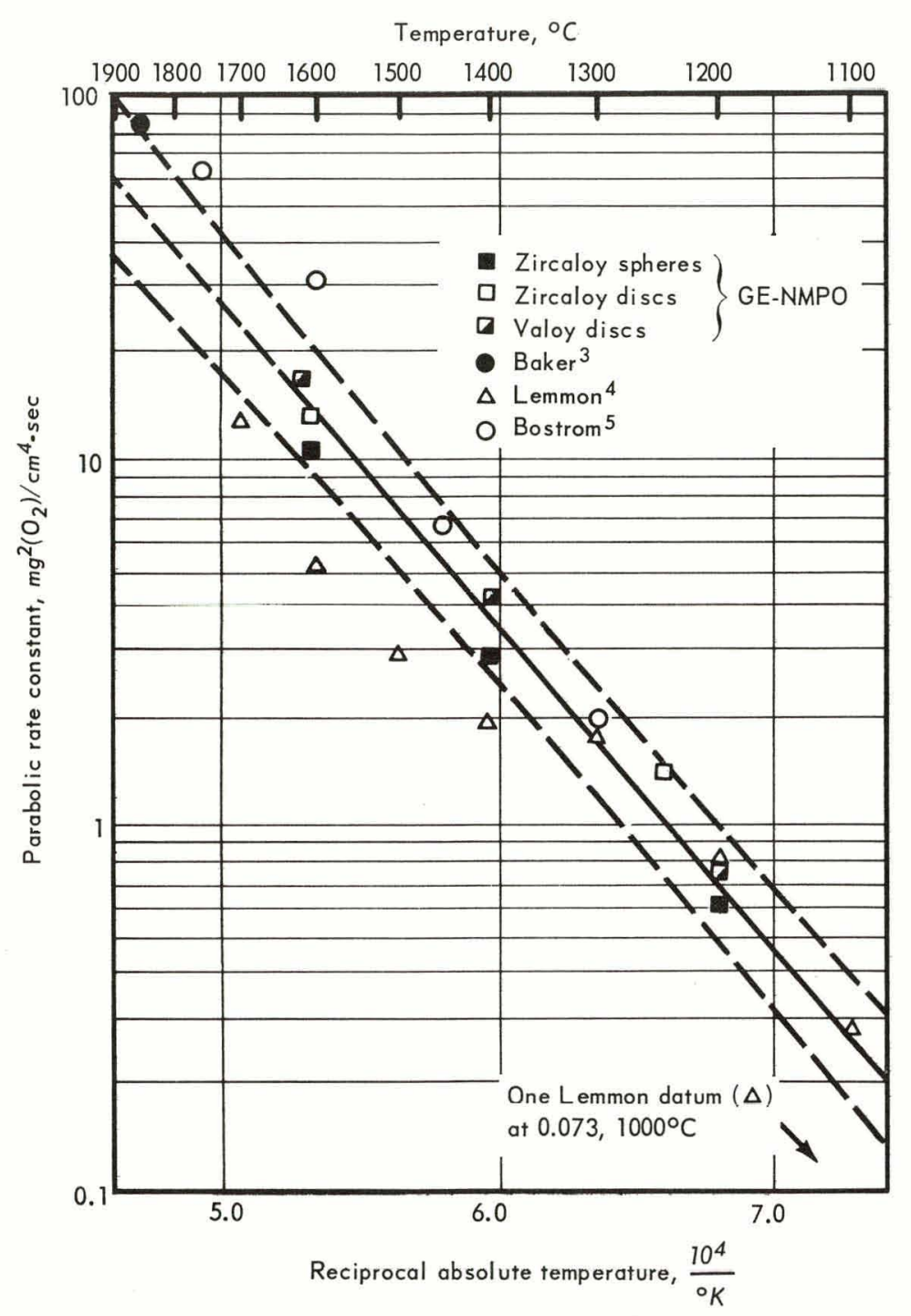

Fig. 10.6-Oxidation of $\mathrm{Zr}$ by steam

The expected extent of corrosion under conditions of steadily rising temperatures was calculated. To perform these calculations, equation (10.5) was first differentiated with respect to time to obtain the corrosion rate at constant temperature:

$$
\mathrm{d}\left(\mathrm{W}^{2}\right) / \mathrm{dt}=\mathrm{K}_{\mathrm{O}} \exp (\Delta \mathrm{H} / \mathrm{RT})
$$

After substituting $\mathrm{a}+\mathrm{bt}$ for $\mathrm{T}$ in this equation, it was integrated and the result is approximated (to within 1 part in $10^{6}$ ) by the following equation:

$$
\mathrm{W}^{2}=\frac{\mathrm{K}_{0} M}{b e^{\mathrm{X}}}\left(1-\frac{\mathrm{x}^{2}+\mathrm{a}_{1} \mathrm{x}+\mathrm{a}_{2}}{\mathrm{x}^{2}+\mathrm{b}_{1} \mathrm{x}+\mathrm{b}_{2}}\right)
$$

where $\mathrm{M}=$ maximum temperature, ${ }^{\circ} \mathrm{K}$

$\mathrm{x}=\Delta \mathrm{H} / \mathrm{RM}$

$\mathrm{b}=$ the heating rate in ${ }^{\circ} \mathrm{K} / \mathrm{sec}$

$\mathrm{a}_{1}, \mathrm{a}_{2}, \mathrm{~b}_{1}$, and $\mathrm{b}_{2}=$ approximating constants 
The square of the weight gain varies as the reciprocal of the heating rate and, in a more complicated way, directly as the maximum temperature.

The oxide film thickness can be calculated on the assumption that the weight increase is entirely accounted for by the formation of fully dense $\mathrm{ZrO}_{2}$. Obvious errors in this assumption include porosity in the oxide, and oxygen dissolved in the metal; these errors partially offset each other. The constants in equation (10.2) above represent GE-NMPO and most published data adequately. Baker and $\mathrm{Just}^{3}$ derived the following equation (converted to express oxygen weight gain and with the same units as in equation 10.5):

$$
\mathrm{W}^{2} / \mathrm{t}=4.1 \times 10^{6} \exp (-45,500 / \mathrm{RT})
$$

The constants from these two equations and equation (10.7) allow a comparison of calculated thicknesses with those measured in dynamic tests in which samples were heated at $0.3^{\circ} \mathrm{C} / \mathrm{sec}$ to maximum temperatures from $1200^{\circ}$ to $1500^{\circ} \mathrm{C}$, as follows:

\begin{tabular}{|c|c|c|}
\hline \multirow[t]{2}{*}{ Measured } & \multicolumn{2}{|c|}{ Calculated } \\
\hline & GE-NMPO & Baker \\
\hline 36 & 105 & 110 \\
\hline 98 & 175 & 190 \\
\hline 164 & 270 & 310 \\
\hline 316 & 400 & 480 \\
\hline
\end{tabular}

Calculated values using both equations are higher than measured values, partially because the oxygen in the $\alpha$ zirconium layers is not considered in the measured values and is considered in the calculated values. More data are needed before a critical evaluation of the two equations can be made.

\section{MELTING BEHAVIOR OF OXIDIZED ZIRCALOY-4-CLAD UO 2}

To establish the behavior of Zircaloy-4 as it melts from $\mathrm{UO}_{2}$ at various stages of cladding oxidation, samples were prepared by heating in steam at rates of $0.3^{\circ}, 0.6^{\circ}, 1^{\circ}$, and $3{ }^{\circ} \mathrm{C}$ per second to temperatures of $1200^{\circ}$ to $1600^{\circ} \mathrm{C}$. Heating rates, maximum temperature attained, and estimated oxide film thickness based on the data in Table 10.1 are shown in Table 10.3.

The oxidized samples were placed in $\mathrm{ZrO}_{2}$ crucibles and heated in argon to the desired temperature at a rate of about $4{ }^{\circ} \mathrm{C}$ per second in a tungsten resistance furnace, held at this temperature for about 5 minutes, then cooled rapidly to room temperature.

TABLE 10. 3

\begin{tabular}{cccc}
\multicolumn{4}{c}{ PREPARATION OF PARTIALLY OXIDIZED CLADDING } \\
\hline Sample No. & $\begin{array}{c}\text { Heating Rate, } \\
{ }^{\circ} \mathrm{C} / \mathrm{sec}\end{array}$ & $\begin{array}{c}\text { Maximum } \\
\text { Temperature, }{ }^{\circ} \mathrm{C}\end{array}$ & $\begin{array}{c}\text { Estimated Oxide Film } \\
\text { Thickness, microns }\end{array}$ \\
\hline C & 3 & 1400 & 40 \\
D & 0.3 & 1200 & 40 \\
E & 1 & 1400 & $80^{\mathrm{a}}$ \\
F & 0.6 & 1350 & $80^{\mathrm{a}}$ \\
G & 1 & 1550 & 200 \\
H & 0.3 & 1450 & 200 \\
I & 0.3 & 1500 & 320 \\
J & 0.6 & 1600 & 320 \\
\hline
\end{tabular}

a This estimate was reported as $120 \mu$ in GEMP-63. 
An argon atmosphere was used to prevent further oxidation during the study of the melting of partially oxidized cladding. Post-test photographs are shown in Figures 10.7 and 10.8 for specimens heated to $1900^{\circ} \mathrm{C}$ and $2050^{\circ} \mathrm{C}$, respectively. (The molten cladding contained in the $\mathrm{ZrO}_{2}$ crucible is at the bottom of each sample.) The sample in the upper left hand corner of each figure is the unmelted reference specimen. Note that the cladding does not show appreciable melting at $1900^{\circ} \mathrm{C}$ when the oxide layer is greater than about $200 \mathrm{mi}-$ crons thick. At $2050^{\circ} \mathrm{C}$, all the samples exhibited varying degrees of melting; the heavier the oxide film, the less apparent melting. Cracking observed in the various samples with 200- and 320-micron-thick oxide films occurred during the test, probably during cooling. Post-test measurements of the $\mathrm{UO}_{2}$ core in the 40-micron-thick oxide samples showed that the diameter decreased; the largest reduction was 625 microns after the $2050^{\circ} \mathrm{C}$ melting.

\section{DYNAMIC TESTING OF TYPE 304 SS-CLAD UO 2}

Tests on stainless steel-clad $\mathrm{UO}_{2}$ were conducted to study the melting behavior of the cladding when heated at $0.3^{\circ} \mathrm{C}$ and $3^{\circ} \mathrm{C}$ per second in steam; an identical sample was heated in an inert atmosphere for comparison. As shown in Figure 10.9, the presence of steam retarded the molten metal runoff, especially at the lower heating rates.

\section{OXIDATION OF TYPE 304 SS BY STEAM}

The isothermal corrosion of Type 304 SS in steam was measured using the thermogravimetric apparatus referred to above in the temperature range of $1000^{\circ}$ to $1350^{\circ} \mathrm{C}$. The samples were discs $0.64 \mathrm{~cm}$ in diameter and about $0.5 \mathrm{~cm}$ thick. The sample undergoing test was placed on a small platinum pan which was suspended from the balance beam and sample temperatures were read directly with a micro-optical pyrometer through a calibrated prism and quartz window. Pyrometer temperature measurements agreed within $\pm 8^{\circ} \mathrm{C}$ with readings from a $\mathrm{Pt} / \mathrm{Pt}-\mathrm{Rh}$ thermocouple placed near the sample.

The corrosion data showed a parabolic reaction rate, following an initial 6- to 28-minute period of linear behavior, and a marked temperature dependence. Reaction rate constants calculated from the parabolic portions of the weight gain versus time curves are shown in Table 10.4 and are plotted versus reciprocal temperature in Figure 10.10. These data yield the following equation by least squares fit:

$$
\mathrm{W}^{2} / \mathrm{t}=2.4 \times 10^{12} \exp \left(\frac{-84,300 \pm 2400}{\mathrm{RT}}\right)
$$

where the symbols are the same as in equation (10.5). Note that, while the Type 304 SS has corrosion rates at low temperatures which are much lower than those for Zircaloy-4, at temperatures of about $1200^{\circ} \mathrm{C}$ and above the rates actually become greater than those for Zircaloy-4. At all test temperatures, rough, dark coatings formed on the Type 304 SS. The coatings which formed at $1200^{\circ} \mathrm{C}$ and $1250^{\circ} \mathrm{C}$ remained in place upon cooling and, although cracked, exhibited some resistance to removal. Those formed at lower temperatures tended to spall when the sample was cooled. There was no evidence that spalling occurred while at test temperature.

For comparison with the Type 304 SS behavior, a sample of mild steel (nominally 0.17 to 0.24 -percent carbon, 0.25 -to 0.60 -percent manganese, balance iron) was tested in steam at $1200^{\circ} \mathrm{C}$. The behavior was similar to that of Type $304 \mathrm{SS}$, but the mild steel has a higher parabolic rate constant $\left[4.6 \mathrm{mg}^{2}\left(\mathrm{O}_{2}\right) / \mathrm{cm}^{4}\right.$-sec] compared to $0.75 \mathrm{mg}^{2}\left(\mathrm{O}_{2}\right) / \mathrm{cm}^{4}$-sec for Type 304 SS. The value for mild steel agrees with that predicted from lower temperature data for iron in air. ${ }^{6}$

\footnotetext{
${ }^{6} \mathrm{~K}$. Heindlhofer and B. M. Larsen, "Rates of Scale Formation in Iron and a Few of Its Alloys," Transactions of the American Society of Steel Treatment, Vol. 21, 1933, pp. 865-895.
} 


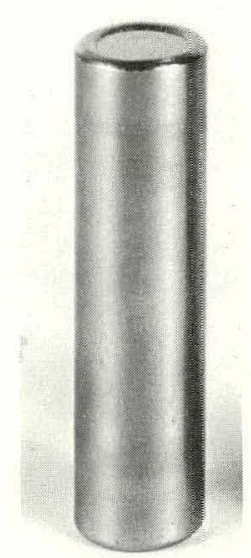

(A) None

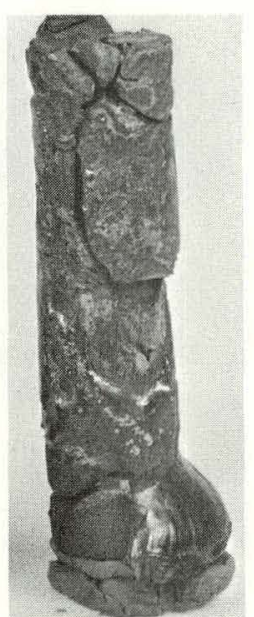

(C) $40 \mu$

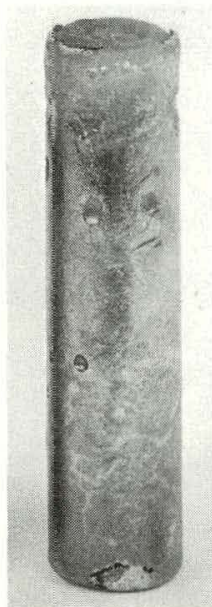

(E) $80 \mu$

(D) $40 \mu$

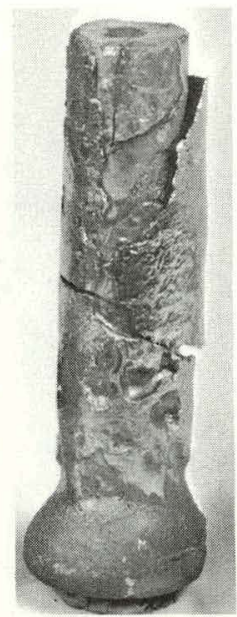

(F) $80 \mu$

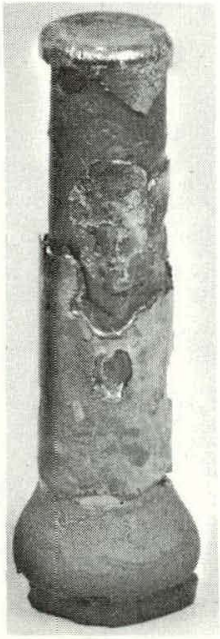

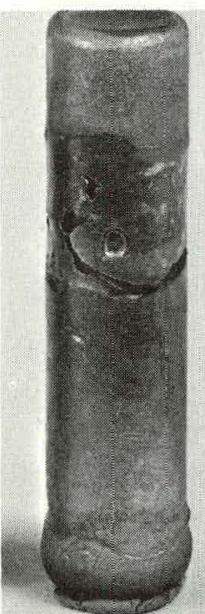

(G) $200 \mu$

(H) $200 \mu$

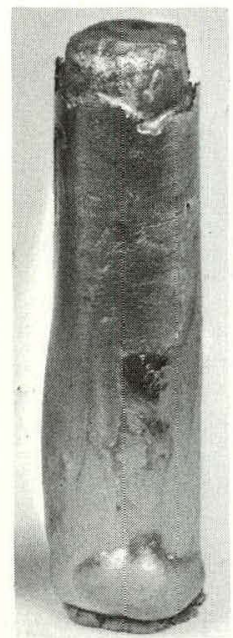

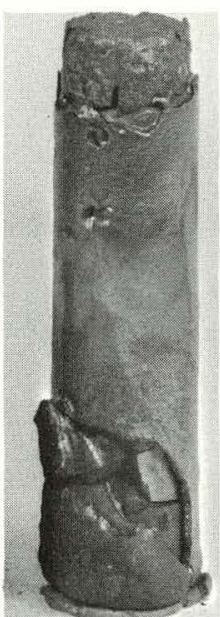

(I) $320 \mu$

(J) $320 \mu$

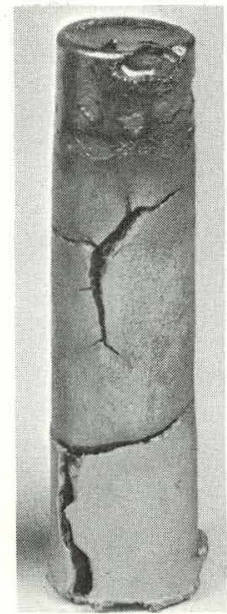

Fig. 10.7-Results of melting Zircaloy-4-clad $\mathrm{UO}_{2}$ at $1900^{\circ} \mathrm{C}$ after various stages of ox dation. Numbers adjacent to the samples indicate oxide film thickness. 


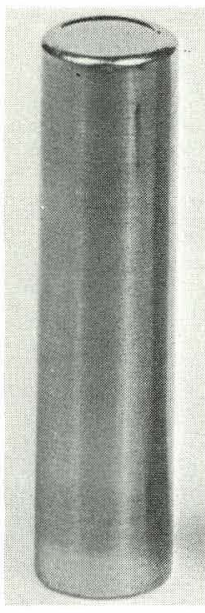

None

None

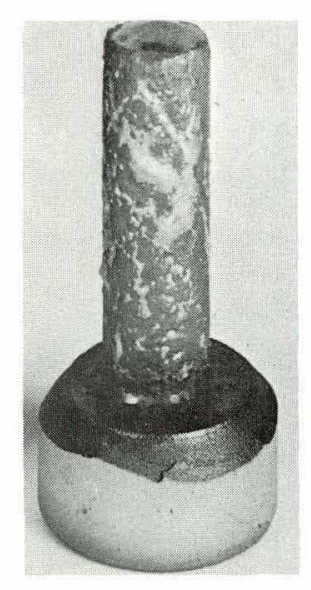

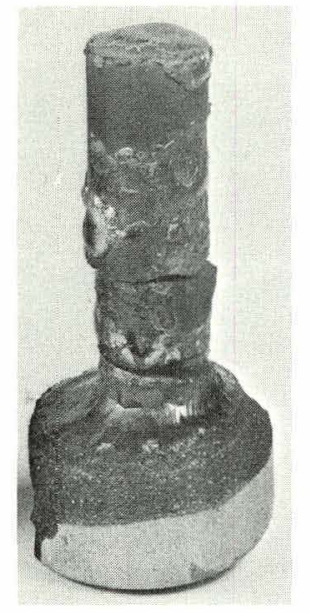

$40 \mu$

$40 \mu$

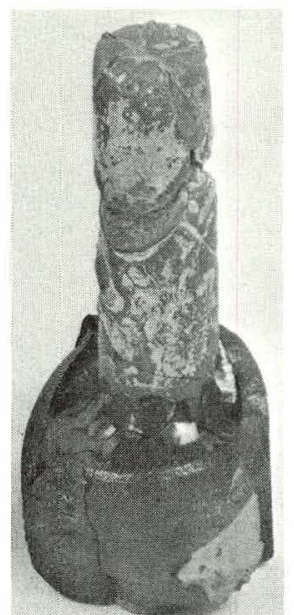

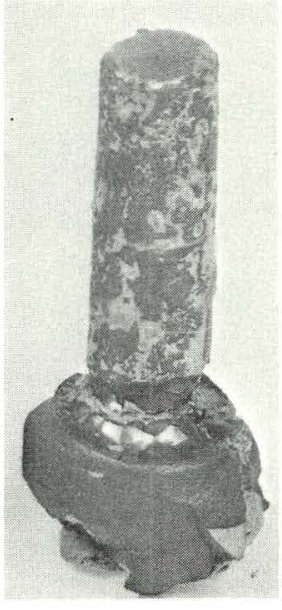

$80 \mu$

$80 \mu$

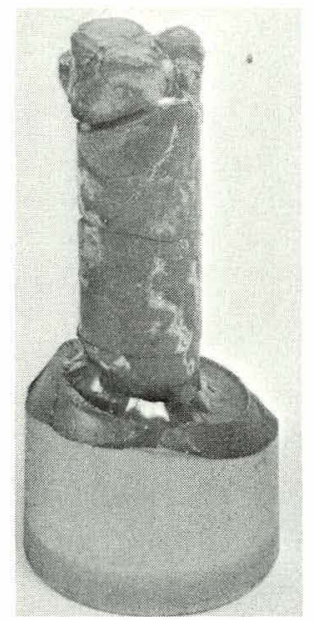

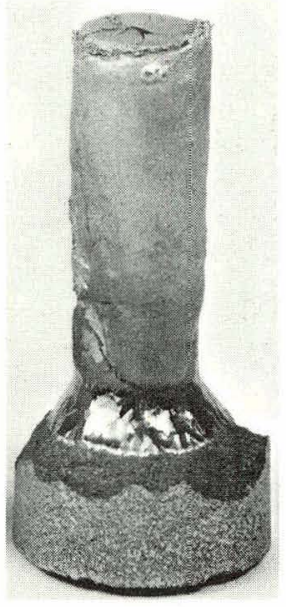

$200 \mu$

$200 \mu$

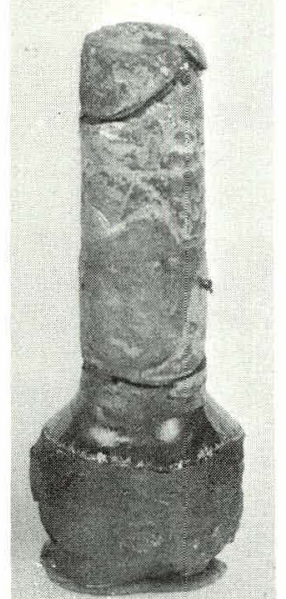

Fig. 10.8 - Results of melting Zircaloy-4-clad $\mathrm{UO}_{2}$ at $2050^{\circ} \mathrm{C}$ after various stages of oxidation. Numbers adjacent to the samples indicate oxide film thickness.

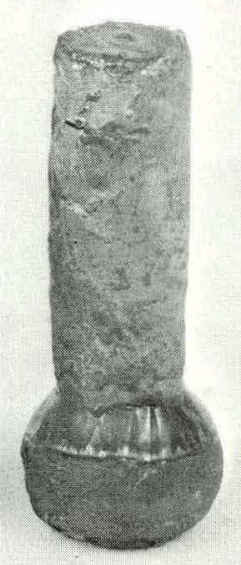

$320 \mu$

$.320 \mu$

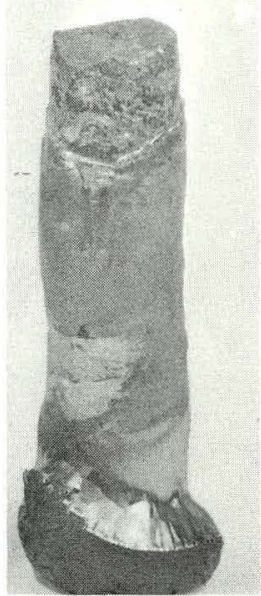




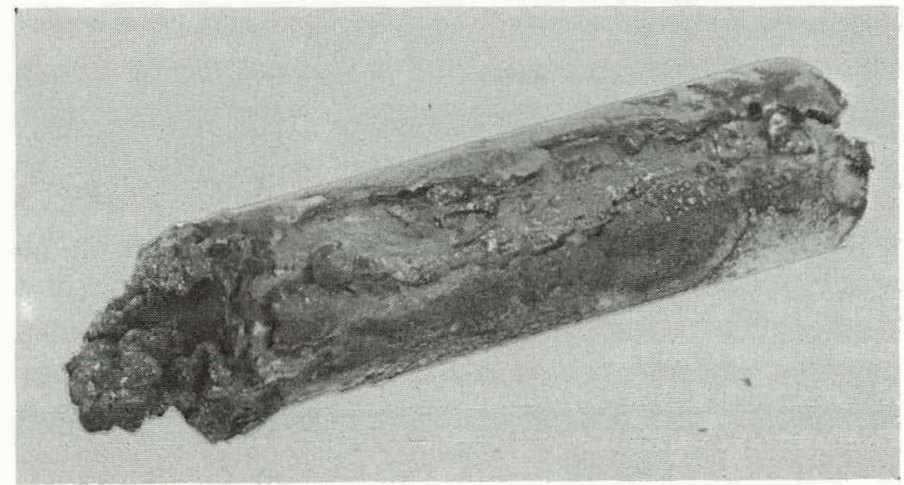

Steam $-0.3^{\circ} \mathrm{C} / \mathrm{sec}$

(Neg. P66-3-15C)

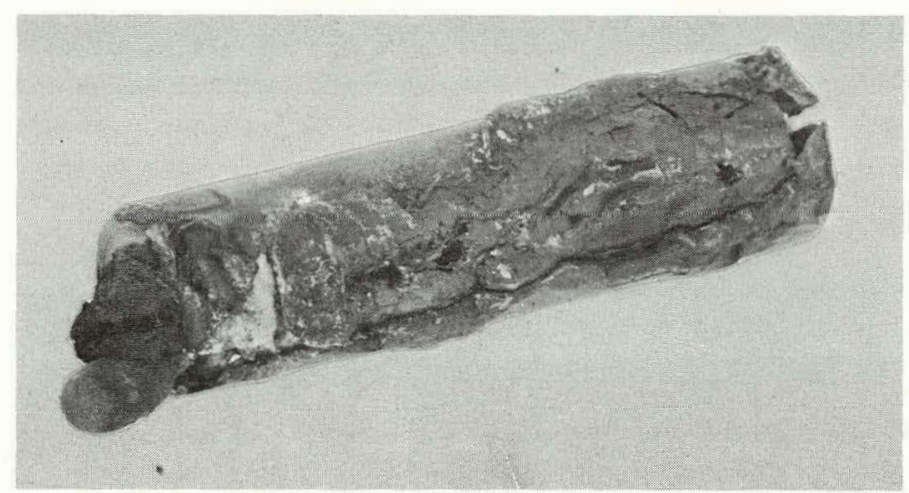

Steam $-3^{\circ} \mathrm{C} / \mathrm{sec}$

(Neg. P66-3-15B)

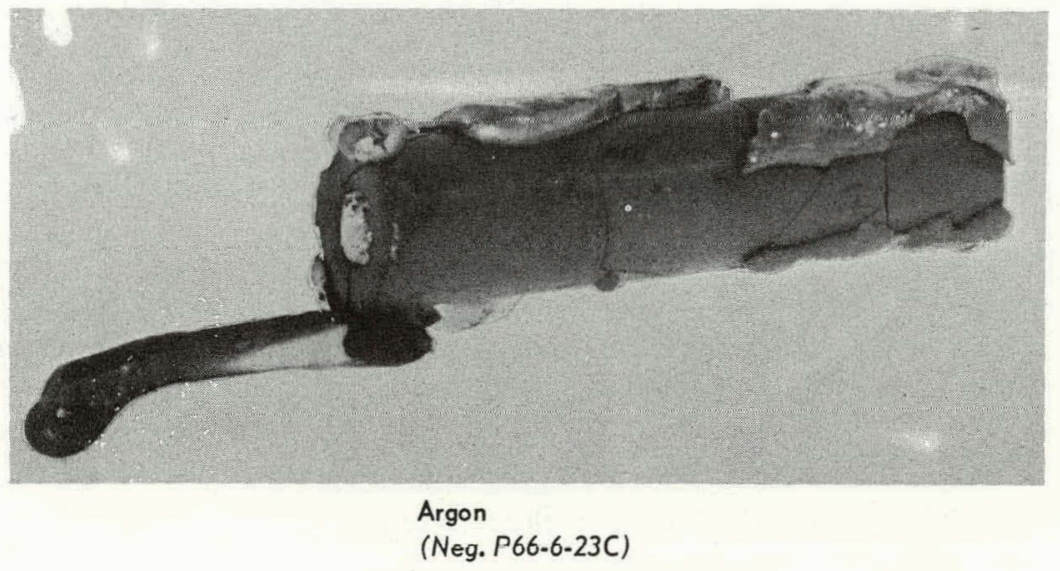

Fig. 10.9 - Melting of Type 304 stainless steel cladding on $\mathrm{UO}_{2}$ heated at $0.3^{\circ}$ and $3^{\circ} \mathrm{C} / \mathrm{sec}$ in steam compared to melting in argon 
TABLE 10.4

RESULTS OF OXIDATION OF TYPE 304 SS BY STEAM

\begin{tabular}{cc}
\hline & $\begin{array}{c}\text { Parabolic Rate, } \\
\mathrm{mg}^{2}\left(\mathrm{O}_{2}\right) / \mathrm{cm}^{4}-\mathrm{sec}\end{array}$ \\
\hline 1000 & 0.0095 \\
1050 & 0.0302 \\
1100 & 0.0950 \\
1150 & 0.180 \\
1200 & 0.750 \\
1200 & 0.800 \\
1250 & 2.07 \\
1300 & 4.38 \\
1350 & 12.97 \\
\hline
\end{tabular}

The microstructure of the oxidized surface formed at $120{ }^{\circ} \mathrm{C}$ on Type 304 SS (see Figure 10.11) shows a multilayered coating; the outer layer is very coarse-grained compared to the Iayers closer to the metal. The electron microprobe indicated the outer coating layer to be essentially $\mathrm{Fe}_{2} \mathrm{O}_{3}$ and the innermost layer to be composed of lower iron oxides mixed with a network of metallic particles. These particles are composed predominantly of iron richer in chromium and nickel than the Type 304 SS. The oxides in this innermost layer have an iron concentration gradient approaching $\mathrm{Fe}_{2} \mathrm{O}_{3}$ next to the outer layer of oxide, $\mathrm{FeO}$ next to the metal, and an intermediate composition between. In the metal, the iron concentration varied from about 60 percent next to the oxide coating to about 69 percent $2.3 \mathrm{~mm}$ into the metal. The concentration of chromium and nickel was essentially constant over the same distance.

To examine the coating formed during the initial period of linear rate behavior, a sample was tested for 5 minutes at $1200^{\circ} \mathrm{C}$. The reaction coating was determined to be $\mathrm{Fe}_{3} \mathrm{O}_{4}$ by $\mathrm{X}$-ray diffraction. The photomicrograph of this sample (Figure 10.12) indicates an oxide layer mixed with a network of metallic particles like the inner oxide layer seen in the longer time tests.

According to Fast,' if iron is in contact with sufficient oxygen at $1000^{\circ} \mathrm{C}$ to eventually convert all the iron to $\mathrm{Fe}_{2} \mathrm{O}_{3}$, then an oxide film will form consisting of three layers: $\mathrm{Fe}_{\mathrm{x}} \mathrm{O}(\mathrm{FeO})$ next to the metal, then $\mathrm{Fe}_{3} \mathrm{O}_{4}$, and $\mathrm{Fe}_{2} \mathrm{O}_{3}$ on the surface. Fast also states that the oxidation proceeds mainly by the diffusion of ferrous ions through the oxide. The activation energies for the diffusion of iron through $\mathrm{FeO}, \mathrm{Fe}_{3} \mathrm{O}_{4}$, and $\mathrm{Fe}_{2} \mathrm{O}_{3}$ are 30.2, 55, and $112 \mathrm{kcal} / \mathrm{mole}$, respectively, while that for $0^{=}$through $\mathrm{Fe}_{2} \mathrm{O}_{3}$ is $146 \mathrm{kcal} / \mathrm{mole} .^{8}$ Based

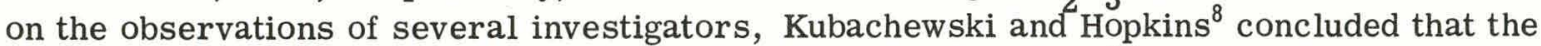
oxidation of iron above $600^{\circ} \mathrm{C}$ is controlled by the diffusion of $\mathrm{Fe}^{++}$ions through $\mathrm{FeO}$, and of $\mathrm{Fe}^{++}$and $\mathrm{Fe}^{+++}$ions through $\mathrm{Fe}_{3} \mathrm{O}_{4}$, while oxygen ions diffuse through $\mathrm{Fe}_{2} \mathrm{O}_{3}$.

\footnotetext{
${ }^{7}$ J. D. Fast, "Interaction of Metals and Gases, Vol. I - Thermodynamics and Phase Relations," Academic Press, New York and London, 1965, p. 65.

${ }^{8}$ O. Kubachewski and B. E. Hopkins, "Oxidation of Metals and Alloys," Academic Press, New York, 1962, p. 33.
} 


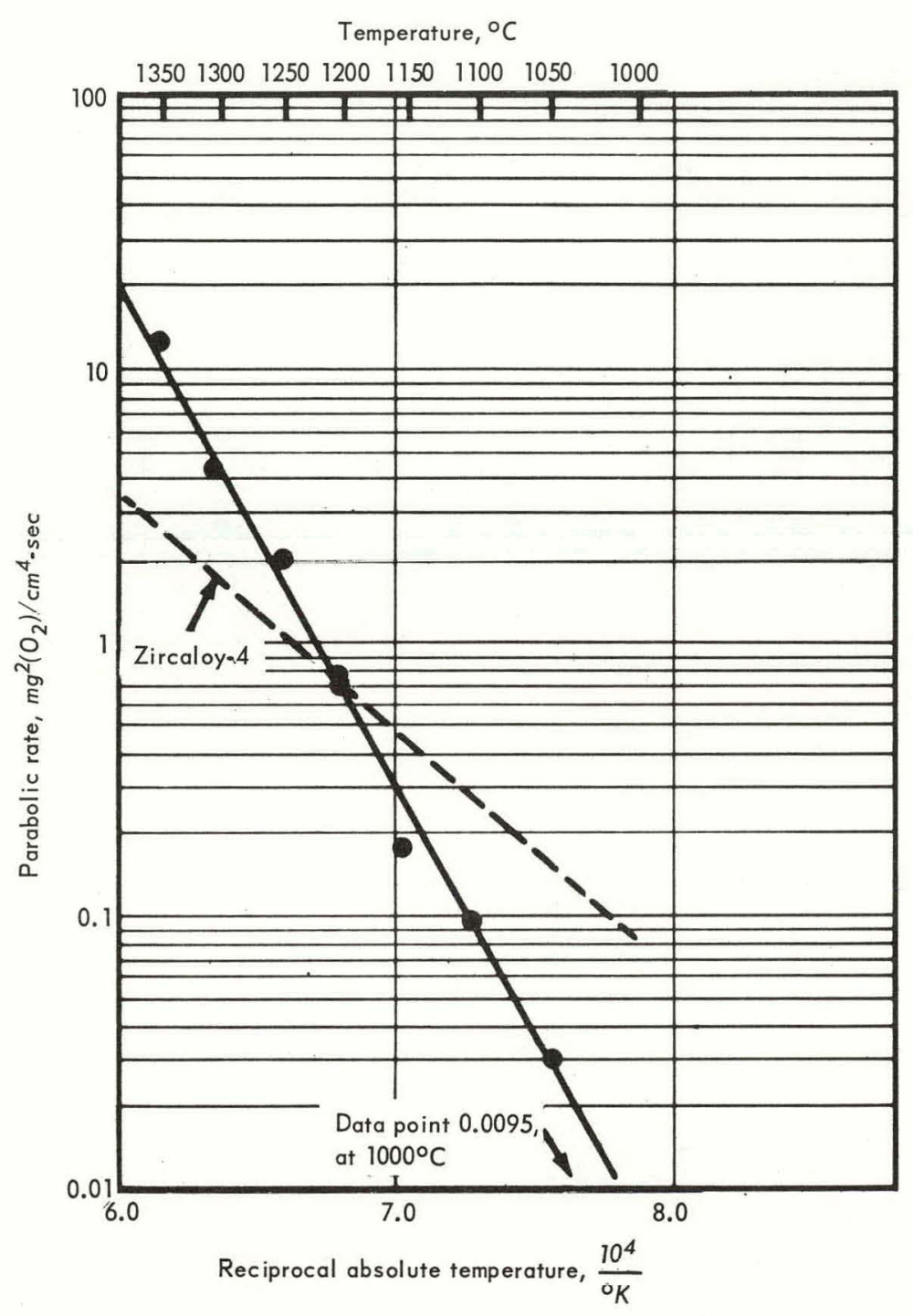

Fig. 10.10-0xidation of Type 304 stainless steel by steam

Hauffe and Pfeiffer ${ }^{9}$ found that iron formed only $\mathrm{FeO}$ at $900^{\circ}$ to $1000^{\circ} \mathrm{C}$ in $\mathrm{CO}_{2}-\mathrm{CO} \mathrm{mix}-$ tures and that the oxygen uptake was linear with time even though the scale was dense. Apparently so much iron can diffuse because of the high concentration of vacancies in $\mathrm{FeO}$ that phase boundary reaction (rather than diffusion) is rate-controlling. This may explain the initial linear weight gain seen in this work.

The results of this investigation suggest that steam oxidation corrosion of Type 304 SS in the $1200^{\circ} \mathrm{C}$ temperature region resembles the oxidation of iron in air at temperatures above $1000^{\circ} \mathrm{C}$.

\section{OXIDATION OF UO 2 BY STEAM}

Although much is known about the oxidation of $\mathrm{UO}_{2}$ at temperatures above $250^{\circ} \mathrm{C}$ in air or oxygen, only a few studies have been made of the reaction of $\mathrm{UO}_{2}$ in steam at elevated

${ }^{9}$ K. Hauffe and H. Pfeiffer, "Kinetics of Wüstite Formation in the Oxidation of Iron," Z. Metallk., Vol. 44, 1953, p. 27. 


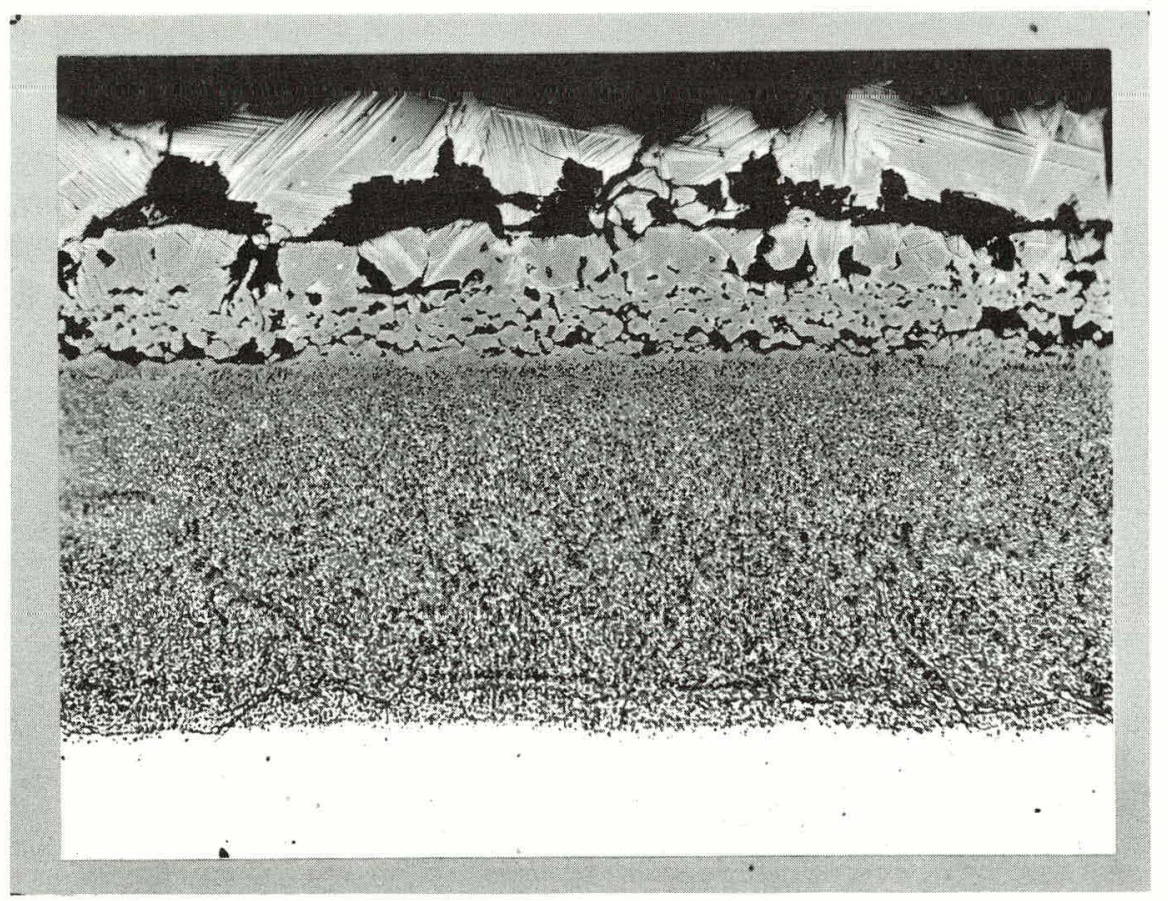

$\mathrm{Fe}_{2} \mathrm{O}_{3}$

$\mathrm{Fe}_{3} \mathrm{O}_{4}$ + metal phase

Fig. 10.11-Photomicrograph of a cross section of Type 304 stainless steel sample held at $1200^{\circ} \mathrm{C}$ in steam for 2 hours

(Neg. 7051, unetched, 100X)

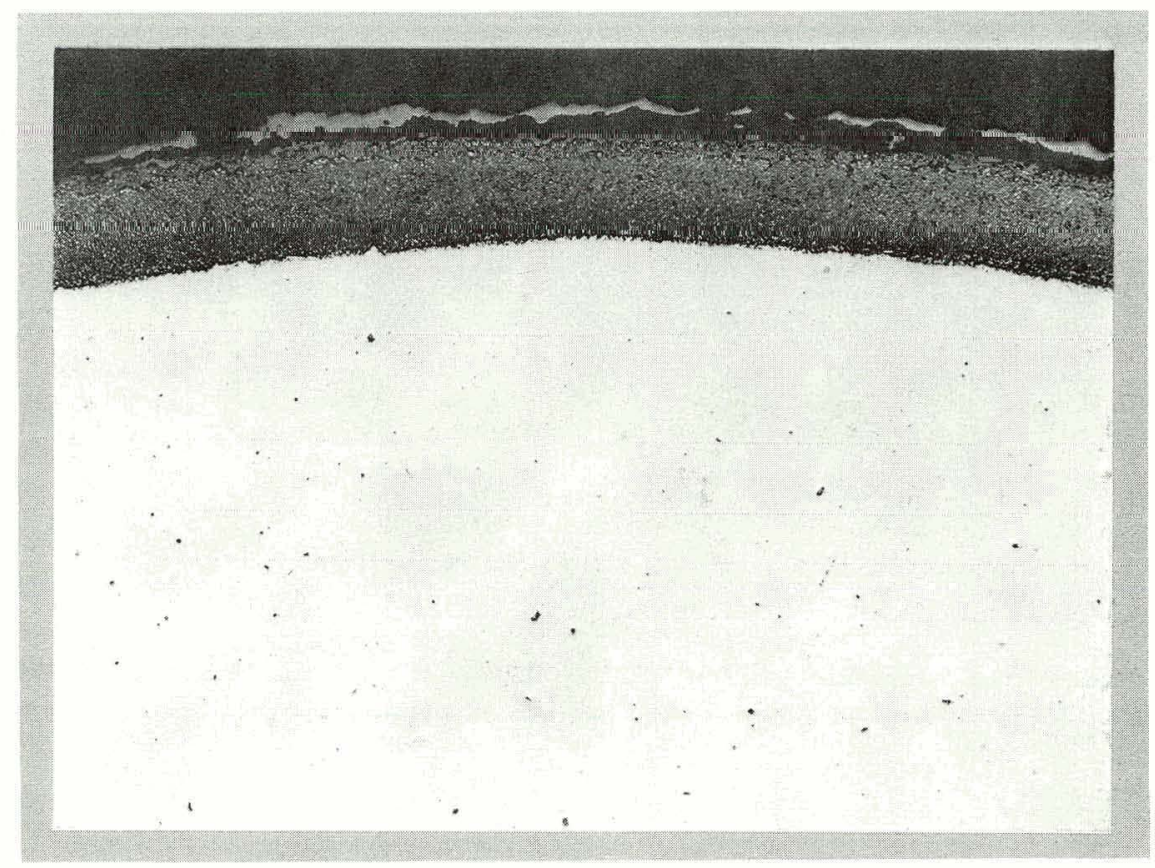

$\mathrm{Fe}_{3} \mathrm{O}_{4}$

Metal

Fig. 10.12-Photomicrograph of cross section of a Type 304 stainless steel sample heated in steam for 5 minutes at $1200^{\circ} \mathrm{C}$

(Neg. 7348, 100X) 
temperatures. Kuhlman ${ }^{10}$ found no significant change when $\mathrm{UO}_{2}$ powder was exposed to oxygen-free water vapor at $450^{\circ} \mathrm{C}$ and $600^{\circ} \mathrm{C}$ for several hours. Belle ${ }^{11}$ reported that, upon sintering $\mathrm{UO}_{2}$ compacts in steam above $1000^{\circ} \mathrm{C}$, a composition up to about $\mathrm{UO}_{2.2}$ can be obtained. Thermodynamically, it is expected that $\mathrm{UO}_{2}$ will reduce $\mathrm{H}_{2} \mathrm{O}$ to form $\mathrm{UO}_{2+\mathrm{x}}$ but not form $\mathrm{U}_{3} \mathrm{O}_{8}$. Recent Argonne ${ }^{12}$ studies of $\mathrm{UO}_{2}$ in steam at $1500^{\circ} \mathrm{C}$ showed parabolic rate behavior for about 1 hour and an $\mathrm{O} / \mathrm{U}$ ratio of about 2.14 , followed by a much lower rate of increase to an $\mathrm{O} / \mathrm{U}$ ratio of about 2.17 after 4 hours.

Steam oxidation of $\mathrm{UO}_{2}$ at temperatures between $1100^{\circ}$ and $1500^{\circ} \mathrm{C}$ was investigated using the thermobalance apparatus previously described. ${ }^{13}$ Solid cylinders of $\mathrm{UO}_{2}\left(\mathrm{UO}_{2.004}\right.$ by chemical analyses), sintered at $1700^{\circ} \mathrm{C}$ for 5 hours in hydrogen to about 95 percent of theoretical density, were cut to approximately $1.27-\mathrm{cm}$ lengths from rods about $1.27 \mathrm{~cm}$ in diameter. Tests were made in steam (generated from distilled water) flowing at a rate of about $300 \mathrm{std}$. ml. per min. The $\mathrm{O}_{2}$ pressure in the steam due to the oxygen dissolved in the water was calculated to be a maximum of about $5 \times 10^{-6}$ atmosphere at equilibrium; this $\mathrm{O}_{2}$ pressure would have negligible effect on the $\mathrm{O} / \mathrm{U}$ ratio at these test temperatures. An argon sweep was used to preclude oxidation of the sample during heating and cooling. A blank run was made in which a sample was heated at $1500^{\circ} \mathrm{C}$ for 2 hours in argon only; a negligible weight change ( +0.0004 gram) and no significant change in appearance or dimensions were noted.

The $\mathrm{UO}_{2}$ cylinders were intact and visually unchanged after all tests; however, there was about 1 - to 2-percent growth in length and diameter ( 3 to 6 vol \%). The samples gained weight at an initially high rate followed by a lower rate in approximate agreement with parabolic kinetics. For long times, however, there is a leveling off of the weight gain as a limiting composition is approached.

Microstructures of samples tested in argon and in steam for 2 hours at $1500^{\circ} \mathrm{C}$ are shown in Figure 10.13. X-ray diffraction examination of the sample exposed to steam showed the presence of about 67-percent $\mathrm{UO}_{2}$ and 33-percent $\mathrm{U}_{4} \mathrm{O}_{9-\mathrm{y}}$ throughout the sample. (Both phases are cubic; the room-temperature lattice parameter for $\mathrm{UO}_{2}$ is $5.4704 \AA$ and that for $\mathrm{U}_{4} \mathrm{O}_{9}$ is $5.4411 \AA^{14}$ ) Electron microprobe examination confirmed that the grain boundaries and the particles within the $\mathrm{UO}_{2}$ grains were oxygen-rich. Since $\mathrm{U}_{4} \mathrm{O}_{9}$ and $\mathrm{UO}_{2}$ form a solid solution of $\mathrm{UO}_{2+\mathrm{x}}$ above $1100^{\circ} \mathrm{C},{ }^{15} \mathrm{U}_{4} \mathrm{O}_{9}$ precipitated out upon cooling to room temperature.

Parabolic rate constants determined from these measurements are given in Table $\mathbf{1 0 . 5}$ along with diffusion data discussed below. These rate measurements are plotted versus reciprocal temperature in Figure 10.14. From these data, the oxidation of $\mathrm{UO}_{2}$ by steam can be expressed as:

$$
\mathrm{W}^{2} / \mathrm{t}=1.64 \times 10^{5} \exp \frac{-50,800 \pm 4800}{\mathrm{RT}}
$$

where the units are the same as in equation (10.5).

\footnotetext{
${ }^{10}$ W. C. Kuhlman, "Treatment of Uranium Dioxide with Water Vapor at High Temperatures," Mallinckrodt Chemical Works, MCW-103, August 13, 1948.

${ }^{11} \mathrm{~J}$. Belle, “Uranium Dioxide: Properties and Nuclear Applications," Naval Reactors, Division of Reactor Development, USAEC, pp. 397-398.

12،'Reactor Development Programs Progress Report,” Argonne National Laboratory, ANL-7115, October 1965, p. 83.

13،'High-Temperature Materials Program Progress Report No. 63,” GE-NMPO, GEMP-63, December 30, 1966, p. 120.

${ }^{14} \mathrm{~F}$. Gronvold, "High Temperature X-Ray Study of Uranium Oxides in the $\mathrm{UO}_{2}-\mathrm{U}_{3} \mathrm{O}_{8}$ Region," Journal of Inorganic Nuclear Chemistry, Vol. 1, 1955, p. 357.

${ }^{15}$ P. E. Blackburn, "Oxygen Dissociation Pressures Over Uranium Oxides," Journal of Physical Chemistry, Vol. 62, 1958, pp. 897-902.
} 


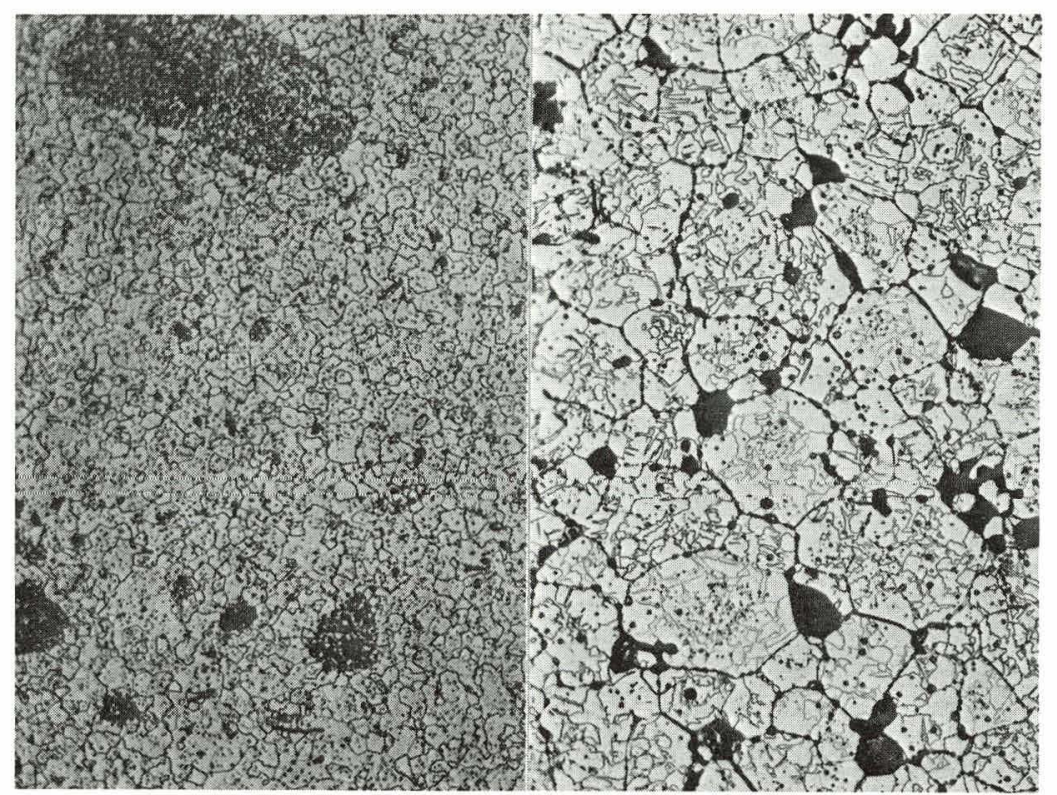

$\begin{array}{ll}\mathrm{UO}_{2} \text { in argon } & \mathrm{UO}_{2+x} \text { in steam } \\ (\mathrm{Neg} .8664) & (\mathrm{Neg} .8660)\end{array}$

Fig. 10.13-Microstructures of $\mathrm{UO}_{2}$ and $\mathrm{UO}_{2+\mathrm{x}}$ after 2 hours in argon and steam at $1500^{\circ} \mathrm{C}$

TABLE 10. 5

RESULTS OF UO $2\left(\mathrm{UO}_{2.004}\right)$ REACTION WITH STEAM

\begin{tabular}{|c|c|c|c|c|c|c|c|c|}
\hline $\begin{array}{c}\text { Temperature, } \\
{ }^{\circ} \mathrm{C}\end{array}$ & $\begin{array}{c}\text { Test Time, } \\
\text { sec }\end{array}$ & $\begin{array}{c}\text { Initial } \\
\text { Weight, } \\
\mathrm{g}\end{array}$ & $\begin{array}{c}\text { Weight } \\
\text { Gain, } \\
\text { g }\end{array}$ & $\begin{array}{l}\text { Parabolic Rate, } \\
\mathrm{mg}^{2}\left(\mathrm{O}_{2}\right) / \mathrm{cm}^{4}-\mathrm{sec}\end{array}$ & $\begin{array}{l}\Delta \mathrm{O} / \mathrm{U} \\
\text { Ratio }\end{array}$ & $\begin{array}{c}\text { Theoretical } \\
\text { Equilibrium } \mathrm{O} / \mathrm{U}^{\mathrm{b}} \\
\text { Ratio }\end{array}$ & $\begin{array}{l}\text { Radius, } \\
\mathrm{cm}\end{array}$ & $\begin{array}{c}\mathrm{D}, \\
\mathrm{cm}^{2} / \mathrm{sec}\end{array}$ \\
\hline 1500 & 1,140 & 16. 4467 & 0.0876 & 0.120 & 0.0899 & 2. 1772 & 0.6331 & $1.2 \times 10^{-5}$ \\
\hline 1500 & 2,400 & 16. 2287 & 0.1009 & 0.0760 & 0.1050 & 2. 1772 & 0.6306 & $8.3 \times 10^{-6}$ \\
\hline 1500 & 4,560 & 16.1417 & 0. 1226 & 0.0587 & 0.1282 & 2. 1772 & 0.6320 & 7. $8 \times 10^{-6}$ \\
\hline 1400 & 5,700 & 16. 0962 & 0.1206 & 0.0464 & 0.1265 & 2. 1834 & 0.6276 & $5.3 \times 10^{-6}$ \\
\hline 1400 & 6,900 & 16. 3291 & 0.1029 & 0.0274 & 0.1064 & 2.1834 & 0.6320 & 2. $75 \times 10^{-6}$ \\
\hline 1200 & 7,020 & 20.6454 & 0.0649 & 0.00773 & 0.0530 & 2.1983 & 0.6769 & 4. $92 \times 10^{-7}$ \\
\hline 1200 & 10,800 & 20. 5758 & 0.0735 & 0.00661 & 0.0603 & 2. 1983 & 0.6687 & $4.22 \times 10^{-7}$ \\
\hline 1100 & 10,500 & 16. 9978 & 0.0331 & 0.00175 & 0.0329 & 2. 2074 & 0.6380 & $9.7 \times 10^{-8}$ \\
\hline 1100 & 10,860 & 16. 5417 & 0.0187 & 0.00056 & 0.0192 & 2. 2074 & 0.6345 & $2.9 \times 10^{-8}$ \\
\hline
\end{tabular}

$\mathrm{a}_{\text {From analytical balance weighings. }}$

${ }^{\mathrm{b}}$ Calculated by using the equation: In $\mathrm{P}_{\mathrm{O}_{2}}=70 \times-3.29 \times 10^{4} / \mathrm{T}-1.05$ given by A. M. Anthony, R. Kigoura, and T. Sata,

"Les Equilibres des Composes Oxygenes de I' Uranium entre 1500 et $2000^{\circ} \mathrm{K}$, " Journal of Nuclear Materials, Vol. 10 , 1963, pp. 8-14.

$\mathrm{c}_{\text {Calculated assuming an inscribed sphere. }}$ 


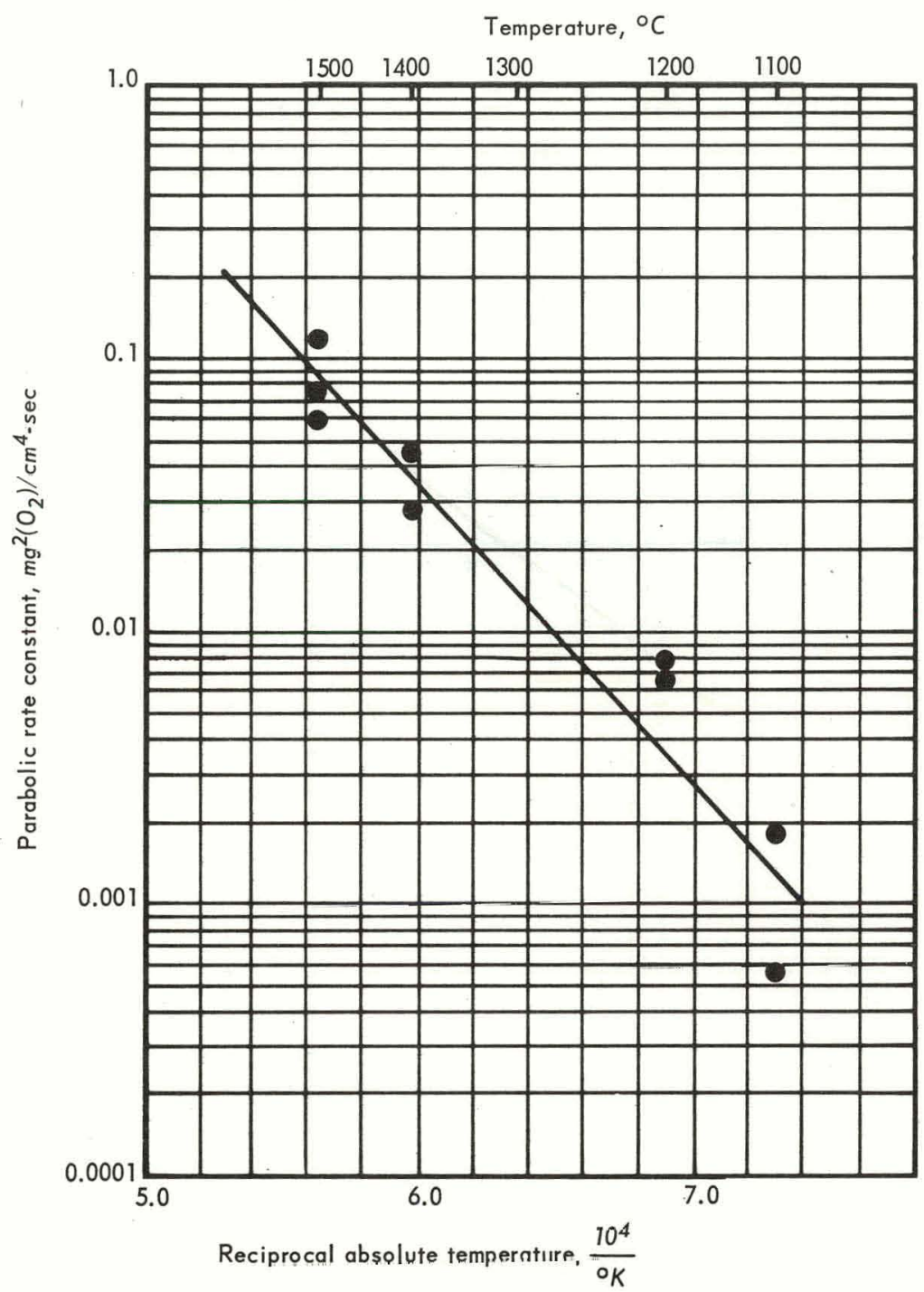

Fig. 10.14 - Oxidation of $\mathrm{UO}_{2}$ by steam

$\mathrm{O} / \mathrm{U}$ ratios obtained from chemical analysis agree well with those calculated from sample weight gains.

Since thermobalance errors at the lower temperatures tended to obscure the small weight changes, diffusion coefficients were calculated from all the tests using weight changes measured on an analytical balance. The $\mathrm{D}$ values were calculated by the following method: First, the total weight gain was converted to a change in $\mathrm{O} / \mathrm{U}$ ratio which was divided by the predicted change to equilibrium $\mathrm{O} / \mathrm{U}$ ratio to obtain fractional completion. Assuming spherical geometry, the corresponding $\frac{\sqrt{D t}}{L}$ value was taken from a graph given in Crank. ${ }^{16}$ The $D$ value was then calculated from the $\frac{\sqrt{D t}}{L}$ number, where D is the diffusion coefficient, $\mathrm{t}$ is the test time in seconds, and $\mathrm{L}$ is the radius in $\mathrm{cm}$. These data are shown in Table 10.5. The calculated diffusion coefficient values are shown plotted versus reciprocal

${ }^{16}$ J. Crank, "Mathematics of Diffusion," Oxford Press, 1956, p. 90. 
absolute temperature in Figure 10.15 along with the data from Auskern and Belle for oxygen self-diffusion in $\mathrm{UO}_{2} \cdot{ }^{17} \mathrm{An}$ activation energy of $61 \mathrm{kcal} /$ mole was calculated for GE-NMPO data using a least squares analysis which is to be compared to $65 \mathrm{kcal} / \mathrm{mole}$ for the data of Auskern and Belle. The line shown in Figure 10.15 drawn through both sets of data gives an activation energy of about $74 \mathrm{kcal} / \mathrm{mole}$. From these results, oxygen diffusion appears to be the controlling mechanism for the steam oxidation of $\mathrm{UO}_{2}$ in the temperature range from $1100^{\circ}$ to $1500^{\circ} \mathrm{C}$. Diffusion coefficients calculated on the same basis from the ANL weight change data ${ }^{12}$ at $1500^{\circ} \mathrm{C}$ showed values in the range from about $8 \times 10^{-6} \mathrm{~cm}^{2} / \mathrm{sec}$ to about $1.2 \times 10^{-5} \mathrm{~cm}^{2} / \mathrm{sec}$, also in close agreement with the results of this work.

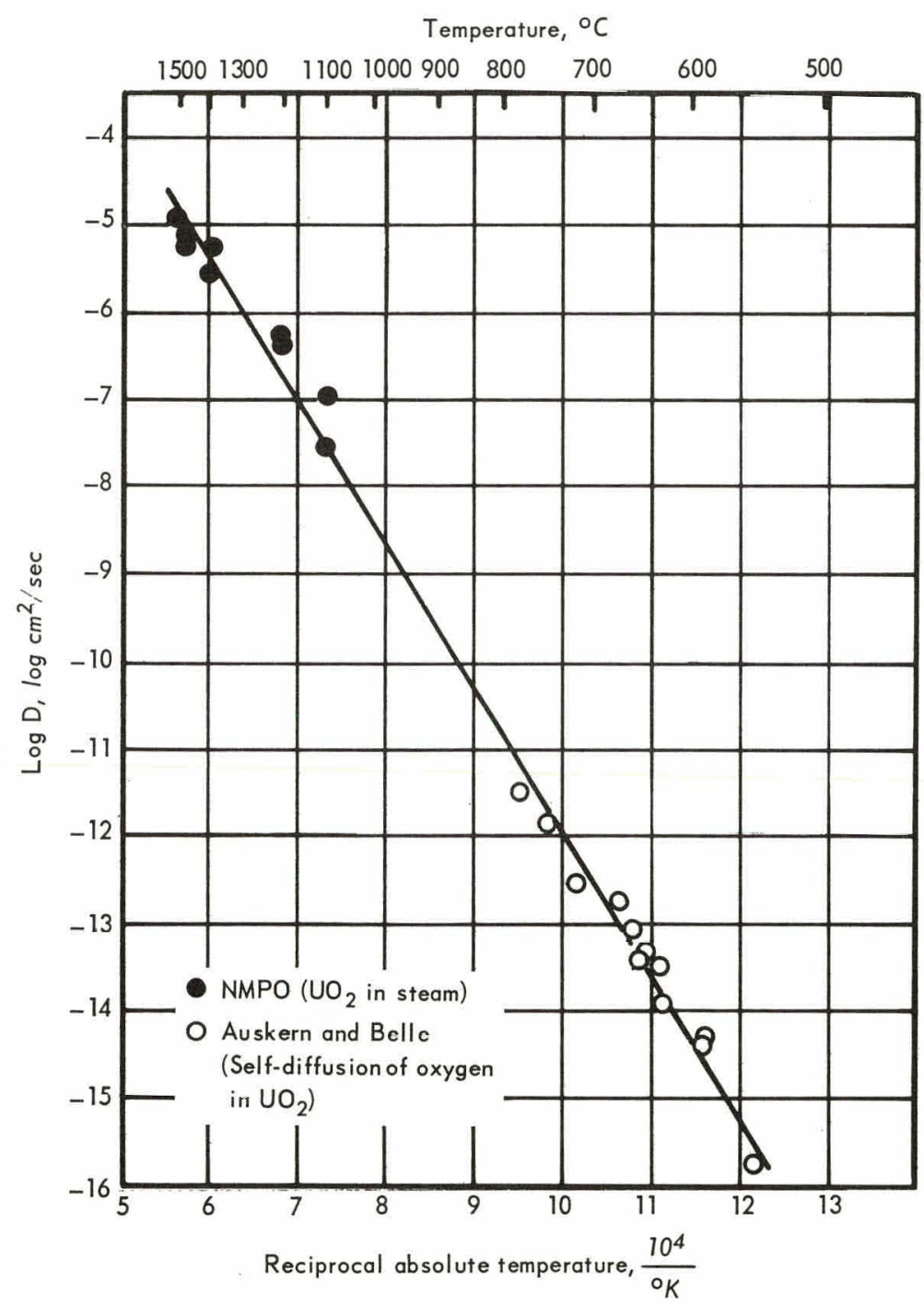

Fig. 10.15-Oxygen diffusion in $\mathrm{UO}_{2}$ : steam oxidation and oxygen self-diffusion

\footnotetext{
${ }^{17}$ A. B. Auskern and J.. Belle, "Oxygen Ion Self Diffusion in Uranium Dioxide," Journal of Nuclear Materials, No. 3 ,
} 1961, pp. $267-276$. 
10.2 PROPERTY MEASUREMENTS (A. D. Feith, R. A. Hein, W. L. McCullough)

\section{THERMAL CONDUCTIVITY OF ZIRCALOY -4}

Thermal conductivity measurements on Zircaloy -4 specimens were performed in the temperature range from $400^{\circ}$ to $1500^{\circ} \mathrm{C}$ in the previously described radial-heat-flow device..$^{18}$ Measurements were made on two samples; these data are shown in Figure 10.16, along with data reported by Scott. ${ }^{19}$ No attempt has yet been made to fit these data to an equation including both phonon and electron contributions since electrical resistivity measurements have not been completed. The limited amount of resistivity data available suggests a more complicated curve for thermal conductivity than the one shown in Figure 10.16. Since the electrical resistivity decreases about 10 percent in the temperature range of $800^{\circ}$ to $900^{\circ} \mathrm{C}$ due to the alpha-to-beta phase transformation, a lower slope would be expected in this range. If there is such a change in slope, however, the scatter in the thermal conductivity data obscures it.

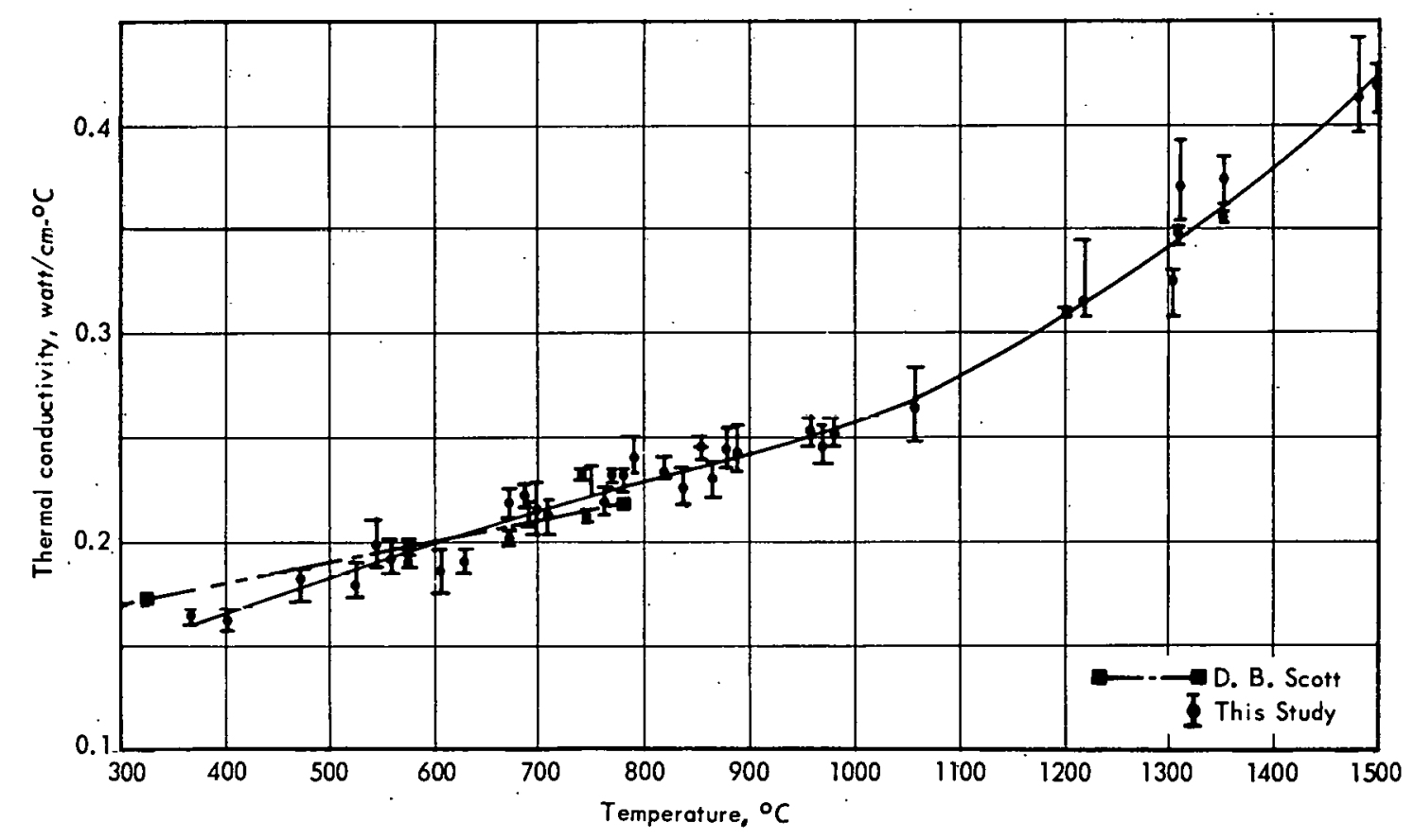

Fig. 10.16 - Thermal conductivity versus temperature for Zircaloy- 4

The properties of zirconium and its alloys are difficult to measure at high temperatures because of their strong tendencies to react with nitrogen and oxygen and because of the formation of eutectics with many refractory metals. Since specimen composition affects thermal conductivity, the composition was monitored at intervals by analyses of small pellets of the material which were placed at the bottom of the specimen holder and exposed to the same environment as the specimen. Table 10.6 shows the composition of this material in the as-received condition, after heating at $400^{\circ}$ to $800^{\circ} \mathrm{C}$ in argon for 100 hours,

${ }^{18}$ A. D. Feith, "A Radial Heat Flow Apparatus for High Temperature Thermal Conductivity Measurements," GE-NMPO, GEMP-296, August 1963.

${ }^{19}$ D. B. Scott, "Physical and Mechanical Properties of Zircaloy-2 and 4," WCAP-3269-41, May, 1965. 
TABLE 10.6

\begin{tabular}{|c|c|c|c|}
\hline \multirow[b]{2}{*}{ Element } & \multicolumn{3}{|c|}{ Impurities, ppm } \\
\hline & As-Received & $\begin{array}{c}\text { Exposed } \\
100 \text { Hours in Argon } \\
\text { at } 400^{\circ} \text { to } 800^{\circ} \mathrm{C}\end{array}$ & $\begin{array}{c}\text { Exposed } \\
200 \text { Hours in Argon } \\
\text { at } 400^{\circ} \text { to } 1500^{\circ} \mathrm{C}\end{array}$ \\
\hline C & 38 & 37 & 52 \\
\hline $\mathrm{O}_{2}$ & 1300 & - & 3140 \\
\hline $\mathrm{N}_{2}$ & 43 & 42 & 210 \\
\hline Al. & 24 & 27 & 87 \\
\hline B & $<1$ & $<1$ & $<1$ \\
\hline $\mathrm{Cd}$ & $<1$ & $<1$ & $<1$ \\
\hline Co & $<10$ & $<10$ & $<10$ \\
\hline $\mathrm{Cu}$ & 176 & 216 & 153 \\
\hline Hf & $<100$ & 130 & $<100$ \\
\hline $\mathrm{Mg}$ & 1600 & 1,500 & $<10$ \\
\hline Mn & 24 & 32 & 13 \\
\hline $\mathrm{Ni}$ & 12 & 7 & 7 \\
\hline $\mathrm{Si}$ & 24 & 28 & 46 \\
\hline $\mathrm{Ti}$ & 18 & 19 & $<10$ \\
\hline $\mathrm{W}$ & $<100$ & $<100$ & $<100$ \\
\hline $\mathrm{Sn}^{\mathrm{a}}$ & 6100 & 11,600 & 3700 \\
\hline $\mathrm{Fe}^{\mathrm{a}}$ & 2300 & 2,400 & 1900 \\
\hline $\mathrm{Cr}^{\mathrm{a}}$ & 860 & 870 & 815 \\
\hline
\end{tabular}

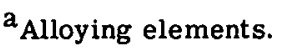

and after an additional 100 hours at $400^{\circ}$ to $1500^{\circ} \mathrm{C}$ in argon. Most of the magnesium was lost during the final heat treatment and also about half of the tin. The nitrogen pickup was slight. The oxygen content in the as-received material was approximately 0.13 percent, whereas it was 0.314 percent in the material heated for 100 hours at $400^{\circ}$ to $1500^{\circ} \mathrm{C}$ in argon. Any change in thermal conductivity. resulting from this change in composition is probably considerably less than the experimental error in the conductivity determination.

Attempts to obtain data at higher temperatures were unsuccessful because of the difficulty in determining the thermal gradient with the degree of confidence necessary for this work. This is reflected by the increased amount of scatter in the results above $1200^{\circ} \mathrm{C}$ (Figure 10.16).

\section{ELECTRICAL RESISTIVITY OF ZIRCALOY -4}

Electrical resistivity of Zircaloy-4 was measured using a specimen fabricated from the same raw material used for the thermal conductivity specimens. This specimen was a rod, $0.64 \mathrm{~cm}$ in diameter and $10.16 \mathrm{~cm}$ long, with grooves $0.16 \mathrm{~cm}$ from each end for emf leads and two $0.25-\mathrm{mm}$-diameter holes centered $7.62 \mathrm{~cm}$ apart for measuring the voltage drop. The first three of five heating cycles were in argon; the last two in helium. The system used for making these measurements was described elsewhere. ${ }^{20}$

Electrical resistivity data from $-196^{\circ} \mathrm{C}$ up to about $900^{\circ} \mathrm{C}$ are shown in Table 10.7 , and are compared with the high-hafnium sample reported by Cook, et al.,$^{21}$ in Figure 10.17.

${ }^{20}$ A. D. Feith, "The Thermal Conductivity and Electrical Resistivity of Molybdenum," GE-NMPO, GE-TM 65-10-1, October 1965.

${ }^{2}{ }^{1}$ L. A. Cook, L. S. Castleman, and W. S. Johnson, "Preliminary Report on Electrical Resistivity of Zirconium," Westinghouse Electric Corp., WAPD-25, December 1950. 
TABLE 10.7

ELECTRICAL RESISTIVITY VALUES FOR ZIRCALOY 4

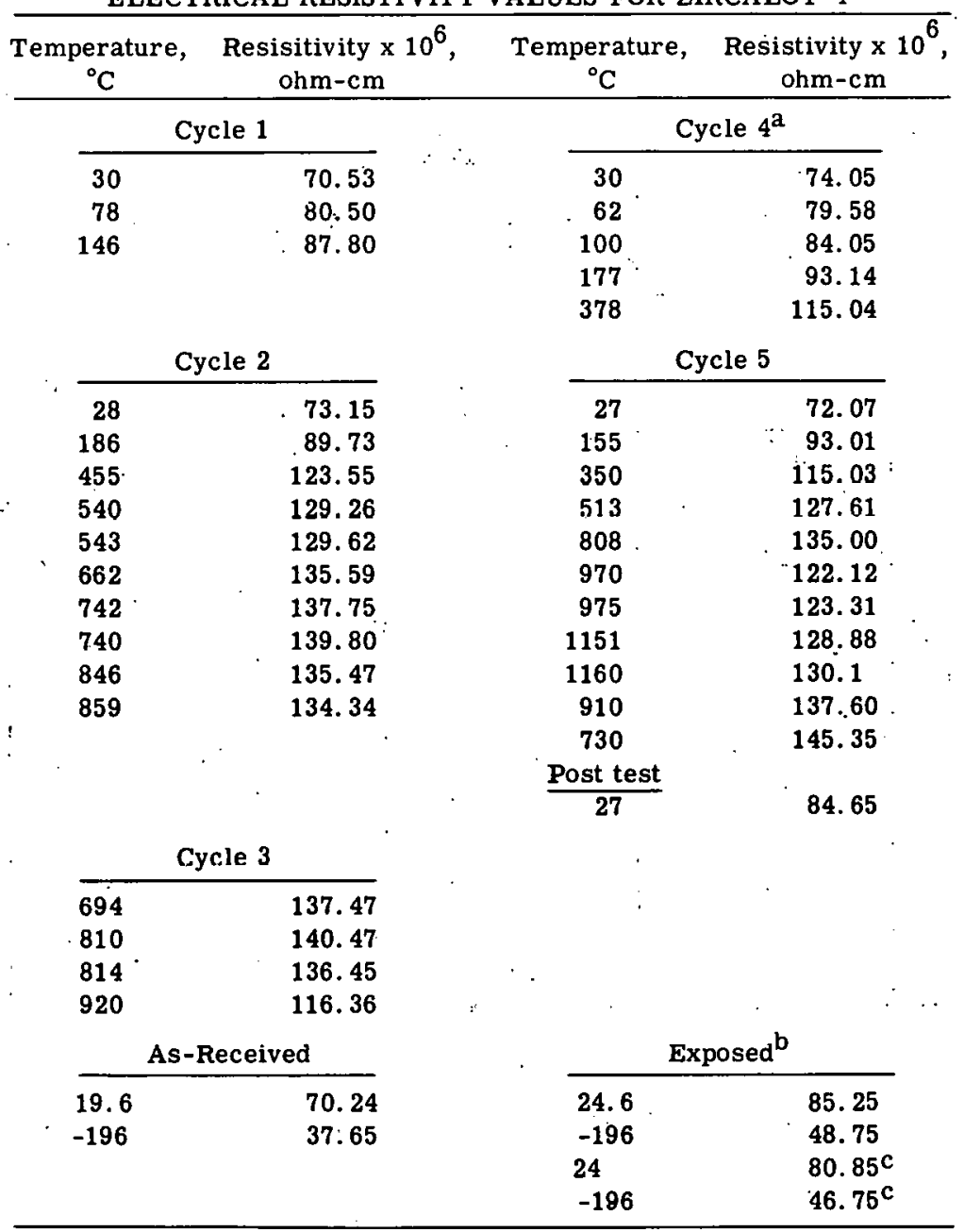

The specimen was removed and cleaned prior to Cycle 4 .

b Measurements after Cycle 5.

$c_{\text {After grinding }} 0.05 \mathrm{~cm}$ from diameter.

These values are based on the distance between the voltage probes at room temperature. The relatively high values in the room-temperature measurements may be due to the alloying elements present in Zircaloy -4 in comparison with the nearly pure sample measured by Cook. Alloying may possibly also account for the slightly lower temperature $\left(810^{\circ} \mathrm{C}\right)$ at which the alpha-to-beta phase transformation takes place.

Koom-temperature ressstivity in argon and helium are the same within 1 percent. The temperature dependence followed very closely that of the initial curve up to the phase transformation temperature. Allowing for an experimental error of about \pm 2 percent, all of the data can be represented by Figure 10.17. Since these data are reproducible, they are believed to represent the electrical resistivity of Zircaloy -4 up to the phase transformation temperature. Values above the phase change appear to have been greatly affected by contamination and, therefore, are not considered representative of the electrical resistivity of Zircaloy-4. The cooling data strongly indicated that contamination had occurred, and 


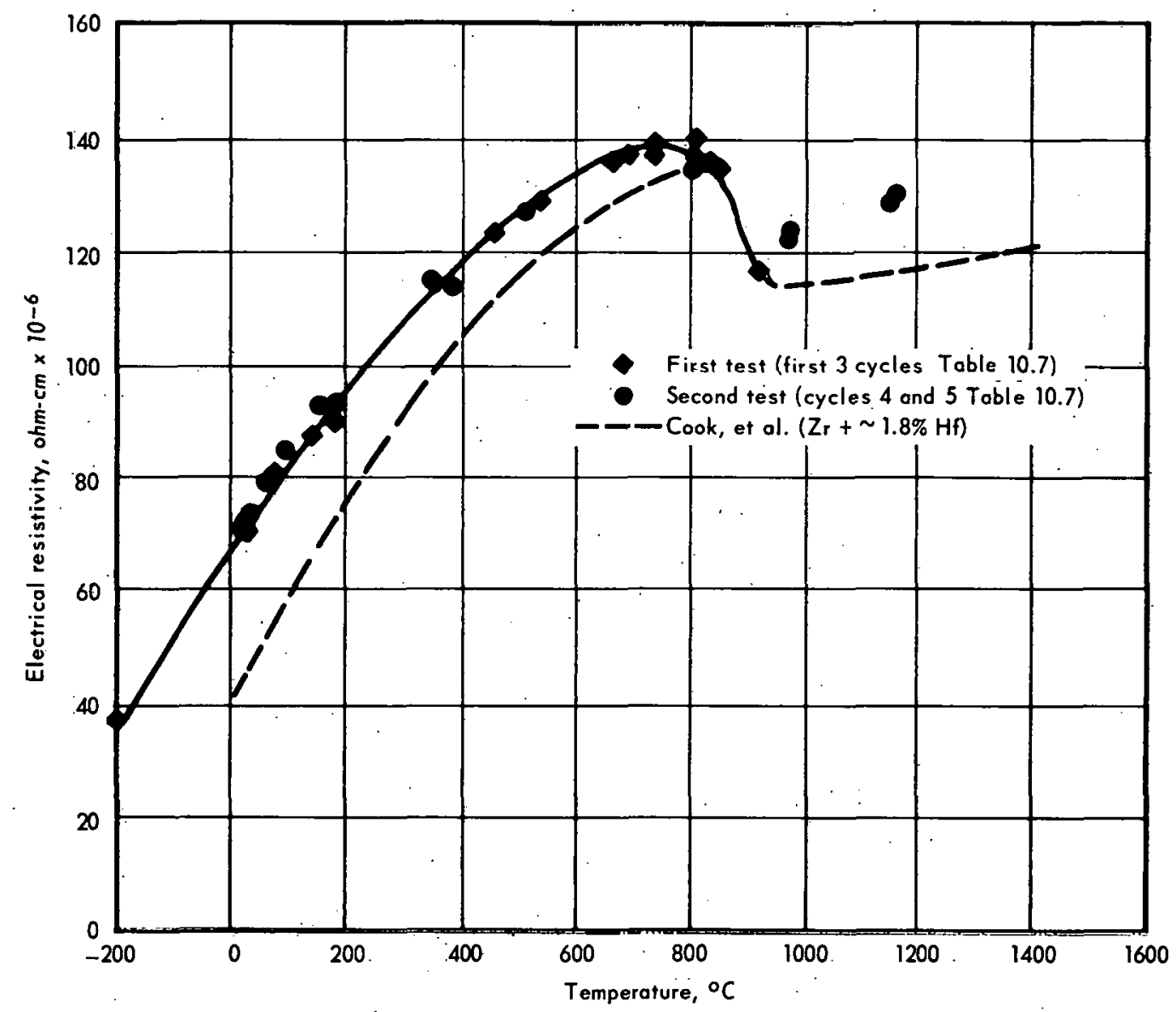

Fig. 10.17 - Electrical resistivity of Zircaloy-4 as a function of temperature

subsequent metallographic examination indicated that contamination extended below the specimen surface.

Electrical resistivity measurement was performed to gain better understanding of the mechanisms of thermal conductivity. Since Zircaloy -4 is an electrical conductor, a large portion of the heat is carried by conduction electrons, and the remainder is propagated by lattice vibrations or phonons. Determining the electrical resistivity therefore permits separating the total thermal conductivity into the electronic and phonon components. This study has shown that, up to the phase transformation temperature, the electronic component of the thermal conductivity represents 90 percent of the total measured value and the phonon component the other 10 percent. Since the electrical resistivity values reported herein are not considered valid above the phase transformation, a similar breakdown could not be made in this temperature range. However, the resistivity data of Cook, et al., indicate that thermal conductivity above the phase change is completely electronic.

\section{HEAT OF FUSION}

A.literature survey was made for available data on the heats of fusion of several materials of interest to this task. Unfortunately, heat of fusion data for Type 304 SS and Zircaloy-4 
are not readily available; therefore, their heats of fusion have been estimated to be those of their principal constituents. The heats of fusion for these materials are:

Material

$\mathrm{UO}_{2}$

$\mathrm{ZrO}_{2}$

Type 304 SS

.Zircaloy-4
Heat of Fusion, cal/gram

$106 \pm 28^{22}$

$169^{23}$

$66 \pm 7^{24}$ (est.)

$54^{24}$ (est.)

\section{MECHANICAL PROPERTIES OF ZIRCALOY -4}

Zircaloy-4 sheet specimens were tensile tested from room temperature to $1800^{\circ} \mathrm{C}$. The room-temperature tests were performed in air, whereas the tests at all other temperatures were performed in an argon atmosphere. All test specimens $(2.54-\mathrm{cm}$ gage length) were fabricated from one $0.076-\mathrm{cm}$-thick sheet, with loading applied in the major rolling direction of the sheet.

Tests at room temperature were performed at a strain rate of $0.005 \mathrm{~min}^{-1}$ using a Baldwin extensometer which provided data for determining the 0.2 -percent yield strength and the modulus of elasticity. The room-temperature results are shown in Table 10.8. The elevated temperature tests were performed at a loading rate of $0.13 \mathrm{~cm}$ per min based on the crosshead speed (no extensometer). Figure 10.18 shows the ultimate tensile-strengthversus-temperature data compared with that of $S \operatorname{cott},{ }^{19}$ while Figure 10.19 gives the ductility (elongation based on the strain at rupture) versus temperature relationship. Maximum elongation of about 90 percent occurs at about $1100^{\circ} \mathrm{C}$.

TABLE 10.8

\begin{tabular}{cccc}
\multicolumn{4}{c}{ ROOM-TEMPERATURE STRENGTH OF ZLRCALOY -4 SHEET } \\
\hline $\begin{array}{c}\text { Specimen } \\
\text { No. }\end{array}$ & $\begin{array}{c}0.2 \% \text { Yield } \\
\text { Strength, } \mathrm{kg} / \mathrm{mm}^{2}\end{array}$ & $\begin{array}{c}\text { Ultimate Tensile } \\
\text { Strength, } \mathrm{kg} / \mathrm{mm}^{2}\end{array}$ & $\begin{array}{c}\text { Young's Modulus, } \\
\mathrm{kg} / \mathrm{mm}^{2}\end{array}$ \\
\hline 1 & 33.80 & 53.00 & 10,100 \\
20 & 34.20 & 52.50 & 9,000 \\
40 & 33.30 & 52.20 & 8,700 \\
\hline
\end{tabular}

Zirconium and most of its alloys are extremely susceptible to contamination by oxygen, nitrogen, and hydrogen at elevated temperatures. Measured strength and ductility, being dependent upon the degree of contamination occurring both before and during testing, thus may not represent the true properties of the basic materials. The argon used for this testing was of high purity, but the tested specimens were not all chemically analyzed after test. In an attempt to evaluate the degree to which the specimens may have become contaminated during testing, room-temperature hardness measurements were obtained before and after test (see Figure 10.19). An increase in hardness indicates contamination with a possible increase in tensile strength and a decrease in ductility. Figure 10.19 gives the hardness results obtained at room temperature after testing at the indicated temperatures. The specimen tested at $900^{\circ} \mathrm{C}$ was slightly harder after testing than before (initial DPH $=220$ ). Hardness of specimens tested above $1200^{\circ} \mathrm{C}$ increased and their ductility decreased. Three of the

\footnotetext{
${ }^{22}$ L. N. Grossman, "High-Temperature Thermal Analysis of Ceramic Systems," presented at the Annual Meeting of the American Ceramic Society, Washington, D.C., May 1966.

${ }^{23}$ C. E. Wicks and F. E. Block, "Thermodynamic Properties of 65 Elements, Their Oxides, Halides, Carbides, and Nitrides," U.S. Bureau of Mines, Bulletin No. 605, 1963.

${ }^{24}$ R. R. Hultgren, et al., "Selected Values of Thermodynamics Properties of Metals and Alloys," Wiley, 1963.
} 


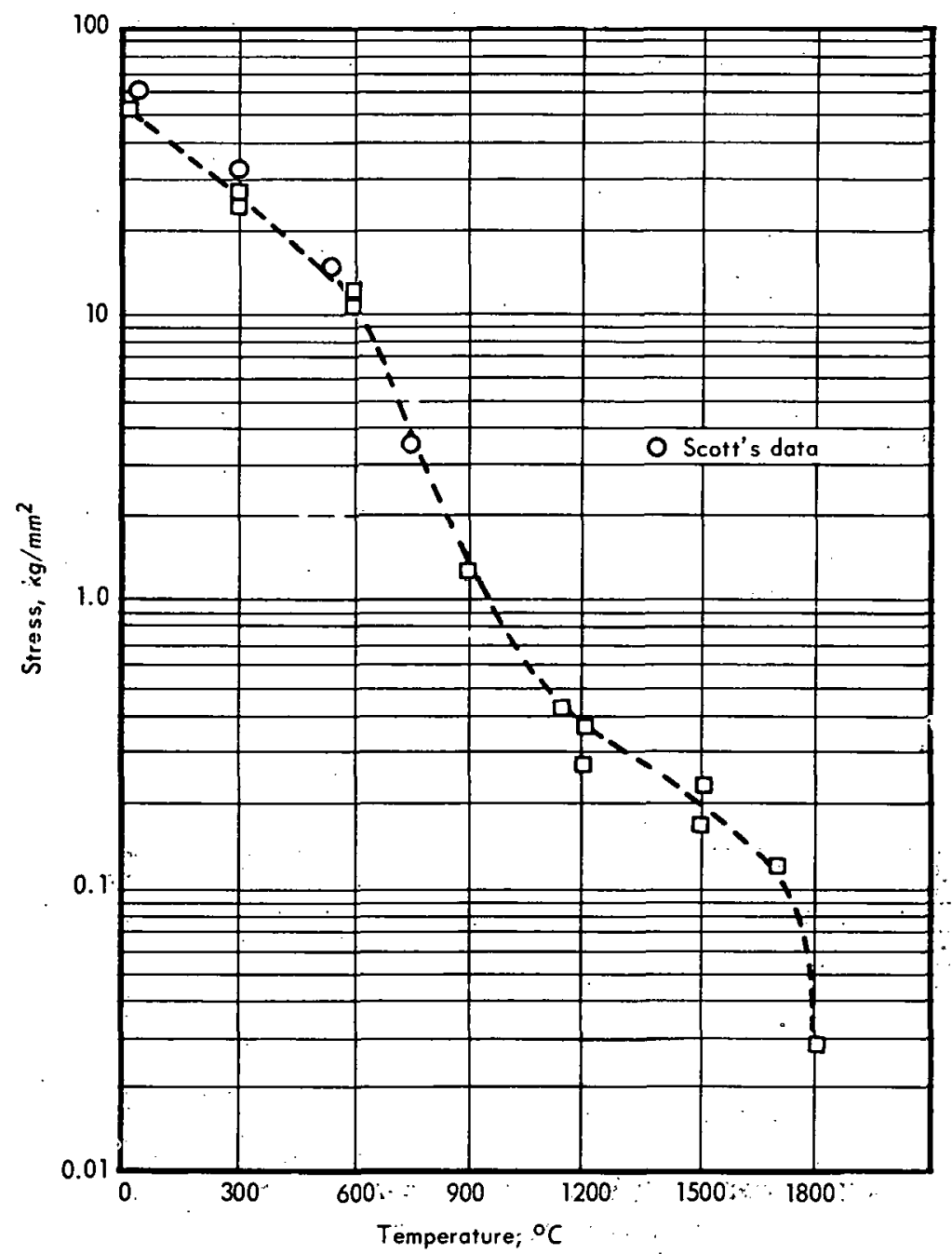

Fig. 10:18-Ultimate tensile strength of $0.076-\mathrm{cm}$-thick Zircaloy-4 sheet in argon

samples were analyzed; the results are given in Table 10.9. These data show that the nitrogen, oxygen, and hydrogen contents-of the $1800^{\circ} \mathrm{C}$ test-specimen had significantly increased as suggested by the high hardness and low elongation.

While the increase in impurities (particularly oxygen and nitrogen) during testing at the higher test temperature indicates that the tensile data are not precise values for the basic material, it should be recognized that the impurity pickup is insignificant relative to the pickups which can be expected in a steam atmosphere, even at a heating rate of $3^{\circ} \mathrm{C}$ per - second.

TABLE 10. $9^{2}$

VACUUM FUSION ANALYSIS OF ZIRCALOY -4 TENSILE SAMPLES

\begin{tabular}{cccccc}
\hline $\begin{array}{c}\text { Tensile Test } \\
\text { Temperature, } \\
{ }^{\circ} \mathrm{C}\end{array}$ & $\begin{array}{c}\text { Sample Hardness } \\
\text { After Testing, } \\
\text { DPH }\end{array}$ & $\begin{array}{c}\text { Elongation } \\
\text { in 2.54-cm } \\
\text { Gage Length, } \%\end{array}$ & \multicolumn{3}{c}{ Contaminant, ppm } \\
\cline { 5 - 7 } RT.(as-received) & 220 & 23.0 & 34 & 1510 & 13 \\
900 & 240 & 79.0 & 11 & 1888 & 33 \\
1800 & 270 & 1.0 & 171 & 4742 & 70 \\
\hline
\end{tabular}



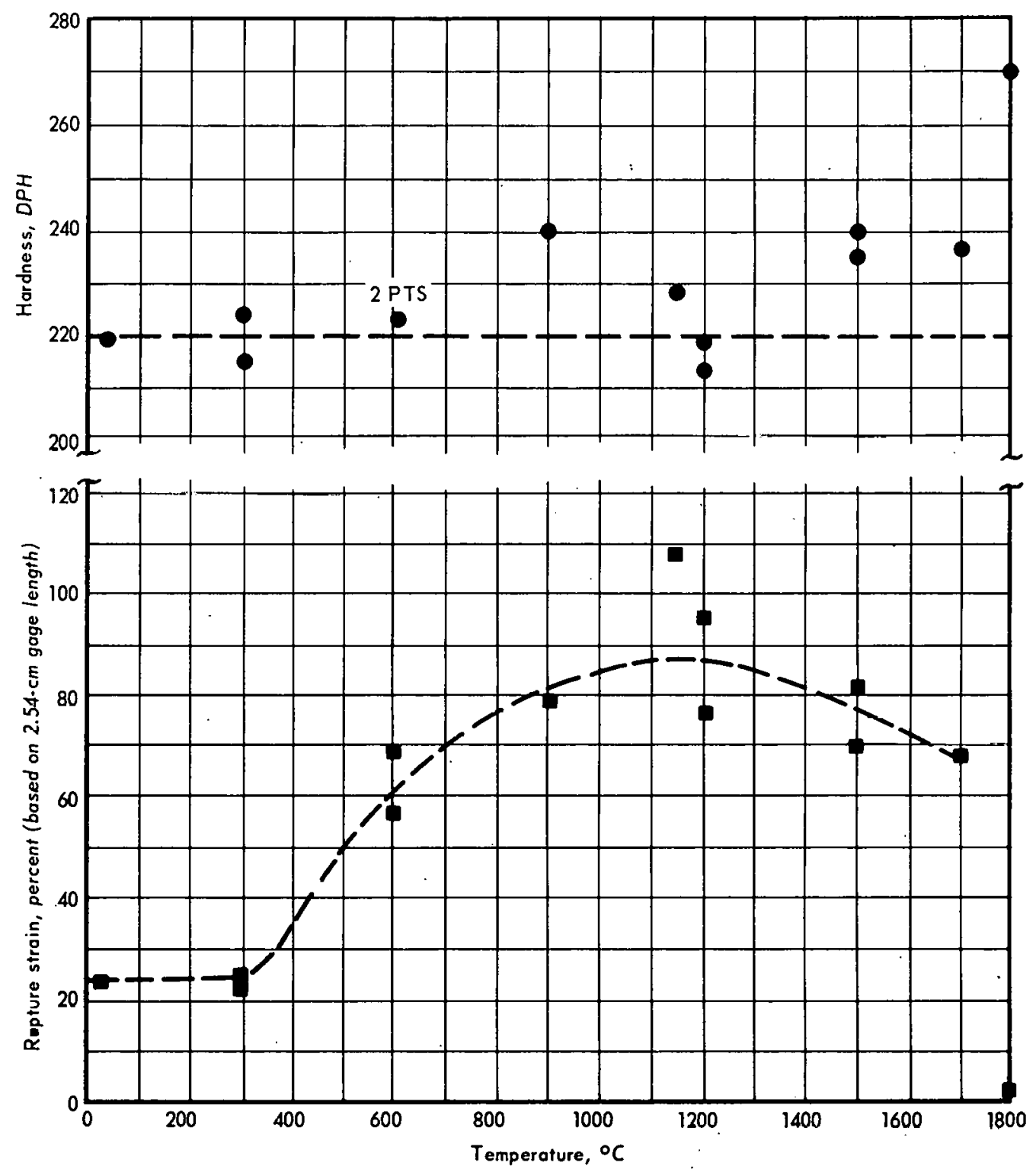

Fig. 10.19 - Room-temperature hardness ofter tensile testing and elongation versus temperature for Zircaloy-4

\subsection{SUMMARY AND CONCLUSIONS}

Oxide films 200 microns thick (or thicker) prevent cladding melting of Zircaloy-4-clad UO ${ }_{2}$ specimens heated to $1900^{\circ} \mathrm{C}$ in argon. Heated to $2050^{\circ} \mathrm{C}$ in argon, however, some of the cladding melts even with an oxide thickness of 320 microns; in such cases, the molten metal also removed snme of the $\mathrm{UO}_{2}$. In the most severe case, about 630 microns of $\mathrm{UO}_{2}$ was removed after the cladding, with an oxide film 40 microns thick, melted at $2050^{\circ} \mathrm{C}$.

The corrosion of Zircaloy -4 by steam was measured under Isothermal conditions at $1200^{\circ}, 1400^{\circ}$, and $1600^{\circ} \mathrm{C}$. These data agree with published data within the estimated $\epsilon$ perimental error. The corrosion of Zircaloy-4 and Zircaloy-2 by steam at a constant temperature between $1000^{\circ}$ and $1600^{\circ} \mathrm{C}$ follows the parabolic law:

$$
\mathrm{W}^{2} / \mathrm{t}=7.1 \times 10^{5} \exp \left(\frac{-40,500 \pm 1200}{\mathrm{RT}}\right)
$$


where $\mathrm{W}=$ the weight gain of oxygen absorbed per $\mathrm{cm}^{2}$ of area, $\mathrm{mg} / \mathrm{cm}^{2}$

$\mathrm{t}=$ time, seconds

$\mathbf{R}=$ gas constant

$\mathbf{T}=$ absolute temperature, ${ }^{\circ} \mathrm{K}$

The corrosion rate of Type $304 \mathrm{SS}$ by steam was measured under isothermal conditions in the temperature range from $1000^{\circ}$ to $1350^{\circ} \mathrm{C}$, and can be expressed as

$$
\mathrm{W}^{2} / \mathrm{t}=2.4 \times 10^{12} \exp \left(\frac{-84,300 \pm 2400}{\mathrm{RT}}\right)
$$

where the units are the same as above. Below $1200^{\circ} \mathrm{C}$, these corrosion rates are lower than those for Zircaloy -4 but at higher temperatures they become greater.

The corrosion of $\mathrm{UO}_{2}$ by steam was measured under isothermal conditions between $1100^{\circ}$ and $1500^{\circ} \mathrm{C}$. These data show that the $\mathrm{UO}_{2}$ oxygen pickup from $\mathrm{H}_{2} \mathrm{O}$ in the temperature range from $1100^{\circ}$ to $1500^{\circ} \mathrm{C}$ can be expressed as

$$
\mathrm{W}^{2} / \mathrm{t}=1.64 \times 10^{5} \exp \left(\frac{-50,800 \pm 4800}{\mathrm{RT}}\right)
$$

in the same units as above.

$\mathrm{U}_{4} \mathrm{O}_{9-\mathrm{x}}$ was identified as the second phase appearing in the exposed sample cooled to room temperature. The diffusion constant for oxygen is $D=339 \exp \left(\frac{-60,800}{R T}\right)$ for this same:temperature range.

The thermal conductivity of Zircaloy-4 was measured to $1500^{\circ} \mathrm{C}$ using a radial-heat-flow device. These data show a linear rise of $\mathrm{k}$ with temperature to about $1000^{\circ} \mathrm{C}$ and a more rapid increase at higher temperatures. Thus, $\mathrm{k}$ is about 0.1 (watt $/ \mathrm{cm}-{ }^{\circ} \mathrm{C}$ ) at $300{ }^{\circ} \mathrm{C}$, increases to about 0.26 at $1000^{\circ} \mathrm{C}$, and then rises more rapidly to about 0.42 at $1500^{\circ} \mathrm{C}$.

The ultimate tensile strength of Zircaloy-4 was found to decrease from about $52\left(\mathrm{~kg} / \mathrm{mm}^{2}\right)$ at room temperature to about 11 at $600^{\circ} \mathrm{C}$, about 0.4 at $1200^{\circ} \mathrm{C}$, and 0.03 at $1800^{\circ} \mathrm{C}$.

\section{4 PLANS AND RECOMMENDATIONS}

The influence of oxide film on the melting behavior of Zircaloy-4-clad $\mathrm{UO}_{2}$ in steam will be studied at higher temperatures, including melting the completely oxidized Zircaloy-4 cladding. Similar tests will also be made: of specimens heated at different rates in steam to measure the failure of the cladding when gas pressure is allowed to build up as the sample is heated.

Transient tests are planned to provide data on (1) the hydrogen release by the Zircaloy-4 $\mathrm{H}_{2} \mathrm{O}$ reaction, (2) the effects of pressure expected in a loss-of-coolant accident, and (3) the oxide film buildup at different heating rates in steam where the sample is heated uniformly. The sample to be used in these tests will be about $45.7 \mathrm{~cm}$ long, and the test rig will be capable of heating the sample both internally and externally.

Studies will continue of the oxidation kinetics of the $\mathrm{UO}_{2}-\mathrm{H}_{2} \mathrm{O}$ reaction.

Measurements will be continued on the high-temperature thermal conductivity of $\mathrm{UO}_{2}$, the thermal conductivity of Type $304 \mathrm{SS}$ to about $1300^{\circ} \mathrm{C}$, and the thermal expansion of Zircaloy-4 and Type 304 SS. If feasible, total emissivity data will be developed for partially oxidized Zircaloy -4 from about $850^{\circ}$ to $1500^{\circ} \mathrm{C}$ and for $\mathrm{UO}_{2}$ to high temperatures. 


\title{
11. HIGH-TEMPERATURE THERMOCOUPLE AND ELECTRICAL MATERIALS RESEARCH
}

(57014)

\author{
E. S. Funston,* W. C. Kuhlman ${ }^{\dagger}$
}

The objective of this program is to identify and establish the properties of reliable hightemperature thermocouple and electronic materials to provide instrumentation and electrical components for long life in high-temperature reactors and reactor experiments.

\section{1 THERMOCOUPLE SYSTEMS FOR HYDROGEN - GRAPHITE ENVIRONMENT}

Details of the tests that led to the selection of materials and construction of a thermocouple system to operate in a graphite - hydrogen, high-temperature environment were reported previously. ${ }^{1}$ Briefly, the probe consisted of a stranded wire (7 strands.of $0.125-$ $\mathrm{mm}$ OD wire) $\mathrm{W}$ versus $\mathrm{W}-25 \mathrm{Re}$ thermocouple insulated with $\mathrm{HfO}_{2}$ (approximately 1.5-mm $\mathrm{OD})$ and protected from the environment by concentric sheaths of tantalum $(1.65-\mathrm{mm}$ OD x 0.05-mm wall) and tungsten (2.4-mm OD x 0.25-mm wall).

Two of the above thermocouple systems were tested at Westinghouse Astronuclear Laboratory by temperature cycling four times to temperatures above $2500^{\circ} \mathrm{C}$ with $15 \mathrm{~min}$ utes at temperature for each cycle. After the first temperature cycle, each of the two. probes exhibited an increased signal above approximately $2300^{\circ} \mathrm{C}$. For the remaining three cycles, the temperature versus thermoelectric output relation was relatively constant. A more complete analysis of the results and data of these tests is in progress by Westinghouse.

\section{SHEATH DEVELOPMENT}

In a hydrogen - graphite environment, the sheath material of a thermocouple system preferably should not hydride with resultant embrittlement and possible mechanical failure. The material should also prevent carbon penetration into the electrical insulation and thermoelements since reactions might occur which would cause failure of or change in the thermocouple electrical output.

Materials with the potential of being both nonhydriding and good carbon barriers at high temperatures were investigated; these included $\mathrm{W}, \mathrm{W}-10 \mathrm{Ta}, \mathrm{Ta}-20 \mathrm{Os}$, and $\mathrm{Ta}-25 \mathrm{Re}$. Evaluations were performed with small capsules of each material containing small pieces of $\mathrm{HfO}_{2}$ inside the capsule. The carbon barrier properties were determined by observing if the $\mathrm{HfO}_{2}$ became carburized to $\mathrm{HfC}$ on its outer surface; the $\mathrm{HfC}$ could be detected by

\footnotetext{
*Project leader.

†Principal investigator.

${ }^{\ddagger}$ All compositions in this section are in weight percent unless otherwise indicated.

${ }^{1}$ W. C. Kuhlman, "Materials Research for a $4900^{\circ} \mathrm{R}\left(2450^{\circ} \mathrm{C}\right)$ Thermocouple," GE-NMPO, GE-NMP $66-508$, August 29, 1966.
} 
its low electrical resistivity. Hydriding properties were measured by determining weight gain and by observing whether severe embrittlement and disintegration of the material occurred.

Capsules were made by powder-metallurgy techniques. Slugs of each material approximately $2 \mathrm{~cm}$ long and $9 \mathrm{~mm}$ in diameter were cold-pressed from the blended powders at approximately $43 \mathrm{~kg} / \mathrm{mm}^{2}$. Holes were drilled in the "as-pressed" material, and the capsules were then vacuum sintered at $2000^{\circ} \mathrm{C}$ followed by a high-temperature sinter in hydrogen to produce an equilibrium microstructure. W, W-base, and Ta capsules were also constructed from commercial, extruded tubing that was approximately $2.5-\mathrm{mm}$ OD.

The conditions and results of these compatibility tests are presented in Table 11.1. Pure tungsten with $1.5-\mathrm{mm}$ wall thickness was a good carbon barrier for 1 hour at $2450^{\circ} \mathrm{C}$; however, this wall thickness would present a space problem in most applications. Tungsten with a $0.75-\mathrm{mm}$ or less wall thickness apparently would be unsatisfactory. The $\mathrm{W}-10 \mathrm{Ta}$ alloy with a $0.75-\mathrm{mm}$-thick wall provided protection for 1 hour, but a $3-\mathrm{mm}$ thickness was not sufficient for 5-hour protection.

The $\mathrm{Ta}-20$ Os and $\mathrm{Ta}-25 \mathrm{Re}$ alloys were found to be nonhydriding and the $3 \cdot \mathrm{nm}$ ' nick $\mathrm{T}_{\mathrm{a}}$... 20 Os was also a good barrier to carbon penetration. Both of these alloys readily cracked during TIG welding which suggests that fabrication of tubing from these alloys would be difficult.

Table 11.1 also shows results of tests with $\mathrm{W}, \mathrm{W}-5 \mathrm{Re}$, and Ta capsules containing CaO. With $\mathrm{W}$ and $\mathrm{W}-5 \mathrm{Re}$, which do not hydride but readily allow carbon penetration, there appeared to be reactions inside the capsules under the indicated conditions that cause internal pressures which rupture the capsules. It is significant that $\mathrm{Ta}$, which has been previously shown ${ }^{2}$ to be the best refractory-metal carbon barrier, prevents these reactions and thus prevents capsule rupturing.

TABLE 11.1

COMPATIBILITY TESTS OF POTENTLAL SHEATH MATERLALS AND ELECTRICAL INSULATING MATERIALS

\begin{tabular}{|c|c|c|c|c|c|c|c|c|}
\hline \multicolumn{2}{|c|}{ Capsule } & \multirow{2}{*}{$\begin{array}{c}\text { Wall } \\
\text { Thickness, } \\
\text { mm }\end{array}$} & \multirow{2}{*}{$\begin{array}{l}\text { Capsule } \\
\text { Contains }\end{array}$} & \multicolumn{3}{|c|}{ Test Conditions } & \multicolumn{2}{|r|}{ Results } \\
\hline Material & Preparation ${ }^{a}$ & & & Atmosphere & Temperature, ${ }^{\circ} \mathrm{C}$ & Time, hr & Oxide & Capsule Material \\
\hline $\mathbf{W}-\mathbf{5 R e}$ & A & 0.2 & $\mathrm{CaO}$ & $\mathrm{H}_{2}-\mathrm{C}$ & 2450 & 1 & Lost to surroundings & Cracked from internal pressure \\
\hline$W-5 R e$ & $\mathbf{A}$ & 0.2 & $\mathrm{CaO}$ & $\mathrm{H}_{2}$ & 2450 & 1 & No observable change & Leak tight after test \\
\hline $\mathbf{W}$ & A & 0.25 & $\mathrm{CaO}$ & $\mathrm{H}_{2}-\mathrm{C}$ & 2450 & 1 & Lost to surroundings & Cracked \\
\hline Ta & A & 0.25 & $\mathrm{CaO}$ & $\mathrm{H}_{2}-\mathrm{C}$ & 2450 & 1. & No observable change & Leak tight after test-Hydrides \\
\hline $\mathbf{T a}$ & $\mathbf{A}$ & 0.25 & $\mathrm{HFO}_{2}$ & $\mathrm{H}_{2}-\mathrm{C}$ & 2450 & 1 & $\begin{array}{l}\text { Darkened but no } \\
\text { carburization }\end{array}$ & Leak tight after test-Hydrides \\
\hline $\mathbf{T a}$ & $\mathbf{A}$ & 0.25 & $\mathrm{HrO}_{2}$ & $\mathrm{H}_{2}-\mathrm{C}$ & 2450 & 3 & $\begin{array}{l}\text { Darkened but no } \\
\text { carburization }\end{array}$ & $\begin{array}{l}\text { Probably leak tIght. Capsule was } \\
\text { so fragite it broke before leak } \\
\text { test completed - Hydrides }\end{array}$ \\
\hline $\mathbf{w}$ & A. & 0.25 & $\mathrm{HfO}_{2}$ & $\mathrm{H}_{2}-\mathrm{C}$ & 2450 & 1 & $\begin{array}{l}\text { Carburized on outer } \\
\text { surface }\end{array}$ & Leak tight after test \\
\hline $\mathbf{w}$ & A & 0.25 & $\mathrm{HfO}_{2}$ & $\mathrm{H}_{2}-\mathrm{C}$ & 2450 & 0.25 & $\begin{array}{l}\text { Carburized on outer } \\
\text { surface }\end{array}$ & Leak tight after test \\
\hline $\mathbf{w}$ & $\mathbf{A}$ & 0.25 & $\mathrm{HrO}_{2}$ & $\mathrm{H}_{2}-\mathrm{C}$ & 2450 & 0.08 & $\begin{array}{l}\text { Carburized on outer } \\
\text { surface }\end{array}$ & Leak tight after test \\
\hline $\mathbf{w}$ & $\mathbf{P}$ & 2.25 & $\mathrm{HrO}_{2}$ & $\mathrm{H}_{2}-\mathrm{C}$ & 2450 & 1 & $\begin{array}{l}\text { Darkened but no } \\
\text { carburization }\end{array}$ & Leaked after test \\
\hline$w$ & $\mathbf{P}$ & $1 . .5$ & $\mathrm{HrO}_{2}$ & $\mathrm{H}_{2}-\mathrm{C}$ & 2450 & 1 & $\begin{array}{l}\text { Darkened but no } \\
\text { carlur lzalluul }\end{array}$ & Leaked afler test \\
\hline$w$ & $\mathbf{r}$ & 0.76 & $\mathrm{HHO}_{2}$ & $\mathbf{H}_{2} \cdots \mathbf{C}$ & 2450 & 1 & $\begin{array}{l}\text { Carburised on outạt } \\
\text { gurface }\end{array}$ & Lagaren aftar test. \\
\hline$w-10 T a$ & $\mathbf{P}$ & 3.0 & $\mathrm{HIO}_{2}$ & $\mathrm{H}_{2}-\mathrm{C}$ & 2450 & 5 & $\begin{array}{l}\text { Carburized on outer } \\
\text { surface }\end{array}$ & Leaked after test \\
\hline $\mathrm{W}-10 \mathrm{Ta}$ & $\mathbf{p}$ & 2.25 & $\mathrm{HHO}_{2}$ & $\mathrm{H}_{2}-\mathrm{C}$ & 2450 & 1 . & $\begin{array}{l}\text { Darkened but no } \\
\text { carburization }\end{array}$ & Leaked after test \\
\hline $\mathrm{W}-10 \mathrm{Ta}$ & $\mathbf{P}$ & 0.75 & $\mathrm{HfO}_{2}$ & $\mathrm{H}_{2}-\mathrm{C}$ & 2450 & 1 & $\begin{array}{l}\text { Darkened but no } \\
\text { carburization }\end{array}$ & Leaked after test \\
\hline $\mathrm{Ta}-20 \mathrm{Os}$ & $\mathbf{P}$ & 3.0 & $\mathrm{HOO}_{2}$ & $\mathrm{H}_{2}-\mathrm{C}$ & 2450 & 1 & $\begin{array}{l}\text { Darkened but no } \\
\text { carburization }\end{array}$ & Leaked after test \\
\hline $\mathbf{T a}-25 \mathrm{Re}$ & $\mathbf{P}$ & 3.0 & $\mathrm{HfO}_{2}$ & $\mathrm{H}_{2}-\mathrm{C}$ & 2450 & $\vdots 1$ & $\begin{array}{l}\text { Carburized on outer } \\
\text { surface }\end{array}$ & Leaked after test \\
\hline
\end{tabular}

$\mathbf{a}_{A}$ designates arc-cast and extruded material

P designates powder-metallurgy material.

${ }^{2}$ Kuhlman, loc. cit. 


\subsection{THERMOELEMENT EVALUATION}

\section{NEW ALLOYS}

Thermocouple alloys that are not subject to thermoelectric output changes due to nuclear transmutation are needed for use in reactors at temperatures to $1800^{\circ} \mathrm{C}$ in hydrogen, inert gas, or vacuum.

A Mo - 1Ru versus Mo - 49Ru (both at. \%) thermocouple contains very low neutron cross section materials and has a useful thermoelectric signal ${ }^{3}$ with a sensitivity of 6.3 microvolts per degree centigrade at $1400^{\circ} \mathrm{C}$. Although this is approximately one-half that of the $\mathrm{Pt}$ versus $\mathrm{Pt}-10 \mathrm{Rh}$ thermocouple, its stability in a nuclear environment would probably be better.

\section{TRANSMUTATION EFFECTS}

$W-5 R e$ and $W-3 R e$ Versus $W-25 R e$

Since commercially available $\mathrm{W}-5 \mathrm{Re}$ and $\mathrm{W}-3 \mathrm{Re}$ versus $\mathrm{W}-25 \mathrm{Re}$ thermocouples are being used in reactor applications, thermoelectric output changes due to nuclear transmutations were investigated. Details of the tests, methods of material preparation, and results were given in previous reports. ${ }^{3,4}$ Essentially, the method consisted of comparing the thermoelectric output of untransmuted compositions with the synthetically produced, theoretically predicted transmuted compositions. The data showed ${ }^{5}$ that the expected thermoelectric deviation from initial calibration of the $W-5 R e$ versus $W-25 R e$ ther mocouple after 6 months in a $10^{14} \mathrm{nv}$ thermal neutron flux was an almost linear function of temperature up to $2000^{\circ} \mathrm{C}$ where the predicted temperature error was minus $120^{\circ} \mathrm{C}$ (see Figure 11.1).

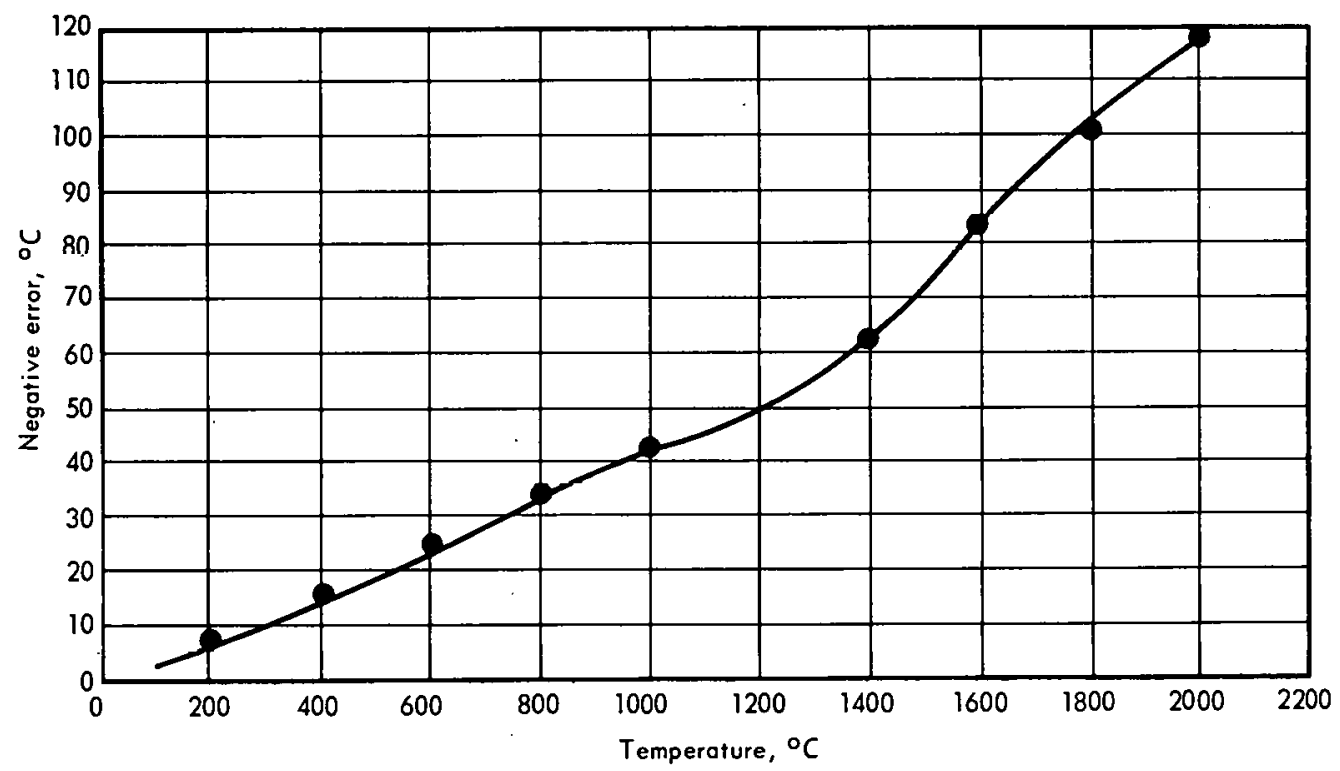

Fig. 11.1-Expected deviation from initial calibrotion of a $W-5 R e$ versus $W-25 R e$ thermocouple alloyed to represent a transmuted composition ( $W-5.6 \operatorname{Re}-0.59 \mathrm{Os}$ ) after 6 months in a $10^{14}$ neutron thermol flux

\footnotetext{
3“"High-Temperature Materials Program Progress Report No. 61," GE-NMPO, GEMP-61, September 30, 1966, p. 171.

4 “'High-Temperature Materials Program Progress Report No. 59, Part A," GE-NMPO, GEMP-59A, May 31, 1966, pp. 56-57.

${ }^{5}$ GEMP-61, pp. 172-173.
} 
The $\mathrm{W}-3 \mathrm{Re}$ versus $\mathrm{W}-25 \mathrm{Re}$ thermocouple after the same neutron dosage showed a rapidly rising positive deviation up to $600^{\circ} \mathrm{C}$ (see Figure 11.2), and then a slight increase from $600^{\circ}$ to $2000^{\circ} \mathrm{C}$ where there was a positive error of approximately $75^{\circ} \mathrm{C} .^{4}$ Since the error of the $W-5 R e$ versus $W-25 R e$ thermocouple was negative and the error of the $W-3 R e$ versus $W-25 R e$ ther mocouple was positive, it is possible that a thermocouple composed of $W$ with between 3 and $5 R e$ versus $W-25 R e$ would have a smaller error.

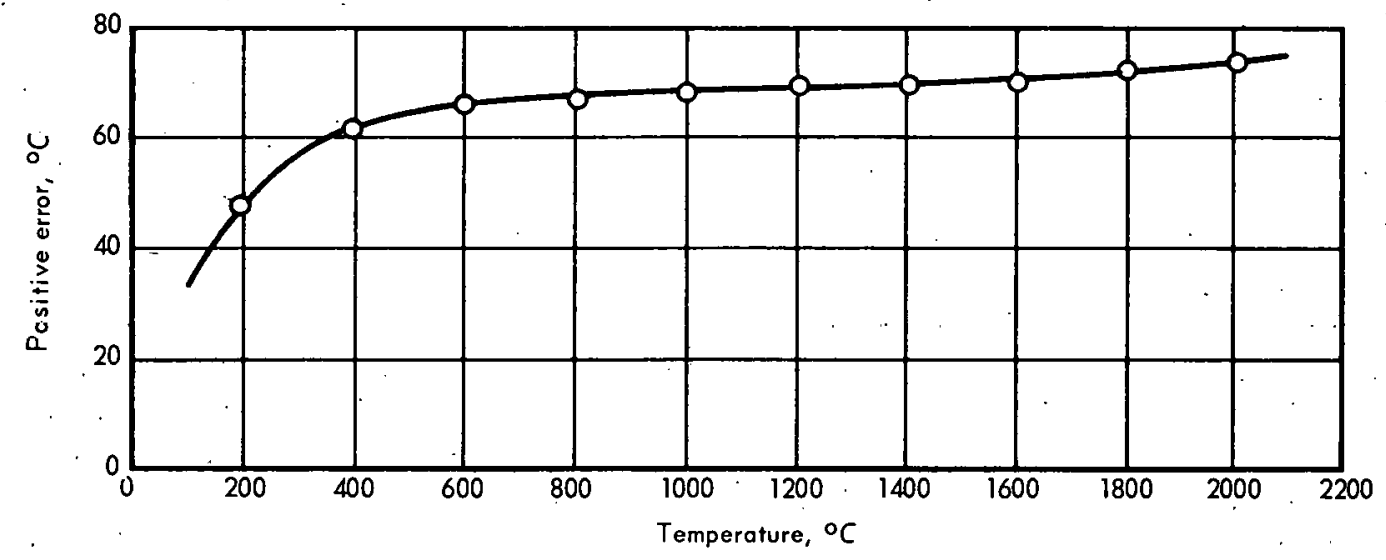

Fig. 11.2-Expected deviation from initial calibration of a W-3Re versus $W-25 R e$ thermocouple alloyed to represent a transmuted composition ( $W-3.8 \operatorname{Re}-0.38 \mathrm{Os}$ ) after 6 months in a $10^{14}$ neutron thermal flux

$\mathrm{W}-0.5$ Os Versus $\mathrm{W}-25 \mathrm{Re}$

It had been shown previously ${ }^{6}$ that a $\mathrm{W}-1$ Os (at. \%) versus $\mathrm{W}-25 \mathrm{Re}$ thermocouple would be expected to show less change in output as a function of time in a nuclear reactor than a $\mathrm{W}$ versus $\mathrm{W}-25 \mathrm{Re}$ thermocouple. This alloy, however, proved to be very difficult to draw into wire form by conventional wire drawing techniques. It was also indicated that Os contents as low as 0.5 atomic percent in $W$ might stabilize the thermoelectric output of a $\mathrm{W}-0.5$ Os (at. \%) versus $\mathrm{W}-25 \mathrm{Re}$ thermocouple.

The $\mathrm{W}-0.5$ Os (at. \%) versus $\mathrm{W}-25 \mathrm{Re}$ thermocouple was evaluated for thermal-neutroninduced errors ${ }^{7}$ by methods discussed above. The resulting data show the thermoelectric stability of the $\mathrm{W}-0.5$ Os (at. \%) versus $\mathrm{W}-25 \mathrm{Re}$ thermocouple is better than the $\mathrm{W}-1$ Os (at. \%) versus $W-25 R e$, the $W-5 R e$ versus $W-25 R e$, or the $W-3 R e$ versus $W-25 R e$ thermocouples. The maximum error measured in the $0^{\circ}$ to $2000^{\circ} \mathrm{C}$ temperature range was a positive $50^{\circ} \mathrm{C}$ as shown in Figure 11.3 .

Reactor Stability of W Versus W-25Re Thermocouple

A reactor test of $W$ versus $W-25 R e$ thermocouples was performed under conditions that simulated their actual usage during reactor tests of experimental fuel elements. This inpile test compared the thermoelectric output of $\mathrm{W}$ and $\mathrm{W}-25 \mathrm{Re}$ thermoelements operating in the ORR to $W$ and $W-25 R e$ thermoelements which were physically placed in the nuclear flux field only long enough to compare their thermoelectric outputs with the continuously irradiated thermocouples. Details of the test capsule as well as the thermoelectric deviations were reported previously. ${ }^{8}$ The results showed that for a maximum neutron dosage of

\footnotetext{
${ }^{6}$ W. C. Kuhlman, "Evaluation of Thermal Neutron Induced Errors in the W versus W-25Re Thermocouple," GE-NMPO, GE-TM 65-4-41, June 14, 1965.

7‘'High-Temperature Materials Program Progress Report No. 63," GE-NMPO, GEMP-63, December 30, 1966, p. 134.

${ }^{8}$ GEMP-63, pp. 129-133.
} 


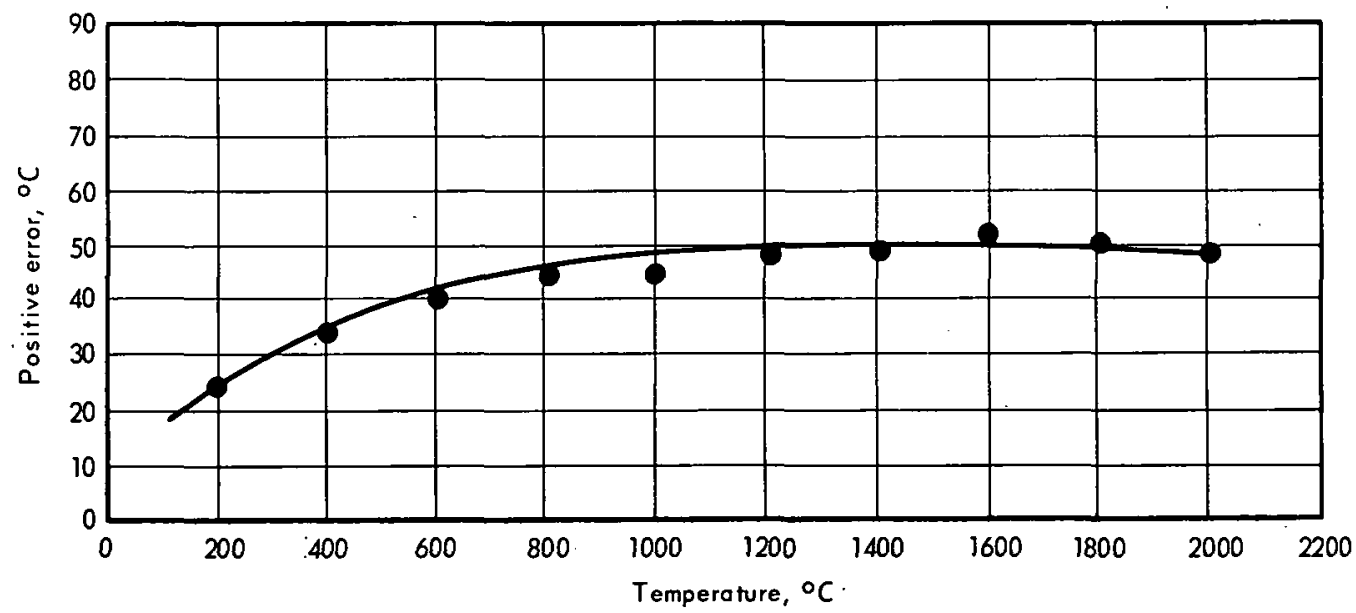

Fig. 11.3-Expected deviation from initial calibration of a $W-0.5$ at. \% Os versus $W-25 R e$ thermocouple alloyed to represent a transmuted composition ( $W-1.16 R e-0.540 s$ ) after 6 months in a $10^{14}$ neutron thermal flux

approximately $6.0 \times 10^{20}$ nvt thermal and $1.0 \times 10^{20}$ nvt fast, thermoelectric change in the $\mathrm{W}-25 \mathrm{Re}$ thermoelement was apparently small; however, it was difficult to interpret the data due to thermal gradients in the $\mathrm{W}$ disc which electrically connects the test and ; reference thermoelements. ${ }^{8}$ The maximum change in the $\mathrm{W}$ thermoelement (see Figure 11.4) would cause an error of plus $10^{\circ} \mathrm{C}$ at $600^{\circ} \mathrm{C}$ and a negative error of $15^{\circ} \mathrm{C}$ at $1900^{\circ} \mathrm{C}$. These latter results were unexpected. Previous work, ${ }^{9}$ based on the synthesized composition technique, had predicted that thermoelectric deviations caused by the $\mathrm{W}$ thermoelement should

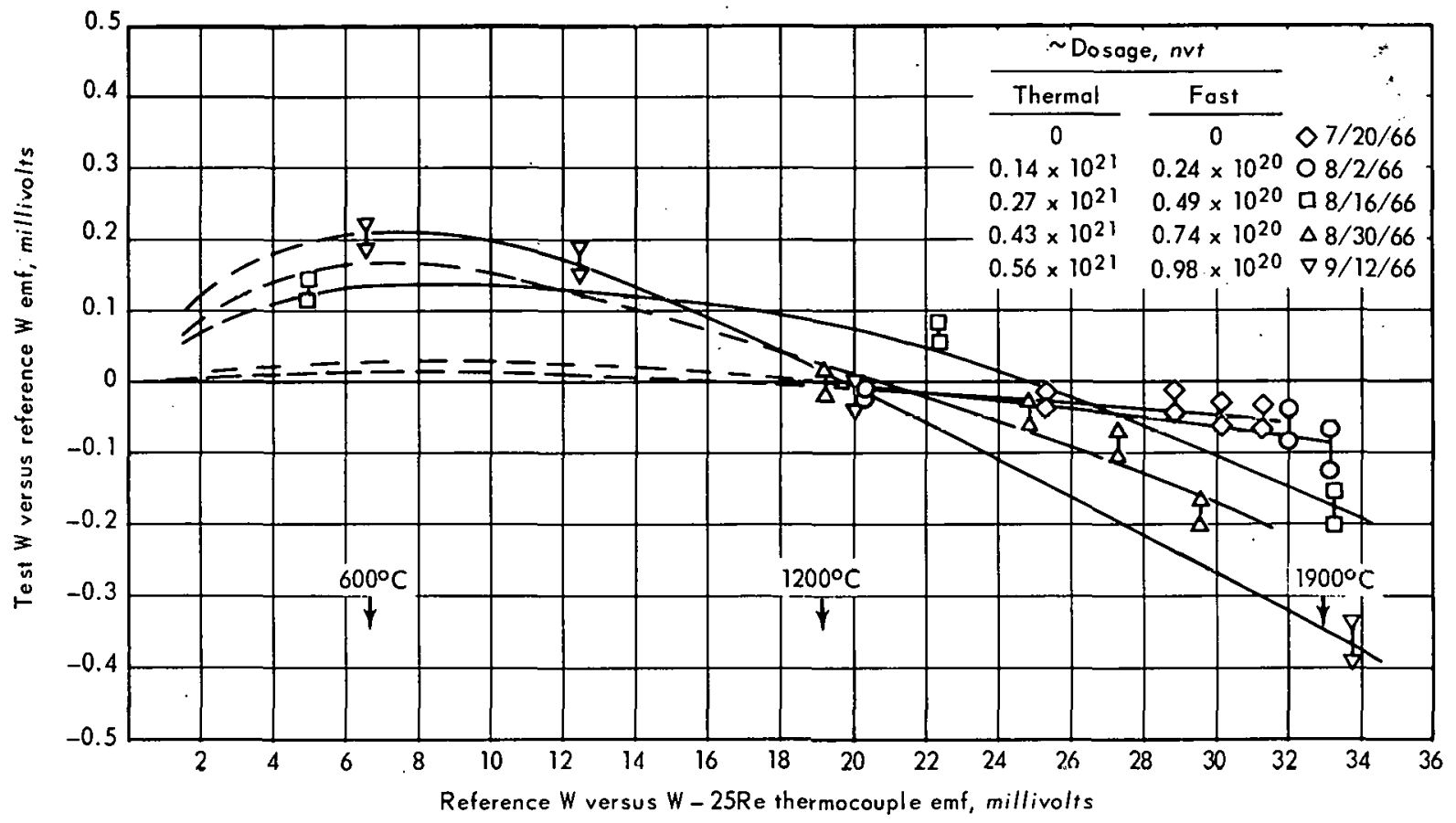

Fig. 11.4-Relative stability of $W$ thermoelements as a function of temperature and time in a $1.2 \times 10^{14} \mathrm{nv}$ thermal flux

${ }^{9}$ W. C. Kuhlman, GE-TM $65-4-41$, loc. cit. 
always be positive, attaining a value of $50^{\circ}$ to $60^{\circ} \mathrm{C}$ at $600^{\circ}$ to $1900^{\circ} \mathrm{C}$. This value is considerably greater than those recently obtained. The relatively large difference between predicted and experimentally obtained errors is believed to be caused by radiation damage in the thermoelements; such damage is due to the fast neutron flux which apparently acts to oppose changes caused by transmutations. Therefore, fast reactors with higher ratios of fast flux to thermal flux than the ORR may have a considerably different effect on thermocouple output than thermal reactors.

\subsection{ELECTRICAL INSULATION DEVELOPMENT}

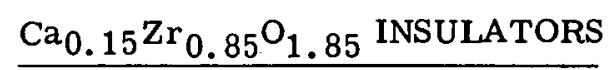

Electrical insulators for thermocouple use above $2500^{\circ} \mathrm{C}$ are needed. The pure oxides of $\mathrm{ThO}_{2}, \mathrm{HfO}_{2}$, and $\mathrm{MgO}$ are limited because of low electrical resistivity at high temperatures and, in the case of $\mathrm{MgO}$, a strong tendency to dissociate at high temperature. $\mathrm{Al}$ though CaO-stabilized $\mathrm{ZrO}_{2}$ has not been used as a thermocouple insulator, recent work

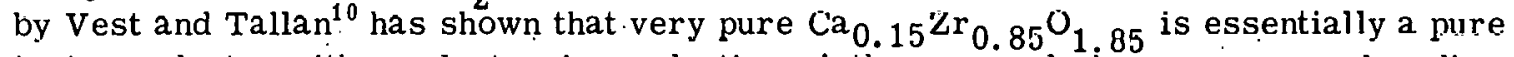
ionic conductor with no electronic conduction. A thermocouple imposes a very low direct voltage on the insulation; if the thermoelement electrodes are blocking to ion flow, no current should flow after polarization within the material is complete. This condition should be equivalent to a very high electrical insulation resistance between the thermocouple leads.

Two-hole, hard-fired thermocouple insulator beads of $\mathrm{Ca}_{0.15} \mathrm{Zr}_{0.85} \mathrm{O}_{1.85}, 2.4-\mathrm{mm}$ OD with $0.375-\mathrm{mm}$-diameter holes spaced $0.25 \mathrm{~mm}$ apart, were made. W.versus $\mathrm{W}-25 \mathrm{Re}$ thermacouples of stranded wire (10 strands of $0: 075-\mathrm{mm}$ OD wires), insulated with these beads, were compared with $W$ versus $W-25$ Re thermocouples (0.5-mm OD wires), insulated with $\mathrm{BeO}$ hard-fired beads, 2.4-mm OD with two 0.5-mm-diameter holes spaced $0.4 \mathrm{~mm}$ apart. Placed in separate, Mo, closed-end wells, the two thermocouples were adjacent to each other so their junctions were in an isothermal zone. The temperaturegradient zone over the length of the thermocouples was approximately $30 \mathrm{~cm}$. As shown in Figure 11.5, the thermoelectric outputs of the two thermocouples were compared in both hydrogen and helium.

In helium, the thermoelectric output of the $\mathrm{Ca}_{0.15} \mathrm{Zr}_{0.85} \mathrm{O}_{1.85}$-insulated $\mathrm{W}$ versus $\mathrm{W}-25 \mathrm{Re}$ thermocouple compared very well to the $\mathrm{BeO}$-insulated $\mathrm{W}$ versus $\mathrm{W}-25 \mathrm{Re}$ thermocouple up to the maximum test temperature of approximately $2300^{\circ} \mathrm{C}$. In hydrogen, a difference in output between the two thermocouples began to occur at approximately $1800^{\circ} \mathrm{C}$. The cause of this difference is believed to be related to a probable difference in oxygen partial pressures between the helium and hydrogen gases in combination with impurities in the $\mathrm{Ca}_{0.15} \mathrm{Zr}_{0.85} \mathrm{O}_{1.85}$. The impurities in $\mathrm{Ca}_{0.15} \mathrm{Zr}_{0.85} \mathrm{O}_{1.85}$ at low oxygen pressures existing in hydrogen would probably cause the resistivity to be lower in hydrogen than in helium. Table 11.2 shows impurities of $\mathrm{Al}, \mathrm{Mg}$, and $\mathrm{Na}$ existing in the $\mathrm{Ca}_{0.15} \mathrm{Zr}_{0.85} \mathrm{O}_{1.85}$; these impurities are believed to be mainly responsible for the low resistivity in hydrogen.

\subsection{SUMMARY AND CONCLUSIONS}

A W versus $\mathrm{W}-25 \mathrm{Re}$ thermocouple system with a $\mathrm{HfO}_{2}$ electrical insulator and clad with Ta and $W$ for use in a hydrogen - graphite environment was developed which produced meaningful temperature data over the 1 -hour expected life of the system.

An investigation was made of possible sheath materials for use in high-temperature, carbon and hydrogen environments. Presently, the $\mathrm{W}-10 \mathrm{Ta}$ alloy is most promising since it resists hydriding and, with a wall thickness of $0.75 \mathrm{~mm}$, is an effective carbon barrier.

${ }^{10}$ R. W. Vest and N. M. Tallan, "High Temperature Transference Number Determinations by Polarization Measurements," lournal of Applied physics, Vol. 36, No. 2, February 1965, pp. 543-547. 


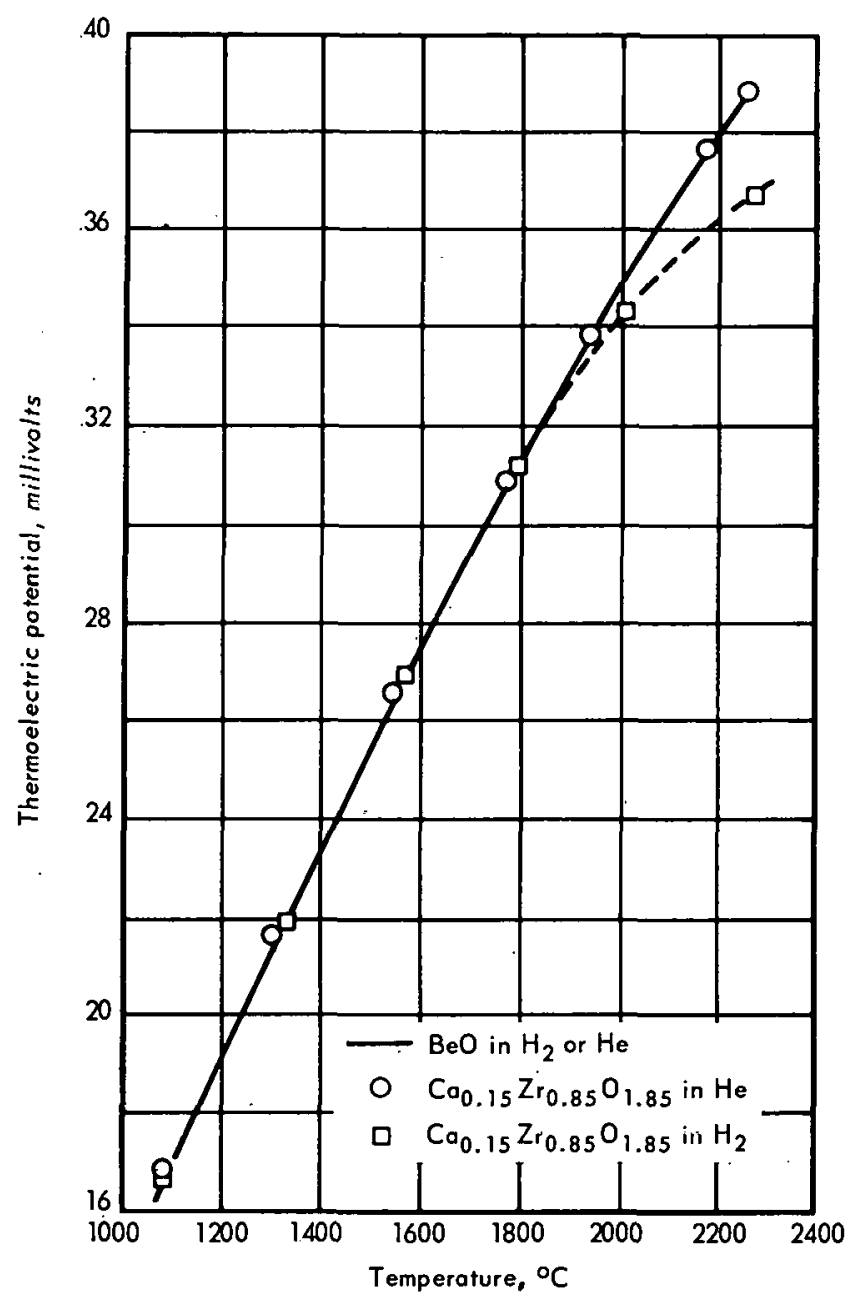

TABLE 11.2

SPECTROGRAPHIC ANALYYSIS FOR IMPURITIES IN CaO-STABILIZED $\mathrm{ZrO}_{2}$

\begin{tabular}{cc}
\multicolumn{2}{c}{ CaO-STABILIZED $\mathrm{ZrO}_{2}$} \\
\hline Element & Impurities, ppm \\
\hline $\mathrm{Al}$ & 280 \\
$\mathrm{~B}$ & 0.6 \\
$\mathrm{Cd}$ & $<0.2$ \\
$\mathrm{Co}$ & $<10$ \\
$\mathrm{Cu}$ & $<20$ \\
$\mathrm{Fe}$ & $<20$ \\
$\mathrm{Hf}$ & $<100$ \\
$\mathrm{Li}$ & $<10$ \\
$\mathrm{Mg}$ & 52 \\
$\mathrm{Mn}$ & $<10$ \\
$\mathrm{Mo}$ & $<20$ \\
$\mathrm{Na}$ & 55 \\
$\mathrm{Ni}$ & $<20$ \\
$\mathrm{~Pb}$ & $<20$ \\
$\mathrm{Si}$ & $<20$ \\
$\mathrm{Sn}$ & $<20$ \\
$\mathrm{Ti}$ & $<20$ \\
$\mathrm{~V}$ & $<20$ \\
$\mathrm{~W}$ & $<50$ \\
$\mathrm{Zn}$ & $<50$ \\
\hline
\end{tabular}

Fig. 11.5 - Comparative calibration for o $W$ versus $W-25 R e$ thermoroup! insulated with BoO or $\mathrm{Ca}_{0.15} \mathrm{Zr}_{0.85} \mathrm{O}_{1.85}$ in hydrogen or. helium

A thermocouple composed of $\mathrm{Mo}-1$ Ru versus $\mathrm{Mo}-49 \mathrm{Ru}$ (both at. \%) was shown to be potentially stable for use to $1800^{\circ} \mathrm{C}$ in a reducing or inert gas environment in a nuclear reactor.

The commercial $W-3 R e$ versus $W-25 R e$ and the $W-5$ Re versus $W-25 R e$ thermocouples were investigated for thermoelectric instability due to nuclear transmutation in a reactor. They were found to have errors as high as $100^{\circ} \mathrm{C}$.

A reactor test to determine thermoelectric stability of the $\mathrm{W}$ versus $\mathrm{W}-25 \mathrm{Re}$ thermocouple was performed in the ORR to a total neutron dosage of $6.0 \times 10^{20} \mathrm{nvt}$ thermal and $1.0 \times 10^{20} \mathrm{nvt}$ fast flux. Maximum error was $15^{\circ} \mathrm{C}$.

$\mathrm{Ca}_{0.15} \mathrm{Zr}_{0.85} \mathrm{O}_{1.85}$ was investigated as a high-temperature electrical insulator for ther mocouples. It was found to be satisfactory to $2300^{\circ} \mathrm{C}$ in helium, and to $1800^{\circ} \mathrm{C}$ in hydrogen.

\subsection{PLANS AND RECOMMENDATIONS}

Thermocouples will be investigated for neutron-flux-induced thermoelectric changes with emphasis on effects of fast neutron dosage. 


\section{2}

Methods of improving thermocouple performance at very high temperatures will be investigated. Improvements in the electrical insulation and other methods and techniques will be considered.

Investigations will continue to determine the optimum material to protect thermocouple systems from carbonaceous and hydrogen environments at all temperatures to $2500^{\circ} \mathrm{C}$.

Optimum sheath, insulating, and thermoelement materials for Liquid Metal Fast Breeder Reactor applications will be investigated. 


\title{
12. HIGH-TEMPERATURE RESEARCH ON CARBIDES FOR FUEL AND STRUCTURAL APPLICATIONS
}

(57073)

\author{
J. F. White," E. F. Juenke ${ }^{\dagger}$
}

The objective of this task is to determine the physico-chemical properties of refractory carbides for reactor fuel and structural applications. Because of their high melting points, refractory carbides are of considerable interest for such applications. These materials generally show a wide range of homogeneity and, therefore, have a tendency to undergo compositional changes at high temperatures which may place restrictions on their application. It is the purpose of this program, therefore, to establish the variations that occur in certain physico-chemical properties of refractory carbides with compositional changes and at different temperatures.

The thermodynamic activity of carbon as a function of the composition of a carbide is a particularly important property since it is related to the carbide's stability and to its compatibility with other materials. For example, if the activities of the metal and carbon in a particular refractory carbide system are known, the behavior of different MC compositions can be determined as functions of temperature and pressure in possible nuclear environments. The composition of the carbide can be determined for the temperatures of interest in specific applications, and the concentration of hydrocarbons that would have to be added to the coolant gas or hydrogen propellant to maintain this composition (or which would build up in a closed system) may be established. In other words, the composition which will give the most desirable combination of physical properties can be selected, and the amounts of hydrocarbon additive required to maintain the given composition will be known.

Tantalum monocarbide was chosen for initial studies because it has one of the highest reported melting points, possesses a broad region of homogeneity, and has a well-established linear variation of unit cell size with composition. The results of the evaluation of the mechanism and kinetics of evaporation in various atmospheres and of preliminary equilibration experiments were reported previously. ${ }^{1,2}$

The results of the following studies are summarized in this section: (1) solid - gas equilibration experiments on tantalum monocarbide, (2) preliminary experiments using rhenium as a carbon-permeable capsule for uranium monocarbide, and (3) extension of the solid - gàs equilibration technique to the determination of carbon activity in uranium monocarbide.

\footnotetext{
*Project leader.

$\dagger_{\text {Principal investigator. }}$

1“"Fourth Annual Report - High-Temperature Materials and Reactor Components Development Programs, Volume II Malerlals," GE-INMPO, GEMP-334B, February $26 \%$, iybb, p. $100 \%$

2"Fifth Annual Report - High-Temperature Materials Programs, Part B," GE-NMPO, GEMP-400B, February 28, 1966, p. 139.
} 


\section{1 EQUILIBRIUM STUDIES ON TANTALUM CARBIDE}

Experiments were continued to determine the variation of carbon activity with composition in the tantalum monocarbide homogeneity range by the solid - gas equilibration technique. Results previously reported primarily covered the composition range between $\mathrm{TaC}_{0.90}$ and $\mathrm{TaC}_{0.99}$. Experiments conducted during 1966 emphasized the range between $\mathrm{TaC}_{0.80}$ and $\mathrm{TaC}_{0.90}$ at temperatures between $1800^{\circ}$ and $2345^{\circ} \mathrm{C}$.

\section{EXPERIMENTAL PROCEDURE}

The experimental apparatus and procedures for these studies have been fully described in previous reports. $.^{2}, 3$ Briefly, the method consists of equilibrating carbide powders with controlled atmospheres containing mixtures of hydrogen and methane to establish the carbon activity at various compositions. Table 12.1 shows the chemical and $\mathrm{X}$-ray analyses characterizing the typical batches of $\mathrm{TaC}_{0.8}$ and $\mathrm{TaC}_{0.99}$ used in these experiments.

TABLE 12, 1

CHEMICAL AND X-RAY ANALYSES FOR THE LIMITS OF TANTALUM CARBIDE COMPOSITIONS USED IN EQQUILIBRATION EXPERIMENTS

\begin{tabular}{|c|c|c|}
\hline Nominal. Composition & $\mathrm{TaC}_{0.8}$ & $\mathrm{TaC}_{0.99}$ \\
\hline Carbon, $\%$ & 4. 94 & 6.32 \\
\hline Uncombined carbon, ppm & 134 & 2700 \\
\hline Oxygen, ppm & 167 & 163 \\
\hline Nitrogen, ppm & 105 & 21 \\
\hline $\mathrm{X}$-ray lattice parameter $\left(\mathrm{a}_{\mathrm{o}}\right), \AA$ & 4. 42577 & 4. 45585 \\
\hline $\mathrm{C} / \mathrm{Ta}$ (chemical analysis) & 0.784 & 0.973 \\
\hline $\mathrm{C} / \mathrm{Ta}$ (X-ray analysis) ${ }^{\mathrm{a}}$ & 0.800 & 0.992 \\
\hline
\end{tabular}

a Based on: A. L. Bowman, "The Variation of Lattice Parameter with Carbon Content of Tantalum Carbide," Journal of Physical Chemistry, Vol. 65, 1961, pp. 1596-1598.

(Note: All compositions for $\mathrm{TaC}_{\mathbf{x}}$ indicated in the text of this report were calculated from the. equation developed by Bowmin.)

\section{EXPERIMENTAL RESULTS AND DISCUSSION}

The experimental results tabulated in Table 12.2, together with the data previously reported, ${ }^{2}$ were analyzed using the statistical model of Hoch. ${ }^{4}$ According to this model, which assumes that the metal sites in the fcc carbide lattice are filled and that vacancies occur in the carbide sublattice, the carbon activity in the carbide is related to the carbon interaction energies by the expression:

$$
A=R T \ln \left(a_{c} \frac{1-x}{x}\right)=E_{c}+E_{c c} x+R T \ln K_{c}(T)
$$

where $A$ is defined as an activity coefficient, $a_{c}$ is the carbon activity, and $x$ is the carbonto-metal ratio. This function is linear in $x$ and $T$, with the coefficient of $x, E_{c c}$, equal to the carbon - carbon interaction energy, and the coefficient of $T, R \ln -K_{c}(T)$, equal to the entropy difference between carbon in graphite and carbon in the carbide.

\footnotetext{
3“"High-Temperature Materials Program Progress Report No. 52, Part B, "GE-NMPO, GEMP-52B, October 20, 1965, p. 31.

"M. Hoch, "Statistical Model for Nonsubstitutional Solutions," Transactions of the Metallurgical Society of AIME, Vol. 230,1964 , p. 138 .
} 
TABLE 12.2

CARBON ACTIVITY AND EXPERIMENTAL VALUES OF $R T \ln \left(a_{c} \frac{1-x}{x}\right)$ FOR SOLID TaC - GAS EQUILIBRIUM EXPERIMENTS AT VARIOUS TEMPERATURES

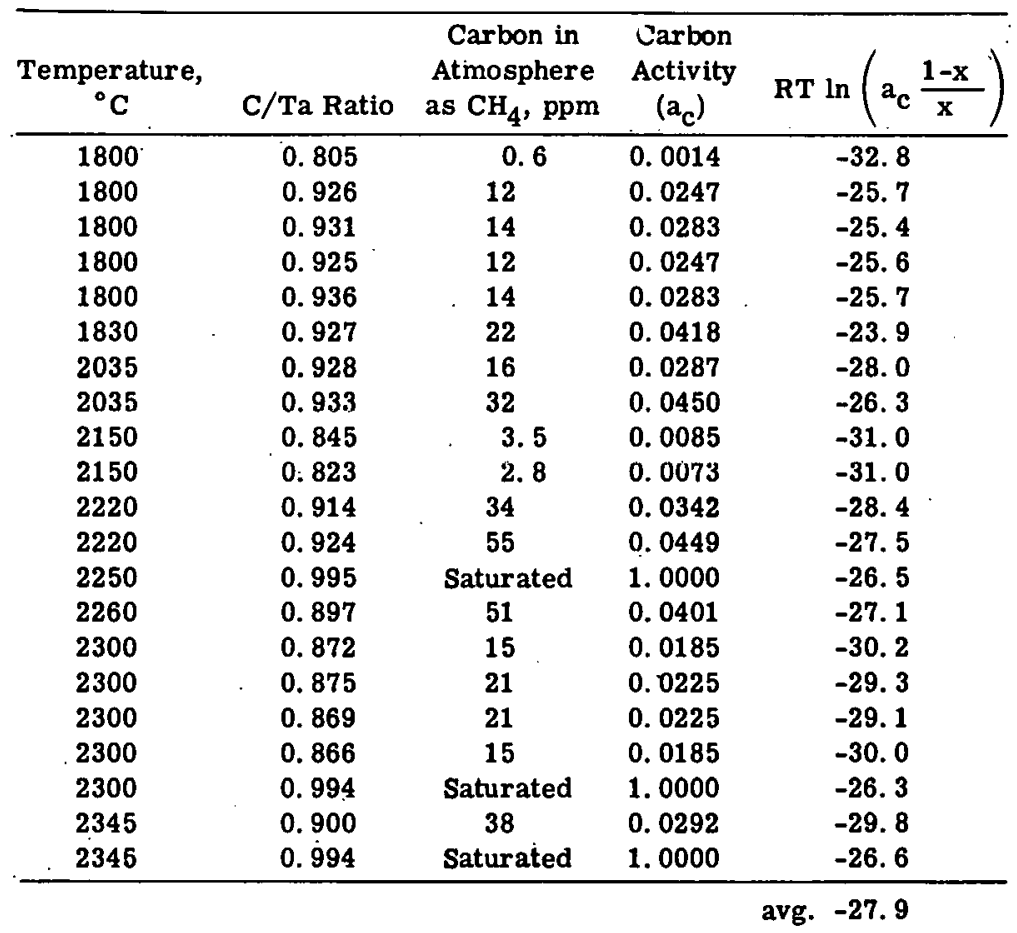

The value of RT $\ln \left(a_{c} \frac{1-x}{x}\right)$ was calculated and is tabulated for each of the samples listed in Table 12.2. The following equation was derived from the experimental data by multiple regression analyses:

$$
A=R T \ln \left(a_{c} \frac{1-x}{x}\right)=-50.6+(36.6 \pm 4.7) x-(4.4 \pm 1.1) 10^{-3} T
$$

where $\mathrm{T}$ is temperature in degrees Kelvin.

Based on this analysis, the carbon - carbon interaction energy in TaC is $36.6 \pm 4.7$ $\mathrm{kcal} / \mathrm{mole}$ and the entropy difference is $-4.4 \pm 1.1$ entropy units. The average value of $-27.9 \mathrm{kcal} / \mathrm{mole}$ shown in Table 12.2 is in good agreement with an approximate value of $-27 \mathrm{kcal} / \mathrm{mole}$ obtained by $\mathrm{Hoch}^{5}$ in an analysis of the evaporation rate data of Coffman, et al. ${ }^{6}$ for $\mathrm{TaC}$ and of Fries ${ }^{7}$ for the refractory carbide $\mathrm{NbC}$.

Carbon activity is plotted as a function of $\mathrm{TaC}_{\mathrm{X}}$ composition and temperature in Figure 12. 1 for the data summarized in Table 12.2. Tentative isotherms have been constructed through the data points in Figure 12.1.

$5_{M}$. Hoch, University of Cincinnati, private communication.

${ }^{6}$ J. A. Coffman, G. M. Kibler, T. R. Riethoff, and A. A. Watts, "Carbonization of Plastics and Refractory Materials Research, Part I," WAPD-TR-60-646, February 1961.

${ }^{7}$ R. J. Fries, "Vaporization Behavior of Niobium Carbide," Journal of Chemical Physics, Vol. 37, No. 2, July 1962, pp. 320-327. 


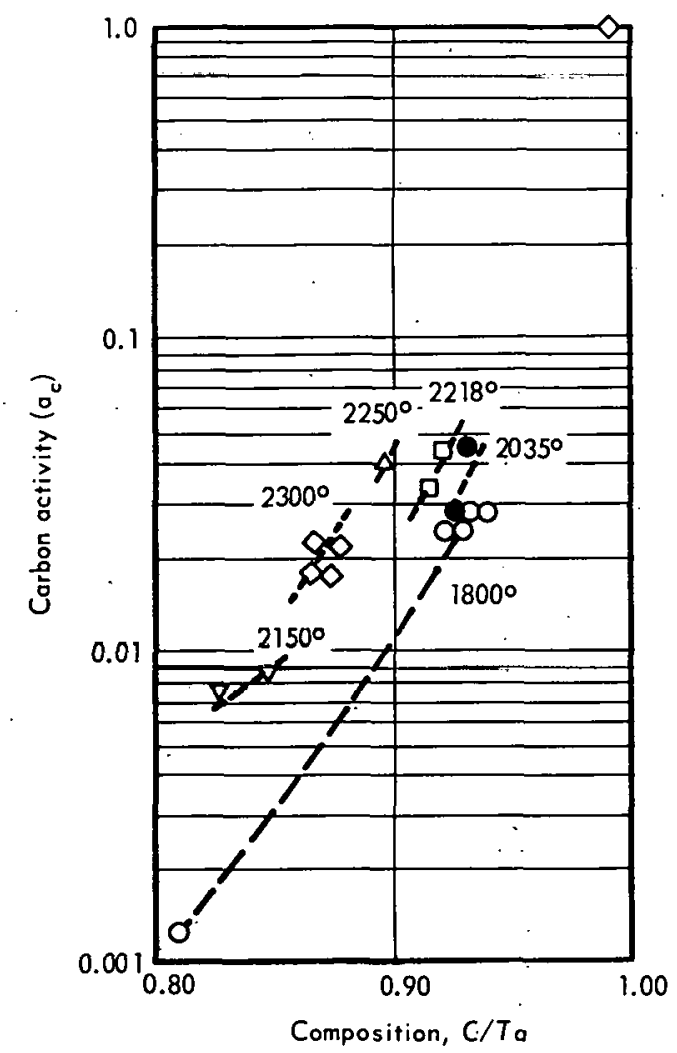

Fig. 12.1 - Carbon activity as a function of composition " of $\mathrm{TaC}_{x}$ at various temperatures $\left({ }^{\circ} \mathrm{C}\right)$

It should be noted here that the presence of water vapor in the test atmosphere has been shown ${ }^{3}$ to have a measurable effect on the composition estimater from lattice parameter measurements due to oxidation of the carbide. The presence of oxygen in the carbide lattice and the consequent low estimate of the $\mathrm{C} / \mathrm{Ta}$ ratio is being investigated to assess the degree of the error due to oxygen contamination in the compositions listed in Table 12.2.

\subsection{EQUILIBRIUM STUDIES ON URANIUM CARBIDE}

Gas - solid equilibrium studies in the uranium monocarbide region of the uranium - carbon system were performed using the rhenium encapsulation technique to establish the carbon activity as a function of composition and temperature.

\section{EXPERIMENTAL PROCEDURE}

The procedure used in the equilibration of tantalum carbide was modified somewhat for application to uranium carbide. The powder was encapsulated in rhenium (Table 12.3 shows the chemical and X-ray analyses of the commercial powder used in these tests) to suppress the free preferential evaporation of uranium. The rhenium served as a permeable membrane with respect to the carbon and hydrogen. The capsule $(0.05 \mathrm{~cm}$ wall thickness) was sealed by electron-beam welding in vacuum and leak-tested prior to the experiments.

A hygrometer was inserted in the line to monitor the water vapor content of the effluent gas. The initial water content was about $15 \mathrm{ppm}$; this level decreased as the furnace temperature was increased. At test temperature, the water vapor content was in the range of 6 to $.10 \mathrm{ppm}$ throughout the runs. When the furnace had cooled to room temperature after each run, the water vapor content decreased further to 3 to $4 \mathrm{ppm}$. The initial relatively 
TABLE 12.3

\begin{tabular}{lc} 
RESULTS OF CHEMICAL AND X-RAY \\
ANALYSES OF URANIUM CARBIDE USED \\
\multicolumn{2}{c}{ IN EQUILIBRIUM EXPERIMENTS } \\
\hline Carbon, \% & 4.77 \\
Uncombined carbon, ppm & .2300 \\
Oxygen, ppm & 6300 \\
Nitrogen, ppm & 140 \\
X-ray lattice parameter (a $), \AA$ & 4.95778 \\
C/U (chemical analysis) & 0.951 \\
C/U (X-ray analysis) & 0.972 \\
\hline
\end{tabular}

large amount of water vapor is attributed to moisture condensed on the furnace walls and fixtures when the system is purged and opened between runs. The 6 to $10 \mathrm{ppm}$ present during the runs is attributed to water and oxygen impurities in the bottled $\mathrm{H}_{2}$ and $\mathrm{H}_{2}+\mathrm{CH}_{4}$ mixtures.

Another modification in the procedure was the introduction of a total-hydrocarbon analyzer into the furnace exhaust line. With this device, continuous monitoring of the test atmosphere was permitted; it reduced the uncertainty about variations in atmosphere composition which arise when only a single sampling of the atmosphere is made during a test run. Figure 12.2 illustrates the experimental apparatus employed in these tests.

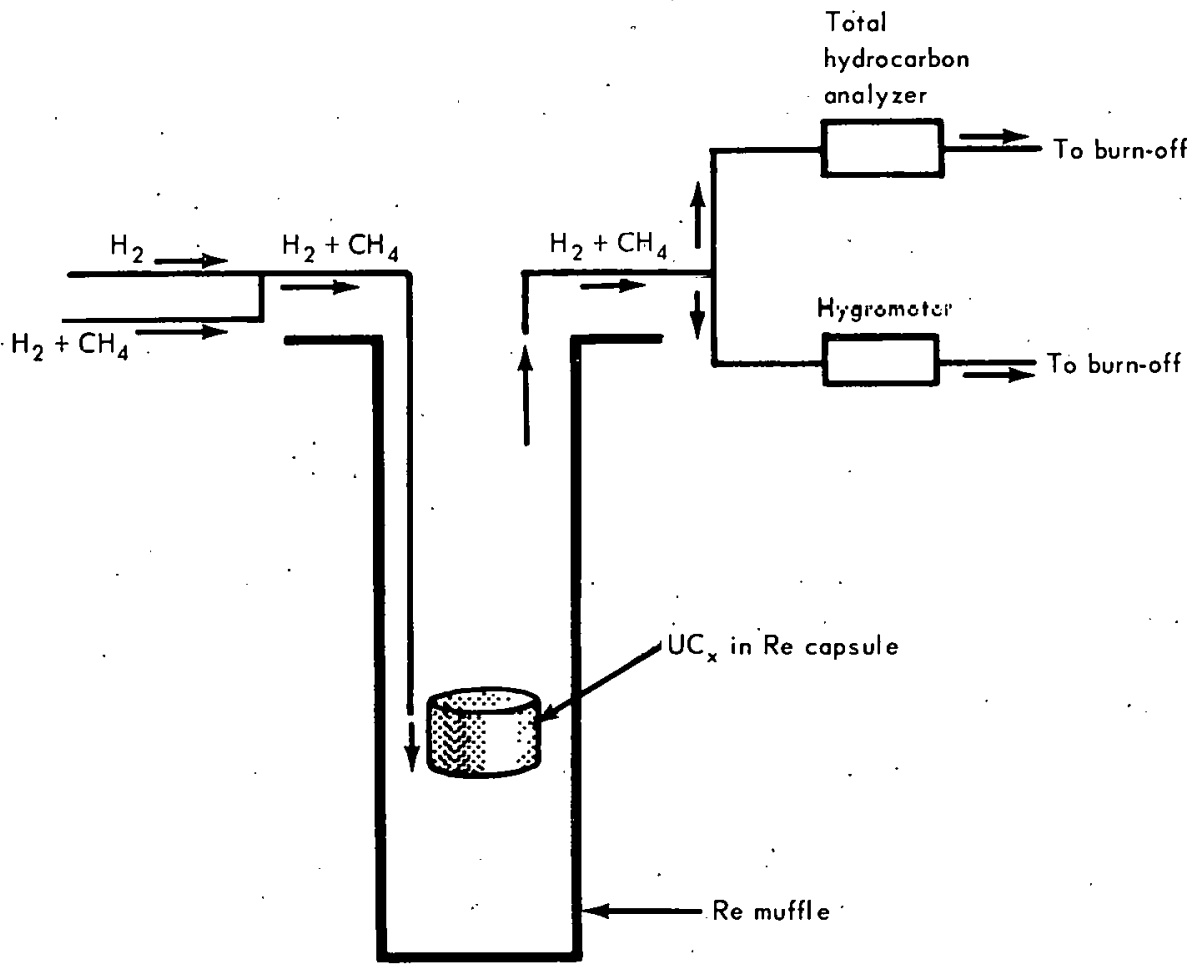

Fig. 12.2 - Schematic diagram of experimental opparatus for equilibration experiments 
Experiments were conducted at $1500^{\circ} \mathrm{C}$ and $1700^{\circ} \mathrm{C}$ in hydrogen atmospheres containing methane in concentrations of about 5 to $50 \mathrm{ppm}$. Test specimens were heated to constant weight; sample weights were recorded at intervals of 5 to 6 hours during each test. The lattice parameters were determined by the X-ray powder-camera technique. The equilibrated powders were packed into capillary tubes and sealed in an argon atmosphere (containing about $22 \mathrm{ppm}$ oxygen and $43 \mathrm{ppm}$ nitrogen) to prevent contamination by contact with air. The specimen compositions were estimated from the lattice parameters using the data of Magnier and Accary ${ }^{8}$ who show the lattice parameters for uranium monocarbide within its homogeneity range to be $4.9563 \pm 0.0003 \mathrm{~A}$ at 48 atomic percent carbon $\left(\mathrm{UC}_{0.92}\right)$ and $4.9607 \pm 0.0003 \mathrm{~A}$ at 50 atomic percent carbon ( $\mathrm{UC}_{1.0}$ ).

Carbon activity for the system was determined from the measured total hydrocarbon content of the furnace effluent gases.

\section{EXPERIMENTAL RESULTS AND DISCUSSION}

Table 12.4 shows the equilibrium composition for each temperature. expressed as $\mathrm{C} / \mathrm{U}$ ratio. These data and the data of Stor $\mathrm{ms}^{9}$ are combined in. Figure 12. to show the activity of carbon in both hypo- and hyperstoichiometric compositions. It was assumed that $x$ (the $\mathrm{C} / \mathrm{U}$ ratio) is made up of $\mathrm{x}_{1}$, the fraction of occupied carbon lattice sites, and $\mathrm{x}_{2}$, the fraction of total carbon sites doubly occupied. The fraction of vacancies is thus $1-x_{1}$, and the fraction of singly occupied sites is $x_{1}-x_{2}$.

When $x$ is appreciably less than 1 , a negligible fraction of lattice sites are: doubly occupied, $x \cong x_{1}$, and

$$
A_{1}=R T \cdot \ln \left(a_{c} \frac{1-x_{1}}{x_{1}}\right) \cong R T \cdot \ln \left(a_{c} \frac{1-x}{x}\right)
$$

When $x$ is appreciably greater than $1, x_{1}$ essentially. equals 1 and $x_{2}=x-1$. For this case

$$
A_{2}=R T \ln \left(a_{c} \frac{1-x_{2}}{x_{2}}\right) \cong R T \cdot \ln \left(a_{c} \frac{2-x}{x-1}\right) .
$$

Near stoichiometry, both equations must be valid and refer to the same carbon activity. Therefore,

$$
A_{1}+R T \ln \frac{x_{1}}{1-x_{1}}=A_{2}+R T \ln \frac{x_{2}}{1-x_{2}}
$$

These equations enable the calculation of a self-consistent set of values of $A_{1}, A_{2}, x_{1}$, and $x_{2}$ when carbon activities $\left(a_{c}\right)$ at several values of $x=x_{1}+x_{2}$ are measured at several temperatures. Starting estimates of average $\bar{A}_{1}$ and $\bar{A}_{2}$ were obtained from samples where $\mathrm{x}$ was appreciably lower and higher than 1 , respectively.

$\mathrm{x}_{1}$ and $\mathrm{x}_{2}$ were calculated for each sample using the relation

$$
\frac{\overline{\mathrm{A}}_{1}-\overline{\mathrm{A}}_{2}}{\mathrm{RT}}=\ln \left(\frac{1-\mathrm{x}_{1}}{\mathrm{x}_{1}} \cdot \frac{\mathrm{x}_{2}}{1-\mathrm{x}_{2}}\right)
$$

\footnotetext{
${ }^{8} \mathrm{P}$. Magnier and A. Accary, "Variations du parametre du monocarbure d'uranium en fonction de sa teneur en carbone," Report CEA-R2731, Centre d'Etudes Nucleaires de Saclay, January 1965.

${ }^{9}$ E. K. Storms, "A Mass Spectrometric Study of the Vapour Pressure of $U(g)$ and $\mathrm{UC}_{2}(\mathrm{~g})$ over Various Compositions in the Uranium-Carbon System," Thermodynumics., Vol. 1, IAEA, Vienna, 1966, p. 309.
} 
TABLE 12.4

COMPOSITION AND CARBON ACTIVITY OF URANIUM MONOCARBIDE AT $1500^{\circ} \mathrm{C}$ AND $1700^{\circ} \mathrm{C}$

\begin{tabular}{ccccc}
\hline $\begin{array}{c}\text { Carbon Content } \\
\text { Temperature, } \\
{ }^{\circ} \mathrm{C}\end{array}$ & $\begin{array}{c}\text { Atmosphere, } \\
\text { ppm }\end{array}$ & $\begin{array}{c}\text { Carbon } \\
\text { Activity }\end{array}$ & $\begin{array}{c}\text { Lattice } \\
\text { Parameter, } \AA\end{array}$ & $\begin{array}{c}\mathrm{C} / \mathrm{U} \\
\text { Equilibrium } \\
\text { Ratio }\end{array}$ \\
\hline 1500 & 10 & 0.0099 & 4.95941 & 0.993 \\
1500 & 11 & 0.0159 & 4.95930 & 0.992 \\
1500 & 53 & 0.0520 & 4.96046 & 0.998 \\
1700 & 6 & 0.0104 & 4.95778 & .0 .970 \\
1700 & 20 & 0.0331 & 4.95856 & 0.985 \\
1700 & 48 & 0.0728 & 4.95919 & 0.990 \\
\hline
\end{tabular}

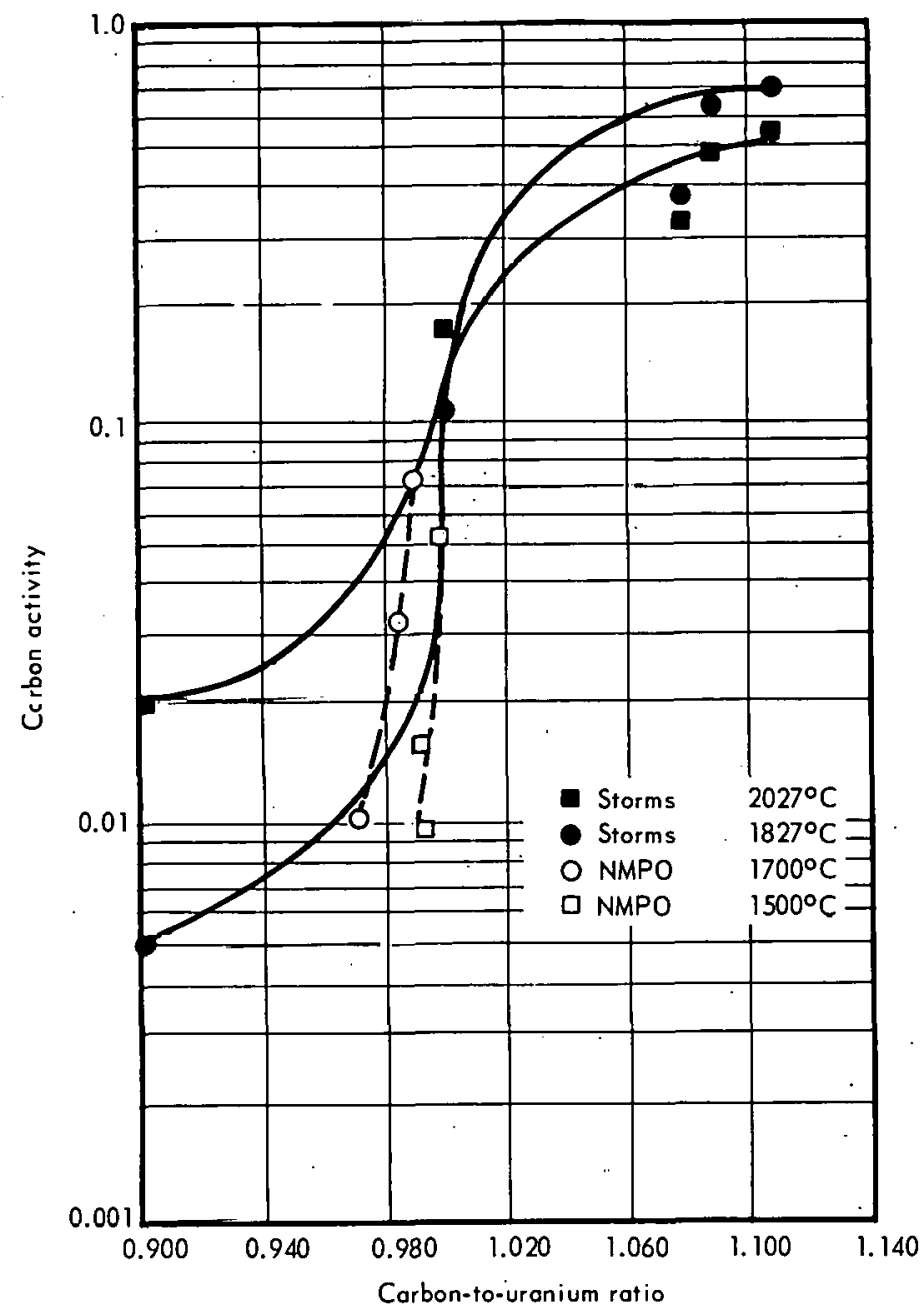

Fig. 12.3 - Carbon activity as a function of composition for UC 
From these values of $x_{1}$ and $x_{2}$, new values of $A_{1}$ and $A_{2}$ were calculated. These were averaged for all samples after weighting proportionately to $\left(1-x_{1}\right)$ for $A_{1}$ and to $x_{2}$ for $A_{2}$ since errors in $\ln \left(1-x_{1}\right) / x_{1}$ and $\ln \left(1-x_{2}\right) / x_{2}$ increase as $\left(1-x_{1}\right)$ or $x_{2}$ approaches zero.

The new values of $\bar{A}_{1}$ and $\bar{A}_{2}$ were then used, and the process was repeated until constant values for $\overline{\mathrm{A}}_{1}$ and $\overline{\mathrm{A}}_{2}$ resulted.

Table 12.5 shows the values so obtained. $\bar{A}_{1}$ is essentially equal to the value of $A$ for $\mathrm{TaC}$ and $\mathrm{NbC}(-27 \mathrm{kcal} / \mathrm{mole})$ when calculated using $\mathrm{x}_{1}$ rather than $\mathrm{x}$ (which yields a more negative value).

The positive value of $\bar{A}_{2}$ indicates that the fraction of doubly occupied lattice sites increases with increasing temperature at the expense of the singly occupied sites.

TABLE 12.5

ACTIVTY COEFFICIENTS $\left(A_{1}, A_{2}\right)$ AND FRACTION OF CARBON SITES $\left(x_{1}, x_{2}\right)$ OCCUPIED BY FIRST AND SECOND CARBON ATOMS IN URANIUM MONOCARBTEE

\begin{tabular}{|c|c|c|c|c|c|c|c|}
\hline$x_{1}$ & $x_{2}$ & $x(C / U)$ & $\underset{{ }^{\circ} \mathbf{K}}{\text { Temperature, }}$ & $\mathrm{a}_{\mathrm{c}}$ & $A_{1}$, & $\mathrm{kcal} / \mathrm{mole}$ & $\mathrm{A}_{2}, \mathrm{kcal} / \mathrm{mole}$ \\
\hline 0.98875 & 0.00525 & $0: 994$ & 1773 & 0.0099 & & -32.03 & 2.21 \\
\hline 0.98734 & .00466 & 0.992 & 1773 & 0.0159 & & -29.94 & 4. 31 \\
\hline 0.99122 & .00678 & 0.998 & 1773 & 0.052 & & -27.07 & 7.15 \\
\hline 0.96552 & .00448 & 0.97 & 1973 & 0.0104 & & -30.96 & 3.28 \\
\hline 0.97787. & .00713 & 0.985 & 1973 & 0.0331 & & -28.21 & 5.99 \\
\hline 0.98143 & .00857 & 0.99 & 1973 & 0.0728 & & -25.83 & 8. 35 \\
\hline $0.98074^{a}$ & .01426 & 0.995 & 2100 & 0.11 & & -25.61 & 8. 47 \\
\hline $0.97351^{\mathrm{a}}$ & .02149 & 0.995 & 2300 & $0.16^{\circ}$ & & -24.85 & 9.07 \\
\hline $0.99590^{\mathrm{a}}$ & .08210 & 1.078 & 2100 & 0.38 & & -26.96 & 6.04 \\
\hline $0.99620^{a}$ & .09080 & 1.087 & 2100 & 0.64 & & -25.10 & 7.75 \\
\hline $0.99685^{a}$ & .11715 & 1.114 & 2100 & 0.66 & & -25.76 & 6.69 \\
\hline $0.99194^{a}$ & .08606 & 1.078 & 2300 & 0.33 & & -27.06 & 5.73 \\
\hline $0.99250^{\mathrm{a}}$ & .09450 & 1.087 & 2300 & 0.47 & & -25.77 & 6. 88 \\
\hline $0.99370^{\mathrm{a}}$ & 0.12030 & 1.114 & 2300 & 0.54 & & -25.94 & 6.28 \\
\hline & & & \multicolumn{2}{|c|}{ Average } & & -27.70 & 6.64 \\
\hline
\end{tabular}

arom Storms (reference 9 ):

\section{URANIUM MONOCARBIDE - RHENIUM COMPATIBILITY}

In experiments on the compatibility of uranium monocarblde with rhenium, it was previously reported ${ }^{10}$ that severe reaction was observed at $2000^{\circ} \mathrm{C}$. Two samples from these studies were subjected to electron microprobe analysis to establish the reaction products. The test samples consisted of evacuated rhenium capsules containing pieces of hot-pressed hypostoichiometric uranium monocarbide. Sample No. 1 had been heated at $2000^{\circ} \mathrm{C}$ in hydrogen for 20 minutes. Sample No. 2 had been heated in a graphite crucible at $2000^{\circ} \mathrm{C}$ in a hydrogen atmosphere for about 4 hours. Figures 12.4 and 12.5 are photomicrographs of typical portions of the specimens showing the rhenium container, the carbide sample, and the interface between the two.

Electron microprobe analysis of sample No. 1 (Figure 12.4) showed reaction at the $\mathrm{Re}-\mathrm{UC}_{1-\mathrm{x}}$ interface to form phases which correspond to $\mathrm{URe}_{2}$ and $\mathrm{UC}_{2}$. Two phases were detected in the carbide region: UC, and a grain boundary phase of the approximate composition $\left(\mathrm{U}_{0.43} \mathrm{Re}_{0.57}\right) \mathrm{C}_{0.34}$, i. e., a metal-to-carbon ratio of $3: 1$. No uranium was detected in the rhenium although some traces of a grain boundary phase were observed in the rhenium.

${ }^{10}$ GEMP-400B, p. 155. 


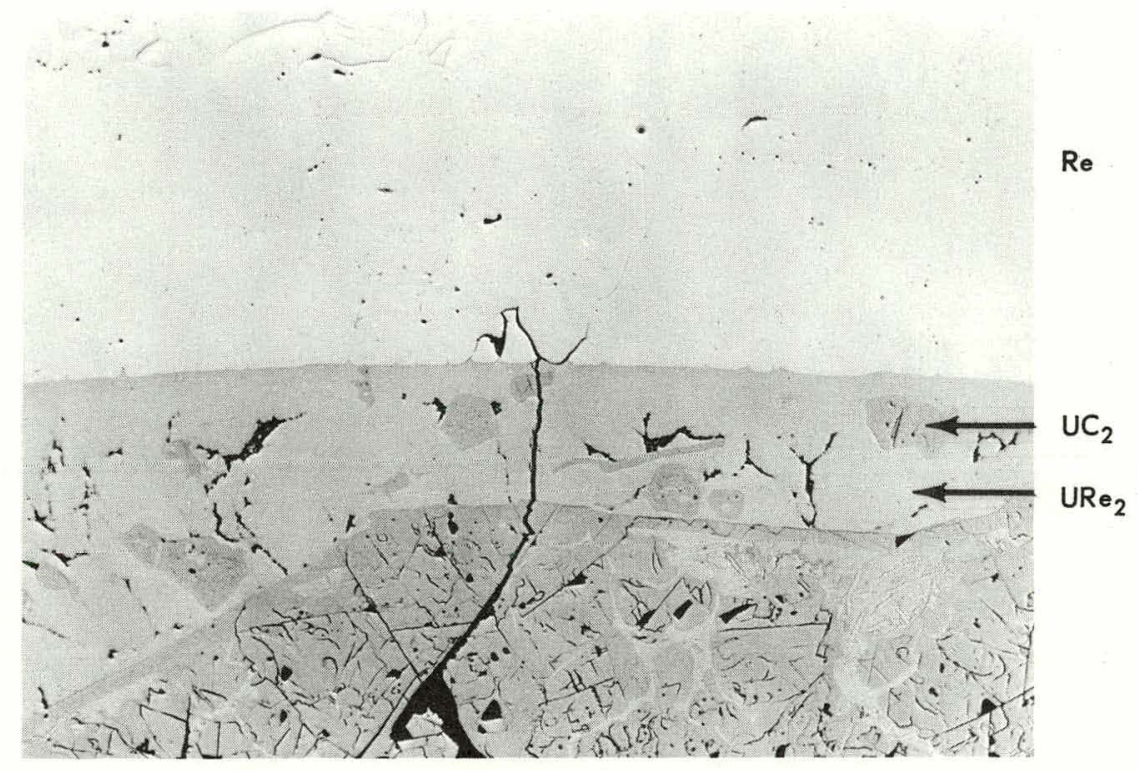

a. Re-UC interface (Neg. 6554)

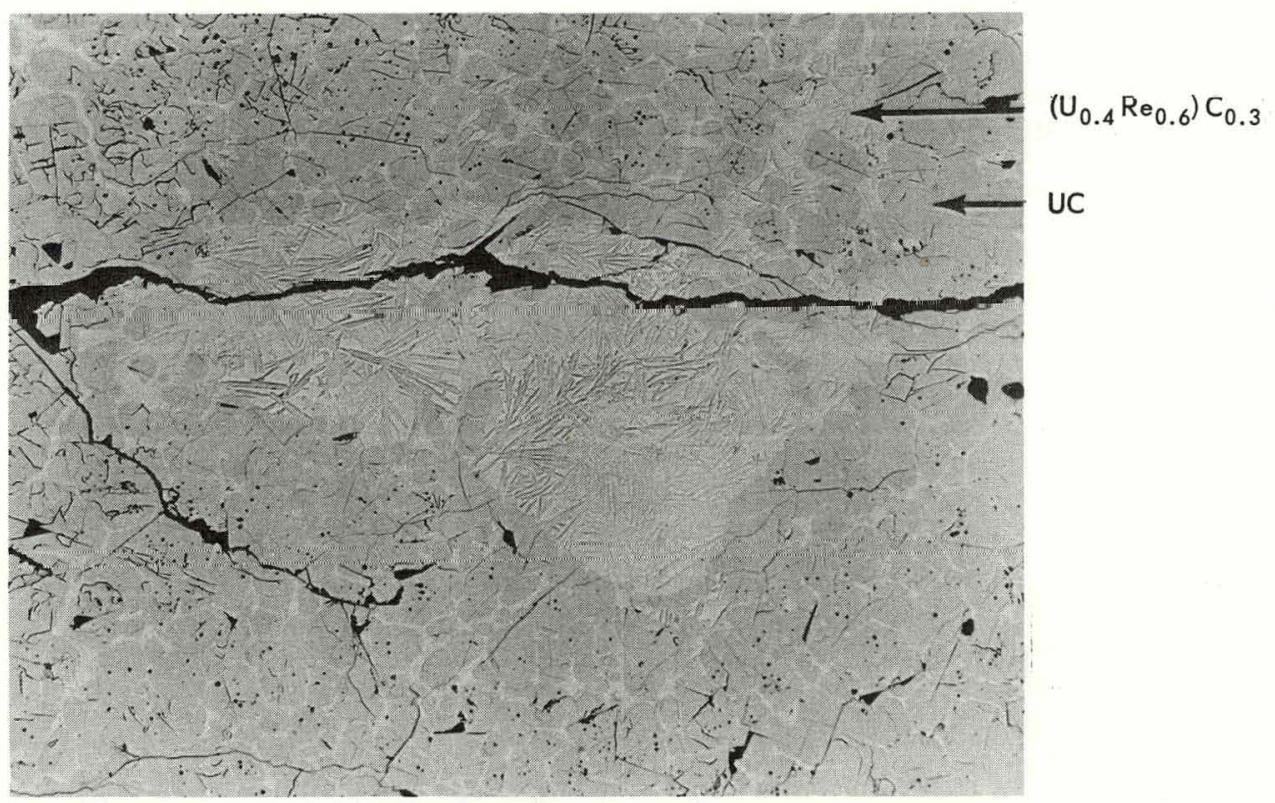

b. Interior of UC sample (Neg. 6553)

Fig. 12.4-Photomicrographs showing Re-UC reaction at $2000^{\circ} \mathrm{C}$ in hydrogen atmosphere (As-polished, 100X) 


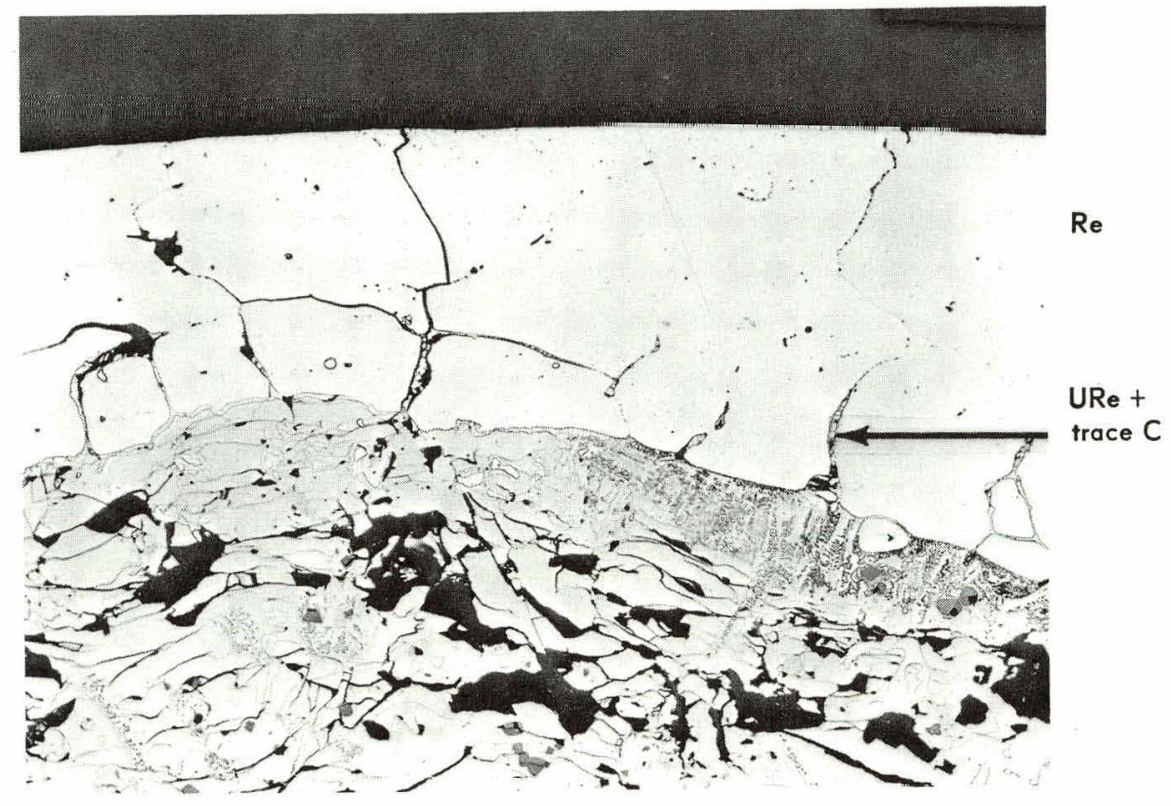

a. Re-UC interface (Neg. 6631)

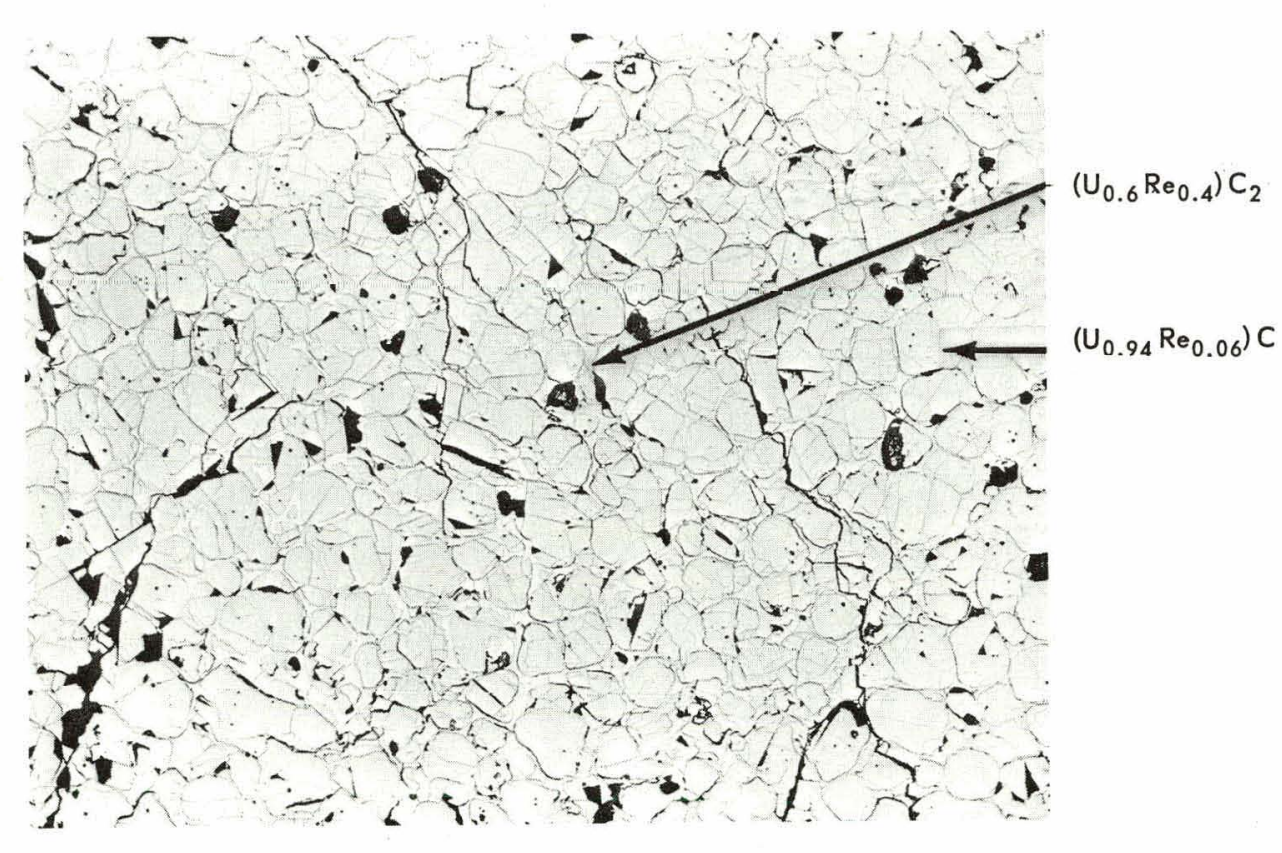

b. Interior of UC sample (Neg. 6630)

Fig. 12.5 - Photomicrographs showing Re-UC reaction when heated in the presence of excess graphite at $2000^{\circ} \mathrm{C}$ in hydrogen ('As-polished, 100X) 
Electron microprobe analysis of sample No. 2 (Figure 12.5) showed no $\mathrm{URe}_{2}$ present. The bulk of the carbide phase was uranium monocarbide with some dissolved rhenium; the approximate composition was $\left(\mathrm{U}_{0.94} \mathrm{Re}_{0.06}\right) \mathrm{C}$. A grain boundary phase was observed with the composition $\left(\mathrm{U}_{0.61} \mathrm{Re}_{0.39}\right) \mathrm{C}_{2}$, i.e., a metal-to-carbon ratio of about 1:2. Again, no intragranular uranium was detected in the rhenium but a grain boundary phase in the rhenium had a composition of URe with a trace of carbon which could not be quantitatively determined.

These results show extensive $\mathrm{URe}_{2}$ formation in the reaction between rhenium and hypostoichiometric uranium monocarbide in the absence of excess carbon. In addition to unreacted $\mathrm{UC}_{1-\mathrm{x}}$, the major intermetallic reaction products contained only small amounts of carbon. In the presence of excess carbon, on the other hand, the major phases in the carbide region all contained carbon, and the intermetallic compound $\mathrm{URe}_{2}$ was not detected.

\section{DIFFUSIVITY OF CARBON IN RHENIUM}

In conjunction with the study of the rhenium-encapsulation technique for the $\mathrm{UC}_{\mathrm{X}}$ solid gas equilibration studies, the rate of carbon loss from graphite sealed in rhenium capsules was measured in a hydrogen atmosphere. The carbon depletion rate was measured by determining weight loss through the $0.05-\mathrm{cm}$-thick rhenium walls as a function of time at $1500^{\circ} \mathrm{C}$ and $2300^{\circ} \mathrm{C}$ (see Figures 12.6 and 12.7). Each of the curves shows a constant rate of weight loss after a short period of time. Under the conditions of these experiments, the interior surface contains dissolved carbon equivalent to the carbon solubility limit at the test temperature. At the exterior surface, the rhenium capsule contains essentially no dissolved carbon since the capsule is suspended in hydrogen gas flowing at a rate of 1 to 2 liters per minute through the furnace.

Since the slope of the linear portion of the weight-loss versus time curves represents the rate of carbon depletion under steady-state conditions, and since the solubility of carbon in rhenium may be determined from the phase diagram, ${ }^{11}$ the diffusion constant (D) for carbon through rhenium may be calculated. The applicable equation ${ }^{12}$ is

$$
F=D \frac{d c}{d x}=D\left(C_{1}-C_{2}\right) / \ell
$$

where $\mathrm{F}=$ rate of carbon loss, $\mathrm{C}_{2}=$ carbon concentration at the exterior surface, $\mathrm{C}_{1}=$ carbon concentration at the interior surface, $D=$ the diffusion coefficient, and $\ell=$ rhenium wall thickness (i.e., length of diffusion path). For the temperatures of the present experiments, the solubility of carbon in rhenium at $2300^{\circ} \mathrm{C}$ is 7.3 atomic percent, and about 4.2 atomic percent at $1500^{\circ} \mathrm{C}$. The solubility of carbon in rhenium at $2300^{\circ} \mathrm{C}$ has been revised downward from the previously estimated 8.1 atomic percent ${ }^{13}$ and the rates of carbon loss for steady-state conditions have been revised slightly. Table 12.6 gives the diffusion coefficients at $1500^{\circ} \mathrm{C}$ and $2300^{\circ} \mathrm{C}$ derived from these experiments.

The activation energy for the diffusion process calculated from these data is $-58.2 \mathrm{kcal} /$ mole on the assumption that diffusivity is independent of concentration. Since diffusivity may vary with composition (as in the case of iron $^{14}$ ), the values of $D$ presented in Table 12. 6 may represent average diffusion coefficients for the carbon concentration ranges encountered in these experiments which are different for the two temperatures. Therefore, the calculated activation energy for the diffusion process is probably somewhat high. Also, it should be noted that the solubility of carbon in rhenium was determined from the carbonrhenium phase diagram. Therefore, any error in the solubilities will be reflected by a corresponding error in the calculated diffusion coefficient.

\footnotetext{
${ }^{11}$ J. E. Hughes, "A Survey of the Rhenium Carbon System," Journal of Less Common Metals, Vol. 1, 1959, p. 377.

${ }^{12} \mathrm{~J}$. Crank, "The Mathematics of Diffusion," Oxford University Press, London, 1956, p. 42.

13، "High-Temperature Materials Program Progress Report No. 63," GE-NMPO, GEMP-63, December 30, 1966, pp. 139-140.

${ }^{14}$ L. D. Darkin and R. W. Gurry, "Physical Chemistry of Metals," McGraw-Hill Book Company, Inc., New York, 1953 , p. 452.
} 


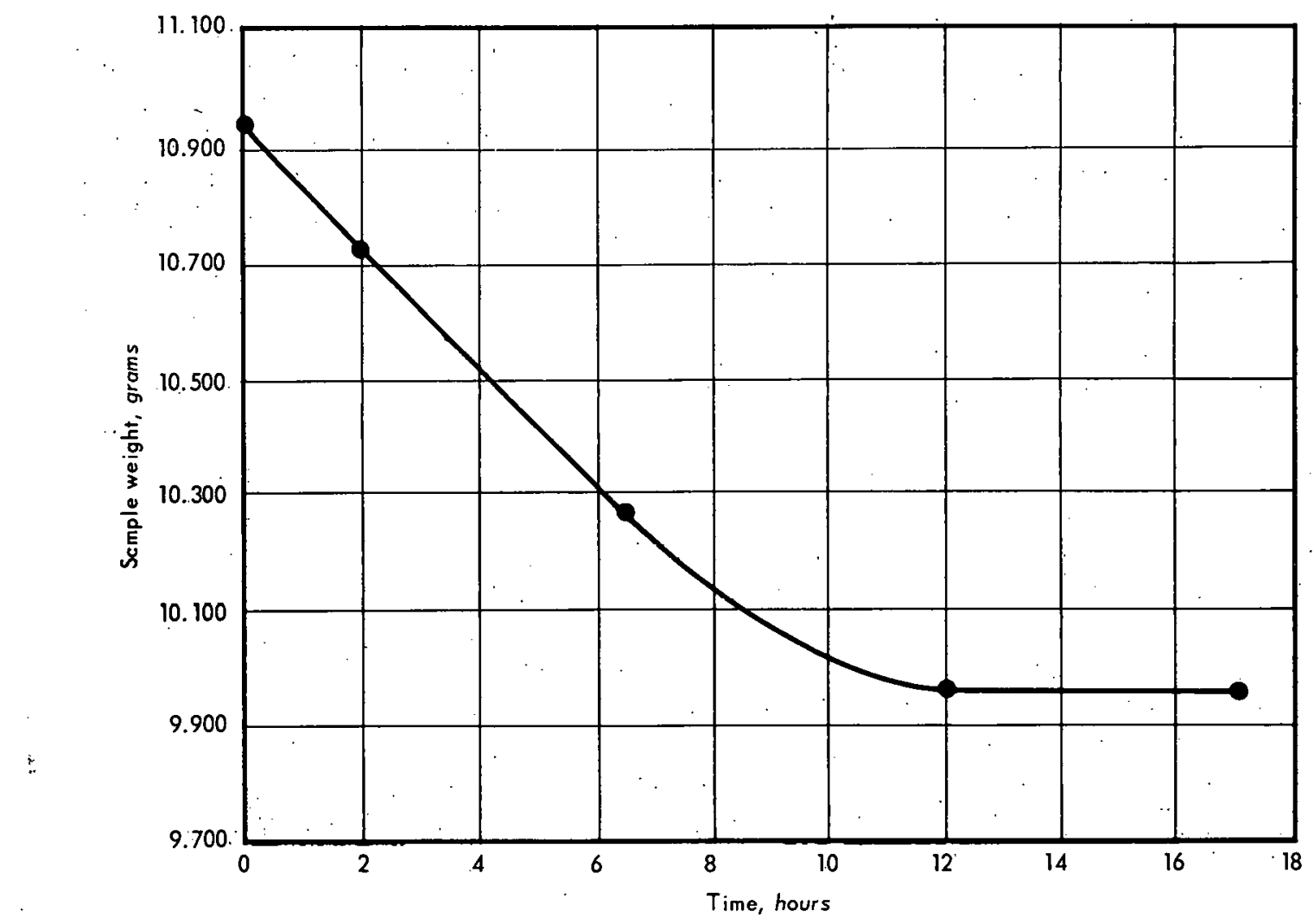

Fig. 12.6 - Weight versus time for graphite powder heated in Re capsule at $2300^{\circ} \mathrm{C}$ in hydrogen

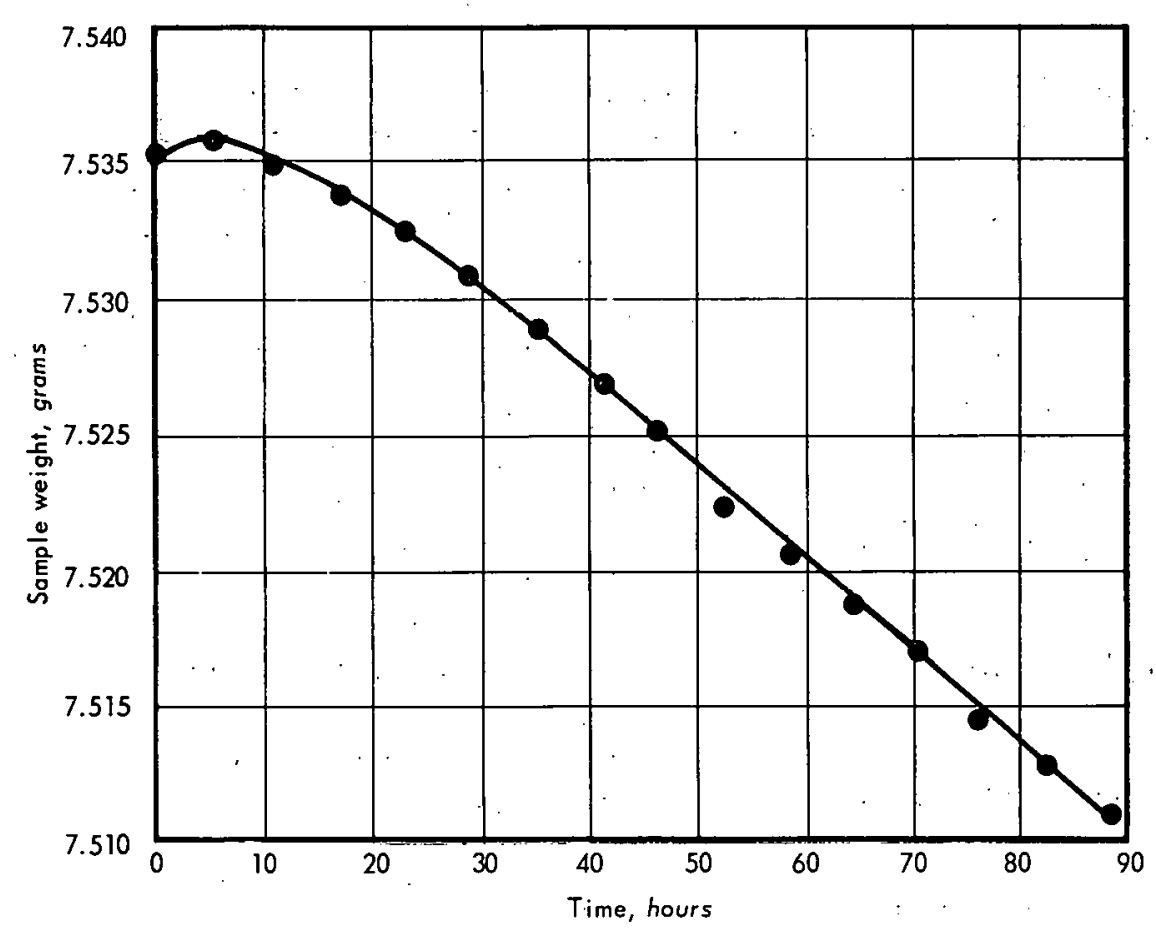

Fig. 12.7 - Weight versus time for graphite powder heated in Re capsule at $1500^{\circ} \mathrm{C}$ in hydrogen 
TABLE 12.6

DIFFUSION COEFFICIENT FOR CARBON IN RHENIUM AT $1500^{\circ} \mathrm{C}$ AND $2300^{\circ} \mathrm{C}$

\begin{tabular}{ccc}
\hline & $\begin{array}{c}\text { Rate of } \\
\text { Temperature, }{ }^{\circ} \mathrm{C}\end{array}$ & $\begin{array}{c}\text { Diffusion Coefficient (Ö) } \\
\mathrm{Cm}^{2} / \mathrm{sec}\end{array}$ \\
\hline 1500 & $9.68 \times 10^{-8}$ & $1.11 \times 10^{-8}$ \\
2300 & $2.92 \times 10^{-5}$ & $1.89 \times 10^{-6}$ \\
\hline a For steady-8tate conditions, sample surface area $=7.6 \mathrm{~cm}^{2}$
\end{tabular}

${ }^{a}$ For steady-state conditions, sample surface area $=7.6 \mathrm{~cm}^{2}$.

\section{3 SUMMARY AND CONCLUSIONS}

Carbon activity as a function of composition and temperature was determined for tantalum monocarbide of compositions between $\mathrm{TaC}_{0.80}$ and $\mathrm{TaC}_{0.99}$ for temperatures in the range between $1800^{\circ}$ and $2345^{\circ} \mathrm{C}$. Carbon activity was found to vary from $0.0014(\mathrm{C} / \mathrm{Ta}=$ $0.805)$ to $0.0283(\mathrm{C} / \mathrm{Ta}=0.936)$ at $1800^{\circ} \mathrm{C}$. At $2300^{\circ} \mathrm{C}$ the activity ranged from 0.0185 $(\mathrm{C} / \mathrm{Ta}=0.872)$ to $1.000(\mathrm{C} / \mathrm{Ta}=0.994)$.

Analysis of the activity and composition data for tantalum carbide in terms of a statistical model assuming filled metal sites in the carbide lattice and partially filled carbon sites yields a carbon - carbon interaction energy of $+36.6 \mathrm{kcal} / \mathrm{mole}$ and an entropy differ ence between carbon in graphite and in the carbide phase of -4.4 entropy units.

Carbon activity as a function of composition and temperature in uranium carbide was studied using the rhenium-encapsulation technique. Experimental results showed the activity of carbon to vary between about $0.0100(\mathrm{C} / \mathrm{U}=0.993)$ and $0.052(\mathrm{C} / \mathrm{U}=0.998)$ at $150{ }^{\circ} \mathrm{C}$ and $0.0104(\mathrm{C} / \mathrm{U}=0.970)$ and $0.0728(\mathrm{C} / \mathrm{U}=0.990)$ at $1700^{\circ} \mathrm{C}$. The data generated in these experiments were combined with the data of Storms to study the activity of carbon in compositions on both sides of stoichiometric UC. The function

$$
\operatorname{RT}\left(\ln a_{c} \frac{1-x}{x}\right)
$$

was evaluated for both first and second carbon atoms on a lattice site. When both types of occupancy of carbon lattice sites are taken into account, the value of this function for singly occupied sites is essentially equal to the value for $\mathrm{TaC}$ and $\mathrm{NbC}(\sim-27 \mathrm{kcal} / \mathrm{mole})$ which do not form the dicarbide. The value for the second carbon $(\sim 6 \mathrm{kcal} / \mathrm{mole})$ is consistent with the increase in doubly occupied sites with increasing temperature.

Compatibility studies between $\mathrm{UC}_{\mathrm{X}}$ and rhenium showed that $\mathrm{URe}_{2}$ is formed at $2000^{\circ} \mathrm{C}$ in hydrogen; in the presence of excess carbon, however, all the reaction products contained carbon, and $\mathrm{URe}_{2}$ was not formed.

Diffusion coefficients for carbon diffusion through rhenium calculated from weight-loss versus time measurements on rhenium-encapsulated graphite powder at $1500^{\circ} \mathrm{C}$ and $2300^{\circ} \mathrm{C}$ were found to be $1.11 \times 10^{-8} \mathrm{~cm}^{2} / \mathrm{sec}$ and $1.89 \times 10^{-6} \mathrm{~cm}^{2} / \mathrm{sec}$, respectively.

\subsection{PLANS AND RECOMMENDATIONS}

Equilibrium studies to determine carbon activity as a function of composition in nonstoichiometric uranium carbide will be continued.

Equilibrium studies will be extended to solid solutions of uranium carbide with refractory metal carbides and UC-ThC solid solutions to determine carbon activity as a function of compositlon and lemperature. 
THIS PAGE

WAS INTENTIONALLY

LEFT BLANK 


\title{
13. RADIATION EFFECTS IN BeO
}

\section{(57063)}

\author{
C. G. Collins *
}

The purpose of this program was to define the irradiation behavior of $\mathrm{BeO}$ in terms of the composition and microstructure variables that contribute to extended radiation stability.

This program was terminated at the end of FY-66. The final measurements completed on the program during the year included a comparison of the diametral compression and transverse bending strength tests on unirradiated $\mathrm{BeO}$, a comparison of the stability of several $\mathrm{BeO}$ compositions in irradiations at $100^{\circ} \mathrm{C},{ }^{1}$ expansion and strength changes in BeO irradiated to about $9 \times 10^{21} \mathrm{nvt}(\geq 1 \mathrm{Mev})$ at $1000^{\circ} \mathrm{C}$, and a summary of thermal diffusivity measurements on both unirradiated and irradiated specimens. ${ }^{2}$ Earlier work was summarized in the previous annual progress report. ${ }^{3}$ This section presents a brief, overall summary of the results of the program.

\subsection{SUMMARY OF RADIATION EFFECTS}

$\mathrm{BeO}$ was found to withstand extensive reactor irradiation under selected conditions. The maximum observed expansion under optimum irradiation conditions ranged up to 5 percent with a slight increase in strength and relatively small changes in other properties. Fine grain size ( $\leq 5$ micron) material proved to possess the best irradiation resistance, highdensity $\left(2.9 \mathrm{~g} / \mathrm{cm}^{3}\right)$ material yielding somewhat better irradiated strength and low-density $\left(\sim 2.6 \mathrm{~g} / \mathrm{cm}^{3}\right)$ material exhibiting less swelling. The optimum irradiation temperature is above $600^{\circ} \mathrm{C}$, higher temperatures being required the higher the neutron flux.

\section{EXPANSION OF IRRADIATED BeO}

Dimensional and volume changes of irradiated $\mathrm{BeO}$ occurred by three main processes: (1) expansion due to the accumulation of interstitials and vacancies as both point defects and clusters; (2) swelling caused by accumulation of helium and oxygen gases formed or released in transmutation reactions; and (3) microcracking; i.e., separation of the grains at the grain boundaries, and the consequent formation of grain boundary voids. Since the significant deleterious property changes occurred in microcracked material, the optimum irradiation conditions are those that can accommodate expansion and/or swelling without microcracking.

\section{Expansion}

Expansion is the predominant growth mechanism, in the absence of microcracking, at dosages up to approximately $10^{21}$ nvt $(\geq 1 \mathrm{Mev})$. Assuming that the concentration of de-

*Project leader and principal investigator.

1“'High-Temperature Materials Program Progress Report No. 58, Part A," GE-NMPO, GEMP-58A, April 29, 1966, pp. $42-47$.

2“"High-Temperature Materials Program Progress Report No. 61," GE-NMPO, GEMP-61, September 30, 1966, pp. $161-169$.

3“"Fifth Annual Report - High-Temperature Materials Programe, Part A," GE-NMPO, GEMP-100A, February 28, 1966, pp. 221- 259. 
fects is directly proportional to the expansion, the concentrations of both interstitial and vacancy defects follow first-order kinetics and are given by

$$
\left(\frac{\Delta V}{V}\right)=\frac{K}{A}[1-\exp (-A t)]
$$

and, for repetitive irradiations, by

$$
\begin{aligned}
& \left(\frac{\Delta V}{V}\right)=\frac{K}{A}[1-\exp (-A t)]+\left(\frac{\Delta V}{V}\right)_{0} \exp (-A t) \\
& K=3.3 \times 10^{23} \phi \\
& A_{i}=0.113 \exp (-22,400 / R T) \\
& A_{V}=6.1 \times 10^{-5} \exp (-10,300 / R T)
\end{aligned}
$$

where $\frac{\Delta V}{V}$ is the expansion exclusive of helium bubbles and microcrack voids; $K$ is the defect production rate per second; $\phi$ is the neutron flux, $\mathrm{nv}(\geq 1 \mathrm{Mev}) ;\left(\frac{\Delta \mathrm{V}}{\mathrm{V}}\right)_{0}$ is the expansion at the start of any repeated irradiation; $A_{i}$ and $A_{v}$ are the overall rate constants for annealing of defects; $\mathrm{R}$ is the molar gas constant, cal $/{ }^{\circ} \mathrm{K}$-mole; $\mathrm{T}$ is the absolute temperature, ${ }^{\circ} \mathrm{K}$; and $\mathrm{t}$ is the irradiation time, seconds.

Lattice Expansion - Lattice expansion is anisotropic, $\Delta c / c$ being greater than $\Delta a / a$. It is equal to the volume expansion, as determined by density methods, at irradiation temperatures up to about $600^{\circ} \mathrm{C}$, while above this temperature, lattice expansion becomes a progressively smaller fraction of the volume increase. At temperatures up to about $600{ }^{\circ} \mathrm{C}$, lattice expansion is described by equations (13.1) and (13.3); while at higher irradiation temperatures, it is given by equations (13.1) and (13.2).

Interstitial defects cluster into stacking faults located on the basal crystallographic plane even at irradiation temperatures of $100^{\circ} \mathrm{C}$. Cluster, or loop, size increases relatively slowly with increasing dosage at a given temperature but varies approximately linearly with increasing irradiation temperature, ranging from 40 to $100 \AA$ at $100^{\circ} \mathrm{C}$ to 800 to $1000 \AA$ at $1000^{\circ} \mathrm{C}$. Some decrease in loop size to approximately $800 \AA$ in $1200^{\circ} \mathrm{C}$ irradiations is attributed to increased influence of thermally induced vacancies. The cluster density is of the order of $10^{17}$ per $\mathrm{cm}^{3}$ at $100^{\circ} \mathrm{C}$ and $10^{15}$ per $\mathrm{cm}^{3}$ at $1000^{\circ} \mathrm{C}$. The contribution of these large interstitial clusters to the volume expansion measured by density change is less than 0.01 percent.

Vacancy Expansion - Expansion due to vacancy defects corresponds to the volume increase in polycrystalline bodies when (1) microcracking does not occur and (2) the accumulation of helium into bubbles and voids is not appreciable. It is given by equations (13.1) and (13.3) throughout the irradiation temperature range. As a consequence of the first-order kinetics, an equilibrium concentration of defects, and a corresponding saturation of the volume expansion equal to $\mathrm{K} / \mathrm{A}_{\mathrm{v}}$, is attained at a given neutron flux and irradiation temperature. Volume increases greater than this equilibrium amount are attributed to swelling mechanisms. Clustering of vacancy defects is not observed other than as a part of the process described as swelling.

Swelling

The accumulation of $\mathrm{He}, \mathrm{H}_{2}{ }^{3}$ (tritium), and $\mathrm{O}_{2}$ gases in irradiated material is a major contribution to the bulk volume expansion under nonmicrocracking conditions. Helium and $\mathrm{H}_{2}{ }^{3}$ are formed in the $(n, 2 n)$ and $(n, \alpha)$ reactions with Be and the destruction of the Be re- 
sults in an excess of $\mathrm{O}_{2}$ which is considered to assume the gaseous state - as opposed to retaining a lattice site - at temperatures above approximately $600^{\circ} \mathrm{C}$. The quantities of these gases formed at NTP are approximately $0.33 \mathrm{cc} \mathrm{He}, 0.07 \mathrm{cc} \mathrm{O}_{2}$, and $0.02 \mathrm{cc} \mathrm{H}_{2}{ }^{3}$ per gram of $\mathrm{BeO}$ per $10^{21}$ nvt $(\geq 1 \mathrm{Mev}$ ), and there is a corresponding volume decrease of about 0.05 percent per $10^{21}$ nvt due to the loss of $\mathrm{BeO}$ molecules.

Most of the gas formed is retained in the material. Gas escape data exhibited considerable scatter; significant variations were obtained with microcracked specimens and with differences in open porosity, density, and grain size of the material. In general, however, 70 to 90 percent of the helium, and presumably of the oxygen, formed was retained in bulk, nonmicrocracked material of high density $\left(2.9 \mathrm{~g} / \mathrm{cm}^{3}\right)$, and a similar fraction of this quantity was retained in the grains.

The retained gases contributed to swelling through formation of bubbles both inside the grains and at the grain boundaries. The amount of swelling appeared to follow the theory advanced by Barnes. ${ }^{4}$ The pertinent equation is:

$$
\frac{\Delta V}{V}=\frac{3^{1 / 4}}{4 \pi^{1 / 4}} k T a_{o}\left(\frac{\dot{m}}{\gamma}\right)^{5 / 4}\left(D_{S} F \ln t\right)^{1 / 4} t^{3 / 2}
$$

which becomes, for $\mathrm{BeO}$ :

$$
\frac{\Delta \mathrm{V}}{\mathrm{V}}=4.42 \times 10^{-29} \mathrm{~T}(\dot{\mathrm{m}})^{5 / 4}\left\{\left[\exp \left(-\frac{4.0}{\mathrm{kT}}\right)\right](\ln \mathrm{t})\right\}^{1 / 4} \mathrm{t}^{3 / 2}
$$

where $\frac{\Delta \mathrm{V}}{\mathrm{V}}$ is volume increase due to bubbles; $\mathrm{k}$ is Boltzman's constant, $\mathrm{T}$ is absolute temperature, ${ }^{\circ} \mathrm{K} ; a_{\mathrm{O}}$ is the lattice parameter; $\dot{\mathrm{m}}$ is the production rate of the gas, atoms/ccsec; $\gamma$ is the surface energy; $D_{\mathbf{S}}$ is the surface diffusion coefficient; $F$ is a force exerted on a bubble by a stressed dislocation (assumed equal to $10^{-4}$ dynes); and $\mathrm{t}$ is irradiation time, seconds.

Intragranular Bubbles - The intragranular bubbles are actually crystalline shaped "voids" elongated in the $c$-axis direction and with sides parallel to the $\{10 \overline{1} 0\}$ planes. The number of bubbles determined after an irradiation at $1000^{\circ} \mathrm{C}$ to $8.5 \times 10^{21}$ nvt was $10^{15}$ per $\mathrm{cm}^{3}$, approximately the same order of magnitude as the number of interstitial loops. Their size ranged, in the same sample, from the lower limit of detection $(\sim 20 \AA)$ to a maximum length of $2000 \AA$, the radius of the equivalent sphere for the largest bubbles being about $1300 \AA$. Their contribution to the swelling amounted to a volume increase of about 0.8 percent in an irradiation at $1000^{\circ} \mathrm{C}$ to $8.5 \times 10^{21} \mathrm{nvt}$ ( $\geq 1 \mathrm{Mev}$ ).

Intergranular Bubbles - Grain boundary bubbles were observed at irradiation temperatures as low as $600^{\circ} \mathrm{C}$ and possibly as low as $370^{\circ} \mathrm{C}$. Although definitive bubble size data were difficult to obtain, a spectrum of bubble sizes was observed and both the number and size appeared to increase with increasing grain size and with increasing dosage at a given temperature. At the maximum dosage examined, $8.5 \times 10^{21}$ nvt at $1000^{\circ} \mathrm{C}$, bubbles with a maximum size of approximately 2 microns diameter were found in material of 5-micron grain size, and the bubble count was such as to account for a volume increase of several percent. Thus, through the formation of larger bubbles with a lower internal gas pressure, the smaller quantity of gas retained in the grain boundaries resulted in a larger volume increase than the gas retained in the grains.

${ }^{4}$ R. S. Barnes, "A Theory of Swelling and Gas Release for Reactor Materials," Iournul of NurLleur "llut criuls, Vol. 11, 1964, pp. 135-148. 
The total swelling in high-density specimens of 5 -micron grain size irradiated at $1000^{\circ} \mathrm{C}$ was about 0.5 percent per $10^{21} \mathrm{nvt}$, as indicated in Figure 13.1. Theory predicts swelling proportional to the $3 / 2$ power of the irradiation time and to the $5 / 4$ power of the gas production rate. For the time periods involved in Figure 13.1 ( $\sim 3 \times 10^{7}$ seconds), the $t^{3 / 2}$ curve is sufficiently close to linear that the data are considered to follow the theory, par ticularly since different neutron fluxes were employed. The temperature dependence of the swelling, which is proportional to $\left[\mathrm{T}\left(\exp \frac{-Q}{\mathrm{kT}}\right)^{1 / 4}\right]$, where $Q$ is the activation energy for surface diffusion, was found experimentally to correspond to a $Q$ of $4.0 \mathrm{ev}$ (92 kcal), as indicated in equation 13. 5 .
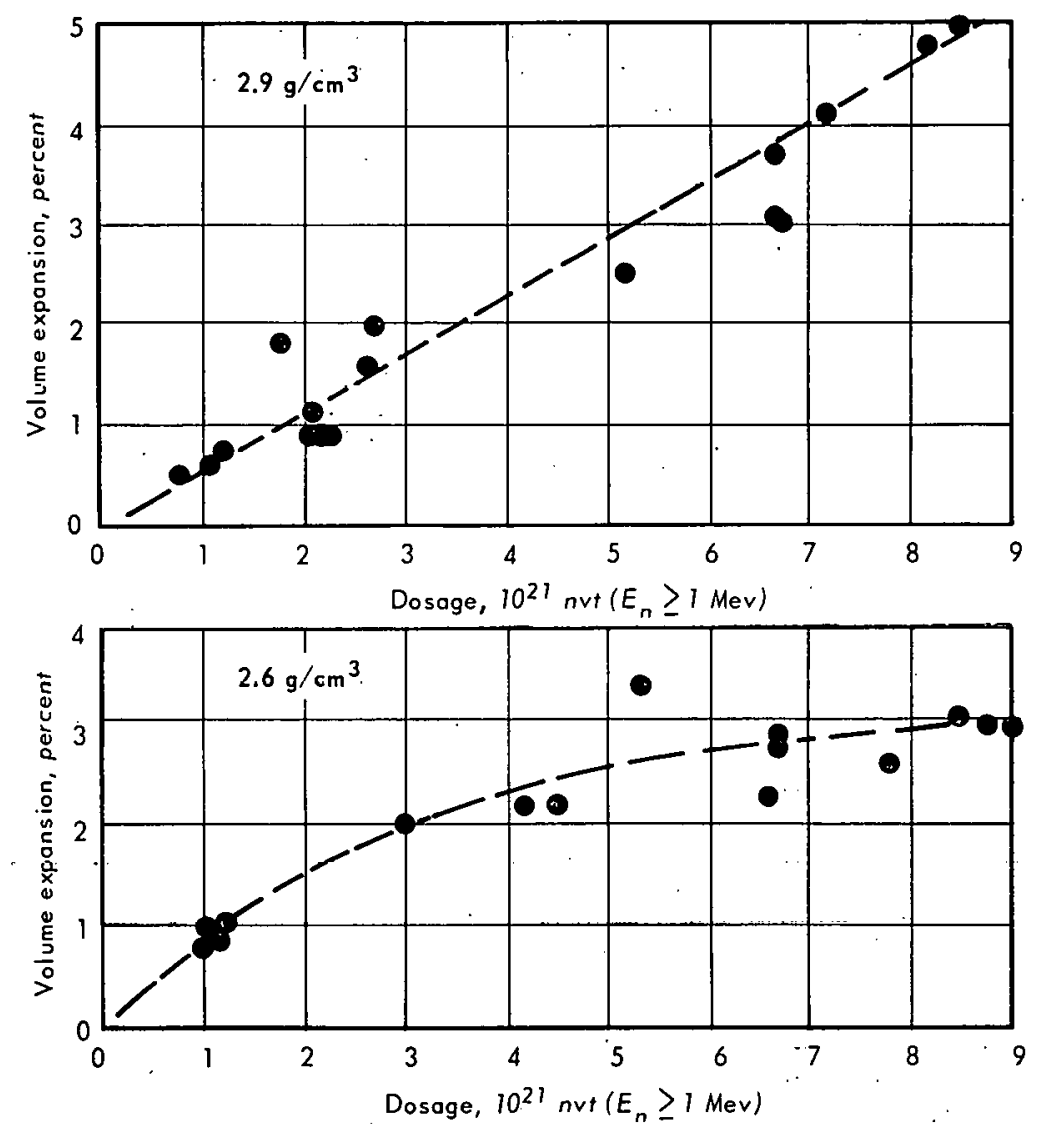

Fig. 13.1 - Volume expansion as a function of dosoge in BeO specimens of $\sim 5$ micron grain size and 2.6 and $2.9 \mathrm{~g} / \mathrm{cm}^{3}$ density irradiated of $1000^{\circ} \mathrm{C}$

\section{Microcracking}

When microcracking occurs, it is a significant contribution to the volume expansion of polycrystalline bodies and can lead to friability and powdering of the material. It is caused by the intergranular stress which results from the anisotropic expansion of the individual grains. The dosage required for microcracking to occur is inversely proportional to the square root of the grain size of the material; i.e., the smaller the grain size the higher the dosage must be before microcracking occurs. In 5-micron grain size material, microcracking occurs at about $2 \times 10^{20} \mathrm{nvt}\left(\geq 1 \mathrm{Mev}\right.$ ) in $100^{\circ} \mathrm{C}$ irradiations and at a bulk volume expansion of 0.5 to 0.7 percent. Once microcracking begins, the bulk volume expansion is usually limited to three times the rate of c-axis expansion. At $100^{\circ} \mathrm{C}$, this amounts to a 
rate of about 0.9 percent volume increase per $10^{20} \mathrm{nvt}(\geq 1 \mathrm{Mev})$, while at higher temperatures, the rate can be approximated by three times the rates of expansion given by equations (13.1) and (13.3).

Although not thoroughly verified, there is considerable evidence to indicate that microcracking occurs at the same volume expansion at different irradiation temperatures provided the expansion is determined by equations (13.1) and (13.3); the gas bubbles in the grains and in the grain boundaries do not appear to contribute to microcracking. Therefore, it is possible to define irradiation temperature and flux conditions required to keep the equilibrium nongas expansional (equal to $\mathrm{K} / \mathrm{A}_{\mathrm{v}}$ ) less than the amount at which microcracking occurs. Under these conditions, illustrated in Figure 13.2, a polycrystalline body can withstand considerable swelling without microcracking.

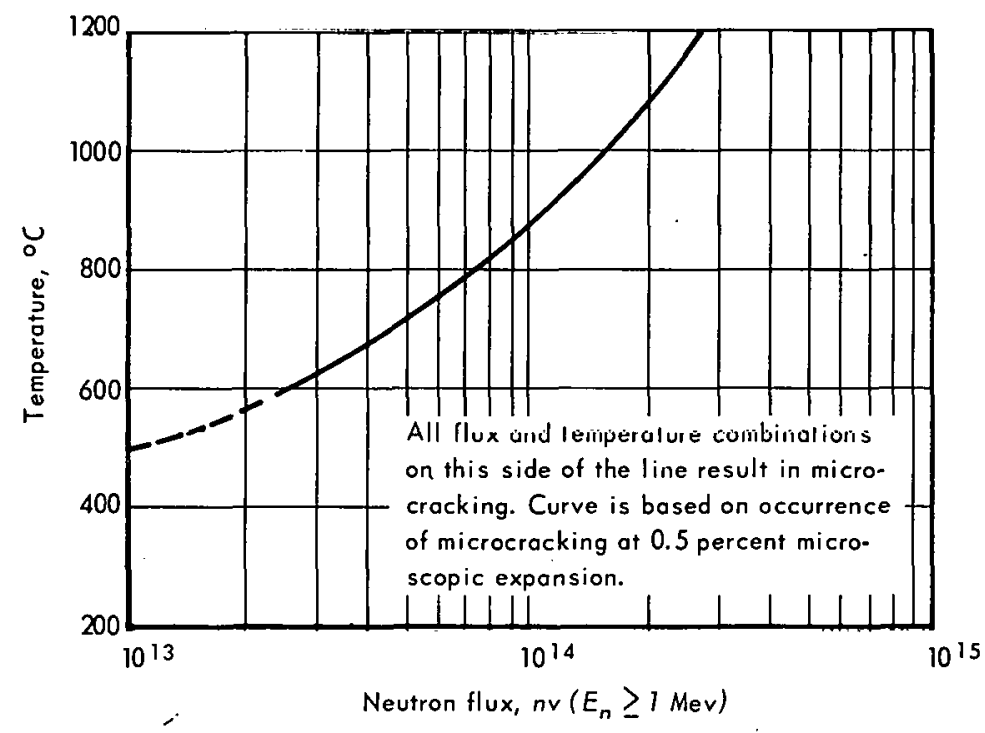

Fig. 13.2 - Estimated minimum irradiation temperature to avoid grain-boundary separation in $\mathrm{BeO}$ of up to 20 -micron grain size

\section{PROPERTY CHANGES IN IRRADIATED BeO}

The properties of irradiated $\mathrm{BeO}$ are markedly dependent on microcracking. No adverse change occurs in the strength and elastic constants in nonmicrocracked material, the strength of the material can actually increase roughly 40 percent in the absence of microcracking. The strength increase occurs at irradiation temperatures up to at least $1200^{\circ} \mathrm{C}$ and is not appreciably affected by the presence of grain boundary helium bubbles nor is the temperature dependence of the strength changed. The strength decreases markedly once microcracking occurs, the extent of the decrease being greater per unit volume increase in materials of larger grain size.

Changes in dynamic elastic constants were of a pattern similar to the strength changes. In the absence of microcracking and swelling, the constants decrease approximately by the amount expected from the decrease in density, while in material involving swelling, the decrease was roughly twice this amount. In microcracked material, the constants decreased rapidly with increasing volume expansion.

Thermal expansion and enthalpy were not changed within a measurement accuracy of 1 percent. The thermal diffusivity decreased by amounts that varied with irradiation and measurement temperature as shown in Figure 13.3. Swelling in the nonmicrocracked condition did not change the diffusivity beyond that attributable to the density decrease. 


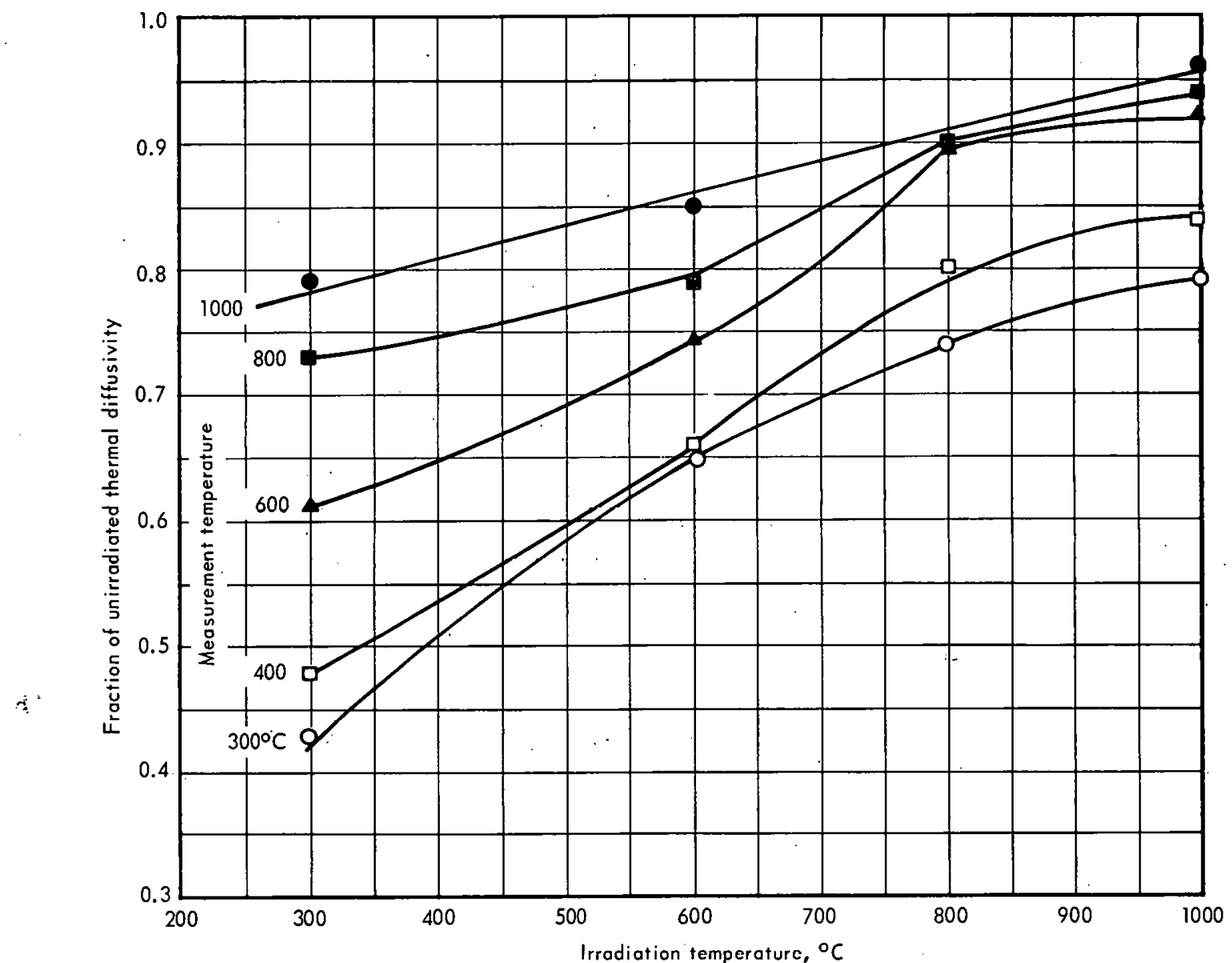

Fig. 13.3 - Fractional decreose in thermal diffusivity of BeO specimens of $\sim 5$ micron grain size and density of $2.9 \mathrm{~g} / \mathrm{cm}^{3}$ after irradiation at various temperotures to $\sim 0.7$ percent crystalline volume expansion

\section{MICROSTRUCTURE AND COMPOSITIONAL EFFECTS ON IRRADIATION BEHAVIOR}

\section{Microstructure}

Grain size, as noted earlier, was the most important microstructural factor influencing irradiation stability. The resistance of fine-grained material ( $\leq 5 \mathrm{microns}$ ) to microcracking extended throughout the irradiation temperature range investigated and provided better strength retention even in the microcracked condition.

Uniformity of grain size and equiaxed grain shape are necessary for the best microcracking resistance. Large variations in the grain size in a given specimen and columnar or rectangularly shaped grains, such as are sometimes obtained with $\mathrm{Al}_{2} \mathrm{O}_{3}$ additions to $\mathrm{BeO}$, both reduced microcracking resistance.

Density was a significant variable in the swelling behavior but did not appear particularly significant in expansion due to defects. In general, low-density materials $\left(2.6 \mathrm{~g} / \mathrm{cm}^{3}\right)$ were slightly inferior to high-density materials in resistance to microcracking. Low-density material, however, reduced the magnitude of swelling through greater accommodation and release of the grain boundary helium.

Open versus closed porosity did not appear to be a significant variable other than the influence of open porosity in reducing swelling. Inter - versus intragranular porosity could not be investigated as a variable independent of grain size. 
Preferred orientation of the $<001>$ fiber texture, i.e., alignment of the c-axis of the grains along the longitudinal axis of specimens, provided some improvement in microcracking resistance in comparison to randomly oriented material of the same grain size. Unfortunately, it was not possible to obtain a significant degree of preferred orientation of this type in small grain size specimens. In large grain size materials in which a high degree $(\sim 80 \%)$ of preferred orientation could be achieved, grain size effects proved more important than the orientation.

\section{Composition}

Specimens made from four grades of commercially available $\mathrm{BeO}$ powders were studied in the program; these powders included UOX and AOX grades from Brush Beryllium Co., Minox AAA grade from Mineral Concentrates Co., and CF grade from NGK Insulators of America. The UOX- and CF-grade powders appeared to be more readily sinterable and yielded materials with somewhat superior irradiation stability; howcver, studies of the Minox AAA and CF grades were less extersive than those of the UOX and AOX grades.

Based on results with the UOX powder, additions of other oxides in small concentrations improved both sinterability and irradiation resistance. Additives studied included: $\mathrm{MgO}$ in 0.5 and 1.0 weight percent concentrations; $\mathrm{Al}_{2} \mathrm{O}_{3}$, bentonite, and three silica glass compositions in 1 weight percent concentration; and $\mathrm{ZrO}_{2}$ in 3 weight percent concentration. The 1 weight percent bentonite composition is that utilized in the Experimental Beryllium Oxide Reactor (EBOR); specimens of this composition included fine-grained material ( 5 micron) prepared at GE-NMPO as well as EBOR production material of 22- to 28 micron grain size.

Three compositions were found that were superior in microcracking resistance to UOX 0.5 weight percent $\mathrm{MgO}$ which, together with $\mathrm{AOX}$, was the most extensively studied. These three compositions included 1 weight percent low-silica glass; $0.4 \mathrm{Al}_{2} \mathrm{O}_{3}+0.1 \mathrm{SiO}_{2},{ }^{*}$ and 1.0 bentonite, all in UOX-grade powder and in specimens of $\leq 5$-micron grain size. The glass-phase additives appear particularly interesting in that specimens of the EBOR production material exhibited better strength retention properties in high-temperature, highdosage irradiations than UOX-MgO and AOX specimens of comparable grain size, even though the EBOR material exhibited greater swelling. Efforts to correlate the improved microcracking resistance of these compositions with nonir radiated characteristics such as strength, open or closed porosity, and microstructure were not succèssful.

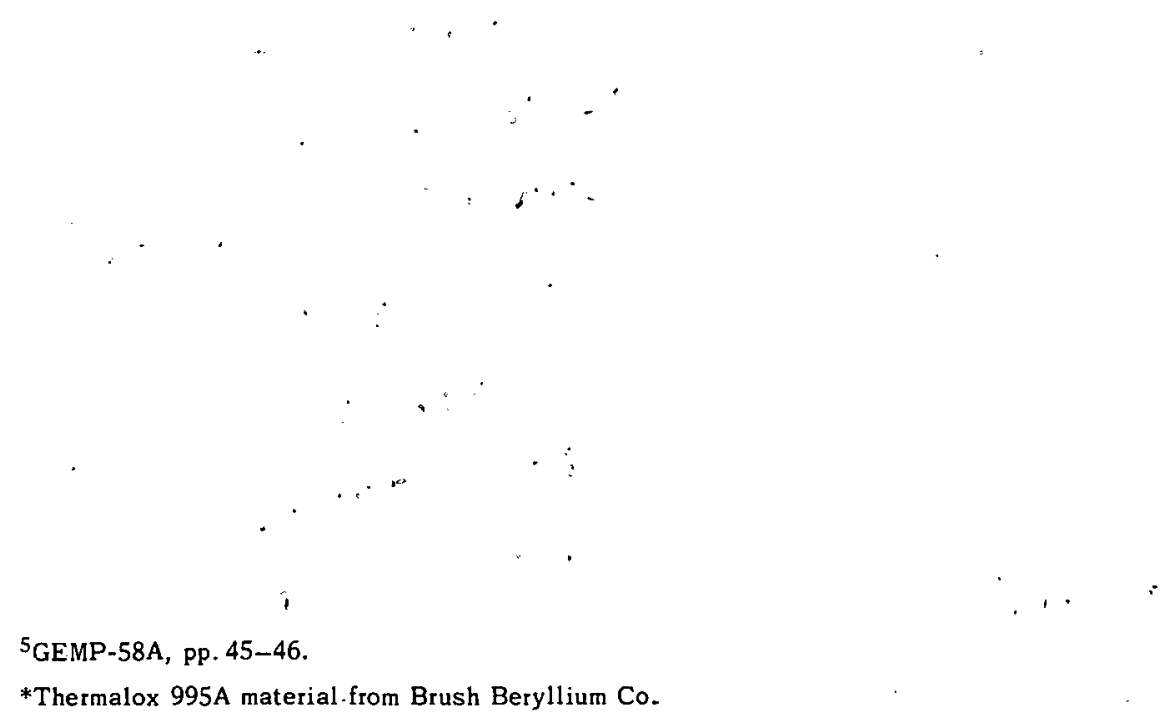




\section{THIS PAGE}

\section{WAS INTENTIONALLY LEFT BLANK}




\section{APPENDIX}

\section{REPORTS ISSUED DURING CALENDAR YEAR 1966}

\section{PROGRESS REPORTS}

GEMP-400 A and B

Fifth Annual Report - High-Temperature Materials Programs, February 28, 1966

GEMP-58A and B

High-Temperature Materials Program Progress Report No. 58; April 29, 1966

GEMP-59A and B

High-Temperature Materials Program Progress Report No. 59, June 15, 1966

GEMP-60

High-Temperature Materials Program Progress Report No. 60, August 15, 1966

GEMP-61

High-Temperature Materials Program Progress Report No. 61, September 30, 1966

GEMP-62

High-Temperature Materials Program Progress Report No. 62, November 30, 1966

GEMP-63

High-Temperature Materials Program Progress Report No. 63, December 30, 1966

TOPICAL REPORTS

A. Prince, "Neutron Cross-Sections for $\mathrm{Cm}^{244}$ and Pu 238 ," GEMP-411, February 1966.

W. Z. Prickett, "Sahara Status Report - A Modified ORNL Reactor Burnup Code," GEMP-432, August 1966.

H. R. Stephan and J. F. Collins, "Iron-Chromium-Aluminum-Yttrium Alloy for Electrical Heating Elements," GEMP-440, October 1966.

J. B. Conway, "Characteristics of Transient Creep Curves," GEMP-449, November 1966.

J. C. Blake and R. J. Freeman, "Thermal Diffusivity Measurements on Pre- and PostIrradiated BeO," GEMP-452, November 1966.

R. L. Ladd and R. C. Rau, "A Single Step Technique for Electrothinning Metal Discs for Transmission Electron Microscopy," GEMP-464, December 1966.

R. H. Stentz, "The Development and Operation of Low-Cycle Fatigue Testing," GEMP-465, December 1966.

R. C. Rau and K. Lacefield, "Microhardness of Irradiated BeO," GEMP-466, Dec. 1966.

T. Slot, J. F. McConnelee, and J. Muteff, "Low Cycle Fatigue Studies - Technical Program," GEMP-467, December 1966. 
E. A. Schaeffer and J. O. Hibbits, "The Determination of Moisture on Thorium by a Coulometric Electrolytic Measurement with Electronic Integration," GEMP-468, Nov. 1966.

C. O. Tarr, "W-25Re Test Capsule for TRW Systems Inc.," GEMP-469, December 1966.

J. L. Kamphouse, "Beryllium Nineteen Group Cross Sections," GEMP-470, Dec. 1966.

F. C. Robertshaw, R. K. Betts, and D. E. Conner, "The Use of Spherical $\mathrm{UO}_{2}$ in Cermet Fuel Plate," GE-TM 66-2-3, February 1966.

T. Slot, "Theoretical Analysis of Stresses and Displacements in Perforated Plates Under Uniform Edge Loading and in Hollow Polygons Under Various Loading Conditions," GE-TM 66-2-2, February 1966.

R. A. Hein, "Measurement of Linear Thermal Expansion of Yttrium Oxide to $2250^{\circ} \mathrm{C}$," GE-TM 66-3-25, March 1966.

E. A. Schaeffer, M. R. Menke, and J. O. Hibbits, "The Determination of $O / U$ Ratios in $\mathrm{UO}_{2 \pm \mathrm{x}}, " \mathrm{GE}-\mathrm{TM} 66-4-9$, April 1966.

R. E. Fryxell and E. A. Aitken, "High Temperature Studies of Urania in a Thermal Gradient," GE-TM 66-5-15, May 1966.

C. G. Collins, "Irradiation Test of NGK BeO Materials," GE-TM 66-6-5, June 1966.

R. A. Hein,..."Enthalpy and Linear Thermal Expansion of Ternary. Fuel Supplied by Phillips Petroleum Co. ," GE-TM:66-7-14, July 1966.

\section{PAPERS PRESENTED AND ARTICLES PUBLISHED DURING CALENDAR -YEAR 1966:}

\section{PRESENTATIONS}

C. S. Wukusick, "Physical Metallurgy: and Oxidation Behavior. of Fe-Cr-Al-Y Alloys,". Conference on Corrosion of Materials;' Schenectady; New York, January 1966; GEMP-414.

J. O. Hibbits and E. A. Schaefer; "The Determination of Free:Metal Species in W-UO, Fuels," NASA Conference on W-UO ${ }_{2}$ Fuels, NASA-Lewis Laboratory, Cleveland, Ohio, January 1966.

C. O. Tarr, "Summary of NMPO Progress in Refractory Metal Tube Production," Materials Advisory Board, Washington, D. C., January 1966.

S. A. Leighton, "Preparation of Radioactive Specimens for Replication," 19th Metallography Group Meeting, pp. 194-207, February 1966.

S. A. Leighton and Willis J. Stapp, "Romote Handling Techniques Used in the Study of Fission Product Diffusion in. Irradiated Metals," 20th Metallographic Group Meeting, Denver, Colơrado, May 1966.

R. S. Pugh and W. S. Chenault, "Capsule Design for Recoil Fission Product Studies and Thermocouple Studies," Internation Symposium or Developments in Irradiation Capsule Technology, Pleasanton, California, June 1966.

W. G. Baxter and J. W. Tenhundfeld, "A Materials Fabrication and Design Feasibility Study for a High Temperature, Uncooled, Articulating Control Rod," Transactions of the American Nuclear Society 1966 Annual Meeting, June 1966, Denver, Colorado, Volume 9, No. 1 , pp. 12-13.

A. J. Lovell, F. D. Kingsbury, and J. Moteff, "Thermal Hardening of Neutron-Irradiated 
Polycrystalline Tungsten," Transactions of the American Nuclear Society 1966 Annual Meeting, June 1966, Denver, Colorado, Vol. 9, No. 1, pp. 54-55.

J. P. Smith, A. J. Lovell, F. D. Kingsbury, and J. Moteff, "The Effects of Neutron Irradiation on the Creep-Rupture Properties of Hastelloy N," Transactions of the American Nuclear Society 1966 Annual Meeting, June 1966, Denver, Colorado, Vol. 9, No. 1, pp. 52-53.

J. Moteff, A. J. Lovell, F. D. Kingsbury, and J. P. Smith, "The Influence of Boron on the Creep-Rupture Properties of a Neutron Irradiated Precipitation Hardening Iron Base Alloy," 69th Annual American Society for Testing and Materials (ASTM) Meeting, Atlantic City, New Jersey, June 1966.

F. D. Kingsbury and J. Moteff, "The Effects of Neutron Irradiation on the Creep-Rupture Properties of W-25Re Alloy," 69th Annual American Society for Testing and Materials (ASTM) Meeting, Atlantic City, New Jersey, June 1966.

'T. Slot, "Experimental Developments in Low Cycle Fatigue Research on Pressure Vessel Steels at Elevated Temperatures," Symposium on Low Cycle and Thermal Stress Fatigue, Schenectady, New York, June 1966.

W. R. Yario, "Dimensional Stability of Refractory Metal Fuel Elements Under Thermal Cyclic Conditions," AIAA Second Propulsion Joint Specialists Conference, Colorado Springs, Colorado, June 1966.

D. L. Newsom and R. H. Danforth, "High-Temperature Long-Time Irradiation Effects on Refractory-Metal-Clad Fuel Elements," ALAA Second Propulsion Joint Specialists Conference, Colorado Springs, Colorado, June 1966.

J. F. White, "Physico-Chemical Studies of $\mathrm{Clad} \mathrm{UO}_{2}$ in Potential Meltdown Environments," AEC Stress Corrosion Symposium, Ohio State University, Columbus, Ohio, July 1966.

J. Colby, W. N. Wise, and D. Conley, "Quantitative Microprobe Analysis by Means of Target Current Measurements," 10th Annual Conference on Applications of X-Ray Analysis, Denver, Colorado, August 1966.

R. C. Rau, "Interstitial Loops in Beryllium Oxide Irradiated at High Temperatures," Twenty-Fourth Annual Meeting, Electron Microscopy Society of America, San Francisco, California, August 1966.

R. C. Rau, "Clustering of Defects in Beryllium Oxide Irradiated at Pile Ambient Temperature," Twenty-Fourth Annual Meeting, Electron Microscopy Society of America, San Francisco, California, August 1966.

E. A. Schaefer, "The Determination of Uranium and Thorium Metals in Fuel Element Core Materials," 10th Conference on Analytical Chemistry in Nuclear Technology, Gatlinburg, Tennessee, September 1966.

W. C. Kuhlman, "Thermocouple Anomalies from Reactor Operations," 21st Annual Instrument Society of American Conference and Exhibit, New York, New York, October 1966.

C. O. Tarr, "Phase Relationships in High Temperature Alloys," AIME Fall Meeting of Institute of Metals Division, Chicago, Illinois, October 1966.

R. E. Fryxell, "Chemical Properties and Behavior of Urania above $1500^{\circ} \mathrm{C}$," Nuclear Metallurgy Symposium on High Temperature Nuclear Fuels, AIME, Delevan, Wisconsin, October 1966.

E. A. Aitken, H. C. Brassfield, and P. P. Turner, "Chemical and Thermal Stability of a BeO Base Fuel System in an Oxidizing Environment," Nuclear Metallurgy Symposium on High Temperature Nuclear Fuels, AIME, Delevan, Wisconsin, October 1966. 
J. W. Colby and D. K. Conley, "A Critical Evaluation of the Absorption and Fluorescence Corrections in Quantitative Microprobe Analysis," Proceedings of the Fourth International Congress on X-Ray Optics and X-Ray Microanalysis, Hermann Publishers, Paris, France, 1966.

A. D. Feith, "Thermal Conductivity and Electrical Resistivity of Zircaloy-4," 6th Conference on Thermal Conductivity, Dayton, Ohio, October 1966.

J. B. Conway, "Standards for High Temperature Thermal Expansion Measurements," ASTM Meeting, Corning, New York, October 1966; and 6th Conference on Thermal Conductivity, Dayton, Ohio, October 1966.

PUBLICATIONS

J. O. Hibbits and E. A. Schaefer, "The Determination of Uranium and Thorium Metals in Fuel Element Core Materials by Selective Decomposition of their Hydrides," Analytical Chemistry, Vol. 38, 1966, p. 1687.

R. C. Rau, "Further Replica Electron Microscopy Studies of Irradiated BeO," Journal of Nuclear Materials, Vol. 17, 1966, pp. 341-343.

K. Lacefield, J. Moteff, and J. P. Smith, "Neutron Radiation Damage in Tungsten Single Crystals," Philosophical Magazine, Vol. 13, May 1966, pp. 1079-1081.

R. C. Rau, "The Crystal Structure of $\mathrm{Eu}_{3} \mathrm{O}_{4}$," Acta Crystollographica, Vol. 20, June 1966, pp. $716-723$.

P. N. Flagella, "Metallurgy of Molybdenum at $4000^{\circ} \mathrm{F}, "$ AIME Refractory Metals and Alloys III: Applied Aspects, Vol. 30, part 2, 1966, p. 917.

J. B. Conway and A. C. Losekamp, "Thermal Expansion Characteristics of Several Refractory Metals to $2500^{\circ} \mathrm{C}$," Transaction of AIME, Vol. 236, May 1966, pp. 702-709.

J. B. Conway and M. J. Mullikin, "A Graphical Solution of the Garofalo Equation," Transaction of AIME, Vol. 236, June 1966, pp. 946-947.

T. Slot and J. P. Yalch, "Stress Analysis of Plane Perforated Structures by Point Wise Matching of Boundary Conditions," Nuclear Engineering and Design, Vol. 4, No. 3, August 1966, pp. 163-176.

J. O. Hibbits, "Gas Chromatographic Determination of Helium in Neutron Irradiated Beryllium Oxide," TALANTA, Vol. 13; 1966, p. 151.

J. R. Beeler, Jr., "Vacancy and Interstitial Cluster Production in Neutron-Irradiated $\alpha$-Iron," Journal of Applied Physics, Vol. 37, 1966, p. 3000.

R. C. Rau, "Interstitial Dislocation Loops in Beryllium Oxide Irradiated at High Temperature," Nature, Vol. 211, July 1966, pp. 71-72.

J. R. Beeler, Jr., "Neutron Irradiation Effects Saturation in $\alpha$-Iron," Crystal Lattice Defects and Their Interactions, edited by R. R. Hasiguti, 1966.

J. R. Beeler, Jr., "Displacement Spikes in Cubic Metals I: $\alpha$-Iron, Copper, and Tungsten," Physical Review, Vol. 150, October 1966, p. 470.

H. L. Gegel, J. R. Beeler, Jr., and R. Speiser, "Effect of Impurities on Annealing of Quenched Gold," Crystall Lattice Defects and Their Interactions, edited by R. R. Hasiguti, 1966.

R. C. Rau, "Transmission Electron Microscope Studies of Neutron Irradiated Beryllium Oxide," Journal of Nuclear Materials, Vol. 20, 1966, pp. 141-152. 
S. F. Bartram, "Crystal Structure of the Rhombohedral $\mathrm{MO}_{3} \cdot 3 \mathrm{R}_{2} \mathrm{O}_{3}$ Compounds $(\mathbf{M}=\mathrm{U}$, $\mathrm{W}$ or Mo) and Their Relation to Ordered $\mathrm{R}_{7} \mathrm{O}_{12}$ Phases," Inorganic Chemistry, Vol. 5, 1966, p. 749.

J. R. Beeler, Jr., "Thermal Growth of the Recombination Volume in $\alpha$-Iron," Bulletin American Physical Society, Vol. 11, 1966, p. 184.

J. B. Conway, "Some Correlation Procedures Based on the Larson-Miller Parameter and Their Application to Refractory Metal Data," Transactions of AIME, Vol. 236, October 1966, pp. 1486-1489.

J. B. Conway and M. J. Mullikin, "An Evaluation of Various Equations for Expressing First Stage Creep Behavior," Transaction of AIME, Vol. 236, October 1966, pp. 1496-1501.

J. R. Beeler, Jr., "Vacancy and Interstitial Clusters in $\alpha$-Iron," Bulletin of American Physcial Society, Vol. 11, 1966, p. 272.

J. B. Conway and M. J. Mullikin, "Techniques for Analyzing Combined First- and SecondStage Creep Data," Transaction of AIME, Vol. 236, November 1966, pp. 1629-1632.

\section{INVENTION DISCLOSURES}

These were fourteen patent dockets submitted to the AEC:

1. A High-Temperature Thermocouple Assembly

2. Geodesic Sphere Thermoelectric Device

3. High-Temperature Thermocouple Alloy Systems

4. Thermoelectric Motor

5. An Improved Tungsten-Base Alloy

6. Improved Composition of Sintered Beryllium Oxide Bodies

7. Improving the Sintering and Dimensional Stability of Refractory-Metal - $\mathrm{UO}_{2}$ Fuel Elements by an Oxide Addition

8. Purification Process to Improve Refractory Metals

9. Alloys of Group III, IV, and V Metals Resistant to Absorbing Hydrogen

10. Chemically Removable Core Filler Material for Refractory-Metal Alloys

11. Alloy Improvemonts for $W-R e$ alld $W-R e-M u$ Alluys

12. Control of Carbide Compositions at High Temperatures

13. The Fabrication of a High-Temperature Control Rod by Special Cermet Processing and Co-Extrusion at Elevated Temperatures

14. Refractory-Metal Alloy Age Hardening at $2200^{\circ} \mathrm{C}$ 
THIS PAGE WAS INTENTIONALLY

LEFT BLANK 
NUCLEAR TECHNOLOGY DEPARTMENT

NUCLEAR ENERGY DIVISION

GENERAL EL ELTRIC 